\title{
Different kinds of precaution. A comparative analysis of the application of the precautionary principle in five different legal orders
}

Citation for published version (APA):

Zander, J. (2009). Different kinds of precaution. A comparative analysis of the application of the precautionary principle in five different legal orders. [Doctoral Thesis, Maastricht University]. S.n. https://doi.org/10.26481/dis.20090417jz

Document status and date:

Published: 01/01/2009

DOI:

10.26481/dis.20090417jz

Document Version:

Publisher's PDF, also known as Version of record

\section{Please check the document version of this publication:}

- A submitted manuscript is the version of the article upon submission and before peer-review. There can be important differences between the submitted version and the official published version of record. People interested in the research are advised to contact the author for the final version of the publication, or visit the DOI to the publisher's website.

- The final author version and the galley proof are versions of the publication after peer review.

- The final published version features the final layout of the paper including the volume, issue and page numbers.

Link to publication

\footnotetext{
General rights rights.

- You may freely distribute the URL identifying the publication in the public portal. please follow below link for the End User Agreement:

www.umlib.nl/taverne-license

Take down policy

If you believe that this document breaches copyright please contact us at:

repository@maastrichtuniversity.nl

providing details and we will investigate your claim.
}

Copyright and moral rights for the publications made accessible in the public portal are retained by the authors and/or other copyright owners and it is a condition of accessing publications that users recognise and abide by the legal requirements associated with these

- Users may download and print one copy of any publication from the public portal for the purpose of private study or research.

- You may not further distribute the material or use it for any profit-making activity or commercial gain

If the publication is distributed under the terms of Article 25fa of the Dutch Copyright Act, indicated by the "Taverne" license above, 


\title{
Different Kinds of Precaution
}

\author{
A comparative analysis of the application of the \\ precautionary principle in five different legal \\ orders
}

DISSERTATION

to obtain the degree of Doctor at the Maastricht University on the authority of the Rector Magnificus Prof Gerard P.M.F. Mols.

In accordance with the decision of the Board of Deans, to be defended in public on (to be decided)

by

Joakim Zander.

Public Defence 17 April 2009 at $10.00 \mathrm{~h}$ 


\section{Supervisor:}

Prof. dr. Ellen Vos

\section{Assessment Committee}

Prof. Dr. Michael Faure

Prof. Dr. Peter van den Bossche

Prof. Dr. Jason Johnston (University of Pennsylvania)

Prof. Dr. Ragnar Löfstedt (King's College, University of London)

Prof. Dr. Hildegard Schneider 


\section{ACKNOWLEDGEMENTS}

I would like to extend my gratitude to the Faculty of Law at Maastricht University, and all its members, for allowing me to carry out this research and teach at the Faculty as a Junior Researcher between 2003 and 2007. In particular, I would like to thank Professor Ellen Vos for providing supervision of this project. Furthermore, I would like to thank my colleagues at the Faculty for their friendship, endless hours of discussion, coffee, hot cocoa and ping-pong. In particular, I would like to mention the study group on risk and regulation, which supplied ample opportunity for the exploration of all angles of the field of risk regulation. Special thanks go to two students at Maastricht University; Anna Fink, who did a great job with the bibliography and table of cases for this book, and Alain Lambert who provided an excellent Dutch translation in a very short time. I would also like to thank Chris Engert in Florence, Italy, for carrying out the language editing and type-setting of the book.

I would furthermore like to thank Professor Cass Sunstein, then at Chicago Law School, and Professor Ragnar Löfstedt at King's Centre for Risk Management, King's College, London, for receiving me as a visiting researcher and taking the time to discuss the precautionary principle. In this context, I would like to thank the The Netherlands Organisation for Scientific Research (NWO) for making this possible by granting me the funds to spend time at Chicago Law School in the autumn of 2005.

Finally, and on a more personal note, I would like to thank my wife, Liisa, for putting up with all of this. I think that we can both agree that it is not at a moment too soon that this project has reached its end. 
TABLE OF CONTENTS

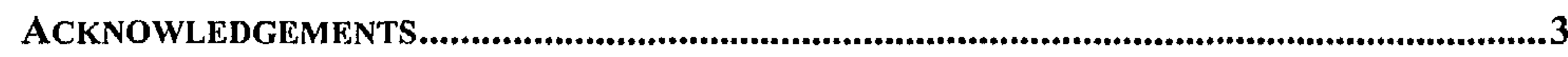

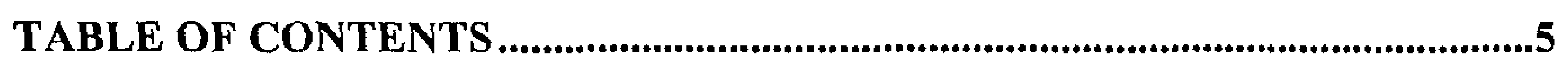

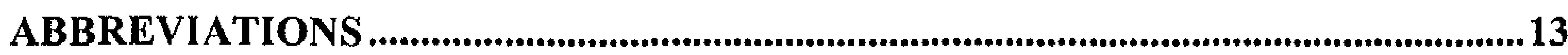

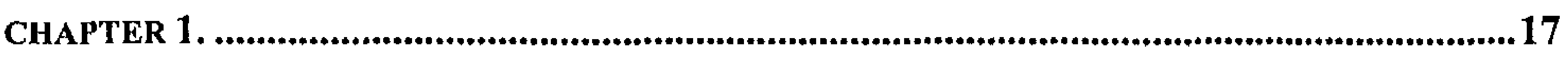

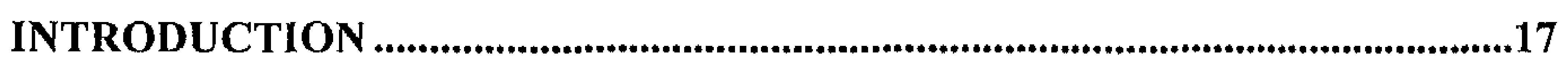

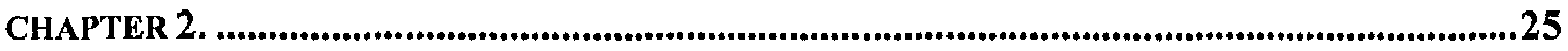

RISK AND UNCERTAINTY: BASIC CONCEPTS AND TOOLS FOR

THE APPLICATION OF THE PRECAUTIONARY PRINCIPLE ........................25

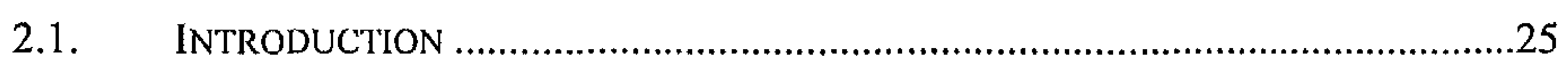

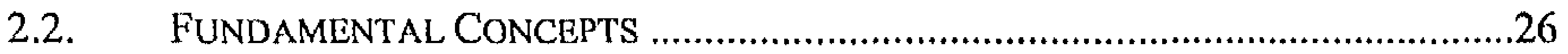

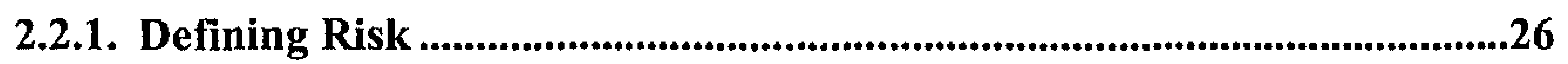

2.2.2. The Perception of Risk ............................................................................29

2.2.3. Scientific Uncertainty, Prevention and Precaution.....................................31

2.3. STRIKING A BALANCE IN RISK REGULATION ................................................33

2.3.1. The Three Phases of Risk Regulation .............................................................33

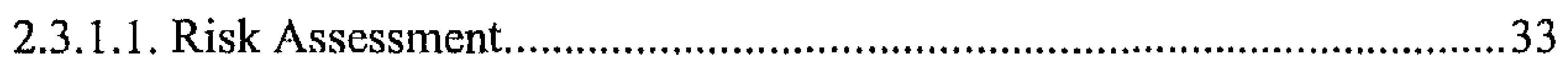

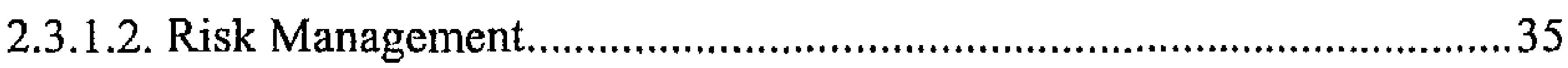

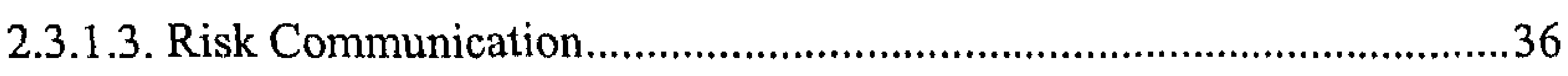

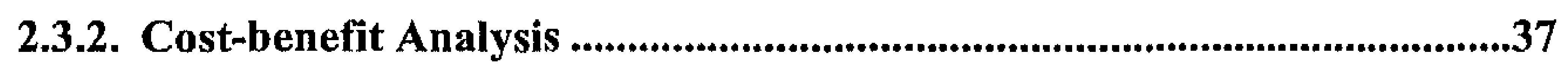

2.3.3. Risk Trade-off Analysis ..........................................................................40

2.4. Attempts at Defining the Precautionary Principle .................................42

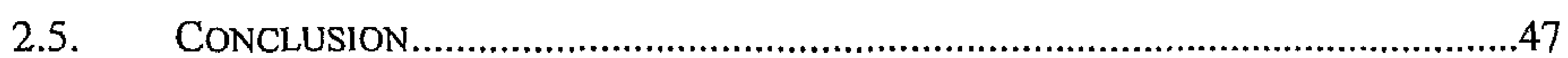

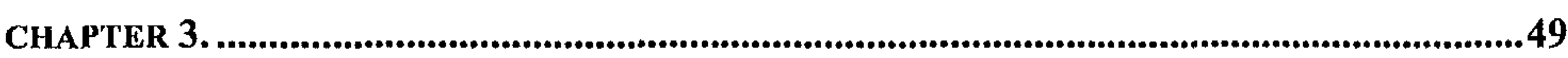

THE PRECAUTIONARY PRINCIPLE IN INTERNATIONAL LAW ...................49

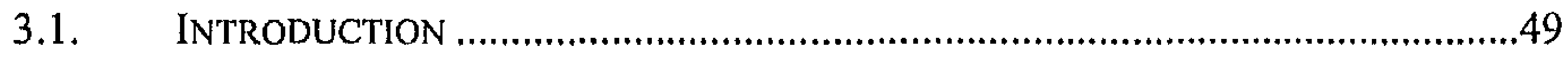

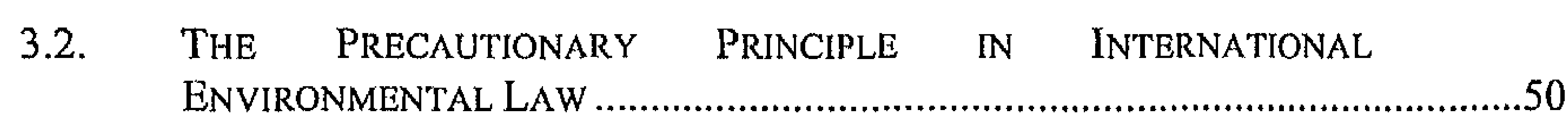

3.2.1. The Precautionary Principle in International Agreements......................50

3.2.1.1. Binding International Agreements ....................................................50

3.2.1.2. Non-Binding International Instruments ..........................................51

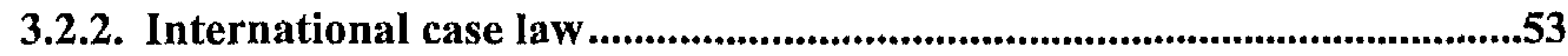

3.3. The Precautionary Principle IN WTO LAW ...........................................55

3.3.1. The Precautionary Principle and the WTO Agreements .........................55 
Joakim Zander

3.3.2. The Role of the Precautionary Principle in WTO Dispute

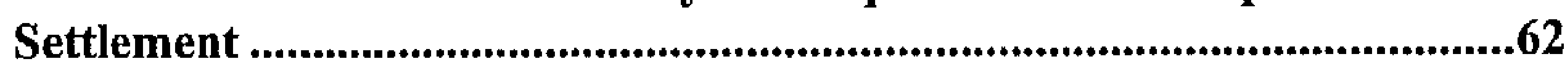

3.3.2.1. The definition of the precautionary principle.....................................62

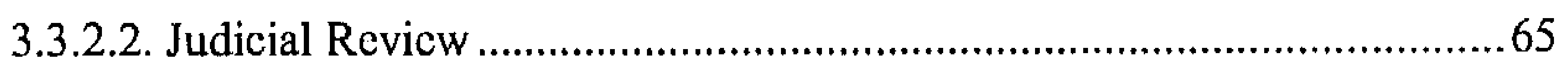

3.3.2.3. Risk Assessment and Risk Management............................................67

3.3.2.4. Scientific Evidence and the Level of Proof..........................................70

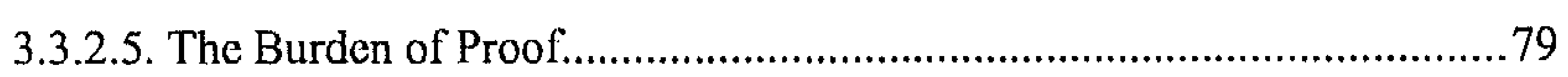

3.3.2.6. The Targeting of Risks, Proportionality and Cost/Benefit Analysis..... 82

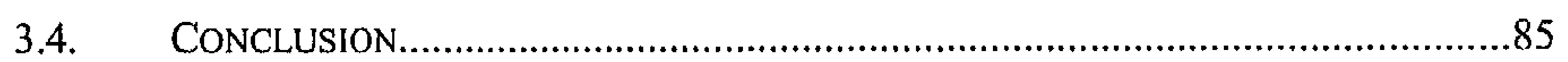

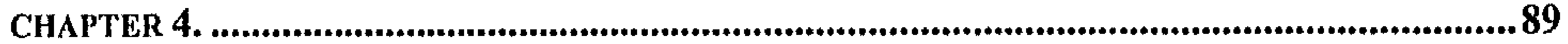

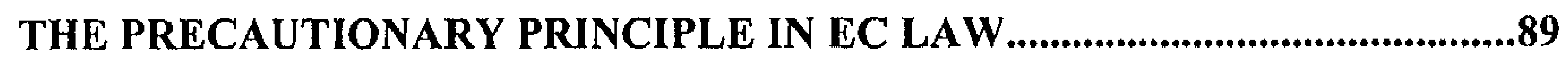

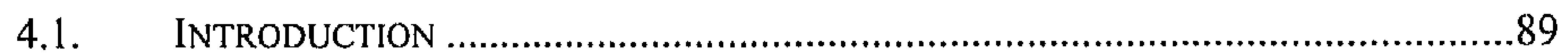

4.2. The Development of the Precautionary Principle in EC TREATIES, LEGISLATION AND SOFT LAW .....................................................91

4.2.1. Early Developments ............................................................................................91

4.2.2. The Single European Act.........................................................................97

4.2.3. The Treaty of Maastricht ...................................................................................100

4.2.4. The Treaty of Amsterdam .........................................................................103

4.2.5. The Commission Communication on the Precautionary Principle ..................................................................................................104

4.2.5.1. The Purpose of the Communication.................................................... 104

4.2.5.2. The Definition of the Precautionary Principle ....................................105

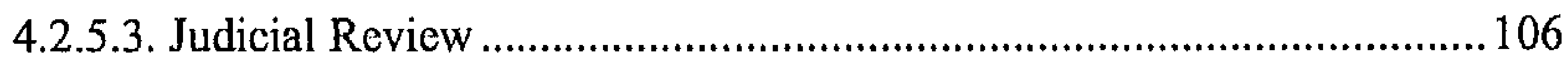

4.2.5.4. Risk Assessment and Risk Management........................................... 106

4.2.5.5. Scientific Evidence and the Level of Proof.......................................... 108

4.2.5.6. The Burden of Proof............................................................................... 109

4.2.5.7. Cost/Benefit Analysis and Proportionality......................................... 110

4.2.5.8. The Targeting of Risks and Risk Trade-offs ......................................... 112

4.2.5.9. Concluding Remarks on Communication (2000)1 .......................... 112

4.2.6. Recent examples of the influence of the precautionary principle in secondary EC legislation........................................................114

4.3. The InTERPRetation of the Precautionary Principle in EC

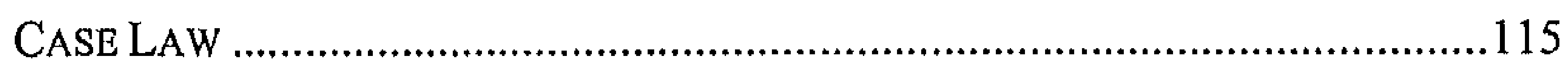

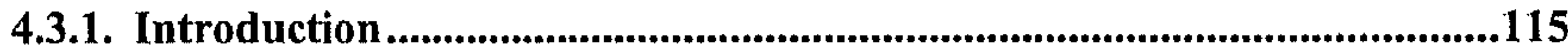

4.3.2. The Definition of the Precautionary Principle . .117 
4.3.3. The Role of Scientific Evidence and the Limits of Judicial Review .120

4.3.4. Risk Assessment and Risk Management.................................................128

4.3.5. The Level of Proof and the Triggering of Precautionary Measures .............................................................................................................131

4.3.6. The Burden of Proof ......................................................................................140

4.3.7. Cost/Benefit Analysis and Proportionality .................................................145

4.3.8. The Targeting of Risks ......................................................................152

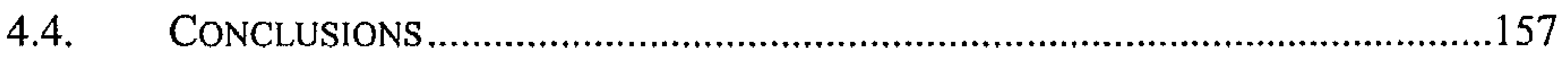

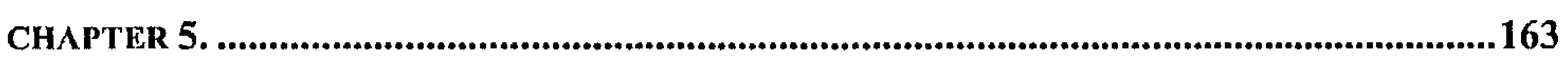

THE PRECAUTIONARY PRINCIPLE IN SWEDEN ......................................163

5.1. The Development and Status of the Precautionary

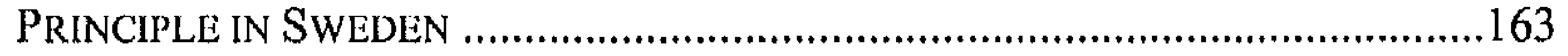

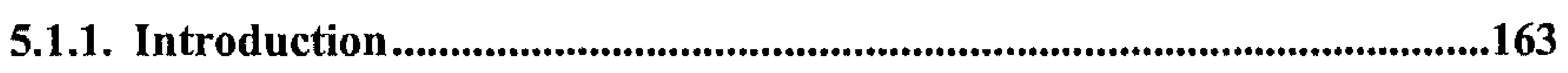

5.1.2. Background and Development.......................................................................164

5.1.3. The Current Context and Definition of the Precautionary

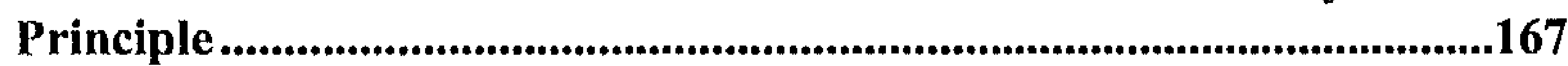

5.1.4. Judicial Review.....................................................................................171

5.1.5. Risk Assessment and Risk Management.................................................174

5.1.6. Scientific Evidence and the Level of Proof ..................................................175

5.1.7. The Burden of Proof .......................................................................................179

5.1.8. Cost/Benefit Analysis .........................................................................................181

5.1.9. The Targeting of Risks ..................................................................................182

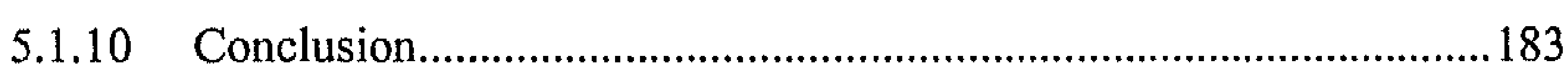

5.2. The Application of the Precautionary Principle in Swedish

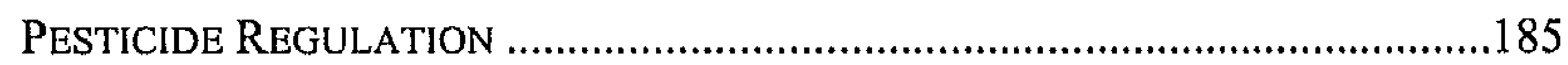

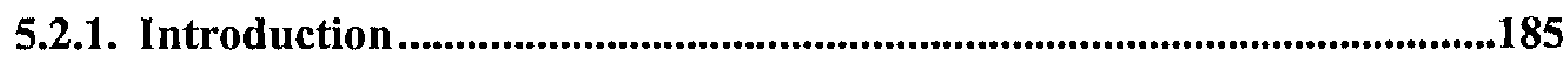

5.2.2. The Legal Framework .........................................................................186

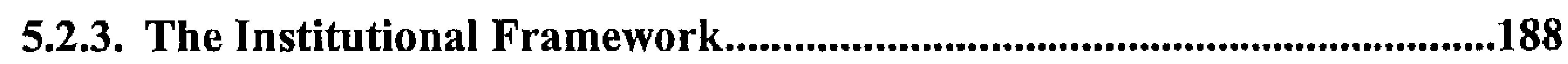

5.2.4. Risk Assessment and Risk Management....................................................190

5.2.5. The Level of Proof and the Triggering of Precautionary Measures ...................................................................................................194

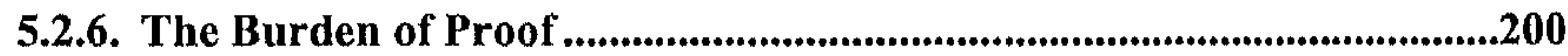

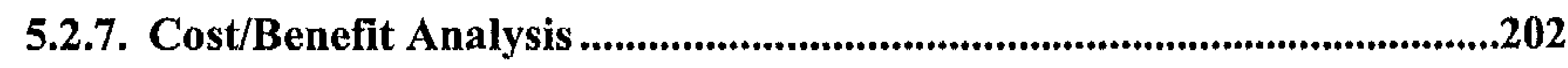

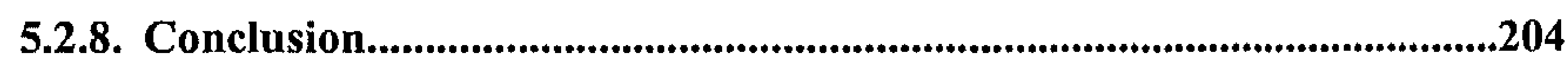


Joakim Zander

5.3. The Application of the Precautionary Principle in the

SWEDISH REGULATION OF BASE STATIONS ...................................................206

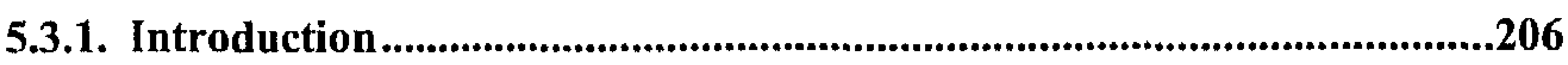

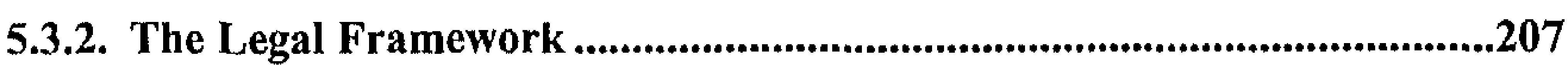

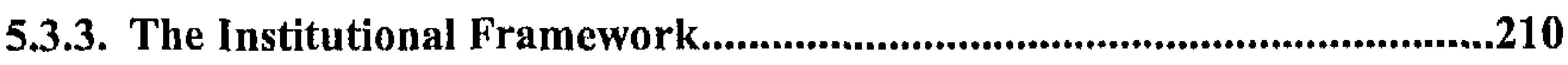

5.3.4. Risk Assessment and Risk Management.................................................213

5.3.5. The Level of Proof and the Triggering of Precautionary

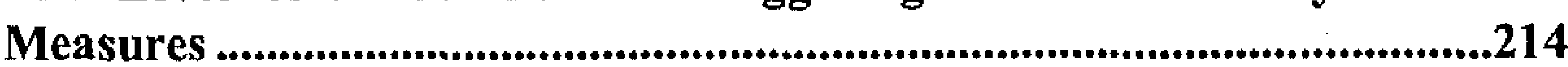

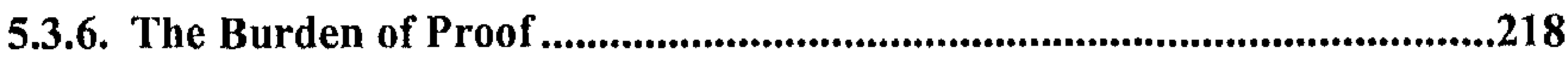

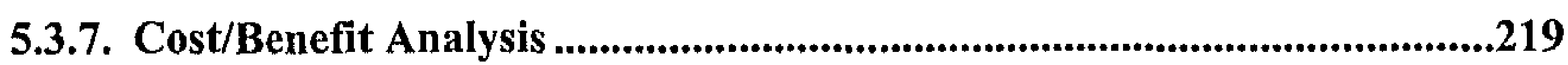

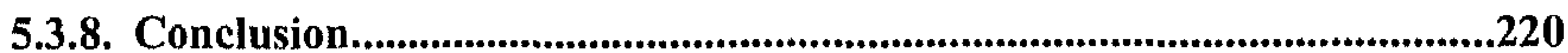

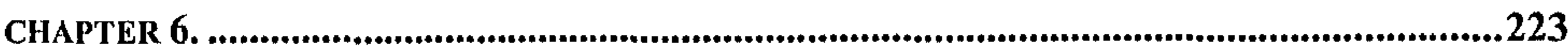

THE PRECAUTIONARY PRINCIPLE IN THE UNITED KINGDOM ..............223

6.1. The DeVelopment and Status of the Precautionary PRINCIPLE IN THE UNITED KINGDOM .........................................................223

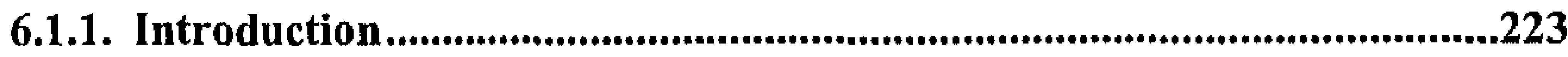

6.1.2. Background and Development....................................................................223

6.1.3. The Current Context and Definition of the Precautionary

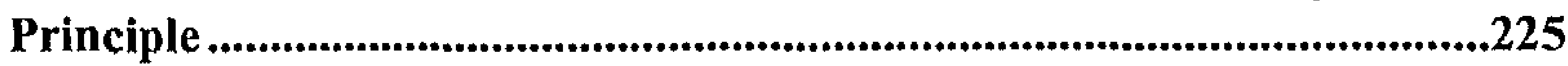

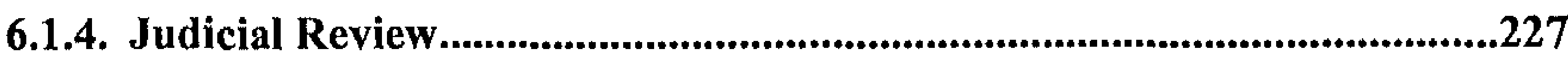

6.1.5. Risk Assessment and Risk Management....................................................229

6.1.6. Scientific Evidence and the Level of Proof ................................................230

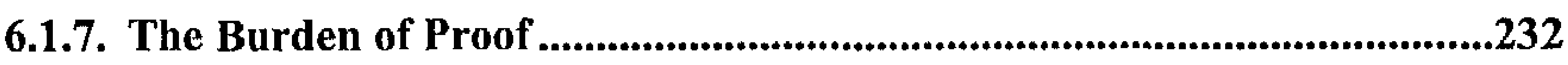

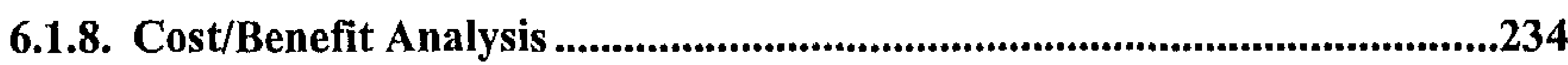

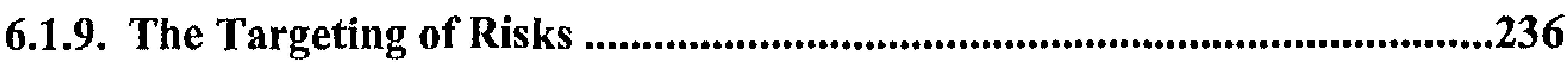

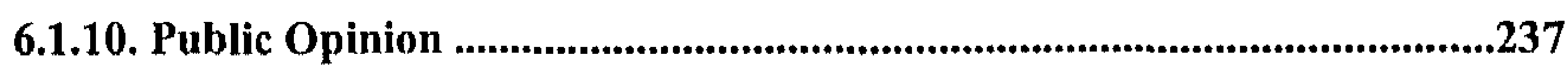

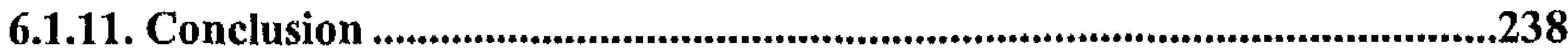

6.2. The Application of the Precautionary Principle in UK

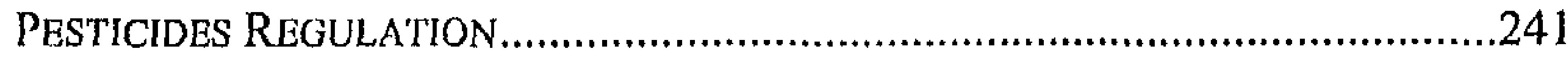

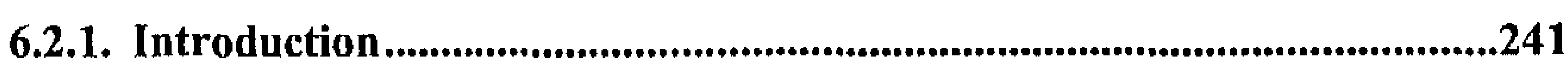

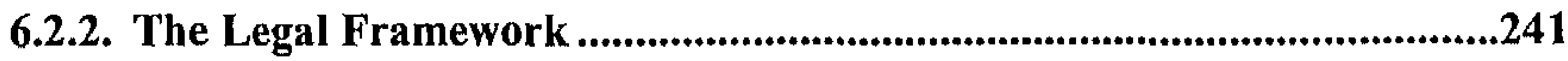

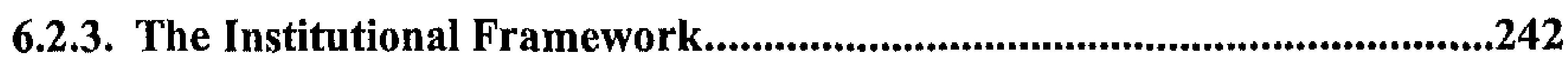

6.2.4. Risk Assessment and Risk Management..................................................245

6.2.5. The Level of Proof and the Triggering of Precautionary

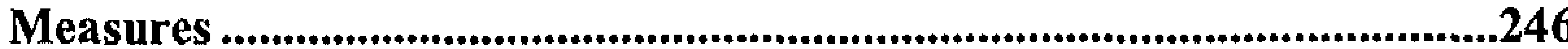

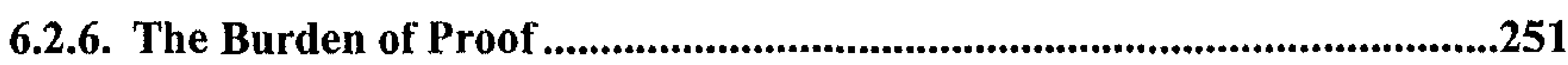




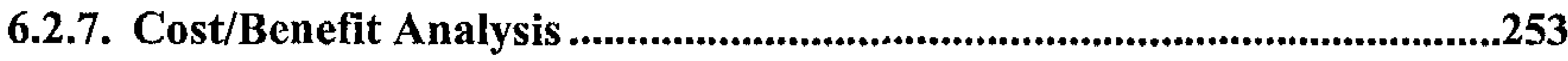

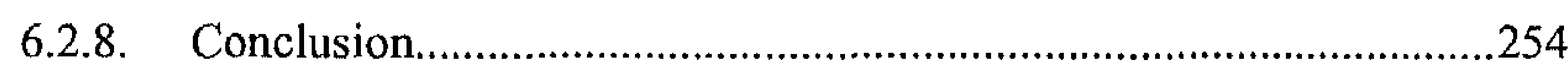

6.3. The Application of The Precautionary Principle in the UK

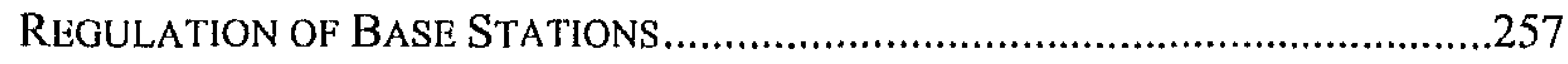

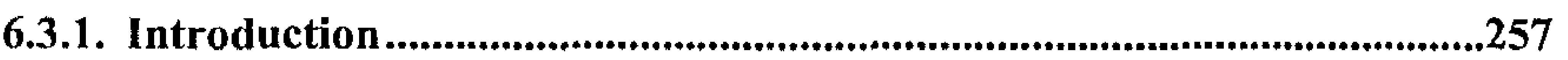

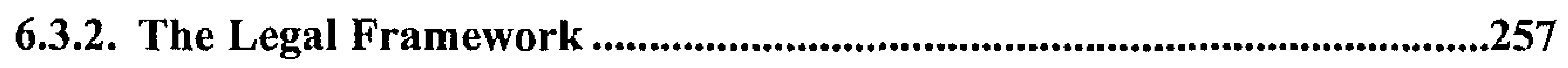

6.3.3. The Institutional Framework.....................................................................258

6.3.4. Risk Assessment and Risk Management.................................................261

6.3.5. The Level of Proof and the Triggering of Precautionary

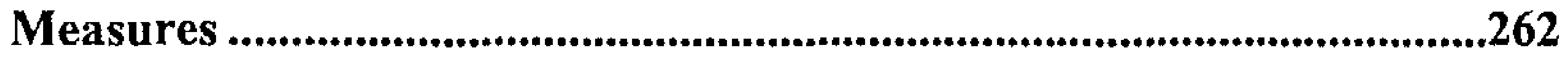

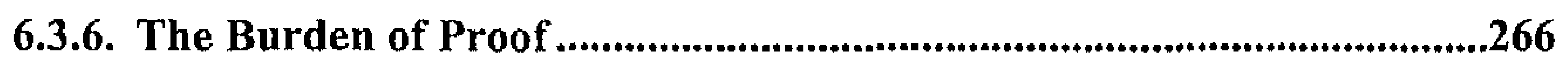

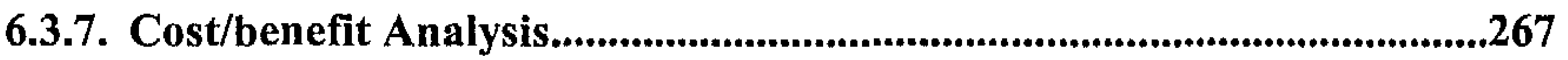

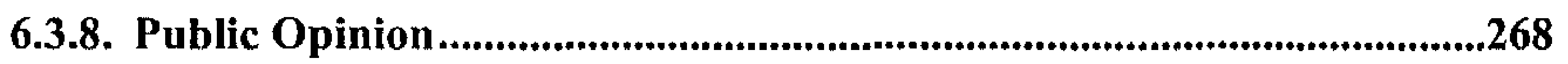

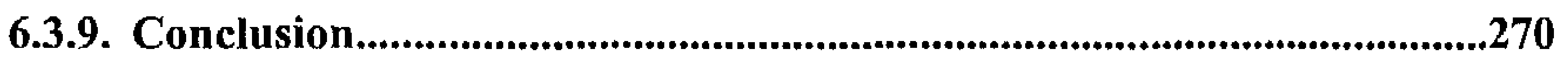

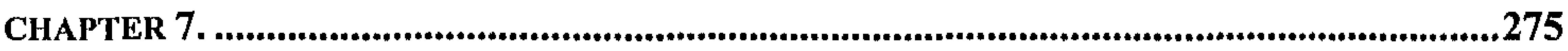

THE DEVELOPMENT AND STATUS OF THE PRECAUTIONARY PRINCIPLE IN THE UNITED STATES .......................................................275

7.1. The Development and Status of the Precautionary PRINCIPLE IN THE UNITED STATES ............................................................275

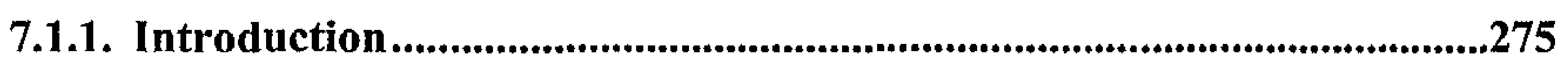

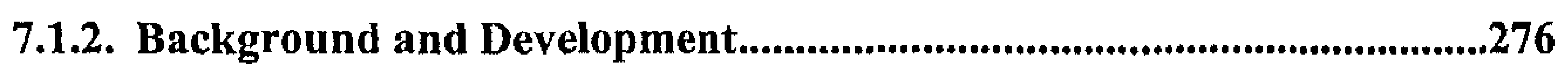

7.1.3. The Current Context and Definition of the Precautionary

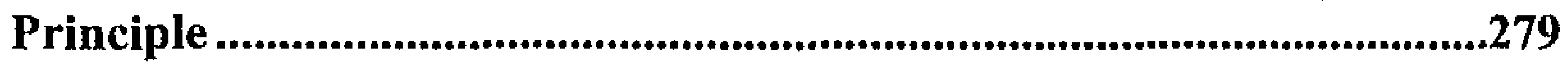

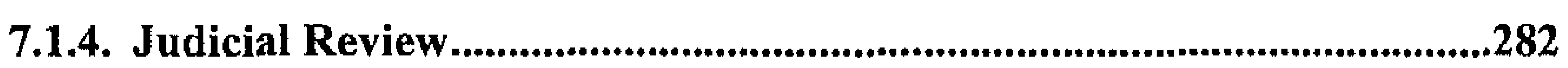

7.1.5. Risk Assessment and Risk Management.....................................................287

7.1.6. Scientific Evidence and the Level of Proof ............................................289

7.1.7. The Burden of Proof ..................................................................................292

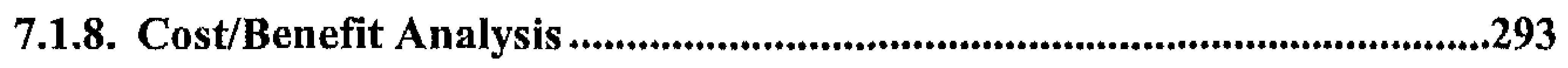

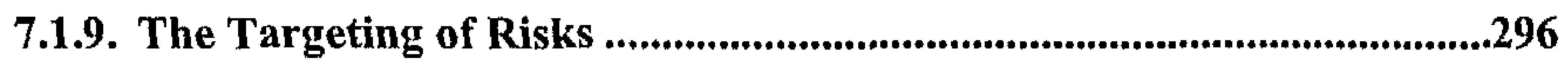

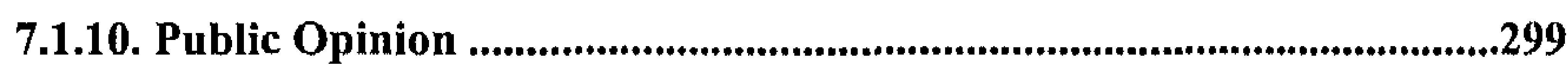

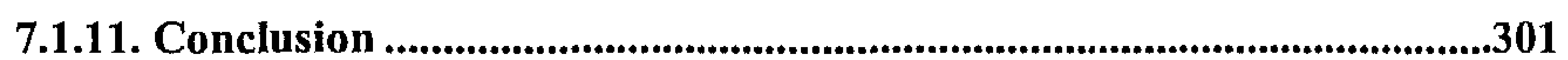

7.2. The Application of the Precautionary Principle in US PESTICIDES REGULATION............................................................................303

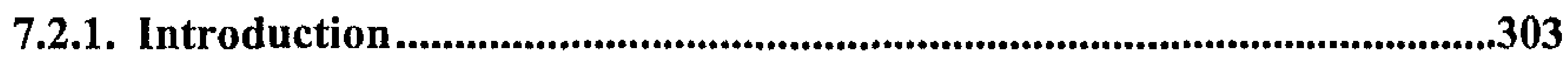

7.2.2. The Legal Framework .............................................................................304

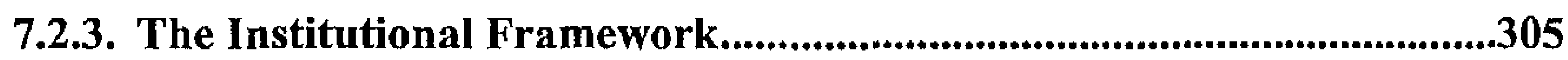


7.2.4. Risk Assessment and Risk Management..................................................307

7.2.5. The Level of Proof and the Triggering of Precautionary Measures ...................................................................................................308

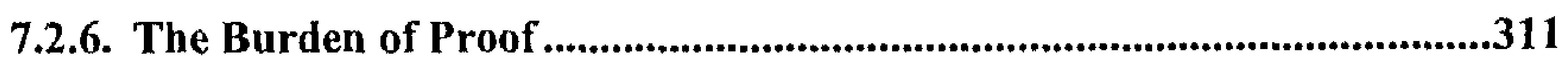

7.2.7. Cost/Benefit Analysis .................................................................................312

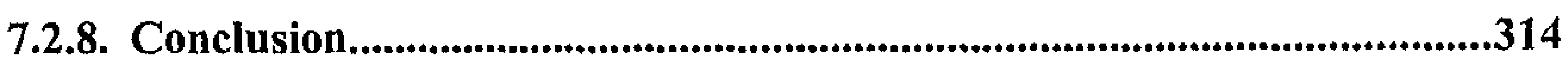

7.3. The Application of the Precautionary Principle in the US

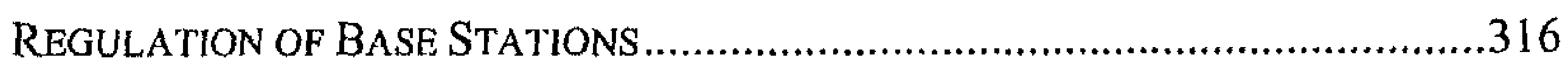

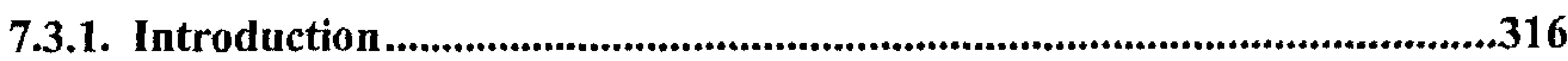

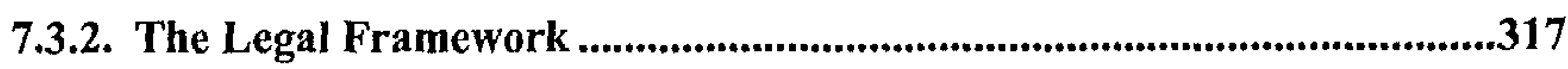

7.3.3. The Institutional Framework.............................................................318

7.3.4. Risk Assessment and Risk Management.......................................................320

7.3.5. The Level of Proof and the Triggering of Precautionary Measures ..............................................................................................................321

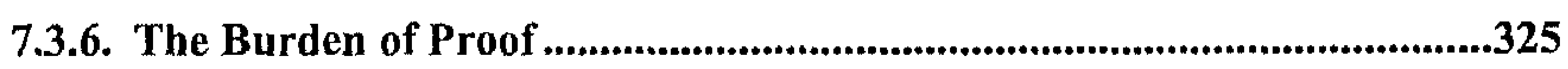

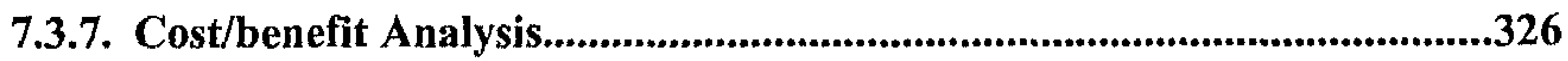

7.3.8. Public Opinion............................................................................................327

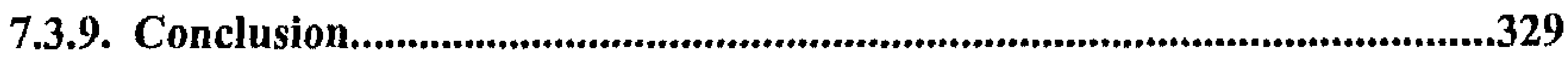

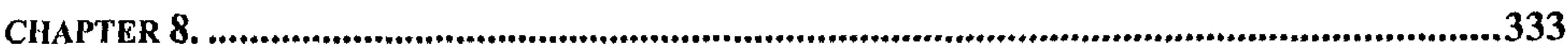

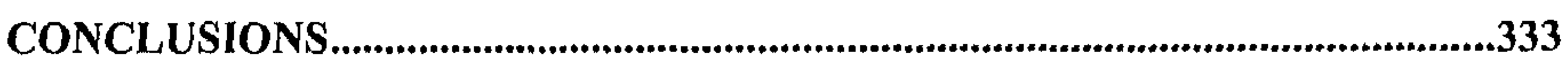

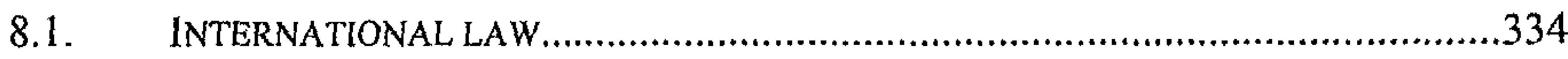

8.1.1. International Environmental Law....................................................334

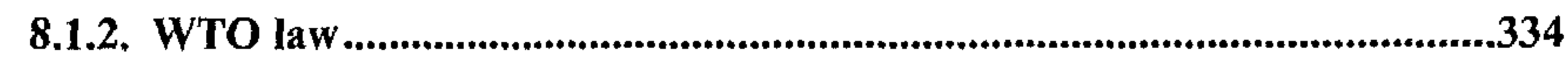

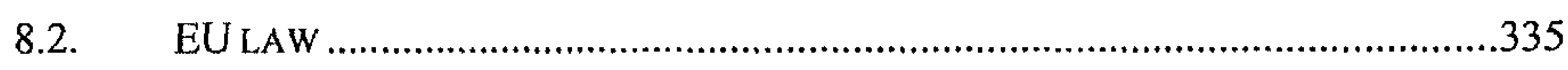

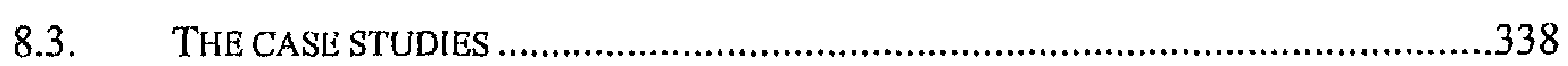

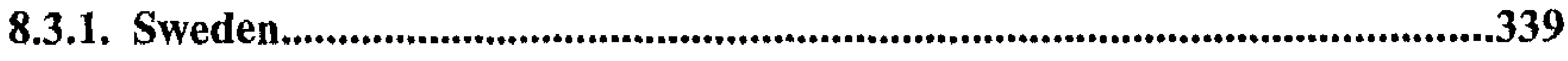

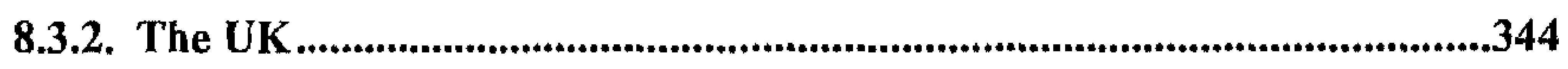

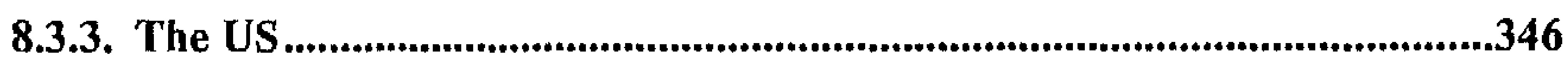

8.4. The DifFerent Types of The Prechutionary Principle ...........................350

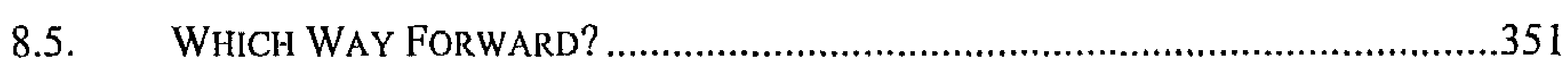

NEDERLANDSE SAMENVATTING.........................................................................355 
Table of Contents

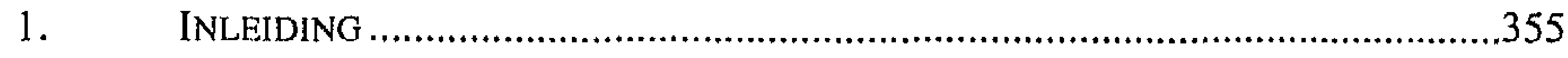

2. HET VOORZORGSBEGINSEL IN INTERNATIONAAL RECHT .............................356

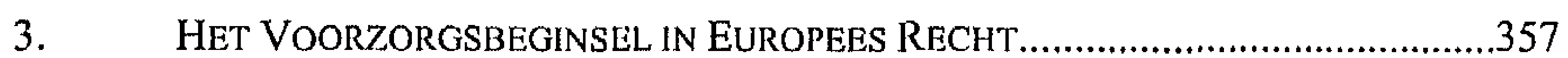

4. HET VOORZORGSBEGINSEL IN ZWEDEN ..................................................358

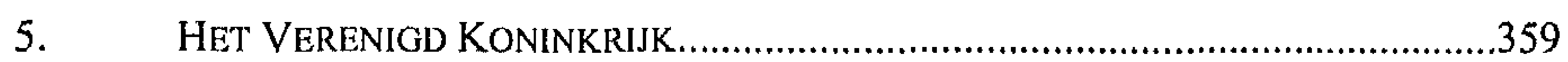

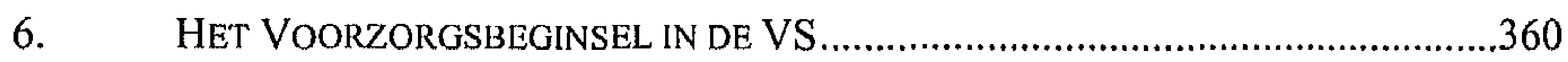

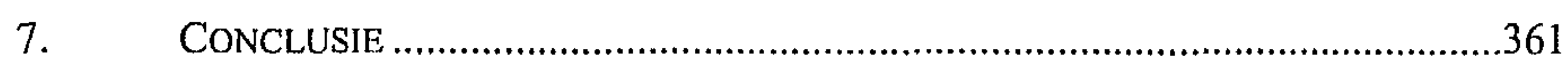

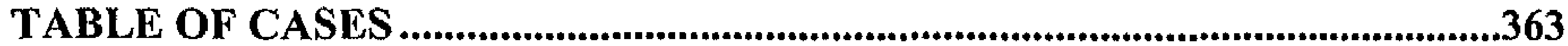

INTERNATIONAL COURT OF JUSTICE AND OTHER INTERNATIONAL TRIBUNALS ..............363

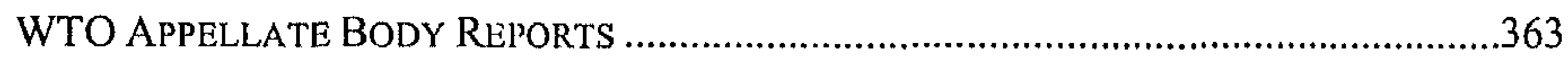

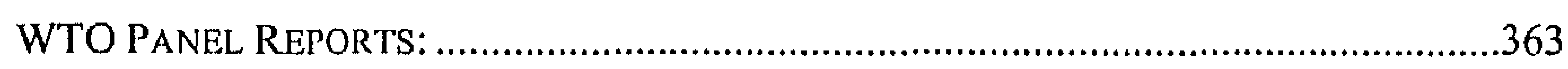

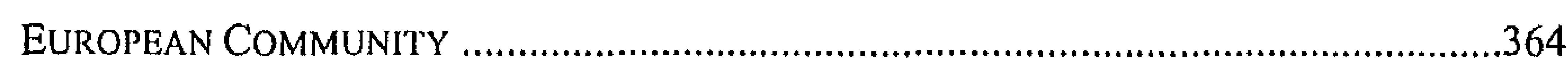

ECJ

CFI

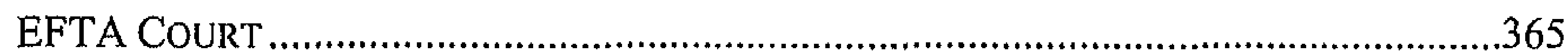

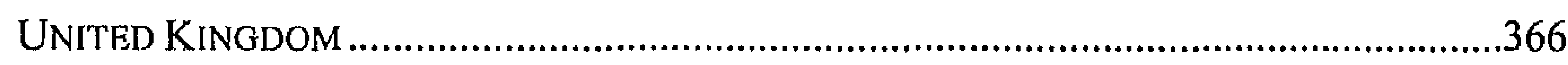

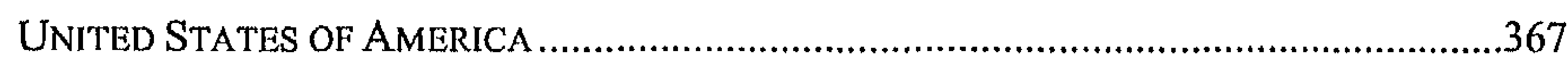

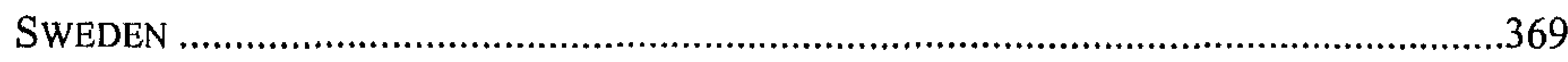

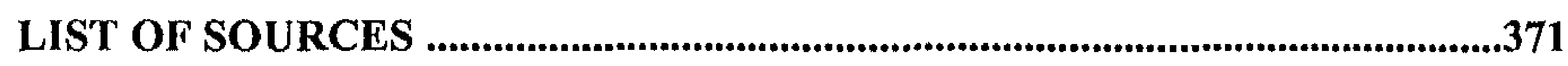

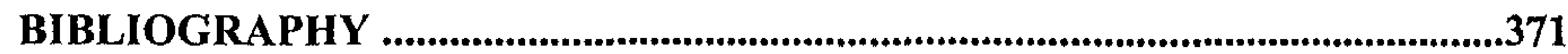

OTHER SOURCES..............................................................................................390

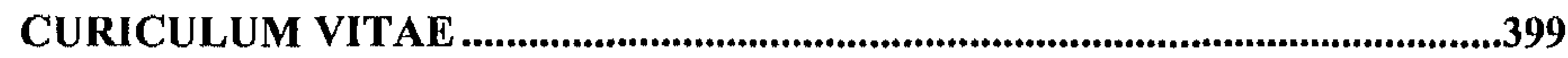




\section{ABBREVIATIONS}

$\mathrm{AB}$

ACP

AGNIR

AIDS

ALARA

ANSI

AOEL

APA

BSE

BST

CBA

CEA

$\mathrm{CFC}$

CFI

CITES

COM

COPR

CRA

CVMP

DDT

DecaBDE

DEFRA

DNA

DSB

DSU

EAP

EBCD

EC

ECJ

EEC

EFTA

EOP

EPA

EU

FACA

FAQ

FCC

FDA

FDCA

FEPA

FIFRA
Appellate Body

Advisory Committee on Pesticides

Advisory Group on Non-Ionising Radiation

Acquircd Immune Deficiency Syndrome

As Low As Reasonably Possible

American National Standards Institute

Acceptable operator exposure levcl

Administrative Procedure Act in the USA

Bovine spongiform encephalopathy

Bovine Somatotrophin

Cost-Benefit Analysis

Cost-Effectiveness Analysis

Chlorofluorocarbons

Court of First Instance

Convention on International Trade in Endangered Species

Commitlee on Mutagenicity of Chemicals in Food, Consumer

Products and the Environment (UK)

Control of Pesticides Regulations

Comparative Risk Analysis

Committee for Veterinary Medicinal Products

Dichloro-Diphenyl-Trichloroethane

Decabromodiphenyl ether

Department of Environment, Food and Rural Affairs in the UK

Deoxyribonucleic acid

Dispute Settlement Body of the WTO

Dispute Settlement Understanding (WTO)

Environmental Action Programme

Ethylencbisdithiocarbamate

European Community

European Court of Justice

European Economic Community

European Free Trade Association

Executive Office of the President in the USA

Environmental Protection Agency in the USA

European Union

Federal Advisory Committee Act in the USA

Frequently Asked Questions

Federal Communications Commission

Food and Drug Administration in the USA

Food, Drug, and Cosmetic Act in the USA

Food and Environment Protection Act

Federal Insecticide, Fungicide and Rodenticide Act in the USA 


\begin{tabular}{|c|c|}
\hline $\mathrm{FPOA}$ & Food Quality Protection Act in the USA \\
\hline (iAO) & General Accounting Office in the USA \\
\hline GATT & General Agresment on Tariffs and Trade \\
\hline (iM & Cienetically Modified \\
\hline (iMO) & Genetually Modilied Organisms \\
\hline HCl's & Hydrechlorofiumocarbons \\
\hline HH:W & United States Department of Health, Fducation, and Welfare \\
\hline HPA & Health Protection Agency \\
\hline IISI: & Health and Safety lixecutive in the UK \\
\hline IC $\mathrm{C}$ & International Court of Justice \\
\hline ICNIRP & International (ommission for Non-Ionising Radiation Protection \\
\hline IIELE & Instifule of Electrical and Electronics Fngineers in the USA \\
\hline IEGiMP & Independent Fexpert (iroup on Mobile Phones in the UK \\
\hline IIGRA & Interdepartmental L iaison (iroup on Risk Assessment \\
\hline HLOS & International Tribunal for the Law of the Sea \\
\hline Keml & Kemikalicinspektionen (Swedish (hemicals Agency) \\
\hline LPAs & Local Planning Authorities in the UK \\
\hline Miljöbalken & The Swedish Environmental Code \\
\hline MOX & Metal Oxide \\
\hline MRL. & Maximum Residue Level \\
\hline NCRP & National Council on Radiation Protection and Measurement \\
\hline NEPA & National Environmental Policy Act in the USA \\
\hline NIOSH & National Institute for Occupational Safety and Health in the USA \\
\hline NIMBY & Not in my Back Yard \\
\hline NRPB & National Radiation Protection Board in the UK \\
\hline OET & Office of Enginecring and Technology in the USA \\
\hline OIRA & Office of Information and Regulatory Affairs in the USA \\
\hline OMB & Office of Management and Budget in the USA \\
\hline OSHA & Occupational Safety and Health Administration in the USA \\
\hline PAN & Pesticide Action Network \\
\hline PBDE & Polybrominated diphenyl ethers \\
\hline PBL & Plan- och bygglagen (Swedish Planning and Building Act) \\
\hline PIC & Rotterdam Convention for Prior Informed Consent \\
\hline PSD & Pesticide Safety Directorate \\
\hline PPPR & Plant Protection Products Regulation \\
\hline PVC: & Polyvinyl Chloride \\
\hline QUAL.Ys & Quality Adjusted Life Years \\
\hline RCIISA & Radiation ('ontrol for Health and Safety Act in the USA \\
\hline
\end{tabular}


REACH

Regeringsformen

Regeringsrätten

RIA

RoHS

SAP

SAR

SCAN

SEA

SPS

SSI

SSM

SSL

Statliga myndigheter

TBT

UK

UNCLOS

USA

U.S.

WTA

WTO

WTP
Registration, Evaluation, Authorisation and Restriction of Chemical substances

The Swedish Constitution

Swedish Supreme Administrative Court

Regulatory Impact Assessments

Restriction of Hazardous Substances Directive

Scientific Advisory Pancl in the USA

Specific Absorbtion Rate

Scientific Committee on Animal Nutrition

The Single European Act

WTO Agreement on the Application of Sanitary and Phytosanitary Measures

Statens Strålskyddsinslitut (Swedish National Radiation Protection Authority)

Statens Strålsäkerhetsmyndighct (Swedish National [page 200]

Strålskyddslagen Swedish Radiation Protection Act

Swedish system of independent governmental authorities

Agreement on Technical Barriers to Trade

United Kingdom

United Nations Convention on the Law of the Sea

United States of America

United States (of America)

Willingness to Accept

World Trade Organisation

Willingness to Pay 


\section{CHAPTER 1.}

\section{INTRODUCTION}

The aim of this book is to discuss the role played by the precautionary principle when deciding on regulatory action in relation to risks posed to modern society, and the effects that such action may have for European and international trade. Primarily, this discussion aims to address the issue of how the EU currently makes use of the principle, and what lessons the EU institutions and Member States should draw from the use of precautionary considerations in a number of national and international regulatory regimes.

The last 30 years have brought a new awareness of the hidden costs of industrialisation and the welfare state. Suddenly, societies experience the realisation of risks which they did not know that they had crealed. Such risks include the highly publicised and potentially catastrophic risks, such as climate change, but also more hidden risks, such as the long-term cffects of exposure to chemicals and low frequency radiation from, for example, mobile phones and electricity networks. Other potential risks are possibly created through the development of new technologies such as gene modification. At the same time, the emergence of highly integrated regional and global markets for trade in goods and services has limited the possibilities for individual states to successfully enact national risk regulatory strategics.

What connects many of the risks that societies are faced with today is the uncertainty which surrounds them. In many cases, the link between an activity and a risk has not been scientifically established. Furthermore, the extent of a risk may be difficult or impossible to ascertain. So far, there has been deep disagreement on how to approach uncertain risks in different practical situations.

Among academic commentators, some claim that uncertain risks are a reasonable price to pay for the advances of society as manifested in the increased quality of life for the individual. The advantages of modern society outweigh its inherent risks. Others resort to pessimism and hold that the state of the world at this moment indeed is so dire that radical measures need to be considered. The German sociologist Ulrich Beck famously wrote in his World Risk Society: 
Joakim Zander

"I know of no greater security and no deeper source of creativity than a pessimism which cannot be outbid. Where everything is at stake, everything can and must be rethought and re-examined."1

It is out of this awareness that the notion of precaution in relation to the environment and health has sprung.

One instrument for dealing with uncertain environmental and health risks to society is the precautionary principle, which has been developing as a legal concept in national legal systems since the late 1960s. The precautionary principle affords the decision-maker an opportunity to act before risks have matcrialised, when only the contours of what might be risks are visible. As the awareness of both perceived and real risks has increased over the years, the importance of "the precautionary principle" has also increased. It should, however, be pointed out that, in practice, governmental intervention before the emergence of scientific certainty is far from a modern concept. What is unique about the precautionary principle is that it appears to treat precautionary action in a more conceptual fashion, and, in some cases, it aims to elevate precautionary action to the status of legal principle.

Different states make different judgements as to what constitutes risks, and subsequently the precautionary principle has been applied differently in different states and regions, as well as in different areas of policy within the same state. At the same time, it has remained a loosely-defined concept with unclear borders in regional and international legal systems. This makes the precautionary principle controversial in today's world of globalised markets, where states no longer are entirely free to pursue their own risk policies.

At EU level, the application of the precautionary principle takes place primarily at two different levels. First, the European institutions apply it when drafting legislation and deciding on the correct implementation of EU rules by the Member States. Second, the EU Member States often seek to make use of the precautionary principle when issuing national policies by using it as a justification in order to obtain derogations from $\mathrm{EU}$ rules. Sometimes, it appears to be used as "a magic wand", the invocation of which can justify virtually any policy choice. In order to safeguard the consistent and foreseeable development of EU law, it is necessary to investigate more closely what is required by the entity wishing to rely on this principle.

I U. Beck, World Risk Society, Blackwell Publishers Ltd., 1999, p. 88. 
Furthermore, it plays a role in international trade law. In a number of cases, WTO panels and the Appellate Body have elaborated on the role of the precautionary principle under the WTO Agreements.

When considering international trade issucs, it is often argued that the EU is a strong proponent of precautionary action and that the USA is an opponent of it. The EU suggests that it employs one specific precautionary principle, the application of which is guided by certain defined requirements. ${ }^{2}$ The USA prefers to use the term precautionary approach, rather than principle, in order to signify that it affords it less legal weight.

When looking at the policies of individual Member States of the EU as well as the national policies of the USA, the picture becomes somewhat more complicated. In certain areas, it appears that there is great disagreement among the Member States of the EU as to what actually constitutes precaution. ${ }^{3}$ Some Member States, such as Sweden, take pride in being "precautionary" in gencral, with a firm, legally-binding precautionary principle in effect in national legislation. It is investigated below whether such a "strong" reliance on the precautionary principle is, indecd, equally applicable in all policy areas and what the basis for such an approach is. Conversely, Member States such as the United Kingdom that do not have a tradition of precautionary action may apply a stricter precautionary approach in certain defined areas than in others. Hcre, too, the issue of how and when the precautionary principle actually comes into play arises.

When considering the differences in the application of the precautionary principle, the question arises as to whether it is possible to talk about one single precautionary principle. This book aims to investigate if it is indeed the case that the "precautionary principle" is defined differently depending upon in which area it is being applied, and by whom. In this context, how the precautionary principle has been applied in EU and WTO law and in the national legal orders of Sweden, the UK and the US is discussed and analysed.

It is investigated whether precautionary considerations are applied differently in relation to comparable risks in different policy areas within the same statc, and between different states. Since the refusal to accept one single, all-encompassing precautionary

2 Communication from the Commission of 2 February 2002 on the Precautionary Principle, COM (2001) 1.

See, for example, J. Scott \& E. Vos, "The Juridification of Uncertainty: observations on the ambiance of the Precautionary Principle with the EU and the WTO", in: Ch. Joerges \& R. Dehousse, Good Governance in Europe's Integrated Market, Oxford University Press, 2002. 


\section{Joakim Zander}

principle does not, in itself, mean that precautionary action is not taken in certain individual cases, this book uses the term "precautionary approach" to indicate a vague and open application of precaution, which is not necessarily based on a conceptual precautionary principle. The term "precautionary principle" is used to describe an institutionalised and systematic use of precaution in one or more policy areas.

This book is based on the presumption that all responsible governments will act out of precaution in certain situations, regardless of whether they are subscribing to "a precautionary principle" or not. Below, the issue of whether it is possible to identify a common precautionary principle, or common principles for precautionary action, which are applicable in all policy areas and in relation to different states, is analysed.

The aim of this analysis is to examine if a common foundation for treating the precautionary principle as a legal principle exists. Whether such a common conceptual framework is, indeed, necessary, or whether it can be concluded that the application of precautionary measures is better left up to the discretion of the individual states in each case, is also discussed. The primary target for this discussion is the EU, and of particular importance in this regard is the inter-relationship between the EU institutions and its constituent Mcmber States.

The first part of this book deals with the reasons for the increased recourse to precaution in environmental and health protection, as well as the legal status of the precautionary principle in European and international trade law. The second part is devoted to the study of two different policy areas in three different countries.

The research builds on the excellent work already carried by several authors with regard to the current Iegal status of the precautionary principle in international, as well as European, law. ${ }^{4}$ This book aims to take the matter a step further and look beyond the

4 See, for example, N. de Sadeleer, Implementing the Precautionary Principle: Approaches from the Nordic Countries, the EU and the USA, Earthscan 2007; J. Scott, The WTO Agreement on Sanitary and Phytosanitary Measures, Oxford University Press, 2007; E. Fisher et al., Implementing the Precautionary Principle, Edward Elgar Publishing 2006; A. Trouwborst, The Precautionary Principle in General International Law: Combating the Babylonian Confusion, 16 Review of European Community and International Environmental Law (RECIEL), nr. 2, 2007, pp. 185-195; M.B.A. van Asselt \& E. Vos, The Precautionary Principle and the Uncertainty Paradox, 9 Journal of Risk Research 4, 2006; P. van den Bossche \& D. Prevost, The Agreement on the Application of Sanitary and Phyto-sanitary Measures, in: P. McRory, A. Appleton \& M. Plummer (eds), The World Trade Organisation: Legal, Economic and Political Analysis, Springer 2005, pp. 231-270; K.-H. Ladeur, The Introduction of the Precautionary Principle into EU Law: A Pyrrhic Victory for Environmental and Public Ilealth Law? Decision-making Under Conditions of Complexity in Multi-level Political Systems, 40 CMLR 6 , 2003,$1455 ;$ J. Scott \& E. Vos, The juridification of Uncertainty: Observations on the Ambivalence of the 
inclusion of the precautionary principle as a concept in legal acts and policy documents at international and European levels. Instead, the primary focus is on the practical application of the concept. Of primary importance in this regard is the study of the relevant case law in the legal systems investigated. Furthermore, the focus is on the concrete application of the principle by a number of states in their national policies. These case studies aim to discuss whether therc are differences between how precautionary considerations are applied in comparable situations in certain areas and in ccrtain countries.

The areas investigated are chemicals (pesticides) and mobilc phone systems (base stations). These areas have been chosen because they are examples of areas surrounded by varying, but comparable, amounts of uncertainty as to the risks associatcd with them, but areas in which different states have chosen to apply different approaches to these risks. The areas surveyed include risks to human health posed by food and technology, and risks to the environment. They share the basic trait that they are, to varying extents, involuntary risks; i.e., risks that are difficult or impossible to avoid even through vigilant behaviour on the part of the subjects to the risk.

Throughout this book the precautionary principle is treated by breaking it down to a number of constituent parts. This means that, in every legal system, the same topics are cvaluated and compared. This includes, in all cascs, an assessment of the definition and status of the precautionary principle in the relevant legal system; the type and scope of judicial review applied by courts; if a separation of risk assessment and risk management is upheld; an analysis of the burden and level of proof in place for the issuing of precautionary measures; if costs and benefits are considered; if risks are targeted rationally, and if trade-offs are considered. All of the above issues necessarily come into place when issuing precautionary measures, whether they are explicitly considered in a decision or not.

Precautionary Principle within the EU and the WTO, in: Ch. Joerges \& R Dehousse (eds), Good Governance in Europe's Integrated Market, Oxford University Press 2002, pp. 253-286; J. Cameron, The Precautionary Principle in International Law, in: Re-interpreting the Precautionary Principle, Cameron May, 2001; W. Douma, The Precautionary Principle; Its Application in International, European and Dutch Law. Proefshchrift Rijksuniversiteit Groningen 6 Jan. 2003; D. Grimeaud, Hoofdstuk II. The Precautionary Principle in International Environmental and Trade Law, in: M. Faure \& E. Vos (eds), Juridische apfakening van het voorzorgbeginsel: mogelijkheden en grenzen, Achtergrondstudie voor de Nederlandse Gezondheidsraad, No. A03/03 2003. A. Trouwborst: Evolution and Status of the Precautionary Principle in International Law, Aspen Publishers 2002; D. Freestone \& E. Hey (eds), The Precautionary Principle in International Law: The Challenge of Implementation, Kluwer Law Intcrnational, 1996. 


\section{Joakim Zander}

The first question to be answered in this book is if it is possible to find an objectively justifiable precautionary principle which is generally agreed upon by the states and organisations investigated below. If the answer to this question is yes, then this principle will be outlined and analysed. If the answer to this question is no, then the discrepancies will be identified and considered. Furthermore, the issue of whether it is necessary or even desirable, to establish such a system is also considered. Finally, the future role to be played by the precautionary principle is discussed. The main focus of this discussion is the EU and how the Mcmber States and the EU institutions can, and should, make use of the precautionary principle in order to safeguard an efficient and reliable risk reduction strategy.

Pesticides regulation is, to a large extent, regulated at EU level. Below it is discussed that, regardless of this, EU Member States might, in some cases, attempt to use the precautionary principle in order to apply their own risk levels. Two Member States of the EU, Sweden and the United Kingdom, have been especially chosen in order to illustrate the different approaches assumed by Member States to the precautionary principle within the EU. These two stales are then compared with the policies adopted by the United States in the same areas.

The reason for choosing to comparc Sweden and the UK is that they traditionally represent different European approaches to precaution when it comes to the environment and health protection. Sweden has a long tradition of far-reaching precautionary thinking when it comes to, for example, chemicals, pollution, and public health protection. ${ }^{5}$ The UK, on the other hand has traditionally applied a less stringent approach. However, recent "food scares", for example, the BSE crisis, has put a new emphasis on environmental and health concerns.

The United States, on the other hand, has a tradition of precaution when it comes to environmental and health protection in domestic policies, ${ }^{6}$ but is today perceived - at least by the EU - as not accepting the precautionary principle within the international arena. Here, the current use of precautionary considerations by the US is investigated and compared with the approach assumed by Sweden, the UK, and the EU.

See, for example, the preparatory works to the original Swedish Chemicals Code of 1973 in Prop. 1973:17, p. 96 et seq.

See, for example, D. Vogel, Ships passing in the night: GMOs and the Politics of Risk Regulation in Europe and the United States, Working Paper No 2001/16, Robert Schuman Centre for Advanced Studies, European University Institute, 2001. 
Introduction

The discussion on how and when to use precautionary measures is likely to continue for the foreseeable future, especially as the public becomes increasingly awarc of the risks to health and the environment. This book aims to contribute to this debate by providing a detailed look at the precautionary principle in a number of areas and states in order to provide some interesting input for the further development of the precautionary principle in the EU and its Member States. 


\section{CHAPTER 2.}

\section{RISK AND UNCERTAINTY: BASIC CONCEPTS AND TOOLS FOR THE APPLICATION OF THE PRECAUTIONARY PRINCIPLE}

\subsection{INTRODUCTION}

When Rachel Carson published her hugely influential book Silent Spring in 1962, she laid the foundation upon which the then recently conceived environmental movement would rest. ${ }^{1}$ With a language which is as dystopian as it is strangely poetic, Carson framed a rhetoric of which the environmental movement would come to make much use. Her fears and predictions with regard to chemicals, in particular DDT, still linger in the public minds of Europeans and Americans alike. Reports published over time maintaining that some of these fears are exaggerated have had nowhere near the same resonance as her original work.

Silent Spring was followed by other works in the 1970s which warned of the environmental consequences of industrialisation: Limits to Growth was published in 1972 and made the spcctacular, and much publicised, claims that, by 1990, the world would have run out of gold, silver, mercury and zinc. ${ }^{2}$ In The End of Affluence, published in 1974, Paul and Anne Ehrlich predicled the dangers following global cooling and the ncar end of fish in the seven seas. ${ }^{3}$ Fortunately, none of these particular claims have materialised. However, in recent years, publications have also emerged with the aim of highlighting the risks to human health and the environment that have actually materialised as a consequence of modernisalion. ${ }^{4}$

As a response to the above literature, some authors have also emphasised the lack of development and innovation that would have resulted had a certain amount of risks not been taken. ${ }^{5}$ Certainly, there is no lack of either nightmare scenarios or sunshine stories in the history of risk regulation.

1 R. Carson, Silent Spring, 104th edition, Marner Books, 2002.

2 D. Meadows et al., The Limits to Growth: A report for the Club of Rome's project on the predicament of mankind, Universe Books, 1974.

3 P.R. Ehrlich \& Anne Ehrlich, The End of Affluence: A blueprint for your future, Ballantine Books, 1974.

4 Late Lessons From Early Warnings: The precautionary principle 1896-2000, Environmental issue Report No. 22, 2002. Available at: http://reports.eca.europa.eu/environmental issue report 2001 22/en.

5 See, for example, A. Wildawsky, Trial and Error versus Trial Without Error, in: J. Morris, Rethinking Risk and the Precautionary Principle, Butterworth-Heinemann, 2000, pp. 22-46. 


\section{Joakim Zander}

At the beginning of the present century, the precautionary principle has emerged in an increasingly risk averse Europe as a "miracle cure" of sorts to the problems of dealing with risks. In allowing for regulation in spite of scientific controversy and the lack of clear scientific evidence, it seems to provide the regulator with the ultimate tool to address any risk decmed necessary. Until recently, the strict interpretation of the precautionary principle has been criticised mainly be American authors. ${ }^{6}$ In Europe, this critical discourse has been elaborated on to a more limited extent. ${ }^{7}$

This chapter aims to provide the theoretical background to the fundamental concepts of risk regulation in gencral and the precautionary principle in particular. Critical to this discussion is the definition of risk and risk perception, scientific uncertainty, how risks are analysed and how the instruments for weighing the costs and benefits of regulation are set up, as well as risk trade-off analysis. Furthermore, some attempts at conceptualising the precautionary principle are brielly summarised.

\subsection{Fundamentai, Concepts}

\subsubsection{Defining Risk}

Throughout the ages, mankind has been subjected to risks, by chance and as a means of surviving, as well as by choice. No doubt, a fundamental part of human existence has been pre-occupied with considering which risks to take and which to avoid, long before this was/became known as "risk regulation". Despite this, the "mastery of risk", the intention to control or apply one's behaviour in accordance with risks, is considered a uniquely modern concept. ${ }^{8}$ The rational science of risk, as we now know it, originally developed as a mathematical puzzle concemed with optimising gambling results. ${ }^{9}$ Later, it matured within the framework of economics and finance. ${ }^{10}$ During the second half of the Twentieth century, the influence of risk as a concept had spread to almost all areas of society and life. In fact, at

6 See, for example, J. Morris, Rethinking Risk and the Precautionary Principle, Butterworth-I Ieinemann, 2000; C. Sunstein, Risk and Reason: Safety, Law and the Environment, Cambridge University Press, 2004; C. Sunstein, The Laws of Fear: Beyond the precautionary principle, Cambridge University Press, 2005; G. E. Marchant, Arbitrary and Capricions: The precautionary principle in the European Union Courts, American Enterprise Institute Press, 2004.

7 See, for example, K..H. Ladeur, The Introduction of the Precautionary Principle into EU Law: A Pyrrhic Victory for Environmental and Public Health Law? Decision-making Under Conditions of Complexity in Mulit-level Political Systems, 40 CMLR 6, 2003, 1455, and L. Bergkamp, Understanding the Precautionary Principle (parts I and II), Env. Liability, Vol. 10, 2002, p. 18-30 and 67-82).

* P.L. Bernstein, Against the Gods: The remarkable story of risk, John Wiley \& Sons Inc., 1996, p. 11.

- D.A. Moss, When All Else Fails: Government as the Ultimate Risk Manager, Ilarvard University Press, 2002 p. 22 et seq.

10 P.L. Bernstein, Against the Gods: The remarkable story of risk, p. 97 et seq. 
present, the "mastering" of risk has become so fundamental for western societies that influential commentators argue that the age of modernisation has given way to a "risk society", in which the assessment and management of risks are its over-riding concerns. "

Generally, the term "risk" is understood to express something about the likclihood that a hazard will occur. ${ }^{12}$ Usually, definitions focus on the possibility of humans altering the chain of events leading to the realisation of a hazard. Thus, the relationship between the actions and the consequences is considered from a non-fatalistic viewpoint. ${ }^{13}$ Building on previous literature, Jaeger et al., have defined the term risk as:

"A situation or event in which something of human value (including humans themselves) has been put at stake and where the outcome is uncertain.".14

Stirling has formulated it in the following fashion:

"[Risk is] a situation under which it is possible to define all possible outcomes and confidently assign a probability to reflect the likelihoods of each outcome." 15

A hazard is a situation which can lead to harm, and harm is vicwed as a loss to a human being, a population group, or a negative impact on nature. ${ }^{16} \mathrm{~A}$ risk, as described here, can be defined as "certain" due to the fact that the hazard is known to exist and because mathematical probabilities can be assigned to its occurrence.

Even if the acknowledgement of risks allows a framework within which to reason about the unknown, risks often come "trailing clouds of vagueness", as Nobel laureate Kenneth Arrow once put it. ${ }^{17}$ Sometimes, these "clouds of vagueness" are so great that they obscure the hazard associated with a risk, or the harm that this hazard may inflict on humans

11 See, for example, U. Beck, Risk Society: Towards a New Modernity, Sage Publishers, 1992, and U. Beck, World Risk Society, Polity Press 1999.

12 See, for examplc, The Royal Society, Risk: Analysis, Perception, Management, The Royal Society, 1992, p. 2; J. Wiener, Precaution in a Mulit-Risk World, Duke Law School Public Law and Legal Theory Working Paper no. 23, December 2001. p. 3.

13 B. Rohrmann \& O. Renn, Risk perception research - An introduction, in: O. Renn \& B. Rohrman, Cross cultural Risk Perception: A Survey of Empirical Studies, Kluwer, 2000, p. 14.

14 C.C. Jaeger, O. Renn, E.A. Rosa \& T. Webler, Risk, Uncertainty and Rational Action, Earthscan, 2001, p. 17.

15 A. Stirling, On Science and Precautionary in the Management of Technological Risk, An Esto Project, Prepared for the European Commission - JRC Institute Prospective Technological Studies Seville, May 1999. p. 40.

16 Royal Society, Risk: Analysis, Perception, Management, p. 3.

17 K.I. Arrow, Know a Hawk from a Handsaw, in: M. Szenberg (ed), Eminent Economists: Their Life and Philosophies, Cambridge University Press, 1992. 
Joakim Zander

or on nature. In these cases, it may not be possible to detcrmine precisely what the hazard entails or the extent (or mere existence) of the harm such a hazard may bring. The probability of the occurrence of harm is, therefore, no longer possible to determine mathematically and the risk becomes "uncertain". The economist John Maynard Keynes once described "uncertain knowledge" in the following manner:

"I do not mean merely to distinguish what is known for certain from what is only probable. The game of roulette is not subject, in this sense, to uncertainty. [...] The sense in which I am using the term is that in which the prospect of a European war is uncertain, or the price of copper and the rate of interest twenty years hence, or the obsolescence of a new invention. [...] About these matters, there is no scientific basis on which to form any calculable probability whatever. We simply do not know!"”8

For the purposes of this book, these risks will be referred to as "uncertain risks".

One way to categorise different risks is thus to separate "certain risks" from "uncertain risks". These two groups of risks can be further divided into the sub-groups of "voluntary risks" and "involuntary risks". Voluntary risks are the risks about which one makes an active choice to be subjected to. Examples of such risks include skydiving and smoking. Involuntary risks are those risks about which one has little or no choice to accept or not. Examples from this category include contaminated drinking water and a society's use of nuclear power. Some authors hold that people in general consider involuntary risks to be more troublesome than voluntary risks. ${ }^{19}$ The reason for this scems to lic in the fact that there is no choice as to whether to take the risk or not, and therefore levels of accepted risk are lower. Connected to this is the lack of control one has of a situation incurred by involuntary risks. As a consequence of this, people are in general assumed to accept a higher level of risk when they have some way in which they can influence the outcome of a situation. ${ }^{20}$

18 J.M. Keynes, The General Theory of Employment, The Quarterly Journal of Economics, Vol. 51, p. 213 ,

C. Starr, Social benefit versus technological risk, Science, 1969, 165, pp. 1232-1238. For a critique of these findings, see P. Slovic, B. Fischoff \& S. Lichtenstein, Facts and Fcars: Understanding Perceived Risk, in: P. Slovic, The Perception of Risk, Earthscan, 2000, pp. 146-148. It is held by Slovic et al that the involuntariness of the risks in the Starr study were not necessarily what caused the aversion. Rather it is suggested that the catastrophic nature of many involuntary risks may be the reason behind the attitudes presented. See, also, S. Jasanoff, Science at the Bar, Harvard University Press, 1995, p. 13, and C. Sunstein, Risk and Reason: Safety, Law and the Environment, note 6, p. 67.

20 C. Sunstein, Risk and Reason: Safety, Law and the Environment, p. 72, For a critique of the above assumptions, see P. Slovic, The Perception of Risk, pp. 146-150. Slovic claims that respondents in the sociological surveys in question may have turned against the often catastrophic nature of involuntary incurred risks, rather than against the risks being involuntary per se. 


\subsubsection{The Perception of Risk}

It has been held that scientific experts no longer play the prominent role in risk regulation that they once did. Increasingly, the media, stakeholders and other scientists comment on, disagree with, and debate scientific findings. ${ }^{21}$ Some commentators find this to be a positive development and argue in favour of further input by lay-people in risk assessments. ${ }^{22}$ However, it is important to bear in mind some cognitive problems when thinking about risks.

Non-experts generally do not view risk in an objective and rational manner. Instead, risks tend to be valued differently depending on how they are presented. In general, people tend to gamble more in order to avoid harm than they arc willing to gamble for gain, even if the mathematical probabilities are equal. Furthermore, lay people tend to over-estimate low probabilities and tend to be generally risk averse. ${ }^{23}$ This bchaviour leads to what Viscusi has called "the precautionary paradox", which means that people apply the contradictory behaviour of taking great care to avoid low probability risks, while, at the same time, engaging in higher probability risks without much thought. ${ }^{24}$ In short, their behaviour is not rational. An expert in a certain field values a risk very differently from someone who is not an expert. 25

Slovic et al., summarised four basic issues that influence lay people's perception of risks. First, cognitive limitations coupled with the anxieties of considering life as a gamble lead to uncertainties being denied, risks being distorted and statements of fact over-estimated. Second, the perception of risks is oflen influenced by the familiarity with cerlain types of hazards. Third, like experts, lay people tend to put emphasis on the frequencies of death. However, unlike experts, they place great significance on qualitative aspects of risks, such as dread, the likelihood of fatal accidents and catastrophic potential. Finally, Slovic et al., concluded that it can be very difficult to change the perception of risk, even when "evidence" is presented. ${ }^{26}$

21 R. Löfstedt, Risk Communication and Management in the Twenty-First Century, International Public Management Journal, Vol 7, Issue 3, 2004, 335-346, at 343.

22 See, for example, M. O'Brien, Making Better Environmental Decisions: An alternative to Risk Assessment, MIT Press, 2000.

23 D. Kahneman \& A. Tversky, Prospect Theory: An Analysis of Decision under Risk. Econometrica, Vol. 47, Number 2, 1979.

24 K. Viscusi, Rational Risk Policy, Oxford University Press, 1998, pp. 11-14 and 25.

25 See S. Breyer, Breaking the Vicious Circle: Towards Effective Risk Regulation, Harvard University Press, 1993, p. 21, Table 4.

26 P. Slovic, B. Fischoff \& S. Lichtenstein, Rating the Risks, in: P. Slovic, The Perception of Risk, p. 119. Similar findings are presented in P. Slovic, B. Fischoff \& S. Lichtenstein, Facts and Fears: Understanding 


\section{Joakim Zander}

Sunstein pointed out three basic tenants that most people use to frame their thinking of risk. First, people tend to think of risks in an all-or-nothing manner. Either the risk is taken, or it is not. However, in most cases, there is a wide spectrum between taking a risk and not taking it. Second, people tend to believe in the "benevolence of nature". Thus, in surveys, people state that they do not fear natural pesticides as much as they fear man-made ones. However, in reality, natural pesticides are just as toxic as man-made pesticides. ${ }^{27}$ Third, people believe in the possibility of zero-risk. As discussed above, science, in most cases, does not lead to certain results, and uncertainty is an integral part of all risks. Therefore, an absolute zero-risk approach is utopian at best, unless all risk-taking was halted, which most people would find less than desirable. ${ }^{28}$

Another key aspect of the perception of risk is the public trust in the risk messenger. Since most information about risks is not received through personal experience, but through second-hand learning, the confidence of the intermediary in this regard is of crucial importance. ${ }^{29}$ Löfstedt holds that the distrust in policy-makers and industry in the 1990 s contributed greatly to the public's declining feeling of safety in Europe, although, in reality, society was safer than ever before. ${ }^{30}$

Furthermore, the perception of risk might be influenced by the fundamental values a person subscribes to, or to which cultural group he or she belongs. The perception of risk may also vary according to national backgrounds. ${ }^{31}$

The apparently inherent irrationality in the public perception of risks has led some commentators to state that public opinion that is ill-informed or based upon biases and heuristics should be disregarded by a responsible risk regulator. ${ }^{32}$ Some have even stated that current risk regulation that is not solely based upon rational criteria leads to a substantial amount deaths which could have been prevented had a rational allocation of resources been

Perceived Risk, in: P. Slovic, The Perception of Risk, pp. 136-153. See, also, P. Slovic, The Perception of Risk, pp. 264-275.

27 K. Viscusi, Rational Risk Policy, pp. 86-88.

${ }_{28}$ C. Sunstein, Risk and Reason: Safety, Law and the Environment, p. 36

29 O. Renn \& B. Ruhrmann, Risk perception rescarch - An introduction, in: O. Renn \& B. Rohrman, Crosscultural Risk Perception: A Survey of Empirical Studies, p. 31.

30 R. Löfstedt, Risk Management in Post-Trust Societies, Palgrave Macmillan, 2005, p. 9

31 O. Renn \& B. Ruhrmann, Risk perception research - An introduction, in: O. Renn \& B. Rohrman, Crosscultural Risk Perception: A Survey of Empirical Studies, pp. 33-38.

32 J. Wiener, Precaution in a Multi-Risk World, p. 4, and B. Duriode, The True Cost of Precautionary Chemicals Regulation, p. 395. 
the determinant factor. ${ }^{33}$ Other commentators have held that allowing public opinion to influence the assessment of uncertain risks is essential in order to allow cthics, values and politics to influence scientific conclusions and create "robust" solutions. ${ }^{34}$

\subsubsection{Scientific Uncertainty, Prevention and Precaution}

Abovc, a distinction between "uncertain" and "certain" risks was made. However, even when dealing with certain risks, uncertainty comes into play, because even if the hazard is known and the probability of harm is possiblc to cstimate, uncertainty will pertain to the exact time and magnitude of its occurrence, as well as to the exact quality of the measurements upon which the estimation is based. ${ }^{35}$

In risk literature, some commentators have defined uncertainty as a situation in which the hazard and harm is known, but it is impossible to assign probabilities to its realisation. Situations in which the outcomes are not known and the probabilities are impossible to assign are then known as ignorance. ${ }^{36}$ Others have focused on a definition of uncertainty as simply a lack of information. ${ }^{37}$ However, Walker et al, have pointed out that uncertainty can also prevail in situations where information is abundant. ${ }^{38}$ More information does not necessarily remove the uncertainty. Walker et al., have, instead, proposed a broad definition which holds that uncertainty is "any departure from the unachievable ideal of complete determinism". 39 Following such a definition, any situation would be fraught with a varying degree of uncertainty. Complete determinism is utopian. In the most commonly accepted definitions of the precautionary principle, it is clearly established that it applies in cases where "full scientific proof" is lacking. ${ }^{40}$ In order for something to be scientifically proven, it not required that all uncertainty be resolved. Instead, scientific certainty is generally accepted to be in place when something can be considered to be $95 \%$ certain. $^{41}$ Thus, the precautionary

33 T.O. Tengs, M.E Adams, J.S. Pliskin, D.G. Safran, J.E. Siegel, M.C. Weinstein \& J.D. Graham, Fivehundred life-saving interventions and their cost-effectiveness, Risk Analysis, Vol. 13, 1995, pp. 369-390.

34 S. Funtowicz \& R. Ravetz, Science fort he Post-Normal Age, Futures, Vol. 25, Issue 2, 1993, pp. 749-752.

3.5 See, for example, F. Knight, Risk, Uncertainty and Profit, Houghton Mifflin Co., 1933.

36 A. Stirling, On Science and Precautionary in the Management of Technological Risk.

37 See, for example, S.O. Funtowicz \& J.R. Ravetz, Uncertainty and Quality in Science for Policy, Kluwcr, 1990.

38 W.E. Walker, P. Harremoes, J. Rotman, J.P van der Sluijs, M.B.A. van Asselt, P. Janssen \& M.P. Krayer von Krauss, Defining Uncertainty: A Conceptual Basis for Uncertainty Management in Model-Based Decision Support, Integrated Assessment Vol. 4, No. 1, 2003, p. 8.

39 Ibid.

40 See, below, Chapter 3 in rclation to the Rio Declaration.

41 J. Lemons, K. Schrader-Frechette \& C. Cranor, The Precautionary Principle: Scientific Uncertainty and Type I and Type II Errors. Foundations of Science Issue 2, 1997, p. 211, and J. Tickner, The Precautionary Principle in Action: A Handbook, Science and Environmental Health Network, 13. Available at: 


\section{Joakim Zander}

principle can be considered to apply in the spectrum between 0 and $95 \%$ certainty. Where something is scientifically certain, it is likely that the principle of preventive action will bc applied. ${ }^{42}$ According to this principle, anyone who carries out an activity has the duty to prevent any harm to the environment or to human health which stems from the activity. It is generally understood that this principle applies where a causal link between the activity and the harm is clearly established. The precautionary principle extends the scope of the preventive action to siluations in which the causal link is not as clear. Using the above dichotomy, the prevention principle applies when tackling certain risks, and the precautionary principle applies when dealing with uncertain risks.

To assist us when thinking in terms of ranges of uncertainties, van Asselt has established a number of degrces of uncertainty, ranging from inexactness to indeterminacy. ${ }^{43}$ First, incxactness is the degree closest to certainty in the spectrum. It seems to encompass any uncertainty that can be described adequately in statistical terms. For example, it represents the uncertainty inherent in all data. Measurements of reality can never represent the "true" value of what is being measured. Inaccuracy or imprecision will always flaw the values established. $^{44}$

The second degree of uncertainty is lack of obscrvations or measurements. This uncertainty is due to a lack of information. With more measurements and research, such uncertainty may possibly be reduced and become scientifically certain.

The third degree of uncertainty can be described as a result of conflicting evidence. ${ }^{45}$ Divergent scientific reports exist, which give different answers to the same question. Such divergent opinions may be resolved when additional research is performed and the level of uncertainty may be decreased to inexactness. Similarly, divergent opinions may indicate that

httr://www.mindfully.org/Precaution/Precaution-In-Action-Handbook.pdf:

42. For a discussion on the status of the precautionary principle in international and European law, see, below, Chapters 3 and 4, respectively.

4.3 M.B.A. van Asselt, Perspectives on Uncertainty and Risk: The PRIMA Approach to Decision Support. Kluwer 2000, p. 91.

44 Walker, Defining Uncertainty: A Conceptual Basis for Uncertainty Management in Model-Based Decision Support, p. 12.

45 M.B.A. van Assclt positions this uncertainty as the second degree ibid and as the fourth degree together with Rotmans, in: J. Rotmans \& M.B.A. van $\Lambda$ sselt, Uncertainty Management in Integrated $\Lambda$ ssessment Modeling: Towards a Pluralistic Approach. Environmental Monitoring and Assessment. Issue 69, 2001, p. 113. This author finds it most useful to position it between lack of information and immeasurability due to the fact it appears to be a more complex form of uncertainty than lack of information in that it is not necessarily enough to conduct more research to reduce the uncertainty. At the same time, it is not as complex as being described as immeasurable due to the fact that different scientists actually have claims to have measured the issue, albeit having reached diverging conclusions. 
no conclusive method exists for evaluating the evidence, and it, therefore, borders on being immeasurable.

The fourth degrec of uncertainty is described as existing due to the fact that the issue is practically immeasurable. It is simply not possible, at least not in the foreseeable future, to obtain the data necessary to reach the desired level of certainty.

The final degree of uncertainty is ignorance, which means that the actual risk is hidden or unexpected and is, therefore, not possible to consider. When considering the other four levels of uncertainty, the risk in question is identified, but its magnitude and probability remains uncertain. With regard to ignorance, the risk itself is "off screen" and cannot, therefore, be considered.

If this system is applied to the discussion above, the conclusion is that the prevention principle applies in the inexactness phase in van Asselt's scheme, since the causal link here is adequately established, probabilities are possible to assign to the risk, and the remaining uncertainty is merely duc to the imperfect nature of all scientific measurements. Ergo, the preventive principlc applies in instances of scientific certainty, i.c., in cases that are estimated to be $95 \%$ certain.

In the second and third phases, lack of information and scientific controversy respectively, the precautionary principle comes into play. Here, the $95 \%$ certainty requirement is impossible to fulfil.

\subsection{Striking a BALANCE in Risk Regulation}

\subsubsection{The Three Phases of Risk Regulation}

\subsubsection{Risk Assessment}

Risk assessment is the general term which refers to the scientific element in risk regulation. ${ }^{46}$ In some of the literature, this phase is referred to as risk estimation, and risk assessment refers to the whole process of making decisions about risks. ${ }^{47}$ However, for the purposes of this study, risk assessment is understood as the scientific evaluation of risk.

Risk assessments can be quantitative, where the cmphasis lies on the expression of numerical results, or they can include qualitative assessments. Broader definitions of risk

46 Sce, for example, National Research Council, Risk Asscssment in the Federal Government: Managing the Process, National Academy Prcss, 1983, 17.

47 See, for example, The Royal Society, Risk: Analysis, Perception, Management, p. 3. 
assessment include the analysis of risk perception, economic considerations and risk trade-off analysis. ${ }^{48}$ Here, such considerations will be considered in the risk management phase.

It has been held that the process of risk assessment contains threc main parts: 1) the identification of potential outcomes; 2) the estimation of the magnitude of these outcomes; and 3) the probability of the realisation of the outcomes. ${ }^{49}$ The aim of the process is to provide the decision-maker in the risk management phase with tangible and accessible data upon which a decision can be based. In the United States four steps are generally emphasised as constituting the risk assessment phase: 1) hazard identification; 2) dose-response assessment; 3) exposure assessment; and 4) risk characterisation. ${ }^{50}$ This has also been the view of the European Commission (hereinafter "the Commission"). ${ }^{51}$

The main reason for maintaining a strict scparation between risk assessment and risk management is to avoid policy prefcrences influencing what should be an "objective" scientific assessment. ${ }^{52}$ However, the question of objective science is a problematical one. The assessment of risks will invariably be influenced by the social interaction between scientists, the reigning scientific and ethical paradigms, and boundary work. ${ }^{53}$ At European level, the late recognition of, and subsequently late reaction to, Creutzfeld-Jakob's disease has been attributed largely to the influence of "British thinking" in the relevant scientific committee. A large number of the members of the committee were British, influential and initially not inclined to favour evidence perceived as negative for the UK. ${ }^{54}$ This is but one example of how outside elements influence scientific work. However, recognising this, and striving to minimise non-scientific influence, is necessary to maintain the credibility of scientific advice. Thus, formally separating scientific assessment from political decisions

48 National Research Council, Risk Assessment in the Federal Government: Managing the Process, p. 17.

49 Royal Society, Risk: Analysis, Perception, Management, p. 3, and J. King, Application of Risk Assessment in Policy and legislation in the European Union and in the United Kingdom, in: P. Calow, Handbook of Environmental Risk Assessment and Management, Blackwell Science 1998, p. 249 et seq.

50 National Rescarch Council, Risk Assessment in the Federal Government: Managing the Process', p. 19-20.

51 Communication from the Commission of 2 February 2002 on the Precautionary Principle, COM (2001), 13 and Annex III.

52 Ibid., 33.

53 For a brief summary of this critique, see S. Jasanoff, The Fifth Branch: Science Advisors as Policymakers, Harvard University Press 1994. p.12-15 See, also, C.C. Jaeger, O. Renn, E. A. Rosa \& T. Webler, Risk, Uncertainty and Rational Action, pp. 213-221, and K. Shrader-Frechette, Scientific Method, AntiFoundationalism and Public Decision, in: E. Löfstedt \& L. Frewer (eds), The Earthscan Reader in Risk and Modern Society, Earthscan, 1998, 45-57. For the theoretical foundation for this critique, see T. Kuhn, The Strucure of Scientific Revolutions, University of Chicago Press, 1962.

54 E. Vos, EU Food Safety Regulation in the Aftermath of the BSE Crisis, Journal of Consumer Policy 23 2000, p. 231 et seq. 
based upon that information is by most commentators seen as essential. As one commentator put it:

"Of course, science has never been value-free, but maybe it should continuously strive to become so and to preclude, rather than to include, external influence." $" 55$

Other commentators have criticised the use of risk assessment on the basis that they are narrow in scope and risk missing important alternative approaches to risks. ${ }^{56}$

\subsubsection{Risk Management}

Risk management has been defined as "the process of evaluating alternative regulatory actions and selecting among them". ${ }^{57}$ In the risk management phase, the results of the risk assessment are considered when deciding on the appropriate response to a specific risk. Two main reasons have been put forth in support of not allowing the scientific assessment alone to provide the answer to how to respond to a risk. First, as discussed above, science is only onc of the components to be considered when deciding on how to respond to a risk. Other factors, such as the costs and benefits of certain regulation, risk trade-offs, and public opinion may be as important as the scientific evaluation of the facts underlying a decision. Most activities are associated with varying degrees of certain or uncertain risks, but the resources of all societies are limited, and a selection of which risks to target must be made taking aspects other than the scientific data into account. ${ }^{58}$

Second, the risk management phase needs to ensure a high degree of lcgitimacy and accountability. Citizens have a right to be able to hold those who make decisions relating to risks accountable for their actions. ${ }^{59}$ Scientists are not accountable to the public in the same way that politicians or other public officials are. Therefore, it is argued that it is important that the final decision rests within a structure that can be held accountable within established democratic systems.

55 B. Duriode, The True Cost of Precautionary Chemicals Regulation, Risk Analysis. Vol. 23. No. 2, 2003, p. 395.

56 See, for example, M. O'Brien, Making Better Environmental Decisions: An alternative to Risk Assessment.

57 National Research Council, Risk Assessment in the Federal Government: Managing the Process, p. 18.

58 K. Viscusi, Rational Risk Policy, p. 84-85.

59 Weber argued along these lines in rclation to bureaucracies needing a structure above it to give it policy guidance. See M. Weber, The Theory of Social and Economic Organization, Henderson and Parson, 1947, p. 335. 
Joakim Zander

Since risk management is disconnected from risk assessment, and there is no universally agreed upon structure for managing risks, different states apply different risk management strategies. It is up to the risk managers of cach state to decide upon what level of protection each state is to employ. ${ }^{60}$ In doing so, different states choose to attribute varying weight to scientific evidence depending on the area which is to be regulated. ${ }^{61}$ The precautionary principle is a risk management tool, which can be used by a regulator to enact measures in the face of uncertainty. ${ }^{62}$

\subsubsection{Risk Communication}

The final step in the chain of risk analysis has traditionally been assigned to the issue of communicating the assessed and regulated risk. In recent years, the interest in risk communication has increased significantly. Therc may be several explanations for this, for example, the increase in transparency and right-to-know laws, but the most tangible reason may be the recent "food scares" experienced in Europe and the subsequent focus on environmental and health issues by the media and the general public. ${ }^{63}$ The more concerned the public becomes, the more it seeks to influence the management of risks. The media, sensing the interest in risk-related issues, spurs the interest they see in citizens by covering risks extensively. However, as mentioned above, the media oflen simplifies the information it transmits and has problems communicating scientific uncertainty. Thus, the public discourse becomes simplified, and public may make demands that risk regulators find difficult to fulfil.

The public tends to be "ambiguity-averse" and demands clear answers to the magnitude and probability of risks. ${ }^{64}$ When the regulator cannot provide an unambiguous answer, the degree of trust in the regulator decreases. The regulator, seeking to avoid this, tries to take public opinion into account at an earlier stage in the risk management phase. However, since public opinion may be ill-informed and simplified, the resulting regulation may be equally flawed. Then, the flawed regulation is again picked up by the media and

60 See, for example, Article 2.1 of the WTO Agreement on the Application of Sanitary and Phytosanitary Measures.

${ }_{61}$ This is returned to and investigated in the case studies in the following chapters.

62 Communication from the Commission of 2 February 2002 on the Precautionary Principle, COM (2001) 1, p. 12.

63 V.T. Covello, Risk Communication, in: P. Calow, Handbook of Environmental Risk Assessment and Management, p. 520.

64 Bernstein refers to Daniel Ellsberg's work on ambiguity aversion, in: P.L. Bernstein, Against the Gods: The remarkable story of risk, p. 280. 
criticised by the public. In this way, what U.S. Supreme Court Justice Breyer has referred to as, a "vicious circle" is created and rc-inforced. ${ }^{65}$

In such a system as that described above, the issue of communicating risk is absolutely central, since it will determine not only how the public reacts to the risk in question, but also how it reacts to related risks in the future. Slovic has held that, in order to inform about risks effectively, risk communicalors must be well-educated in the fundamentals of the risk assessments which have been carried out, including its limitations and its unresolved uncertainties. Furthermore, the risk communicator must be aware of the limitations of the public understanding of risks. As discussed briefly above, lay peoples' perceptions of risks are often flawed and deeply-held beliefs are difficult to modify. Furthermore, comparing risks statistically to other risks may be a useful way of putting things into perspective. ${ }^{66}$

Fischoff emphasises that risk communications strategies have to be developed on a case-by-case basis, but identifies seven "developmcntal stages" for risk communications. These include, getting the numbers right, communicating the numbers, explaining the meaning of the numbers, showing that similar risks have been accepted in the past, showing that accepting the risks is actually a good deal, treating the public nicely, and, finally, making the public partners in the risk management. ${ }^{67}$

Furthermore, the issue of trust in the risk manager is central to how the risk communication will be received. Löfstedt ${ }^{68}$ and Slovic ${ }^{69}$ have noted that there is a strong correlation between high perceived risks and high distrust in risk managers. Furthermore, it is much easier to lose trust than to build it up again. In order to inform and cducate the public about risk effectively, the risk communicator must be aware of the level of trust enjoyed by the regulator, as well as be informed about the perception of the risk in the public. ${ }^{70}$

\subsubsection{Cost-benefit Analysis}

Today, most commentators consider some kind of cost-benefit consideration an essential instrument in order to cnsure an effective and efficient regulatory approach to risks. This is

65 S. Breyer, Breaking the Vicious Circle: Towards Effective Risk Regulation, p. 50-51.

66 P. Slovic, Informing and Educating the Public about Risk, in: P. Slovic, The Perception of Risk, pp. 183-191.

67 B. Fischoff, Risk Perception and Communication Unplugged: Twenty Years of Process, in: R. Löfstedt \& L. Frewer, The Earthscan Reader in Risk and Modern Society, pp. 133-145.

68 R. Löfstedt, Risk Management in Post-Trust Societies, p. 9.

69 P. Slovic, Perceived Risk, Trust and Democracy, in: P. Slovic, The Perception of Risk, pp. 317-318.

70 R. Löfstedt, Risk Management in Post-Trust Societies, pp. 4-11. 


\section{Joakim Zander}

duc to the fact that it is simply not possible to eliminate all risks in societics in which the funds are limited. Thus, risk managers need to be selective. ${ }^{71}$ Some commentators have held that regulation that does not take adequate account of the relcvant costs leads to wasteful allocation of resources and even unnecessary loss of lives. ${ }^{72}$ In some cases, blindness to the costs of regulation has led to exorbitant costs in order to eliminate small or negligible risks. One aspect of this is that, in some cases, a regulator might incur $90 \%$ of the costs of regulation in order to eliminate the last $10 \%$ of the risk. ${ }^{73}$ This is what Breyer has called "the problem of "the last ten percent"." ${ }^{74}$

Cost-benefit analysis has been defined as "[...] a full accounting of the consequences of risk reduction, in both quantitative and qualitative terms". ${ }^{75}$ It seeks to investigatc "[...] whether the expected benefits from a proposed activity outweigh its expected costs". ${ }^{76}$ In the United States, the use of cost-benefit analysis as an instrument in the risk management phase has been enshrined in executive orders issued by every president since Reagan, even if it lacks firm support in the law. ${ }^{77}$ However, bearing in mind that Republican (Rcagan, Bush I and Bush II) as well as Democrat (Clinton) presidents have supported the concept, there seems to be a close political consensus relating to its practice. ${ }^{78}$

In Europe, discussions on the use of the cost-benefit instrument are much more recent. A non-binding reference to it is included in the Commission Communication on the Precautionary Principle. ${ }^{79}$ Furthermore, EC legislation is subjected to the over-riding principle of proportionality, ${ }^{80}$ which contains the application of some form of cost-benefit analysis, although it is not defined or formalised. ${ }^{81}$

${ }^{71}$ K. Viscusi, Rational Risk Policy, p. 85.

See, for example, T.O Tengs, M.E Adams, J.S. Pliskin, D.G. Safran, J.E. Siegel, M.C. Weinstein \& J.D. Graham, Five-hundred life-saving interventions and their cost-effectiveness; J.D. Graham, Legislative Approaches to Achieving More Protection Against Risk at Less Cost, U Chi L F 13, 1997.

73 K. Viscusi, Rational Risk Policy, 99.

74 S. Breyer, Breaking the Vicious Circle: Towards Effective Risk Regulation, pp. 11-12.

${ }^{75}$ C. Sunstein, Risk and Reason: Safety, Law and the Environment, p. 106.

76 P. Slovic, The Perception of Risk, p. 122.

77 C. Sunstein, Risk and Reason: Safety, Law and the Environment, p. 6. For an early and influential evaluation of the costs associated with regulation in a number of different areas, see R.W. Hahn \& J.A. Hird, The Costs and Benefits of Regulation: Review and Synthesis, 8 Yale J. on Reg. 233, 1991.

78 Graham has argued forcefully for Congress to mandate in law the Executive Office of the President to carry out cost/benefit analyses and a clear prioritisation of risks. See J.D. Graham, Legislative Approaches to Achieving More Protection Against Risk at Less Cost, p. 7 \& pp. 49-57,

$79 \operatorname{COM}(2000) 1$, p. 18.

${ }^{80}$ Article 5 of the Treaty establishing the European Communities.

81 See J. Jans, Proportionality Revisited. Legal Issues of Economic Integration, Vol. 27. Issuc 3, 2000, pp. 239. 265. 
In order for it to be possible to carry out a cost/benefit analysis, non-economic values, such as environmental protection and human lives, need to be monetised in order for them to be compared with the costs associated with protecting them. For economists, this is not a controversial issue since it enables the necessary comparison and gives "real" value to issues that might otherwise be ignored. ${ }^{82}$

However, the use of cost-benefit analysis has been criticised on the grounds that, when it comes to uncertain risks, there is not sufficient information for a cost-benefit analysis provide a clear answer. ${ }^{83}$ Since the causal link between a risk and an activity may be hidden, or the magnitude of a risk may be impossible to estimate, some variables in the cost-benefit equation might be overlooked, or assigned flawed values. Thus, the result of a cost-benefit analysis may not adequately depict reality, and, according to some, only blur the picture. Instead of "scrambling" the picture with a cost-benefit analysis, it is argued that it is bettcr to vicw all the facts individually. ${ }^{84}$ Connected to this is the issue that regulators may overestimate technology and processes which are well-understood by them and which they may already be promoting. ${ }^{85}$

Others have argued that, far from being value-free, cost-benefit analysis is valuebased, especially when it comes to assigning costs and benefits to future events. How much is a human life worth? How do we value the benefits of our children having the opportunity to enjoy untouched forests? In order to carry out a cost-benefil assessment, monetary estimations have to be assigned to these variables. There is obviously no objectively scientific method for doing this, so the regulator falls back on socictal values to make hypothetical estimations. ${ }^{86}$ Connected to the above are the arguments of critics who hold that cost-benefit analysis is, in general, immoral or unethical, in that it forces human lives and other immeasurable entities to be assigned a monetary value. ${ }^{87}$

82 K. Viscusi, Monetizing the Benefits of Risk and Environmental Regulation, 33 Fordham Urb. L. J. 1003, 2006, 1003-1004.

83 P. Slovic, The Perception of Risk, p. 124. For a recent general critique of the use of cost/benefit analysis in regulation, see F. Ackerman \& L. Heinzerling, Priceless: On Knowing the Price of Everything and the Value of Nothing, The New Press. 2004.

84 L. Heinzerling, Regulatory Costs of Mythic Proportions. Yale Law Journal Vol. 107 1981, p. 2069.

${ }^{85}$ See, in this regard, J.C. Johnston, A Game Theoretic Analysis of Alternative Institutions for Regulatory Cost-Benefit Analysis, University of Pennsylvania Law Review Vol. 150: 5 2002, p. 1343-1411.

86 M. Douglas \& A. Wildawsky Risk and Culturc, p. 70-73.

87 See E. Anderson, Value in Ethics and Economics, Harvard University Press 1993. 
Joakim Zander

It is important to bear the criticisms of cost/benefit analysis in mind when considering the basis for regulation. However, not even the most hardened defenders of the rational regulation of risks consider that cost/benefit analysis should function as the be-all and end-all of risk regulation. Instead, it has been highlighted that it should work together with other analytical tools, such as risk assessment and the understanding of risk perception. ${ }^{88}$ It has also bcen highlighted that, at the end of the day, regulatory decisions regarding risks are not merely technocratic, but of policy nature. Thus, it is likcly that criteria other than the strictly rational criterion will influence the outcome of most decisions. ${ }^{89}$

Cost-benefit analysis for the purposes of this book is not understood as an all-ornothing formula for providing an unequivocal answer to the question of whether to regulate or not. Instead, it is to be understood as a tool for the decision-maker to use in order to put the bencfits as well as the costs of the proposed regulation "on screen" in order to be able to make an informed choice on regulation. ${ }^{90}$

The transparency offered by a careful cost-benefit analysis can also be successfully used as a tool to explain different regulatory options in a very tangible way to citizens. When rationally comparing costs and benefits with each other, cognitive errors and biases may be corrected. In this way it is hoped that emotional interpretation will not find its way into a formalised weighing of the facts. ${ }^{91}$

\subsubsection{Risk Trade-off Analysis}

The procedures to identify hidden risks, weigh risks against each other and rank them according to the order in which they should be dealt with in order to ensure maximum safety for the lowest cost are complementary to cost-benefit analysis. In employing such approaches, focus is turned away from individual risks and toward a holistic view, encompassing the whole risk spectrum.

88 J.D. Graham, Legislative Approaches to Achieving More Protection Against Risk at Less Cost, pp. 20-22, and J.D. Graham \& J.K. Hartwell, The risk management approach, in: J.D. Graham \& J.K. Hartwell (eds), The Greening of Industry, Harvard University Press, 1997, p. 1-2.

${ }^{89}$ R.W. Hahn \& J.A. Hird, The Costs and Benefits of Regulation: Review and Synthesis, p. 259.

90 C. Sunstein, Risk and Reason: Safety, Law and the Environment, p. 29.

${ }^{21}$ In this regard, it should be noted out that some commentators, although agreeing that a weighing of costs and benefits can help correct biases and heuristics, holds that the main problem of risk regulation is that centralised systems lack the political capital to enter into effective bargaining. Therefore, Johnston considers decentralisation of risk regulation to be the most beneficial way to ensure an effective allocation of resources. See J.C. Johnston, Paradoxes of the Safe Society: A Rational Actor Approach to the Reconceptualization of Risk and the Reformation of Risk Regulation, University of Pennsylvania Law Review Vol. 151: 747 2003, p. 747-784. 
The benefits of such approaches are scveral. First of all, risks do not appear in isolation. ${ }^{92}$ The removal, or targeting, of one risk may be accompanied by countervailing risks. A countervailing risk is the risk of an adverse outcome from a measure that was intended to address a target risk. An example of this would be side-effects of medication. The medication targets one risk, but is accompanied by the risk of creating other harm. ${ }^{93}$

Furthermore, the targeting of one risk may result in a risk offset. This means that removing one risk opens up the field to other, potentially more harmful, risks. One example of this is when the EU, after heavy lobbying from Greenpeace, decided to ban PVC plastics in children's toys. However, since only the PVC component was targeted, other plastics, about which very little was known, flooded the market. Thus, the positive effect of targeting the risk posed by PVC was offset by the new risks that emerged as a result of it. ${ }^{94}$

When one risk replaces another risk for the same affected people, this is called risk substitution. Finally, when a countervailing risk poses a new potential outcome for a different group of people than those who benefited from the targeting of the first risk, this is known as risk transformation. ${ }^{95}$

If the goal of the regulator is to achieve over-all safety for citizens, all of these factors need to be taken into account. It is not sufficient to focus on the targeting of one risk, since this may be accompanied by an increase in other risks for the same or for another group of pcople. This is especially important, as well as complicated, in cases of uncertainty. Just as not targeting a risk may lead to adverse effects, the actual targeting of a risk may lead to unforeseen or overlooked countervailing effects or risk offsets. As in the case of cost-benefit analysis, thinking in terms of risk trade-offs does not provide a scientifically acceptable, unequivocal miracle cure, but it does allow the regulator to put some of the hidden consequences of regulation, as well as non-regulation, "on the screen". Once all the effects of rcgulation are visible, the regulator can choose the "risk superior" approach to regulating the risk. This means that the regulator aims at the approach that best focuses on the overall risk level, not on the isolated risk. This may include the ranking of risk-reducing policies. This

92 See, for example, U. Bcck, World Risk Society, p. 75.

93 J.D Graham \& J. B Wiener, Risk versus Risk: Trade-offs in Protecting Health and the Environment, Harvard University Press 1995. p. 23.

94 B. Duriode, Plastic Panics: European Risk Rcgulation in the Aftermath of BSE, in: J. Morris (ed). Rethinking Risk and the Precautionary Principle, pp. 142-167.

95 J.D Graham \& J.B Wiener, Risk versus Risk: Trade-offs in Protecting Health and the Environment, p. 25. 
ranking may be based upon cost effectiveness, ${ }^{96}$ but also on how best to ensure overall safety, regardless of costs. ${ }^{97}$ This issue is returned to in some more detail in the section on the United States, where Regulatory Impact Assessments (RIAs) often function as an objective basis upon which risk assessments are compared side by side.

\subsection{Attempts at Defining the Precautionary Principle}

No singular "universally accepted canonical formulation of the precautionary principle" exists today. ${ }^{98}$ As is shown throughout the following chapters, a myriad of definitions exist at national level as well as at domestic level. It is telling that, when interviews were performed with civil servants at the Swedish Ministry of Environment, a strong proponent of early and strict precautionary action, and the question of the definition of the precautionary principlc was raised, one civil servant asked which precautionary principle we were talking about, the one included in the Swedish Planning Code or the one included in the Environmental Code. ${ }^{99}$ Thus, it would appear that not even in what is, perhaps, the strongest bastion of precautionary action is one singular principle in effect.

Some attempts to define the precautionary principle in the academic literature have been non-specific and have focused on the importance of protecting nature and human health in general. ${ }^{100}$ Other views of the precautionary principle are influenced in one way or another by the wording of Principle 15 of the Rio Declaration, which is returned to in some detail in the following chapter. These definitions tend to be more specific and focus on the serious or irreversible nature of the specific risk incurred, as well as the cost-effectiveness of the chosen

96 M. Douglas \& A. Wildawsky, Risk and Culture, p. 69.

97 See, in this regard, M.W. Viscusi, Monetizing the Benefits of Risk and Environmental Regulation, 1034, who holds that a wasteful allocation of funds would not further the health agenda even if the paramount objective in risk regulation would be health and safety, and no consideration would be given to cost.

98 P. Sandin, A Paradox Out of Context: Harris and Holm on the Precautionary Principle, Cambridge Quarterly of Healthcare Ethics, 15, 175 (2006), p. 175. In fact, Sandin has, in a work from 1999, identified 19 different versions of the principle. With the increased discussion on the principle since then, it is likely that cven more definitions could be identified today. See P. Sandin, Dimensions of the Precautionary Principle, Hum. and Ecological Risk Assessment, 5, 889, 1999.

99 Interview with case handler at the Swedish Ministry of Environment, 8 September 2004.

${ }^{100}$ See, for example, K. Geiser, Establish a General Duty of Precaution in Environmental Protection Policies in the United States: A Proposal, in; C. Raffensperger \& J. Tickner (eds), Protecting Public Health and the Environment: Implementing the Precautionary Principle, Island Press 1999, xxi and xxiv. Such a general application is also in cffect in Swcdish legislation, see, below, Chapter 5.1. See, also, B. Wahlström, The Precautionary Approach to Chemicals Management: A Swedish Perspective, in: C. Raffensperger \& J. Tickner (eds), Protecting Public Health and the Environment: Implementing the Precautionary Principle, pp. 52-54, and M. Karlsson, The Precautionary Principle, Swedish Chemicals Policy and Sustainable Development, Journal of Risk Research Vol. 9, No. 4, 2006, 344-348. 
measures. ${ }^{101}$ In the European Union context, the Commission has defined the precautionary principle as being applicable,

"in those specific circumstances where scientific evidence is insufficient, inconclusive or uncertain and there are indications through preliminary objective scientific evaluation that there are reasonable grounds for concern that the potentially dangerous effects on the environmental, human, animal or plant health may be inconsistent with the chosen level of protection." 102

Furthermore, according to the Commission, all measures enacted should be proportional, non-discriminatory, consistent, subject to cost/benefit analysis and should also take scientific developments into account. It has been held by Löfstedt and Fairman that an application of the precautionary principle along the lines outlined by the Commission would be acceptable to most policy-makers, but that, in practice, this approach is not always likely to be upheld. ${ }^{103}$

Common criticisms of the precautionary principle include claims that it is poorly defined, absolutist and ignores scientific evidence. ${ }^{104}$ In the United Kingdom, the House of Lords Select Commiltee on Economic Affairs even went as far as to state that "ill-defined and ambiguous terms", such as the precautionary principle, "are generally unhelpful". ${ }^{105}$ Furthermore, it has been held that it does not provide adequate safeguards against politicians

101 See, for example, C.F. Cranor, Asymmetric Information, the Precautionary Principle, and Burdens of Proof, in: C. Raffensperger and J. Tickner (eds), Protecting Public Health and the Environment: Implementing the Precautionary Principle, pp. 74-99.

102 Commission Communication on the Precautionary Principic, COM (2000) $1,10$.

103 Written evidence evaluated by Housc of Lords Select Committee on Economic Affairs. Select Committee on Economic Affairs, Government Policy on the Management of Risk, 5th Report of Session 2005-2006, Vol. II: Minutes of Evidence, Authority of the House of Lords, 2006, 217-218. Available at: http://www.publications.parliament.uk/pa/ld200506/ldselect/deconaf/183/183ii.pdf. For a critique of the Commission's approach, see J.D. Graham \& S. Hsia, Europe's Precautionary Principle: Promise and Pitfalls, Journal of Risk Research 5:4, 2002, 371-390. The issue is returned to in detail below in Section 4.2.5.

104 See, for example, D. Bodansky, Scientific Uncertainty and the Precautionary Principle, Environment, September 1991, p. 4-5, and D. Bodansky, Commentary: The Precautionary Principle, Environment, April 1992, p. 4-5. For an overview of the conceptual criticism levied against the precautionary principle, as well as a defence against it, see P. Sandin, M. Peterson, S.-O. Hansson, C. Rudén \& A. Juthe, Five Charges Against the Precautionary Principlc, Journal of Risk Research, 5: 4, 2002, 288-299.

105 Select House of Lords Committee on Economic Affairs, Government Policy on the Management of Risk, 5th Report of Session 2005-2006, Vol. I, para. 73. Similar sentiments have been expressed by the House of Commons, which have urged the UK government to avoid using the term "precautionary principle" due to its unclear meaning. See House of Commons Select Committce on Science and Technology, Scientific Advice, Risk and Evidence Based Policy Making, 7th Report of Session 2005-2006, Vol. I, Authority of the House of Commons, 2006, para 166. Available at: hltp:/www.publications.parliament.uk/pa/cm200506/cmselect/cmsctech/900/900-i.pdr. 


\section{Joakim Zander}

using the precautionary principle to take ill-informed decisions in response to public outcries. ${ }^{106}$ Some commentators have held that, in order for the precautionary principle not to be misused, it needs to be applied within a formal framework, such as the Commission Communication on the Precautionary Principle. ${ }^{107}$

Sandin holds that there are two basic ways of looking at the precautionary principle: namely, as argumentative or as prescriptive. ${ }^{108}$ The argumentative version of the principle deals with which reasons or arguments may be valid when taking decisions under uncertainty. An cxample of this is Article 15 of the Rio Declaration, which holds that uncertainty cannot be used as a reason for postponing preventive measures. ${ }^{109}$ Thus, the uncertainty surrounding a certain risk should not be allowed to be used as an argument in favour of inaction. The prescriptive version, on the other hand, prescribes a ccrtain form of behaviour in cases of uncertainty. This is a stricter version of the principle and functions along the generic lines that "if there is (1) a threat, which is (2) uncertain, then (3) some kind of action (4) is mandatory". 110

Other authors have analysed the different definitions of the versions of the precautionary principle and organised them in schemes ranging from more general noncommitting versions, to a strict and rigid application of precaution. Wiener and Rogers, for example, have identified three different versions ranging from "uncertainty does not justify inaction", via "uncertainty justifies action", to "uncertainty requires shifting the burden and standard of proof". 111 The first of these is the mildest version, which mercly states that precautionary action may be taken when full scientific certainty is lacking, while the last one is the strictest in that it requires the proponent of an action to show that the action is without risk. All of the above versions are, however, relatively unworkable, in that they are silent on the crucial issues of how and what to do when scientific certainty is not in effect. ${ }^{112}$

\footnotetext{
106 J.D. Graham \& S. Hsia, Europe's Precautionary Principle: Promise and Pitfalls. See, also, G.E. Merchant \& K.L. Mossman, Arbitrary and Capricious: The Precautionary Principle in the European Union Courts, International Policy Press, 2005. Available at: http:/www.policynetwork.net/uploaded/pdt/Arbitraryweb.pdf.

107 R. Löfstedt, Risk Communication and Management in the Twenty-First Century, International Public Management Joumal, Vol 7, Issue 3, 2004, 335-346, in particular, at p. 342.

${ }_{108}$ P. Sandin, A Paradox Out of Context: Harris and Holm on the Precautionary Principle, p. 177.

109 Article 15 of the Rio Declaration is considered in more detail in Chapter 3.

110 P. Sandin, A Paradox Out of Context: Harris and Holm on the Precautionary Principle, p. 177.

$11 \mathrm{~J}$, Wiener, Comparing precaution in the United States and Europe, Journal of Risk Research, Vol. 5 2002, $317,320-321$

112 Ibid., 321 .
} 
Karlsson has gone a step further to identify five constituent parts of a strict precautionary principle in chemicals policy. These include worst-case classification, prioritisation based on intrinsic properties, preventive mcasures (including substitution), maximin decision-making and a reversal of the burden of proof. ${ }^{113}$

For the purposes of this book, the term "precautionary approach" is uscd to denote a vaguc and open application of precaution, which is not necessarily based on a conceptual precautionary principle. The term "precautionary principle" is used to describe an institutionalised and systematic use of precaution in one or more policy areas. The use of the precautionary principle can be weak, i.e., reminiscent of what Sandin refers to as the argumentative version, or strong version, which refers to the fact that the principle is deemed to have more prescriptive characters. No one version is absolute, but consists of various degrees of rigidity. Concrete examples of the above distinctions are dealt with in considerable detail in the following chapters.

The differing definitions and applications of the precautionary principle also raise questions as to what kind of a legal concept the precautionary principlc really is. The law is often divided into threc categories of varying characteristics and importance: rules, principles, and policy. ${ }^{114}$ The name of the concept in discussion here would seem to indicate that it would be a principle of law, but perhaps the issue is not so clear-cut. Dworkin, building on the works of Hart and the legal positivists, ${ }^{115}$ has held that a rule is to be defined as a simple function which is to apply similarly in all circumstances. In its simplest form: if A), then $B) .{ }^{116}$ If two rules are in conflict with one another, one will prevail and the other will have to be declared void. Two opposing rules cannot apply to a similar set of circumstances. Principles, on the other hand, are open-ended in character and do not apply in an all-ornothing fashion. Instead, scveral principles can apply at the same time, and one can take precedence without the other being considered void or invalid. While rules give direct guidance in concrete situations, principles aim to give instruction in relation to " $[. .$.$] justice or$ fairness or some other dimension of morality". 117 Finally, policies differ from principles in that they "[...] set out a standard to be reached, generally an improvement in some economic,

\footnotetext{
${ }^{113}$ M. Karlsson, The Precautionary Principle, Swedish Chemicals Policy and Sustainable Development, pp. 341-344.

114 R. Dworkin, A Matter of Principle, Harvard University Press 1985, pp. 43-45.

115 See, for example, H.L.A. Hart, The Concept of Law, Oxford Clarendon Press, 1961.

116 R. Dworkin, A Matter of Principle, p. 45.

117 Ibid., pp. 45-46.
} 
political, or social feature of the community $[\ldots] "{ }^{118}$ A policy differs from a principle for different reasons. First, policies are vaguer in character than principles. Where a principle gives a relatively clear direction as to what action should be taken in order to be in compliance with it, a policy states a more general goal to be reached. Second, the content of a principle, according to Dworkin, relates to the concept of justice and how a just legal system is to be maintained. A policy, on the other hand, is not limited to issues of justice and fairness, and can encompass any economic, social, or political ambitions. ${ }^{119}$

Where the precautionary principle fits in depends, to a great extent, on how it has been applied in the relevant legal orders. However, even in legal systems where the principle is codified and endorsed by the courts, it usually remains ambiguous and undefined. Consequently, it is unlikely that the precautionary principle will be considered to apply in the all-or-nothing fashion generally expected from a rule. Instead, it would often have to be considered as either a principle or a policy. With regard to considering it as a principle, there are some concerns. First of all, the precautionary principle does not aim to safeguard the just and fair application of the law, in the manner that traditional legal principles do. Second, it is shown below that there are serious difficultics in establishing what the content and limits of the principle are. Third, even in states where the precautionary principle is heavily relied upon in certain areas, it is entirely left out of the application of the law in other areas. ${ }^{120}$ All of this makes it difficult to treat it as a legal principle which technically should apply equally in similar circumstances. Thus it emerges that the application of the precautionary principle is perhaps bcst treated as a policy choice. In the following chapters the treatment of the precautionary principle in different states and policy areas is analysed in detail, and this conclusion is returned to within that framework.

\footnotetext{
118 Ibid., p. 43.

119 A more nuanced view of the distinction, or lack thereof, between rules, principles, and policy has been taken by de Sadeleer, who holds that norms, at least at international level, arc open-ended in character. Thus, norms, however they are characterised, function together and are subject to dialogue and negotiations far from the seemingly "black-letter law" approach by the positivists and, to some extent, the normativists. This post-modern approach would erode the border between the different types of norms. De Sadeleer also introduces a set of norms he names "directing principles" whose aim it is to spur public policy and allow courts to weigh directly opposing legal interests against each other. The precautionary principle would be an example of such a norm. How this practically would change the way the precautionary principle is viewed is as of yct not clcar. See N. De Sadelcer, Environmental Principles: From Political Slogans to Legal Rules, Oxford University Press, 2002, p. 237. 


\subsection{CONCLUSION}

The aim of this chapter has been to give an overvicw and trace the background to concepts that are central to this book and to risk regulation in general. This is necessary in order to understand the content, purpose and scope of the precautionary principle, which is but one instrument to be used in the broad field of risk regulation.

The concept of uncertainty is essential to the issue of the precautionary principle. In this book, uncertain risks are used to denote risks for which the causal link between the activity and the hazard is unknown. Certain risks are risks for which the causal link is established. It is generally understood that the precautionary principle allows for the regulation of uncertain risks.

Lay people perccive risks in different manner than experts. For example, biases and heuristics make people over-estimate the occurrence of low probability risks. This has led some authors to conclude that opinion based on heuristic errors should be totally disregarded by a responsible government. ${ }^{121}$ Others have held that "[f]ar from being egalitarian, it is real exclusion that begins when prejudice or opinion are taken to be a sound basis for decisionmaking". ${ }^{122}$ Therefore, in order to safeguard a rational basis for risk regulation, including the application of the precautionary principle, it is generally accepted that the relevant scientific advice should be analysed before regulation is decided upon. Thus, the risk assessment phase should be separated from the risk management phase, in which the decision is taken as to whether, and, if so, how, to regulate a certain activity. In order to ensure that the general public is continuously informed about the analysis and response to societal risks, it is important to communicate regulatory strategies effectively. This helps to increase the trust and the acceptability of the regulatory choices that have been made.

A number of tools are of relevance in the risk management phase, of which the assessment of scientific evidence is but one of them. Other important sources of information are cost/benefit and cost/effectiveness analyses. Such tools can be designed to be binding on the decision-maker, but they can also be used as sources of information in order to put all the costs and benefits of a particular regulation "on screen". Further tools include risk trade-off analyses, which aim to assume a more holistic view of the effects of regulating one specific risk. These tools can be used together in order carry out comparative risk analyses, which

121 J. Wiener, Precaution in a Muli-Risk World, p. 4.

122 B. Duriode, The True Cost of Precautionary Chemicals Regulation, p. 395. 


\section{Joakim Zander}

allow the decision-maker(s) to choose between, and rank, several risk-reducing stratcgies the following chapter, it is investigated whether, and if so, how, these issues are applice practice

As stated above, no single definition exists of the precautionary principle. The $\mathbf{t}$ has been used to denote everything from a generally "environmental" approach to spec and binding decision-making rules. The principle has both been praised as a groundbreak way to protect environment and health and criticised as vague, unscientific and arbitr. Since no single precautionary principle exists, it is difficult to categorise it as a legal no and, due to its inherent ambiguity and its lack of a concrete definition, it is probably 1 viewed as a policy choice. 


\section{CHAPTER 3.}

\section{THE PRECAUTIONARY PRINCIPLE IN INTERNATIONAL LAW}

\subsection{INTRODUCTION}

The development and status of the precautionary principle in international environmental law has been chronicled in detail by a number of scholars. ${ }^{1}$ The purpose of this chapter is not to reiterate their findings in detail, but merely to highlight a number of the most important and influential international instruments and cases which have shaped the modern application of the precautionary principle. More specifically, the focus of this chapter is on how states can use precautionary considerations to justify trade restrictive measures. In this regard the WTO agreements are of primary importance.

The role of the precautionary principle under the WTO agreements has been a highly contested issue over the last ten years, and it has been the subject of a number of disputes before the WTO dispute settlement bodies. Generally, the European Union and its Member States have emerged as champions of a precautionary approach which functions as an instrument to justify national or regional regulation in the face of scientific uncertainty and controversy. On the other hand, the United States, Canada, and other countries have positioned themselves as advocates of a more "science-based" approach. The stakes involved have often been high and the rhetoric heated.

Like the other chapters of this book, this one aims to go beyond the political statements and the various definitions of the "precautionary principle", and derivates thereof, to investigate in detail how WTO panels and the Appellate Body (AB) have come to describe how and when Members of the WTO can act "precautionary". The chapter begins with an overview of the relevant provisions in the WTO agreements which may embody a

1 A. Trouwborst, The Precautionary Principle in General International Law: Combating the Babylonian Confusion, 16 Review of European Community and International Environmental Law (RECIEL), nr. 2, 2007, pp. 185-195; D. Grimeaud, Hoofdstuk II, The Precautionary Principle in International Environmental and Trade Law, in: M. Faure \& E. Vos (eds), Juridische afbakening van het voorzorgbeginsel: Mogelijkheden en grenzen, Achtergrondstudie vor de Nederlandse Gezondheidsraad, No. A03/03 2003; W. Douma, The Precautionary Principle; Its Application in International, European and Dutch Law. Proefshchrift Rijksuniversiteit Groningen 6 Jan. 2003; S. Marr, The Precautionary Principle in the Law of the Sea: Modern Decision Making in International Law, Martinus Nijhoff Publishers, 2003.A. Trouwborst, Evolution and Status of the Precautionary Principle in International Law, Kluwer 2002; J. Cameron, The Precautionary Principle in International Law. In: Reinterpreting the Precautionary Principle, Cameron May 2001. 


\section{Joakim Zander}

precaulionary principle or approach. Of prime importance here is the WTO Agrecment on the Application of Sanitary and Phytosanitary Measures (SPS Agreement), since it is the agreement which so far has been mostly relied on by WTO Members to justify precautionary action. However, the General Agreement on Tariffs and Trade 1994 (GATT 1994) and the Agreement on Technical Barriers to Trade (TBT Agreement) are also discussed.

When the attention is turned to the issue of how panels and the $A B$ have approached the topic, the SPS Agreement is of primary importance since it is the agreement that so far has been the most commonly relied upon before the dispute settlement bodies in cases concerning the justification of precautionary measures.

This chapter, like the following chapters, identifies a number of constituent parts of the precautionary principle and deals with them separately in order to illustrate all the aspects of relevance when decisions are taken under scientific uncertainty. These aspects include the treatment of issues such as the scope of judicial review, scientific evidence, burden of proof, cost/benefit analysis, and public opinion. Finally, this chapter discusses the status and scope of the precautionary principle in the WTO.

\subsection{The Precautionary Principle in International Environmental LaW}

\subsubsection{The Precautionary Principle in International Agreements}

\subsubsection{Binding International Agreements}

First appearing in environmental agreements in the $1980 \mathrm{~s}$, reference to the precautionary principle has in recent years had what has been described as a "meteoric rise" in international agreements. ${ }^{2}$ However, even though it took until 1985 and the Vienna Convention on Ozone Depleting Substances for the word precaution to find its way into a preamble of an international agreement, precautionary thinking had been influencing earlier international agreements. Among these the 1968 African Convention on the Conservation of Nature and Natural Resources, ${ }^{3}$ the 1971 Ramsar Convention, ${ }^{4}$ the 1972 World Heritage Convention, ${ }^{5}$ the $1973 \mathrm{CITES}^{6}{ }^{6}$ and the $1982 \mathrm{UNCLOS}^{7}$ can be found, to name a few. ${ }^{8}$

2 D. Cameron \& J. Abouchar, The Status of the Precautionary Principle in International Law, in: D. Freestone \& E. Hey (eds), The Precautionary Principle in International Law: The Challenge of Implementation, Kluwer Law International 1996, p. 29.

3 A frican Convention on the Conservation of Nature and Natural Resources, Algers 1968.

4 The Convention on Wetlands, Ramsar, 1971.

5 Convention Concerning the Protection of the World Cultural and Natural Heritage, Paris 1972.

6 The Convention on International Trade in Endangered Species of Wild Fauna and Flora, Washington DC 1973. 
Binding international agreements often stop short of defining precautionary action, and instead make general reference to "the precautionary principle" or "a precautionary approach". However, many agreements make referencc to the fact that precautionary measures are designed to be used where full scientific certainty is lacking, and that the lack of such evidence should not be a reason to postpone action. ${ }^{10}$ Yet again, some international agrecments do not mention the precautionary principle, but are essentially precautionary in function. "Furthermore, it should be noted that all binding international agreements where the precautionary principle is mentioned are sectoral in nature.

\subsubsection{Non-Binding International Instruments}

If the inclusion of precautionary aspects in legally binding international treaties still is relatively scarce, the inclusion of notions of precaution in non-binding international documents is much more common. In fact, the mentioning of precaution in international policy documents is now so widely spread that it is nearly impossible to provide an exhaustive list. ${ }^{12}$

The most influential of the soft law instruments relating to the precautionary principle is Principle 15 of the Rio Declaration, which was agreed upon on April $21992 .{ }^{13}$ During the negotiations there had been diverging opinions on the exact wording of Principle 15, but, interestingly, it appears that most states active in the negotiations agreed on the basic idea of including a statement dealing with precaution in one way or another. ${ }^{14}$ In its final version, the principle reads:

7 The United Nations Convention on the Law of the Sea, Montego Bay 1982.

8 For a more detailed list of, and in depth discussion on, early international agreements encompassing precaution, see A. Trouwborst, Evolution and Status of the Precautionary Principle in International Law, Kluwer Law International 2002, p. 63 et seq.

9 See, for example, the preamble to Protocol (to the 1985 Convention for the Protection of the Ozone Layer) on Substances that Deplete the Ozone Layer, Vienna 1985 and Article 6 of Agreement for the Implementation of the Provisions of the 1982 UNCLOS Relating to the Conservation and Management of Straddling Fish Stocks and Highly Migratory Fish Stocks, New York 1995.

10 Sce, for example, Article 3(3) of the Convention on the Ban on Import into Africa and the Control of Transboundary Movement and Management of Hazardous Wastes Within Africa, Bamako 1991; Article 3(3) of the Framework Convention on Climate Change, New York 1992; Article 6 of the Agreement for the Implementation of the Provisions of the 1982 UNCLOS Relating to the Conservation and Management of Straddling Fish Stocks and Highly Migratory Fish Stocks, New York 1995; and Article 10(6) of the Protocol (to the 1992 Convention on Biological Diversity) on Biosafety, Cartagena de Indias 2000.

11 See, for example, the Protocol to the 1992 Framework Convention on Climate Change, Kyoto 1997.

12 For a good overview, see A. Trouwborst, Evolution and Status of the Precautionary Principle in International Law, Kluwer Law International, 2002, pp. 112-156.

13 Declaration of the United Nations Conference on Environment and Development, Rio de Janeiro 1992.

14 W. Douma, The Precautionary Principle: Its Application in International, European and Dutch Law, PhD thesis, Rijksuniversiteit Groningen, 6 January 2003, p. 77-84. 


\section{Joukim Kander}

"In order to protect the environment, the precautionary approsch shall be widely applied by States according $t$ their capabilitise. Where there are threats of serious or irreversible damatge. lack of full scientific certainty shall non be used as a reason for pwstponing cost effective measures to prevent environmental degradation."

The wording of Principle 15 appears to be an amalgam of earlier versions of Articles in international documents dealing with the precautunary principle. The use of the term "scrious or irreversible damage" as a threshold for the application of a precautionary approach stems from the 20 year older Stexkholm Declaration. ${ }^{19}$ The use of the wording indicates that some form of minimum level of risk has to be met in order for precautionary measures to be issued. Nothing in the Rio I Declaration aims to clarify how this is to be interpreted in practice. Furthermore, the principle adopts the "triple-negative" definition to state that the lack of seientific certainty shall not be used as reason for not taking precautionary measures. This model was previously used in the Bergen Declaration ${ }^{16}$ and in the 1991 OECD Council Recommendations. ${ }^{17}$ Furthermore, the Rio Declaration makes explicit reference to the need for the precautionary measures to be cost-effective. Reference to the weighting of costs and benefits had previously been included in the World Charter for Nature. ${ }^{18}$ In the case of the World Charter for Nature this took the form of a cost/benefit analysis. However, the cost-effectiveness requirement in the Rio Declaration would seem to aim to restrict the regulator of an activity on precautionary grounds to choose the least economically cumbersome way of doing so. The requirement in the World Charter for Nature aims to reverse the burden of proof, away from the regulator and onto the regulated party, to prove that the benefits of the proposed activity outweigh the potential risks. One innovation in the Rio Declaration as compared with previous documents is that it holds that states should apply the precautionary approach according to their own capabilities.

Finally, it should be pointed out that the Rio Declaration makes use of the weaker argumentative version of the precautionary principle, rather than a stronger prescriptive version. ${ }^{19}$ Principle 15 of the Rio Declaration is a landmark in the development of the precautionary principle on the international arena. Contrary to many of the previously

15. Declaration of the United Nations Conference on the Human Fnvironment, Stockholn, 1972

- Ministerial Declaration on Sustainable Development in the F. CI Region, Bergen 1990.

I7 OrCD Council Recommendation $(90) 164$ on Integrated Pollution Prevention and Control, 31 January 1991

18 United Nations General Assembly Resolution 37/7 and Annex: World ('harter for Nature, 28 (ktober 1982

14 This issue has been discussed in some detail above in Chapter 2. 
discussed documents in this chapter, the Rio Declaration is a global and general instrument, which firmly establishes that some form of minimum precautionary approach is widely accepted in the world community. Once again, though, its importance should not be overstated. As has been pointed out, it is weak in character and does not constitute a binding instrument of international law. ${ }^{20}$

\subsubsection{International case law}

International tribunals have been faced with parties basing their arguments on the precautionary principle on a number of occasions. The first time the International Court of Justice was confronted with a case relating to the precautionary principle was in French Nuclear Tests II of 1995, where New Zealand asked the Court to investigate the compliance of France with Paragraph 63 of its judgment in French Nuclear Tests 1 of $1974 .^{21}$ However, the Court chose to interpret its own jurisdiction rather narrowly and concluded that the object of the present case was not the same as in the original case. Because of these procedural obstacles the Court was not to rule on the substance of the case. However, in the three dissents added to the judgment, judges Weeramantry, Palmer and Koroma tentatively discussed the status of the precautionary principle. They all stopped short of declaring that it has any binding effects in the international law. However, Judge Weeramantry held that the principle may be "gaining increasing support as part of the international law". 22 Judge Palmer went as far as to say that it "may" be the case that the precautionary principle forms part of customary international law. In his dissent he discussed at length that cost/benefit considerations would need to be taken into account before issuing precautionary measures. ${ }^{23}$

In the Gabcikovo-Natymaros Case of 1997 the parties agreed to the fact that the precautionary principle posed "a new requirement" of international environmental law, but there were differences as to the interpretation of the principle. ${ }^{24}$ The ICJ decided not to

20 For a description of the negotiations leading up to the acceptance of principle 15 of the Rio Declaration, sec W. Douma, The Precautionary Principle: Its Application in International, European and Dutch Law.

21 Request for an Examination of the Situation in Accordance with Paragraph 63 of the Court's Judgement of

20 December 1974 in the Nuclear Tests (New Zealand v France) ICJ Reports 1995.
Dissenting Opinion of Judge Weeramantry in Request for an Examination of the Situation in Accordance with Paragraph 63 of the Court's Judgement of 20 December 1974 in the Nuclear Tests (New Zealand v France), ICJ Reports 1995, p. 342.

23 Dissenting Opinion of Judge Palmer in Request for an Examination of the Situation in Accordance with Paragraph 63 of the Court's Judgement of 20 December 1974 in the Nuclear Tests (New Zealand v France) ICJ Reports 1995, p. 412.

24 Gabcikovo-Nagymaros Project (Hungry/Slovakia), Judgment, ICJ Reports 1997, p. 7 


\section{Joakim Zander}

evaluate the content of the precautionary principle, but instcad left it to the parties to negotiate the application of the principle. ${ }^{25}$

The precautionary principle ended up before an international tribunal again in the Southern Bluefin Tuna Case of $1999,{ }^{26}$ which was decided upon by the International Tribunal for the Law of the Sea (hereinafter referred to as "ITLOS") under the United Nations Convention on the Law of the Sea (hereinafter referred to as "UNCLOS"). In the case New Zealand and Australia argued that the precautionary principle would prevent Japan from carrying out its experimental fishing programme for southern bluefin tuna. Japan, on the other hand, held that the programme would enable a more accurate assessment of the relevant fish stocks. In its judgment ITLOS ordered that the expcrimental programme should be halted and that all parties should adhere to the last agrecd upon limits. The case has been seen by some commentators as proof of the increasing importance of the precautionary principle in international law, and even as an indicator of its status as customary international law. ${ }^{27}$ But, as has been pointed out by others, the ITLOS does not refer to the precautionary principle at all in its judgment in this the casc. ${ }^{28}$ Furthermore, instead of acting out of precaution, it could be argued that ITLOS is merely stating that the management of fish stocks is to be carried out in agreement of the states concerned. This could be taken to imply that the ITLOS views precaution (or prevention for that matter) not as an objective principle centred on environmental protection, but rather a subjective approach, the content of which may be negotialed between parties involved.

The above conclusion of the ITLOS was confirmed in the MOX Plant Case of 2001, which regarded an Irish claim against the UK for failing to investigate properly the impact on the marine environment in the Irish Sea of the establishment of a Metal Oxide (MOX) plant. ${ }^{29}$ Ireland argued, among other things, that the precautionary principle would place the burden of proof on the UK to show that no harm would arise from the establishment of the MOX plant. ${ }^{30}$ The UK did not dispute the relevance of the precautionary principle as such but

25 Ibid., para. 112.

26 Southern Bluefin Tuna Cases (New Zealand v Japan; Australia v Japan (Joined Cases)), ITLOS, Order of August 271999.

27 See, primarily, J. Cameron, The Precautionary Principle in International Law, p. 129, and A. Trouwborst, Evolution and Status of the Precautionary Principle in International Law, pp. 171-174.

28 See, for example, W. Douma, The Precautionary Principle: Its Application in International, European and Dutch Law, p. 172.

29 The MOX Plant Case (Ireland v U.K.), (Provisional measures), (ITLOS), Order of 3 December 2001.

Ibid., para. 71 . 
stated that it considered the risk of harm to be "infinitesimally small."." As in the Southern Bluefin Tuna Case, the ITLOS refrained form making a ruling based upon the precautionary principle, and left it up to the parties to share information on the risks and to communicate with each other in the spirit of "prudence and caution." 32 Thus, also in the Mox Plant Case, the ITLOS left it up to the parties to negotiate the content and limits to what should constitute precaution.

\subsection{The Precautionary Principle in WTO Law}

\subsubsection{The Precautionary Principle and the WTO Agreements}

The WTO agreement of primary importance when discussing the legality of precautionary measures in the WTO regime is the Agreement on the Application of Sanitary and Phytosanitary Measures. ${ }^{33}$ A sanitary and phytosanitary measure is any measure that meets onc of the four definitions established in Paragraph 1 of Annex A to the SPS Agreement. First, the Agreement applies to measures aimed at protecting animal, plant or human life from risks stemming from the entry of organisms carrying pests or disease. Second, measures aimed at protecting human or animal life against risks arising from additives, contaminants, toxins or disease-causing organisms in foods, beverages or feedstuffs are covered. Third, the Agreement concerns measures aimed at protecting human life or health against risks from diseases carried by animals, plants, or products thereof, or from the entry, establishment or spread of pests. Finally, measures aimed at preventing or limiting other damage from the entry, establishment or spread of pests are to be considered SPS measures. ${ }^{34}$ Most precautionary measures will have one of these objectives. However, measures not matching

31 Ibid., para. 72

32 Ibid., para. 89.

33 For a rccent commentary to the SPS Agreement, see J. Scott, The WTO Agreement on Sanitary and Phytosanitary Measures, Oxford University Press, 2007. See, also, P. van den Bossche \& D. Prevost, The Agreement on the $\Lambda$ pplication of Sanitary and Phyto-sanitary Measures, in: P. McRory, A. Appleton \& M. Plummer (eds), The World Trade Organisation: Legal, Economic and Political Analysis, Springer, 2005, pp. 231-270.For a general overview of earlier legal scholarship in the area of the SPS Agreement, see J. Atik \& D.A. Wirth, Science and International Trade - Third Generation Scholarship, 26 B.C Int'l \& Comp. L. Rev. 171, 2003. See, also, C.R. Kelly, Power, Linkage and Accomodation: The WTO as an International Actor and Its Influence on Other Actors and Regimes, 24 Berkely. J. Int'l L. 79, 2006, 110 and note 220.

34 Article 1, Annex A attached to the SPS Agreement. In Panel Report, European Communities-Mcasures Affecting the Approval and Marketing of Biotech Products, WT/DS291/R, WT/DS292/R WT/DS293/R, adopted on 21 November 2006 (EC-Approval and Marketing of Biotech Products) the Pancl elaborated on the definition of a SPS measures (see Panel Report, EC-Approval and Marketing of Biotech Products, para. 7.149). See, also, D. Provost, Opening Pandora's Box: The Panels' findings in the EC-Approval and Marketing of Biotech Products Dispute, Legal Issues of Economic Integration Vol. 34, Issue 1, 2007, pp. 7378. 
this definition will fall under the other agreements, notably the TBT Agreement and/or GATT 1994. ${ }^{35}$

The TBT Agreement applies to technical regulations, standards and conformity assessment procedures. ${ }^{3 *}$ A technical regulation is defined as a document that lays down mandatory product characteristics or their related processes and production melhods, including relevant administrative provisions. Technical regulations can, for example, relate to terminology, symbols, packaging. marking or labelling. ${ }^{37}$ Standards are defined as documents approved by a recognized body, which provide non-mandatory rules, guidelines or characteristics for common or repeated use for products or related processes and production methods. ${ }^{3 *}$ Finally, conformity assessments are procedures which aim to determine the compliance with technical regulations or standards. ${ }^{39}$

In situations where measures can be considered to meet the definitions in the SPS Agreement and the TBT Agreement simultaneously, Article 1.5 of the TBT Agreement establishes that the SPS Agreement takes precedence. That this is the case has also been upheld in a number of Panel Reports ${ }^{40}$

Whereas the SPS Agreement and the TBT Agreement apply to the certain categories of measures outlined above, the GATT 1994 applies to all measures affecting trade in goods, regardless of their content and purpose. As was also discussed above, the TBT Agreement and the SPS Agreement are mutually exclusive. However, the SPS Agreement and the GATT 1994 may apply simultaneously. As is stated in Article 2.4 of the SPS Agreement, measures which fulfil the obligations of the SPS Agreement shall be presumed to be in compliance with the GATT obligations, especially the provisions of Article XX(b). Indeed, one of the motives behind the SPS Agreement was to clarify and flesh out the Article XX(b) exception in GATT 1994. However, the SPS Agreement goes further than GATT 1994 in that it

35 For a discussion on how the WTO Agreements relate to each other when the precautionary principle is considered, see N. Bernasconi-Osterwalder et al., Environment and Trode; A Guide to WTO Jurisprudence, Earthscan 2006, p. 256-264.

TBT Agreement, Articles 1,2 and 3 of Annex 1.

37 TBT Agreement, Article 1 of Annex 1.

7* TBT Agreement, Article 2 of $\Lambda$ nnex 1.

39 TBT Agreement, Article 3 of Annex 1.

40 Panel Report, RC Measures Conceming Meat and Meat Products (llormones) (US) WT/DS26/R (Panel Report, EC. Ilormones (US)), para. 8.29 and Panel Report, EC Measures Concerning Meat and Meat Products (Hormones) (Canada). WT/DS48/R (Pand Report, HC Ilormones (Canada)), para. 8.32 and Panel Report, EC-Approval and Marketing of Biotech Products, para. 7.167. 
imposes a new and comprehensive set of rules. ${ }^{41}$ In the light of the above, it is unlikely that provisions of the SPS Agreement and the GATT 1994 would clash. However, should this nonctheless be the case, the SPS Agreement prevails. This follows from the General Interpretative Note to Annex $1 \mathrm{~A}$ of the WTO Agreement, which holds that in the event of a conflict between the GATT 1994 and another multilateral trade agreement on tradc in goods, the latter shall prevail. ${ }^{42}$

The SPS Agreement applies to SPS measures "which may, directly and indirectly, affect international lrade" according to its Article 1.1. This makes the scope of the SPS Agreement broader than the GATT 1994, which concerns specific obligations. The GATT 1994 obligations include respect for the non-discrimination principles, i.e., the Mostfavoured-nation principle in Article I, and, pcrhaps of particular importance when the precautionary principle is concerned, the national treatment obligation in Article III. They also include the rules on market access, which comprise of the elimination of quantitative restrictions in favour of tariffs. ${ }^{43}$

Furthermore, the presumption concerning the legality of measures in the SPS Agreement is opposite to the presumption in the GATT 1994. Article 2.1 of the SPS Agreement explicitly states that Members have a right to take SPS measures. In the GATT 1994 derogating measures are exceptions to the rules on non-discrimination and equal treatment. At the outset it is thus up to the party wishing to challenge an SPS measure to show that the measure is not in conformity with the regime laid down in the agreement, rather than for the party issuing the measures to show that they are in conformily with the agreement. ${ }^{44}$ In contrast, under the GATT 1994, a challenging Member would have to show prima facie that a measure taken by another Member is not in conformity with the obligations relating to non-discrimination or market access. It would then be for the challenged Member to show that the measures fit under the exceptions in Article XX of the GATT 1994.

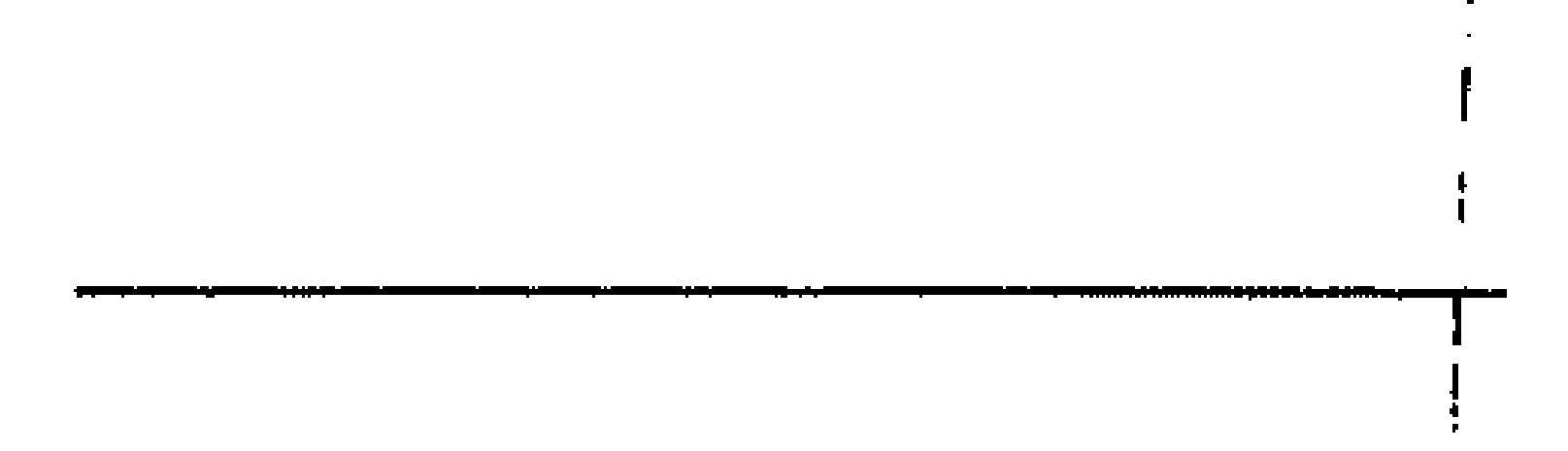

41 P. van den Bossche, The Law and Policy of the World Trade Organization, 2nd edition, Cambridge University Press, 2008, Section 8.4.3.2.

42 In this regard, van den Bossche holds that it would be "logical, in a dispute involving an SPS measure, to begin by examining the measure under the SPS Agreement." P. van den Bossche, The Law and Policy of the World Trade Organization, 1st edition, Cambridge University Press, 2005, p. 463. See, also, C. Button, The Power to Protect: Trade, health and uncertainty in the WTO, Hart 2004, pp. 9-43. This is also supported by the Panel in Panel Report, EC-Hormones (US), para. 8.42, Panel Report, EC-Hormones (Canada), para. 8.45 .

43 GATT, Article XI and XIII.

44 See a detailed discussion below in this chapter under Sections 3.3.2.4 and 3.3.2.5. 
The preferred level of protection that is to function as a basis for SPS measures is internationally agreed upon standards. ${ }^{45}$ Members may either base or conform their measures to such standards. Measures conforming to international standards are to be deemed as proportionate and in conformity with other relevant WTO provisions. ${ }^{46}$ However, Members are allowed to base their measures on the wish to maintain or introduce a higher level of protection than that provided for in international standards if they fulfil the criteria laid down in Article $5 .{ }^{47}$

Article 5.1 makes it clear that SPS measures are to be based on a risk assessment, the definition of which is provided in paragraph 4 of Annex A of the SPS Agreement:

\begin{abstract}
"The evaluation of the likelihood of entry, establishment or spread of a pest or disease within the territory of an importing Member according to the sanitary or phytosanitary measures which might be applied, and of the associated potential biological and economic consequences; or the cvaluation of the potential for adverse effects on human or animal health arising from the presence of additives, contaminants, toxins or disease-causing organisms in food, beverages or feedstuffs."
\end{abstract}

As can be deduced from the wording of the above, two slightly different risk assessments are prescribed depending on the origin of the risk in question. With regard to pests or diseases, the "likelihood" of the risk needs to be assessed together with the potential biological and economic consequences. However, with regard to risks present in food, beverages or feed, the "potential for adverse effects" is to be assessed. No reference is made to the economic consequences of the proposed measures. ${ }^{48}$

Article 5.2 further elaborates on what should be included in a risk assessment. This includes the available scientific evidence, processes and production methods, inspection and sampling methods, relevant existing specific diseases or pests, areas which are free of diseases or pests, relevant ecological and environmental conditions, as well as quarantines or other treatments.

45 In this regard, the $A B$ has held that "the object and purpose of Article 3 is to promote the harmonisation of the SPS measures of Members on as wide a basis as possible, while recognizing and safeguarding at the same time, the right and duty of Members to protect the life and health of their people. $A B$ Report in $E C$ Hormones, para. 177.

46 SPS Agreement, Article 3.2. For a discussion on the role of international standards under the SPS Agreement, see J. Scott, The WTO Agreement on Sanitary and Phytosanitary Mcasures, p. 243-280.

47 SPS Agreement, Articlc 3.3.

48 For a discussion on these requirements, see P. van den Bossche, The Law and Policy of the World Trade Organization, 2nd edition, Scction 8.4.5.1. See, also, below in this chapter in Sections 3.3.2.3 and 3.3.2.4. 
An cxception from the obligation to base measures in a risk assessment is included in Article 5.7:

\begin{abstract}
"In cases where relevant scientific evidence is insufficient, a Member may provisionally adopt sanitary or phytosanitary measures on the basis of available pertinent information, including that from the relevant international organizations as well as from sanitary or phytosanitary measurcs applied by other Members. In such circumstances, Members shall seek to obtain the additional information necessary for a more objective assessment of risk and review the sanitary or phytosanitary measure accordingly within a reasonable period of timc."
\end{abstract}

This means that a measure may provisionally be maintained or introduced even though it has not been adequately backed up by scientific evidence provided that "scientific evidence is insufficient". ${ }^{49}$ Arlicle 5.7 is the clearest reflection of the precautionary principle in the SPS Agreement. Howcver, the principle is not limited to this article. This issue is returned to below in the following sections.

In the event that a measure does not meet the definition of a SPS mcasure, the TBT Agreement may be relevant. The TBT Agreement restates some of the basic principles found in the GATT 1994, for instance the most-favoured-nation principle and the principle of national treatment. ${ }^{50}$ Where the purpose of the SPS Agreement is to allow for the introduction of trade restrictive SPS measures in certain cases, the TBT Agreement establishes clearly that the presumption is that like products should be treated equally. However, like the GATT 1994, the TBT Agreement allows Members to introduce or maintain technical regulations as long as they do not create "unnecessary obstacles to international trade". Furthermore, they must be "necessary to fulfil a legitimate objective, taking account of the risks non-fulfilment would create". ${ }^{51}$ Objectives that can be considered necessary include human health or safety, animal or plant life or health, and the environment. ${ }^{52}$ The list provided in Article 2.2 is not exhaustive. ${ }^{53}$ A trade restriclive measure that is introduced, and considered necessary, must continuously be assessed to

\footnotetext{
This discussion is returned to in detail below in Section 3.3.2.4 on scientific evidence.

50 TBT Agreement, Article 2.1.

51 Ibid., Article 2.2.

52 Ibid.

53 P. van den Bossche, The Law and Policy of the World Trade Organization, 1st edition, p. 460.
} 


\section{Joakim Zander}

ensure that it remains necessary. ${ }^{54}$ In this sense the requirements in the TBT Agreement correspond to those in the SPS Agreement. Necessity is a requirement in both, as well as the requirement to dismantle the measures when the situation changes. ${ }^{55}$ Further similarities include the recognition of international standards as a basis for the introduction of measures. ${ }^{56}$ If a TBT measure is based on such a standard and meets one of the objectives in Article 2.2 it is presumed not to create an unnecessary obstacle to international trade. The TBT Agreement does not go as far as to identify which international standards are appropriate, but it does state that Members "shall use them, or the relevant parts of them" unless the international standards are to be considered an ineffective or inappropriate way of fulfilling the policy objectives prescribed in Article 2.2, If this is the case, Members may as an exemption, depart from the international standards. ${ }^{57}$

Where the SPS Agreement only allows for measures to be taken after a thorough scientific risk assessment, ${ }^{58}$ the TBT Agreement appears to be more lenient in its appreciation of which measures may be allowed. Article 2.2 only states that:

"In assessing such risks, relevant elements of consideration are, inter alia: available scientific and technical information, related processing technology or intended enduses of products." 59

This signifies that available scientific information is an important aspect to be considered when determining risks under the TBT Agreement. However, there is no strict obligation to rely on scientific information under the TBT Agreement. As was shown above, the SPS Agreement places grcat weight on an assessment based in "scientific principles" and obliges a Member maintaining or introducing SPS measures to justify this with "sufficient scientific evidence". ${ }^{60}$ By stating that "relevant elements" of the assessment of risks include "inter alia" scientific and technological information, etc. Article 2.2 of the TBT Agreement seems to indicate that other issues than strictly scientific ones possibly could be considered when assessing risks.

\footnotetext{
54 TBT Agreement, Article 2.3.

55 For an in-depth discussion on the necessity requirement in the WTO regime, see N. Bernasconi-Osterwalder et al., Environment and Trade: A Guide to WTO Jurisprudence, pp. 149-201.

56 TBT Agreement, Article 2.4.

57 TBT Agreement, Article 2.4.

58 SPS Agreement, Articles 5.1 and 5.2.

59 TBT Agreement, Article 2.2.

60 SPS Agreement, Article 2.2.
} 
Furthermore, no corresponding article to Article 5.7 of the SPS Agreement is to be found in the TBT agrecment. Therefore no clear distinction appears to be made between mcasures taken under scientific certainty and scientific uncertainty. It thus appears that precautionary measures could be taken under Article 2.2 of the TBT Agreement and that these measures would not necessarily have to be of interim character as is the case in the SPS Agreement. ${ }^{61}$ Clearly, such measures would have to respect the requirement in Article 2.2 of not being more trade restrictive than necessary, taking into account of the risks non-fulfilment would create. Room is left for the precautionary principle in the broad sense in the preamble, where it is stated that no country should be prevented from taking measures necessary to protect human, animal or plant life or health or the environment, at levels it considers appropriate. $^{62}$

As was established above, when deciding on cases relating to the precautionary principle, Pancls would generally begin by considering the SPS Agreement, and only turn to the TBT Agreement or the GATT 1994 if the provisions in that agreement do not appear applicable. ${ }^{63}$ Both are covered by the Interpretative Note to Annex $1 \mathrm{~A}$ and should be considered before turning to GATT $1994 .{ }^{64}$ Thus a Member cannot choose to rely on the agreement most suitable for its needs. Instead the general principle of lex specialis applies.

Under the GATT 1994, measures breaching the GATT obligations need to be justified under the exceptions listed in Article XX in order to be allowed. As far as the precautionary principle would be argued under the GATT 1994 it would have to be justified by one of the exceptions listed in the Article. The list there has generally been interpreted to be exhaustive. ${ }^{65}$ The most relevant parts read:

"Subject to the requirement that such measures are not applied in a manner which would constitute a means of arbitrary or unjustifiable discrimination between countries where the same conditions prevail, or a disguised restriction on

61 However, as mentioned above, all measures taken under the TBT Agreement need to be updated if the circumstances change in accordance with Article 2.3. This requirement appears to be wcaker than the corresponding requirement relating to precautionary measures in the SPS agreement. Primarily, Article 5.7 of the SPS agreement obliges the Member applying SPS measures to carry out research in order to end the state of uncertainty. This will be monitored by the DSB. Article 2.3 appears to be far more general in character.

62 N. Bernasconi-Osterwalder et al., Environment and Trade: A Guide to WTO Jurisprudence, p. 257-258.

63 Panel Report, EC-Hormones (Canada), para 8:45 and Panel Report, EC-Hormones (US), para. 8.42.

64 See, above, note 42.

65 Sec, for example, J. Scott, The European Regulation of GMOs and the WTO, 9 Colum. J. Eur. L., 213, 2003, p. 230. 
Joakim Zander

international trade, nothing in this Agreement shall bc construcd to prevent the adoption or enforcement by any contracting party of measures:

$[\ldots]$

(b) necessary to protect human, animal or plant life or hcalth;

$[\ldots]$

(d) necessary to secure compliance with laws or regulations which are not inconsistent with the provisions of this Agreement, including those relating to customs enforcement, the enforccment of monopolies operated under paragraph 4 of Article II and Article XVII, the protection of patents, trade marks and copyrights, and the prevention of deceptive practices;

$[\ldots]$

(g) rclating to the conservation of exhaustible natural resources if such measures arc made effective in conjunction with restrictions on domestic production or consumption."

\subsubsection{The Role of the Precautionary Principle in WTO Dispute Settlement}

3.3.2.1. The definition of the precautionary principle

The precautionary principle evidently lacks definition or even explicit support in the WTO agreements. ${ }^{66}$ Some authors have held that there are equally no rules in the WTO agreements which would prohibit the application of a precautionary principle or approach. ${ }^{67}$ However, as is discussed in detail below, the apparently strict reliance on scientific cvidence in the SPS Agreement makes it difficult to see prima facie how the precautionary principle would find reflection in the WTO agreements, outside of Article $5.7 .^{68}$ This, in combination with the fact that the principle was not considered to be part of international customary law, has been stressed by the Appellate Body $(\mathrm{AB})$ as a reason not to basc rulings on it alone. ${ }^{69}$ However, the $\mathrm{AB}$ has also pointed out that the principle "finds reflection" in Article 5.7 of the SPS

66 See J. Scott, The WTO Agreement on Sanitary and Phytosanitary Measures: $\Lambda$ Commentary, p. 127 and C. Button, The Power to Protect: Trade, health and uncertainty in the WTO, p. 120-122.

67 N. Bernasconi-Osterwalder et al., Environment and Trade: A Guide to WTO Jurisprudence, p. 256.

68 Even if a more thorough analysis of the relevant case law suggests that a possibility of taking precautionary measures may exist outside of Article 5.7. This issue is returned to below.

69 AB Report, EC-Hormones, para. 123 and 124.This was also repeated more recently in Panel Report, ECApproval and Marketing of Biotech Products, para. 7.89. 
Agreement and that "there is no need to assumc that Article 5.7 exhausts the relevance of a precautionary principle", especially since it is also reflected in the sixth paragraph of the preamble and Article 3.3 of the SPS Agreement. ${ }^{70}$ In any case, the precautionary principle cannot be considered to override the strict requirements on scientific evidence and risk assessment in Articles 2.2, 5.1 and 5.2 of the SPS Agreement. ${ }^{71}$

Even if the requirement of a risk assessment is strict, this does not mean that the $A B$ does not recognise the fact that the assessment of a risk may not provide conclusive evidence of the existence of risk. Therefore the AB holds that the term "sufficient scientific evidence", which is laid down in Article 2.2 of the SPS Agreement as the basic requirement for the enactment of all measures under the agreement, docs not only refer to mainstream scientific opinion. ${ }^{72}$ In cases of unresolved scientific controversy, which is one instance of scientific uncertainty, ${ }^{73}$ Members may base their measures on the opinions of the scientific minority. ${ }^{74}$ Especially justified is this in cases where the risk involved is perceived as life threatening and imminent. ${ }^{75}$ As was shown in previous chapters, scientific uncertainty is not a static or monolithic concept, but can exist in various degrees and be due to several different causes. ${ }^{76}$ This creates a situation where Members, in cases of scicntific uncertainty due to scientific controversy, may issue precautionary measures without sceking recourse in Article 5.7, as long as other basic SPS requirements are abided by. In Japan-Apples, the Panel acknowledged this, and held that "scientific uncertainty" and "insufficient scientific evidence" are not interchangeable concepts. ${ }^{77}$ Furthermore, in Japan-Apples, EC-Approval and Marketing of Biotech Products and US-Continued Suspension of Obligations-EC Hormones, the $\mathrm{AB}$ and the Panels showed that they vicw insufficient scientific evidence as a product of lack of quantitative as well as qualitative evidence. ${ }^{78}$

It might be argued that this shows that the $A B$ has made use of a more sophisticated approach to scientific uncertainty than it sometimes is given credit for. Furthermore, it

70 AB Report, EC-Hormones, para. 124.

71 Ibid., para. 125.

72 Ibid., para. 194.

73 Sce above Chapter 2.3.1.

74 AB Report, EC-Hormones. para. 194.

75 Ibid.

76 See, above, Sections 2.3.1 \& 2.3.2.

77 Panel Report, Japan-Apples, para. 184.

78 AB Report, Japan-Apples, para, 179 Panel Report, EC-Approval and Marketing of Biotech Products, Annex $\mathrm{K}$ and Panel Report, US-Continued Suspension of Obligations-EC Hormones, para. 7.608. The matter is returned to in more detail below in relation to the section on scientific evidence and the level of proof. 


\section{Joakim Zander}

indicates that it does not view the precautionary principle in the WTO agreements as limited to Article 5.7 of the SPS Agreement. This is also supported in EC-Hormones where the AB's conclusions can be interpreted to mean that "the precautionary principle is also reflected in other provisions (than Article 5.7) of the SPS Agreement". As mentioned above, the AB specifically alluded to Article 3.3 and the preamble. ${ }^{79}$

What is also clear is that the requirement of a risk assessment is absolute outside of Article 5.7, and that the risk assessment must yield a minimum of scientific evidence for the application of precautionary measures to be allowed. Thus, outside of Article 5.7, the lack of scientific evidence is not what triggers the use of the precautionary principle. On the contrary, some scientific evidence must be the basis for the measure. The level of proof which is required by the Member wishing to maintain precautionary measures will be returned to shortly. The conclusion as regards the content of Article 5.7 must be that it does not exhaust the application of the precautionary principle. The only thing it docs is to establish one carefully circumscribed situation, lack of data, where, temporarily, measures do not need to be backed up by a risk assessment.

Members who do not wish to base their precautionary measures on the results of a risk assessment must thus rely on Article 5.7. In order to do this they must fulfil four requirements found in Article 5.7 and confirmed by the AB in Japan Agricultural Products II and more recently by the Panels in EC-Approval and Marketing of Biotech Products and USContinued Suspension of Obligations-EC Hormones. ${ }^{80}$ First, the measures must be imposed in respect of a situation where "relevant scientific information is insufficient". Second, they must be adopted "on the basis of available pertinent information". Third, additional information must be sought in order to conduct "a more objective assessment of risk". Finally, the measures must be of temporary nature, and should be reviewed within a reasonable period of time. The requirements are cumulative in nature and it is enough for one of them not to be present for a measure to fall outside the scope of Article 5.7.

79 N. Bernasconi-Osterwalder et al., Environment and Trade: A Guide to WTO Jurisprudence, p. 264. Scott also finds that the $\mathrm{AB}$ in EC-Hormones saw a role for the precautionary principle outside of Article 5.7. See J. Scott, The WTO Agreement on Sanitary and Phytosanitary Measures: A Commentary, p. 128.

80 Report of the Appellate Body. Japan-Measures Affecting Agricultural Products. WT/DS76/AB/R (Japan Agricultural Products II). paras. 89 and 90. See also Panel Report, EC-Approval and Marketing of Biotech Products para. 7.3007 and Report of the Panel, US-Continued Suspension of Obligations-EC Hormones (US-Continued Suspension of Obligations-EC Hormones), WT/DS320/R, para. 7.593.

81 AB Report, Japan Agricultural Products II, para. 89 and Pancl Report, US-Continued Suspension of Obligations-EC Hormones, para 7.594 and 7.826. 
It should be pointed out that the Panel in EC-Approval and Marketing of Biotech Products stated that relying on Article 5.7 is an autonomous right of Members, and does thus exempt them from other obligations in the SPS Agreement, such as Articles 2.2 and 5.1. ${ }^{82}$ This issue is returned to in more detail below.

\subsubsection{Judicial Review}

In WTO dispute settlement, Pancls have been empowered by the agreements to take an active part in fact-finding, consultation with, and appointment of, scientific or technical experts and substantive review of scientific evidence put before them. ${ }^{83}$ All of this aims to provide for an "objective assessment of the facts". ${ }^{44}$ How deep a Panel needs to go in order to assess the evidence is not clear. One author has claimed that the panel in EC-Hormones positioned itself somewhere in-between a deferential review and a de novo assessment of the facts: "[A] Panel should use all of the information at its disposal, including the evidence presented by the two partics, third party submissions, expert witnesses the Panel chooses to call, or any other relevant sources." ${ }^{85}$ This approach gives a considerable freedom to the Panels in determining on what evidence it will base its decisions. Bohanes has held that "[i]t is difficult to overestimate the implications of this: standards of review affect the entire balance of power in a supranational organization, where sovereign members yield powers of interpretation of an agreement to a tribunal". ${ }^{86}$ Croley and Jackson hold that the issue of judicial review was one of the most contended during the Uruguay Round negotiations, which led to the creation of the WTO. ${ }^{87}$

In order for the Panels to adequately assess the often complex and technical information put before them, the agreements provides for the appointment of experts to assist

82 Panel Report, EC-Approval and Marketing of Biotech Products para. 7.3007. See, also, D. Prevost, Opening Pandora's Box: The Panel's Findings in the EC-Approval and Marketing of Biotech Products Dispute, p. 8384.

83 GATT 1994 Annex II: Understanding on Rules and Procedures Governing the Settlement of Disputes (DSU), Article 13 and SPS Agreement, Article 11. For a detailed discussion on the judicial review in health matters under the WTO Agreements, see C. Button, The Power to Protect: Trade, health and uncertainty in the WTO, Hart 2004, Chapters 5-7. See, also, D. Palmeter, The WTO Standard of Review in Health and Safety, in: G.A. Bearmann \& P.C. Mavroidis, Trade and Human Health and Safety, Cambridge University Press, 2006, pp. 224-235.

84 Ibid., DSU, Article 11.

85 C. Bisgaard, Assessing the Standard of Review for Trade-Restrictive Measures in the Sanitary and Phytosanitary Agrcement, in: E. Brown Weiss \& J.I. Jackson, Reconciling Environment and Trade, Transnational Publishers, 2001, p. 367.

86 J. Bohanes, Risk Regulation in WTO Law: A Procedure-based Approach to the Precautionary Principle, 40 Colum. J. Transnat. L. 323, 2001-2002, p. 346.

87 S.P. Croley \& J.H. Jackson, WTO Dispute Procedures, Standard of Review and Deference to National Governments, 90 AM. J. Int'l L. 193, p. 211. 


\section{Joakim Zander}

them. ${ }^{88}$ In all cases where panels have made usc of expert advice, individual experts rather than expert review groups have been appointed. The reason for this appears to be that panels have wished to avoid appointing a "panel within the panel" and the fact that co-ordinating the work in expert groups may be excessively time-consuming. ${ }^{\text {(9) }}$

The $A B$, on the other hand, is prohibited from revising the factual conclusions reached by the Panels. ${ }^{1 / 1}$ In EC-Sardines, EC-Hormones and Japan-Apples, the AB stated that:

"Determination of the credibility and weight properly to be ascribed to (that is, the appreciation of) a given piece of evidence is part and pareel of the fact finding process and is, in principle, left to the discretion of a panel as the trier of facts." 11

Only if an interpretation of the panel puts its "objective assessment of the facts" in question is it going to be reviewed by the $\mathrm{AB}$. However, a simple misinterpretation of the facts by a Panel is not going to make the $A B$ revise its judgment. Instead the $A B$ has held that the Panel must have "deliberatcly disregarded," "refused to consider," "wilfully distorted" or "misrepresented" the evidence before it for this to be the case. ${ }^{92}$ Thus, the discretion of the Panels when interpreting scientific evidence is very broad. The discretion of the $A B$, on the other hand, is limited to considering formal aspects of the judgment and only to make an assessment in rem regarding the question of if the Panels have intentionally made a biased assessment of the facts. ${ }^{93}$

See, in particular, Articles 11.2 of the SPS Agrecment and 13.2 of the Dispute Settlement Understanding in this regard.

89 J. Pauwelyn, The Use of Experts in WTO Dispute Settlement, ICLQ, Vol. 51, 325, 2002, p. 328-329. Pauwelyn generally sees the use of experts as very beneficial for the swift and rational decision-making in panel proceedings and he even argues for an extended use of scientific experts, including the appointment of panel members and secretariat with scientific training (lbid, 363-364). See, also, J. Pauwelyn, Expert Advice in WTO Dispute Settlement, in Trade and Human Health and Safety, p. 235-256. However, other authors are more sceptical to the appropriateness of placing such great weight on scientific evidence. See for example, R. Howse, Democracy, Science, and Free Trade: Risk Regulation on Trial at the World Trade Organization, 98 Mich. L. Rev. 2329, 2000, p. 2333-2338. For a general critique of the reliance on scientific advice in public decision-making, see S. Jasanoff, The Fifth Branch: Science Advisers as Policymakers, IIarvard University Press, 1990.

9) Article 17.6 of the DSU holds that "An appeal shall be limited to issues of law covered in the panel report and legal interpretations developed by the panel."

91 AB Report, Furopean Communities - Trade Description of Sardines, WT/DS231/AB/R (EC-Sardines), para. 300.; AB Report, EC-IIormones, para, 132; Report of the Appellate Body. Japan ... Measures Affecting the Importation of Apples. WT/DS245/AB/R (Japan-Apples), para. 138.

$92 \mathrm{AB}$ Report, EC-Hormones. para. 133. For a critique of the objective standard of review performed by the $\mathrm{AB}$, see C. Button, The Power to Protect: Trade, health and uncertainty in the WTO, p. 163-191.

9) For a discussion on the review permitted under Article 17.6 of the DSU, see P. van den Bossche, The Law 
The conscquence of this deep review by the panels in relation to the precautionary principle is that science appears to become the arbiter in many cases. ${ }^{94}$ This issue is analysed in detail below.

\subsubsection{Risk Assessment and Risk Management}

The $\mathrm{AB}$ has held that the requirement of a risk assessment stated in Article 5.1 of the SPS Agreement is strict and that it aims to ensure that the general goal in Article 2.2 is met. ${ }^{95}$ The relevant part of Article 2.2 state that an SPS measure must be "necessary", "based on scientific principles" and "not maintained without sufficient scientific evidence". 96

In relation to pests and diseases, the $\mathrm{AB}$ in Australia-Salmon established that a risk assessment under Article 5.1 must address three requirements. First, it must identify the risk and the biological and economic consequences the realisation of it would bring. Second, the likelihood of the realisation must be established. Finally, the likelihood of the realisation of the risk must be established according to the SPS measures which might be applied. ${ }^{97}$ The third requirement means that it is not enough to evaluate the situation in relation to SPS measures already in place, but other possible measures must be considered. The $A B$ has later emphasised that this is an important factor in the risk assessment. ${ }^{98}$ The three requirements stressed in Australia-Salmon are based on the definition of risk assessment included in Annex A to the SPS Agreement. ${ }^{99}$

Concerning food-borne risks, Panels and the Appellate Body have stressed two requirements which should be addressed when carrying out a risk assessment under paragraph 4 of Annex A of the SPS Agreement. First, the adverse effects to human or animal health stemming from the food, beverage or feedingstuff need to be identified. Sccond, the

and Policy of the World Trade Organization, 1st edition, pp. 250-252.

94 Bohanes, for example, has held that the judicial revicw is one of the main problems when applying the precautionary principle; see J. Bohanes, Risk Regulation in WTO Law: A Procedurc-based Approach to the Precautionary Principle, p. 345-346.

95 AB Report, EC-Hormones. para. 180.

96 In Australia - Measures Affecting the Importation of Salmon (Australia-Salmon) WT/DS18/AB/R (paras. 137-138), the $A B$ elaborated on the relationship between Article 5.1 and the more general Article 2.2. It concluded that if the Article 5.1 is breached, it can be presumed that Article 2.2 also is breached. There has not yet been a case where this presumption has not been found to be true. For a discussion on this see $\mathrm{N}$. Bernasconi-Osterwalder et al., Environment and Trade: A Guide to WTO Jurisprudence, 260. See also J, Scott, The WTO Agreement on Sanitary and Phytosanitary Measures: A Commentary, p. 84-91.

97 AB Report, Australia-Salmon. para. 120

98 AB Report, Japan-Apples. para. 209.

99 Article 4. Anncx A attached to the SPS Agreement. See, also, D. Winickoff et al., Adjudicating the GM Food Wars: Science, Risk, and Democracy in World Trade Law, 30 Yale J. Int'l Law 81, 2005, at footnote 173. 
"potential" occurrence of these risks needs to be assessed. ${ }^{100}$ In this regard, the Panel in USContinued Suspension of Obligations in the EC-Hormones Dispute came to the conclusion that although the EC had evaluated the potential effects of the hormones at issuc for public health, it had "not evaluated specifically the possibility that these adverse effects come into being, originate, or result from the consumption of meat or meat products [containing traces of the hormones]". ${ }^{101}$ Due to this fact the Panel did not find that the requirements in paragraph 4 of Annex A of the SPS Agreement had been met.

Furthermore, the $A B$ has found it of importance that the assessed data is specific enough. In EC-Hormones the data presented by the EC in support of its measures was not based on the hormones at issue per se, but rather on a whole category of hormones. This the Panel as well as the $\mathrm{AB}$ considered to be "[...] relevant but do not appear to be sufficiently specific to the case at hand". ${ }^{102}$ It thus seems that the AB did find the data to be of use, but too gencral in scope to justify the EC measures. ${ }^{103}$

When assessing the data the Member is not bound to a specific assessment of the risk but remains free to choose the appropriate methodology. The methodology chosen must be in conformity with Article 4 of Annex A to the SPS Agreement. ${ }^{104}$ Article 5.2 of the SPS Agreement lists a number of topics that should be covered by a risk assessment. This list should, however, not be considered as exhaustive. Instcad it is indicative of issues that may be of relevance. Nothing should prevent a Member from including other aspects that more accurately depicts the relevant risk "in the real world where people live and work and die". 105

As discussed above, the $\mathrm{AB}$ in $\mathrm{EC}-$-Hormones emphasised that a risk assessment not necessarily should be limited to the mainstream scientific opinion. Instead it stressed that divergent views on a risk may indicate that the issue is surrounded by scientific uncertainty. However, it also stressed the importance of a clear link between the divergent opinions and the risk at issue. ${ }^{106}$

\footnotetext{
${ }^{100}$ Panel Report, EC-Hormones (US), para. 8.98, Panel Report, EC-Hormones (Canada), para. 8.101 and AB Report, EC-Hormones, para. 184-186.

101 Panel Report, US-Continued Suspension of Obligations-EC Hormones), para. 7.537.

102 AB Report, EC-Hormones. para. 200.

103 See, also, J. Scott, The WTO Agreement on Sanitary and Phytosanitary Measures: A Commentary, p. 94.

${ }_{104} \Lambda \mathrm{B}$ Report, Japan-Apples. para. 205.

105 AB Report, EC-Hormones. para. 187.

${ }^{106}$ Ibid., para. 194.
} 
The Panel in the EC-Hormones case made a distinction between risk assessment and risk management. It held that risk assessment is a strictly scientific undertaking and not a "policy" exercise. ${ }^{107}$ Risk management on the other hand it described as "non-scientific". 108 On appeal the $\mathrm{AB}$ did not agree with this reasoning. It found no textual basis in the SPS Agreement for separating the two stages; Article 5 only pertains to the issue of risk assessment. The $\mathrm{AB}$ therefore denounced the "restrictive notion of risk assessment" that it considered the Panel to be advocating. ${ }^{109}$ This seems to imply that the $\mathrm{AB}$ is open to considering "risk assessment" to be less restrictive than the traditional science-based interpretation that the Panel had advocated. ${ }^{110}$ One commentator has held that this conclusion of the $\mathrm{AB}$ leaves the governments "great freedom in risk management even where exercise of this freedom may inhibit trade". "It remains unclear what the practical implications of this finding will be. It could be argued that the view assumed by the Panel ensures a more systematic approach with clearer implications than the conclusion the $A B$ came to. It could therefore be argued that it would have made sense for the $A B$ to build on the findings of the Panel and primarily confine risk management choices to Article 3.3 of the SPS Agreement. It would then have been clear that the selting of the appropriate level of protection is a risk management decision, while the establishment of the scientific basis for that decision is an eminently scientific enterprise. ${ }^{112}$

When carrying out a risk assessment, Article 5.1 holds that Members shall take into account risk assessment techniques developed by relevant international organisations. In USContinued Suspension of Obligations-EC Hormones, the US held that the failure of the EC to strictly adhere to the risk assessment techniques suggested in the Codex Alimentarius constituted a breach of Article 5.1. ${ }^{113}$ However, the Panel concluded that it was not of

107 US Panel Report. EC Hormones. para. 8.94 and Canada Panel Report. EC Hormones. para. 8.97.

108 US Panel Report. EC Hormones. para. 8.95 and Canada Panel Report. EC Hormones. para. 8.97.

109 AB Report, EC-Hormones. para. 181.

${ }^{110}$ For a discussion on the differing approaches assumed by the panel and the $\mathrm{AB}$ in $E C$-Hormones in relation to the content of risk asscssments, see J. Scott, Of Kith and Kine (and crustaceans): Trade and Environment in the EU and WTO, available at: hitp:/www.jeanmonnetprogram.org/papers/99/990307.html. The Panel had first established a clcar scparation between scientific risk assessment and the decision-making taking place in the risk management phase. The $A B$ found that such a clcar scparation was not to be found in the SPS Agreement and argued that risk assessment can include broader considerations than strictly scientific analysis (EC-Hormones, para. 187). However, as is seen in the following, the requirement on scientific evidence is still paramount.

111 J. Bohanes, Risk Regulation in WTO Law: A Procedure-based Approach to the Precautionary Principle, p. 341.

112 For a further discussion on the separation of risk assessment and risk management, see, above, Section 2.4.5.

113 Panel Report, US-Continued Suspension of Obligations-EC Hormones, paras. 7.450-7.454. 
Joakim Zander

primary importance that the party invoking protective measures follow all the steps outlined in the Codex Alimentarius. Instead it considered it enough that the relcvant risk assessment techniques "had been taken into account" during the assessment. ${ }^{114}$

As mentioned above, the only time the strict risk assessment requirement may be wavcred is in cases where Article 5.7 applies. According to the article, precautionary measures may be applied "on the basis of pertinent information" in cases where "relevant scientific evidence is insufficient." This must be compared to the wording of Article 2.2 where it is held that measures cannot be maintained or introduced "without sufficient evidence". The latter the $\mathrm{AB}$ has considered meaning that measures may not be maintained where there is no "rational or objective relationship" between the measure and the relevant scientific evidence." 115 Thus, it describes a situation where enough scientific evidence exists in order to carry out a risk assessment, but the results of the risk assessment do not support the conclusions drawn by the party wishing to maintain or introduce the measures. ${ }^{116}$

With regard to Article 5.7 the $\mathrm{AB}$ has held that the aim is to cater for a situation where "the body of available scientific evidence docs not allow, in quantitative or qualitative terms, the performance of an adequate assessment of risks as required under Article 5.1 and as defined in Annex A to the SPS Agreement." 117 What the AB here refers to is a situation where a risk assessment is impossible to carry out due to the lack of scientific evidence. The lack of scientific evidence can, according to the Panel in EC-Approval and Marketing of Biotech Products, be qualitative as well as quantitative. ${ }^{118}$ In such cases, and only in such cases, measures can be maintained without support in a risk assessment. However, it can be discussed if a risk assessment must not at least be attempted in support of measures. One could be forgiven for asking how a Member would know that relevant data was lacking before it has made an attempt at evaluating it.

\subsubsection{Scientific Evidence and the Level of Proof}

This analysis has revealed that there are two ways of maintaining or introducing precautionary measures under the SPS Agreement. First, measures can be maintained in a situation where a risk assessment is carried out and a rational and objective relationship

\footnotetext{
114 Ibid., paras. 7.467-7.469.

115 AB Report, Japan-Apples, para. 147.

${ }^{116}$ For a further discussion on what it means for a measure to be based on a risk asscssment, see J. Scott, The WTO Agreement on Sanitary and Phytosanitary Measures, pp. 104-110.

117 AB Report, Japan-Apples, para. 179.

118 Letter appended to Panel Report, EC-Approval and Marketing of Biotech Products at Annex K.
} 
between the scientific evidence and the precautionary measures is identified. In this situation scientific uncertainty may exist due to diverging opinions or insufficient data to make the risk scientifically certain.

Sccond, measures can be maintained in a situation where a Member can claim that the scientific data available is so insufficient that it renders the performance of a risk assessment impossible. In this section it is investigated what the party wishing to maintain measures needs to show in the two respective situations.

As was discussed above, the Panel is the trier of the facts under the DSU. The AB performs a limited review, restricted to interpreting the legality of measures. It will only revise the factual findings of the Panel if it finds that it has made an intentionally biased assessment of the facts. The Pancl on the other hand goes to great lengths to interpret the evidence presented to it and to determine that measures are in conformity with Articles 2.2 and 5.1 of the SPS Agreement. Four requirements found in the Articles nced to be fulfilled by the Member wishing to maintain measures outside of Article 5.7 of the SPS Agreement. ${ }^{119}$ First, a risk assessment must be carried out. ${ }^{120}$ Second, the measures must be shown to be necessary with regard the goal they aim to achieve. Third, measures must be based on scientific principles. Finally, the measures may not be maintained without "sufficient scientific evidence". The last two of these requirements are dealt with here.

In EC-Hormones ${ }^{121}$ the Panel found that the main problem with the scientific evidence brought before it by the EC was that it was not specific enough. ${ }^{122}$ The ECHormones case related to a number of specific hormones used as growth promoters in cattle. However, most of the evidence brought by the EC did not relate to these specific hormones, but rather to entire categories of hormones. ${ }^{123}$ Such studies were considered by the Panel to be relevant, but not "sufficiently specific to the case at hand", and therefore did not fulfil the requirement in paragraph 4 of Annex A of the SPS Agreement. ${ }^{124}$

\footnotetext{
119 AB Report, EC-Hormones, paras. 179 and 180.

120 See the discussion above in Section 3.3.2.2.

121 The case was brought before a panel by Canada and the US, which held that the EC legislative regime prohibiting beef treated with a number of homones from entering its market was not in conformity with the SPS Agreement, notably Articles 2.2 and 5.1. For a detailed discussion on the case, see N. Bernasconi et al., Environment and Trade: A Guide to WTO Jurisprudence, pp. 268-278 and J. Scott, Of Kith and Kine (and Crustaceans).

122 US Panel Report. EC Hormones. paras. 8.129 \& 8.134

123 Ibid., para. 8.127.

124 AB Report, EC Hormones, para. 199.
} 


\section{Joakim Zander}

The more specific evidence brought by the EC was limited. ${ }^{125}$ Particularly damning for the EC was that its own scientific expertise had come to the conclusion that no scientific evidence indicating the harmfulness of the hormones existed. ${ }^{126}$ A dissenting scientific opinion by one expert was considered. He held that there was a measurable risk associated with the hormones. However, the Panel found that the risk proposed by the expert, $0-1$ in a million, was not enough to signify that an "identifiable risk" existed and that the use of the hormones for growth promotion purposes was safe. ${ }^{127}$ The Panel disagreed with the opinion for two main reasons. First, it considered the fact that the risk proposed referred to the total amount of oestrogen in cattle, not to the amount connected to growth promoters. Second, it held that a risk of such low probability is not even a scientifically identified risk. ${ }^{128}$

As was discussed in the previous section, on appeal the $A B$ was critical of the narrow scope the Panel had confined to risk assessment. It was also critical of the Panel's use of the term "probable" since it considered it to imply "a higher degree of threshold of potentiality or possibility". ${ }^{129}$ This the $A B$ found to lead to a situation where a quantitative risk assessment would have to yield as a result a risk of a certain magnitude. ${ }^{130}$ This would not be commensurable with the SPS Agreement. Instead, the AB considered that the establishment of a possible cause and effect chain would be sufficient to justify SPS measures. ${ }^{131}$ It should be noted that the risks in EC-Hormones were food-borne and therefore the second tier of the definition of risk assessment in paragraph 4 of Annex A of the SPS Agreement was considered by the Panels and the AB. Therefore, the conclusions of the $\mathrm{AB}$ with regard the level of proof required relates to the cstablishment of "potential" risk, as opposed to the "likelihood" requirement in the first tier of the definition relating to pest or disease. It appears that the difference in the wording should be taken to indicate a less stringent level of proof in cases relating to food-borne risks than in cases of pests and disease. ${ }^{132}$

Even if the $\mathrm{AB}$ in $\mathrm{EC}-\mathrm{H}$-Hormones went to some lengths to point out that it construed the requirement of risk assessment and scientific evidence to be somewhat different (and perhaps morc lenient) than the Panel had, in reality the ruling by the $\mathrm{AB}$ is more ambiguous.

\footnotetext{
${ }^{125}$ US Pancl Report. EC Hormones, para. 8.119-8.122.

${ }^{126}$ Ibid., para. 8.123.

127 Ibid, para. 8.124.

128 Ibid., note 331.

129 AB Report, EC-Hormones, para. 184.

130 Ibid., para. 186.

${ }^{131}$ For a discussion on this, see J. Scott, Of Kith and Kine (and Crustaceans).

132 P. van den Bossche, The Law and Policy of the World Trade Organization, 2nd edition, Section 8.4.5.1.
} 
In fact, it appears that the difference between the approaches adopted has more to do with linguistics than with any functional discrepancies. Like the Panel, the $A B$ holds that "theoretical uncertainty" as to the risk is not what is to be assessed under Article 5.1. ${ }^{133} \mathrm{Scott}$ has interpreted this as meaning that "[a] hypothetical possibility of risk, arising from the failure of scicntists to demonstrate with absolute certainty that there is no risk either now or in the future, is not capable of rationally grounding an SPS measure". ${ }^{134}$ Thus, the reliance on scientific cvidence is strongly emphasised also by the AB. And since the performance of comprehensive risk assessments is the most common, if not only, way to scientifically prove the existence of a risk, also the performance of risk assessments are endorsed by the AB.

In Japan-Apples, the US challenged measures introduced by Japan to protect itself from the introduction of lire blight through the importation of apples from the US. ${ }^{135}$ Fire blight is a bacterium, which causes apples to whither and darken. The risk thus meets the first tier definition in paragraph 4 of Annex A of the SPS Agreement, and what needed to be assessed is the "likelihood" of the risk rather than its "potential".

Japan held that its risk assessment had yiclded enough evidence to maintain its protective regime against the US. As a secondary motion it relied on Article 5.7, in case the Panel would find that the scientific evidence was not enough to justify the measures under Article 5.1.

Two issues needed to be examined by the Panel to determine the risk to Japan of fire blight spreading through the importation of apples. First, it had to be established if mature and symptomless fruit (the only type exported by the US to Japan) could harbour fireblight bacteria. Second, if this be the case, can such apples carry the bacteria and spread it to other fruit after it has entered Japan?

To begin with, the Panel and the $A B$ turned their attention to the issue of if the measures could be said to be supported by "sufficient scientific evidence" in accordance with Article 5.1 and 2.2 of the SPS Agreement. In order to understand the scientific evidence before it, the Panel relied on the advice of appointed experts to clarify the detailed scientific

\footnotetext{
133 AB Report, EC-Hormones, para. 186.

134 J. Scott, Of Kith and Kine (and Crustaceans).

135 For another analysis of the Japan-Apples case, see N. Bernasconi-Osterwalder et al., Environment and Trade: A Guide to WTO Jurisprudence, pp. 288-291.
} 
Joakim Zander

issues. ${ }^{136}$ The evidence consisted of relevant scicntific reports and monographs in combination with the empirical knowledge obtained over many years of trading with apples.

The Panel found that the bulk of the scientific evidence relating to the infection and infestation of mature and symplomless apples on which Japan relied was "[...] relativcly confused, difficult to interpret or even unconvincing $[\ldots]^{\prime 137}$ and that the results they predicted were "extremely rare" at best. ${ }^{138}$

The second stage of this survcy dcalt with the issue of the cause and effect relationship between the potential prevalence of fireblight in mature symptomless apples and the spread of fireblight to other apples. Japan's own risk assessment had failed to find support for such a link ${ }^{139}$ but Japan held that it would be a matter of "common sense" that transmission could be completed through rain, insects, etc. ${ }^{140}$ The Panel was not convinced by this argument. It cited experts in the licld who held that large-scale experiments had failed to show a link. Furthermore the historic in vivo evidence suggested the risk to be "negligible" and defined this as a likelihood of between zero and one in a million. ${ }^{141}$ Experts also held that the risk of travellers to Japan bringing with them infected or infested apples was higher than that associated with wholesale import. ${ }^{142}$ The only precautionary measure expressed by the expcrts was that apples from heavily fireblight infested orchards should not be exported, even if mature and symptom free. ${ }^{143}$

Finally, the Panel held that fruit other than "mature and symptomless" apples may harbour the bacteria, and that such bacteria may survive the transport to Japan. ${ }^{144}$ However, the US emphasised that such apples were not exported to Japan and that rigorous tests were in place to ensure that this would be abided by. In the light of this, the Panel held that the risk of such apples entering Japan would purely be due to errors in handling or illegal actions. These risks were acknowledged by the experts, but were deemed to be "small" or "dcbatable". 145

\footnotetext{
${ }^{136}$ See, for example Panel Report, Japan - Measures Affecting the Importation of Apples, WT/DS245/R (Panel Report, Japan-Apples), para. 8.125\&8.169.

137 Ibid., para. 8.125.

138 Ibid., para. 8.131

${ }^{139}$ Ibid., para. 8.147.

${ }^{140}$ Ibid., para. 8.146.

141 Ibid., para. 8.146 \& 8.149.

${ }^{142}$ Ibid., para. 8,150

$143 \mathrm{Ibid}$., para. 8.151

144 Ibid., pars. 8.154-8.157.

${ }^{145}$ Ibid., para. 8.161.
} 
On the basis of this, the Panel concluded that "sufficient scientific evidence" had not been produced in favour of the SPS measures, and these wcre thus in violation of Article 2.2 of the SPS Agreement. ${ }^{146}$ The AB further clarified this on appeal and reiterated its position in Japan-Agricultural Products II where it stated that the absence of "an actual causal link" between the protective measure and the scientific evidence indicates that "sufficient scientific evidence" is lacking in support of the measures. ${ }^{147} \mathrm{~A}$ "causal link" must in turn be interpreted as establishing a "rational or objective relationship". ${ }^{148}$

Having concluded that sufficient scientific evidence did not exist, the Panel turned to investigate if the measures could be maintained in the absence of scientific evidence under Article 5.7. Here, it began by separating the mcaning of the wording of Article 5.7 from that of Article 2.2. The requirement that "relevant scientific evidence is insufficient" in Article 5.7 is not to be equated with Article 2.2's statement that measures may not be maintained "without sufficient scientific evidence". ${ }^{149}$ The Panel concluded:

\footnotetext{
"The current "situation", where scientific studies as well as practical experience have accumulated for the past 200 years, is clearly not the type of situation Article 5.7 was intended to address. Article 5.7 was obviously designed to be invoked in situations where little, or no, reliable evidence was available on the subject matter at issue. With regard to fire blight, not only a large quantity but a high quality of scientific evidence has been produced over the years that describes the risk of transmission of fire blight through apple fruit as negligible. Moreover, this is evidence in which the experts have expressed strong and increasing confidence. We therefore are of the view that the first condition of the first sentence of Article 5.7 is not met." 150
}

Thus, it appears that the Panel viewed Article 5.7 as something recourse can be had to in cases of scicntific uncertainty due to the lack of observations and scientific data. If such data is not insufficient in the context of Article 5.7, the requirements of Article 2.2 must be met. The conclusion of the above is that "sufficient scientific evidence" in Article 2.2 is intended to mean "sufficient scientific evidence in favour of the SPS measure," whereas "insufficient scientific evidence" in Article 5.7 refers to scientific evidence relating the

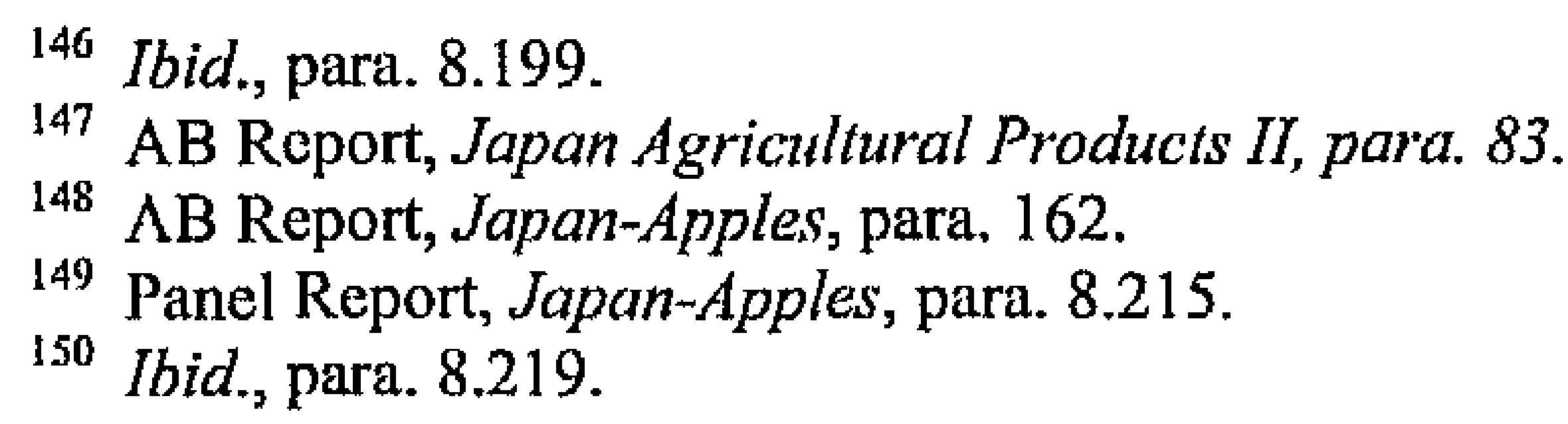


subject matter in general. ${ }^{151}$ In relation to this, some authors have held that the scope of Article 5.7 should be allowed to be broader since scientific evidence is perceived as rarely leading to entirely reliable or conclusive results. ${ }^{152}$ However, it should be noted that it does not appear to be referring to reliability or conclusiveness in absolute terms, but rather it uses them as relative terms to distinguish situations falling under Article 5.7 from those falling under the strict risk assessment requirement in Articles 2.2 and 5.1. This distinction was also emphasised by the Panel in EC-Approval and Marketing of Biotech Products. ${ }^{153}$

Furthermore, and importantly, the $\mathrm{AB}$ has clcarly stated that, in order to invoke Article 5.7, a Member would not have to show the complete lack of scientific findings, but the article applies where the body of available scientific evidence does not allow, in quantitative or qualitative terms, the performance of an adequate assessment of risks as required under Article 5.1. ${ }^{154}$ Every situation has to be decided on a case-by-case basis. ${ }^{155}$ In relation to this, in US-Conlinued Suspension of Obligations-EC Hormones, the Panel stated that it did not consider the purpose Article 5.7 to be to "lower" the level of proof a Member has to meet in order to introduce or maintain protective measures. Rather it considered Article 5.1 and Article 5.7 to apply to the separate situations outlined above. ${ }^{156}$ The Panel in US-Continued Suspension of Obligations-EC Hormones also stated that the intended level of protection of the Member introducing or maintaining SPS measures under Article 5.7 is irrelevant when considering if the measures can be allowed. What triggers the use of the article is not the intended level of protection, but the lack of available scientific evidence. ${ }^{157}$

151 Bohanes also addresses this issue and he stresses the point that since no Member as of yet has successfully invoked Article 5.7 it is unclear what will be required to show in order to do so. It is here argued that only the lack of scientific findings can motivate temporary measures under Article 5.7. See J. Bohanes, Risk Regulation in WTO Law: A Procedure-based Approach to the Precautionary Principle, p. 338-339. See, also, the discussion on sufficient scientific evidence in J. Scott, The WTO Agreement on Sanitary and Phytosanitary Measures: A Commentary, p. 86-91.

${ }^{152}$ D. Winickoff et al., Adjudicating the GM Food Wars: Science, Risk, and Democracy in World Trade Law, p. 113-114. The authors argue that the greater the disparity of the scientific advice, and the greater the lack of consensus on it validity, the greater the possibility would be to rely on Article 5.7. However, this is in contrast to the conclusion of the argument made by this author, who sees Article 5.7 not as a "safe haven" but simply as an exemption from the requirement on performing risk assessments in urgent cases where this is difficult or impossible. Thus, the $A B$ has rightly employed a narrow interpretation of the article since the over-arching requirement of performing a risk assessment should not be eroded.

153 Panel Report, EC-Approval and Marketing of Biotech Products, para. 7.2995.

154 AB Report, Japan-Apples, para. 179. This statement was also rciterated more recently in Panel Report, USContinued Suspension of Obligations-EC Hormones, para. 7.608.

155 AB Report, Japan-Apples, para, 185.

156 Panel Report, US-Continued Suspension of Obligations-EC Hormones, para. 7.605.

157 Ibid., para. 7.612. 
In US-Continued Suspension of Obligations-EC Hormones, the Panel also addressed the issue of whether available scientific cvidence can "become insufficient" if it has previously been held that the available evidence was sufficient. The Panel held that this could indeed be the case, but only following the emergence of "a critical mass of new evidence and/or information that calls into question the fundamental precepts of previous knowledge so as to make relevant, previously sufficient, evidence now insufficient." 158 A "critical mass" of information and scientific evidence would have to be "such that they are at the origin of a change in the understanding of a scientific issue". ${ }^{159}$ Having stated this, the Panel addressed all the hormones at issue in the case and stated that sufficient scientific evidence in order to perform a risk assessment existed with regard to all of them. ${ }^{160}$

As was argued above, the precautionary principle can also function under Articles 2.2 and 5.1, and these articles do not require conclusive evidence to be invoked. ${ }^{161}$ The only thing that Article 5.7 adds to the equation is that in urgent cases where littlc or no scientific evidence is available, Members should not be prevented from issuing temporary protective measures. In all other cases a risk assessment should be performed. However, as has been repeatedly accounted for above: the risk assessment does not have to yield a scientifically certain result for measures to be upheld. Thus the precautionary principle can be invoked outside of Article 5.7 as long as a link is cstablished between the evidence and the measures invoked. ${ }^{162}$ This assertion is also supported by Button, who holds that most risk assessments are uncertain to one degree or another, and that this uncertainty does not mean that measures cannot be maintained under Articles 2.2 and 5.1 of the SPS Agreement. ${ }^{163}$ Scott also sees the possibilities of maintaining precautionary measures outside of Article 5.7, as long as a risk assessment has been carried out. She cven holds that the official view of the EU with regard to risk assessments preceding the application of the precautionary principle implies that the view of the European institutions may not be a far cry from that of the WTO agreements. ${ }^{164}$

\footnotetext{
158 Ibid., para. 7.648.

159 Ibid., note 782 at para. 7.648 .

160 The Panel summarised these findings at ibid., para. 7.831-7.837

161 If the requirement had been that a fact would have had to be shown conclusively in order to function as a basis for measures under Article 5.1, minority opinions, for example could not be relied upon. An instance where a reliable scientific minority opinion exists is per definition an area where the evidence must be seen as uncertain and thus inconclusive. See AB Report, EC-Hormones. para. 194, and the discussion above in Section 3.3.2.1.

162 This is line with the interpretation assumed by the AB in EC-Hormones, para. 124.

${ }^{163}$ C. Button, The Power to Protect: Trade, Health and Uncertainty in the WTO, p. 114.

164 J. Scott, The WTO Agreement on Sanitary and Phytosanitary Measures: A Commentary, p. 128.
} 
Joakim Zander

Van den Bossche, on the other hand, considers that the conclusions of the $A B$ in ECHormones and the consistent approach assumed by the Pancl in EC-Approval and Marketing of Biotech Products in practice confines the application of the precautionary principle to Article 5.7 situations, due to the fact that the principle cannot be considered to add "flexibility" to the scientific disciplines under the SPS Agreement. ${ }^{165}$ However, as has been argued above, the precautionary principle can be used by Members without adding "flexibility" to the scientific disciplines in the SPS Agreement. Since full scientific certainty is not required for the issuing of measures, and minority opinions can be relied upon, it could be argued that the "flexibility" needed for Member States to rely on the precautionary principle is in fact already built into the SPS regime, although it does not feature as an indepcndent ground to invoke as justification for measures.

In a letter to the partics attached to the Panel Report in EC-Approval and Marketing of Biotech Products, the Pancl claborated slightly on its view on scicntific evidence. ${ }^{166}$ In line with previous findings, it held that the insufficiency of scientific evidence, which triggers the use of Article 5.7, can be qualitative as well as quantitative. The Panel also repeated the position advanced in EC-Hormones, that the risk assessed is "a real world risk", and does not only have to be ascertained in a laboratory. Furthermore, the Pancl recognised that scientific evidence is not necessarily static. Instead it emphasised that the emergence of new scientific evidence may contradict a previous risk assessment and lead to a situation where sufficient scientific evidence to perform a risk assessment may not bc available.

Panels and the $\mathrm{AB}$ in cases under the GATT 1994 have also emphasised the imporlance of a link between protective measures and scientific evidence. ${ }^{167}$ As in the case of the SPS Agreement, minority opinions may be relied upon to substantiate such a link. ${ }^{168}$ No explicit reference has been made to precautionary action in the GATT itself or in subsequent case law. However, in relation to EC-Asbestos it has been argued that the $\mathrm{AB}$ offered some deference to Members to act quicker and on the basis of less scientific evidence in cases where health scares have resulted in a "panicked public opinion". 169

${ }^{165}$ P. van den Bossche, The Law and Policy of the World Trade Organization, 2nd edition, Scction 8.4.5.3.

${ }^{166}$ See the letter attached to Panel Report, EC-Approval and Marketing of Biotech Products, Annex K.

167 Report of the Appellate Body, European Communities - Measures Affecting Asbestos and AsbestosContaining Products. WT/DS135/AB/R (EC-Asbestos), para. 115.

168 Ibid., paras. 178 and 194.

${ }^{169}$ L.A. Ruessmann, Reflections on the WTO Doha Ministerial Conference: Putting the Precautionary Principle in its Place: Parameters for the Proper Application of a Precautionary Approach and the Implications for 
The TBT Agreement has so far not been the object of interpretation by the DSU as to issues of scientific evidence, etc. ${ }^{170}$

As can be deduced from the above, panels as well as the $A B$, have so far failed to identify a clear levcl of proof that needs to be met by a party wishing to maintain a measure. In US-Wool Shirts and Blouses, the AB held that the level of proof required "will necessarily vary from measure to measure, provision to provision, and case to case." 171 Panels and the $A B$ have explicitly stated that they will focus their attention on the establishment of a link between the scicntific evidence presented and the measure at stake, and that the level required can be relatively low (since also minority opinions can be relied upon, "a preponderance of evidence" can hardly be required). Pauwelyn has criticised the case-by-case approach on the grounds that it risk lcading to different levels of proof being applied in different cases. ${ }^{172}$ However, even though it would be helpful from a legal certainty point of vicw to identify a fixed level of proof that applies equally in all cases, it is difficult to foresee how this would work in practice.

It should be pointed out that some authors have generally criticised the importance given to scientific evidence by Panels and the $\mathrm{AB}$. It has been held that this limits the Member government's ability to choose their own levels of acceptable risk. ${ }^{173}$ However, as has been argued here, the scope of precautionary action is significantly broader under the SPS Agreement than it is generally given credit for.

\subsubsection{The Burden of Proof}

The basic approach to the allocation of the burden of proof under the WTO agreements was identified by the $A B$ in 1997 in US-Wool Shirts and Blouses. The $A B$ found that international tribunals, as well as most domestic legal orders, positioned the burden of proof on the party asserting a fact in the affirmative. This it found to be the case regardless of whether the party assumed the complaining or defending role. The level of evidence to be

Developing Countries in Light of the Doha WTO Ministerial, 17 Am. U. Int'l L. Rev. 905-949 (2002). p. 925-926.

170 "This has, according to Scott, rendered it "profoundly under-determined and intensely ambiguous" in relation to future regulatory regimes, notably the EU regulatory regime in relation to genetically modified crops and products. See J. Scott, The European Regulation of GMOs and the WTO, p. 231.

171 Report of the Appellate Body. United States-Measure Affecting Imports of Woven Wool Shirts and Blouses From India. WT/DS33/AB/R (US-Shirts and Blouses), para. 14.

172 J. Pauwelyn, The Use of Experts in WTO Dispute Settlement, p. 360

173 See, for cxample, N. de Sadeleer, The Precautionary Principle in EC Health and Environmental Law, Vol. 12 $E L J$ No. 2, 2006, p. 139. 


\section{Joakim Zander}

reached in this initial phasc is to "raise a presumption that what is claimed is true". ${ }^{174}$ Wha in fact required to be shown, the $\mathrm{AB}$ held, varies from case to case depending on circumstances in each situation. Once the prima facie case has been madc, the burden proof shifts to the other party, which must provide "sufficient evidence" to rebut the claim As India was claiming that the US was in breach of one of the WTO agreements 1 Agreement on Textiles and Clothing) in US-Wool Shirts and Blouses, it had to prov "evidence and legal argument sufficient to demonstrate" the non-compliance of the US Once India successfully did this, the onus was shifted onto the US to bring forth evide showing its compliance.

When it comes to the SPS Agreement, the Pancl, in EC-Hormones, began by sta1 that il considered that the initial burden of proof lies with the complaining party to pror prima facie evidence that a measure is not complying with a WTO agreement. Howe when SPS measures are concerned, the Panel stated, it would be up to the party invoking exception to support this with scientific evidence. In this case, the Pancl ruled, the EC had "evidentiary burden" to show that it had acted in accordance with the Agreement sinc chose to invoke what the panel characterised as the exception in Article 3.3. ${ }^{177}$ The AB not agree with the position assumed by the Panel and called its conclusion a "gens unqualified, interpretative ruling" which lacked support in the WTO agreements and inconsistent with previous $\mathrm{AB}$ reports. ${ }^{178}$ Instead, it held, consistently with its position US-Wool Shirts and Blouses, that the initial burden of proof should rest with the $p$ claiming a fact. Thus, it reversed the Panel's ruling and held that the US and Canada in Hormones bore the responsibility of showing prima facie non-compliance on the side of EC. Once that had been done, the burden of proof was shifted onto the EC to disprove claims of the US and Canada. ${ }^{179}$ A prima facie case the $A B$ defined as "one which, in absence of effective refutation by the defending party, requires a panel, as a matter of lau rule in favour of the complaining party presenting the prima facie case". ${ }^{180}$ In the cas

\footnotetext{
174 US-Shirts and Blouses, p. 14.

175 Mbid.

176 Ibid., p. 16.

177 US Pancl Report. EC Hormones, paras. 8.151 and 8.165 and Canada Panel Report US-Shirts and Blo para. 8.154 and 8.168

178 AB Rcport, EC-Homnones. para. 99 and 102.

${ }^{179}$ Ibid., para. 108 and 109.

180 Ibid., para. 104.
} 
issue, the $A B$ found that the US and Canada had managed to do this, despite not being required to do so by the Panel. ${ }^{181}$

In Japan-Apples, the AB held that, in relation to the SPS Agreement, the requiremont by a complaining party to provide a prima facie case related to the non-compliance of the defending party of the SPS Agreement, not to the scientific issue at the heart of the matter. Thus, it was sufficient for the US to claim that the Japanese measures were maintained without reliance on a risk assessment or a sufficient scientific basis, to shift the onus onto Japan. Japan, in turn, would then have the burden to show that it had performed a risk assessment and that this had yielded sufficient scientific evidence to be in compliance with Article 2.2. ${ }^{182}$ The burden to provide scientific reasoning in favour of its claims thus rested firmly with Japan. More specifically, Japan had made certain statements as to the possibilities of the completion of the pathway for fireblight in infected apples. ${ }^{183}$ The AB found that, since the Panel had found it to be "reasonably assumed" that these facts would not materialise in reality, Japan carried the burden of proving them before the $\mathrm{AB} .{ }^{184}$ The level which would have to be met was discussed above. ${ }^{185}$

Japan also made a secondary motion to rely on Article 5.7 of the SPS Agreement. In relation to this, the Panel held that the burden of proving compliance with this article would rest with Japan. This would appear consistent with the general approach accounted for here above, since it was Japan that asserted compliance with Article 5.7. The issue was not raised on appeal. $^{186}$

In EC-Approval and Marketing of Biotech Products, the Panel took a different view on the burden of proof under Article 5.7 compared to the approach assumed by the Panel in Japan-Apples. In contrast with the Panel in Japan-Apples, the Panel in EC-Approval and

181 Ibid., footnotes 71 and 180 . That the conclusion arrived at by the $A B$ is the most efficient also in law and economics terms is argued forcefully by Grando in: M.T. Grando, Allocating the Burden of Proof in WTO Disputes: A Critical Analysis, 9 JIEL 3,615, 2006, 650. The issue of what constitutes sufficient scicntific cvidence to maintain measures was dealt with in the section on scientific evidence and the level of proof.

182 AB Report, Japan-Apples., para. 160.

183 See, for example, Panel Report. Japan Apples, paras 4.82 \& 4.83.

184 AB Report, Japan-Apples, para. 228.

185 See previous section.

186 AB Report, Japan-Apples, para. 175, and note 316. Bernasconi-Osterwalder, on the other hand, holds the approach by the Panel to be inconsistent with the previous practice. It appears that this is based on the assumption that it is always the party asserting a breach of the agrecments that has the initial burden of proof. However, as was accounted for above, it is clear from US-Wool Shirts and Blouses that it is the party asserting a fact, whether it be the complainant or the defendant. See N. Bernasconi-Osterwalder, Environment and Trade: A Guide to WTO Jurisprudence, p. 290. 
Marketing of Biotech Products stated that it is for the complainant to show that an SPS measure is in breach of one of the requirements in Article 5.7. ${ }^{187}$ If this approach is upheld in future practice, it would lead to a situation where Article 5.7 would be an exemption from the general rules on the burden of proof under the WTO Agreements. It would possibly bc more prudent to view the approach assumed by the Panel in Japan-Apples as the correct one. Thus Article 5.7 should be considered an exception from the general rule in Article 2.2, and the party wishing to invoke the exception would carry the burden of proving that the requirements for the cxception are fulfilled. That Article 5.7 is to be construed as an exception to Articlc 2.2 is also supported by the wording of Article 2.2 which states that the requirements on scientific evidence need to be met "except as provided for in paragraph 7 of Article 5". ${ }^{188}$ The issue has so far not been raised on appeal, so no AB report has as of yet dealt with the issuc.

The allocation of the burden of proof with regard to precautionary measures thus depends on which provision is invoked by the Member issuing the measures. A Member challenging a measure has to show prima facie that the measures are introduced or maintained without basis in a risk assessment which has yielded "sufficient scientific evidence" in support of the measures. This burden does not necessarily extend to the scientific issue at hand. Instcad it is enough that the challenging party makes a prima facie case that the defending party is in violation of the WTO Agreements. The burden is then shifted onto the defendant to show that sufficient scientific evidence does exist in support of the measure. Alternatively, the defendant can invoke Article 5.7, in which case it has the burden of proving that the requirements of the article are met.

\subsubsection{The Targeting of Risks, Proportionality and Cost/Benefit Analysis}

Article 5.5 and 5.6 of the SPS Agreement lays down a number of qualitative requirements, which SPS measures applied in different situations must fulfil. Articlc 5.5 states that when Members set their chosen level of protection they must avoid arbitrary or unjustifiable distinctions or distinctions that result in discrimination or a disguised restriction on international trade. Therefore, measures that result in the setting of a level of protection

\footnotetext{
${ }^{187}$ Panel Report, EC-Approval and Marketing of Biotech Products, paras. 7.2969 \& 7.2976.

${ }^{188}$ This issue is also discussed briefly in D. Prevost, Opening Pandora's Box: The Panel's Findings in the EC Biotech Products Dispute, p. 84-85, footnote 81 . See, also, similar opinion in J. Scott, The WTO Agreement on Sanitary and Phytosanitary Measures: A Commentary, p. 114-115. See, also, a general discussion on the burden of proof under the WTO Agreements in M.T. Grando, Allocating the Burden of Proof in WTO Disputes: A Critical Analysis, Journal of International Economic Law Vol. 9, Edition 3, 2006, p. 615-658.
} 
breaching the article shall be avoided. Furthermorc, Article 5.6 holds that measures introduced or maintained are not more trade-restrictive than required to achieve their intended aim, taking into account technical and economic feasibility.

The $\mathrm{AB}$ in EC-Hormones stated that Article 5.5 is must be read in the context of Article 2.3 which holds that measures issued by Member shall not arbitrarily or unjustifiably discriminate between Members where identical or similar conditions prevail. The two provisions aim together to ensure a "consistent" application of measures enacted to ensure the chosen level of protection. ${ }^{189}$ On close inspection, the AB found that Article 5.5 prescribes that in order for the Article to be breached three requirements must be fulfilled. ${ }^{190}$ First, the Member imposing the SPS measures must have adopted different levels of protection in several comparable situations. Second, the contested measures must be arbitrary or unjustifiable in comparison with other comparable measures. Third, these arbitrary or unjustifiable differences must result in discrimination or a disguised restriction on trade. The requirements are, in principle, considered cumulative, but the $A B$ has specifically emphasised the existence of the last two. ${ }^{191}$ In EC-Hormones, the AB identified five different situations where different levels of protection against hormones in food were applied by the EC. ${ }^{192}$ For example, it chose to ban hormones used as growth promoters, but it did not take any action at all against hormones occurring naturally in, for instance, broccoli and eggs. The Panel found that this was enough of a discrepancy to consider the arbitrary or unjustifiable criteria fulfilled. ${ }^{193}$ The $A B$, however, found it impossible to equate the regulation of naturally occurring hormones with added hormones. Thus, it could not be considered inconsistent that the EC did not regulate naturally occurring hormones in the same way it regulated added hormones. 194

The $\mathrm{AB}$ found the fact that the $\mathrm{EC}$ chose to regulate the use of hormones as growth promoters in beef but allowed for the use of antibiotics as growth promoters in pork, to be more problematical. Especially this was this was the case since the carcinogenic risk to

\footnotetext{
189 AB Report, EC-Hormones. paras. 212 and 213.

${ }^{190}$ For a discussion on this, see L.A. Ruessmann, Reflections on the WTO Doha Ministerial Conference: Putting the Precautionary Principle in its Place: Parameters for the Proper Application of a Precautionary Approach and the Implications for Developing Countries in Light of the Doha WTO Ministerial, p. 933-935.

$191 \mathrm{AB}$ Report, EC-Hormones. paras. 214 and 215

192 Ibid., para. 218.

193 US Panel Report. EC-Hormones. paras, 8.213,8.264 \& 8.265; Canada Panel Report. EC Hormones, paras. $8.216,8.267$ and 8.268 .

194 AB Report, EC-Hormones, para. 221.
} 


\section{Joakim Zander}

humans appeared to be greater in the latter situation. The Panel found that this was enough to consider that the measures were in violation of Article 5.5. ${ }^{195}$ This the $\mathrm{AB}$ agreed with, but it found that this did not necessarily mean that the third requirement - that the measures constituted a disguised restriction on trade - had been fulfilled. Instead, it investigated the reasons behind the EC approach and found no justification for assumptions made by the Panel that the EC had acted out of protectionist concerns. This was further highlighted by the fact that the measures applied equally to Europcan and foreign produce. The $\mathrm{AB}$ concluded that it found no other reasons behind the EC ban than a genuine wish to protect its population from cancer. ${ }^{196}$ Thus, the $\mathrm{AB}$ found that the measures could not be considered to "result in a disguised restriction on international trade". ${ }^{197}$

The $A B$ furthermore stated that a measure may be allowed, even if it is arbitrary or unjustified as long as it does not result in a disguised restriction on intcrnational trade. To investigate if a measure constitutes a disguised restriction on international trade the $A B$ appears to investigate not only the effects of the measures, but also the reasons behind them. ${ }^{198}$ In EC-Hormones the $\mathrm{AB}$ put weight on the fact that when investigating the internal legal acts constituting the measure it was clear that the intention behind the measures was to protect citizens against cancer rather than protecting the $\mathrm{EC}$ market. Furthermore, the $\mathrm{AB}$ investigated the objective criteria of whether the disputed mcasures led to a morc favourable treatment of domestic goods than of imports. It found this not to be the case. ${ }^{199}$

Thus, the conclusion is that Members are, in principle, allowed to target risks provided that these measures do not lead to the setting of a level of protection that is unjustified or arbitrary. However, even when unjustified and arbitrary, measures can be maintained as long as they do not constitute a disguised restriction on trade. The Panel in ECHormones had wished to go further in setting stricter efficiency requirements on Members. The $A B$, on the other hand, did not only stay clear of establishing efficiency or cost/effectiveness requirements for measures, but it limited itself to established a minimum test to ward off outright protectionism.

\footnotetext{
${ }^{105}$ US Panel Report, EC-Hormones, para. 8.182; Canada Panel Report, EC-Hormones para. 8.240.

${ }_{196}$ AB Report, EC-Hormones, paras. 244 and 245.

${ }^{197}$ Ibid., para. 246.

198 Ibid., 244-245.

${ }^{199}$ For a brief discussion on this, see J. Pauwelyn, The WTO Agreement on Sanitary and Phytosanitary (SPS) Measures As Applied in the First Three SPS Disputes, JIEL Vol. 2(4), 641, 1999, p. 654.
} 


\subsection{Conclusion}

In international environmental law, the precautionary principle has emerged rapidly over the last two decades. In international agrecments, reference to the principle is often included in sector-specific agreements, but more rarely elaborated on in any detail. The non-binding Principle 15 of the Rio Declaration is the most cited and conclusive definition of the principle in effect at the international level. However, international tribunals have proven reluctant to base rulings on the precautionary principle as a fully-fledged part of international custom or as a general principle of international law.

In general, relatively widespread international agreement seems to exist on the importance of acting in a precautionary fashion when dealing with the environment. Thus, a broad definition of the precautionary principle, without direct legal effects, secms to enjoy wider consensus.

However, at present international consensus does not appear to exist on a narrower, prescriptive definition of the precautionary principle, including negative measures and a reversal of the burden of proof. In all cases from international tribunals discussed above, partics have agreed to the importance of precaution in the face of uncertainty, but disagreed as to the modalitics, means and goals of that precaution.

Potentially, the weak, de minimis version of the precautionary principle, which today appears to enjoy international acceptance is more reminiscent of a policy goal than a legal principle. A policy, according to Dworkin, sets out a standard to be reached in some political, social or economic area. ${ }^{200}$ It does not enjoy the same legal effects that are associated with legal principles. In sum, at present, it must be concluded that the precautionary principle does not constitute a generally binding norm of international law.

In WTO law, it is obvious that scientific evidence is of great significance when Members issue or maintain protective measures. The precautionary principle as such is not mentioned or defined in the WTO agreements. However, it has widely been understood, by Panels and the $\mathrm{AB}$, as well as by commentators, that it finds its clearest embodiment in situations covered by Article 5.7 of the SPS Agreement. Precautionary measures under Article 5.7 are only allowed in situations where so little scientific evidence exists that a risk assessment is impossible to carry out. If the precautionary principle was deemed to be limited

\footnotetext{
${ }^{200}$ See the discussion above in Chapter 2.5.
} 


\section{Joakim Zander}

to this article, precautionary measures could only be taken under one type of scientific uncertainty, namely where scientific evidence is lacking. In instances where other types of uncertainty prevail, such as scientific controversy, it would not be possible to apply more precautionary measures than has been prescribed in international standards.

It is important to note that this, however, is not the only place the precautionary principle assumes in the WTO regime. The situation in Article 5.7 only aims at describing situations where a risk assessment does not need to precede the enactment of precautionary measures. However, the $\mathrm{AB}$ has made it clcar that a risk assessment must also include an assessment of minority scientific opinion, and it is not excluded that such opinion may fulfil the requirement on sufficient scientific evidence, which may justify precautionary measurcs. As was discussed above, in Chapter 2, situations where minority scientific evidence exists are per definition situations surrounded by uncertainty due to conflicting scientific evidence. In allowing for either majority or minority opinion to be the basis for regulation, there is a role to be played for the precautionary principle under scientific uncertainty due to conflicting evidence.

Moreover, the scientific evidence relied upon by a Mcmber to justify precautionary measures must establish a clear link between the activity and the risk but the risk established must not be scientifically certain. This also leaves room for Members to act precautionary. However, so far, in all cases where the precautionary principle has been at issue, the parties wishing to maintain precautionary measures have failed to establish such a link. Furthermore, the evidence must be specific enough to the case in hand. More general evidence, for example, the risks associated with a general category of substances, will be considered but is not enough on its own. Measures may not aim to establish a zero-risk level on the market of the Member issuing the measures.

A number of issues influence the issuing of precautionary mcasures outside of Article 5.7. First, a risk assessment must be carried out. Second, the risk assessment must establish some sort of a link between the scientific evidence and the measures that are being introduced. Third, the link established does not have to be based on the majority of scientific studies. A minority scientific opinion, provided that it is specific to the case in question and comes from a reputable source, can be relied upon. Finally, the measures need to fulfil a few qualitative requirements. For example, they must be the proportional, the least trade restrictive, etc. Panels and the $\mathrm{AB}$ will investigate measures as well as scientific studies on 
which they are based very closely. The review in the WTO regime is deep and wide compared to most other legal systems discussed below.

The burden of proof under uncertainty follows the general burden of proof under the WTO Agreements. The party asserting a fact has the burden of proving that fact. Since the presumption under the SPS Agreement is that SPS measures are allowed, the initial burden of proof rests with the challenging party to show that the contested measures are not in conformity with the agreement. Once a prima facie case showing this has been made, it is up to the party wishing to maintain the measures to show that they werc issued and upheld in conformity with the agreement. With regard to the invoking of Article 5.7, Panels have rcached different conclusions concerning the burden of proof. However, it appears reasonable to consider Article 5.7 to be an exception to the requirement of scientific evidence in Article 2.2 , and thus the party invoking the exception would have the burden of proving that the requirements of the exception are fulfilled. Thus, a Member that claims that the scientific data is so scarce that a risk assessment cannot be carried out has the burden of proving that this indeed is the case.

Even if SPS measures are found to be allowed in principle, they must not lead to the imposing of a level of protection which would be in violation of Article 5.5 of the SPS Agreement as was mentioned above. In order for Article 5.5 to be breached, comparable levels of protection must have been adopted in several situations. The chosen level of protection cannot be found to be arbitrary or unjustifiable or result in discrimination or a disguised restriction on international trade when compared to other situations. Furthermore, and most importantly, the chosen level of protection must not result in a disguised restriction on international trade. $\mathrm{By}$ this the $\mathrm{AB}$ appears to mean that the rationale behind the chosen level of protection may not be a wish to protect a Member's own market. In investigating this, the $A B$ will go to great lengths to investigate the intent behind measures imposed by a Member. However, the $\mathrm{AB}$ does not make any cost/benefit or other efficiency demands on measures, and Members are, in practice free to larget risks at will.

In sum, precautionary measures under the WTO regime must be based in science and conform to the basic SPS obligations of Articles 2.2 and 5.1. The only exemption from this rule is when the scientific evidence is so scarce that it is not possible to carry out a meaningful assessment of it. However, the firm reliance on science does not exclude the use of the precautionary principle. $\mathrm{The} A \mathrm{~B}$ has made it clear that it does not require conclusive or 


\section{Joakim Zander}

even majority scientific evidence to allow measures under the SPS Agreement. This indicates that the precautionary principle can also come into effect in cases of scientific controversy. However, the party wishing to maintain its measures must show that scientific evidence providing a clear link between the action and the risk exists. It is not enough to justify precautionary measures with a wish to maintain scientifically unsubstantiated higher levels of protection or the opinion of the public. So far no Member has successfully relied on minority opinion before the WTO DSB. Furthermore, the bulk of the case law has been based on the SPS Agreement, therefore it is unclear if what has been established by panels and the AB there is directly applicable on measures taken under the GATT 1994 and the TBT Agreement. However, it would appear that this would be the case since the WTO strives to ensure consistency in the application of WTO law. 


\section{CHAPTER 4.}

\section{THE PRECAUTIONARY PRINCIPLE IN EC LAW}

\subsection{IN'TRODUCTION}

That the European Union is an outspoken champion of the application of a precautionary principle with clear legal implications in the international arena was shown in the above chapter. ${ }^{1}$ Originally developed in Germany, the principle has matured at European level only in the last ten to fifteen years. The original German vorsorgeprinzip has been interpreted as a highly ideological policy instrument with a wider and more complex scope than the precautionary principle generally discussed in today's literature and international trade conflicts. ${ }^{2}$ The purpose of the original concept answered to an unease in German society with regard to the risks inherent in modern society, ${ }^{3}$ and was part of a wider ideology that was sometimes called "ecological modernisation". 4 Some commentators hold that Germany, fearing that its own industries would be disadvantaged by its strict environmental policies, pushed through the precautionary principle at the European level in order to create least common denominator of environmental protection in its most important export market. ${ }^{5}$ Others see the development as a natural response to the growing awareness of the risks inherent to modemisation. ${ }^{6}$ During the 1990 s, the appeal of the precautionary principle increased dramatically among European citizens as well as among their elected politicians and policy makers. Especially poignant is the rise of the use of the principle in health and consumer protcction. Several explanations have been proposed to explain this newfound fondness for the precautionary principle in Europe, ranging from theories of political cycles

1 See, for example, the Report of the Appellate Body, EC Measures Concering Meat and Mcat Products (ECHormones). WT/DS26/ $\mathrm{B} / \mathrm{R}$ and Panel Reports, European Communities-Measures $\Lambda$ ffecting the Approval and Marketing of Biotech Products, WT/DS291/R, WT/DS292/R WT/DS293/R (EC-Biotech Products). See, also, J. Scott, The WTO Agreement on Sanitary and Phytosanitary Measures: A Commentary, Oxford University Press, 2007, p. 128.

2 See, for example, K. von Moltke, The Vorsorgeprinzip In West German Environmental Policy, in: Royal Commission On Environmental Pollution, Twelfth Report: Best Practicable Environmental Option, Cmnd 310, HMSO: London.

3 See U. Beck, Risk Society: Towards a New Modernity, Sage Publishers, 1992, and U. Beck, World Risk Society, Polity Press 1999.

4 M. Hajer, Environmental Discourse, Clarendon Press, 1995; A. Jordan, The Precautionary Principle in the European Union, in: J. Camcron et al., Reinterpreting the Precautionary Principle, Cameron May 2001; A, Weale, Ecological Modernisation and the Integration of European Environmental Policy, in: J.D. Lifferink, European Integration and Environmental Policy, Belhaven Press, 1993.

5 A. Jordan, The Precautionary Principle in the European Union.

6 See, for example, U. Beck, Risk Society: Towards a New Modernity. 
Joakim Zander

in regulation, ${ }^{7}$ to the assertion that European legal systems are more suited to the principle as such. ${ }^{8}$

The most readily-available explanation as to why the EU has become more "precautionary" and risk-averse since the mid-1990s, lies in the food scares experienced in Europe in the late 1990s. BSE in cattle, foot-and-mouth disease and AIDS-contaminated blood are examples of unfamiliar, unnatural and involuntary risks, which tend to be deemed to be less acceptable by the public than familiar, natural and voluntary risks. ${ }^{9}$ These recent risks were highly publicised in the media and thus firmly planted in the public conscience. It is possible that the perception of risks in relation to, for example, BSE, might have "spilled over" to, for example, uncertain risks in relation to GMOs. The perceived link between the two causally unrelated areas being that both were creating involuntary risks to the public by "unnatural" bchaviour, such as the feeding of bone meal to cattle, and alternating DNA codes to create new kinds of crops. This seems to have led to an increased pressure on European legislators to regulate uncertainty by erring on the side of caution. The instrument chosen for this has, in many cases, been a strict interpretation and application of the precautionary principle.

This chapter begins with an outline of the development of the precautionary principle in EU environmental law, and its subsequent emergence in the field of public health and consumer protection.

The precautionary principle in the EU is a double-edged sword. ${ }^{10}$ First, it can be used by the European institutions as a basis for legislation in harmonised areas. This is the most widely-discussed use of the precautionary principle in the $\mathrm{EU}$, and the one that will receive the most attention below. Second, the precautionary principle can be used by individual Member States as a shield against the free movement of products in non-harmonised areas under Article 30 of the Treaty of the European Communities (EC). It may also be possible for

7 R. Löfstedt \& D. Vogel, The Changing Character of Consumer and Environmental regulation: A comparison of Europe and the United States, Risk Analysis 21 2001, pp. 399-405.

8 J. Wiener \& M.D. Rogers, Comparing Precaution in the US and Europe, Journal of Risk Research 5 2001, p. 340-342.

9 P. Slovic, Perceptions of Risk, Science 236.p p. 28-285.

10 For a similar analogy, see J. Scott \& E. Vos, The juridification of Uncertainty: Observations on the Ambivalence of the Precautionary Principle within the EU and the WTO, in: Ch. Joerges \& R Dehousse (eds), Good Governance in Europes's Integrated Market, Oxford University Press, 2002, pp. 253-286. 
Members States to make use of the principle in harmonised areas by invoking the exemptions to harmonisation measures included in Article 95 (4) and (5) EC.

Due to the restraints on the judicial review permitted by the Europcan Court of Justice (ECJ) the margin of discretion afforded to the European institutions, primarily the European Commission, in harmonised areas is considerable. ${ }^{\text {"T }}$ The same is true with regard to Member State measures in non-harmonised areas. This raises some concern in relation to the implications and actual content of the precautionary principle in the EU. Is there a workable definition of the principle, and what are the thresholds to be met in order to invoke it in the EU? What are the implications of the limits of the Court's judicial review with regard to the precautionary principle? If the Court does not evaluate the scientific evidence put before it, how can a claimant successfully argue that the European institutions have acted erroneously? This raises questions as to how the European institutions and the Court deal with issues of scientific uncertainty and scientific evidence. Furthermore, what are the implications for the completion of the internal market if Member States are allowed to employ their own precautionary reasoning in the face of harmonising measures? Finally, and perhaps most importantly, does the application of the precautionary principle in the EU today lead to a situation in which the risks are targeted in an efficient and comprehensive way? This chapter aims to address these questions by analysing the constituent parts of the precautionary principle. In this regard, it follows the outlined of the previous chapter on the precautionary principle in WTO law.

\subsection{The Development of the Precautionary Principle in eC Treaties, LEGISLATION AND SOFT LAW}

\subsubsection{Early Developments}

The wish of responsible governments to protect public health and sometimes err on the side of caution is not somcthing that was born with the concept of the precautionary principle. Instead, it is a fundamental part of most legal systems. ${ }^{12}$ However, what is investigated here is the origin of the principle of precaution as applied in the EU today.

11 See, for example, the rulings of the ECJ in Case T-13/99 Pfizer Animal Health SA v Council of the European Union [2002] ECR II-03305 case and Case C-3/00 Denmark v Commission [2003] ECR I-02643.

12 D.P. Fidler, International Law and Public Health, Transnational Publishers Inc. 2000; T. Christoforou, Science, Law and Precaution in Dispute Resolutions on Health and Environmental Protection: What Role for Scientific Experts?, in: J. Bourrinet \& S. Maljean-Dubois, Le commerce international des organismes génétiquement modifies, Aix-Marseilles/Paris 2002. 


\section{Joakim Zander}

It is widely assumed that the precautionary principle stems from environmental law as it developed from the 1970s onwards. Some authors claim that this development did, in fact, borrow precautionary thinking from the field of health protection, which, in many legal systems, already employed pre-market authorisation requirements for cerlain products, etc. ${ }^{13}$ In the EU context, the first time that the embryos of the precautionary principle were considered in policy documents and legislation was in the environmental context. In the First Environmental Action Programme (1973-1976) (EAP I), ${ }^{14}$ precaution was discussed as something to be considered for emergency measures, as it was pointed out that available knowledge might, in some cases, be inadequate. Consequently, technological knowledge in the Community was to be improved and research was to be cncouraged:

"[This] ought not, however, to have any delaying effect on the application of emergency measures in cases where there is a real or potential danger to man or his environment, since these measures can be reviewed and modified subsequently in the light of the results of research carried out." 15

The reference here to "potential danger" suggests that measures taken without full scientific knowledge would also be covered. It is also interesting to note that no distinction was made between health and environment, and the wording seems to apply to both. However, more emphasis was placed on potentially precautionary measures later on in the same document:

"[In certain cases] urgent reasons based on the protection of human health or protection of the environment may require that provisional common standards be laid down before criteria and quality objectives have already been established at Community level, where the relevant criteria already existing on an international or national lcvel are considered to be adequate." 16

The measures referred to are to be of provisional character and are to be employed pending further research. They are to be taken upon the basis of urgent reasons in response to a threat to health or the environment. It is not spelled out that the measures are of a

13 Christoforou, Ibid., p. 217-218.

14 Declaration of the Council of the European Communities and of the Representatives of the Governments of the Member States, meeting in the Council on the Programme of action of the European Communities on the Environment, OJ 1973, C112/1.

15 Ibid., p. 33 .

16 Ibid., p. 49 . 
precautionary nature, bul, in holding that they should be issued before "criteria and quality objectives" have been established, it would seem that emerging uncertain risks might be referred to. In this regard, it should be pointed out that the provision bears resemblance to the wording of the SPS Agreement. ${ }^{17}$

It is curious to notice that the EAPs that followed during the 1970 s and the first half of the 1980s no longer made explicit references to precaution. EAP IV ${ }^{18}$ was issued in the same year as the Brundtland Report, but did not mention sustainability or precaution by name. However, it prescribed precautionary approaches in a number of identified sectors, such as gene technology and nuclear power. ${ }^{19}$ Other policy documents elaborated on different environmental principles such as the polluter pays and prevention, but they all stayed clear of precaution. ${ }^{20}$ However, in the Dublin Declaration on the Environmental Impcrative of 1990 , the EU Heads of State for the first time expressed their intention that action by the Community as well as by the Member States "will be developed on a co-ordinated basis and on the principles of sustainable development and preventive and precautionary action". ${ }^{21}$ Although this concept was not developed further, it shows the willingness of the EU to cmbrace the precautionary principle on a horizontal level to function as an underlying principle for all action in the EU. Two years later, the principle was to find its way into the EC Treaty. ${ }^{22}$

Precautionary legislation predating the Maastricht Treaty tends to be sectoral, applying a precautionary rationale vertically to a specific area. The actual word precaution is not mentioned until the Dublin Declaration of 1990 as discussed above. However, even though the word "precaution" was not mentioned or formulated as an overarching, horizontal policy or principle, a general wish to be precautionary heavily influenced certain areas.

17 For a discussion on the wording of the SPS Agreement, see, above, Section 3.3.1.

18 Resolution of the Council and Representatives of the Governments of the Member States, meeting within the Council on the continuation and implementation of an EC policy and action programme on the environment (1987-1992), OJ 1987, C328/1.

19 For example, it is established that the ALARA (As Low As Reasonably Possible) principle should be guiding nuclear safety (Point 4.6.3). In relation to biotechnology it was held that "special precautions may be necessary" (Point 4.4.8).

20 W. Douma, The Prccautionary Principle; Its Application in International, European and Dutch Law, Proefshchrift Rijksuniversiteit Groningen, 6 Jan. 2003, pp. 202-216.

21 Bulletin EC 6-1990, Conclusions of the Presidency, Point 1.14 and Annex II.

22 For a more in depth account of early soft law dealing with sustainable development and precaution in the EC, sec W. Douma, The Precautionary Principle: Its Application in International, European and Dutch Law, Pp. 191-254. 


\section{Joakim Zander}

In 1965, Directive 65/65 established a prior approval mechanism for the placing of medicinal products on the market. ${ }^{23}$ The same is true with regard to the Directive on Dangerous Substances, which also established a prior approval system (positive or reverse listing) for substances such as pesticides. This meant that substances were not allowed onto the markets unless proven safe. ${ }^{24}$ Establishing a system for the testing of products before they are allowed onto the market is essentially precautionary in that it foresees certain possible risks and aims to analyse these risks before the products in question are allowed. Thus, these proved to be early examples of a precautionary approach common to many legal systems. The same is true, for example, for Directive 70/534 concerning Additives in Feeding Stuff, ${ }_{2}^{25}$ Directive 75/319 on Medicinal Products, ${ }^{26}$ Directive 75/442 on the Reduction or Avoidance of Risks relating to Waste, ${ }^{27}$ and Directive $79 / 831$ relating to the Testing of Chemicals. ${ }^{28}$

Other examples of early precautionary thinking include the Birds Directive of $1979,{ }^{29}$ especially since this directive includes the protection of birds in no imminent danger of extinction. Council Decision 80/732 Concerning CFCs in the Environment even mentions precaution explicitly, and is thus "the earliest example of an explicit reference in EC legislation to a precautionary measure". 30

The ECJ contributed greatly to affording weight and justification to precautionary measures during the 1980s. In the landmark Cassis de Dijon case, the ECJ had already established that it would be possible for Member States to restrict the free circulation of goods in the absence of Community harmonisalion measures. These restrictions, which would have be based upon Article $30 \mathrm{EC}$ (now Article $36 \mathrm{EEC}$ ), had to be necessary to

23 Directive 65/65/EEC of 26 January 1965 on the approximation of provisions laid down by Law, Regulation or Administrative Action relating to proprietary medicinal products, OJ 1965 L 22 p. 369. See T. Christoforou, Science, Law and Precaution in Dispute Resolutions on Health and Environmental Protection: What Role for Scientific Experts?, p. 232.

24 Directive 67/548/EEC of 27 June 1967 on the Approximation of the Laws, Regulations, and Administrative Provisions of the Member States Relating to the Classification, Packaging, and Labelling of Dangerous Substances, OJ 1967 L 196 p. 1.

25 Directive 70/524/EEC of 23 November 1970 concerning additives in feeding-stuffs, OJ 1970 L 270, p. 1.

26 Directive 75/319/EEC of 20 May 1975 on the approximation of provisions laid down by Law, Regulation or Administrative Action relating to proprietary medicinal products , OJ 1975 L 147, p. 13.

27 Direcitve 75/442/EEC of 15 July 1975 on waste OJ 1975 L 194, p. 39.

28 Directive 79/831/EEC of 18 September 1979, amending for the sixth time Directive 67/548/EEC on the approximation of the laws, regulations and administrative provisions relating to the classification, packaging and labelling of dangerous substances, OJ 1979 L 259, p. 10.

29 Directive 79/409/EEC of 2 April 1979 on the conservation of wild birds, OJ 1979 L 103 p. 1.

30 Nigel Haigh as quoted in A. Trouwborst, Evolution and Status of the Precautionary Principle in International Law, Kluwer 2002, p. 143. 
satisfy mandatory requirements such as fiscal controls, fair trading practices and consumer protection. As the Court held:

"Obstacles to movement within the Community resulting from disparities between the national law relating to the marketing of the products in question must be accepted in so far as those provisions may be recognised as being necessary in order to satisfy mandatory requirements relating in particular to the effectiveness of fiscal supervision, the protection of public health, the fairness of commercial transactions and the defence of the consumer." 31

The list provided in the case was not intended to be exhaustive. ${ }^{32}$ In the early 1980 s, the Court decided to give the Member States the freedom to set the level of protection also in complex cases surrounded by scientific uncertainty as to the effects and causality of products. In the Melkunie case, a Dutch ban on certain milk products was upheld by the Court. The ban was motivated by a wish by the Dutch authoritics to maintain a high level of protection for consumers who might be particularly sensitive towards non-pathogenic micro-organisms in pasteurised milk. That the exact effects of the consumption of the micro-organisms were uncertain was not contested by the parties. The court stated that the Dutch prohibition was a measure having equivalent effect to a quantitative restriction under Article $28 \mathrm{EC}$ (then Article $30 \mathrm{EEC})$. However, this was justified under the exemptions stated in Article $30 \mathrm{EC}$ (then Article $36 \mathrm{EEC}$ ). In the words of the Court:

"[...] the data available at the present stage of scientific research do not make it possible to determine with certainty the precise number of non-pathogenic microorganisms above which a pastcurised milk product becomes a source of danger to human health. In the absence of harmonization in this field, it is for the Member States to determine, with due regard to the requirements of the free movement of goods, the level at which they wish to ensure that human life and health are protected." 33

Thus, the conclusion of the Court was that, in non-harmonised areas, when the present state of scientific research does not allow for a certain estimation, it is up to the individual Member State to set the level at which it considers life and health to be protected. However,

31 Case 120/78 Rewe v Bundesmonopolverwaltung ('Cassis de Dijon") [1979] ECR 649, para. 8.

32 L. Krämer, EC Environmental Law, Sweet and Maxwell 2000, p. 75.

33 Case 97/83 Melkunie [1984] ECR 2367, para. 18. 


\section{Joakim Zander}

the Member State is still bound to respect the principle of proportionality in enacting measures to reach these levels. ${ }^{34}$ This has been called, by some authors, the "reversed Cassis de Dijon principle", and signifies the limits put upon the principle of mutual recognition. ${ }^{35}$ The Melkunic judgment significantly demonstrates how the $\mathrm{ECJ}$ had come to regard both risk regulation and its own abilities to review measures taken under uncertainty. Here, trade restrictions based upon uncertain risks were allowed to over-ride the Cassis de Dijon principle of mutual recognition. In allowing for this, the Court recognised how sensitive the issue of risk regulation is for the Member States in Europe. By approving restrictive measures based upon scientific uncertainty, the Court essentially allowed the Member States to enact precautionary measures in non-harmonised areas.

Furthermore, the Court effectively relieved itself of the responsibility basing its judgment on the merits of the scientific evidence put before it in such cases. The level of proof needed to be met by the derogating party is low. It would seem to be clear that the latter does not need to show that the risk, in this case the presence of non-pathogenic microorganisms in milk, is likely. Instead, the court seemed satisfied that it was unclear at what moment the risk might appear. ${ }^{36}$ In the light of this approach by the Court, it is hardly surprising that it would impose limits on its judicial review in order to avoid the sensitive issue of scientific evidence in harmonised areas as well. This is dealt with in more detail below.

In the Heijn ${ }^{37}$ and Mircpoix ${ }^{38}$ cases, the ECJ considered pesticides to constitute a major risk to human and animal health since "the quantities absorbed by the consumer can neither be predicted nor controlled It is interesting to note that the Court took the notion of uncertainty into account not only with regard to the product, but also with regard to the (involuntary) consumption of the substance, as a justification of precautionary measures. Even more notable is the fact that the Court clearly stated that, when pesticides are

34 J. Jans, Proportionality Revisited, Legal Issues of Economic Integration, 27, 2000, p. 252.

35 L. Krämer, EC Environmental Law, p. 75 et seq.

36 Such a level would be found somewhere between 0 and presumable/acceptable in the chart on burden of proof introduced in the previous chapter. It appears that a challenging party would have to reach at teast proven/verified in the same chart to be successful. However, the Court does not touch on questions of uncertainty or burden of proof in detail.

${ }^{37}$ Case 94/83 Heijh [1984] ECR 3263.

${ }^{38}$ Case 54/85 Mirepoix [1986] FCR 1067. 
concerned, a risk does not need to be established for the individual product since it is not disputed that pesticides per se constitute a major risk to human and animal health. ${ }^{39}$

\subsubsection{The Single European Act}

As the SEA came into force 1 June 1987 the term "the internal markct" was introduced in the Treaties of the (then) European Economic Community (EEC). This came to be the central notion around which the European Communities (and later the EU) would gravitate. The fundamental idea of a mutually beneficial common market for the Member States to make use of has proven to be the incentive needed for increased integration. It is, therefore, understandable that derogations from what has been commonly decided in relation to the internal market, and regarding the free movement of goods in particular, has been viewed by the European Commission as potentially threatening to the completion of the internal market.

Not only did the SEA introduce the concept of the internal market, it also abolished the unanimity requirement for decisions relating 10 its completion. Instead, a system of qualified-majority voting was established in Article 100a of the SEA. However, some Member States feared that they would be over-ruled in the Council under the new provisions and were reluctant to agree on a qualified-majority regime. In order to meet these fears, Article $100 \mathrm{a}(4)$ was included in the SEA. ${ }^{40}$ This article provides that:

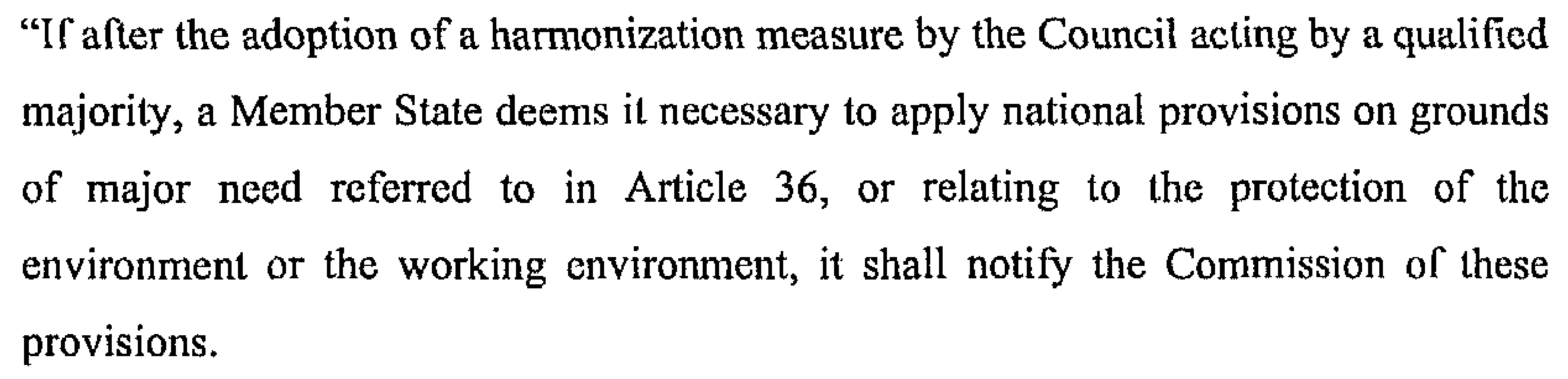

The Commission shall confirm the provisions involved after having verified that they are not a means of arbitrary discrimination or a disguised restriction on trade between Member States [...]."

The article proved controversial and received a fair share of criticism from commentators who feared that it would erode the application of internal market legislation. ${ }^{41}$

Case 94/83 Heijn, para. 13 and Case 54/85 Mirepoix, para. 13.

C.-D. Ehlerman, "The Internal Market Following the Single European Act", (1987) 24 CMLRev 9.

See, for example, P. Pescatore, "Some critical remarks on the "Single European Act",, (1987) 24 CMLRev 9. 


\section{Joakim Zander}

These fears have, at least until recently, appeared to be relatively unfounded, since only few derogations have been notified and allowed under the provision. ${ }^{42}$

The second major development in the SEA was the inclusion of environmental protection as a major aim of European co-operation. ${ }^{43}$ It was not included as one of the tasks of the EEC as enumerated in Article 2, but Article 130R, S and T established that the objectives in relation to the environment should bc:

“(i) to preserve, protect and improve the quality of the environment;

(ii) to contribute towards protecting human hcalth;

(iii) to ensure a prudent and rational utilisation of natural resources"

The SEA continued to establish that three environmental principles should guide environmental protection in the EEC: the principle of preventative action, the rectification-atsource principle and the polluter-pays principle. ${ }^{45}$ The precautionary principle was not yet mentioned, due to the fact that it had not yet received sufficient support among the Member States. ${ }^{46}$ Five years later, at the time of the signing of the Treaty of Maastricht, this had changed.

The inclusion of environment and health protection as important objectives in the SEA signified competition for the traditional free movement objectives. A balance had to be struck between the protection of health and the environment on the one hand, and the completion of the internal market on the other. It fell to the Court to find this equilibrium. In this, the Court was helped by Article 130R(3), in which it was established that scientific and technical data was to be the basis for legislation in this area, and that all measures should be subjected to a cost/benefit analysis. This made the environment a unique policy area since no

42 However, as of late, this may be changing. See, for example, J. Scott \& E. Vos, The juridification of Uncertainty: Observations on the Ambivalence of the Precautionary Principle within the EU and the WTO, and J. Zander, The Green Guarantee in Article 95 of the EC Treaty: Two recent cases, 16 Journal of Environmental Law 1, 2004.

43 The ECJ had already in Case 240-83 Waste Oils [1985] ECR 531 made it clear that it considered environmental protection to be an essential objective of the Community and that it may justify certain limitations as to the free movement provisions.

44 Article 130R(1) EEC.

45 Ibid, Article 130R(2) EEC.

46 N. Haigh, The Introduction of the Precautionary Principle into the UK, in: T. O'Riordan \& J. Cameron (eds), Interpreting the Precautionary Principle, Earthscan, 1994. 
other field was subjected to a cost/benefit analysis as a formal requirement. ${ }^{47}$ However, it could be argued that cost/benefit analysis was nothing new to the EEC legal order, or specific to environmental and health protection for that matter. The exemptions from the free movement provisions included in Article $36 \mathrm{EEC}$ (now $30 \mathrm{EC}$ ), with its emphasis on necessity, proportionality and least trade restrictivcness, entail elements of cost/benefit reasoning. This would also be supported by the reasoning in the Cassis de Dijon case. ${ }^{48}$ Following this assumption, not only is environment and health protection subject to some cost/benefit balancing, but so are all derogations from basic free movement provisions under Article 30 EC. However, it should be pointed out that a cost/benefit analysis within the framework of the proportionality principle in Article $30 \mathrm{EC}$ refcrs primarily to the weighing of the proportionality of the measures in relation to their possible hindrance of intracommunity trade. Cost/benefit analysis strictu sensu, as it is gencrally understood, has a broader scope, which aims to compare the general cost effectiveness of a measure with other policy choices. ${ }^{49}$

The best examples of precautionary legislation enacted by the EC legislature in the time between the Treaty changes in 1987 and 1992 are the directives on genetically modified organisms of $1990 .^{50}$ The precautionary principle is not mentioned explicitly, but the directives, nevertheless, establish a highly precautionary approach to GMOs. Directive 90/220/EC provides for a comprehensive system for the authorisation of GMOs to be released into the environment in the EU. Anyone wishing to release GMOs into the environment needed to produce an assessment of the risks associated with the organism in question to the competent authority. ${ }^{51}$ Before the product could be placed on the market, all other Member States were to be consulted. ${ }^{52}$ Such a system, including risk assessment requirements and wide consultation among Member States in the risk management phase, has become the model of European precautionary regulation in relation to GMOs.

47 W. Douma, The Precautionary Principle; Its Application in International, European and Dutch Law, p. 258-259.

48 See, for example, the reasoning of Jans in J. Jans, Proportionality Revisited.

49 For a detailed discussion of the scope and purpose of cost/benefit analysis, see, abovc, Section 2.3.2.

50 Directive 90/219/EEC of 23 April 1990 on the contatined use of genetically modified micro-organisms, OJ 1990, L 117, p. 1 and Directive 90/220 of 23 April 1990 on the Deliberate Release into the Environment of Genetically Modified Organisms, OJ 1990, L 117, p. 15.

51 Directive 90/220/EEC, Article 11(1).

52 Ibid., Article 13. 


\section{Joakim Zander}

\subsubsection{The Treaty of Maastricht}

As the Treaty of the European Community came into force on 1 November 1993, the precautionary principle assumed its name and official place in the European legal order. Included in the modificd Article 130R, it was clear that it was now an environmental principle considered to be on an equal footing with the principles of prevention, the rectification-at-source and polluter-pays. ${ }^{53}$

It is interesting to observe that, in the first paragraph of the article, the wording on human health has been strengthened. Where the articlc inserted into the EEC Treaty by the SEA stated that action by the Community should aim to "contribute towards protecting human health", the new version states that it should aim at "protecting human health". The use of the more direct language introduced by the SEA signilies an increased emphasis on health protection in the EU.

At the time of its inclusion in the Treaty, the precautionary principle drew limited attention from authors active in the field of European environmental law. Kiss and Shelton elaborated somewhat on the concept, and argued that a distinction should be made between a strong version of the principle and a weaker version. The former would have the capacity to be used as a legal justification for regulating uncertain risks and reversing the burden of proof. ${ }^{54}$ However, the precautionary principle included in Article 130R lacked any concrete definition, and case law explicitly referring to the principle was not yet present, so the reluctance of commentators to speculate is understandable.

It took until the late 1990s for the discussion to take off in the wake of the BSE crisis, the Treaty of Amsterdam and the subsequent publication of the Commission Communication on the Precautionary Principle. ${ }^{55}$ In the meantime, the European institutions, primarily the ECJ and the European Commission, tentatively started to make use of the principle. In

53 The relevant parts of the Article reads:

"Community policy on the environment shall contribute to pursuit of the following objectives:

-preserving, protecting and improving the quality of the environment;

-protecting human health

-prudent rational utilization of natural resources;

-promoting measures at international level to deal with regional or worldwide environmental problems.

Community policy on the environment shall aim at a high level of protection taking inot account the diversity of situations on the various regions of the Community. It shall be based on the precautionary principle and on the principles that prventive action should be taken, that environmental damage should as a priority be rectified at source and that the polluter should pay. Environmental protection requirements must be integrated into the definition and implementation of other Community policies [...]".

54 A.C. Kiss \& D. Shelton, International Environmental Law, Transnational Publishers 1994.

55 Communication from the Commission on the precautionary principle, COM 2000/1/Final. 
addition, in European legislation, the precautionary principle began to appear in the time between the Treaties of Maastricht and Amsterdam, even though it was still not made explicit in the legislative acts. ${ }^{56}$

The real turning-point, which propelled the prccautionary principle into a force to be reckoned with in Europe, came with the BSE crisis in 1996. Until the crisis was a reality, Community regulation on food safety was established ad hoc and mainly guided by pragmatic considerations. ${ }^{57}$ The EU system of independent scientific committees was widely regarded as a functioning solution in a community which was not primarily concerned with risk regulation. This image was severely damaged by the failure to act adequately at an early stage against the threat posed by BSE. ${ }^{58}$

Bovine spongiform encephalopathy was discovered as early as 1985 , but it was not until March 1996 that the UK authorities went public with their finding that BSE could (possibly) be transferred to humans and appear as Creutzfeldt-Jacob disease. Following the UK report, the Commission acted immediately and issued a Decision banning the importation of British beef to the rest of the EU. ${ }^{59}$ The decision bore all the hallmarks of a precautionary measure, even if the word "precaution" was not employed as such. However, in the preamble the Commission made it clear that a definitive stance on the possibility of the transmission of BSE was not possible at that that time, but that it could not be excluded that it might be the case. Furthcrmore, the preamble refers to the serious concern that this uncertainty had caused among European consumers. For these reasons, a temporary ban on the importation of British beef was deemed warranted. ${ }^{60}$ But when the UK report was published and the ban had been issued by the Commission, it was already too late: the confidence crisis in not just British, but also European, food safety regulation was already a fact. ${ }^{61}$ Inquiries set up to investigate how the BSE crisis had been allowed to go as far as it had revealed that the European scientific committees were very-strongly influenced by "British thinking", and that the UK policy-

56 See, for example, Directive $94 / 67$ of 16 December 1994 on the incineration of hazardous waste, OJ $1994 \mathrm{~L}$ $365 / 34$, which aimed, among other things, to regulate dioxin emissions, even though scientific evidence regarding the effects of dioxin was not yet conclusive at the time of adoption and Directive $96 / 61$ of 24

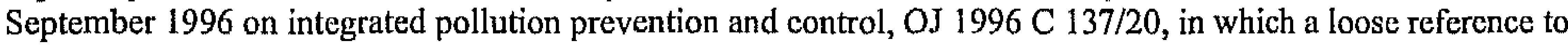
the precautionary principle is made in Annex IV.

57 E. Vos, EU Food Safety Regulation in the Aftermath of the BSE Crisis, Journal of Consumer Policy 232000. pp. 231.

58 Ibid.

59 Council Decision $96 / 239$ of 11 June 1996 on emergency measures to protect against bovine spongiform encephalopathy, OJ 1996, L 078.

60 Ibid, recital 9.

61 E. Vos, EU Food Safety Regulation in the Aftermath of the BSE Crisis. 
makers had been instructed to defend the economic interests of farmers at the same time as they were to take health measures restricling the trade of the same farmers. ${ }^{62}$ This inevitably confused the roles and delayed any decisive form of action from the British authoritics as well as the European authorities. A lack of transparency in the decision-making process delayed the reaction of the public.

As the ban on British beef was challenged before the ECJ, it became clear that the Court would allow outright precautionary measures by the European institutions taken in the facc of uncertainty. ${ }^{63}$ The case was to become the foundation of a new, outspoken precautionary principle in the EU. It also became clear that the Court did not see the principle to be confined to environmental protection alonc but also to the protection of human health.

Faced with the factual findings of the Inquiry Committee on BSE, which had been set up by the European Parliament to investigate the scandal, as well as severe criticism from the media of how it handled the crisis, the Commission quickly developed a new approach to food safety. One part of the approach consisted of systematising the scientific committees and placing them under the joint heading of DG XXIV (now DG SANCO) in order to be able to control them and protect them from "external" and "non-scientific" influence. ${ }^{64}$ A second part of the Commission's response was the issuing of a communication outlining a new approach to food safety in the EU. ${ }^{65}$ In this new approach, the Commission moved away from an approach centred on food security as previously considered in relation to agricultural policy, and moved towards the protection of the consumer. According to the Commission, there were two distinct aspects of the precautionary principle: the political decision to act or not to act, and the decision upon which measures to use when action has been decided upon. It stressed that three instruments were essential for an effective consumer health policy: namely, scientific advice, risk analysis, and control. The Commission also defined the three stages of dcaling with risks: risk assessment, risk management, and risk communication. ${ }^{66}$ Furthermore, it made it clear that scientific advice is the basis of all regulatory initiatives in

62 Ibid, and P Zwanenberg \& E. Millstone, 'Mad cow diseasc' 1980s-2000: how reassurances undermined precaution, in: Late Lessons From Early Warnings: The precautionary principle 1896-2000, Environmental issue Report No. 22, 2002. Available at: hitp://reports eea.europa.eu/environmental issue report 2001 22/en/.

63 The BSE case before the European Court of Justicc is dealt with in detail below.

64 E. Vos, EU Food Safety Regulation in the Aftermath of the BSE Crisis, p. 233-234.

65 Communication of the Commission on consumer health and food safety, COM/97/83/Final.

$66 \mathrm{COM} / 2000 / 1$, p. 12 et seq. 
the area of food safety and consumer protection, and, to ensure this, it emphasised the importance of the scientific committees.

\subsubsection{The Treaty of Amsterdam}

The focus on science-based decision-making in environmental and health matters was also highlighted in the Treaty of Amsterdam:

\footnotetext{
"The commission, in its proposals envisaged in paragraph 1 concerning health, safety, environmental protection and consumer protection, will take as a base a high level of protection, taking account in particular of any new development based on scientific facts. Within their respective powers, the European Parliament and the Council will also seek to achieve this objective." 67
}

This was not the only change to the former Article 100(a) that was to be undertaken when the article was transformed into Article 95 by the Treaty of Amsterdam. The treaty also clarified the legal basis and requirements for Member States to derogate from harmonisation measures taken under Article 95. As mentioned briefly above, the derogation possibilities in Article 100(a)(4) were perceived (according to its wording) as being limited to the maintenance of stricter national legislation, and did not appear to stretch as far as authorising Member States to introduce new, stricter legislation in the face of harmonisation. However, the exact state of the law was unclear at this point. When Article 95 clearly separated the maintenance of the existing measurcs from the introduction of new ones, it became clear that both situations were allowed provided that somewhat different requirements were fulfilled. ${ }^{68}$

One of the main aims of the new provisions was to establish in which situations derogation would be allowed. ${ }^{69}$ That the possibilities for Member States to derogate under the new provisions seem greater than under Article 100(a)(4) has been motivated by the fact that the introduction of the protection of health and environment as fundamental objectives of the EU shifted the focus of the EU away from strictly economic considerations. Allowing Member States to maintain or introduce stricter regulation than the harmonisation measure

67 EC Treaty (after Amsterdam) Article 95(3).

68 The Treaty of Amsterdam thereby ended the primarily academic discussion during the 1990s on whether Article 100(a) also could make room for the introduction of new measures, i.e, a national measure introduced after a harmonization measure had been enacted. The issue remained open until the Treaty of Amsterdam came into force since the Commission had not had the opportunity to issue any decisions in reply to such derogation requests. (L. Krämer, EC Environmental Law, p. 98 \& 103).

69 G. van Calster, International and EU Trade Law: The environmental challenge, Cameron May 2000, p. 398. 


\section{Joakim Zander}

gave them the opportunity to be more protective than the rest of the EU. ${ }^{70}$ However, an excessively lenient view of such derogation might also lead to greater fragmentation of the internal market, since the harmonisation rules might be set aside if the relevant requirements were fulfilled. ${ }^{71}$

Once again, it was up to the Court and the Commission to decide on how to dislinguish between the two paragraphs, how to define key concepts such as "new scientific evidence", and where the outer boundaries for the application of what has been called the "green guarantee" should be drawn. The issue of the application of the Article 95 exemptions will be returned to shortly, in the section on case law. ${ }^{72}$

\subsubsection{The Commission Communication on the Precautionary Principle}

4.2.5.1. The Purpose of the Communication

In answer to an appeal by the Council, the Commission issued a Communication in 2000 which aimed to establish guidelines for the application of the precautionary principle in the EU. ${ }^{73}$ The addressees of the Communication are clearly the Community institutions and the Member States, but are also the trading partners of the EC, who had started to fear that the precautionary principle might be used to protect the European market against foreign competition. ${ }^{74}$ The Communication aimed to outline a systematic, scicncc-based approach to precaution, and thus ease some of the concerns of the critics of the precautionary principle. It also attempted to link the European approach to Article 5.7 of the SPS Agreement. ${ }^{75}$ This indicates that the EU sees a broader scope for precautionary action under this article than had been considered by WTO panels and the Appellate Body. As discussed in the previous chapter, Article 5.7 SPS has consistently been considered by panels and the Appellate Body

70 N. de Sadelcer, "Procedures for derogations from the principle of approximation of laws under article 95 EC", (2003) 40 CMLRev 889. p. 890.

71 The relevant parts of Article 95 EC read:

"4. If, after the adoption by the Council or by the Commission of a harmonisation measure, a Member State deems it necessary to maintain national provisions on grounds of major needs referred to in Article 30 , or relating to the protection of the environment or the working environment, it shall notify the Commission of these provisions as well as the grounds for maintaining them.

5. Moreover, without prejudice to paragraph 4, if, after the adoption by the Council or by the Commission of a harmonisation measure, a Member State deems it necessary to introduce national provisions based on new scientific evidence relating to the protection of the environment or the working environment on grounds of a problem specific to that Member State arising after the adoption of the harmonisation measure, it shall notify the Commission of the envisaged provisions as well as the grounds for introducing them".

72 The issue of the application of the Article $95 \mathrm{EC}$ exemptions is returned to below.

$73 \mathrm{COM} / 2000 / 1$.

74 This is highlighted by the fact that the Communication was submitted to the WTO Trade and Environment and Technical Trade Barriers Committees. See WTO documents WT/CTE/W147 and G/TBT/W137 respectively.

$75 \mathrm{COM} / 2000 /$, , p. 11-12. 
to apply in situations of insufficient scientific data. ${ }^{76}$ In situations in which the data available has been sufficient to allow for differing scientific conclusions, the article has not been considered to apply. This indicates, as was concluded in the previous chapter, that Article 5.7 SPS only applies in situations in which the available scientific situations are not sufficient to allow for a risk assessment to be concluded. If a risk assessment can be performed, the other articles of the SPS agreement apply, notably Articles 2 and 5.1. Thus, it appears that precautionary action under Article 5.7 SPS is limited to allowing for measures to be enacted without recourse to a risk assessment in certain well-circumscribed cases. However, this does not limit the role that the risk assessment plays under the WTO agreements. ${ }^{77}$ Precautionary action can be taken if a scientific link can be argued to exist between the risk at hand and the measures enacted. This risk does not have to be conclusively shown, and it can be based upon minority opinions. It would have been wise for the European Commission also to address this issue, and to stress in the Communication that precautionary action under the WTO regime is not confined to Article 5.7 of the SPS Agreement.

\subsubsection{The Definition of the Precautionary Principle}

The Communication, like the EC Treaty, does not provide a definition of the precautionary principle. It merely indicates the circumstances in which it should be employed by stating that it:

"covers those specific circumstances where scientific evidence is insufficient, inconclusive or uncertain and there are indications through preliminary objective scientific evaluation that there are reasonable grounds for concern that the potentially dangerous effects on the environment, human, animal or plant health may be inconsistent with the chosen level of protection." 78

Furthermore, the application of precautionary mcasures may not be of arbitrary nature. $^{79}$

It has been held by proponents of a strict application of the precautionary principle that a universally-acceptable definition of the principle is utopian and unnecessary due to the case by case based approach that a state needs to employ in order to achieve its desired level

76 Compare with the discussion outlined above in Section 3.3 .

77 Ibid.

$78 \mathrm{COM} / 2000 / 1, \mathrm{p}, 10$.

79 Ibid., p. 13, 16, 19 and 22. 
of protection. Moreover, the level of acceptable risk may vary over time due to public acceptance and scientific advances; therefore the exact definition of the instrument used to achieve the level may also vary. ${ }^{80}$ Critics of the approach claim that the lack of a definition runs the risk of turning the principle into a self-serving instrument which can be used to achieve any desired result. ${ }^{81}$

\subsubsection{Judicial Review}

The Commission emphasises that it is ultimately the responsibility of the Court to decide upon the legality of Community measures based upon the precautionary principle. However, the Commission points out that, in so doing, the ECJ is restricled with regard to the nature and scope of its review. Consistent case law holds that, in cases where the Community institutions enjoy broad discretionary powers, the review of the Court is limited to examining whether manifest errors have been committed, or whether the relevant institution has misused its powers or otherwise acted ultra vires. ${ }^{82}$ This has led to a situation in which the judicial review of the Court is restricted and limited in nature.

\subsubsection{Risk Assessment and Risk Management}

The Communication establishes that the approach to risk analyses should be based upon a structured approach which separates risk assessment, risk management and risk communication. ${ }^{83}$ The content of the risk assessment is further elaborated on in Annex III, where its four components are listed: hazard identification, hazard characterisation, appraisal of exposure, and risk characterisation.

Three factors need to be initially present in order to trigger the use of the precautionary principle: 1 . Potentially negative effects. 2 . A scientific evaluation. 3. Scientific uncertainty. $^{84}$

After potentially negative effects of a certain activity have been identified, these have to be evaluated scientifically in order to ascertain (or at least estimate) their gravity This is done by conducting a scientific evaluation (or "risk assessment", as it may be more commonly known). Interestingly enough, the Commission does not consider this obligation

80 T. Christoforou, Science, Law and Precaution in Dispute Resolutions on Health and Environmental Protection: What Role for Scientific Experts?, p. 218.

81 L. Bergkamp, Understanding the Prccautionary Principle (Part I), Env. Liability, Vol. 10, 2002, p. 21

${ }^{82}$ See the discussion on judicial review below in Section 4.3.3.

$83 \mathrm{COM} / 2000 / 1$, p. 8.

${ }^{84}$ Ibid., p. 13 
to be absolutely binding. It states that a risk assessment "should be considered where feasible", which would seem to allow for a risk assessment not to be carried out where it is not "feasible". 85 How, and by whom, this is to be determined is not clear. It would appear that, even in cases of decp uncertainty, a risk assessment could be carried out, even if the result would turn out to be inconclusive. As discussed in Chapter 2, a risk assessment cannot always be expected to put an end to the scientific uncertainty surrounding a risk. ${ }^{86}$ However, a risk assessment can identify the nature, scope and degree of the scientific uncertainty in question. ${ }^{87}$ This will assist the risk manager when deciding on the appropriate measures to take, and the assignment of the burden of proof. It must thus be considered that, also under uncertainty, a risk assessment provides essential information. This is also indicated in the Communication. However, the wording of the Communication seems to imply that the "possibility" of conducting a risk assessment could be a policy decision, thus leaving it up to the policy-maker to decide whether it is feasible to conduct a risk assessment or not. ${ }^{88}$ This could be interpreted as undermining the strictly science-based approach otherwise advocated in the Communication and stressed in Article 95(3) EC. A strict requirement to conduct a risk assessment, which makes allowance for the possibility that it may not provide a final scientific answer, would have been preferable in order to avoid any confusion. This becomes particularly significant in the WTO context, where, as has been shown abovc, the performance of a risk assessment before taking precautionary action is strict. ${ }^{89}$ The only exemption under the SPS Agreement is for a Member to seek recourse in Article 5.7, but this can only be done in the clearly defined situation in which the scientific data upon which to base a risk assessment is insufficient. ${ }^{90}$ Panels will thoroughly investigate whether this is the case. In comparison to the strictly science-oriented approach in the WTO regime, the Commission's approach in the Communication appears to be significantly weaker.

Finally, the activity to be regulated needs to be scientifically uncertain. The Commission affords a broad interpretation to the term "scientific uncertainty", which generally corresponds to the interpretation referred to in Chapter 2. In addition, the risk assessment should show that the desired level of protection for the environment or a

85 Ibid.

86 See, above, Sections 2.3.1 \& 2.3.2.

87 See, for example, M. van Assclt, Perspectives on Uncertainty and Risk: The PRIMA Approach to Decision Support, Kluwer Academic Publishers. pp. 82-92.

$88 \mathrm{COM} / 2000 / 1$, p. 13.

89 At least under the SPS Agreement, see, above, Section 3.3.2.3.

90 lbid. 


\section{Joakim Zander}

population group could be jeopardised. Furthermore, the conclusions should include an assessment of the scientific uncertainty, and an assessment of the consequences of inaction may be used by the decision-maker to trigger action. ${ }^{91}$

\subsubsection{Scientific Evidence and the Level of Proof}

That the Commission wants to emphasise its view that the application of the precautionary principle is fundamentally science-based is clear. The term "scientific evidence" is mentioned 12 times in the 22-page document. This can be seen as a wish on the part of the Commission to ensure its trading partners that it, too, wishes to comply with the science-oriented approach to risk regulation that has crystallised within the WTO regimc. However, the Commission's requirements on what is needed to trigger precautionary action are somewhat different than those established in the WTO, even if obvious similarities in the approaches also exist.

First of all, like in the regime under the SPS Agreement, the Commission does not require that the scientific evidence relied upon represents the majority opinion of the scientists active in the ficld. The Communication explicilly allows for reference to minority opinion provided that it is credible and comes from a reputable source. ${ }^{92}$ Furthermore, the Commission holds that all evaluation of scientific evidence requires "reliable scientific data and logical reasoning". ${ }^{93}$ However, the manner in which this is to be determined is not clear. In the following sentence, it is established that the desired level of protection may not aim at zero risk. ${ }^{94}$ This requirement, which is consistent with statements made by the WTO panels and the $A B$, seems to indicate that some level of scientific evidence must be met before precautionary measures can be taken. The emphasis on this may have been included as a response to critics who claimed that the EU was aiming to use the precautionary principle to justify policy choices without having to provide appropriate justification. ${ }^{95}$ However, the Commission seems to have undermined this by enigmatically stating:

$91 \mathrm{COM} / 2000 / 1$, p. 17 . In particular, the inclusion of a requirement to assess the existing scientific uncertainty should be welcomed. As discussed in Chapters 2.3.1 and 2.3.2, scientific uncertainty can be due to a magnitude of factors and is far from being a monolithic concept. Different types of uncertainty warrant different approaches and this should be identified and analysed at as early a stage as is possible.

$92 \mathrm{COM} / 2000 / 1$, p. 17. As shown above in Sections 3.3.2.4 and 3.3.2.5, this is also the opinion held consistently by panels and the $A B$ in under the SPS Agreement.

93 Ibid., p. 14.

94 Ibid., p. 17.

95 See, for cxample, The Battle Over Caution, Newsweek, December 13, 2003. Available at: htp: //www.newsweek.com/id/60863. 
"However, in certain cases, an incomplete assessment of the risk may considerably limit the number of options available to the risk managers." $" 96$

The meaning of this sentence is ambiguous, and it implies that the prohibition of zero risk levels may be negotiable. Like the hollow requirement to perform risk assessments dealt with above, the Commission here does not seem to want to create strict recommendations as to what risk levels the decision-maker is to employ. Not only does this confuse the issue of the meaning of zero risk, but it also concludes the Commission's opinion on risk levels and scientific evidence. Undoubtedly, it is impossible to establish a general formula that would be generally applicable for how scientific evidence is to be cxamined and what levels of risk are to be met. However, in avoiding this topic in its entirety, the Commission has missed an important opportunity to strengthen the legal certainty and consistency in the application of the principle. More claborate formal requirements on scientific evidence would have provided the EC institutions (including the ECJ) with information against which the application of the principle could be tested. This reluctance to be specific does not help to clarify the content of the precautionary principle and seriously undermines the practical use of the Communication.

The Commission finally stresses that, when precautionary measures are taken, further scientific research should be conducted with the aim of ending the scientific uncertainty. As with the above-mentioned requirements, a strict application of this would provide the Court with a formal test of the actions taken by the decision-maker when enacting precautionary measures. Such a formal test would be possible for the Court to carry out, even under the marginal review it currently employs. ${ }^{97}$

\subsubsection{The Burden of Proof}

With regard to the legally controversial issue of the reversal of the burden of proof in cases of scientific uncertainty, the Commission begins by stating that one way that this instrument can be used is through prior authorisation schemes, or so-called positive lists. ${ }^{98}$ This approach has a long tradition in EU Member States, at Community level and in third countries. ${ }^{99}$ Even though thcy might be burdensome for some actors, such systems are relatively accepted and

COM/2000/1, p. 17.

${ }^{7}$ COM/2000/1, p. 20-21.

98 Ibid., p. 21.

99 For a brief discussion of prior authorisation schemes on the Community level, see, above, Section 4.2. 


\section{Joakim Zander}

uncontroversial since they are generally in place before a product is developed and manufactured. Thus, the actor wishing to market a product knows what is required and can decide whether it wishes to pursue the activity or not. Thus, the legal situation is consistent and foresceable.

The situation in which no such authorisation scheme exists and the burden of proof is reversed ad hoc is more contentious, though. Here, the Commission, once again, omits to give any guidance. It is satisfied to state that action taken under the heading of the precautionary principle "must, in certain cases, include" 100 a reversal of the burden of proof, and that this is to be determined on a "case-by-case basis". ${ }^{101}$ It is clear that the entity wishing to rely on the precautionary principle has to provide some form of proof of the potential occurrence of a risk in order to trigger the use of the precautionary principle. ${ }^{102}$ What is required to fulfil this is not clear, but it indicates that the initial burden of proof lies with the party invoking the principle, and, once an uncertain level of proof has been met, the burden shifts to the other party. In practice, this would mean that, if a Member State wished to restrict the free movement of goods on the internal market by invoking an exemption in Article $30 \mathrm{EC}$, or Article 95 (4) or (5) in a harmonised area, it would have to show that some kind of risk was present. Similarly, the European Commission or Council would have to make a case in favour of taking precautionary measures when they were mandated to do so. However, as in the case of the WTO, a party challenging a precautionary measure would have to show prima facie that a legislative provision had been breached before the burden could be switched. ${ }^{103}$

\subsubsection{Cost/Benefit Analysis and Proportionality}

The cost/benefit analysis envisaged in the Communication appears, at first sight, to bc a strict requirement, and seems to be operating outside of the proportionality test. ${ }^{104}$ As discussed earlier in this chapter, the proportionality test in EC law is aimed at weighing the restrictions measures impose on trade in the intcrnal market. Cost/benefit analysis, on the other hand, is

${ }^{100} \mathrm{COM} / 2000 / 1,21$.

${ }^{101} \mathrm{Ibid}$.

102 Ibid., p. 13: "The precautionary principle is relevant only in the event of a potential risk [...]."

${ }^{103}$ Thus, it would be for a challenging party to show, for example, that a particular measure or set of measurcs infringes the basic free movement provision in Article $28 \mathrm{EC}$. Once this burden has been fulfilled, it is for the party which has invoked the measures to justify these under one of the exemptions in Article $30 \mathrm{EC}$. For a discussion on the general burden of proof regime in the WTO context, see, above, Section 3.3.2.5.

${ }^{104} \mathrm{COM} / 2000 / 1$, p. 18: "A comparison must be made between the most likely positive or negative consequences of the envisaged action and those of inaction [...]." 
generally understood as a procedure which aims to analyse the general cost-effectiveness of a measure. ${ }^{105}$ This may include effects on trade, but also includes comparisons with how the same resources could have been put to use in other areas of policy. However, such a wide analysis seems to be precluded from the concept of proportionality on the internal market. ${ }^{106}$

The Commission rightly states that a cost/benefit analysis cannot be reduced to taking only economic considerations into account, but must also include non-economic considerations. This is essential if a cost/benefit analysis is going to be performed when applying the precautionary principle, since the principle aims primarily to protect noneconomic interests. If only economic interests were taken into account, the precautionary principle would rarely be applied. It must also be considered appropriate that the Commission considers public health concerns to be of greater weight than economic concerns. Any other approach would seem callous. ${ }^{107}$ However, the Commission goes on to state that an economic cost/benefit analysis should only be carried out where this is "appropriate and possible". Once again, it seems that a requirement which, prima facie, appears to be binding is, in fact, hollow, and it is, thus, left to the discretion of the decision-maker to take into account or not.

Once again, one can suspect that the treatment of cost/benefit analyses in the Communication has morc to do with formally aligning the EU policy towards the precautionary principle with the SPS Agreement, than with a heartfelt desire to rationalise the targeting of risks. In Article 5.3 of the SPS Agreement, cost/benefit analysis is established as one of the requirements made on all measures taken with the SPS Agreement as a basis. However, panels and the $\mathrm{AB}$ have stopped well short of turning this requirement into a binding qualitative norm, and they have, instead, chosen to investigate subjectively whether contested measures were taken for protectionist reasons or not. ${ }^{108}$ Thus, the WTO jurisprudence, like the Commission and the ECJ, is also closer to the performance of a proportionality test which centres on the effects that measures will have on trade, rather than on setting efficicncy requirements for the members.

105 See, above, Section 2.4.2.2.

${ }^{106}$ For an authoritative discussion on the proportionality assessment in EC law, see J. Jans, Proportionality Revisited.

${ }^{107}$ Scc, bclow, how the ECJ has used this requirement worded as "public health concerns always take precedence over economic concems" in the $B S E$ case and more recent case law. This is a stricter and much more problematical formulation.

108 See, above, Section 3.3.2.6. 


\section{Joakim Zander}

\subsubsection{The Targeting of Risks and Risk Trade-offs}

As was touched upon above in the context of judicial review, the Communication echoes the opinion of the ECJ with regard to limited judicial review in cases where broad discretionary powers have been vested in the Community institutions. ${ }^{109}$ This means that the Court's powers are circumscribed to the consideration of formal complaints and manifest error in the actions of the institutions. The reason for this is that it is not for the Court to determine the appropriateness of the content of certain measures, but only to consider whether they have becn issued in the appropriate fashion.

The rationale behind this is established in the Communication, in which the Commission holds that '[j] udging what is an 'acceptablc' level of risk for socicty is an eminently political responsibility". 110 Therefore, it is not for the Commission or the Court to second-guess what has been agreed upon by clected politicians. Nothing in the Communication indicates that risks need to be dealt with in an effective or comprehensive manner. This leads to the situation in which politicians may decide to target certain risks while leaving other risks unregulated.

It would have been possible for the Commission to state that the institutions would have to consider, for example, risk tradc-offs when preparing legislation, and that the Council and European Parliament would have to take this into account when deciding on measures. As shown in the previous chapter, allowing such concerns to play a role in risk regulation leads to the consideration of the whole risk spectrum, rather than targeting individual risks in a seemingly haphazard fashion. The deferential approach advocated in the Communication is in line with how the issue has been dealt with at WTO level. ${ }^{111}$

\subsubsection{Concluding Remarks on Communication (2000) 1}

The Commission Communication on the Precautionary Principle is of non-binding character. Nonetheless, it is of great significance when discussing the precautionary principle in the EU. In particular, this is due to the fact that, when it was issued, it aimed both to codify the precautionary principle as it was being interpreted and used at the time, and to function as guidance for the future. The significance of the document was further underlined by the fact

109 See, below, under Section 5.2.4.2.

$110 \mathrm{COM} / 2000 / 1$, p. 4.

111 See, above, Sections 3.3.2.2 \& 3.3.2.6. 
that it was formally supported by the Council, ${ }^{112}$ the Luropean Parliament, 113 and, in principle upheld in $\mathrm{ECJ}$ case law. ${ }^{34}$ Thus, it is prudent to view the (ommunication as a formal manifestation of the oflicial $\mathrm{EU}$ view on the precautionary principle. As such, the Communication is used below as a benchmark against which the application of the precautionary principle can be measured in casu at blu level as well as at Member State level.

However, the communication provides little in the way of concrete requirements on the parties to which it is addressed. Instead, it describes a number of issues that are to be viewed as components of the principle. However, in many cases, it also allows for the party that is applying the principle to derogate from a strict interpretation of these guidelines. A number of such cases have been dealt with above. This is particularly the case in relation to the requirements on risk assessment, costhenelit analysis and risk trade-ofls. In not elaborating on these issues, the communication fails to make any qualitative requirements on the application of the precautionary principle.

A number of other weaknesses of the Communication have been pointed out. ${ }^{115}$ First, it does not make it clear who is to use the precautionary principle. It seems that its primary addressees are the European institutions and the trading partners of the EU. Recently, however, it has seemed that there is increasing pressure from the Member States to make use of the principle as a shield against Community legislation under Articles 30 and 95 (4) and (5) $\mathrm{EC} .{ }^{116}$ A widespread use of the principle to derogate from the basic free movement provisions and the harmonisation measures on the internal market could pose a serious threat to the completion of the internal market. However, this issue is not dealt with in the Communication.

Second, and related to the first, the Communication remains silent on the institutional framework for the application of the principle. This risks creating ambiguity and disagreement with regard to at which level the principle is to be applied within the Community structure.

"12 Conclusions of the Presidency, Curopean Council at Nice 7-10 December 2000, Annex III, Point 1. Available at:

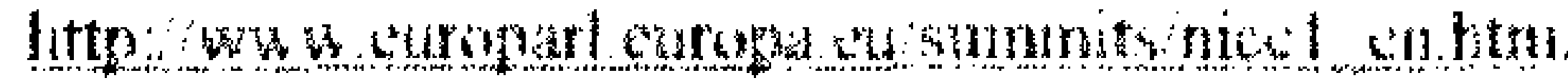

13 FU Bulletin 12-2000, Chapter 10 Community institutions, point 1.4 .75

Iit See, below, Section 4.3 .

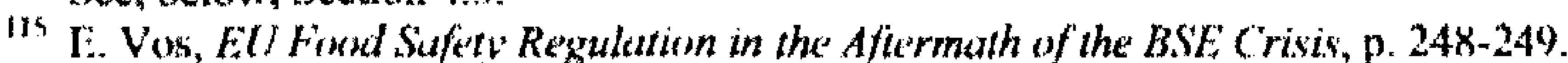

ith See, for example, (ase $C .3 / 00$ lenmurk $\vee$ Commission (discussed below) and Joined (ases $T-366 / 03$ and $T$ 235/04, Cismany v Austria [2005] ICR 11-40015. For a discussion on earlier case law in this regard, see J. Scott \& E. Vos, The juridification of Uncertainty: Observations on the Ambivalence of the Precautionary Principle within the EU and the WTO. 


\section{Joakim Zander}

Third, in not clarifying the usefulness of cost/benefit analysis or considering risk tradeoffs the Commission fails to make any qualitative requirements for the application of precautionary measures.

Despite this lack in rigour and clarity, the Communication is the only document at European level that provides some form of de minimis requirements on the precautionary principle. Because of this, it remains a useful blucprint for the structure around which to build a discussion on the precautionary principle in the EU.

\subsubsection{Recent examples of the influence of the precautionary principle in secondary EC legislation}

Since the publication of the Commission Communication, the precautionary principle has been a fundamental element of EC harmonising measures in areas affected by health and environmental concerns.

The rules regulating the use of genelically modified organisms (GMOs) in the EU do not define the use of the prccautionary principle, or even explicitly mention it. However, the establishment of an authorisation procedure in Directive 2001/18/EC is essentially precautionary in nature. ${ }^{117}$ The rules regarding labelling and traceability are also intended to address the uncertainties regarding GMOs. ${ }^{118}$ The labelling requirements allow consumers to avoid genetically organisms if they wish, and the traceability requirements allow for the possibility of tracing individual GMOs should risks materialise.

In the EU General Food Law, a comprehensive definition of the precautionary principle is included. ${ }^{119}$ The definition is nuanced and stresses that provisional precautionary measures can be introduced in order to safeguard a "high level of health protection". Such measures must be preceded by a risk assessment and should be revisited in the light of emerging scientific data. ${ }^{120}$

117 Directive 2001/18/EC of the European Parliament and of the Council of 12 March 2001 on the delibcratc relcase into the environment of genetically modified organisms and repealing Council Directive 90/220/EEC, OJ L 106, p. 1.

118 Regulation (EC) No 1829/2003 of the European Parliament and of the Council of 22 September 2003 on genetically modified food and feed, OJ L 268, p. 1, 18.10.2003.

119 Article 7 of Regulation (EC) No 178/2002 of the European Parliament and of the Council of 28 January 2002 laying down the general principles and requirements of food law, establishing the European food Safety Authority and laying down procedures in matters of food safety, OJ L 31, p. 1, 1.2.2002.

120 Article 7 of Regulation (EC) No 178/2002 holds:

" 1 . In specific circumstances where, following an asscssment of available information, the possibility of harmful cffects on health is identified but scientific uncertainty persists, provisional risk management measures necessary to ensure the high level of health protection chosen in the Community may be adopted, pending 
Most recently, the REACH Regulation concerning the EU's legislative framework for registration, evaluation, authorisation and restriction of chemicals is based upon the precautionary principle. ${ }^{121}$ As a consequence of this, a registration system has been established for chemicals, and the burden of providing the scientific evidence when applying for registration has been placed on the applicant. ${ }^{122}$

\subsection{The Interpretation of the Precautionary Principle in EC Case LaW}

\subsubsection{Introduction}

One of the criticisms of the Commission's Communication on the precautionary principle is that it does not treat the issue of who is to apply the precautionary principle in any detail. The inclusion of the precautionary principle in the EC indicates that it should function as an instrument to be used by the European institutions. However, the Member States also rely on precautionary considerations when derogating from the basic free movement provisions under Article $30 \mathrm{EC}{ }^{123}$ and, perhaps increasingly, when derogating from harmonisation measures using exemptions included in safeguard clauses and in Article 95 (4) and (5). ${ }^{124}$ The ECJ has generally allowed for precautionary considerations in its case law by refraining from assessing the scientific evidence put before it in any detail, and, instead, allowing the Member States or the European institutions to choose the level of protection that they find appropriate $^{125}$

further scientific information for a more comprchensive risk assessment.

2. Measures adopted on the basis of paragraph1 shall be proportionate and no more restrictive of trade than is required to achieve the high level of health protection chosen in the Community, regard being had to technical and economic feasibility and other factors regarded as legitimate in the matter under consideration. The measures shall be reviewed within a reasonable period of time, depending on the nature of the risk to life or health identified and the type of scientific information needed to clarify the scientific uncertainty and to conduct a more comprehensive risk assessment".

${ }^{121}$ See, especially, Article 1.3 of Regulation (EC) No 1907/2006 of the European Parliament and of the Council of 18 December 2006 concerning the Registration, Evaluation, Authorisation and Registration of Chemicals (REACH), establishing a European Chemicals Agency, amending Directive 1999/45/EC and repealing Council Regulation (EEC) No 793/93 and Commission Regulation (EC) No 1488/94 as well as Council Directive 76/769/EEC and Commission Directives 91/155/EEC, 92/67/EEC, 93/105/EC and 2000/21/EC, OJ L 396, p. 1, 30.12.2006.

122 See, for example, Article 7 and 19 of Regulation (EC) No 1907/2006.

${ }_{123}$ See, for example, Case 94/83 Heijn [1984] ECR 3263 and Case 54/85 Mirepoix [1986] ECR 1067

124 In relation to safeguard clauses, see Case C-236/01 Monsanto Agricoltura [2003[ ECR I-8105 and Joined Cases T-366/03 and T-235/04 Austria v Commission. In relation to the general provisions in Article 95 (4) and (5), see Case 512/99 Germany v Commission [2003[ ECR I-845 and Case C-3/00 Denmark v Commission. For a discussion on the reliance by MS on the precautionary principle, see J. Scott \& E. Vos, The Juridification of Uncertainty: Observations on the Ambivalence of the Precautionary Principle within the EU and the WTO, pp. 260-265.

${ }_{125}$ See, for example, Case 227/82 van Bennekom [1983] ECR 3883, Case 174/82 Sandoz BV [1983] ECR 2445 and Case 331/88 Fedesa and others [1990] ECR I-4023. 
Joakim Zander

Below, a number of cases are dealt with in detail, all of which address different aspects of how the court approaches precaution and the precautionary principle. ${ }^{126}$ In early cases, such as the BSE cases ${ }^{127}$ and the Greenpeace case, ${ }^{128}$ the Court explicitly endorsed precautionary measures and used the term "precautionary principle" for the first time. More recently, in the Plizer case ${ }^{129}$ the Court of First Instance made use of the Commission Communication on the Precautionary Principle to flesh out the content of the principle. Some authors have done important work in comparing how Member States on the one hand, and the European institutions on the other, have made use of the precautionary principle. ${ }^{130}$ Others have treated the precautionary principle as applied by the Member States and the European institutions interchangeably in order to identify common properties in its application. ${ }^{131}$ In the case law of the ECJ, it appears that the Court often refers to how the precautionary principle has been applied under other provisions than those at issue in the case in order to reach its decisions. This indicates that the Court views the precautionary principle as a concept with inherent properties which should be applied similarly, regardless of whether it is being invoked by a Member State or an EU institution. ${ }^{132}$ This approach is followed below. Whenever discrepancies between the use of the precautionary principle by a Member State and by an EU institution appear, this highlighted.

This section, like other sections in this book, is divided into a number of sub-sections, each dealing with different (but often related) aspects of the precautionary principle as interpreted in EC case law. As mentioned above, the Commission Communication is used as

${ }^{126}$ For other recent studies of EC case law in the area see, N. de Sadeleer, The Precautionary Principle in European Community Health and Environment Law: Sword or Shield for the Nordic Countries?, in: N. de Sadeleer, Implementing the Precautionary Principle: Approaches from the Nordic Countries, EU and USA, Earthscan 2007, p. 10-59; N. de Sadeleer, The Precautionary Principle in EC Health and Environmental Law, 12 ELJ 2, 2006, 139-172; and E. Fisher, Risk Regulation and Administrative Constitutionalism, Hart Publishing 2007, p. 218-243.

${ }^{127}$ Cases C-157/96 The Queen v Ministry of Agriculture. Fisheries and Food, ex parte National Farmers' Union et al. [1998] ECR I-2211 and C-180/96 United Kingdom $\vee$ Commission [1998] ECR I-2265 respectively. For the purposes of this discussion the two cases are identical and for the sake of clarity footnotes below refer to Case C-180/96 (BSE).

${ }^{128}$ Case C-6/99 Association Greenpeace France and Others v Ministere de l'Agriculture e de la Pêche and Others [2000] ECR I-1651.

${ }^{129}$ Case T-13/99 Pfizer Animal Health SA y Council of the European Union [2002] ECR II-3305.

${ }^{130}$ J. Scott \& E. Vos, The Juridification of Uncertainty: Observations on the Ambivalence of the Precautionary Principle within the EU and the WTO.

131 N. de Sadeleer, The Precautionary Principle in EC Health and Environmental Law, p. 139.

132 See, for example, the approach assumed by the ECJ in Case C-192/01 Commission v. Denmark [2003] ECR I9693, para. 49 and C-41/02 Commission v Netherlands [2004] ECR I-11375, para. 45 which both dealt with measures imposed by MS under Articles 28 and 30, but where the ECJ relied on the definition of the precautionary principle elaborated on in Case 157/96 National Farmers' Union and Others [1998] ECR I-2211, which dealt with measures imposed by the EU institutions to ban the import of British beef. 
a blueprint for how the EC institutions intended to make use of the principle. The topics dealt with here are loosely based upon the Communication, and the document is used to compare and contrast how the ECJ and the Court of First Instance (CFI) have chosen to interpret the principle in their case law.

\subsubsection{The Definition of the Precautionary Principle}

Even though precautionary approaches had been applied in specific cases earlier in EC case law, ${ }^{133}$ it was not until the BSE case ${ }^{134}$ that the made it clear that it intended to treat the precautionary principle as a general principle. ${ }^{135}$

The Court stated in paragraph 99 of the judgment that:

"Where there is uncertainty as to the existence or extent of risks to human health, the institutions may take protective measures without having to wait until the reality and seriousness of those risks become fully apparent."

This has become a frequently cited definition of the precautionary principle in the EU. ${ }^{136}$ Some commentators claim that it is the only definition needed in EC law. ${ }^{137}$ Others have pointed out that the BSE case related to emergency measures and that the Court itself emphasised that it was of importance that they be reviewed following a re-examination of the situation. ${ }^{138}$ This could imply that, since the measures authorised in the BSE case were of interim character, the definition provided might also be restricted to emergency measures with a limited temporal scope. This view would posit the precautionary principle in the EU

133 Sec, for example, Case 331/88 and Case C-405/92 Etablissement Armand Mondiet SA v. Amement Ijslais SARL [1993] I-6133.

134 Case C-180/96, op cit. note 127. For a discussion of the background to the ban, see, for example, L. Antonopolou \& van P. Meurs, The precuationary principle within European Union public health policy; The implementation of the principle under conditions of supranationality and citizenship, Health Policy 66 (2003), pp. 185-189, and P. Zwanenberg \& E. Millstone, 'Mad cow disease' 1980s-2000: how rcassurances undermined precaution. It should be noted that the English language version of the judgment refers to the principle of preventative action, but not explicitly to the precautionary principle. However, other language versions do make reference to the precautionary principle. Compare for example the wording of paragraph 100 of the judgment in the French version which refers to "principes de précaution et d'action preventive", or the Swedish version which refers to "försiktighetsprincipen och principen om förebyggande ätgärder".

135 For a discussion on the definition and status of the precautionary principle in the EU, see, also, N. de Sadeleer, The Precautionary Principle in European Community Health and Environmental Law: Sword or Shield for the Nordic Countries?, pp. 12-15.

136 It was also included in Annex I to the Commission's Communication on the precautionary principle.

137 See T. Christoforou, Science, Law and Precaution in Dispute Resolutions on Health and Environmental Protection: What Role for Scientific Experts?. p. 219.

${ }^{138}$ G. Majone, The Precautionary Principle and Regulatory Impact Analysis. Paper presented at the International Seminar on Reulatory Impact Analysis. Rome 15 June 2001. p. 9, and J. Scott \& E. Vos, The juridification of Uncertainty: Observations on the Ambivalence of the Precautionary Principle within the EU and the WTO. 


\section{Joakim Zander}

closer to that in place under the WTO regime, ${ }^{139}$ than to the wider and more permanent interpretations of the principle employed by some EU Member States. ${ }^{140}$

One important aspect of the Court's statement in the BSE case was that it clearly established that the precautionary principle extended beyond the environmental regulation to which Article $174 \mathrm{EC}$ - secmingly - confined it. Subsequent case law has put beyond any doubt the fact that the precautionary principle is today applicable to consumer and health protection, ${ }^{141}$ and it has been rightly pointed out that it is in this field that it has so far had most significance. ${ }^{142}$

In its subsequent case law, the ECJ has consistently cited the same paragraph introduced in the BSE case. ${ }^{143}$ In the Greenpeace case, the Court continued to develop its vicw on the principle. The background to the case was the referral of two questions to the ECJ by a French court. The questions related to how a Member State which has issued a favourable opinion to the request for placing a GMO on the market, is to relate to the authorisation of the same GMO by the Commission. In short, is the Member State bound to follow the decision of the Commission, or docs it still retain some discretion relating to the authorisation of the GMO? ${ }^{144}$ The Court found that some discretion still remained with the Member States and stated: ${ }^{145}$

"Observance of the precautionary principle is reflected [...] in the right of any Member State [...] provisionally to restrict or prohibit the use or sale on its territory of a product which has reccived consent where it has justifiable reasons to consider that it constitutes a risk to human health or the environment."146

Once again, the Court emphasised the provisional character of the application of precautionary measures, but the measures at hand in the case in question could hardly be

139 See, above, Chapter 3.

140 Compare with the chapter on the precautionary principle in Sweden below, Chapter 5.

141 Case C-236/01 Monsanto Agricoltura Italia and Others [2003] ECR I-8105, paras. 128 and 133, Case T-13/99 Pfizer Animal Health SA v. Council of the European Union, paras. 139 and 140; Case T-70/99 Alpharma v Council [2002] ECR II-3495, paras. 152 and 153; and Case T-177/02 Malagutti-Vezinhet $v$ Commission [2004] ECR II 827, paras. 54, and C-41/02 Commission v Netherlands, para. 45.

${ }^{142}$ N. de Sadeleer, The Precautionary Principle in EC Health and Environmental Law, p. 172.

${ }^{143}$ Sce, for example, Case C-192/01 Commission v Denmark, para. 49, Case 236/01 Monsanto Agricola, para. 111 and Case C-41/02 Commission v. Netherlands, para. 52.

144 Case 6/99 Aasociation Greenpeace France and Others v Ministere de l'Agriculture e de la Pêche and Others [2000] ECR I-1651, paras 1 and 2.

145 The Court's reasons for this will be returned to below.

${ }^{146}$ Case 6/99 Greenpeace and Others v. Ministere de l'Agriculture e de la Pêche and Others, para. 44. 
considered to be of an emergency character. The above-mentioned references to the precautionary principle have been echoed by the CFI in a number of cases. ${ }^{147}$

The general definitions of precautionary principle that the Court provided in the BSE and Greenpeace cascs differ in some ways. For example, the Grecnpeace definition spells out the provisional requirement and holds that "justifiable reasons" must be provided in order to invoke measures. However, in practice, they are used intcrchangeably to denote the application of the principle.

The precautionary principle in the EU can be used in two significant ways: first, it can be positively used by the EU institutions to issue EU legislation in areas surrounded by scientific uncertainty; second, the precautionary principle can be used by Member States to derogate from free movement provisions or harmonisation measures, provided that they can justify their need to maintain stricter environmental and health regulations than otherwise would be provided for. ${ }^{148}$ That the precautionary principle is not mandatory for the Member States to rely on is relatively clear, although it is shown below that it functions as an exception which is available to Member States in certain circumstances. However, the issue of whether the EU institutions must rely on the precautionary principle when issuing legislation is more complicaled. The CFI held, in the Artegodan case, that the precautionary principle is "a general principle of Community law requiring the competent authorities to take appropriate measures". ${ }^{149}$ In the Pfizer case, the CFI held that the EU institutions could, in certain cases, be required to act out of precaution. ${ }^{150}$ However, it is often far from clear what precautionary action does, in fact, involve in a concrete situation. Issuing precautionary regulations in one area may lead to countervailing risks in other areas. When targeting one risk, other, often greater, risks are left unregulated. ${ }^{151}$ To require that the EU institutions act in a precautionary manner, it would first have to be defined precisely what the term "precautionary action" is intended to mean. It is argued here that this should be done rationally, by comparing different regulatory strategies with one another. Only then can it be estimated what a precautionary approach truly is, and, only if this were done, could the EU

${ }^{147}$ Case T-199/96 Laboratoires pharmaceutiques Bergaderm SA and Goupil v Commission [1998] ECR II-2805. paras 66 and 67, Case T-70/99 Alpharma Inc. v Council of the European Union [2002] ECR II-3495, para. 138 and T-13/99 Pfizer Animal Health SA v Council of the European Union, para. 115.

148 For a discussion on this, see J. Scott \& E. Vos, The Juridification of Uncertainty: Observations on the Ambivalence of the Precautionary Principle within the EU and the WTO.

149 Case T-74/00 Artegodan, para. 184.

${ }^{150}$ Case T-13/99 Pfizer Animal Health SA v Council of the European Union, para. 444.

151 These issues were discussed in detail in Sections 2.4.2.2 and 2.4.2.3. 
Joakim Zander

institutions be requied to act in a truly precautionary manner. ${ }^{152}$ At present, as is shown in more detail below, few such requirements are made on the EU institutions. Thus, it is appears that the precautionary principle enables the EU institutions to act in situations in which scientific certainty is lacking, but does not require them to do so. ${ }^{153}$ However, in the recent case Sweden v Commission, the CFI revoked a decision to authorise the pesticide paraquat upon the basis that the Commission had not acted in a sufficiently precautionary manner when issuing the authorisation. ${ }^{154}$ This would indicatc that the Community institutions would, in some cases, be bound to act in a precautionary manner. It remains to be seen if this approach is upheld in the future practice of the courts.

The next section examines how the principle is actually applied, and what requirements the Court has set up for its practical application.

\subsubsection{The Role of Scientific Evidence and the Limits of Judicial Review}

The ECJ has generally proved reluctant to make use of scientific evidence in order to rule on the merits of cases in which issues of scientific uncertainty have been involved. In nonharmonised areas where Member States have taken precautionary measures under Article 30 EC, the Court has held that:

"discretion relating to the protection of public health is particularly wide where it is shown that uncertainties continue to exist in the current state of scientific research." 155

This statement of the Court confirms the consistent previous case law which allows Member States a large amount of leeway when choosing their own levels of protection in cases of scientific uncertainty. ${ }^{156}$ As is discussed in more detail below, the Member States do not need to show the existence of a link between the scientific evidence presented and the

${ }^{152}$ For a further discussion on this issue, sec, above, Sections 2.4.2.3.

${ }^{153}$ Fisher holds that the EU institutions "may" rely on the precautionary principle; see E. Fisher, Risk Regulation and Administrative Constitutionalism, p. 212. It has been held by de Sadeleer that the cxistence of the precautionary principle in EC law requires that the EU institutions to "take a position justifying their decisions". Thus, they need to reflect on their choices in the light of the precautionary principle, and this is the real benefit of the principle, regardless of its compulsory or non-compulsory status. See N. de Sadeleer, The Precautionary Principle in EC Health and Environmental Law, p. 164-165.

154 Case T-229/04 Sweden v Commission, Judgment of 11 July 2007, not yet reported.

155 Case C-41/02 Commission v Netherlands, para. 43.

${ }^{156}$ See, for example, Case 227/82 Van Bennekom and Case 174/82 Sandoz BV. 
measure introduced, which is the case under the SPS Agreement. Instead, it is sufficient to demonstrate that uncertainty is present. ${ }^{157}$

Likewise, where broad discretionary powers have been delegated within the EU structure, the ECJ is, in principle, unwilling to investigate the scientific evidence upon which basis a measure has been taken. ${ }^{158}$ Since cases in which the precautionary principle is concerned per definition relate to scientific unccrtainty, the Court's review is of a limited character. ${ }^{159}$ In the EC legal order, this doctrine was developed by the Court in the Fedesa case. ${ }^{160}$ The fact that judicial review has its boundaries in relation to government action is recognised in most legal systems. The outer limits of judicial review are generally established in constitutional provisions, ${ }^{161}$ but pragmatic considerations also restrain courts. ${ }^{162}$ Such concerns may include the highly controversial nature of certain policy areas and the lack of expertise on the part of the courts. ${ }^{163}$ It should be pointed out that, when judicial review is limited by constitutions or treaties, this is a restraint put in placc by the legislator. When judicial review is limited due to pragmatic considerations, the restraints are put in place by the courts themselves, and, consequently, can also be modified by the courts themselves. Thus, there exist two different strands of possible restraints on judicial review. The first one is a formal restraint enacted by the legislator. The second one is a voluntary restraint imposed by the courts using their own discretion. In the case of the ECJ, the limited review in place has been established by the Court itself. This is important, since it means that the Court could also develop its judicial review doctrine, without being bound by statute. ${ }^{164}$

In the Fedesa case, the Court was asked to make a preliminary ruling on the validity of national regulations which aimed to implement Directive $88 / 146 / \mathrm{EC}$ prohibiting the use of

157 J. Scott \& E. Vos, The Juridification of Uncertainty: Observations on the Ambivalence of the Precautionary Principle in the EU and the WTO, p. 264-265.

158 Sec, also, N. de Sadelecr, The Precautionary Principle in European Community Health and Environmental Law: Sword or Shield for the Nordic Countries?, pp. 36-41.

159 That this does not mean that the Court does not in certain cases perform a review of scientific evidence is dealt with below in this section.

160 Case 331/88 Fedesa.

161 In the EC legal order the Court is limited by the provisions provided for in the treaties.

162 J. Jowell, "Of Vires and Vacuums: The Constitutional Context of Judicial Review", in: C. Forsyth (ed), Judicial Review and the Constitution, Hart Publishing, 2000, pp. 329-334. Jowell here describes the limits of discretion in common law systems, but a good case can be made in favour of similar restrictions being in place in the EC legal order. See, for example, E. Fisher, "Is the Precautionary Principle Justiciable?" in Journal of Environmental Law 13(3), p. 322.

${ }^{163}$ Sec the general discussion in J. Jowell, "Of Vires and Vacuums: The Constitutional Contcxt of Judicial Review", pp. 329-334.

164 It is shown below that for example the US federal courts have developed the margins of its judicial review over time. See, below, Section 7.1 . 
a number of hormones in livestock. The UK High Court of Justice asked the ECJ to answer, primarily, whether the ban on hormones was invalid since it was not based upon scientific evidence, and, therefore, infringed a number of legal principles, such as legal certainty, proportionality and equality. ${ }^{165}$

The ECJ began by stating that the aim of the Directive in question was to harmonise the divergent national legislations on the matter, and, in doing so, respond to the fears of the consumers of some Member States with regard to the safety of the regulated hormones in question. ${ }^{166}$ Fedesa had held that these anxieties lacked any foundation in science, and that, as a consequence, the principle of legal certainty for traders in the hormones was being violated. The Court declined to make a judgment with regard to the scientific evidence underlying the Directive, and stated:

"Even if it were to be held, as the applicants in the main proceedings have argued, that the principle of legal certainty requires any measure adopted by the Community institutions to be founded on a rational and objective basis, judicial review must, having regard to the discretionary power conferred on the Council in the implementation of the common agricultural policy, be limited to examining whether the measure in question is vitiated by a manifest error or misuse of powers, or whether the authority in question has manifestly exceeded the limits of its discretion." 167

In applying this reasoning, the Court effectively confined itself to a narrow, marginal review, concerned with form and not with content, in cases in which broad discretionary powers have been delegated to the EC institutions. The only material review that the Court allows itself is to consider whether a manifest error on the part of the legislator has been committed. If not, every substantive challenge will be disregarded.

Having stated this, the Court turned to consider the concept of scientific uncertainty. Here, it appears that the Court was satisfied with the fact that different national authorities had made divergent assessments regarding the risks of scientific uncertainty that was in question/present/at issue:

\footnotetext{
${ }^{165}$ Case 331/88, para. 4.

${ }^{166}$ Ibid., para. 6.

${ }^{167}$ Ibid., para. 8 .
} 
"In the light of the foregoing, the claim based on the existence of scientific evidence demonstrating the safety of the five hormones in question cannot be upheld. It is not necessary to order any measures of inquiry to verify the accuracy of that allegation; it need merely be stated that, faced with divergent appraisals by the national authorities of the Member States, reflected in the differences between existing national legislation, the Council remained with in the limits of its discretionary power in deciding to adopt the solution of prohibiting the hormones in question [...]."

This passage establishes that the Court considers any interpretation of scientific evidence to be within the Council's discretion whenever scientific uncertainty is in question. The limited evaluation of the scientific data performed by the Court merely aims to establish whether the case is surrounded by scientific unccrtainty or not. If this is found to be the case, the Court considers itself to be prevented from assessing whether the Council's decision was the appropriate one. Conversely, if the case is found not to be surrounded by scientific uncertainty and the Court finds that the Council had acted contrary to the scientific evidence, a manifest error may have been commilted.

It thus becomes important to establish when the Court considers scientific uncertainty to be present. In the Fedesa case, the fact that different Member States had made different assessments with regard to the risks involved was sufficient. ${ }^{169}$ One problem with the Court's restraint when judging under scientific uncertainty is that the issue of the risk is neglected. As was shown in Chapter 2, uncertainty is not necessarily absolute or static. There are different degrees of uncertainty, and research can - partially or completely - help to disperse scientific uncertainty. An uncertain risk can thus be more or less probable, even if an exact probability per definition cannot be assigned to it, depending on the degree of uncertainty it is surrounded by. When the Court stops short of investigating the degree and cause of scientific uncertainty, it also effectively excludes itself from considering whether the risk that measures in question are intended to protect against is probable or not.

The limits imposed here are based upon the Court's own view of its judicial review. Nothing in the relevant Article 230 of the EC Treaty limits the Court's powers to this effect. A more activist Court could extend the scope of its review. In the US legal system, for

\footnotetext{
${ }_{168}$ Case 331/88 Fedesa, para. 9 .

169 Ibid.
} 


\section{Joakim Zander}

example, the scope of the court's judicial revicw when judging on scientific evidence has changed over time. ${ }^{170}$

Since the Fedesa case, the Court has upheld its view on the limits to its judicial review on a number of occasions. In the BSE case, ${ }^{171}$ the UK held that, due to the inconclusive evidence establishing a link between the outbreak of BSE with the outbrcak of Crcutzfeld Jakob disease, the ban on the importation of British beef to the rest of the EU was unjustified. In answering this, the Court began by pointing out that it considered itself to be restricted to investigating if the Commission decision was vitiated by a manifest error or a misuse of powers. ${ }^{172}$ This was repeated in the Safety Hi-Tech case, which regarded an exemption from the general ban on hydrochlorofuorocarbons (HCFCs) for use in fire fighting equipment. Safety Hi-Tech held that the Regulation (EC) 2037/2000 on substances that deplete the ozone layer had not taken the available scientific data into account. If it had, Safety Hi-Tech claimed, it would have been clear that other, more dangerous substances, had bcen left unregulated. Here, the Court held that its task was not to judge, upon the basis of scientific evidence, which risks were to be regulated, and that Safety Hi-Tech had not managed to show manifest error on the part of the Council when issuing the ban. ${ }^{173}$

In the Pfizer case, the Court of First Instance continued to emphasise its limited review doctrine and stated:

"It follows that, in this case, in which the Community institutions were required to undertake a scientific risk assessment and to evaluate highly complex scientific and technical facts, judicial review of the way in which they did so must be limited. The Community judicaturc is not entiticd to substitute its assessment of the facts for that of the Community institutions, on which the Treaty confers sole responsibility for that duty. Instead, it must confine itself to ascertaining whether the exercise by the institutions of their discretion in that regard is vitiated by a manifest error or a misuse

${ }^{170}$ For an in-depth discussion on this, see S. Jasanoff, Science at the Bar, Harvard University Press, 1995, pp. 6992.

171 For a background to the BSE affair, see, above, and, for example, L. Antonopolou \& P. van Meurs, The precautionary principle within European Union public health policy; The implementation of the principle under conditions of supranationality and citizenship, Health Policy 66 (2003) pp. 185-189, and P. Zwanenberg \& E, Millstone, 'Mad cow disease' 1980s-2000: how reassurances undermined precaution.

${ }_{172}^{172}$ Case C-180/96 United Kingdom v Commission, para. 60

${ }^{173}$ Case C-341/95 Gianni Bettati v Safety Hi-Tech [1998] ECR I-4335 paras. 50-53. 
of powers or whether the institutions clearly exceeded the bound of their discretion." 174

However, even though the Court, in the Pfizer case, continued to find itself restricted from judging on the merits of the scientific evidence, it indicated that it required the scientific evidence to fulfil certain requirements in order to be able to be relied upon. It, thus, held that it would not be sufficient for the EU institutions to take any decision that it pleases, but that decisions had to be backed up by a scientific assessment. How this scientific assessment was to be conducted is subject to scrutiny, but the conclusions drawn from a flawless assessment are outside the reach of the Court. However, the Court failed to make any generally applicable, normative requirements on the scientific assessment, and only stated that it must be "as thorough as possible". ${ }^{175}$ Some questions regarding the systematic approach of the Court must also be raised. The Communication on the Pprecautionary Pprinciple holds that scientific evaluation is made up of four constituent parts: hazard identification, hazard characterisation, the appraisal of exposure, and risk characterisation. ${ }^{176}$ The Court did not test the institutions against these requirements, but was satisfied that the institutions had based their decision upon "sufficiently reliable and cogent information" and that they had understood "the ramifications of the scientific question raised". ${ }^{177}$ Nothing is mentioned with regard to how the Court actually reached this conclusion. ${ }^{178}$

Here, it should be pointed out that, when not applying strict requirements, such as those included in the Communication, in the case law, it becomes possible for both the Member States and the EU institutions to circumvent the requirements and the purpose of a risk assessment. This affords the institutions considerable freedom, not only to evaluate scientific advice, but also to decide on how the scientific advice is obtained. In order to avoid situations in which the EU institutions and the Member States devise their risk assessments to obtain particular, pre-ordained results, it would have been helpful if the Court had created strict, formal requirements on how the scientific evaluation was to be carried out. This is

${ }^{174}$ Case T-13/99, para 169. The Court also referred back to this statement later in the case. See, for example, para. 323.

$175 \mathrm{~T}-13 / 99$, para. 162.

$176 \mathrm{COM} / 2000 / 1$, p. 13 and Annex III.

$177 \mathrm{~T}-13 / 99$, para 162.

${ }^{178}$ For further discussion on the failure of the Court to test the scientific evaluation against the guidelines laid down in the Communication (including the choice to be guided by the diverging Danish scientific opinion rather than SCAN), see E. Vos, Antibiotics, the Precautionary Principle and the Court of First Instance, Maastricht Journal Vol, 11, Issue 2, 2004, p. 3-6. 


\section{Joakim Zander}

something that must have bcen within the Court's reach, without stretching the boundaries of the limited judicial review it has afforded itself. However, as is returned to below, the Court appears to have considered the opinion of the relevant scientific committee, which, at least to some extent, was the basis for the final decision, and in so-doing, seems to have respected the Communication requirements, at least in spirit. ${ }^{179}$ Clarity, on this point, is an essential starting-point for a systematic and science based application of the precautionary principle.

It also needs to be pointed out that, even though the Court explicitly states that it does not rule on the merits of the scientific evidence or substitute its assessment for that of the other institutions, ${ }^{180}$ it still takes the scientific evidence presented into consideration. ${ }^{181}$ However, instead of judging on the case, it uses the scientific evidence to establish the existence of scientific unccrtainty. ${ }^{182}$ How the court proceeds to perform this is dealt with in detail below.

Furthermore, it should be mentioned that, surprisingly, the CFI diverted from its limited review doctrine in a case regarding the inclusion of the pesticide paraquat in Annex 1 of Directivc 91/414/EC concerning the Placing of Plant Protection Products on the Market. ${ }^{183}$ Paraquat had been included in Annex I by a Commission decision following the comitology procedure prescribed in Directive 91/414/EC, and was thus authorised to be placed on the market. Sweden challenged this decision in 2004 , and sought to have the decision reversed due to the hazardous effects of paraquat on humans and animals. Without referring to its limited review in cases in which discretion had been given to the Community institutions, the CFI made an expansive reading of the formal requirements on scientific evidence in the relevant legislative act and went on to investigate in detail the scientific reports underlying the Commission's decision. ${ }^{184}$ Despite the statements madc in previous case law that the European Courts should not substitute the assessment of the Community institutions with that

\footnotetext{
${ }^{179}$ See, for example, T-13/99 Pfizer Animal Health SA v Council of the European Union, paras. 194 \& 209.

${ }^{180}$ Case T-13/99 Pfizer Animal Heallh SA v Council of the European Union, para. 393.

${ }^{181}$ See, for example, the statement of the Court in Case 97/83 Melkunie, para. 15 and the detailed scientific analysis in the Case T-13/99 Pfizer Animal Health SA v Council of the European Union accounted for below.

182 That uncertainty is a precondition for the application of the precautionary principle and thercfore has to be established before measures can be introduced has been held consistently by the ECJ. See for example Case 132/03 Codacons and Federconsumatori, [2005] ECR I-4167, para. 61, and Case C 236/01 Monsanto Agricoltura Italia and Others, para. 111. See, also, the discussion by van Asselt \& Vos, in: M.B.A. van Asselt \& E. Vos, The Precautionary Principle and the Unccrtainty Paradox, 9 Journal of Risk Research 4, 2006, and N. de Sadelecr, The Precautionary Principle in European Community Health and Environmental Law: Sword or Shield for the Nordic Countries?, p. 20

183 Case T-229/04 Sweden v Commission.

184 lbid., paras. 108-110 and 174-190.
} 
of their own, the CFI in the Sweden v Commission proceeded to do precisely this. By concluding that the assessments of the scientific evidence by the relevant scientific committee, as well as that of the rapporteur Member State and the Commission, were flawed, the CFI revoked the Decision of the Commission. ${ }^{185}$ This judgment is extraordinary since it is apparently inconsistent with the previous settled case law with regard to judicial review of scientific evidence. This creates the highly paradoxical situation in which the ECJ and the CFI, in some cases, limit the possibilities of effective redress for parties affected by precautionary measures with reference to their limited judicial review, ${ }^{186}$ and, in other similar cases, are willing to make a detailed assessment of scientific evidence in order to prescribe a more precautionary approach. The possible implications of the judgment for the application of the precautionary principle are returned to below in the section on the level of proof. Recently, in Commission v Parliament, the ECJ also overturned the Commission's decision to exempt the brominated flame retardant DecaBDE for use in polymers from the general ban on flame retardants of the PBDE family. ${ }^{187}$ However, the conclusion of the ECJ was based upon the fact that the Court had concluded that the authorisation meant a de facto total exemption for the substance, whereas the Restriction of Hazardous Substances Directive (RoHS) Directive clearly established that exemptions could only be granted for certain applications of products, not the products per sc. ${ }^{188}$ Thus, the ECJ avoided examining the issue of the evaluation of the scientific evidence in the case.

Finally, it should be mentioned that the European Court's general approach to judicial review in cases of the precautionary principle differs significantly from how Panels and the $\mathrm{AB}$ have approached the subject within the WTO structure. ${ }^{189}$ The focus on a thresholdfinding of risk is present in the WTO structure, whereas, in the EU structure, it is generally sufficient for the party invoking the measures to show that the area is surrounded by uncerlainty. The scope of the judicial review is intimately connected to the varying degrecs of proof required within the two legal frameworks. Since the WTO Panels look for a link between the scientific evidence and the measures invoked, their review must be deeper in scope. What is required in the EU structure is examined in the following section.

\footnotetext{
185 Ibid., paras. 180-181 and 185-186.

186 See the discussion of, for example, Case 331/88 Fedesa and Case T-13/99 Pfizer Animal Health SA v Council of the European Union above.

187 Joined Cases C-15/06 and C-295/06 European Parliament v Commission, judgment of 1 April 2008, not yct reported.

188 Ibid., 68-79.

189 See, above, Section 3.3.2.2.
} 


\section{Joakim Zander}

\subsubsection{Risk Assessment and Risk Management}

The decision to cnact precautionary measures is a political decision based upon scientific evaluation and advicc. ${ }^{190}$ The reasons for keeping the decision of whether to issuc measures separate from the technical and scientific advice was largely accounted for in Chapter 2 . The fact that the Member States have to perform a risk assessment before taking precautionary measures under Articles 28 and $30 \mathrm{EC}$ has been consistently stated by the ECJ. ${ }^{191}$ In addition, in cases in which Member States wish to derogate from harmonising measures taken under Article $95 \mathrm{EC}$, this must have been preceded by a risk assessment performed by the Member States wishing to derogate. ${ }^{192}$

At EU level, the formal source of scientific advice generally comes from the various scientific committees, or, increasingly, the specialised European agencies. ${ }^{193}$ This advice is not binding, but, when enacting measures which depart from the recommendations of the relevant committee, the EU institutions need to reason why it makes a different assessment of the situation. ${ }^{194}$ Thus, the scientific committees essentially perform the scientific assessment, and the Commission or Council act as the risk managers.

As was shown carlicr, in the Pfizer case, the Commission was allowed to derogate from the risk asscssment presented in the opinion of the Scientific Committee on Animal Nutrition (SCAN) due to the fact that the CFI employed a very restricted review of the Commission's actions in combination with a low level of proof. This indicates that the risk manager (the Commission) has a large margin of appreciation when making use of the scientific assessment (the SCAN Opinion). The CFI also concluded, both in the Pfizer and in the Alpharma cases, that the purpose of a risk assessment is to inform the decision-maker adequately. In "exceptional circumstances and where there are adequate guarantecs of scientific objcctivity in cases of particularly complex scientific facts" the decision-maker is not bound to submit the matter to the relevant scientific committee. ${ }^{195}$ However, and

190 For a discussion on the roles of risk assessment and risk management in EC risk regulation, see N, de Sadeleer, The Precautionary Principle in European Community Health and Environmental Law: Sword or Shield for the Nordic Countries?, p. 27-35. See, also, E. Fisher, Risk Regulation and Administrative Constitutionalism, p. 238241.

191 Casc C-41/02 Commission v Netherlands, para. 48; Case C-192/01 Commission v Denmark, para. 47; Case C24/00 Commission $\vee$ France, para. 54.

192 See, generally, Case C-512/99 Germany v Commission ECR I-845 and Case C-3/00 Denmark v Commission.

193 E. Vos, Antibiotics, the Precautionary Principle and the Court of First Instance, p. 1.

194 Case T-13/99, paras. 199 and 200. See, also, Case C-405/92 Armand Mondiet ECR I-6133 paras. 31-32, and Case C-120/97 Upjohn [1999] ECR I-223, para. 47.

${ }^{195}$ Case T-13/99 Pfizer Animal Health SA $\vee$ Council of the European Union, para. 298 and T-70/99 Alpharma, para. 213. 
remarkably, the CFI did not discuss the matter in any greater detail, and did not suggest how this notion can be rcconciled with principles of scientific objectivity, impartiality, proper scientific basis and transparency, which it had emphasised elsewhere in its judgments. ${ }^{196}$

In Denmark v Commission, the Danish authorities successfully managed to challenge the decision by the Commission upon the basis of it not having taken the relevant scientific committee advice into consideration when issuing its decision. ${ }^{197}$ Similar emphasis was put on the opinion of the scientific committee in Germany $v$ Commission. ${ }^{198}$ Both of these cases regarded requests for derogations under Article $95 \mathrm{EC}$. In deciding on such requests, the Commission has had broad discretionary powers delegated to it. This is in conformity with the Court's case law in similar cases. ${ }^{199}$ However, nowhere in either Denmark v Commission or in Germany v Commission does the Court signify that it finds its judicial review limited, and it does review the acts of the Commission in far greater detail than it did in the Pfizer case, for example. This would seem to indicate that the Court considers the risk manager (the Commission) less bound by the risk assessment (the opinion of the Scientific Committee) in certain cases than in others.

As mentioned, this inconsistency may be due to pragmatic considerations by the Court. However, the inconsistency with regard to how much force the Court intends to give to risk assessments and how much freedom the risk manager has to act creates scrious concerns with regard to legal certainty.

In order to illustrate the awkward results of the failure to maintain a strict separation between risk assessment and risk management, the Monsanto case serves as a good example. $^{200}$ In the case, Monsanto asked the French authorities to classify bovine somatotrophin (BST) as a substance for which no Maximum Residue Level (MRL) had to be established. This would indicate that the product was considered safe to place on the market from a public health perspective. The matter was passed to the Committee for Veterinary Medicinal Products (CVMP), which expressed an opinion which supported Monsanto's

${ }^{96}$ Case T-13/99 Pfizer Animal Health $S A \vee$ Council of the European Union, para. 213. For a more detailed discussion of this and other aspects of the Pfizer and Alpharma judgements, see E. Vos, Antibiotics, the Precautionary Principle and the Court of First Instance, 11 MJ 2, 1, 2004, 7.

197 Case C-3/00, para, 111: "The contested decision did not take sufficient account of the 1995 opinion. It failed to mention in that connection that the maximum amounts of nitrites set in Directive $95 / 2$ are called into question by the 1995 opinion".

198 Case C-512/99 Germany v Commission ECR I-00845.

199 See the discussion on judicial review above in Section 4.2.5.3.

200 Case T-1 12/97 Monsanto v Commission. 


\section{Joakim Zander}

application, in which it stated that it could sec no public health risks with BST. ${ }^{201}$ However, the Commission, instead of passing the request on to the regulatory committee, which the relevant legislation provided for, ${ }^{202}$ took its own decision not to list BST in the Annex of substances for which no MRL would have to be issued. The reason for its action was that a moratorium affecting the placing of BST on the market existed in the EU, which would effectively prevent the marketing of BST regardless of whether it was declared safe or not. ${ }^{203}$

Monsanto brought the Commission before the Court of First Instance to challenge its decision, and the CFI ruled that a marketing ban on a substance did not preclude the inclusion of the same substance in an Annex declaring it safe for public health. The CFI based this primarily upon its previous ruling in an almost identical case, in which it had ruled that the Commission could not base its decision solely upon the existence of a moratorium. ${ }^{204}$ The CFI placed special emphasis on the fact that a moratorium introduced for socio-economic reasons ${ }^{205}$ must not be used as an excuse to declare a substance not safe from a public health perspective. $^{206}$

France appealed against the judgment in the ECJ. After dealing with procedural issues relating to the case before the $\mathrm{CFI}$, the Court turned to the substantive question. Herc, the Court stated that the decision to establish (or the decision not to establish, as it were) an MRL was intrinsically linked to the placing of a product on the market. Thus, the Court argued, that if the placing of a product on the market was effectively made impossible, for example, by the existence of a moratorium, the question of establishing an MRL did not need to be answered. ${ }^{207}$ In stating this, the Court reversed the ruling of the CFI, which had argued for a separation of the scientific decision regarding the safety of the product from the political decision relating to whether to allow the product on the market or not. In combining the two decisions, the Court blurred the line between what was essentially risk regulation (the issue of whether the substance in question is safe or not) and agricultural politics (whether the

201 Ibid., paras. 4-8

202 Council Regulation (EEC) No $2377 / 90$ of 26 June 1990 laying down a Community procedure for the establishment of maximum residue limits for veterinary medicinal products in foodstuffs of animal origin, OJ $L$ 224, p. $1,8.8 .1990$

${ }^{203}$ Council Decision 90/218/EEC of 25 April 1990 concerning the Administration of Bovine Somatotrophin (BST) and Council Decision 94/936 of 20 December 1994 amending Decision 90/21 8/EEC concerning the placing on the market and administration of bovine somatotrophin (BST) respectively.

204 Case T-120/96 Lilly Industries v Commssion [1998] ECR II-2571.

205 More specifically to maintain the milk quotas negotiated between the Member States within the framework of CAP.

${ }^{206}$ Case T-1 12/97 Monsanto v Commission, para. 91.

207 Case C-248/99, France v Monsanto [2002] ECR I-1, para. 80. 
substance is to be allowed or not from a socio-economic perspective). The somewhat radical conclusion of the above is that the Court allows a political decision regarding milk quotas to determine the level of health protection to be applied in the EU. In doing so, it becomes possible for the Commission and the Council to enact politically-motivated measures which are disguised as measures aimed at regulating risks. If this confusion is maintained in future case law, it risks seriously undermining the systematic approach to risk regulation in general, and the precautionary principle in particular.

This is not to say that the transparency and information-flow between the risk assessment and the risk management phase should not be improved. Development in this direction will allow risk asscssors to understand the concerns of both the risk managers and the general public, and will also allow the risk managers to understand the reasoning behind, and the limits to, scientific advice. ${ }^{208}$ However, it has to be possible to determine on what grounds the decision is motivated, and where scientific assessments end and political decisions begin. ${ }^{209}$

\subsubsection{The Level of Proof and the Triggering of Precautionary Measures}

In the two preceding sections, it was discussed that Member States as well as European institutions must perform a risk assessment before invoking precautionary measures, but that the judicial review performed by the ECJ when evaluating the content of such assessments is very limited. It was established that the Court, in general, is content with finding that scientific uncertainty is present, and, once this has been established, it leaves the Member States or the institutions considerable leeway in deciding upon what measures to take. ${ }^{210}$ The issue of the general problems arising in relation to decision-making under scientific uncertainty were dealt with in detail above, in Chapter 2.

${ }^{208}$ For an in-depth discussion on this issue, see, above, Section 2.3.1.

${ }^{209}$ N. de Sadeleer does not agree with this notion, but seems to argue that by allowing for essentially political considerations in the risk assessment phase, the accountability of decision-makers is increased. This author does not agree with the assertion by de Sadeleer. When scientific reasoning is not distinguished from socio-economic considerations it becomes difficult to understand the rationale bchind decisions. It also increases the possibilities of officials to mask dccisions as science-based, when they are really not motivated by concerns relating to risk reduction. Compare N. de Sadeleer, The Precautionary Principle in EC Health and Environmental Law, p. 160.

${ }^{210}$ See, for example, Case 132/03 Codacons and Federconsumatori, [2005] ECR I-4167, para. 61, and Case C 236/01 Monsanto Agricoltura Italia and Others, para. 111. See, also, the discussions in J. Scott \& E. Vos, The Juridification of Uncertainty: Observations on the Ambivalence of the Precautionary Principle in the EU and the WTO, p. 265; M.B.A. van Asselt \& E. Vos, The Precautionary Principle and the Uncertainty Paradox, 9 Journal of Risk Research 4, 2006; and N. de Sadeleer, The Precautionary Principle in European Community Health and Environmental Law: Sword or Shield for the Nordic Countries?, p. 20. It was also discussed that the CFI in T-229/04 Sweden v Commission appeared to ignore the limited review doctrine in order to overtum a decision of the Commission based on a different reading of the scientific evidence. This issue is returned to below in this section. 
Joakim Zander

In the BSE case, the precautionary ban on British Bcef was to stay in place "[p]ending an overall examination of the situation $[\ldots]^{\prime 2} .{ }^{211}$ In essence, the measure reversed the burden of proof, forcing the UK to show the absence of risk in order to challenge the Decision successfully. However, the UK did not strive to prove this; instead, it challenged the Commission's Decision upon the basis that it was not sufficiently supported by science. Thus, the reversal of the burden of proof was not dealt with in detail, and only the level of required proof needed to initiate precautionary measures was dealt with. As mentioned above, the Court held that it would apply a limited review of the measure. ${ }^{212}$ The Court continued to state:

"In the present case, the publication of new scientific information had established a probable link between a disease affecting cattle in the United Kingdom and a fatal disease affecting humans for which no known cure yet exists." 213

Thus, first, the Court emphasised that scientific evidence had been produced in support of the measures taken by the Commission. The UK did not submit evidence showing that the risk was not probable, or that a different assessment of the data was more probable. It is unclcar how such proof would have been evaluated by the ECJ.

Second, the level of proof here had been set for the Commission to make it "probable" that the link existed. This is a higher level of proof than a mere suspicion, in that it incorporates an element of likelihood, yet it is not as high as, for example, "verified" or "manifest". 214

Third, the perceived risk in the BSE case was very grave since it was described as life threatening and incurable. ${ }^{215}$ It could be argued that this suggests that, the more serious the risk is perceived to be, the more the Court is inclined to allow precautionary measures. Having established this, and once again having emphasised the uncertainty and the gravity of

211 Commission Decision 96/239/EC of 27 March 1996 on emergency measures to protect against bovine spongiform encephalopathy, OJ L 078 , 28/03/1996. p. 0047-0048. Article 1.

${ }^{212}$ Case C-180/96 United Kingdom v Commission. para. 60.

213 Ibid., para. 61 .

214 See definitions in The New Oxford Dictionary, Oxford University Press 1998.

215 An interesting analogy here is Article 15 of the Rio Declaration in which precautionary measures can be invoked to combat a "serious or irreversible" risk. It is however unclear if the Court in referring to the life threatening and incurable risk of Creuzfeld-Jakob disease intended to allude to the this agreement. 
the risk in question, the Court concluded that the Commission had not exceeded its powers when issuing the ban. ${ }^{216}$

In the Toolex case, the level of proof imposed by the Court appears to be lower. Where the Court in the BSE case relied on the existence of new scientific evidence, the probability of risk and the seriousness of the risk, the Court in Toolex mentioned the existence of new scientific evidence with regard to the possibility of trichloroethylene being a carcinogen, but did not require the authorities to show the probability of this risk. ${ }^{217}$ Instead, the Court was satisfied with the fact that it was unclear at what exact dose the substancc was hazardous for a total ban to be justificd. This implies that the requirements for the triggering of precautionary measures in Toolex were lower than those used in BSE, and that neither of them fully match the vague requirements laid down in the Commission's Communication. ${ }^{218}$ This indicates that the ECJ may be cven more lenient to assessments made by the Member States under Article $30 \mathrm{EC}$, which was the case in Toolex. In more recent case law, the ECJ has downplayed the suggestion in the BSE case that a risk would have to be "probable" in order to trigger the use of the precautionary principle. In Monsanto Agricoltura, the court emphasised that what had triggered the precautionary measures in the BSE case was "the uncertainty as to the existence of risks to human health". ${ }^{219}$ However, the measures cannot be based on "purely hypothetical considerations". 220

If the case law so far had failed to provide a uniform interpretation of what is required in order to invoke precautionary measures, things were not much clarified when the CFI fleshed out the use of the precautionary principle in the Pfizer case. However, the CFI applied a somewhat more ambitious approach. The case related to the invocation by Denmark of a safeguard procedure included in the Council Directive concerning additives in feedingstuffs. ${ }^{221}$ As support for banning the antibiotic virginiamycin as a growth promoter, Denmark relied on a report from its National Veterinary Laboratory. The Commission submitted the

216 Case C-180/96 United Kingdom v Commission. para. 62.

217 Case C-473/98 Kemikalieinspektionen v Toolex [2000] ECR I-5681. AB. paras. 42-45.

218 The Commission remains vague on the issue of the level of proof required. It merely holds that the precautionary principle can not be allowed to lead to zero-risk levels being employed and that the triggering of precautionary measures must be preceded by "identification of the potentially negative cffects of a phenomenon". (COM/2000/1, p. 13).

219 C-236/01, Monsanto Agricoltura, para. 111.

${ }^{220}$ C-236/01, Monsanto Agricoltura, para. 106, Case C-192/01 Commission v Denmark, para. 49, Case C-24/00 Commission v France, paras. 56, and Case C-41/02 Commission v Netherlands, para. 52.

${ }^{221}$ Council Directive 96/51/EC, amending Directive 70/524/EEC concerning additives in feeding-stuffs (1996) OJ L235, p. 39. 


\section{Joakim Zander}

Report to the Scientific Committee on Animal Nutrition (SCAN), which found the link between using virginiamycin as a growth promoter in cattle and resistance towards the use of the antibiotic as a human medicine to be weak. It concluded that the use of virginiamycin did not constitute an immediate risk to health in Denmark. Despitc this, the Commission, relying on the precautionary principle proposed a ban of the product, which, following the adequate procedure was issued by the Council. ${ }^{222}$

Pfizer brought the case before the CFI, where it essentially argued that the decision of the Council was not based on scientific evidence. It argued that a loose interpretation of what needs to be shown when the precautionary principle is invoked risks leading to a situation of probatio diabolica. ${ }^{223}$ This would, according to Pfizer, mean a reversal of the burden of proof in all situations involving the precautionary principle, and a party wishing to challenge a measure would always have to show the lack of risk in order to be successful. This is a situation that both the Communication on the Precautionary Principle and the Advocate General have denounced. ${ }^{224}$

The CFI agreed with Pfizer in principle, and held that the Community institutions must show that a risk is not "purely hypothetical", 225 but "adequately backed up with scientific data". ${ }^{226}$ These requirements, the CFI considered to be fulfilled in the case in question, without mentioning how it had come to this conclusion. However, it must be considered that this initial step, which corresponds with point 5.1.1 Identification of potentially negative effects in the Communication on the precautionary principle, ${ }^{227}$ apparently only serves to trigger a risk assessment, not precautionary measures. Consequently, the requirements need not be very high; as it is sufficient for a potential risk to be perceived, the likelihood and severity of which is to be examined scientifically. ${ }^{228}$ The CFl, then, importantly, pointed out that, in the case in question, a zero-risk approach is particularly inappropriate since it is simply not possible to show scientifically that a future

${ }^{222}$ Council Regulation $2821 / 98 / \mathrm{EC}$ amending the withdrawal of the authorisation of certain antibiotics, Directive 70/524/EEC (1998) OJ L351, p. 4.

${ }^{223}$ Case T-13/99 Pfizer Animal Health SA v Council of the European Union, para. 130.

224 Opinion of AG Mischo in Case C-6/99 Association Greenpeace France and Others v Ministere de l'Agriculture $e$ de la Pêche and Others, para. 72.

${ }_{225}$ Case T-13/99 Pfizer Animal Health SA v Council of the European Union, para. 143.

226 Ibid., para. 144.

$227 \mathrm{COM} / 2000 / 1$, p. 13.

${ }^{228}$ Case T-13/99 Pfizer Animal Health SA v Council of the European Union, para. 148. 
risk does not exist with virginiamycin. ${ }^{229}$ Having stated that a potential risk may exist and that a zero-risk approach is not to be applied, the CFI turned to the scientific assessment of the potential risk.

The Court here identified two stages of the risk assessment procedure: ascertaining what level of risk is unacceptable and the scientific assessment of that risk. ${ }^{230}$ This is a somewhat confusing and unfortunate distinction. It appears that the CFI here blurs the distinction between what is traditionally seen as risk assessment (scientific evaluation of the data) and risk management (setting the appropriatc risk levels). ${ }^{231}$ As was stated above, ${ }^{232}$ it is not helpful for the clarity of complex decisions in cases of great uncertainty when the terminology is not stringently upheld and is allowed to indicate that political considerations may be a part of what should be a scientific assessment. ${ }^{233}$

As the Court turned to the scientific assessment, which it held must be "as thorough as possible", 234 the systematic approach of the Court can be questioned. The Communication on the Precautionary Principle holds that scientific evaluation is made up of four parts: hazard identification, hazard characterisation, appraisal of exposure, and risk charactcrisation. ${ }^{235}$ As mentioned above, the Court does not test the institutions against these requirements, but is satisfied that the institutions have based their decision on "sufficiently reliable and cogent information" and that they understood "the ramifications of the scientific question raised". ${ }^{236}$

${ }^{229}$ Case T-13/99 Pfizer Animal Health SA v Council of the European Union, para. 144. It should be noted that the Communication actually leaves the door open to the setting of zero-risk levels in stating on p. 13 that "[precautionary measures] must not aim at zero risk [...]. However, in certain cases, an incomplete assessment of the risk may considerably limit the number of options available to the risk managers". This enigmatic formulation indicates that the more limited the risk assessment is and, conversely, the greater the uncertainty, the closer to zero risk the risk levels are allowed to be set. It could be argued that limited scicntific data alone should not be a cause for higher risk levels, but that the seriousness of the perceived risk also must be weighed in.

230 Ibid., para. 149.

231 In Ibid., para. 151 the Court states that "Therefore, determining the level of risk decmed unacceptable involves the Community institutions in defining the political objectives to be pursued under the powers conferred to them by the "Treaty". Thus it would be clear that what the CFI here means is a political consideration which should be found in the risk management stage rather than in the risk assessment stage.

232 See in relation to the Monsanto case above.

233 As was argued in Chapter 2, scientific assessments are also coloured by the appointments of scientists, their individual convictions, the reigning scientific paradigms etc. However, in order to be as objective as possible science should strive to rid itself of concerns of a non-scientific nature and therefore it is important that decision-making procedures formally separate what are scientifically-based decisions from policy considerations.

234 T-13/99 Pfizer Animal Fealth SA v Council of the European Union, para. 162.

${ }^{235} \mathrm{COM} / 2000 / 1$, p. 13 and Annex III.

236 T-13/99 Pfizer Animal Health SA v Council of the European Union, para 162. For further discussion on the failure of the Court to test the scientific evaluation against the guidelines laid down in the Communication (including the choice to be guided by the diverging Danish scientific opinion rather than SCAN), see E. Vos, 


\section{Joakim Zander}

It would have been helpful if the Court had created strict formal requirements on how the scientific evaluation is to be carried out. This is something that must have been within the Court's reach without stretching the boundaries of the limited judicial review it has afforded itself. However, it should be borne in mind that the Court appeared to have considered the SCAN opinion, which, at least to some extent, was the basis for the final decision, to live up to the Communication requirements, at least in spirit. ${ }^{237}$ Clarity on this point is, however, an essential requirement on which to build a systcmatic and science based application of the precautionary principle. ${ }^{238}$

With regard to the invoking of the precautionary principle, it appears that this can be done even when scientific evidence shows that the risk is unlikely to occur, or that a different interpretation of the scientific evidence gives a more probable outcome than that proposed by the party invoking the measures. In the Pfizer case, the Standing Committee on Animal Nutrition concluded that the substance in question, virginiamycin, did not pose an immediate risk to public health in Denmark. ${ }^{239}$ In short, the Commission's own risk assessment declared the risk needed for the triggering of precautionary measure to be less than probable. However, it also stated that uncertainty still persists in this field, and this is what the Commission, and later the CFI, considered to be crucial. ${ }^{240}$ It was thus not sufficient for the SCAN to have rejected the Danish asscssment, on which Denmark had based its original request, and described it as "misleading", 241 "made on the basis of a single unsubstantiated statement", 242 "unsound and without foundation", 243 and "contains no evidence that existing therapics are likely to be compromised". ${ }^{244}$ Instead, the CFI found the Commission's decision to be justified in the light of the remaining scicntific unccrtainty. ${ }^{245}$ It held that a situation in

Antibiotics, the Precautionary Principle and the Court of First Instance, pp. 3-6.

${ }^{237}$ See, for example, T-13/99 Pfizer Animal Health SA v Council of the European Union, paras. 194 and 209.

${ }^{238}$ The failure of the ECJ to identify what is required by risk assessments preceding precautionary action has been criticised by other commentators, see for example N. de Sadeleer, The Precautionary Principle in European Community Health and Environmental Law: Sword or Shield for the Nordic Countries?, p. 26.

${ }^{239}$ Opinion of the SCAN on the immediate and longer-term risk to the value of Streptogramins in Human Medicinc poscd by the use of Virginiamycin as an animal growth promoter (produced at the request of the Commission in response to the action taken by Denmark under a safeguard clause to ban viginiamycin as feed additive), of 10 July 1998.

${ }^{240}$ Case T-13/99 Pfizer Animal Health SA v Council of the European Union, paras. 220-232.

241 Opinion of the SCAN, comment to conclusion 4.

${ }^{242}$ Ibid., comment to conclusion 5.

${ }^{243}$ Ibid., comment to conclusion 6 .

$244 \mathrm{Ibid}$, comment to conclusion 8.

245 Ibid., final Conclusion II: "[...] it is of the opinion that a full risk assessment cannot be made until quantitative evidence of the extent of transfer of antimicrobial resistance from livestock sources is obtained and the significance of this within the overall use of antimicrobials for clinical and non-clinical purposes evaluated." 
which the precautionary principle applies per definition coincides with the lack of scientific certainty and that a risk assessment cannot be required to give conclusive evidence in one way or another. ${ }^{246}$ However, the scientific uncertainty surrounding virginiamycin is not absolute. In its report, the SCAN held that it "firmly" believes that the risk will not materialise in the time it would take to rcach full scientific certainty. ${ }^{247}$ Thus, the risk does not, in the eyes of SCAN, appear to be acute, but, rather exist in the distant future. In the light of this, it is difficult to see how this risk cannot be viewed as leaning towards hypothetical, something which both the Commission ${ }^{248}$ and the $\mathrm{CFI}^{249}$ have pointed out is not sufficicnt to enable the precautionary principle. ${ }^{250}$ The conclusion of this must be that the proof of scientific uncertainty required for invoking precautionary measures in the Pfizer case was even lower than in the case law under Article 30 described above.

It should be pointed out that the Court of Justice of the EFTA States ("the EFTA Court") has made a somewhat more stringent interpretation of what is required for the triggering of precautionary measures. In EFTA Surveillance Authority v Norway, ${ }^{251}$ the Court stated that a mere lack of perceived nutritional need for a product in a state's population did not suffice to justify trade restrictions. ${ }^{252}$ It has to be shown that the measure is motivated by the wish to protect human health. Such a risk to human health must be concrete and cannot be based purely on hypothetical or acadcmic considerations. ${ }^{253}$ Like the Commission's Communication, the Court stressed the importance of risk assessment when taking measures to protect human health, and this shall include risk identification and an evaluation of the risks. ${ }^{254}$ In order to trigger precautionary measures in cases of uncertainty, the EFTA Court positions itself closer to the ECJ in the BSE case. ${ }^{255}$ The conclusions of the

${ }^{246}$ Case T-13/99 Pfizer Animal Health SA v Council of the European Union, para. 142

247 Opinion of the SCAN, op. cit., note 239, final Conclusion II: "SCAN is therefore firmly of the opinion that any risk that might be posed in the future by the use of virginiamycin as a growth promoter will not materialise in the time requircd to make such an evaluation and most probably not for some years afterwards".

$248 \mathrm{COM} / 2000 / 1$, p. 13.

249 Case 13/99 Pfizer Animal Health SA v Council of the European Union, para. 143.

250 At least, this would be true for the time it would take to finalize the risk assessment. The SCAN Opinion here stopped short of calling the risk "hypothetical" in that timeframe but said that the risk "will not materialise in the time required to make such an cvaluation and most probably not for some years afterwards".

${ }^{251}$ Case E-3/00 EFTA Surveillance Authority v. Norway [2000-2001] EFTA Court Report 73.

252 Ibid., para. 29.

253 Ibid., para. 29.

${ }^{254}$ Ibid., para. 30.

255 Or at least established a "likely considerable harm," which has by some been argued some to be close to the probability requirement in the $B S E$ case (see L. Bergkamp, Understanding the Precautionary Principle (Part II) Env. Liability Vol. 10, 2002, p. 68). 


\section{Joakim Zander}

EFTA Court have since been echoed by the ECJ in a number of more recent judgments under Articles 28 and 30 EC. ${ }^{256}$

The Court of First Instance in the Pfizer case scparated the triggering of a risk assessment from the triggering of precautionary measures. This corresponds to the systematic approach in the Communication on the Precautionary Principle. In order to trigger a risk assessment the requirements are rightly low. When the CFI turned to the question of what level needs to be shown in the scientific evaluation, it was satisfied with the fact that scientific uncertainty persisted in relevant aspects of the case. The degree and type of this uncertainty was not investigated by the Court. It also declined to turn the formal requirements of the Communication into binding casc law. The result of this reluctance on behalf of the Court indicates that the CFI is salisfied with the party wishing to invoke precautionary measures showing the existence of an uncertain risk. However, no thresholds or benchmarks have been established against which this can be measured and each situation is examined on a case-by-case basis.

The Community courts do not require a link to be established between the scientific cvidence presented and a particular risk. Instead, it is sufficient to show that an area is surrounded by scientific uncertainty. However, as discussed above in Chapter 2, complete certainty is unattainable, and scientific certainty, generally interpreted as corresponding to $95 \%$ certainty, is an extremely high level of proof to meet for a challenging party. ${ }^{257}$ The approach assumed by Community courts is in sharp contrast to how WTO Panels and the AB have approached the issue. Recognising that precautionary measures must be allowed, panels will investigate scientific evidence to establish a link between the scientific evidence and the risk. This link does not have to be certain, but it needs to be supported by "sufficient scientific evidence". 258

The approach taken by the European courts, particularly in the Pfizer case, has bcen rightly criticised by Karl-Heinz Ladeur along the same lines as outlined above. ${ }^{259}$ The primary problem resulting form the current case law is that the wide discretion for the

${ }^{256}$ Case C-192/01 Commission v Denmark, para. 54, Case C-24/00 Commission v France, paras. 59 and 60, and Case C-41/02 Commission v Netherlands, para. 69.

257 See Sections 2.3.1. \& 2.3.2

${ }^{258}$ See, above, Sections 3.3.2.4.\& 3.3.2.5.

${ }^{259}$ K.-H. Ladeur, The Introduction of the Precautioanry Principle into EU Law: A Pyrrhic Victory for Environmental and Public Health Law? Decision-making Under Conditions of Complexity in Multi-level Political Systems, 40 CMLR 6, 2003, p. 1455. 
Community institutions and the Member States in cases of uncertainty leads to situations in which decisions - in practice - become impossible to appeal successfully. As a function of this, the discretion of the Community institutions or the Member States becomes virtually boundless, and effective redress for affected parties becomes almost impossible. ${ }^{260}$

In some cases relating to Articles 28 and $30 \mathrm{EC}$, the courts may be beginning to recognise the dangers of too loose a requirement on scientific evidence, and too much influence of policy judgements on issues of risk regulation. In his Opinion in Commission v Netherlands, Advocate General Poiares Maduro held that the discretion afforded to Member States under Article 30 "as regards recourse to the precautionary principle is increasingly restricted the further they depart from scientific analysis and the more they rely on policy judgment". ${ }^{261}$ Unfortunately, this statement was not included in the final judgment of the court, which, nevertheless, concluded that the Netherlands had not provided "any scientific studies showing that any intake over the recommended daily allowance of any of the six nutrients in question, regardless of by how much, cntails a real risk for public health". ${ }^{262}$ The measures were, therefore, not considered to be justified by Article 30 EC.

Finally, it should be mentioned that, in Commission v Sweden, the CFI appears to have considered that, once a certain level of proof has been met, the Community institutions not only have the possibility of issuing precautionary measures, but also have an obligation to do so. In the case, which related to the authorisation of the pesticide paraquat under Directive 91/414/EC, the CFI investigated in detail the scientific evidence on which the relevant Commission Decision was based. In a surprising break with previous case law, the CFI held that the responsible scientific committee and the Commission had misinterpreted some of the scientific evidence. For example, it held that a Guatemalan field study whose results had been extrapolated to address the situation in the EU should have been interpreted to indicate that a more precautionary approach was warranted. ${ }^{263}$ In this case, the decision of the CFI appears to be based upon the fact that one person in the Guatemalan test showed test-results which exceeded the accepted exposure levels. The fact that the Guatemalan study had been considered by the Scientific Committee, and that the Scientific Committee had found it

${ }^{260}$ Ladeur's proposed "solution" to the problem includes formal requirements on the decision-maker, cost/benefit analyses, and priority-setting. These issues are all dealt with below in this text under the appropriate headings.

261 Opinion of the Advocate General delivered on 14 Scptember 2004 in Case C-41/02 Commission v Netherlands, para. 30.

262 Case C-41/02 Commission v Netherlands, para. 59

263 Case T-229/04 Sweden v Commission, paras 178-181. 


\section{Joakim Zander}

flawed due to the non-adherence of the test subjects to the relevant safety and hygiene provisions, did not convince the CFI. ${ }^{264}$ In a similar vein, the CFI reversed the interpretation of a French study of paraquat, which had also been considered by the Scientific Committec and the Commission. ${ }^{265}$ Furthermore, the CFI went on to establish that the Commission had not taken all the studies on the effect of paraquat in birds and hares into account, and that the substance did pose a significant risk to animals. ${ }^{266}$

The conclusion of Sweden v Commission is that the CFI found that, if a certain level of proof was met, the Commission must act in a precautionary manner. Interestingly, it appears that the CFI in the case is willing to review the scientific cvidence on which a decision to authorise a product is based in order to establish if such a level has been met.

\subsubsection{The Burden of Proof}

Generally, when Member States wish to maintain or introduce measures to protect the environment or health under Article $30 \mathrm{EC}$, the burden of proving the necessity of such measures rests with them. ${ }^{267}$ The fact that this is also the case in situations in which the precautionary principle is concerned has been confirmed by the ECJ in a number of recent cases. ${ }^{268}$ In the rulings of the ECJ, it is emphasised that "real risks" need to be demonstrated in the "light of the results of international scientific research". 269 Thus, Member States bear the initial burden to show that precautionary measures can be taken under Article $30 \mathrm{EC}$. However, as shown in the previous chapter, Member States do not need to show a definite link between the evidence and the risk; instcad, it is sufficient to show that the area in question is surrounded by scientific unccrtainty. The Community institutions will then evaluate the case brought by the Member State. Since a wide margin of discretion is left to the Member States in non-harmonised areas, it is rare that measures taken in cases of scientific uncertainty will be overturned.

264 Ibid., para. 180.

265 Ibid., para. 185.

2 t66 Ibid, para, 228-242.

267 See, for example, Case 227/82 van Bennekom, para. 40 and Case 178/84 Commission v Germany (Reinhieitsgebot) [1987] ECR 1227, para. 46, and the discussion in J. Scott \& E. Vos, The Juridification of Uncertainty: Observations on the Ambivalence of the Precautionary Principle within the EU and the WTO, 261.

${ }^{268}$ C-41/02 Commission v Netherlands, para. 47, Case C-192/01 and Commission v Denmark, para. 46 and Case C$24 / 00$, para. 53.

269 Ibid. 
In harmonised areas, Member States can scek to invoke the precautionary principle under safeguard clauses or Article 95 (4) and (5) EC. ${ }^{270}$ Here, too, it is the responsibility of the Member States to show that the measures that they wish to invoke meet the requirements laid down in the articles or relevant safeguard provisions included in legislative acts. ${ }^{271}$ Situations in which Member States wish to maintain measures under Article 95(4) are similar to situations of derogations under Article $30 \mathrm{EC} .^{272}$ It is likely that the European courts will show equal deference in judging on the merits situations concerning Article $95 \mathrm{EC}$ as they do under Article $30 \mathrm{EC}$, even though a substantial body of case law so far is lacking. On the other hand, situations in which Member States wish to introduce precautionary measures after harmonisation measures have been established arc likely to be scrutinised in more detail. This is due to the fact that the grounds on which Member States can rely are more limited under Article 95 (5), ${ }^{273}$ and, particularly, that Member States - according to the requirements in the article - have to support measures with "new scicntific evidence" which shows that the risk the Member State wishes to protect itself from is country-specific. In Austria v Commission, the CFI made it clear that it agreed with the Commission that the proof provided by the Member States would have to "cast doubt" on the assessment performed at EU level, and also state why the specific Member State in question would be more vulnerable to the risk in question. ${ }^{274}$ The reasoning indicates that, in order to invoke the precautionary principle under Article 95(5) EC, something more than scientific uncertainty would have to be shown by the Member States in order to derogate. This also appears to be the case when Member States wish to invoke safeguard clauses included in harmonising measures. In Monsanto, the court emphasised the temporary nature of safcguard measures and held that, in order to trigger them, Member States would have to provide "detailed grounds" indicating a "specific risk". 275

\footnotetext{
${ }^{270}$ For a discussion on the distinction between the different requirements in 95 (4) and (5), see ${ }^{270}$ Case C-3/00 Denmark v Commission ECR I-02643 and Case C-512/99 Germany v Commission, as well as the discussion of the cases in J. Zander, The Green Guarantee in Article 95 of the EC Treaty: Two recent cases, 16 Journal of Environmental Law 1, 65, 2004.

271 Case C-3/00 Denmark v Commission, para. 84, and Joined Cases T-366/03 and T-235/04 Austria v Commission, para. 63.

272 With the addition that Member States can rely on the grounds included in Article $30 \mathrm{EC}$, as well as on grounds relating to protection of the environment or working environment.

273 Only environment and working environment.

274 Joined Cases T-366/03 and T-235/04 Austria v Commission, paras. 65-68.

275 C-236/01, Monsanto Agricoltura, 108-110.
} 


\section{Joakim Zander}

As was shown above, the level of proof that the Community institutions require when invoking precautionary measures varies on a case by case basis. The court has concluded that broad discretion rests with the institutions not only when choosing measures, but also when deciding on when to invoke them. ${ }^{276}$ The ECJ and the CFI have, in several cases, held that, in cases of scientific uncertainty, they are not going to "second-guess" the actions of the other institutions. The requirement for invoking precautionary measures secms to stop at the prima facie existence of scientific uncertainty. The challenging party is then forced to end the scientific uncertainty and show the non-existence of the risk in order to avoid regulation. This is furthermore complicated by the reluctance of the Court to investigate the scientific evidence upon which the measures are based. That this is the case is supported in detail in the case law of the CFI.

A particular illustration of this interpretation can be found in the Pfizer case. Here, the CF1 cstablished that a low initial burden of proof lies with the party wishing to invoke precautionary measures. In order to fulfil this, the party needs to demonstrate the existence of a non-hypothetical risk in a field shrouded by uncertainty. ${ }^{277}$ Since the Court finds its own judicial review limited, it considers itself prohibited from investigating the matter on the merits of the scientific evidence upon which the measure is based. As discussed above, the Commission's scientific assessment in the Pfizer case was carried out by the SCAN. Even though recommending that precautionary measures were not necessary, it also stated that uncertainties with regard to the effects of Virginiamycin persisted. The Danish report, on which the Danish authorities relied, went on to emphasise the risks of Virginiamycin. These conclusions were refuted by the SCAN.

However, the ECJ considered the Danish report on virginiamycin to show sufficient risk, and the SCAN opinion to show sufficient uncertainty, for precautionary measures to be justified. When challenging these measures, the burden of proof was shifted onto Pfizer to show the non-existence of the risks suggested in the Danish report. The CFI indicated that the level of proof that Pfizer needed to meet was to "prove conclusively" the non-existence of the risk. ${ }^{278}$ It follows logically that the only way to prove something conclusively in the face of uncertainty is to end the scientific uncertainty. Only then does conclusive proof exist in one

276 See, above, Section 4.2.5.3.

277 Ibid. This is also supported in the Commission's Communication on the precautionary principle, p. 16.

${ }^{278}$ Casc T-13/99 Pfizer Animal Health SA v Council of the European Union, para. 392. 
direction or another. Pfizer had, earlier in the case, hcld that such an interpretation would lead to a situation of a probatio diabolica. ${ }^{279}$ Thus, it did not endeavour to end the scientific uncertainty, but rather to show that the scientific evidence brought forth by the Danish authorities was "very unlikely" to be correct and that other "plausible explanations" existed. ${ }^{280}$ This line of argument was based on the findings of the SCAN, and amounted to Pfizer arguing that its interpretation was more probable than that of both the Danish authorities and the Commission. However, this was not sufficient for the CFI.

Given the low levels of proof required by the CFI for the invoking of precautionary measures, and the reluctance of the Court to evaluate scientific data, the only possibility for Pfizer to show manifest error on the side of the Commission was to end the scientific uncertainty. This means that the burden of proof was shifted onto Pfizer, and the level of proof needed was raised to the impossible. ${ }^{281}$ Like SCAN pointed out, a full risk assessment of the effects of virginiamycin on human health was underway but it was time consuming. ${ }^{282}$ Thus it was impossible for Pfizer to rely on a full risk assessment at the time of the case and successfully challenge the decision of the Commission.

The above conclusions of the CFI created a situation of total discretion for the Commission when deciding on precautionary measures. The Court clearly declared that it will neither "assess the merits of either of the scientific points" nor "substitute its assessment for that of the Community institutions". ${ }^{283}$ But the CFI maintained that risk and uncertainty must be present for precautionary measures to be introduced. In order to establish this, a limited assessment on the merits of the scientific evidence must surely be performed? ${ }^{284}$

What, then, would be the difference if the CFI had increased the level of proof to requiring the Commission to makc a case for the existence of a probable link between the evidence and the measures? First of all, as shown above, the probability requirement was used by the ECJ in the BSE case and by the EFTA court so that it would not mean that the CFI was introducing an alien concept to the precautionary principle discussion. ${ }^{285}$ If the $\mathrm{CFI}$

279 Ibid., para. 130.

280 Ibid., para. 392.

281 See discussion on the impossibility of conclusive evidence above in Sections 2.3.1. \& 2.3.2.

${ }^{282}$ Opinion of the SCAN, final Conclusions II.

283 Case T-13/99 Pfizer Animal Health SA v. Council of the European Union, Note 393.

${ }^{284}$ For a discussion on the paradoxical use of scientific evidence in the Pfizer case, see M.B.A. van Asselt \& E, Vos, The Precautionary Principle and the Uncertainty Paradox.

${ }^{285}$ To which the CFI even alludes in para. 143 of Case T-13/99 Pfizer Animal Health SA v Council of the European Union. It would thus appear that it considers it at least of interest for the development of the law in this field. 


\section{Joakim Zander}

had, indeed, considered a requirement based on probability, it would have forced the Commission to reason why it had decided to disregard the SCAN Opinion and show that its alternative risk assessment somehow put the SCAN Opinion into question. In the case, the Communities' own risk assessment, as carried out by the scientific committce, severely discredited the Danish report. Nevertheless, the Danish report was interpreted as providing sufficient evidence for the Commission to invoke the measures.

One problem with a strict interpretation of the probability requirement is that, if it were to be made the standard, it might possibly hinder the effective use of the precautionary principle. In order to respond to situations of grave risks and sudden crises, it could be argued that a lower level of proof would be more appropriatc. Nevertheless, once the burden of proof had been shifted in the Pfizer case, it would have been more appropriate if Pfizer had been faced with the task of making its claim more probable, instcad of showing conclusively that the Commission was at fault. This would have forced the CFI to investigate scientific evidence in no greater in detail than it already does, but it would force the party wishing to invoke precautionary measures to focus on demonstrating a link between the evidence and the risk, rather than merely showing that the issue is surrounded by uncertainty. It is clear from case law stretching back as far as the Melkunie judgment that the ECJ already examines scientific evidence to establish the existence of risk and scientific uncertainty, regardless of its limited judicial review. ${ }^{286}$

As discussed extensively above in Chapter 2, the concept of scientific uncertainty probably covers the majority of situations. In fact, not many situations can be described as meeting the $95 \%$ certainty threshold generally accepted as scientific certainty. By allowing for any type of regulation in cases of uncertainty, regardless of the fact that a challenging party may show that different conclusions are more probable on the basis of the same scientific evidence, the parties are effectively hindered from successfully challenging measures affecting them.

${ }^{286}$ Case 97/83 Melkunie, para. 15 where the Court holds that: [...] it appears first of all from the documents before the court that the presencc of active coliform bacteria in a milk product means that the there is a risk of pathogenic micro-organisms being present and is therefore a direct indication that the product may be a source of real danger to human health." This conclusion could not have been reached without examining the scientific evidence ("the documents before the court"). For a more recent example, see the reasoning of the CFI in the Pfizer case largely accounted for above. 
A movement in the direction of decreasing the level of proof when challenging a precautionary measure from "showing conclusively" a fact, to making it more probable would be a step towards affording real judicial protection and adequale safeguards for parties affected by precautionary mcasures. It is also likely to decrease the risk of arbitrariness and inconsistency in the application of the precautionary principle which, despite the Commission's claims of the contrary, continue to tarnish the reputation of the principle.

Finally, it should be pointed out that, in cases where a challenging party does not manage to show that its interpretation of a set of facts is more probable, the measure suggested by the Community institutions should be upheld by the Courts.

\subsubsection{Cost/Benefit Analysis and Proportionality}

Having discussed what the Community judiciary requires for the triggering and invoking of precautionary measures, it is time to turn to what it requires from the measures per se. ${ }^{287}$

The Commission stresses in its Communication on the Precautionary Principle that precautionary mcasures should be proportional and based on a cost/benefit analysis. The proportionality requirement has a long history in the $\mathrm{EU},{ }^{288}$ and is often divided into two parts. ${ }^{289}$ The first part relates to whether a certain level of protection is proportional in relation to the risk it aims to avert, while the second part deals with whether the measure itself is proportional to the aim of ensuring the said level of protection. The Commission's Communication on the Precautionary Principle only deals with the second aspect of the proportionality principle, ${ }^{290}$ and the case law in relation to the precautionary principle has also been primarily concerned with considering cost/benefit analysis and the proportionality in relation to the actual measures, and not whether the aims of the measures are proportional in themselves. ${ }^{291}$ This has been justified by the fact that, as discussed above, the EU courts apply a limited review of measures enacted by the Community institutions using their discretion. If they were to deal with the first tenant of the principle of proportionality, they

${ }^{287}$ In this regard, see, also, N. de Sadeleer, The Precautionary Principle in European Community Health and Environmental Law: Sword or Shield for the Nordic Countries?, pp. 37-41.

288. It is also included in Article 5(3) of the EC Trcaty.

289 J. Jans, Proportionality Revisited, p. 239, and N. McNelis, EU Communication on the Precautionary Principle, Journal of International Economic Law (2000) p. 550.

290 N. McNelis, EU Communication on the Precautionary Principle, p. 550.

${ }^{291}$ For an in-depth discussion on the general devclopment of the principle of proportionality, see E. Ellis (ed), The Principle of Proportionality in the Laws of Europe, Oxford University Press 1999, and J. Jans, Proportionality Revisited. 
would effectively judge on the appropriateness of a particular level of protection, something they have tricd to avoid as far as possible. ${ }^{292}$

The reason behind making all trade-restrictive measures subject to a proportionality requirement is the importance afforded to the free movement of goods within the EU. Any limitations of that freedom have to be necessary. In order to determine whether measures are necessary to protect health or environment they must be balanced against the restraints that they impose on the free movement provisions. Some authors have claimed that a strict application of this reasoning by the ECJ would lead to free movement provisions always prevailing whenever they come into conflict with environmental and health concerns. ${ }^{293}$ However, an analysis of the case law of the ECJ does not support this assertion. ${ }^{294}$ Instead, Jans claims that it appears that the nature of the interest to be protected is relevant to how the Court determines the necessity of a measure. ${ }^{295}$ Since protection of health and the environment are considered to be essential objectives of the $\mathrm{EU}$, the Court is more inclined to look favourably upon restrictions imposed on the free movement based on these principles. Furthermore, when it comes to precautionary measures in the face of uncertainty, the test appears to be tilted in favour of the perceived risk.

Jans has identified three cumulative parts of the Court's assessment in relation to the proportionality of a measure: 1 . Is the measure suitable? 2 . Is the measure necessary? 3 . Is the measure proportional strictu sensu? ${ }^{296}$ With the third aspect, Jans refers to the balancing of interests between the positive and negative impacts of a disputed measure on intracommunity trade. Such an analysis, the Commission emphasises, is not to take purely economical considerations into account, but also non-cconomic concerns and the acceptability of a measure to the public should be taken considered. ${ }^{297}$ The Commission, however, seems to indicate in its Communication on the Precautionary Principle that the

${ }^{292}$ See for example the reasoning of the ECJ in Monsanto Agricoltura, where it states that it finds its performance a proportionality test confined to checking measures against ultra vires and manifest error. C-236-01 Monsanto Agricoltura, paras. 134-138.

293 L. Krämer, EC Environmental Law, (4th edition), Sweet and Maxwell, 2000. p. 78.

${ }^{294}$ See, for example, Case C-320/93 Ortscheit [1994] ECR I-5243 para. 16, in which the Court held that the health and life of humans rank foremost among the Article 36 (now Article 30) exemptions from the frce movement provisions. More recently, in Case T-13/99 Pfizer Animal Health SA v Council of the European Union, the CFI stated that the least health concerns always take precedence over cconomic concerns, which is also supported in the Communication on the precautionary principle. This would imply that the scales have tipped in the other direction.

295 J. Jans, Proportionality Revisited, p. 246.

${ }^{296}$ J. Jans, Proportionality Revisited, pp. 243-249.

${ }^{297} \mathrm{COM} / 2000 / 1$, p. 18-19. 
cost/benefit analysis is something that takes place outside of the proportionality test. ${ }^{298}$ It should be borne in mind that the proportionality principle is a complicated notion, and that the separation of its different aspects is an abstraction. This division often collapses in the practice of the ECJ, since the Court chooses to employ the division in some cases and disregards it in others. In the Pfizer case, the CFI loosely followed the structure advocated by Jans, in that it separated the "inappropriateness" of the measure", 299 "the duty to take other, less onerous, measures", 300 the comparison between the objective pursued and the right to property, ${ }^{301}$ and "errors in the cost benefit analysis". ${ }^{302}$ However in dealing with each subheading, the Court overlaps and continuously refers to the comparison of costs and benefits and the proportionality under every heading.

In addition, when the Court rules on the proportionality of precautionary measures, it also considers itself restricted by the limits it has imposed on its judicial review. ${ }^{303}$ Within this confinement, the Court has stated its intent to establish whether the measure introduced is the least onerous one available to the decision-maker. ${ }^{304}$ As already mentioned, the Court finds itself restricted to investigating whether the decision by the Community institutions is vitiated by a manifest error. ${ }^{305}$

In the Hi-Tech case, the ECJ hold that the fact that one product is singled out for regulation, while other products with similar risks attached to them are left unregulated, is not necessarily disproportionate. This is allowed if the function of the regulated product can bc carried out by "effective substitutes" and the functions of the similar products cannot. ${ }^{306}$ In a similar situation in the Toolex case, the Swedish authorities had left a system in place for the approval of the banned substance in cases where no other effective substitutes might be available. The ECJ considered this to be sufficient for the requirements of proportionality to be fulfilled. ${ }^{307}$ It has been pointed out that it is essential that such a system is open to judicial

${ }^{298}$ Ibid., p. 17, where it lists the "general principle" of "examination of the benefits and cots of action or lack of action" separately from the "general principle" of proportionality.

299 Case T-13/99 Pfizer Animal Health SA v Council of the European Union, para. 413.

300 Ibid., para. 440.

301 Ibid, para. 451.

${ }^{302}$ Ibid., para. 463.

303 See Case C-331/88 Fedesa, para. 14 and Case C-180/96 BSE, para 97.

304 Case C-331/88 Fedesa, para. 13.

${ }^{305}$ Case C-331/88 Fedesa. para. 14 and Case C-180/96 BSE, para. 97.

${ }^{306}$ Case C-341/95 C-341/95 Gianni Bettati v Safety Hi-Tech, para. 55.

307 Case C-473/98 Kemikalieinspektionen v Toolex, para. 47-48. 


\section{Joakim Zander}

review by national courts in order to be cffective. ${ }^{308}$ Furthermore, precautionary measures are allowed to be discriminatory towards one Member State, if it can be justified that the risk in question stems only from this particular Member State. ${ }^{309}$

In the Pfizer case, the CFI specifically turned its attention to the interpretation of the cost/benefit analysis mentioned in the Communication on the Precautionary Principle. The Court stated that it considered cost-benefit analysis to be a "particular expression of the principle of proportionality in cases involving risk management". ${ }^{310}$ As mentioned above, the Court, in contrast to the Commission, does not view the cost/benefit analysis as something independent from the proportionality requirement. It should be noted that one of the reasons for the Commission to stress that the use of cost/benefit analysis was to counter criticism from trading partners that claimed that the current use of the precautionary principle did not take cconomic concerns sufficiently into account. ${ }^{311}$ The inclusion of the cost/benefit requirement in the Communication on the Precautionary Principle may thus aim less at introducing a new legal concept and more at clarifying that the EU also intends to weigh the pros and cons included in risk regulation. The $\cos 1 /$ benefit analysis viewed in this fashion could be reminiscent of what Jans calls the proportionality principle strictu sensu. ${ }^{312}$ However, as shown above, the concept of cost/benefit analysis is usually understood to be a wider concept, which aims to estimate the general efficiency of a measure, rather than a mere measure of how certain regulation would have an impact on trade. ${ }^{313}$

If the intention of the Commission was to relieve some fears in relation to measures adopted under the auspices of the precautionary principle, the Court effectively undermined this in the Pfizer case. By declaring that health concerns always take precedence over economic concerns, the Court retorted to rather careless rhetoric. ${ }^{314}$ This statement by the CFI can be criticised on several grounds.

First, it is quite clear that, in practice, health concerns do not always take precedence over economic concerns. Society allows for a magnitude of high-risk activities that would be

\footnotetext{
308 J. Scott \& E. Vos, The juridification of Uncertainty: Observations on the Ambivalence of the Precautionary Principle within the EU and the WTO, p. 262.

309 Case C-180/96 BSE, para. 115.

${ }^{310}$ Case T-13/99 Pfizer Animal Health SA v. Council of the European Union, para. 410.

311 For a general discussion on cost/benefit analysis, sce, above, Section 2.4.2.2.

312 J. Jans, Proportionality Revisited.

${ }^{313}$ See, above, Section 2.4.2.2.

314 Case T-13/99 Pfizer Animal Health SA v Council of the European Union, paras 456 and 471.
} 
banned if only the health risks attached were considered, and not the benefits associated with them. ${ }^{315}$ For example, in his opinion on two cases relating to a ban of the Swedish tobacco product "snus" Advocate General Geelhoed pointed out that a total ban on smoking would be preferable from a health perspective. However, such a ban "would lead to unreasonable compliance costs" and the appearance of an "illegal market". 316 Clearly, the Advocate General was here alluding to cost/benefit considerations to justify the inaction on smoking with the high costs associated with strict regulation. In the following paragraph, however, he stated explicitly that:

"when it comes to products of small economic importance, [the Commission] can abstain from a difficult cost-benefit analysis and can restrict itself to an assessment of the health effects of the intended measure [...]."

Thus, he seems to imply that a cost-benefit analysis does not need to be performed where the costs associated with regulation are low. Despite this statement, the comparison of costs and benefits is absolutely central to his opinion. In its preliminary ruling, the ECJ did not discuss the issue of the comparison of costs and benefits, it merely considered that, in order to achieve a high level of protection, the Community institutions were acting within their discretion when banning the relevant product. ${ }^{318}$

Second, the question may be raised as to what the use of comparing costs and benefits actually is, if it is clear from the outset that one side will always prevail? The purpose of a cost/benefit analysis is generally understood to be an objective comparison of the pros and cons of the proposed regulation. It has been argued, even by critics of the precautionary principle, that cost/benefit analysis is a tool for the decision-maker to use in order to obtain a more complete picture of what is involved in a precautionary decision. The result of the analysis should not necessarily be applicd mechanically to decide upon the action to be taken. ${ }^{319}$ Instead, it can be used as a tool to allow the regulator to decide on the trade-offs he or she wishes to make, and act accordingly. ${ }^{320}$ Thus the cost/benefit analysis is conceived as

315 As way of example, activities such as driving, alcohol, cigarettes, and sports could be mentioned.

316 Opinion of the Advocate General delivered in Cases C-434/02 Arnold André GmbH \& Co. KG v Landrat des Kresies Herford [2004] ECR I-11825 and C-210/03 Swedish Match AB and Swedish Match AB UK Ltd v Secretary of State for Health [2004] ECR I-11893, para. 62.

317 Ibid., para. 63.

${ }^{318}$ Case C-210/03 Swedish Match AB and Swedish Match AB UK L.td v Secretary of State for Health, para. 56.

319 Sec, for example, C. Sunstein, Risk and Reason, Cambridge University Press 2002. pp. 104-105.

${ }^{320} \mathrm{Ibid}$. To illustrate the flaws of a purely mathematical application of weighing costs and benefits Sunstein uses 


\section{Joakim Zander}

an analytical tool, rather than as a tool to decide the outcome of a certain decision. In order for this analytical tool to be helpful to the decision-maker, it is of essence that the interests to be compared are alforded as real a value as possible, rather than weighted in one direction in order to provide the desired result. In affording health concerns absolute importance, the Court is unfortunately not depicting the complete reality of policy choices made in cither the EU or in the Member States. Resources in society are finite, and, in order to allocate them appropriately, some form of analysis of costs and benefits must be made. ${ }^{321}$ In the same vein, Sunstein has stated: "No sensible regulatory program [...] can be indifferent to cost.",322

In order to address these issues, the Commission has, since 2002, begun to place greater emphasis on the performance of impact assessments before issuing regulatory measures. ${ }^{323}$ It has since been emphasised that such analyses are a fundamental part of the Commission's better regulation agenda. ${ }^{324}$ In 2005 , the Commission published Guidelines for the Performance of Impact Assessments, which held that all items on the Commission's Work Programme, including regulatory proposals, White Papers, expenditure programmes and negotiating guidelines for international agreements should be preceded by impact assessments. ${ }^{325}$ The Guidelines include general considerations to be taken into account when determining the impact of the proposed regulation, but stop short of establishing a concrete system for comparing regulatory alternatives. ${ }^{326}$ They do, however, establish a set of basic questions, minimal analytical standards and a common reporting format, and also provide some guidance regarding how to carry out quantitative economic analyses, including discount

the example of the whether one would rather lose $20 \$$ right away or suffer the $1 \%$ possibility of losing $1980 \$$. Statistically the latter choice is somewhat "less bad" but most people would rather accept the limited certain loss than risking to lose a greater sum. If a binding cost/benefit analysis were applied the latter choice would be applied unequivocally.

${ }^{321}$ For a discussion on this, see, for example, J. Applegate, Worst Things First: Risk, Information, and Regulatory Structure in Toxic Substances Control, 9 Yale J, on Reg. 277, 1992, 294-295.

${ }^{322}$ C. Sunstein, After the Rights Revolution: Reconceiving the Regulatory State, Harvard University Press, 1990 , p. 90.

${ }^{323}$ Communication from the Commission on Impact Assessment, COM/2002/726, adopted 5 June 2002. For a discussion on the development of a impact analysis in the EU, see R. Lofstedt, The Swing of the Regulatory Pendulum in Europe: From Precautionary Principle to (Regulatory) Impact Analysis, Journal of Risk and Uncertainty, Vol, 28, Issue 2, 2004, pp. 237-260. See, also, R. Lofstedt, The Plateau-ing of the European Better Regulation Agenda: An analysis of Activitics Carried out by the Barroso Commission, Journal of Risk Research, Vol, 10, Issue 4, 2007, pp. 423-447.

${ }^{324}$ Communication from the Commission to the Council and the European Parliament, Better Regulation for Growth and Jobs in the European Union, COM (2005) 97 adopted 16 March 2005.

${ }^{325}$ Impact Assessment Guidelines, SEC/2005/791 adopted 15 June 2005, p. 6.

${ }^{326}$ For discussions and critique of the Commission's impact assessments, sec F. Chittenden, T. Ambler \& D. Xiao, Impact Assessment in the EU, in: S. Weatherill, Better Regulation, Hart Publishing, 2007, pp. 271-286, and A.C.M. Meuwese, Inter-institutionalising EU Impact Assessment, in: S. Weatherill, Better Regulation, Hart Publishing, 2007, pp. 287-309. 
rates and the value of a statistical life. ${ }^{327}$ Cost/benefit analysis and cost/effectiveness analysis are defined and briefly discussed in the annexes to the Guidelines. ${ }^{328}$ However, in the text of the Guidelines, multi-critcria analysis, which does not aim to monetize costs and benefits but merely to identify their existence, is highlighted. Cost/benefit and cost/cffectiveness analyses are presented as "alternative approaches". 329

Evaluations of EU impact assessments have frequently criticised the Commission for not taking adequate account of the costs and benefits of the regulation in question. ${ }^{330} \mathrm{~A}$ study of 111 EU impact assessments published in December 2007 found that impact assessments had become more informative since 2003, but that important information was still lacking. Primarily, this gap was considered to be due to an inadequate quantification of the benefits and various analytical assumptions. ${ }^{331}$

In conclusion, at least partly, the cost-benefit analysis as put forth by the Commission in the Communication on the Precautionary Principle and interpreted by the ECJ and the CFI seems to be a particular manifestation of the proportionality principle already in effect in European law. As such, it primarily addresses the proportionality of measures contra their effects on intra-community trade. Other interpretations of the concept of cost-benefit analysis are broader. They stress that the analysis is to be used as a tool to estimate the level of protection every unit of money buys. In doing so, each measure can be analysed and measured not only against its estimated effect on trade, but also against othcr measures in the same area and in related areas. ${ }^{332}$ Different risk reducing actions and strategics may then be constructed and ranked according to importance. Such an interpretation goes beyond what the Court seems to find in the proportionality principle. However, since 2002, the Commission has increasingly used Regulatory Impact Assessments (RIA) when elaborating regulatory policy. Most commentators appear to agree that more emphasis needs to be placed on the comparison of costs and benefits when such assessments are carricd out.

327 Annexes to Impact Assessment Guidelines, pp. 37-42.

${ }^{328}$ Ibid., 42.

${ }^{329} \mathrm{Ibid} ., 39$, and footnote 45.

${ }^{330}$ See, for example, Danish Environmental Assessment Institute, Getting Proportions Right: How far should the EU impact assessments go?, Environmental Assessment Institute, 2006, which found that quantification of data had only been properly carried out in 19 of the 58 impact assessment that had been studied. See also, A. Renda, Impact Assessment in the EU: State of the Art and the Art of the State, Center for European Policy Studies, 2006.

331 C. Cecot, R. Hahn, A. Renda \& L. Schrefler, An Evaluation of the Quality of Impact Assessment in the European Union with Lessons for the U.S. and the EU, AEI-Brookings Joint Center for Regulatory Studies, Working Paper, December 2007, p. 11-12.

332 See, above, Sections 2.4.2.2. \& 2.4.2.3. 
Joakim Zander

Furthermore, it appears that a challenge based on the inappropriateness of measures, an erroncous application of the proportionality principle, or a flawed cost/benefit analysis are likely to be as difficult to makc before the ECJ. When it comes to which measures to choose, the Court is also reluctant to criticise assessments made by the European institutions and the Member States using thcir discretion.

\subsubsection{The Targeting of Risks}

In this sub-section the attention is turned to the issue of how much leeway the Member States and the EU institutions enjoy when deciding on which risks to address. Society can never deal with all risks, so regulators incvitably have to make choices as to which risks to target, as well as how to target them. As has been stated repeatedly above, in the EU, Member States and the EU institutions enjoy considerable freedom to take decisions under scientific uncertainty. Generally, what the Member States are required to show in order to take precautionary measures in non-harmonised areas under Articles 28 and 30 is that the risk that they are addressing is surrounded by a degree of scientific uncertainty. Neither the European Commission nor the European Courts make any requirements on the Member States to target risks comprehensively or efficiently. ${ }^{333}$ One example of this is that the ECJ and the EFTA courts have consistently held that Member States are allowed to prohibit an uncertain risk in one set of products, without having to deal with the existence of the risk in other products, as long as they abide by the principle of proportionality. ${ }^{334}$ Thus, it appears that Member States are free to choose to target one source of a risk and leave other sources of the same risk unregulated.

With regard to the situation in harmonised areas, one case in which a Member State wished to maintain protective measures under Article 95(4) indicates that the European Commission and the ECJ will make higher demands on consistency in such situations. In Denmark $v$ Commission, Denmark wanted to maintain stricter measurcs in relation to

333 This is hardly remarkable when considering the limited role played by cost/benefit analyses and the principle of proportionality in areas surrounded by scientific uncertainty.

334 Case E-3/00 EFTA Surveillance Authority v Norway, para. 20; Case C-192/01 Commission v Denmark, para. 50; Case 41/02 Commission $v$ Netherlands, para. 50. In these cases the ECJ and the EFTA Court allowed for the considering of "cumulative effects" of the use of nutrients and vitamins when issuing precautionary measures under Articles 28 and 30. Thus, a nutrient or vitamin could generally bc allowed on the market of a Member State, but import of a specific type of product containing the nutrient or vitamin could be restricted if it is found that the total intake in the population would lead to uncertain risks. In Case 178/83 Commission v Germany (Reinheitsgebot), the ECJ stated that a total ban on additives in beer could not be considered to fulfil the requirement of proportionality under Article $36 \mathrm{EC}$ (now Article $30 \mathrm{EC}$ ) (paras. 44-53). 
sulphites than what the relevant EU legislation provided for. ${ }^{335}$ The Commission did not allow this derogation, since it considered that Denmark had not justified its wish to allow for sulphites in 16 out of the 61 areas provided for in the harmonising directive, and that the Danish measures would, therefore, be inconsistent. ${ }^{336}$ The Commission especially stressed the arbitrary nature of the Danish measures in relation to the fact that Denmark had taken no measures to address sulphites in wine, which appeared to be one of the major sources of sulphite intake in the Danish population. Denmark, instead, wished to address the risk of sulphites by restricting its use in other products. ${ }^{337}$ It thus appears that neither the European Commission nor the ECJ considered the "cumulative effect" doctrine that it had previously elaborated on under Article $30 \mathrm{EC}^{338}$ The situation in Denmark v Commission was similar to that of the Pfizer case, in which the Commission chose to combat one source of the risk of resistance to virginiamycin, but left another source unregulated. However, the results in the two cases were diametrical opposed. Moreover, the review of the ECJ is also different in Denmark v Commission in comparison to that of the CFI in the Pfizer case. Where the Court in Pfizer had hidden behind its limited judicial review, the ECJ actively condoned the Commission Decision in the Denmark v Commission case:

"[...] the presence of large amounts of sulphites in wine cannot justify, under the procedure laid down in Article 95(4) EC, a general prohibition on the use of sulphites as additives in foodstuffs. To the extent that an applicant Member State requests authorisation to maintain national provision derogating from Directive $95 / 2$ in respect of certain foodstuffs, it has the task of justifying those national provisions in relation to those foodstuffs, and not in relation to other products." 339

In relation to the actions of the EU institutions, the Community judicature has stressed that it considers its judicial review limited in such a way that it may not "second-guess" the relevant decision-maker when choosing to regulate risks. ${ }^{340}$ That this is the case when deciding upon whether to issue precautionary measures under scientific uncertainty was discussed in detail above in this chapter. As long as the regulatcd risk matches an objective

\footnotetext{
335 Case C-3/00 Denmark v Commission.

336 Case C-3/00 Denmark v Commission, para. 86.

${ }^{337}$ Case C-3/00 Denmark v Commission, paras. 89 and 90.

${ }^{338}$ See, above, footnote 329 .

339 Case C-3/00 Denmark v Commission, para. 89.

${ }^{340}$ Case T-13/99 Pfizer Animal Health SA v Council of the European Union, paras 169 and 323.
} 


\section{Joakim Zander}

found in the EC Treaty, the regulator is free to act, on condition that respect is maintained for other provisions provided for in the Treaty, notably the proportionality principle. ${ }^{341}$

In the Hi-Tech case, it was claimed by Hi-Tech Security that the Commission had chosen to consider only one of many aspects when it banned the product that the company manufactured. If the Commission had taken other ways in which similar substances posed a threat to the environment into account, it would have found that the use of other substances involved greater risks. ${ }^{342}$ Since the Commission chose to regulate one substance but left other, more dangerous, substances unregulated, the action did not aim to protect the environment as a whole, but to protect the cnvironment against onc particular substance, alone. ${ }^{343}$ The Court found this to be fully in line with Article 174 (130r) of the EC Treaty. ${ }^{344}$ The conclusion of the Hi-Tech case indicates that the ECJ focuses on what the Treaty enables the regulator to do, and not on the effectiveness of the measures introduced. If the aim is to protect the environment, the Court is not going to investigate whether the introduction of the measure does so in a coherent or effective manner. One could argue that such an interpretation is necessary to ensure that the political control of risk regulation remains with democratically accountable institutions. However, two other examples will show some serious problems with regard to consistency and arbitrariness, not to mention effectiveness, with such a system.

In the Pfizer case, the Commission revoked the authorisation of virginiamycin as a growth promoter on the basis that the use of the product risked leading to resistance in humans against antibiotics of the streptogramin class. ${ }^{345}$ Pfizer held that this measure was manifestly inappropriate in that it singled out viginiamycin as a growth promoter, where the real problem with resistance stems from the over-prescription of antibiotics in human medicine. ${ }^{346}$ Here, the Council decided to target a small risk, the existence and realisation of which was surrounded by a great amount of uncertainty. At the same time, it left the great and unambiguous risk of the over-prescription of antibiotics in human medicine untargeted. The Court also acknowledged this:

\footnotetext{
${ }^{341}$ Case C-341/95 Gianni Bettati v Safety Hi-Tech, para. 41.

${ }^{342}$ Ibid., para 38.

${ }^{343}$ Ibid., para, 39

${ }^{344}$ Ibid, para. 41.

${ }^{345}$ Council Regulation 2821/98 amending, with regard to the withdrawal of the authorisation of certain antibiotics, Directive 70/524/EEC concerning additives in feedingstuffs [1998] OJ L 351/4.

${ }^{346}$ Case T-13/99 Pfizer Animal Health SA v Council of the European Union, para. 414.
} 
"It appears from the documents before the Court that there is broad consensus among experts that this phenomenon is primarily caused by the excessive and inappropriate use of antibiotics in human medicine." 347

However, the Court did not find that this prevented the Council from issuing the debated measures. Instead, it held that the issuing of the ban of virginiamycin was one way of addressing the risk, and did not prevent the Council from taking "further measures", i.e., combating the over-prescription at a later date. ${ }^{348}$ It is interesting to note that this is a development since the Hi-Tech case. Where the Court, in Hi-Tech, held that the institutions are free to choose among several risks which to target, ${ }^{349}$ it held, in Pfizer, that, also among several sources of one risk, the institutions are free to decide which ones to address. ${ }^{350}$ Effectiveness with regard to lowcring the overall risk level is not an issue that needs to be taken into account. If it were, measures restricting a low, uncertain risk would not be enacted, while a scientifically ccrtain risk of a much greater magnitude was left unregulated. Later, the CFI further emphasised and clarified that it considered any such efficiency control to lie outside the scope of its judicial review:

"As regards the last aspect, the Court is empowered only to examine whether the opinion contains a statement of reasons from which it is possible to ascertain the considerations on which the opinion is based, and whether it establishes a comprehensible link between the medical and/or scientific findings and its conclusions." 351

Thus, the Court rests when the link has been established, and no comparison with similar situations will be allowed to influence the interpretation of the appropriateness of the measures.

It must be stressed that this development provides little in the way of consistency and opens the door to arbitrary regulations being passed without any possibility for judicial

347 Ibid., para. 34.

348 Ibid., para. 419

349 In the Hi Tech case, the ECJ allowed for the targeting of the substance based on its Ozone Depletion Potential (ODP). The Council did not have to take other risks common in several similar substances into account, i.e., Apmospheric Lifetime (ALT) or Global Warming Potential (GWP). If this had been done, Hi-Tech claimed, other substances would have posed a greater cumulative risk. See Case C-341/p5 para. 38 .

350 The risk stemming from virginiamycin and over-prescription of antibiotics is the same. Both may lead to resistance of streptogramin type antibiotics.

${ }^{351}$ Case T-74/00 Artegodan [2000] II-04945, para. 200. 


\section{Joakim Zander}

protection for the affected party. From a regulatory point of view, what the European institutions provide is far from effective risk regulation. If, in the Pfizer case, it had scriously intended to combat the very real and immediate risk of resistance in humans towards antibiotics, it should have aimed to regulate the "main offender", i.e., over-prescription in human medicine, instead of aiming for the easy target of growth promoters. ${ }^{352}$

Another issuc of great significance when using the precautionary principle to target a certain product or set of products is whether the proposed regulation does, in fact, lead to the emergence of other risks. When the precautionary principle is used to enable regulation under uncertainty, but its application does not require consideration of the overall risk level, some controversial results may emerge. As an example of this, it has been shown that the EU regulation of phthalates in children's toys led to the emergence of other substitute products, of which very little was known. ${ }^{353}$ Thus, the health benefits brought by the ban on phthalates were offset by the emergence of other health risks.

In summary, it appears that the Community institutions can target risks at will, and that the ECJ will not investigate the consistency or effectiveness of those measures. The same may be true for Member States that wish to invoke the Article $30 \mathrm{EC}$ exemptions. However, Member States who wish to derogate from harmonisation measures must show a consistent and effective risk policy and the ECJ will materially review these measures. On the face of it, such disparity seems difficult to reconcile with the requirement of a consistent application of the precautionary principle as advocated in the Commission's Communication on the Precautionary Principle. ${ }^{354}$

The rationale behind the stance of the Courts is, however, not difficult to understand, and has more to do with the politics of European integration than with effective risk regulation: derogations from harmonisation measures threaten the uniform application of the internal market and must be restrictively interpreted. ${ }^{355}$ The work of the European institutions, on the other hand, is often subjected to political considerations and sensitive compromises, which the judiciary does not wish to upset. Consequently, it limits its review in

${ }^{352}$ For a general discussion on the comparison of regulatory alternatives when issuing precautionary measures, see, above, Section 2.4.2.3.

${ }^{353}$ B. Duriodć, Plastic Panics: European risk regulation in the aftermath of BSE, in: J. Morris, Rethinking Risk and the Precautionary Principle, Butterworth-Heincmann, 2000, pp. 140-166.

${ }^{354} \mathrm{COM} / 2000 / 1$, p. 18.

${ }^{355}$ See, for example, Opinion of the Advocate General delivered on 30 May 2002 in Case C-3/00 Denmark v Commission para. 76 . 
these cases. However, these pragmatic concerns aside, consistency and efficiency in risk regulation should be a minimum requirement on the Member States as well as at EU lcvel.

In the Opinion by Advocate General Geeloed referred to above, the issue was raised of whether the Community was allowed to target certain tobacco products with a ban (in this case, the Swedish product "snus") while allowing the smoking of cigarettes. ${ }^{356}$ It appeared in the case that "snus" posed a lesser evil to smoking by a ratio of somewhere between 1 to 10 and 1 to $1,000 .^{357}$ Despite this, the Advocate General found that the banning of "snus", while leaving the more hazardous activity of smoking subject to less strict regulation, to be justified. The Advocate General motivated this with the fact that the economic costs of banning "snus" would be much less than banning smoking. He also referred to the long and ambitious European policy towards tobacco products in general and the fact that he believes that "snus" may work as a stepping stone towards smoking. ${ }^{358}$

In its preliminary ruling in Swedish Match $\mathrm{AB}$ and Swedish Match $\mathrm{AB}$ UK Ltd v Secretary of State for Health, the ECJ essentially upheld the reasoning of the Advocate General, and stated that, due to the fact that "snus" has properties detrimental to human health, the ban is justified. ${ }^{359}$ Thus, the Court agreed with the Advocate General that the Community institutions can choose to target one source of a risk, and are not obliged to assume a consistent policy towards the same risk stemming from different sources. Once again, the conclusion must be that, when targeting risks, the institutions are not bound to target them in an effective or comprehensive manner.

\subsection{Conclusions}

The purpose of this chapter has been two-fold. First, it has described the development of precautionary thinking and the precautionary principle in EC law. In the main, this is a story of the growing attention that environmental and health concerns received during the last decades of the Twentieth century, and especially since the mid-1970s until today. But it also makes it clear that precautionary considerations date back to a time long before the precautionary principle came into vogue. It has been shown that precaution was the basis for

${ }^{356}$ Opinion of the Advocate General delivered on 7 September 2004 in Cases C-434/02 Arnold André GmbH \& Co. KG v Landrat des Kresies Herford and C-210/03 Swedish Match AB and Swedish Match AB UK LId v Secretary of State for Health.

357 Ibid., para. 48.

358 Ibid., paras. 52,62 and 63.

359 Case C-210/03 Swedish Match AB and Swedish Match AB UK Ltd v Secretary of State for Health, paras. 52-58. 


\section{Joakim Zander}

regulation as far back as in the 1960 s, even though it was not mentioned explicitly. During the 1970s newfound environmental concerns meant that precaution began to be mentioned explicitly in Environmental Action Programmes and other instruments of soft law character. In the second half of the 1980s, sustainable development and the precautionary principle began to become concepts to be considered in legislative form. In 1992, the same year in which the Rio Declaration was agreed upon, the precautionary principle became a part of the EC Treaty. During the sccond half of the $1990 \mathrm{~s}$, the precautionary principle became a much used and hotly debated instrument in the wake of the BSE-crisis and other highly publicised food and health crises. Now, in the first decade of the twenty-first century, precaution seems to have matured into the precautionary principle and begs to be applied as a legal instrument.

This leads to the second, and more important, part of this chapter: What does the precautionary principle entail and how is it to be applied and challenged before the European courts? To investigate this issue, the attention was turned to the European Commission's Communication on the Precautionary Principle and to the case law before the ECJ and the CFI. Having found the Communication to be vague and without either a definition, or unequivocal guidelines for the practical use of the precautionary principle, the main attention was focussed on the case law.

The Courts, recognising the controversial nature of risk regulation at EU level, have largely applied a hands-off approach to cases relating to the precautionary principle. A lot of leeway has been granted to the Member States and the other European institutions when applying the principle. The definitions provided for in the BSE and the Greenpeace cases have been echoed by the Courts in subsequent case law. However, the two definitions differ on important issues. Whereas the BSE-definition merely establishes that Member States may take protective measures before the reality of risks are apparent, the Greenpeace-case holds that such matters must be provisional and backed up with "justifiable reasons". In limiting its judicial review to dealing with the form of a decision, rather than the substance of the same, the Court effectively prevents itself from providing more detailed definitions.

The ECJ and the CFI have consistently held in their case law that the precautionary principle is to be applied under uncertainty, provided that a "non-hypothetical" and "sciencebased" risk is present. This implies that a threshold of scientific evidence needs to be met in order to invoke precautionary measures. However, in practice the limited review carried out by the courts means that the party, Member State or EU institution, invoking the 
precautionary principle does not need to show a link betwcen the scientific evidence presented and the proposed risk. It is sufficient for the specific area to be surrounded by varying degrees of uncertainty. It appears that the Courts are at their most deferential in cases in which Member States invoke the precautionary principle under Article $30 \mathrm{EC}$ and when the EU institutions issue precautionary regulations using the powers which they have had delegated to themselves. The courts will make higher requirements on Member States which wish to derogate from existing harmonisation measures under safeguard proccdures and Article 95(5) EC.

Once the Court has established the existence of scientific uncertainty, the burden of proof is shifted onto the regulated party. Since the Court finds its judicial review limited to ruling on errors in form and manifest error, the level of proof needed to challenge the original decision is very high. In fact, the only way to show manifest error on the part of the regulator under conditions of uncertainty is to prove the regulator wrong by ending the uncertainty. In most cases involving deep uncertainty, this is not possible, and thus a successful challenge against precautionary measures often appears futile.

Since unequivocal rules for what level of scientific evidence is required for precautionary measures to be invoked are lacking, and the possibilities for an affected party to seek redress are severely limited, the Community institutions enjoy a near absolute discretion when issuing precautionary measures. The same is true for Member States acting under Article 30. The Courts have allowed for this by restricting their judicial review to an absolute minimum, instead of taking a more active role in evaluating the scientific evidence brought before it. Here, the European courts differ greatly from the deep review performed within the framework of WTO dispute settlement. In direct contrast to the above, the judgment of the CFI in Sweden v Commission entailed a detailed review of the scientific evidence underlying the decision to authorise the pesticide paraquat. Based on this assessment, the CFI overturned the decision of the Commission which had authorised the pesticide. It remains to be scen what the implications of the judgment are for the future of the judicial review of precautionary measures in the EU.

The European courts have also proved deferential in relation to the quality of the measures introduced. In the Commission Communication on the Precautionary Principle, it is established that cost/benefit analysis is to be an integral part of precautionary decisionmaking. However, this requirement is neither binding nor elaborated upon. In the case law, 


\section{Joakim Zander}

this requirement appears, for the most part, to be substituted by a traditional proportionality test. However, whereas the proportionality test aims to test the effects of regulation on intracommunity trade, a cost/benefit analysis is generally perceived as having a wider scope. In assigning values to all aspects of regulation, the total costs and benefits can be compared. This includes effects on trade, but the primary focus is on how many lives every monetary unit saves. If cost/benefit analysis were elaborated on and integrated into EC risk regulation, it would provide an invaluable tool for the decision-maker when deciding upon precautionary measures.

The same is true for risk trade-off analysis, which so far has not been elaborated upon at EC level. Every risk that is mitigated leads to the cmergence of other risks. Taking this into account when deciding on risk policies is essential and can help to avoid situations such as that which arose from the regulation of PVC plastics. ${ }^{360}$

Science, despite its shortcomings, remains the basis upon which precautionary legislation must be founded. Nothing except science can provide us with something which resembles objective information with regard to the nature of uncertain risks. In the Europcan legal order, the independence of science has been safeguarded by the separation of risk assessment and risk management. In order to maintain a systematic approach to risk regulation, such an approach must be maintained. Only then does it become clear what constitutes scientific considerations and what constitutes political considerations, and only then can regulatory regimes be understood and explained. In the EU, risk assessment is primarily carried out by scientific committees consisting of independent experts. The exact effects of their advice remain unclear. In the case law of the ECJ and the CFI, it appears that the Community institutions are not bound by their advice in the lcast, as long as they provide a very rudimentary reasoning in order to explain why they do not wish to follow the advice. Member States, on the other hand, can rely on the opinions of the scientific committees in order to avoid being bound by harmonisation measures.

In summary, the application of the precautionary principle as an independent legal instrument in the EU is still in its infancy. However, its development has so far been somewhat worrying; it is unclear what is required for the invoking of the principle, which, in turn, leads to a limited redress for regulated parties; the burden and level of proof are not

\footnotetext{
${ }^{360}$ B. Duriodé, Plastic Panics: European risk regulation in the aftermath of BSE.
} 
clearly defined, and the consequences of regulation are not appropriately considered. In order for the precautionary principle to be successfully used and justified on the international arena, it nceds to find its place in a more systematic framework. An improved and stricter model for Regulatory Impact Assessment needs to be established. Such a model should be built on risk assessment, cost/benefit analysis and risk tradc-off analysis. This will show the state of the risk and the consequences of regulation. This RIA can then be presented to the decisionmaker. In the decision-making phase, the general public should be involved and have full access to the results and methods behind the RIA. ${ }^{361}$ Only when such a systematic approach is in place can risk regulation in general, and the precautionary principle in particular, be successful and reach its aim of protecting the environment and the public from uncertain risks.

361 Sec, for example, R, Löfstedt, Risk Communication and Management in the Twenty-First Century, International Public Management Journal, Vol 7, Issue 3, 2004, pp. 335-346, in particular, at 340-341. 


\section{CHAPTER 5.}

\section{THE PRECAUTIONARY PRINCIPLE IN SWEDEN}

\subsection{The Development and Status of the Precautionary Principle in Sweden}

\subsubsection{Introduction}

Precautionary considerations have a long tradition in Sweden. Some commentators have traced a "precautionary principle" as far back as the 1940s in some areas of Swedish law.' Since the late $1960 \mathrm{~s}$, something resembling a modern precautionary principle guiding all environmental and health regulation has been in effect. Despite this, the precautionary principle, and risk regulation in general, has attracted little attention from scholars in the area. One reason for this is that nature and health protection is historically an uncontroversial issue in Sweden. The culture of spending free time in the forests and on the coast is very strong. The Nordic countries are the only ones in the world which sustain the concept of "allemansrätt", which means that everyone enjoys a total freedom of access to nature. The fact that Swedish decision-making is traditionally is consensus-based may also have been an influence. This is further emphasised by the unique political stability that Sweden has enjoyed. In the last 70 years, the social democratic party has been out of governmental power for a total of only ten years. This has enabled the government to pursue a steady and continuous dialogue with industry.

Even though the precautionary principle rarely functions as an individual legal principlc in Swedish law, but, instead, functions together with other legal norms, an attempt is made here to isolate the influence and the meaning of the principle. The same structure as was followed when discussing the precautionary principle in EC and WTO law is followed here. Thus, the constituent elements of the principle, such as its definition, the role of scientific evidence and judicial review, and the burden of proof are examined_ and discussed separately. Preparatory work to legislation is an important source of Swedish law and relevant parts are dealt with in detail. The scarce case law that exists has been identified and analysed. The case law analysis has been limited to its beginning in 1992, the year the precautionary principle became part of EC law. Sweden joined the then EC in 1995. Special

1 G. Michanck, Chapter 7: Sweden, in: N. de Sadcleer (ed), Implementing the Precautionary Principle: Approaches form the Nordic Countries, EU and USA, Earthscan 2007, p. 121. For an outline of earlier Swedish regulation of hazardous substances, see M. Karlsson, The Precautionary Principle, Swedish Chemicals Policy and Sustainable Development, Journal of Risk Research, Vol. 9, Issue 4, 2006, pp. 344-347. 


\title{
Joakim Zander
}

emphasis has been put on cases from the new system of environment courts. Finally, Swedish the vicws of legal commentators are accounted for and discussed.

\subsubsection{Background and Development}

Rudimentary precautionary reasoning in Swedish legislation has been traced back as far as the Swedish Water Code of $1941 .^{2}$ However, explicit reference to a "precautionary principle" as such was never made in Swedish law. Despite this, an essentially precautionary approach has guided all Swedish environmental and health regulation since the Swedish Environmental Protcction Act was introduced in $1969 .{ }^{3}$ Its Article 5 held:

\begin{abstract}
"Anyone who takes or intends to take an environmentally harmful action shall take the safety measures, accept the limits put on the enterprise, and observe the general precautionary measures that can reasonably be demanded to prevent or repair any detriment. The responsibility to remedy detriment remains also after the action has occurred.
\end{abstract}

The extent of the requirements, according to the first paragraph, is determined by the basis in what is technically feasible for an enterprise of the kind in question and with regard to public, as well as private, interests."

The wording of the article does not make reference to scientific uncertainty. However, Article 5 was, to a certain degree, elaborated on in the preparatory work to the Environmental Protection Code. ${ }^{5}$ It should be mentioned that preparatory work is an important source for the interpretation of Swedish law, second only to the actual text of the law. Both the courts and the administration make constant reference to the often very detailed reasoning found in Bills (Proposition (hereinafter referred to as Prop.)) presented to the Swedish Parliament and expert reports preceding Bills (Statliga Offentliga Utredningar (hereinafter referred to as SOU))..$^{6}$

2 G. Michanek, Att väga säkert och vikten av att säkra, in: E.M. Basse et al. (cds), Fågelperspektiv på rättsordningen: Vänbok till Staffan Westerlund, lustus Förlag 2002, p. 74 and note 23.

3 Miljöskyddslag (SFS 1969: 387).

4 "Den som utövar eller ämnar utöva miljöfarlig verskamhet skall vidtaga de skyddsåtgärder, tåla den begränsning av verksamheten och iakttaga de försiktgihetsmått I ovrigt som skäligen kan fordras för att förebygga eller avhjälpa olägenhet. Skyldigheten att avhjälpa olägnehter kvarstår även efter det att olägneheten upphört." Omfattningen av åligganden enligt första stycket bedöms med utgångspunkt $\mathrm{i}$ vad som är tekniskt möjligt vid versamhet av det slag som är i fråga och med beaktande av såväl allmänna som enskilda intressen. (Translation by author).

5 Proposition 1969: 28. Förslag till Miljoskyddslag, p. 210.

6 For an introduction to the sources of Swedish law, see B. Lehrberg, Praktisk juridisk metod, Iustus Förlag 2001. For a brief introduction to the jurisprudential foundation of the Swedish legal system, see G. MacCormack, 
The Minister of the Environment, who presented the Bill which proposed an Environmental Protcction Code to the Swedish Parliament, included the following rationale without explicitly mentioning precaution:

\begin{abstract}
"I consider it clear that uncertainty regarding the hazardousness of a substance shall not be to the detriment of the public at large, but should instead be to the detriment of the party emitting the substance into the air or into the water. This fundamental thesis is also of the utmost practical importance. It implies that one does not have to wait for damage to occur before action can be taken. It also implies that the party wishing to emit an insufficiently-known substance which one has a reasonable cause to presume to be harmful must be able to show that inconvenience does not need to be feared."7
\end{abstract}

In relation to how science should be taken into account when regulating risks, the Minister of the Environment only pointed out that all action should be based upon current scientific findings and the best technology available. ${ }^{8}$

On the face of it, Article 5, read in the light of the preparatory work, appears to be a manifestation of the strictest form of the precautionary principle. It lays the responsibility for all uncertainty relating to a substance squarely on the side of the party wishing to carry out an activity. It is sufficient that a "reasonable cause to presume" the realization of a risk exists for this to be the case. Furthermore, the realisation of the risk does not have to bring "harm" but rather "inconvenience". ${ }^{9}$ [ This implies that not only more or less quantifiable degrees of damage are considered, but also varying degrees of nuisance.

However, Michanek has pointed out that the Environmental Protection Act was created on the basic presumption that industry generally brings economic welfare. Thus, the rcigning opinion was that industrial activity should, in principle, be allowed and only major environmental or health disturbances should trigger prohibition. In practice, prohibition was

Scandinavian Realism, The Juridical Review, 1970, pp. 33-55.

7 Proposition 1969:28, p. 210. "Jag anser det natruligt att den osäkerhet som kan råda rörande ett ämnes farlighet inte skall gå ut over allmänheten utan bör drabba den som släpper ut ämnet I luften eller vattnet. Denna grundsats är ocksă av största praktiska betydelse. Den innebär att main inte behöver vänta med aett ingripande till dess skador har inträffăt. Den innebär också att den som vill släppa ut ett otillräckligt känt ämne som man har grundad anledning anta är skadligt måste kunna visa att olägenhet inte behöver befaras." (Translation by author).

8 Proposition 1969:28, p. 218 and 219.

9 The Swedish word "olägenhet" must be interpreted to be wider in scope than the word "skada" (harm). Compare with the wording of Chapter 9, Articlc 3 of the Swedish Environmental Code, which holds that an "olägenhet" for human health is anything that may pose a negative effect to human health that is not negligible or temporary. 
very rare and the precautionary approach was, instcad, used to minimise the effects of hazardous activities on nature and health. ${ }^{10}$ This is also emphasised by the Minister of the Environment in the preparatory work, wherc he stated that "all means" must be exhausted with the aim of avoiding inconvenicnce to industry while maintaining high protection. Examples of compromise-solutions include cleansing options for emissions, and the recycling of waste. If prohibition is the only remaining option, it has to be made effective after a timeperiod which allows the industry in question to adjust its production methods. "It was also emphasised that all production-methods, as well as the demands made by the government on industry, had to be based on the best available technology. In considering what this entailed, regard had to be given to what was economically feasible for an individual enterprise. ${ }^{12}$ This appears to have been something akin to an objective proportionality principle. The main focus does not scem to have been on the detriment that a certain activity may have caused as compared to the benefits it might have brought. Instead, it centred on the economic conditions of the individual party that wished to carry out an activity. If an enterprise was found to have economic difficulties when fulfilling an environmental norm, exemption from the norm could be granted. The apparent aim and result of this approach was that economically more successful undertakings were judged according to a stricter environmental and health standard than less successful undertakings. ${ }^{13}$

In addition to the proportionality requirement, a cost/benefit analysis was applied in certain individual cases. Where the costs associated with an enterprise abiding by binding environmental norms were excessively high and the benefits small or negligible, exemptions were sometimes granted. The discrepancy between costs and benefits in such cases had to be so great that it could not be considered "environmentally justifiable"14 to demand that the higher standard be abided by. ${ }^{15}$

The early version of the precautionary principle or approach in Swedish legislation certainly looks strict on paper. It is important to note that precaution is not singled out and

10 G. Michanek, Att väga säkert och vikten av att säkra, p. 74 and 75, and G. Michanek, Chapter 7: Sweden, p. 121-123.

11 Proposition 1969: 28, p. 216.

12 Ibid., p. 218.

13 G. Michanek, Att väga säkert och vikten av att säkra, pp. 75 and 76, and G. Michanek, Chapter 7: Sweden, p. 121-123.

14 "Miljömässigt motiverat." Translation by author.

is G. Michanek. Att väga säkert och vikten av att säkra, p. 76. For a more detailed analysis of this very limited practice, see S. Westerlund, Miljöskyddslagen: En analytisk lagkommentar, Åmyra Förlag, 1990, Section 7.21, and S.O. Svärd \& T. Rahm, Prövning enligt miljöskyddslagen, Gebers Förlag, 1975, p. 166. 
treated as a concept to be applied solely in cases of scientific uncertainty, which the "modern" version of the precautionary principle mandates. ${ }^{16}$ Instead, it appears to have developed as a wider concept which encompassed other aspects of risk regulation such as prevention. The strict statement of the Minister of Environment in the preparatory works was not upheld in practice, but appears to have served more as a policy than a legally-binding norm. It appears that the Swedish government wanted to retain the possibility of applying a strict precautionary approach but also of granting exemptions where it saw fit. The reluctance of the government to bind itself to a coherent and general application of the environmental norms in the Environmental Protection Code was emphasised by the Minister of the Environment in the preparatory work. For example, he explicitly rejected the laying down of legally-binding cmission-standards. Instead, he favoured a system of recommendations and individual permits, thus maintaining both flexibility in the system and the power in the hands of the Swedish government to decide in each individual case. ${ }^{17}$ The power of the government was further emphasised by the fact that the government itself was, in many cases, the highest authority to which administrative decisions could be appealed. ${ }^{18}$ This allowed for a limited influence of the courts in the interpretation of Swedish environmental law, and allowed the government an almost unlimitcd flexibility in applying the law.

\subsubsection{The Current Context and Definition of the Precautionary Principle}

In January of 1999, the Swedish Environmental Code came into force. ${ }^{19}$ The Code $^{20}$ is the first attempt to collect all Swedish environmental legislation into one law. Previously, environmental legislation was not systematically treated as one independent area of the law but, instead, environmental regulations were to be found in separate laws. Fundamental to all environmental laws was the Environment Protection Act discussed above, but more specific regulations were scattered across the legal system. Topical issues here, such as pesticide regulation and radiation protection, were found in unrelated laws. The result of this was that the environmental legislation became increasingly difficult to overview. The introduction of

16 For a discussion on the development of the precautionary principle in international law, see Sections 3.2.\& 3.3. For a discussion on the definition of the precautionary principle in EU law, see Section 4.2.5.2.

17 Proposition 1969: 28. p. 219.

18 This issue is discussed in more detail below in relation to judicial review; see Section 5.1.4.

19 Lag (1998: 808) om inforrande av miljöbalken, Article 1.

20 Miljlöbalken (1998: 808). 
the Environmental Code sought to respond to this issue by co-ordinating the legislation, but it also aimed to update, clarify and strengthen relevant parts of the legislation. ${ }^{21}$

The scope of the Environmental Code includes the protection of the environment as well as the protection of human health. ${ }^{22}$ Section 2 of the Code establishes the general rules and principles relating to the respect and protection of both the environment and human health. It is interesting to note that already Article 1 of Section 2 establishes that it is the party wishing to carry out an activity that has to show that the rules and principles are abided by. The onus of protecting the environment is thus put squarely on anyone performing an activity. $^{23}$

In Article 2:2, it is specified that anyone intending to carry out an activity must acquire the knowledge needed considering the nature of the activity. The precautionary principle finds its reflection in the successive Article. The first paragraph of Article 2:3 is virtually identical to Article 5 of the Environmental Protection Act referred to above. However, an effort to modernise the language ever so slightly has been made, and the fact that "best technology available" is to be used when professional activity is concerned has been mentioned explicitly in the text of the law. The first paragraph of Article 2:3 states in its present form:

"Persons who pursue an activity or take a measure, or intend to do so, shall implement protective measures, comply with restrictions and take any other precautions that are necessary in order to prevent, hinder or combat damage or detriment to human health or the environment as a result of the activity or measure. For the same reason, the best possible technology shall be used in connection with professional activities." 24

In the second paragraph, one sentence has becn added to emphasise that it is not just preventive measures that fall under the scope of the Article:

21 See Proposition 1997/98: 45 Miljöbalk, p. 1.

22 Miljöbalken (1998: 808), Article 1:1.

23 That this is an intentional construction aimed at reversing the burden of proof is emphasised in the preparatory works. See Proposition 1997/98: 45, p. 209 and 650.

24 "Alla som bedrivcr eller avser att bedriva en verksamhet eller vidta en åtgärd skall utföra de skyddsåtgärder, iaktta de begränsningar och vidta de försiktighetsmått i övrigt som behövs för att förebygga, hindra eller motverka att verksamheten eller åtgärden medför skada eller olägenhet för människors hälsa eller miljön. I samma syfle skall vid yrkesmässig verksamhet användas bästa möjliga teknik." Official English translation, available at: hetp://www.regeringen.se/conten $/ 1 / \mathrm{c} 4 / 13 / 48 / 385$ efl 2il.pdf. 
"Such precautions shall be taken as soon as there is cause to assume that an activity

or measure may cause damage or detriment to human health or the environment." 25

In the preparatory work, it is pointed out that the aim of this inclusion is to reflect the precautionary principle in the Code explicitly. ${ }^{26}$ However, when it comes to fleshing out the content and use of the principle, neither the Code nor the preparatory work offer much assistance. As mentioned briefly above, bills presented by the government to the Swedish Parliament provide not only the text of the law but also explanations and discussions on the purposes behind the legislation. In the case of Proposition 1997/98: 45, the discussion is divided into two parts. The first part is a general discussion on the purposes and principles behind the Environmental Codc. The second part is Article-specific, and introduces the text of the law followed by an explanation of each Article and how it is to relate to the previous legislation. In relation to Article 2:3, the government holds that the aim is to replace Article 5 of the Environmental Protection Act. ${ }^{27}$ In substance, few changes are intended, except the fact that the scope of the Environmental Code is wider than the scope of the Environmental Protection Act. ${ }^{28}$ Thus, the elaboration on precaution by the Minister of the Environment in the preparatory work to the Environmental Protection Code is still relevant. However, degrees of precautionary action have been introduced to correspond to the varying levels of harm that the different aclivities bring. In Article 2:9, it is stated that, if it is feared that an activity or measure may lead to "an injury or nuisance of significant importance" only the government can issue an authorisation, and only where there are "particular reasons" for the action to take place. If an activity or a measure risks leading to a situation in which "a large number of people" may see their "living conditions significantly altered," it may not be carried out at all. ${ }^{29}$ This is what is known as the "stop-rule". In the preparatory work, it is indicated that Article 2:9 can only come into play when the other rules in Chapter 2 are not sufficient. ${ }^{30}$ As examples of when the rule might be employed, the preparatory work offers

25 "Dessa försiktighetsmått skall vidtas så snart det finns skäl att anta att en verksamhet eller åtgärd kan medföra skada eller olägenhet för människors hälsa eller miljön." (Official English translation, available at httn://www.regeringen.se/content/1/c4/13/48/385efl2a.ndf).

26 Proposition 1997/98: 45, p. 656.

27 Ibid., p. 653.

28 This is of no particular relevance for the discussion here. The Environmental Protection Act regarded only hazardous activity stemming from the usc of the ground, buildings or constructions. In the Environmental Code the source of the disturbance is of no relevance. Thus, for example transports fall under the provision. See ibid., pp. 653-654.

29 Miljlöbalken, Article 2:9, para. 2.

30 Prop. 1997/1998: 45. p. 583. 


\section{Joakim Zander}

the building of new roads or the establishment of harbours as examples. ${ }^{31}$ This may indicate that the rule is primarily intended for large-scale projects of a planning nature. However, the preparatory work also holds that, when applying the principle, all other Chapter 2 rules must have been exhausted. Here, the substitution-principle (or product-choice-principle) is mentioned, which may indicate that hazardous substances may also be concerned. It should be borne in mind that a large number of people must be affected by the risk for it to be of any relcvance. What is clear is that, the greater the risk are perceived to be, the stricter the precautionary principle becomes in its application. It could be argued that precautionary action under Article 2:3 of the Environmental Code is aimed at mitigating risk, rather than prohibiting activities associated with it. This is supported by the indicative list of measures which may be considered by the regulator under Article $2: 3 .^{32}$ If this were the case, and no case law exists to draw the line between the two articles, it would mean that Article 2:3 lays down the basic "precaution requirement" in Swedish law and functions as a legal basis for setting precautionary standards for an otherwise allowed activity. ${ }^{33}$ In order to ban a product or an activity, the requirements of Article 2:9 would have to be fulfilled, i.e., an injury or nuisance of significant importance would have to be present. However, that the line is not so clear-cut is clarified in a reccnt case from the environmental appeals court, in which it was held that the "precautionary principle" allows the environmental appeals court to ban a practice that it finds to be in violation of the principle. ${ }^{34}$ Since Article $2: 3$, according to the preparatory work, embodies the precautionary principle in Swedish legislation, this implies that Article 2:3 is referred to. Instead, it has been held that Article 2:9 should be interpreted to encompass a definite burden for the proponent of an action to show that the action is without risk when the risk associated with the action is likely to cause significant damage or inconvenience to human health or the environment. If this burden is not met, and even if other protective and mitigating measures have been taken, the action may not be carried out. $^{35}$

The prccautionary principle is defined as a broad, individual responsibility to act with care. This includes the fact that it can enable prohibitive action as in EC law or under the SPS

31 Ihid., p. 665 .

32 Ibidl., p. 656 .

33 It is indicated in the preparatory works that a keyword for what would be allowed under this article is "best available technology." If it can be shown that the best available technology is being used, the activity should be allowed, unless the requirements for a ban under Article 2:9 are fulfilled. Ibid.

34 Judgment of the Environmental Appeals Court of 12 May 2005, case nr. M 3225-04, p. 9.

35 G. Michanck, Chapter 7: Sweden, p. 128-129. 
Agreement. However, it is not restricted to being used by the regulator in such instances, even though this is what will be focused on here. The notion of precaution is closely connected to other rules in Chapter 2, such as the knowledge requirement, the substitutionprinciple, and the principle of economising the use of natural resources.

\subsubsection{Judicial Review}

Since 1999, many decisions relating to human health and the environment have been appealed in a specialised court system. Instead of being brought before the general administrative courts, appeals are raised before a new category of environmental courts (Miljödomstolar). ${ }^{36}$ The environmental courts consist of at least one judge and one environmental expert. Complex cases may require an additional judge, an additional expert and up to two advisors with a background in regional issues, industry or the environment. ${ }^{37}$ The procedure in the environmental courts follows the general procedure in the administrative courts. ${ }^{38}$ In some cases, civil suits may be brought before the environmental courts. In such cases, rules relating to civil procedure are applicd. The composition of the court remains as described above.

Judgments from the environmental courts can be appealed to the Environmental Court of Appeal (Miljööverdomstolen). Svea Hovrätt, one of the regional appeals courts, hosts the Court. ${ }^{39}$ The composition of the Environmental Court of Appeal is made up of at least three judges and one environmental expert. ${ }^{40}$ The role of the environmental experts and advisors to the courts is to make a substantial review of complicated technical issues possible. ${ }^{41}$ That the environmental courts have an obligation to investigate the facts is stipulated in the Environmental Code. ${ }^{42}$ It has been pointed out in the preparatory works that this is to be interpreted as a "complete obligation" 43 to investigate the facts of a case. ${ }^{44}$ This follows the general Swedish rule in administrative court procedures. ${ }^{45}$ Based on this it could confidently

36 Miljöbalken, Article 20:3.

37 Ibid., Article 20:4 and 20:5

38 Ibid., Article 20:3

39 For an overview of the Swedish court system, see the publication The Swedish Judicial System - A Brief Presentation, published by the Swedish Ministry of Justice, available at: http://www.regeringen.se/content/1/c4/33/41/b05a8599.pdf.

40 Miljöbalken. Article 20:11.

41 Prop. 1997/98:45. p. 460

42 For the Environmental court see Miljöbalken Article 22:11 para. 2 and for the Environmental Appeals Court, see Article 23:4.

43 "Fullständig utredningsskyldighet."

44 Prop. 1997/98:45, p. 459.

45 Förvaltningsprocesslag $(1971: 291)$ Article 8. 


\section{Joakim Zander}

be argued that the scientific evidence on which a case is based should be analysed in detail by the Swedish environmental courts. Furthermore, this is underscored by the technical expertise included in the courts' composition. Judgments of the Environmental Court of Appeal relating to administrative decisions by regional governments or government authorities cannot be appealed further. ${ }^{46}$

Despitc the "state-of-the-art" Swedish environmental court system, some important decisions have been exempt from this procedure. Importantly for this research, decisions relating to the approval of pesticides, as well as planning decisions, have, until recently, been appealed against by the government or in the ordinary administrative courts, rather than in the new courts. ${ }^{47}$ With regard to pesticides, the appeal procedure was changed in 2006 , and decisions by the Swedish Chemicals Agency (Kemikalicinspektionen (hereinafter referred to as KemI)) are now subjected to appeal in the environmental courts. ${ }^{48}$ Planning permission, which is highly relevant for the regulation of base stations and is discussed in more detail in the following chapters, is still subject to appeal within the traditional administrative court system. ${ }^{49}$ Planning and zoning decisions are subject to more deferential review in accordance with Chapter 10 of the Local Government Act. ${ }^{50}$ The often highly political nature of planning and zoning rules means that local government enjoys wide discretion when taking such decisions, and appeals can only be made on the basis of procedural mistakes, ultra vires action on the part of the local government, or the illegality of the decision. ${ }^{51}$

The reason for maintaining, until recently, the Swedish government as the highest level of appeal for decisions by public authorities in rclation to, for example, pesticides, was that such decisions often entail sensitive political considerations and/or the exercise of powers within a certain margin of discretion afforded to a government authority. In such cases, it was not considered appropriate for courts to "second-guess" the decisions taken by essentially political bodies. ${ }^{52}$ This resembles the reasoning that the European Court of Justice

46 Miljöbalken, Article 23:8.

47 With regard to appeals of decisions by the Swedish Chemicals Agency relating to requests for approval of pesticides see Article 29, Förordning (1998:947) om bekämpningsmedel. Planning permission relating to base stations for mobile telephone systems are appealed through the traditional system of administrative courts; see Chapter 13 Plan- och Bygglag (1987:10).

48 Article 53, Förordning (2006:1010) om växtskyddsmedel, which refers to the environmental court procedure in Chapter 19 of Miljöbalken.

49 Plan- och Bygglag, Chapter 13, Article 2.

50 Plan-och Bygglag, Chapter 13, article 1, which refers to Kommunallagen (1991:900), Chapter 10.

51 J.e., what, in Sweden, is known as "rättsprövning".

52 Proposition 1987/88:69. pp. 23-25. 
(hereinafter referred to as "the ECJ") has brought forth in its case law. ${ }^{53}$ In the late $1980 \mathrm{~s}$, however, the possibility for a limited review of government decisions by the Supreme Administrativc Court was created. This review was limiled to instances in which citizens' rights or obligations were involved. ${ }^{54}$ In the preparatory works to the Act on the Judicial Review of Certain Administrative Decisions, it appears that Swedish courts may go further than the ECJ has allowed itself. ${ }^{55}$ Where the ECJ refrained from trying the facts on which basis a decision is based, the Swedish Supreme Administrative Court (Regeringsrätten) is explicitly authorized to review "the appraisal of the facts which is the foundation for application of regulation". ${ }^{56}$ Excluded from the judicial review are issues that are of a clearly political nature. But also in such cases the Swedish Constitution, Regeringsformen, stipulates, in Article 7:2, that decisions taken by the government must be prepared adequately, and can be overturned if they are shown not to have been. However, it appcars that the courts are content with a formal, rather than substantial, review of whether such adequate preparation can be said to have been carried out. ${ }^{57}$

In certain cases, the Supreme Administrative Court can refer an appealed decision back to the responsible authority for review. ${ }^{58}$ In relation to an appealed decision stemming from KemI, the Supreme Administrative Court made it clear that the Agency was bound to try the case again, and that it would have to review all the facts that the challenging party had brought forth. The review carried out by $\mathrm{Kcml}$ was not allowed to be restricted to considering whether the original decision was vitiated by a manifest error, ${ }^{59}$ but a full review on the merits needed to be carried out. ${ }^{60}$ In a case relating to the expansion of a power station in the north of Sweden, the Supreme Administrative Court also decided to overrule the decision that the Government had taken, based on a different interpretation of the facts of the case. ${ }^{61}$ However, in other cases, the Supreme Administrative Court has held that a delegation of

53 See, above, Section 4.2.5.3.

54 See Lag (1988:205) om rättsprövning av vissa förvaltningsbeslut

55 Even if the preparatory works relate directly to appeals to the Supreme Administrative Court, there is no reason to assume that what is stated there is not analogously applicable to other appeal courts. Nothing indicates that the judicial review by the RR should be construed as wider or narrower than the review of other courts.

56 Prop. 1987/88:69, p. 23. Translation by author.

57 See, for example, the judgment of the Supreme Administrative Court in RA 1999 Ref. 76 regarding the highly political decision of when and where to begin the termination of Swedish nuclear plants.

58 Förvaltningslag (1986:223) Article 27.

59 "Uppenbart oriktigt". Translation by author.

60 Judgment of the Supreme Administrative Court in case RA 1996 Ref. 51, p. 208.

61 Judgment of the Supreme Administrative Court in case RA 2004 Ref. 14. 


\section{Joakim Zander}

discretionary powers from government to another authority restricts its substantive judicial review. ${ }^{62}$

The Supreme Administrative Court has showed considerable restraint in reviewing measures and has failed to claborate on the scope and means of its review in cases in which wider appreciation of the facts has becn performed. Similar restraint has not necessarily hindered other courts. In one of several controversial cases relating to permitting the resumption of the construction of a tunnel in southern Sweden (Hallandsåsen), the relevant environmental court substantially reviewed and amended the initial decision of the relevant regional authority. ${ }^{63}$ Upon appeal, the Environmental Court of Appeal modified certain purely technical and construction methodological requirements that the environmental court had imposed. ${ }^{64}$ Thus, both courts showed a clear inclination to review the substance of a decision made by a government authority using its discretion. However, it does not seem to be an unequivocal rule that the environment courts make full use of their duty of investigation. In one case relating to the uncertain health risks posed by a wood burner in a populated area, the environmental court reversed the ban from the relevant government authority on the grounds that the scientific evidence had not been sufficiently substantiated. This was reversed by the Environmental Court of Appeal, which did not make any effort to resolve the scientific uncertainty. Instead, it held that any ambiguities in the scientific evidence should be to the detriment of the party wishing to carry out an action. ${ }^{65}$ In summary, it could be argued that Swedish courts have a relatively far-reaching possibility of performing a deep judicial review. However, in practice, it appears that the courts often let pragmatic considerations restrict them, and it appears that, in cases of uncertainty, they are inclined to place the responsibility for resolving uncertainties on the applicant, rather than seeking to resolve them. ${ }^{66}$

\subsubsection{Risk Assessment and Risk Management}

How scientific advice should be assessed, and the role that risk assessment should play in risk regulation is not generally established in Swedish law. However, a government report

62 See, for example, the judgments of the Supreme Administrative Court in cases R 1999 Ref. 76 p. $430 ; \mathrm{R} \AA$ 2001 not 6 and $R \AA 2003$ Ref 43.

63 Judgment of 14 February 2002 of the Environmental Court at Växjö Tingsrätt, Case nr. M [3/99.

64 MÖD 2003:100.

65 Mål nr. MÖD 2005:9.

66 In this regard, it should be emphasised that very few judgments exist in Sweden regarding the content and application of the precautionary principle. Thus, any conclusions on the basis of case law necessarily reflect this. See, also, G. Michanek, Chapter 7: Sweden, p. 133-134. 
stemming from 1993 holds that decisions relating to risks to human health or the environment are to be based on risk assessments. ${ }^{67}$ A strict separation between risk assessment and risk management is, nevertheless, not upheld. As a matter of fact, debate on the issue is nonexistent in preparatory work and legislation as well as in the case law and the literature. ${ }^{68}$

A system of strictly scientific bodies as found on the European level is lacking in Sweden. Assessment as well as management tasks are generally entrusted to government authoritics or agencies. The authorities relevant for this study are the National Radiation Protection Authority (Statens Strålskyddsinstitut (hercinafter referred to as "SSI") and $\mathrm{Kcml} .{ }^{69}$ In the internal workings of the institutes, the border between what are risk assessment choices and what are risk management choices appears to be blurred. In interviews at KemI, it transpired that most authorisation decisions were taken after ad hoc meetings between various civil servants in the agency. Since the burden of information is put squarely on the applicant, the independent investigation of KemI is limited. "Common sense" plays a big role in the decision-making. ${ }^{70}$ In an interview in the Ministry of the Environment, it transpired that it is the Minister of the Environment who decides when scientific research needs to be commissioned or evaluated by a committee. A lot of the day-to-day decisionmaking is based upon ad hoc contacts with industry and environmental organisations. ${ }^{71}$ Somewhat paradoxically, it was pointed out by representalives of $\mathrm{KemI}$ that upholding a clear separation between political decisions and scientific evaluation was essential. ${ }^{72}$

In cases of activities for which permits are needed, the requirement of risk assessment appears strict and based on the knowledge requirement in Article 2:2 of the Environmental Code. Thus, it is for the applicant to carry out the risk assessment. What needs to be shown is returned to below.

\subsubsection{Scientific Evidence and the Level of Proof}

It has been argued above that the precautionary principle in Swedish legislation is not exclusively an instrument that the regulator can make usc of when a certain set of

67 Miljöbalk - förslag till åtgärder för ett framtida miljöskyddsarbete, SOU 1993:27., p. 201

68 See, for example, G. Michanek, Chapter 7: Sweden, p. 133, who holds that risk assessment and risk management should function as separate phases, but does not elaborate on how this should be maintained in practice.

69 Their tasks, organisation and composition are laid down in Governant ordinances. See Förordning (1988:525) med instruktion för Kemikalieinspektionen and Förordning (2006: 524) med instruktion för Statens strålskyddsinstitut. This will be returned to in some more detail in relation to the case studies below.

70 Interview with officials at KemI, 2004-09-09.

71 Intervicw with official at the Swedish Ministry of Environment, 08 September 2004.

72 Interview with officials at, KemI, 2004-09-09. 


\section{Joakim Zander}

requirements has been met. Instead, it is a broad, overarching obligation that anyone ca out activities which may have an impact on the environment or on human health must by. However, in determining what constitutes a breach of the principle, the issues of a level an obligation to act in a precautionary manner ensues and what needs to be shc counter a demand for precautionary action needs to be discussed.

The issue of the levcl of proof required for precautionary action is not establis the Environmental Code or elaborated on in any detail in the preparatory work. Government Report, which is part of the preparatory work to the Environmental scientific uncertainty was rccognised, but only defined as a situation in which:

"[...] science as of yet has not reached the point where the connection between an action or activity and nuisance or damage to human health and environment can be proven, cven if a causal relationship can be assumed to exist.,73

As noted above, the Minister of the Environment held, in the preparatory work earlier version of the environmental legislation, that uncertainty should be to the detrim a proponent of an activity. ${ }^{74}$ In the preparatory works to the Hazardous Substances , 1973, it was acknowledged that some properties of chemicals are inherently uncertain can thus not be deemed appropriate that a manufacturer or importer of a chemical is for show "the complete absence of harm" ${ }^{\text {"75 }}$ in a product. ${ }^{76}$

Judgments that directly deal with the issue of level of proof in cases of scii evidence are lacking. However, in a recent judgement, the Swedish Supreme Court has that, in order to have standing before the court when challenging a hazardous activity, th associated with the activity cannot be allowed to be theoretical or entirely insignific Whether this only relates to the issue of legal standing in civil suits or whether it cor applied by analogy to other issues of risk is not clear.

Nothing in more recent legislation has been designed to counter the statement 1 Minister of Environment in 1973, but the interpretation of the Environmental Code ind

73 [...] där vetenskapen ännu inte har kommit så lângt att sambandet mellan en åtgärd eller verdsamb olägenheter eller skador på människors hälsa och miljön kan bevisas, även om ett orsassamband kar föreligga." SOU 1996:103 Del 1. Miljöbalken: En skärpt och samordnad miljölagstiftning för en utveckling. p. 239.

74 Proposition 1969: 28 .

75 "[...] fullstảndig frånvaro av skadlighet [...]." Translation by author.

76 Proposition 1973:17, p. 92.

77 NJA 2004 s. 590. 
The Precautionary Principle in Sweden

that a stricter view may be taken on the matter. Article 2:2 of the Environmental Code entails a knowledge requirement. It states that anyone carrying out an activity needs to acquire the relevant knowledge associated with the activity. The Article applies to anyone carrying out an activity that may have effects on the environment or on human health. However, it has been indicated in the preparatory work that industry might have a more extensive burden than individuals. ${ }^{78}$ That this Article functions together with the precautionary principle in Article $2: 3$ to create a general duty of care provision has been elaboratcd on by the Environmental Appeal Court in a few cases. ${ }^{79}$ In a case relating to the use of chemicals in the forest industry, the Environmental Appeal Court held that the Article, when read in the light of the precautionary principle, led to the conclusion that all chemicals that may pose any detriment to the environment or health should be kept in a register by the user?. If uncertainties pertain to the effects of the chemicals used, the undertaking using them is obliged, if necessary, to conduct its own laboratory experiments to establish the effects. ${ }^{80}$ This construction creates a situation in which it appears that the undertaking has something rescmbling strict liability for all chemicals that are not ancillary to its production. ${ }^{81}$ The level of proof needed to be met by the company is very high, considering that the chemicals at issue were legally imported or manufactured on the Swedish market. The recognition of scientific uncertainties emphasised in the preparatory works of 1973 are thus played down. ${ }^{82}$

In a more recent case from the Supreme Court, a limit of sorts to the knowledge requirement was elaborated. In the case, the Environmental Appeal Court had prescribed that the Swedish pharmaceuticals company Akzo Nobel could not use chemicals for which there is a lack of "documented knowledge concerning detriment for health and the environment based on poor biodegradability, chronic toxicity and potential for bioaccumulation" in its production. On appeal to the Supreme Court, Akzo Nobel argued that such conditions were impossible to fulfil, and that it would not be prudent to regulate matters of product choice in such a fashion. Furthermore, it claimed that the ruling of the Environmental Appeal Court

78 Prop. 1997/98:45. p. 210.

79 That the precautionary principle and the knowledge requirement are intrinsically connected are indicated in the SOU 1996:103, p. 239-241. The two requirements are here dealt with under the same heading.

80 See, for example, Judgment of 30 March 2005 of the Environmental Appeals Court in case nr. M 9408-03. pp. 10-11; and Judgment of 12 May 2005 of the Environmental appeals court in casc nr. M 3225-04 pp. 9-10.

81 Ibid. In Case nr. M 9408-03, the Environmental Appeal Court drew a line between chemicals which were to be used in the general production and chemicals of more ancillary or marginal use.

82 The database was probably required by the court in order to facilitate and enforce the use of the substitution principle, which requires an individual or undertaking to use a less hazardous substance if possible. 


\section{Joakim Zander}

would be in breach of Article 28 of the EC Treaty. In its judgment, the Supreme Court found that the requirements in Chapter 2 of the Environmental Code have, in general, been considered too vague to be coupled with penal sanctions. ${ }^{83}$ The conditions that the Environmental Appeal Court had established, i.e., "documented knowledge", the Supreme Court considered to be "lacking any precision" and stated that it would be impossible for the complainant to identify what and how the conditions should be met. It concluded that the conditions stipulated by the Environmental Appeal Court could not be upheld in their present shape, but it did not exclude that it could be changed to be sufficiently precise. ${ }^{84}$

In the literature, it has been pointed out that the guidance in Swedish legislation and case law relating to levels of proof in cases of scientific uncertainty is so scarce that it makes any conclusions hypothetical at best. ${ }^{85}$ Discussions in the literature have, instead, built on analogous reasoning built on civil or criminal procedure, ${ }^{86}$ or tort law. ${ }^{87}$

Nilsson quotes the preparatory works to the Hazardous Substance Act as the best definition of the precautionary principle in Swedish law. From this definition, she concludes that the level of proof required to trigger precautionary measures is that a "reasonably wellfounded suspicion" of a risk should be sufficient to trigger precautionary measures. ${ }^{88}$ Lindblom holds that the general rule in the Environmental Code is not that the regulator needs to show suspicion of risk, but rather that a party wishing to carry out an activity needs to show that the risk will not materialise. This indicates that the level of proof needed to be met by the regulator is low and the burden of the regulated party subsequently is high. ${ }^{89}$ This is returned to in the following chapter. Westerlund has held that it should never be the case that the regulator would have to show that a risk stemming from a chemical product is more than $50 \%$ probable..$^{90}$ In conclusion, there seems to be a general consensus among Swedish commentators that the level of proof needed to be met in order to trigger precautionary measures is generally low. This is also supported by the wording of Article 2:3 of the

83 Prop. 1997/98: 45, 524

84 Case number T2303-05, NJA 2006 s. 188.

85 A. Nilsson, Att byta ut kemikalier, Nerenius och Santerus 1997, p. 258.

86 P.H., Lindblom, Miljöprocess Del II, Iustus 2002.

87 B. Bengtsson, Miljöbalkens ăterverkningar, Norstedts 2001.

88 "[...] rimligt välgrundad misstanke [...]."A. Nilsson, Att byta ut kemikalier, p. 271.

89 P.H. Lindblom, Miljöprocess Del II, pp. 493-499.

90 S. Westerlund, Lag om kemiska produkter: Kommentar, CE Fritzes Förlag, 1985, p. 179. 
Environmental Code, where it is held that precautionary measures shall be taken on any occasion where there is "reason to presume" the existence of risk."

\subsubsection{The Burden of Proof}

As shown in the previous chapters, the application of the precautionary principle in international, WTO and EC law owe a lot to the definition in the Rio Declaration. The triple negative definition found there states that the lack of scientific evidence is not to mean that precautionary measures cannot be taken where there is a threat of a serious or irreversible naturc. This implies that the "normal" state is that an activity is allowed. Only when a suspicion of risk is raised may precautionary measures be taken. ${ }^{92}$ The burden of proof is then shifted, and the proponent of the activity has the onus to show that the risk will not materialise. It appears that, under this definition, precautionary measures are an option open to a regulator, rather than an obligation. ${ }^{93}$

The rules included in the Swedish Environmental Code appear, at first glance, to change the onus entirely onto the proponent of an activity. ${ }^{94}$ The applicant is obliged to consider precautionary measures before any activity is initiated. However, as was shown in the previous section, this obligation does not ensue until it is "presumable" that the proposed activity entails a risk. ${ }^{95}$ The effect of this is that, when the regulator exercises its power to judge on the admissibility or prohibit an activity or product, it must first show that the risk is presumable. Thus, the burden of proof is not initially reversed, but, instead, rests with the regulator. Once the "presumable-level" has been reached, the burden is shifted onto the proponent of the activity to show that concerns relating to the risk are unfounded. What looks like a strict obligation to take precautionary measures is, in practice, made contingent upon the meeting of a low level of proof on the part of the regulator. Thus, the "real", or initial, burden of proof lies with the regulator rather than with the proponent of the activity or product. $^{96}$

91 [...] skäl att anta [...]. The Swedish word "anta" [to presume] has the same basis as the word "antagligt" used as an adjective by Ekelöf.

92 For a discussion on the burden of proof under the WTO regime, see, above, Section 3.3.2.2, and, in EC law, above, in Section 4.3.3.

93 Even if it appears that the European Court of Justice has sidestepped this notion in the recent Case T-229/04 Sweden v Commission; Judgment of 11 July 2007, not yet reported. The issue is returned to below.

94 Miljöbalken Article 2:3, para. 1.

${ }^{5}$ Miljöbalken Article 2:3 para. 2.

96 This situation of a low level of proof on one side and which triggers a higher level on the other side may lead to the conciusion that the burden of proof rests with the regulated party form the outset. That this is not the case has been elaborated on by Ekelöf (P.O. Ekelöf, Rättegång IV). He has named situations such as this one as 
Joakim Zander

The issue that remains to be discussed is thus what actually needs to be shown by the proponent of an activity or a product, once the challenging party has fulfilled its burden of proof. The text of the law does not give any guidance with regard to the level of proof required after the initial burden of proof has been met. The preparatory work to the Environmental Code cites the preparatory works to the 1969 Environmental Protection Act. ${ }^{97}$ There it was stated that:

"[...] the party wishing to release an insufficiently known substance which one has founded reason to presume is hazardous must be able to show that detriment need not be feared." $" 98$

This wording re-establishes that the proponent of an activity has the burden of proof shifted onto it, once a "founded reason" has been established, and that it is not sufficient for it to show that the non-cxistence of the risk is as likely as the existence of the risk. The fact that it must be shown that the rcalisation of the risk "need not be feared" suggests that a higher level of proof must be met by the proponent of an activity or a product, once the burden of proof has been shifled. This is further emphasised by the preparatory work to the Chemicals Act of 1973. In relation to risks stemming from chemicals, it is held here that it must be shown:

"[...] as far as is possible based on the current state of scientific research that the suspicion is unfounded." 99

Nilsson sees two ways in which this requirement can be fulfilled: Either the original scientific method used can be discredited and another, more accurate, proposed, or it can be shown that the results proposed in the original research do not adequately depict reality. Thus, what needs to be shown here, according to Nilsson, is that the line of evidence presented by the regulator is flawed, not that a different set of scientific facts solves the

subjected to a "false burden of proof" on the side of the regulated party, whereas the real burden of proof actually needs to be fulfilled by the regulator. That the burden then is shifted onto the regulated party follows normal procedural rules. Once one party has fulfilled its burden of proof it is for the other party to prove this wrong. What makes the situation precarious is the marked difference in levels of proof required.

97 Proposition 1997/98:45. p. 209.

98 Proposition 1969:28. p. 210. "[...] den som vill släppa ut otillräckligt känt ämne som man har grundad anledning anta är skadligt måste kunna visa att olägenhet intc behöver befaras." Translation by author.

99 Proposition 1973:17, p. 97. "[...] så långt det pă vetenskapens nuvarande ståndpunkt är möjligt att misstanken är ogrundad." Translation by author. 
issue. ${ }^{100}$ It cannot be sufficient to show that other equally possible solutions exist. ${ }^{101}$ The fact that this notion is further cmphasised if the decision is taken by using the discretion bestowed upon a government authority has becn supported in some of the case law. ${ }^{102}$ The level of proof needed to be met by the party affected by precautionary regulation is then significant. However, it appears lower than in EC law, where a challenging party needs to show "manifest error" or the part of the regulator. ${ }^{103}$ Lindblom has pointed out that, once the burden of proof has been reversed, the required level of proof is likely to be more stringent in the new Environmental Code than in the previous legislation. ${ }^{104}$ Support for this is to be found in the preparatory work. ${ }^{105}$ He suggests that the level to be met now would be to prove or verify that a risk will not materialise. ${ }^{106}$

5.1.8. Cost/Benefit Analysis

According to Article 2:7 of the Environmental Code, Articles 2:2 to 2:6 are subject to a rcasonableness requirement, with special emphasis on costs and benefits. ${ }^{107}$ Thesc Articles include inter alia the knowledge requirement (Article 2:2), the precautionary principle (Article 2:3), the "best location" requirement (Article 2:4), the principle of economising (Article 2:5) and the substitution-principle (Article 2:6). The stop-rule in Article 2:9 of the Environmental Code is thus explicitly excluded from the scope of any cost/benefit considerations.

The aim of the article is to provide a safety valve for measures for which the environmental benefits do not correspond to the costs associated with them. ${ }^{108}$ The article does not establish a general cost-efficiency test for environmental regulation, nor does it

${ }^{100}$ A. Nilsson, Att byta ut kemikalier, p. 272. She here uses the term "eliminationsbevis," which means literally "elimination proof." What needs to be eliminated is the evidence brought forth by the other party.

101 Ibid.

102 See, for example, the judgment of the Supreme Administrative Court in R $\AA 1998$ ref, 56 relating to if a decision regarding the authorisation of herbicides by $\mathrm{Keml}$ was in conformity with $\mathrm{EC}$ law; and the judgment of the Supreme Administrative Court in RA 2003 not 43, where the issue of the spread of allergens from stables for horses to a neighbouring housing development was under scrutiny. Here, recommendations from the Swedish National Board of Health and Welfare were relied upon by the court, despite the fact that they lacked support in specific scientific evidence. Instead, the recommendations were based on analogous recommendations for smell, noise, flies, and other allergies. Older, as well as more recent, albeit inconclusive, scientific evidence found in reports by other government agencies and reputable researchers in the field advocating a less onerous policy were rejected by the court.

103 See discussion above in Section 4.3.3.

104 P.H., Lindblom, Miljöprocess Del II, note 86, p. 494.

105 Prop. 1997/98:45 Del 2. p. 454.

${ }^{106}$ P.H., Lindblom, Miljöprocess Del II, note 86, p. 494.

107 For a brief discussion on the cost/benefit balancing in the Environmental Code, see G. Michanek, Chapter 7: Sweden, p. 129-130.

108 Proposition1997/98:45. p. 231. 


\section{Jotakim Kande'r}

function as a tratitional proportinality test. Invtedad, it establishes that the costs incurred may nut be "unreasonahle" in relation to the emirenmental benefits. The article was intended to

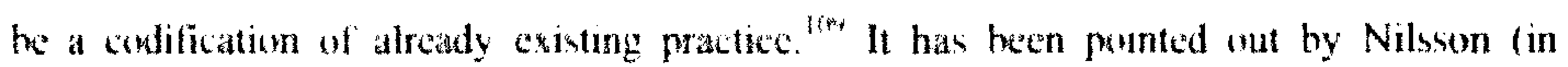
relation to chemical regulation that gudance as to how the weighing of interests is to be carried out is, in practec, tow scarce to allow tor almowt any comelustoms at all. ${ }^{\text {the }}$ This rings true also cutside of chemical regulatum. Two interestng points have, huwever, heen made by Bengtsen. lirst, what needs to he considered is whether a measure is "unreasonable"."11 This implies a higher level of profe than, for example, "anpropertional". Second, the burden of showing the unreasonahle nature of a measure rests with the party making the claim. ${ }^{12}$ The interests included in the balancing act out only include monelary values contra environmental benefits, but also general "societal interests". "In relation to the demand for best available technology in Article 2:3, the rewgning opinion is that it is "unreasonable" to dernand better techoolugy from an undertaking than is coconomically feasible. ${ }^{114}$

\subsubsection{The Targeting of Risks}

As shown above, the Swedish courts have often proved reluctant to "second-guess" government authorities when acting within a margin of discretion. This makes the issue of challenging a decision upon the basis that it does not follow a rational prioritisation of risks difficult. since the decision of which risks to target is eminently a political one. ${ }^{1 \text { s }}$

However, in 1999, the Swedish Parliament ratified a Bill which laid down 15 environmental quality objectives designed to ensure sustainable development. ${ }^{116}$ A Council for co-ordinating, following up, and informing the public about the environmental quality objectives was established. It maintains a website on which the various ministries and authorities responsible for the different objectives continuously report their progress and the problems they experience in fulfilling the objectives. ${ }^{117}$ In April of 2001, the Swedish Parliament ratified a Bill laying down 71 concrete partial goals, or benchmarks, and time-

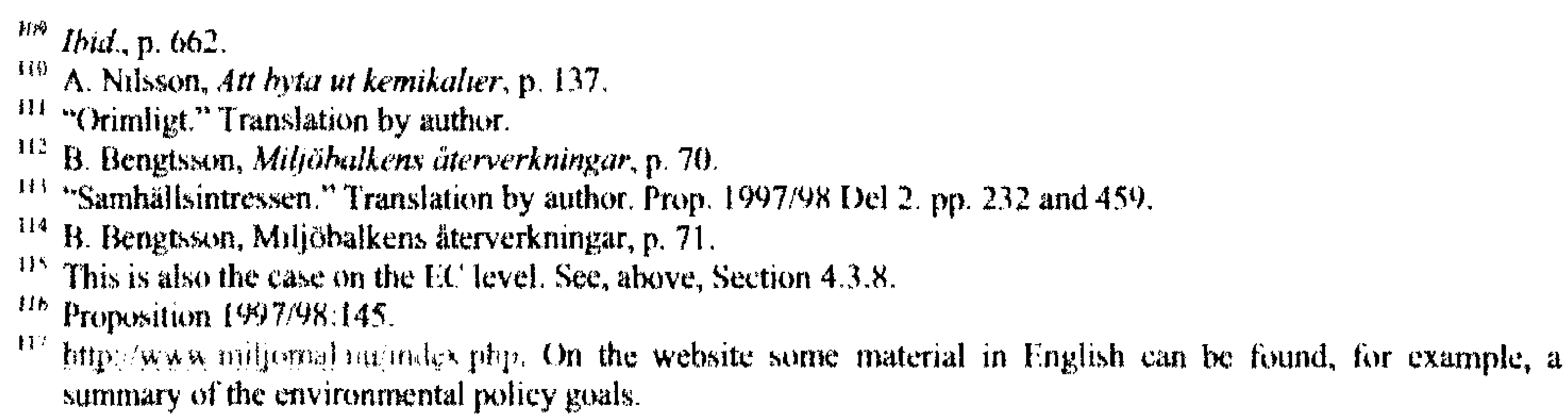


frames for the realisation of the objectives. ${ }^{118}$ The environmental quality objectives are of a policy character, but provide an intercsting insight into the transparent targeting of risks employed by the Swedish government. However, it should be borne in mind that the environmental quality objectives were not chosen upon the basis of a regulatory impact assessment, or upon the basis of any other cost-efficiency modelling, but are political in nature. They also treat risks in absolute, rather than in relative terms. Thus, all the identified risks to human health or the environment should be treated simultaneously, and are not ranked in order of priority.

Of prime interest for this study are objectives Number 4. "A Non-Toxic Environment", and Number 6. "A Safe Radiation Environment". As stated above, the environmental quality objectives are not ranked from 1 to 15 , but are, instead, to be fulfilled simultaneously within one generation. ${ }^{119}$ The benchmarks established to enable each objective to be fulfilled are supposed to guide Swedish legislation, assist in the interpretation of the existing legislation, and function as guidelines for Swedish negotiations in the international arena. ${ }^{120}$ In summary, the environmental quality objectives show a clear, and, in some cases, very detailed, agenda for the targeting of risks in Sweden. The specific goals of the reduction of chemicals and radiation protection will be discussed in detail bclow.

\subsubsection{Conclusion}

The precautionary principle has developed in Sweden in a relatively unchallenged manner. Instead of being singled out as an independent legal principle, it functions together with other legal norms, such as the principle of preventive action, the requirement to economise on the use of natural resources, and the "knowledge-requirement", to create, in many cases, a broad duty of care. However, it is possible to identify instances in which Article 2:3 of the Environmental Code has been instrumental in bringing about decisions based on strictly precautionary considerations.

The precautionary principle in Sweden is a broad and individual requirement directed to all citizens in order to act in a precautionary manner. It is not presented as just a tool to be used by the regulator in cases of uncerlainty. The principle works together with, and inspires, the other norms in Chapter 2 of the Environmental Code. The result of the broad scope of the

\footnotetext{
118 Proposition 2000/01:130.

119 Proposition 1997/98:145 Part 3. p. 4.

${ }^{120}$ Proposition 2000/01:130. p. 16.
} 
principle is that, in many cases, it can be viewed more as a general duty of care than the precautionary principle that has been previously discussed at International and European levels.

Even though the judicial review of government decisions in Sweden appears broader than in EC law when considering the reasoning in the preparatory work, courts have often proven reluctant to review substantially decisions taken by agencies and the government using their discretions. However, the new environment courts appear to be more inclined to perform more detailed reviews of scientific evidence. In several cases, they have based their judgments on a very detailed scientific analysis of evidence put before them.

Sweden does not conduct a clear separation of risk assessment and risk management. In cases in which agencies have had decision-making powers delegated to them, the scicntific analyses and the management decisions are often taken by the same peoplc. "Common sense" plays a major role in the decision-making. The applicant must, in most cases, carry out the scientific assessment. When the government needs general scientific advice, reports arc commissioned on an ad hoc basis.

The presumption in Swedish law appears, at first, to be that it is the party carrying out an activity or manufacturing a product that has the burden to show the absence of risk. However, this is a "false" burden of proof. When issuing a precautionary measure, the initial burden of proof actually rests with the regulator. The level of proof required is low. Some support exists for the notion that it must be based on scientific evidence and not be theoretical. The text of the law, in the light of preparatory work, case law and commentators, seems to put the level needed at "presumable". Once this low level of proof has been met by the regulator, it shifts on to the party facing regulation, and is subsequently high. Commentators have held that what is required is to disprove the chain of evidence provided by the regulator, rather than proving the activity or product to be safe. This seems to lead to a situation in which the level of proof required is slightly lower than that required by the ECJ. It probably rests at "proven, verified". However, guidance on this issue from the $/ 0$ preparatory work, as well as the case law and the literature, is scarcc at best. Future research in this area should centre upon investigating the basis of government decisions and judgments from lower courts.

According to Article 2:7 of the Environmental Code, measures issued must be "reasonable". The article seems to encompass what courts previously referred to as the 
requirement that measures must be "environmentally justifiable", as wcll as some form of proportionality requirement. The term "environmentally justifiable" was as a form of cost/benefit requirement aimed at hindering measures to improve the environment when the benefits were so small that they could not justify the great costs associated with them. It is important to note that this was not developed as a traditional cost-efficiency requirement, but was, instead, used to prevent cases of extreme differences between costs and benefits. The reasonableness requirement is also not based on cost-efficiency reasoning. Instead, it appears to be aimed at focussing on the regulated party and its economic ability to sustain the regulation in question. Thus, economically successful undertakings have been deemed to be able to accept stricter regulation than weaker ones. Once again, it has been pointcd out by commentators that information regarding how this balancing is carried out by courts is, in practice, generally lacking.

Swedish policy on the environment and human health regulation is laid down in 15 broad environmental quality objectives which arc to be reached within one generation. These are, in turn, divided into partial goals, which have been given deadlines for completion. This system provides for a broad, but relatively detailed, system of communicating which risks will be targeted. This prioritisation is not based on rational concepts, such as risk assessment and cost/benefit analysis, but appears strictly political in nature.

\subsection{The Application of the Precautionary Principle in Swedish Pesticide REgulation}

\subsubsection{Introduction}

The Swedish version of the precautionary principle is wide in scope and often strict in application. In the previous chapter, it was discussed how the principle has come to be defined in the law, in the preparatory work, and in the case law. It was concluded that the concept of precautionary action is firmly integrated in the Swedish legal system, but that it is difficult to establish with any degree of authority when and how a strict version of the principle will be applied. This is largely due to the lack of discussion on decisions taken under conditions of uncertainty by the legislator, as well as in the case law and the literature.

The aim of this chapter is to narrow the focus and centre on how the principle influences the regulation of pesticides. Sweden has a long history of low tolerance towards chemicals, and, in recent years, this has culminated in the policy goal: "A Non-Toxic environment". The explicit aim of this policy is to eradicate all man-made toxic substances 


\section{Joakim Zander}

from the environment by the ycar 2020. The inherent uncertainty associated with chemicals has been stated as the basis for this radical policy. Thus, it appears that the Swedish regulatory aim in relation to chemicals is precautionary in the extreme, since it docs not distinguish between substances with which real risks are associated, but, instead, aims at banning a whole category of products, regardless of the actual risks associated with them under normal use. However, the precautionary principle in the area of chemicals is far from limited to influencing policy. It also functions as a legal concept in its own right, and is then closely-connected to the principle of substitution. In this chapter, the different parts of the precautionary principle are analysed and discussed in relation to how they have becn applied in the area of pesticide regulation. The issues touched upon include the structure and independence of the relevant government agency, how risks are assessed, the levcl and burden of proof, and cost/benefit analysis.

Since pesticide regulation today is largely carried out at EU level, the radical Swedish approach is compared with the relevant EU legislation. The discrepancies between the two levels are highlighted, and the problems that Sweden will encounter if it wishes to maintain its highly precautionary approach to pesticides are discussed. As an example, the regulation of the pesticide paraquat in Sweden and the EU is mentioned. This issue is particularly interesting since it shines the light on some of the conflicts that different approaches to the precautionary principle can lead to at European and international levels.

\subsubsection{The Legal Framework}

In 1962, the first comprehensive regulation of chemicals was introduced into Sweden with the Chemicals Act. The same year, a new decree on pesticides was established. ${ }^{121}$ Interestingly, the Pesticides Decree only affected chemical products and not biological ones. ${ }^{122}$ For chemical pesticides, a general approval scheme was established and KemI was appointed the relevant authority to which requests for authorisation were to be made. ${ }^{123}$ Biological pesticides, on the other hand, were not originally subjected to a general authorisation scheme. Instead, they were allowed on the market unless they were in breach of any of the general provisions in the Environmental Protection Code. ${ }^{124}$ It was not until 1992, and the Biological Pesticide Authorisation Act, that the scope was widened to include also

\footnotetext{
${ }^{121}$ Förordning (1985:836).om bekämpningsmedel (SFS 1985:836). For a summary of earlier Swedish chemicals policy, see M. Karlsson, The Precautionary Principle, Swedish Chemicals Policy and Sustainable Development. ${ }^{22}$ Ibid., Article 1

${ }^{123}$ Ibid., Article 3.

${ }^{124}$ Miljlöskyddslagen (1969:387).
} 
the pre-authorisation of biological pesticides. ${ }^{125}$ It is interesting to note that the stricter measures here were originally taken towards what were considered man-made substances, rather than against "natural" substances, despite the fact that there is nothing to suggcst that a chemical substance is intrinsically more hazardous than a naturally occurring substance. ${ }^{126}$

The division between biological and chemical pesticides was maintained when the Environmental Code (Miljöbalken) ${ }^{127}$ was issued in $1998 .{ }^{128}$ However, since the entry of Sweden to the EU, pesticides have been subject to the authorisation regime laid down in Directive 91/414/EC, which does not distinguish between the two types. ${ }^{129}$ The fact that all types of pesticides, chemical as well as biological, need to be authorised by either another EU country or $\mathrm{Keml}$ is also made clear in Article 14:13 of the Environmental Code.

The procedure for the authorisation of pesticides is established in Chapter 14:14 of the Environmental Code, and fleshed out in Directive 91/414/EC and the updated Decree on Plant Protection Products. ${ }^{130}$ Directive 91/414/EC subjects the authorisation of active substances in pesticides to a comitology procedure in accordance with Council Decision 1999/468. ${ }^{131}$ The application for the authorisation of a pesticide on the Swedish market is to be made to $\mathrm{KcmI}$ as mentioned above. ${ }^{132}$ Provided that the provisions in Article 4 of Directive 91/414/EC arc fulfilled, the request can be granted. In short, this means that the product's active substances must be listed in Annex I to the Directive, that the product is sufficiently effective, and that it does not cause unnecessary suffering to animals or has unacceptable harmful effects on human or animal health or on the environment. Furthermore, the physical and chemical properties of the product have to have been establishcd and

${ }^{125}$ Lag (1991:639) om förhandsgranskning av biologiska bekämpningsmedel.

126 Sunstein refers to the common mistake of believing man-made substances to be more hazardous than naturally occurring ones as a symptom of loss aversion. See C. Sunstein, Laws of Fear: Beyond the Precautionary Principle, Cambridge University Press, 2004, 44. See, also, P. Rozin, Technological Stigma: Some Perspectives from the Study of Contagion, in: J. Flynn, P Slovic \& H. Kunverther (eds), Risk, Media, and Stigma: Understainding Public Challenges to Modern Science and Technology, Earthscan, 2001, p. 38. Rozin holds that, on the whole, more lives are lost to naturally occurring disasters than to man-made ones.

127 Miljöbalken (1998:808).

${ }^{128}$ The term "chemical pesticide" is defined in Article 5 of the Environmental Code and the tcrm "biological pesticide" in Article 6.

129 For a discussion on the relationship between Swedish and EU legislation in the area of chemicals, see A. Nilsson, The Precautionary Principle in Swedish Chemicals Law and Policy, in: N. de Sadeleer, Implementing the Precautionary Principle: Approaches from the Nordic Countries, EU and USA, Earthscan 2007, pp. 295313.

130 Förordning (2006:1010) om växtskyddsmedel.

131 Council Decision 1999/468 of 28 June 1999 laying down the procedures for the exercise of implemeting powers conferred on the Commission. OJ L 184, p. 23. 17/07/1999. As referred to in ibid., Article 19.

132 Chapter 14: 13 of the Environmental Code and Article 4 of the Förordning $(2006 ; 1010)$ om växtskyddsmedel. 


\section{Joakim Zander}

considered appropriate for the intended use. The product cannot be authorised until maximum residue levels have been provisionally established by Keml and notified to the Commission. Once this has been done, EU-wide maximum residue limits are established using the regulatory committee procedure provided for in Article 19 of the Directive.

In situations in which a pesticide is introduced onto the Swedish market and has already been authorised in another Member State, the principle of mutual recognition comes into effect. ${ }^{133}$ Sweden, or any other country, cannot, as a general rule, require renewed testing of a product already authorised. However, if it can show that, for example, particular dietary requirements in its country's population demand a stricter policy, it can restrict the authorisation of a product. ${ }^{134}$ If a Member State rcfuses to recognise tests performed in another Member State or an authorisation in its entirety, the Commission should be notified and the matter will be brought before the regulatory committec provided for in Article 19. ${ }^{135}$

In Article 11 of the Directive, a safeguard clause has been included. This clause enables Member States provisionally to restrict or prohibit the use of a product it has authorised or is under obligation to authorise. In order to do so, the Member State must have "valid reason" to consider the product "a risk to human or animal health or the environment".

\subsubsection{The Institutional Framework}

Sweden employs an intricate system of independent governmental authorities (statliga myndigheter), which are entrusted with various advisory, controlling and regulatory functions. At present, around 550 agencies exist. ${ }^{136}$ They are established by law or decree, and their budgets and tasks are controlled by the government through the so-called budget control documents. ${ }^{137}$ Agencies are protected from direct interference by the government in individual cases by the Swedish constitution, ${ }^{138}$

KemI was set up by decree in $1985 .^{139}$ The original decrec was replaced by another decree in 1988, which is still in force. ${ }^{140} \mathrm{KemI}$ 's mandate is to function as the main agency for issues relating to the risks to health and the environment posed by chemicals. More

\footnotetext{
${ }_{134}$ Directive 91/414/EC Article 10 and Articles 17-19 of the Förordning (2006:1010) om växtskyddsmedel.

Ibid., Article 1.

135 Ibid., Article 3.

136 According the Swedish Agency for Public Management. See hittp://www.statskontoret.se/ Statskontoret/Templates/Newspage 2875.aspx.

137 "Regleringsbrev." Translation by author.

138 Regeringsformen Article 11:7.

139 Förordning (1985:643) med instraktion för kemikalieinspektionen, Article 2.

${ }^{140}$ Förordning (SFS 1988:525) med instruktion för kemikalieinspektionen.
} 
specifically, KemI's tasks include exercising control over, and issuing authorisations for, chemical and bio-lechnological substances, registering and keeping the records of chemical and bio-technological substances, and investigating, compiling and documenting activities and risks in the arca. ${ }^{141}$

The Authority is led by a Director General, who leads the work in the agency and chairs KemI's board, which consists of 8 members. ${ }^{142}$ Both the Director General and the board members are appointed by the government. ${ }^{143}$ The Director General is not formally subordinated to the board but can decide which issues the board should decide and which issues the Director General can decide on its own.

In general, Swedish government agencies decide on their own internal organisation. ${ }^{144}$ However, with regard to KemI, it has been established that a "Toxicological Council" 145 is to function as an cxpert organ for consultation and advice with regard to toxicological questions. ${ }^{146}$ The role of the Council is strictly advisory and nothing indicates that $\mathrm{KemI}$ is bound to consult it in individual cases. On the contrary, it is emphasised that the Council functions as an "informal" consultation body. ${ }^{147}$ A large part of the work of the council is made up of organising seminars and training activities, as well as functioning as a bridge between academic researchers and Keml. The Toxicological Council is chaired by the Director General, and its members consist of representatives of other agencies, as well as independent rescarchers. The government appoints the members of the toxicological council for a specified period of time. ${ }^{148}$

KemI is formally an independent agency, and the government is prevented from interfering in individual cases pending before it. Despite this, the government retains influence over the agency through the possibility of appointing the Director General and the members of the board, assigning its budget and giving detailed instructions in the budget control documents. Furthermore, the government has reserved the power to approve the scientific experts in the toxicological council. This is further emphasised by the fact that the

\footnotetext{
141 Ibid., Article 2.

142 For a list of current members of the board, see http://kemi.se/templates/Page 3137 aspx.

143 Verksförordning (1995:1322), Articles 32 and 33.

144 Ibid., Article 17.

145 "Toxikologiska rådet." Translation by author.

146 Förordning (1988:525) med instruktion för kemikalieinspektionen, Article 7.

147 See the website of KemI, http://www.kemi.se/templates/Page 2832.aspx.

148 Förordning (1988:525) med instruktion för kemikalieinspektionen, Article 8.
} 
Joakim Zander

government appointed Director General chairs the expert council. In short, it could be argued that the lack of a formal separation between risk assessment and risk management, in combination with the strong controlling powers retained by the government, raises some concern as to the true independence of the agency, as well as the objectivity of its decisions.

\subsubsection{Risk Assessment and Risk Management}

The authorisation of pesticides is dealt with in Chapter 14 of the Environmental Code which is the general chapter dealing with chemicals. Chapter 14 of the Environmental Code does not repeat or specify the general precautionary principle or the substitution principle, which were both established in Chapter 2 of the Environmental Code. ${ }^{149}$ However, Article 14:7 develops the knowledge requirement established in Chapter 2 of the Environmental Code into a requirement for a risk assessment when handling chemicals. It thus appears that that anyone handling any chemical product in Sweden is responsible for the fact that "satisfactory investigation for the assessment of what health or environmental damage the product or organism may cause" 150 exists. The investigation to be carried out is more specified in Article 14:7 of the Environmental Code than the general requirement in Article 2:2 of the Environmental Code. While Article 2:2 of the Environmental Code makes a general demand on anyone carrying out an activity which may cause environmental damage to have "knowledge" about this activity, Article 14:7 of the Environmental Code holds first that the investigation must be done "in accordance with science and verified experience." 151 Second, it makes four requirements with regard to what the investigation needs to fulfil. First, the substances or organisms which may give the product hazardous properties must be identified. Second, the kind and degree of the hazardous properties must be distinguished. Third, actions to protect health and environment should be suggested. Finally, actions required to deal with waste from the product or organism must be spelled out. The risk assessment is not limited to situations in which a hazardous substance, or a substance with new or unknown properties, is introduced onto the Swedish market, but is a gencral requirement for all chemical products.

The risk assessment is the foundation on which further measures can be based. With regard to precautionary measures, the substitution principle plays a an important role. In short, the substitution principle means that substances which pose a risk to health or to the

\footnotetext{
149 For discussion on this, see the previous section.

150 "Tillfredsställande utredning för bedömning av vilka hälso- eller miljöskador produkten eller organismen kan orsaka." (Translation by author).

151 "I enlighet med vetenskap och beprövad erfarenhet." (Translation by author).
} 
environment should be replaced by less risky substances whenever such an alternative exists. It is explicitly stated in the preparatory work to Article 2:7 of the Environmental Code that not only substances that have been confirmed as hazardous should be affected by the rule, but also substances surrounded by uncertainty. ${ }^{152}$

Keml does not employ a formal separation of risk assessment and risk management. The officials working for the agency are responsible for assessing scientific information as well as for deciding on the appropriate measures to be taken upon the basis of the scientific information. ${ }^{153}$ The burden of investigation and information about chemical products is put squarely on the applicant. ${ }^{154}$ Little independent research is carried out by KemI itself, and the Toxicological Council has a strictly advisory function, of which KemI is not required to make use. ${ }^{155}$ Often decisions on, for example, authorisations are taken in a highly informal manner by civil servants and KemI, in which "common sense" plays a large role. ${ }^{156}$

The procedures that KemI adheres to when approaching pesticides are summarised in a Report from 1992 (hereinafter referred to as "the Keml Report"). ${ }^{157}$ The KemI Report, which was drawn up by the agency itself, establishes a substantive framework for regulating the risks from pesticides. As mentioned above, a strict separation of risk assessment and risk management is not in effect in Swedish pesticide regulation. The Report is essentially of risk management character, in that it lays down a framework for how to deal with risks provided that certain thresholds are met. However, as mentioned earlier, the report is drafted by KemI itself, and $\mathrm{KemI}$ is also the body which assesses and classifies individual risks on a case by case basis. Thus, it appears that KemI functions both as risk manager and risk assessor. The tasks are not separated within the agency, either. Instead, the risks are evaluated on an ad hoc basis, often in meetings of an informal nature. ${ }^{158}$

\footnotetext{
152 Proposition 1997/98:45, 659-660.

153 The lack of formal requirements on the collection and evaluation of scientific evidence can also be discerned from A. Nilsson, Chapter 16: The Precautionary Principle in Swedish Chemicals Law and Policy, p. 302. She holds that the "Swedish approach [...] allows for listening to the facts presented by the scientists, evaluating them as facts and then acting in accordance to what is appropriate from a legal or political point of view."

154 Article 5 of Förordning (2006:1010) om växtskyddsmedel.

155 For an account of the composition and tasks of the Toxicological Council, see http:/www.kemi.se/templates/Page 2988.aspx.

156 Interview with officials at KemI, 2004-09-09.

157 Principles for Identifying Unacceptable Pesticides, KemI Report, No. 4/ 92, (National Swedish Chemical Inspectorate, 1992).

158 Interview with officials at $\mathrm{KemI}, 2004-09-09$.
} 


\section{Joakim Zander}

The Keml Report separates the health effects of pesticides from effects on the environment. Health effects are considered with regard to acute toxicity, eye and skin irritation, sensitisation, subacute, subcronic and chronic toxicity, carcinogenicity, mutagenicity, and reproductive toxicity. Environmental effects are looked at form the point of view of degradability, bioaccumulation, mobility, and effects on non-target organisms. In each category, a substance's "danger class" is established. The four classes are: 1. Extremely dangerous products (Very toxic), 2. Very dangerous products (Toxic, highly corrosive), 3. Dangerous Products (Corrosive, harmful, irritant), and 4. Moderately dangerous products (Moderately harmful). ${ }^{159}$ The danger class to which a pesticide is assigned prescribes how the pesticide will be treated. Below, the focus will be primarily on health effects.

The most controversial aspect of the Keml Report is the establishment of so-called "cut-off criteria". For many categories of risk, cerlain levels of acceptable hazard are established. If a pesticide exceeds this level, it is automatically not allowed on the market. For example, with regard to acute toxicity, the cut-off criterion is when a pesticide is considered "very toxic", i.e., when Danger Class 1 is met. ${ }^{160}$ For corrosive and carcinogenic substances, Class 2 is sufficient. ${ }^{161}$

In a case regarding a pesticide with the active ingredient mancozeb, a so-called EBCD-substance, which reached the Swedish. Supreme Administrative Court (Regeringsrätten), Rohm and Haas, the manufacturer, appealed against a decision by KemI to decline a request for prolonged authorisation for the substance. ${ }^{162}$ A large part of the case dealt with the principles of precaution and substitution, and this will be discussed in more detail below. However, the court also touched generally on how the cut-off criteria are to be interpreted in the light of EU legislation, primarily Directive 414/91/EC. Rohm and Haas argued that Directive $91 / 414 / \mathrm{EC}$ and its annexes give clear guidance as to how the risk assessment and the approval of substances is to be carried out. KemI's use of cut-off criteria was in violation of this, since it allowed $\mathrm{KemI}$ to refuse the authorisation of pesticides without trying the substance under "normal conditions". ${ }^{163}$ This is the case since the conclusion of the system of cut-off criteria, according to the plaintiffs, is that it is sufficient

${ }^{159}$ Principles for Identifying Unacceptable Pesticides, KemI Report, No. 4/ 92, 9.

160 Ibid., 11.

161 Ibid., 12 and 15.

162 The Judgment of the Supreme Administrative Court in Case RA 1998 ref. 56.

${ }^{163}$ Compare with Article 4 of Directive 91/414/EC: "[...] and having regard to all normal conditions under which it may be uscd." (Emphasis added). 
for a substance to be present in the pesticide for action to be taken by Keml in order to prevent it from reaching the market. This would be the case even if the actual circumstances in which the pesticide was being used would prevent handlers or the environment from being adverscly affected by the substance. Furthermore, decisions on the basis of the cut-off criteria in cases in which a substance has been approved in another Member State is, according to the plaintiff, in violation of the mutual recognition clause included in Article 10 of the Directive. $^{164}$

At the time when the case was decided, Annex 1 of the Directive had not yct come into force. This circumstance was doubtless of relevance to the Court's decision to uphold Keml's original assessment. In the absence of Annex 1, the Court found that stricter rules than the ones provided for in the Directive were possible to maintain. Mutual recognition under Article 10 is dependent upon the inclusion of the substances in Annex 1. Interestingly, the Court did not clearly statc that this was the case only before Annex 1 came into forcc. Instead, it held that this must be the conclusion, "at least"165 under the present circumstances. ${ }^{166}$ Thus, the Court did not limit the possibilities of maintaining stricter rules for issues stemming from the period before Annex 1 was in force. This does not mean that the Court explicitly undermined the mutual recognition clause, but it indicates that it did not necessarily view it as absolute. One related issue is that it appears that the Court did not view the area of pesticides as being harmonised before the Annexes to the Directive were in place. This is clear since it continuously refers to the possibilities of refraining from respecting requests for mutual recognition upon the basis of Articles 30 and 36 EEC(currently Articles 28 and $30 \mathrm{EC}$ respectively) instead of Article 100a EEC(currently Article $95 \mathrm{EC}$ ), which would have becn the appropriate legal basis had the area been harmonised.

In a more recent case, the Supreme Administrative Court reversed decisions by Keml and, on appeal, reversed decisions by the government, which subjected a pesticide containing the active ingredient glyfosate to a morc limited authorisation than was the case at $\mathrm{EU}$ level. ${ }^{167}$ The Court here put great emphasis on the fact that the substance had been included in Annex 1 to Directive 91/414. ${ }^{168}$ Thus, the Court reasoned, a risk assessment at EU level

\footnotetext{
164 The Judgment of the Supreme Administrative Court in Case RA 1998 ref. 56, p. 1-2.

165 "i vart fall" (Translation by author).

166 The Judgment of the Supreme Administrative Court in Case R $\AA 1998$ rcf. 56, p. 10.

${ }^{167}$ The Judgment of the Supreme Administrative Court in Case R $\AA 2005$ ref. 2.

168 Ibid., p. 6.
} 


\section{Joakim Zander}

had declared the substance safe for use. KemI and the Swedish government, on the other hand, claimed that that the substance would entail risks if released into the ground water in particularly sensitive areas. The Supreme Administrative Court found little evidence to support this assertion. Instead, it stated that the decisions seemed to be based upon "[...] a general opinion on the part of the government authoritics that pesticides containing glyfosate bring a risk of pollution of water $[. .$.$] " rather than concrete risk assessments. { }^{169}$ Due to this fact, it declared the stricter Swedish rules to be disproportionate. ${ }^{170}$ By holding that the measures were "disproportionate", rather than in direct violation of the Directive, the Court carefully avoided discussing in any detail the issue of whether stricter, proportional, measures can be maintained even though a substance has been included in Annex 1 .

\subsubsection{The Level of Proof and the Triggering of Precautionary Measures}

The general rules of care in Article 2 of the Swedish Environment Code apply in all areas in which the environment or health protection is concerncd. Thus, the precautionary principle is the foundation upon which Swedish pesticide regulation is built. As discussed above, the Swedish interpretation of the precautionary principle is generally wide, and, in many cases, resembles a general duty of care more than the precautionary principle discussed at European and international levels. ${ }^{171}$ The principle of substitution, or product choice as it is also commonly known, can be viewed as a particular manifestation of the Swedish version of a strict precautionary principle. Nowhere is this more tangible than in the area of chemicals regulation. An example of how far-reaching precautionary considerations are in the area of chemicals regulation is the ambitious environmental quality objective of "A Toxic Free Environment" established by the Swedish Parliament in $1999 .{ }^{172}$ The explicit goal stated there is to eliminate all man-made substances with toxic properties from the environment, and to restore naturally occurring substances to their original levels by the ycar 2020 . This goal was further specified in another bill before Parliament in 2001 titled "A Chemicals Strategy for a Non-Toxic Environment". ${ }^{173}$ The explicit reason for this radical policy was that the lack of knowledge and the persistent uncertainty associated with many chemicals calls for a precautionary approach. ${ }^{174}$ The environmental quality objectives are of a policy character and

169 Ibid., p. 7

170 Ibid.

171 M. Karlsson, The Precautionary Principle, Swedish Chemicals Policy and Sustainable Development, p. 350.

172 Proposition 1997/98:145.

173 Proposition 2000/01:65. "Kemikaliestrategi för en giftfri miljö." (Translation by author), pp. 9-14.

174 Ibid., p. 7. 
are thus not legally-binding. ${ }^{175}$ However, the impact that the objective "A Toxic Free Environment" has had for the work of Keml seems difficult to exaggerate.

As mentioned above, the main requirement for authorisation of a pesticide at European level is the inclusion of its operative components in Annex I of Directive $91 / 414 / \mathrm{EC}$. The information needed to be supplied together with an application is detailed and laid down in Annex II to the Directive. For the authorisation for pesticides, the required documentation needed is established in Annex III. The general principles which need to be fulfilled for authorisation are laid down in Annex VI. In summary, the EC rules establish absolute rules for how pesticides are to be authorised. If a pesticide is considered safe for use under the relevant rules, it can be allowed on the market regardless of other products existing there already. The Swedish substitution-principle, on the other hand, establishes that it is not sufficient for a pesticide to be safe for use. If there are other products of equal efficacy on the market which are associated with less risk, the pesticide should not be allowed. ${ }^{176}$ Thus, the Swedish rules are not absolute, but, instead, establish a moving target. Essentially, this is a very strict application of the precautionary principle with the explicit aim that, in the end, only risk-free and near risk-free products will exist on the market. This appears to be a concrete legal application of the environmental quality objective "Toxic Free Environment". If such an application is upheld in practice, it is likely to be in conflict with the relevant harmonised EU legislation. The question then arises as to what levcl of proof must be provided by KemI before taking precautionary action, including invoking the substitution principle.

In previous chapters, it was stated that the guidance as to what needs to be shown by the regulator when intending to take precautionary measures is generally weak in Swedish legislation, as well as in the preparatory work and the case law. ${ }^{177}$ With regard to pesticides, the clearest embodiment of precautionary considerations is the establishment of cut-off criteria. The use of cut-off criteria focuses the risk assessment on the individual substances which are found in a given product. If a substance is sufficiently risky, the product is

175 See, also, M. Karlsson, The Precautionary Principle, Swedish Chemicals Policy and Sustainable Development, pp. $352-353$.

176 Ibid., p. 661 .

177 See, above, Section 5.1 . 


\section{Joakim Zander}

automatically banned. Often, this appears to be the case without real consideration of the actual risks that the actual product poses when uscd in practice. ${ }^{178}$

In case 4704-1996, Keml based its decision not to prolong the authorisation for a pesticide with the active substance mancozeb upon the grounds that it was considered carcinogenic. The basis for this conclusion appears to have been primarily two scientific reports of Swedish and Finnish origin, and unspecified "studies on rats". ${ }^{179}$ Other mainstream reports, indicating that mancozcb does not possess significant carcinogenic properlies even at high doses, and no carcinogenic effects at doses which may be present in the actual use of the pesticide in question, were disregarded. In fact, at the time of the decision, it appears that no animal studies suggested that mancozeb was carcinogenic at the low dosages which normal use of the pesticide would entail. Despite this, KemI referred to "studies in rats" to justify its decision. ${ }^{180}$ Which studies this referred to was not further spccified. Most other European countries had, at the time, authorised mancozeb, and the clcar majority of scientists considered the product in question safe for use. ${ }^{181} \mathrm{KemI}$ recognised the uncertainty surrounding the product, but stated that the ban was warranted by the precautionary principle. This was based on the fact that uncertainties pertained to the substance in question, even though the current state of scientific research held that the risks of the pesticide under normal use were negligible. ${ }^{182}$ In the light of the low risk associated with the product and the weak scientific evidence supporting the assertion of any risk at all when used under normal circumstances, the KemI measure must be considered to be an application of a remarkably strict form of the precautionary principle.

In the more recent case regarding pesticides containing the active substance glyfosate, KemI gave a limited authorisation, instead of the full authorisation sought by Monsanto. Glyfosate is included in Annex I to Directive 91/414/EC. If a Member State wishes to maintain or introduce a conditional authorisation of a substance which has been included in Annex I, it has to conduct an individual assessment of the product, which indicates a

${ }^{178}$ For an argument in this direction, see R. Nilsson, Science and Politics in the Regulation of Chemicals in Sweden, in: M. Gough (ed), Politicizing Science: The Alchemy of Policymaking, Hoover Institutions Press, 2003, pp. 227-259.

179 KemI Memo (P. Bergkvist), PM inför beslut om fortsatt godkännande för EBDC-medel. 1994-11-08 (Not published, but available with author), p. 2.

180 In the material obtained here, the reference was not more specific than "studies in rats".

181 See the following sub-section.

${ }^{182}$ KemI Memo (P. Bergkvist), Yttrande over kompletterand material från Rohm and Haas och Elf Atochem Agri angående överklagandena av Kemikalieinspektionens beslut den 9 november 1994 i fråga om bekämpningsmedel innehållande EBDC, 1995-08-23, p. 1-2. 
particular risk for its population. In the case in question, KemI had not supported its decision with any detailed assessment of the product. Instead, the Swedish Supreme Administrative Court found that the decision seemed to be based on a "general opinion on the part of the authority that pesticides containing glyfosate entails risk". ${ }^{183}$. Thus, it appears that the court here required more scientific cvidence for precautionary measures to be justified than in the earlier case. Mere policy concerns were not considered acceptable here. However, it remains unclear exactly where the courts will draw the line. However, what does appear to be clear is that conflict will pertain between Keml's precautionary stance, which focuses on a chemical's intrinsic properties, and the EU approach under Directive 91/414/EC, where the focus is on the risks posed by a pesticide under normal use.

A good example of this conflict is the controversy surrounding the pesticide paraquat, which was dealt with recently by the Court of First Instance in Case T-229/04. ${ }^{184}$ Paraquat was added to Annex I of Directive 91/414/EC in December of 2003, by using the regulatory committee procedure provided for in the Directive. However, paraquat has been banned in Sweden since 1983 due to its acute toxicity when ingested. That the substance is toxic is an uncontested fact among both its proponents and its critics. ${ }^{185}$ Paraquat has been known, for cxample, to be used as a suicide agent, primarily in developing countries. ${ }^{186}$ The risk of paraquat poisoning is scientifically certain and can, therefore, best be described as a "certain risk" as previously discussed in Chapter 2. The high toxicity of paraquat led to it being included in the "Dirty Dozen" list of hazardous pesticides established by the Pesticide Action Network (PAN) in 1982. The PAN has actively lobbied for global bans of the "Dirty Dozen" pesticides since the list was drawn up. Today, the list includes 18 pesticides and, of these, all but three have been listed under the Rotterdam Convention for Prior Informed Consent (PIC listed). ${ }^{187}$ Paraquat is not among them.

${ }^{183}$ Judgment of the Supreme Administrative Court in Case RA 2005 ref. 2.

184 Case T-229/04 Sweden v Commission, Judgment of 11 July 2007, not yet reported.

185 See, for example, Syngenta's webpage: http:/www.syngenta.com/en/social responsibility/gramoxone.aspx; International Program on Chemical Safety (INCHEM) Poison Information Monograph (PIM) Nr. 399. Available at: http:/www.inchem.org/documents/pims/chemical/pim399.htm; J. Madeley, Paraquat - Syngenta's controversial herbicide, SSNC Report 2002. pp. 10-12. Available at: http://www.snf.se/pdf/rap-inter-syngentaparaquat.pdf; B. Dinham, Why Paraquat Should Be Banned. Outlook on Pest Management. December 2004. p. 269.

186 J. Madeley, Paraquat - Syngenta's controversial herbicide, p. 12.

187 Rotterdam Convention on the Prior Informed Consent Procedure for Certain Hazardous Chemicals and Pesticides in International Trade. Rotterdam, 10 September 1998. Available at: hitp://www.pic.int/en/ViewPage.asp?id =104. 


\section{Joakim Zander}

Syngenta, which manufactures the paraquat-based pesticide Gramoxone, and other proponents of the use of paraquat, hold that, despite its acute toxicity when ingested orally, the substance's general toxicity is not worse than other houschold chemicals or pesticides. In order to prevent accidental oral ingestion, Syngenta has added a blue dyc, a strong odour, and an agent to induce vomiting to Gramoxone. This is in line with measures taken to prevent poisoning in relation to other products. ${ }^{188}$ There is general agreement that the addition of the above agents have substantially mitigated the risk of poisoning through oral ingestion of Gramoxone. It has been pointed out that the risk still pertains with regard to independent manufacturers of paraquat who do not add the agents. ${ }^{189}$ Some other reports have suggested that paraquat exposure may lead to Parkinson's disease. ${ }^{190}$ Scientific uncertainty surrounds this issue. A relationship appears to exist between the pesticide and disease, but a causal link remains to be found.

It is not entirely clear on what scientific cvidence the Opinion of the relevant regulatory committee, in this case the Standing Committce on the Food Chain and Animal Health (hereinafter referred to as the Standing Committee), was based. Requesting an opinion from a scientific committee is not mandatory under Directive 91/414. However, the Commission had put four questions relating to the safety of paraquat before the Scientific Committee on Plants in 2001, and it is likely that the reply to these questions influenced the Commission. ${ }^{191}$

The Opinion of the Scicntific Committee focused entirely on the toxicity of paraquat. No mention was made, for example, of reduced lung capacity or Parkinson's disease. With regard to the toxicity, it admitted that paraquat is very toxic when orally ingested or when absorbed by the lungs. However, skin and eyes were not deemed particularly sensitive to exposure. ${ }^{192}$ The results were based on animal studies. The Scientific Committee concluded

${ }^{188}$ See, for example, http:/www.syngenta.com/en/products services/gramoxone page.aspx.

189 B. Dinham, Why Paraquat Should Be Banned, Outlook on Pest Management, December 2004.

${ }^{190}$ M. Thiruchelvam et al. The Nigrostriatal Dopaminergic System as a Prefertial Target of Repeated Exposures to Combined Paraquat and Maneb: Implications for Parkinson's Disease, The Journal of Neuroscience, Vol. 20, No. 24, 2000. p. 9207-9214; J. Peng et al., The Ilerbicide Paraquat Induces Dopaninergic Nigral Paoptosis through Sustained Activation of the JNK Pathway, J. Bio. Chem., Vol. 279, Issue 31, 2004, p. 32626-62632 and M. Thiruchelvam, et al., Overexpression of Superoxide Dismute or Glutathione Peroxidase Protects against the Paraquat + Maneb-induced Parkinson Discase Phenotype, J. Biol. Chem. ,Vol. 280, Issue 23, 2005, p. 22.53022539.

191 Opinion of the Scientific Committee on Plants on Specific Questions from the Commission regarding the Evaluation of Paraquat in the Context of Council Directive 91/414/EEC, SCP/PARAQ/002-Final, 16 January 2002.

192 Ibid., pp. 6-12. 
that the risks with paraquat can be adequately dealt with through the use of protective equipment for operators. Some predictive exposure models that the Scientific Committee reviewed indicated that operator exposure might exceed the acceptable operator exposure level (AOEL) ${ }^{[93}$ However, the Scientific Committee considered such models to "markedly over-estimate the actual exposure to paraquat in real working situations". ${ }^{194}$ Instead, it decided to rely on field exposure studies, which indicated exposure to paraquat within the AOEL. It is highly interesting to note that the Scientific Committee relied on the risks of paraquat at normal use, and not the risks associated with the substance in isolation. Clearly, a degree of scientific uncertainty surrounded the situation of how the product would affect handlers, but this was not deemed to be sufficient for the Scientific Committee to suggest a more precautionary use of the pesticide.

Sweden, on the other hand, focuses on the fact that the active substance paraquat, in isolation, has highly toxic properties. In February of 2004, Sweden took action against the European Commission under Article $230 \mathrm{EC}$, claiming that the decision to authorise paraquat was in violation of the precautionary principle as formulated in Article $174 \mathrm{EC} .{ }^{195}$

The primary focus of the Swedish challenge was the scientific evidence reviewed by the Regulatory Committee and the Commission when deciding upon the authorisation. Swcden emphasised that the scientific reports based on predictive exposure modelling had unequivocally shown that exposure in excess of the AOEL would always be a fact. ${ }^{196}$ Furthermore, Sweden held that the field studies that the decision was ultimately based upon were flawed and did not provide sufficient evidence to conclude that paraquat could be used safely. Sweden held that, in two of the three field studies existing on paraquat, one person had suffered exposure which exceeded the AOEL. ${ }^{197}$ The Swedish Government also held that, by ignoring the data existing in relation to the potential link between paraquat and Parkinson's disease, the decision was arbitrary and once again in violation of the precautionary principle. ${ }^{198}$ Finally, it held that the risk reduction measures suggested by the Commission in its decision with regard to animals were unlikcly to be upheld in practice. For

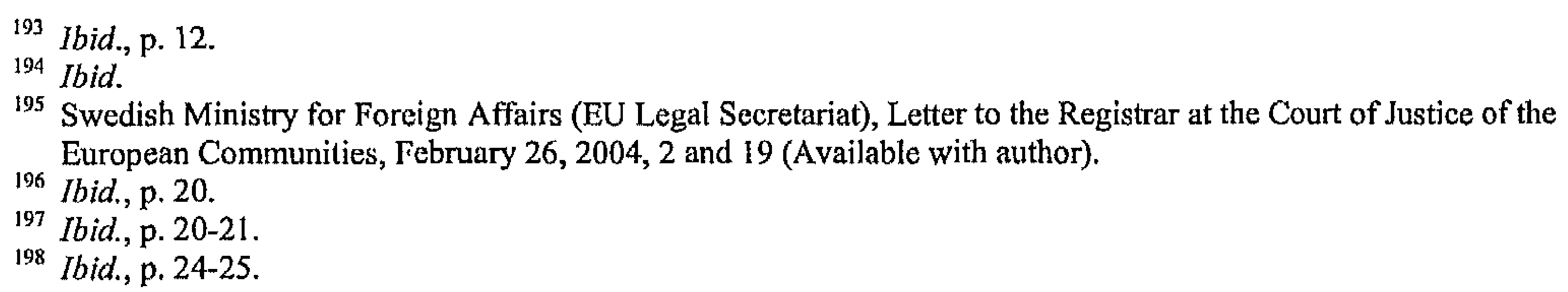


these reasons, Sweden considered the rules laid down in Directive 91/414/EC with regard to the protection of animal health to be breached. ${ }^{199}$

In summary, it can be held that, in its challenge, Sweden firstly considered paraquat to be so toxic that it should not be allowed under any circumstances. Secondly, Sweden held that the uncertainties pertaining to the risk posed by the normal use of paraquat warrants a more precautionary approach than that advocated at EU level. The case of paraquat is significant in that it highlights the different approaches adopted by Sweden and the EU when considering scientific evidence and the precautionary principle. Swedish civil servants have described the case as "the environmental case of the decade". 200

In its judgment of 11 July 2007, the Court of First Instance found in favour of Sweden. In short, it concluded that the Commission had neglected formal requirements under Directive 91/414/EC when adding paraquat to Annex I, as well as having under-estimated the risks of the substance to human health as well as to the environment. ${ }^{201}$ The case is interesting since it shows that serious conflicts between national legal systems and the EU institutions exist in the field of pesticide regulation. Furthermore, it is interesting to note that, in this case, Sweden managed successfully to bring an action against the Commission for not being precautionary enough. Thus, it would appear that the Commission is under an obligation under $\mathrm{EU}$ pesticide legislation to act in a precautionary manner. However, it is important to note that, in this case, the Court of First Instance did not vindicate the general Swedish policy towards pesticides, but merely ruled that, in the case before it, the Commission had opted for a level of protection that could not be considered sufficiently precautionary in the light of the existing scientific evidence.

\subsubsection{The Burden of Proof}

As discussed above, it is for the applicant to support a request for the authorisation of a pesticide with the relevant scientific information. ${ }^{202}$ This information must show that the pesticide in question corresponds to the level of protection prescribed by the relevant legislation accounted for above, and specified in the KemI Report. However, in each individual case, KemI has the burden of showing that the application is not in conformity

${ }^{199}$ Ibid., p. 27.

${ }^{200}$ Statement by Swedish Foreign Office official Anders Kruse, quoted in Swedish daily newspaper Svenska Dagbladet, August 24, 2004. Available at: http//www.svd.se/dynamiskt/inrikes/did 8027374.asp.

${ }^{201}$ For a further discussion on the substance of the case, see, above, Chapter 4.

202 Article 5 of Förordning (2006:1010) om växtskyddsmedel. 
with the relcvant rules. ${ }^{203}$ What the applicant is required to show, in order to challenge Keml's decision, has been dealt with, to some extent, in the scarce and rather inconsistent case law on pesticides.

In the case regarding the mancozcb-based pesticide discussed above, the plaintiff, Rohm and Haas, questioned the scientific evidence on which KemI had based its decision. Among other things, it held that KemI had not paid sufficient attention to certain scientific evidence. Furthermore, it held that the Government, which had tried the case before it was appealed to the Supreme Administrative Court, had not been able to conduct a complcte investigation. This was due to the fact that $\mathrm{KemI}$, which clearly was a party to the suit, was the only expertise that the government relied on for its decision. ${ }^{204}$ The Court held that it found that mancozeb can be "suspected on scientific grounds" 205 to possess properties that can be hazardous for both human health and the environment. ${ }^{206}$ Once this has been established, the burden of proof falls on the plaintiff to disprove this assertion. The Court found support for this in the preparatory work to the Chemical Substances Act. ${ }^{207}$

The scientific evidence brought forth by Rohm and Haas was not considered sufficient by the Court to reverse the decision by the Agency. KemI based its decision primarily upon two Swedish scientific reports which suggested that mancozeb contained carcinogenic properties. ${ }^{208}$ Rohm and Haas disputed this evidence in a memo attached to a letter to KemI in $1995 .^{209}$ Since the Swedish Ministry of Environment decided to make this report confidential, it is not possible to make a valid judgment on the scientific evidence it contains. However, it can be assumed that it would be along the lines of the Danish Ministry of the Environment Report which functioned as the risk assessment for Denmark regarding mancozeb in 1993 and was also relied on by Rohm and Haas in the case. ${ }^{210}$ The conclusion of this report was that mancozeb did not possess any considerable carcinogenic properties and was safe for use. The Danish conclusions were based upon a plethora of reports from various

${ }^{203}$ See, for example, the conclusions of the Supreme Administrative Court in its judgment RA 2005 ref. 2, which was discussed above.

204 The Judgment of the Supreme Administrative Court in RA 1998 ref. 56.

205 "På vetenskapliga grunder misstänkas." (Translation by author).

206 The Judgment of the Supreme Administrative Court in RA 1998 ref. 56.

$207 \mathrm{Ibid}$. Since the case was decided before the Environmental Code entered into force, the Court here refers to the Chemical Substances Act and its preparatory works. However, as was mentioncd above, no material change was intended in this regard when the Environmental Code was adopted. If anything, the present regulation may be stricter.

208 Keml Memo 08 November 1994, p. 2-4.

209 N. Gocha, Rohm \& Haas, Comments on DeZäta Granulat Registration Withdrawal by KemI, 18 January 1995.

210 Miljøstyrelsen, Vedrørende Dithane DG, 9 June 1993 (Available with author). 


\section{Joakim Zander}

European, as well as non-European, countries. As discussed above, KemI held that studies in rats had shown that mancozeb was carcinogenic. ${ }^{211}$

However, the Danish report held that carcinogenicity had only been indicated in one out of three animal studies. And, even then, it only became mcasurable at much higher doses than the normal use of the product in question would involve. ${ }^{212}$ The Court did not consider it sufficient that Rohm and Haas had presented the fact that no carcinogenic effects had been shown to stem from the substance at the dosages involved in the normal application of the pesticide. KemI, the government and the Court were all unmoved by the exhaustive (at the time) evidence presented by Rohm and Haas. It is difficult to imagine what more Rohm and Haas could have done to disprove the assertion of the government. The focus on the risks associatcd with the active substance of a pesticide, rather than the product under normal use, makes it very difficult for a party to challenge a precautionary decision. Since all substances pose risks at a sufficiently high level of cxposure, the approach adopted by Keml gives it nearly unlimited powers to regulate substances, and, subsequently, it is ncarly impossible for a challenging party to appeal against a decision successfully.

However, since the coming into force of Annex 1 to Directive 91/414, the leeway of $\mathrm{KemI}$ is being restricted. In the more recent case relating to Glyfoasate referred to above, the court seems to put more emphasis on the need for scientific evidence in cases relating to pesticide regulation. However, in the case, the reversed burden of proof was not touched upon since the court found that $\mathrm{KemI}$ had not reached its initial level of proof. ${ }^{213}$

\subsubsection{Cost/Benefit Analysis}

In relation to pesticides, the general "unreasonable-test" in Article 2:7 of the Environmental Codc must be considered to be applicable. As discussed above, this is neither a traditional cost/benefit analysis nor a proportionality requirement. Instead, it aims to codify the carlier Swedish practice which stated that actions to protect the environment should only not be taken where this is not "environmentally motivated". The presumption is thus that measures should be taken. Only where great costs would only result in marginal environmental improvement should they not be taken.

211 P. Bergkvist, PM inför beslut om fortsatt godkännande för EBDC-medel, p. 2.

${ }^{212}$ Miljøstyrelsen, Vedrørende Dithane DG.

213 The Judgment of the Supreme Administrative Court in RA 2005 ref. 2. 
In the preparatory work to the Environmental Code, the weighing of costs and benefits when considering authorisations for pesticides is emphasised, but not elaborated on in any detail. ${ }^{214}$ However, interestingly enough, the substitution principle is connected to this requirement. The preparatory work held that, if other similar or more efficient but less risky substances exist, this should influence the estimation of the benefit that the pesticide would bring. ${ }^{215}$ In the case law this has further been elaborated on. In Case 4704-1996, Rohm and Haas held that, by making use of the substitution-principle, Keml had utilised comparative evaluations which were not in conformity with Directive 91/414/EC. However, the court found that the substitution-principle could be found to be in conformity with the general cost/benefit considerations which should be performed under the Direclive:

"It docs not appear as incompatible with the Direclive to, as a part of the benefitevaluation, pay some notice to the fact that other products with the same area of use but differing health and environmental effects exist on the market." 216

Furthermore, in the case, Rohm and Haas argued that a strict application of the cut-off criteria discussed above is in violation of Directive 91/414/EC, since the Directive calls for a more nuanced evaluation of pesticides. Annex VI to the Directive calls for a weighing of the costs and benefits of the proposed regulation, as well as an evaluation of the pesticide under the conditions in which it will actually be used. Thus, it is not exclusively concerned with the intrinsic hazardousness of a particular substance. ${ }^{217}$ The application of cut-off criteria, on the other hand, allows for a bypassing of this. Once the criteria are met, the product should not be allowed on the market, regardless of the circumstances under which the pesticide is to be used and potential benefits which it may have. That the evaluation is based solely on the basis of the intrinsic properties of the substance in question is made clear in the KemI Report:

"Pesticides which fulfil the cut-off criteria are regarded as unacceptable within the meaning of the Ordinance solely on the basis of their intrinsic properties."218

\footnotetext{
214 Proposition 1997/98:45, 812.

215 Ibid.

216 Ibid., p. 11. The decree guiding the work in government agencies also states that agencies must consider the costs of planned regulation and make such evaluations available (Verksförording, Article 27).

217 See Section 1.8 of Annex VI to Directive 91/414/EC.

$218 \mathrm{Kem} /$ Report, p. 7.
} 
Joakim Zander

However, in the case at hand, the court found that KemI had still performed a more extensive risk assessment, and that the cut-off criteria had not exclusively determined the result. Thus, the Court found the decision to be in conformity with the Directive. The Decision was upheld in this part, too. In particular, before the entry into force of Annex $\mathrm{l}$, the Court found it possible to maintain stricter rules than the Directive provided for. As mentioned above, later case law may indicate that the Directive is now given more weight than the Supreme Administrative Court gave it here. ${ }^{2(1)}$ This could lead to a situation in which the costs and benefits of a pesticide will be weighed by Keml, rather than just the risk being considered. However, in interviews at $\mathrm{Keml}$, it transpired that cost/benefit analysis is not a part of the decision-making process in relation to pesticides. On the direct question of how costs and benefits were evaluated, officials replied unequivocally that economic considerations did not influence the decision of whether to authorise pesticides or not. ${ }^{220}$

\subsubsection{Conclusion}

A strict version of the precautionary principle lies at the heart of Swedish pesticide regulation. This is clcarly illustrated by the policy goal "A Non-Toxic Environment," which states that all man-made substances with toxic properties are to have been removed from the environment by the year 2020 , regardless of whether they are toxic at normal use or not.

KemI is the agency entrusted with issuing authorisations and detailed rules regarding pesticides. The agency is formally independent, but the government retains important powers of control and command through the issuing of instructions and appointments. No formal separation of risk assessment and risk management is in effect. Instead, decisions are often taken after informal deliberations between civil servants in the agency.

One concrete effect of the precautionary nature of Swedish pesticide regulation is the focus of $\mathrm{KemI}$ on the risks posed by individual substances included in a product, rather than on the risk posed by the whole of a product under normal use. This approach leads to a situation in which the level of accepted risk is extremely low. As a product of this, the level of proof needed to be met by $\mathrm{Kcml}$ when taking precautionary measures is low. Earlier case law seems to have indicated that mere policy considerations could, in some cases, be sufficient to warrant restrictive measures. However, in one case which stems from after the coming into full effect of Directive $91 / 414 / \mathrm{EC}$, the Supreme Administrative Court held that

\footnotetext{
219 See the judgment of the Supreme Administrative Court in Case R\2005 ref. 2.

220 Interview with officials at KemI, 9 September 2004.
} 
the mere "opinion" of the agency was not enough to justify precautionary measures. Some form of scientific basis is required.

Once the low burden on the part of the regulator $(\mathrm{KemI})$ is met, the burden is shifted onto the regulated party to show that the agency was mistaken. The level of proof which the regulated party needs to meet is high. In one case in which KemI had referred to "studies on rats" in order to justify a precautionary ban, it was not sufficient for the contesting party to show that no studies on rats that indicated any risk from the product in question under conditions of normal use existed. ${ }^{221}$ The Supreme Administrative Court agreed here with KemI that it did not matter that the product as such could be used at a comparably low risk. In order to be successful, the challenging party must show that each constitutive substance which makes up the product is without risk. In the casc mentioned here, the plaintiff argued that it would be unreasonable to have to show that the substance in question (mancozeb) was safe for use at high doses, since normal use of the product would only concern significantly lower doses. KemI and the Court were unmoved by these pleas. The conclusion with regard to the burden of proof, once it has been shifted onto the regulated party, is thus that it is not sufficient to show that a pesticide is without risk when used under normal circumstances. Instead, each substance which the pesticide entails must be shown to be risk free. Such reasoning ultimately leads to a situation in which only zero-risk products are tolerated.

The substitution principle is connected to the above discussed issues of what level of risk is tolerated. This principle, in practice, constitutes a particular manifestation of the precautionary principle, and means that if safer pesticides of equal effect than the one in question exist on the market, it should not be allowed. Thus, it establishes comparative assessments, instead of absolute requirements with regard to what level of risk should be tolerated. Such moving targets are difficult to comply with, and may lead to situations of considerable legal uncertainty. The Supreme Administrative Court has held that the substitution principle is a part of the balancing which should be carried out before regulation is issued.

As discussed in the previous chapters, the proportionality principle in Swedish environmental law is not quite comparable to the one at European level. The Swedish version aims to address situations in which it is not "environmentally motivated" to take action. The

221 The Judgment of the Supreme Administrative Court in R $\AA$ 1998, ref. 56. 
Joakim Zander

threshold for this to be the case appears to be high. Thus, it does not establish an unequivocal cost/benefit requirement, or even a proportionality test in the EU sense, but is limited in scope to situations in which the environmental benefits are very low and the costs associated with regulation very high. In contrast, it appears that when KemI evaluates substances, it only considers the risk and not benefits associated with the product. This enables it to apply a very restrictive policy towards products. If the benefits of a substance are not considered, the risks associated with it arc impossible to justify. This is returned to within the framework of US pesticide legislation.

The issue of the regulation of paraquat at EU level provides a clear illustration of how different views on the precautionary principle can lead to conflicts not only within the EU, but also in their continuation at international level. By focussing its assessment of pesticides on individual substances, rather than on the risks posed by the actual product under normal use, Sweden's approach is strict and is in conflict with the position assumed by most other EU Member States and the Commission. Furthermore, by making different conclusions to those of the Commission and emphasising scientific reports which suggest risks not taken into account when drawing up the decision to authorise paraquat, Sweden made it clear that, in its view, the precautionary principle is to be interpreted strictly at EU level, too. Whether this is also the view of the ECJ remains to be seen.

\subsection{The Application of the Precautionary Principle in the Swedish Regulation of Base Stations}

\subsubsection{Introduction}

Where the regulation of chemicals has an impressive history ranging back to the middle of the eighteenth century, the regulation of radiation in general and mobile telephony in particular, is, for natural rcasons, a much more recent arca of regulation. Only since 1976 has the emission of radio waves been regulated at national level in Sweden. ${ }^{222}$ This is due to the fact that radio technology itself, as well as the awareness of the potential risks stemming from it, is relatively new. With regard to radiation in general, some types of risks are welldocumented. Most famously, this is the case with regard to ionising radiation, which is lethal even in very small doses. But non-ionising radiation can also be severely hazardous.

In Sweden, as in the other legal systems investigated here, the legal framework in relation to base stations is complicated due to the fact that radiation protection rules have to

${ }^{222}$ SSI Information, Strålning från basstationer för mobilielefoni, 2001:3, (August 2001), p. 2. 
be used in combination with general environmental rules as well as planning provisions. The distinction between the different laws is not clear-cut and they often overlap. Furthermore, the terminology is not unambiguous. The meaning and application of concepts central to the precautionary principle scem, in some cases, to be interpreted differently, for example, in relation to base stations than they were in relation to pesticides. To complicate things further, the government has not established legally-binding safety standards, but the relcvant agency has, instead, opted for the issuing of non-binding recommendations. So far, little casc law exists to clarify the situation, especially from the higher courts. Below, an attcmpt is made to interpret the main provisions and considerations which influence the Swedish policy towards radiation from base stations. An attempt is made to clarify the roles of the relevant government agency and local government when deciding on safety standards and the placement of base stations. The definition of the precautionary principle in rclation to radiation is examined in detail, as are the concepts of relevance to its implementation, such as risk assessment and risk management, cost/benefit analysis and the role of the public.

\subsubsection{The Legal Framework}

A number of laws regulate the area of base-stations for mobile telephones in Sweden at present. With regard to the type and the amount of radiation that is allowed to be emitted, the Radiation Protection Act (Strålskyddslagen) (hereinafter referred to as "SSL") is relevant. ${ }^{223}$ The placement of actual base-stations is regulated in the Planning and Building Act (Planoch bygglagen) (hereinafter referred to as "PBL") ${ }^{224}$ and, to some extent, the Environmental Code. The amount of exposure that workers who routinely come into contact with radiation are allowed to be exposed to is established in the Work Environment Act (Miljöskyddslagen). ${ }^{225}$ However, the special rules relating to workers will not be investigated in detail below.

First, it should be pointed out that ionising, as well as non-ionising radiation, are considered "environmentally hazardous" activities according to the Environmental Code, if they "may cause detriment to the surroundings". 226 "Detriment to human health" is defined as meaning "any disturbance that is liable to have adverse effects on health in medical or

\footnotetext{
${ }^{223}$ Strålskyddslag (1988:220) (Translation by author).

224 Plan- och bygglagen (1987:10) (Translation by author).

225 Arbetsmiljölag (1977:1160) (Translation by author).

${ }^{226}$ Miljöbalken Article 9:1.
} 
Joakim Zander

hygienic terms which are not minor or temporary". ${ }^{227}$ Considering the wording of the relevant provisions, it would appear that not only activities whose effects are scientifically certain should be considered as environmentally hazardous. This is in conformity with the general precautionary principle in Article 2:3 of the Environmental Code. The main effect of declaring an activity environmentally hazardous is that it can be subjected to an authorisation procedure and subjected to various degrees of governmental control. ${ }^{228}$ The establishment of basc-stations is not subjected to an authorisation procedure, except for the procedures at local level provided for in the planning regulations. However, Swedish courts have declared that radiation from third generation mobile telephony base stations is considered to be an environmentally hazardous activity and should thus be subjected to control, primarily at local level. ${ }^{229}$ It is interesting to note that the Environmental Court of Appeal considers the radiation emanating from base stations to be environmentally hazardous. Especially in the light of the fact that, as is discussed in more detail below, courts generally have not been inclined to pay any particular attention to uncertain risks in relation to the issue. However, the practical effects of declaring an activity to be environmentally hazardous are unclear. In drafting the Environmental Code, it was pointed out by some stakeholders that the term was unnecessary since the Code makes all activities, regardless of whether they are declared environmentally hazardous or not, subject to the general duty of care (including the precautionary principle) included in Article 2 of the Environmental Code. ${ }^{230}$

The general framework provision for regulating the radiation emanating from basestations is the SSL. purpose of this act is to protect humans, animals and the environment from the detrimental effects of radiation. ${ }^{231}$ The tcrm "radiation" in the Radiation Protection Act encompasses ionising as well as non-ionising radiation. ${ }^{232}$ Following the general approach in Swedish environmental and health regulation, ${ }^{233}$ the onus is on the performer of an activity involving radiation to avoid or minimise detrimental effects. ${ }^{234}$ This also includes the responsibility to make sure that installations emitting radiation have been equipped with

\footnotetext{
${ }^{227}$ Miljöbalken Article 9:3.

${ }^{228}$ Miljöbalken Article 9:6.

229 Judgment of the Environmental Court of Appeal in Case MÖD 2005:55.

230 See the opinion of Koncessionsnämnden in Proposition 1997/98:45, 325-326.

231 Article 1 of the Radiation Protection Act.

232 Article 2 of the Radiation Protection Act.

${ }^{233}$ Compare with the general duties of care in Chapter 2 of the Environmental Code accounted for above in Section 5.1.

234 Strå̆lskyddslagen Article 6.
} 
the appropriate safety-arrangements. ${ }^{235}$ It is explicitly stated that precautionary measures are included in this obligation also under the Radiation Protection Act. ${ }^{236}$

The government, or any authority appointed by it, may establish further detailed provisions regarding protection and control of radiation. ${ }^{237}$ The Swedish Radiation Protection Agency (Statens Strålskyddsinstitut (hereinafter referred to as SSI)) has been given this task and will be returned to below. ${ }^{238}$

As mentioned above, the establishment of base stations for mobilc telephony is not subjected to a centralised authorisation scheme like the one which is in place for pesticides. Instead, the establishment falls under general planning rules. Such rules arc laid down in the Planning and Building Act, according to which, it is up to local authorities to plan the use of land and water. ${ }^{239}$ The relationship between the Environmental Code, which lays down the gencral environmental rules, and the Planning and Building Act, which is lex specialis for planning and building issues, is not entirely clear. ${ }^{240}$ The rules are, to a large extent, of similar character and can be said to complement each other. However, some serious discrepancies are apparent. For example, the Planning and Building Act does not include anything resembling the precautionary principle included in the Environmental Code. According to the preparatory works to the Planning and Building Act, the rules relating to the care for common interests are of a deliberate general character, in order to allow for interpretation in the light of societal changes. ${ }^{241}$ This would indicate that the precautionary principle, as well as the other general considerations in Chapter 2 of the Environmental Code, could bc of relevance for the Planning and Building Act. This is further supported in the preparatory works, where it is held that the Environmental Code is to influence the interpretation of the Planning and Building Act and that that the increasing importance of environmental concerns and the considerations in Chapter 2 of the Environmental Act should

235 Strålskyddslagen Article 6.

${ }^{236}$ Strålskyddslagen Article 6, point 1.

237 Strålskyddslagen Article 12.

238 Förordning med instruktion för Statens strălskyddsinsititut (1988:295). After the complesion of this thesis, SSI was reorganised and remaned Statens stålsäkerhetsmyndighet (SSM). The application of the rules of relevance for this book has not changed. See http:/www.stralsakerhetsmyndigheten.se/Allinanhet.

239 Plan- och Bygglagen Article 2.

${ }^{240}$ See, for example, B. Bengtsson, Speciell fastighetsrätt, Iustus 1999, p. 20 and M. Eriksson, Placera masten rätt: Miljö och naturskyddskrav på 3G-utbyggnaden, Svenska Naturskyddsföreningen Rapport, (Svenska Natuskyddsföreningen 2003), p. 10.

241 Proposition 1994/95:230, p. 30. 


\section{Joakim Zander}

play a role in the application of the Planning and Building Act. ${ }^{242}$ This issue $\mathbf{h}$; discussed in some highly interesting cases in which the plaintiffs have relied precautionary principle to challenge planning permission relating to base stations bey Swedish courts. This issue is returned to below.

In order to establish a base station, planning permission from the releva: authorities needs to be sought. ${ }^{243}$ Every local government should have a building-cosy which receives applications and grants planning permissions. ${ }^{244}$ In general, permission regarding base stations is granted provided that the provisions in Articles and 3:10-3:13 of the Planning and Building Act are fulfilled. ${ }^{245}$ These articles primarily aesthetic requirements, both with regard to other buildings in the area and Only in Article 3:2 of the Planning and Building Act is it pointed out that installations to interfere negatively with traffic or otherwise pose "significant detriment" surroundings. ${ }^{246}$

\subsubsection{The Institutional Framework}

Base stations for mobile telephony is regulated on two main levels in Sweden. F Radiation Protection Act establishes that the government, or an authority set up government, may issue binding regulations for radiation safety. ${ }^{247}$ This task entails the of safety standards for different types of radiation, including mobile telephony. This $\mathbf{b}$ delegated by decree to the SSI. ${ }^{248}$ Second, local governments have been authorised, the Planning and Building Act, to decide on the location of base stations. This separ competences indicates that the SSI is the appropriate body to set the level of risk all relation to base stations. Local authorities should thus be exempt from taking a more precautionary stance than that set by the SSI. Their task, provided that the reque building permit meets the SSI standard, is limited to ordinary planning concerns. The this issue is far from uncontroversial is returned to shortly.

${ }^{242}$ Proposition 1997/98:90, Följdlagstiftning till Miljöbalken mm., p. 158.

${ }^{243}$ Plan- och Bygglagen 8:2 p. 5 establishes that radio or telephone masts or towers are subjected to requirement of authorisation.

244 Plan- och Bygglagen Article 8:19.

245 Plan- och Bygglagen Article 8:11 p. 3 in conjunction with Plan- och Bygglagen Article 3:14. Slight d in the procedure are in effect depending on whether the area where the installation is to be established included in a detailed area plan or not (Compare Plan- och Bygglagen Articles 8:11 and 8:12). Itowe differences are of no relevance for the discussion here.

246 "Betydande olägenheter." (Translation by author).

${ }^{247}$ Strålskyddslagen Article 12.

${ }^{248}$ Förordning med instruktion för Statens strålskyddsinstitut (1988:295) 
Like the Swedish agency responsible for chemicals, KemI, which was discussed above, the SSI is an independent agency and the government is prevented from interfering with its work directly. However, and also as in the case of KemI, the government retains important possibilities to exert control over the SSI and direct its work through both appointments and budget control documents.

The SSI has a number of tasks relating to rescarch and advice. It is the co-ordinator of radiation research in Sweden, and is responsible for providing information to the public in this field. ${ }^{249}$ It may inform and issue recommendations regarding radiation protection, ${ }^{250}$ and it has been given the power to issue prohibitions or other conditions where this is necessary for the fulfilment of the objectives in the Radiation Protection Act. ${ }^{251}$ As with other Swedish agencies, the work of the SSI is led by a Director General who is appointed by the government. ${ }^{252}$ The Director General is seconded by, but not subordinated to, a board whose members are also appointed by the government. ${ }^{253} \mathrm{~A}$ research council assists the Director General and the Board in setting the research agenda for the SSI. ${ }^{254}$ The function of the research council is advisory and here, too, the government retains powers through being responsible for appointing its chair. The other six members of the research council are appointed by the board of the SSI. ${ }^{255}$ Otherwisc, the SSI, like other agencies, is free to decide on its internal organisation. ${ }^{256}$ Furthermore, as in the casc of KemI, no apparent separation of risk assessment and risk management is in effect.

Furthermore, the SSI has the power to issue binding regulations within the framework outlined above, ${ }^{257}$ in order to ensure that the aims of the Radiation Protection Act are fulfilled. Such regulations are frequently issued by the agency. ${ }^{258}$ With regard to base stations, the SSI has stopped short of issuing binding requirements, and has, instead, opted for issuing non-binding General Advice. ${ }^{259}$ It is stated in the General Advice that it aims to

249 Ibid., Article 2, points 1-7 and 11.

250 Ibid., Article 2, point 6.

251 Strålskyddslagen Article 32.

${ }^{252}$ Förordning med instruktion för Statens strålkskyddsinstitut Article 5.

253 Verksförordning (1995:1322) Articles 32 and 33.

${ }^{254}$ Förordning med instruktion för statens strålskyddsinstitut Article 8.

${ }^{255}$ Förordning med instruktion för statens strålskyddsinstitut Article 9.

256 Verksförordning Article 17.

257 "Föreskrifter" (Translation by author).

${ }^{258}$ For a list of regulations issued by SSI which have been translated to English, see; http:/www.ssi.se/forfutming/Eng ForfattLista.html.

259 Statens strålskyddsinstituts föreskrift SSI FS 2002:3, Allmänna råd om begränsning av allmänhetens exponering för clcktromagnetiska fält (General Advice on Limiting the Public's Exposure to Elcctomagnetic Fields 


\section{Joakim Zander}

provide guidance for the interpretation of Article 6 of the Radiation Protection Act. ${ }^{260}$ As mentioned above, Article 6 of the Radiation Protection Act establishes that radiation should be allowed only when it is at a level that is safe for humans, and that it should include a precautionary approach. The issue is returned to below. Even though it is not formally obliged to, it appears that courts have, so far, proven inclined to rely extensively on the SSI General Advice when deciding on issues relating to the risks stemming from base stations. ${ }^{261}$ For the most part, this may be due to the fact the General Advice is the only comprehensive advice issued by a government body and that it effectivcly codifies the international standards in the area.

Since the General Advice is not binding, local authorities are not formally bound by it when dealing with planning matters which come before them. This could potentially create some leeway for authorities to make their own risk assessments. However, the Government, and, on appeal, the Supreme Administrative Court, have, in three judgments, stated that planning permissions regarding base stations cannot be challenged on health grounds when the radiation emitted from them is in line with the General Advice. ${ }^{262}$ In Case 1163-2001 the County Administration ${ }^{263}$ in Dalarna went as far as to state:

"The County Administration must, when deciding upon the appeal, consider what can be considered scientifically proven at the time of the decision."264

The decision of the County Administration was upheld in both the Government Decision and the Decision of the Supreme Administrative Court. It thus appears relatively clear from the case law that the courts consider the General Advice of the SSI to be the relevant provision against which to judge the risks stemming from base stations. In the light of this, local authorities should be exempt from taking a more precautionary stance than the

(hereinafter referred to as "the Gencral Advice").

260 The General Advice, Article 1 .

261 See the following judgments from the Swedish Supreme Administratvie Court: Judgment of the Supreme Administrative Court in Case nr. 1163-2001 delivered on 12 July 2001 (not reported); judgment of the Supreme Administrative Court in Case nr. 3635-1999 delivered on 14 October 1999 (not reported) and judgment of the Supreme Administrative Court in Case nr. 3650-1999 delivered on 14 October 1999. The latter was also reported in a note in the yearbook of the Swedish Supreme Administrative Court (RA 1999 not 217). See, also, judgments from lower Environmental Courts in, for example, M390 05, Växjö Tingsrätt, Judgement of 3 262 Ibid.

${ }^{263}$ Länsstyrelsen (translation by author) is the first instance of appeal of decisions taken by local government. October 2005 and M3123 04, Östersunds Tingsrätt, Judgment of 12 January 2005.

264 "Länsstyrelsen måste vid sin prövning av överklgandet ugtå från vad som kan anses vara vetenskapligt belagt vid tidpunkten för prövingen." (Regeringsrättens dom i mål nr, 1163-2001). 
one advocated there. That this is also the view of the government was cmphasised in a recommendation from the National Board of Health and Welfare, ${ }^{265}$ which was addressed to local governments, in which it was stated that the precautionary principle cannot bc used by them to limit the planning of base stations. ${ }^{266}$ The National Board of Health and Wclfare has a stake in the regulation of base stations since it is the agency which is generally responsible for health issues in Sweden.

Finally, it should be mentioned that, since radiation from base stations is considered environmentally hazardous according to Chapter 9 of the Environmental Code, local governments have the authority to oversee the fact that the activities are safe. However, when doing so, it appears that they should use the SSI General Advice as a benchmark. ${ }^{267}$ This issue is returned to in the following.

\subsubsection{Risk Assessment and Risk Management}

Due to the imporlance given to the SSI General Advice by courts, as well as the administration, it can safely be argued that it codifies the Swedish approach to radiation from base stations. A closer look at the General Advice and the risk assessment on which it is based is, therefore, warranted.

As has been mentioned throughout this chapter, a separation of risk assessment and risk management is generally not in place in Sweden. ${ }^{268}$ With regard to radiation, the SSI has the task of preparing research as well as taking decisions based upon it. With regard to base stations, the General Advice is not based upon an original risk assessment by the SSI. Instead, the aim is to incorporate the EU Council Recommendations dating from 1999 in Sweden. ${ }^{269}$ Thus, the SSI has substituted the major part of its risk assessment with that which has been accepted by the Council. It, in turn, merely incorporates the recommendations issued by the International Commission for Non-Ionising Radiation Protection (ICNIRP), which is based upon a literature study performed by ICNIRP.

The actual risk assessment performed by the SSI is limited to establishing whether the radiation emitted in Sweden falls within the scope of the ICNIRP recommendations. This

\footnotetext{
265 Socialstyrelsen.

266 Meddelandeblad från Socialstyrelsen till kommunala miljö- och hälsoskyddsnämnder, länsstyrelser och andra berörda myndigheter, June 2005. Available at: http://www.ssi.se/ickejoniserande stralning/Magnetfaelt/Forsiktighetspincip.html.

267 Sce the reasoning by the Environmental Court of Appeal in Case MÖD 2005:55.

268 See, above, Section 5.1.4.

269 Article 1.1, SSI FS 2002:3.
} 


\section{Joakim Zander}

assessment is performed in an SSI Report which precedes the issuing of the General Advice. ${ }^{270}$ In this report, the SSI presents findings from empirical studics of emitted radiation relating to mobile telephones in different situations. The study centres solely on the amount of radiation emitted, not on the actual or perceived effects it has or may have. The values measured are then compared with the ICNIRP values and declared to be in conformity with them. 271

\subsubsection{The Level of Proof and the Triggering of Precautionary Measures} The precautionary principle is intended to guide all areas of environment and health protection in Sweden. This is stated in Article 2:3 of the Environmental Code, which has bcen discussed extensively above. That the precautionary principle is also meant to guide issues relating to radiation is established in Article 6 of the Radiation Protection Act, in which it is held that "precautionary measures" should be considered in order to mitigate the risks from radiation. In the preparatory works, it is emphasised that areas of scientific uncertainty should be covered by the provision. ${ }^{272}$ The Planning and Building Act does not include any explicit reference to the precautionary principle. The courts and some government agencies have made it clcar that prccautionary considerations should not be guiding local governments when issuing planning permission for base stations. Thus, it appears that the precautionary principle is not a tool that can be applied at local level, but can be applied only by the central government or its agencies.

In 1996, a number of government agencies, including the SSI, issued a joint statement (hercinafter referred to as "the Joint Statement") with the aim of clarifying the application of the precautionary principle for low frequency electromagnetic radiation. ${ }^{273}$ The prime target for the Joint Statement was the "ordinary sources" of electromagnetic radiation, such as houschold electricity, but it was indicated that it should also be used by analogy in other situations in which radiation may be a concern. In the commentary to the General Advice, the SSI has explicitly referred to the Joint Statement in relation to base stations for mobile phones. ${ }^{274}$ Thus, it can be assumed that the Joint Statement indicates how the precautionary

${ }^{270}$ U. Bergqvist, et al., Exponering för radiofrekventa fält och mobiltelefoni, SSE rapport: 2001:09 (April 2001).

271 Ibid., p. 32-33.

272 Proposition $1987 / 88: 88$, p. 65.

${ }^{273}$ Myndigheternas försiktighetsprincip om lågfrekventa electriska och magnetiska fält- en vägledning för beslutsfattare, available at http://www.av.se/dokument/publikationer/adi/adi 477 .pdf.

274 Kommentarer till Statens strålskyddsinstituts allmänna råd (SSI FS 2003:3) om begränsning av allmänhetens exponering för elektromagnetiska fält. (Translation by author), p. 2. Available at: htip://www.ssi.se/fortatming/pdt/2002 3Komment.pdi. 
principle is to be applied even in the field of mobile telephones. In the Joint Statement, the precautionary principle is defined as follows:

"If measures, which generally reduce exposure, can be taken at reasonable costs and other consequences onc should strive to reduce fields that deviate significantly from what can be considered normal in the local environment. As regard new electrical installations and buildings, one should strive already at the planning stage to shape and place these so as to reduce radiation."275

According to the SSI, this definition of the precautionary principle corresponds to the one included in Article 2:3 Environmental Code. ${ }^{276}$ However, a closer look at the wording suggests that the Joint Statement is significantly weaker than the wording of the precautionary principle in the Environmental Code. By making precautionary measures contingent upon whether they can be taken incurring "reasonable costs and other consequences", it appears that some form of extended cost/benefit analysis (costs and "other consequences" are included) is at the centre of the equation. This would be in contrast to the Environmental Code, in which it appears that precautionary measures should always be taken unless manifestly unreasonable. ${ }^{277}$ Furthermore, the definition provided by the government agencies holds that precautionary measures should only be triggered when radiation "deviates significantly" from what is "normal in the local environment". This seems to indicate that risk levels are not absolute, but that they may vary between different areas. Such an approach appears a far cry from the strict and absolute precautionary principle in the Environmental Court.

That the precautionary principle is applied very differently when it comes to base stations than is the case in pesticide regulation becomes clear when considering the General Advice in detail. The General Advice is based directly on the ICNIRP recommendations, as accepted by the Council Recommendations. Thus, the precautionary' considerations taken when constructing the ICNIRP values are the ones in effect in Sweden.'However, the ICNIRP guidelines are based on "scientific data alone". ${ }^{278}$ This means that only scientifically-

${ }^{275}$ Myndigheternas försiktighetsprincip om lågfrekventa elektriska och magnetiska fălt- en vägledning för beslutsfattare, p. 2.

${ }^{276}$ Kommentarer till Statens strålskyddsinstituts allmänna råd (SSI FS 2003:3) om begränsning av allmänhetens exponering fờr elektromagnetiska fält.

${ }^{277}$ See, above, Section 5.1.

${ }^{278}$ International Commission on Non-Ionizing Radiation Protection, Guidelines for Limiting Exposure to TimeVarying Electric, Magnetic, and Electromagnetic Fields (up to 300 GHZ). Health Physics. Vol 74. No. 4, 1998, 


\section{Joakim Zander}

cerlain $^{279}$ data is taken into account when setting the suggested exposure limits. That this is the case is illustrated by the discussion on potential cancer risks in the ICNIRP Guidelines. It is recognised here that epidemiological research has suggested a potential connection between exposure to low frequency electric magnetic fields and the development of cancer in humans. This issue is also receiving increasing attention from well-reputed researchers in the area. ${ }^{280}$ But since the data is "insufficient", the ICNIRP does not consider it necessary to adjust the exposure guidelines in the light of this. ${ }^{281}$ It furthermore indicated that epidemiological studies alone are not sufficient to warrant stricter guidelines. The results of such studies must be substantiated by laboratory experiments. ${ }^{282}$ Scientific unccrtainty is recognised by the ICNIRP, but is not allowed to influence the setting of exposure limits. A more recent review by the ICNIRP Standing Committee on Epidemiology found that current epidemiological studies were not only marred by inconsistencies but were also lacking in substantive quality. Thus, they did not warrant any stricter guidelines than the ones already in place. ${ }^{283}$ The approach suggested by the ICNIRP, which is implemented in the EU Council Recommendations as well as in the SSI's General Advice, must be considered to be protective against scientifically certain risks, but does not aim to be protective under conditions of uncertainty. They do not "err on the side of caution", but disregard risks that are not scientifically-verified. Thus, the guidelines are more preventive than precautionary in character.

The above conclusion does not stop the SSI from holding explicitly that "base station antennas for mobile telephony do not pose any risk from the point of view of radiation protection". ${ }^{284}$ This is taking the matter a step further even than the ICNIRP, in which, at least, the uncertainties are emphasised, rather than merely glossed over with categorical statements.

p. 494-522 (hereinafter referred to as "the ICNIRP Guidelines"), at p. 495.

279 Data that is certain with at least a $95 \%$ probability. Compare discussion above in Sections 2.3.1 - 2.3.3.

${ }^{280}$ See, for example, M. Blank, The Prccautionary Principle Must Be Guided by EMF Research, Electromagnetic Biology and Medicine, Vol. 25, 2006, pp. 203-208.

281 ICNIRP Guidelines. p. $496 \& 503$.

282 Ibid., p. 503.

${ }^{283}$ ICNIRP (International Commission for Non-Ionizing Radiation Protection) Standing Committee on Epidemiology. Epidemiology of Health Effects of Radiofrequency Exposure. Environmental Health Perspectives, Vol. 112, No. 7. December 2004.

284 "SSI gör den sammanfattande bedömningen att basstationsantenner för mobiltelefoni inte innebär năgon risk ur strålskyddssynpunkt." Taken from FAQ on basestations and masts on SSI's homepage. Frågor och svar om basstationer och master. Available at: www ssi.se/ickejoniserande stralning/mobiltele/FAO/FAQ2 bas master.html. 
The courts have also proven inclined to rely only on what is scientifically verified in cases relating to base stations. For example, one of the cases discussed above was brought by a woman who claimed to be overly sensitive to electromagnetic fields. ${ }^{285}$ She held that due to her condition, base stations in the area she lived caused her significant problems. She based her argument upon a number of scientific reports, which suggested biological effects as a result of exposure to electromagnetic fields. ${ }^{286}$ The County Administration, however, ignored the scientific reports introduced by the plaintiff, seemingly on the basis that they were marred by uncertainty. As cited above, the Court even went as far as to state that it would only base decisions on what can be considered scientifically proven at the time. Thus, the Court merely concluded that, since the emission of radiation affecting the plaintiff was within the ICNIRP guidelines, no other measures nceded to be considered. The case was upheld in full on appeal to the Government as well as to the Supreme Administrative Court. When this approach is compared to the approach assumed in relation to pesticides, the differences are significant. Where uncertainties in relation to pesticides are cmphasised and used as a foundation for precautionary regulation, they are downplayed to the point of ignorance in relation to base stations.

In a more recent case, however, the Environmental Court of Appeal took a more nuanced view of the potential risks stemming from base stations. In its judgment of October 2005 , it recognised that thermal effects may not be the only risk in relation to base stations, but that some scientific findings also indicate biological effects which are not accounted for in the ICNIRP values. This, the court found sufficient to declare the siting of base stations an environmentally hazardous activity. ${ }^{287}$ The practical implications of this finding are, as was touched upon above, however, unclear. It does not appear that, in practice, it would require a more precautionary approach to be assumed. Interestingly, the court also mentioned that it found the psychological unease and worry of people living near base stations sufficient to consider the activity as environmentally hazardous. ${ }^{288}$ In practice, it is unlikely that the findings of the Environmental Appeal Court will entail any concrete change with regard to what needs to be shown regarding the risks associated with base stations.

${ }^{285}$ The judgment of the Administrative Supreme Court Case nr, 1163-2001.

286 Ibid.

287 Judgment of the Environmental Supreme Court in Case MÖD 2005:55.

288 Ibid. 


\section{Joakim Zander}

The reluctance of both the SSI and the courts to take assume a more precautionary stance have, in some cases, prompted local government to contemplate taking precautionary mcasures on its own. The discussion has been centred on using planning decisions taken under PBLto create so-called "radiation-free zones". At the time of writing, only one Swedish local government has been clearly identified as intending to establish radiation-free zones within its area. Here, the concern was primarily with pcople who appear to be overly sensitive towards electromagnetic fields. ${ }^{289}$ Planning decisions are not legally-binding, but are intended to guide the development at local lcvel. Due to their inherent nature of the policy, it is unlikely, at this point, that a planning decision establishing a radiation-free zone could be successfully challenged before the courts. The cases referred to in this chapter have all dealt with cases in which individuals have challenged planning permission, which have clear and unambiguous legal effects. However, it could be foreseen that a request for a building permit regarding a base station could be denied on the basis that the area in question has been declared radiation-free. In that case, the decision to deny the permit could be challenged before the courts, and they would, in turn, be forced to consider whether the establishment of radiation-free zones are within the ambit of the PBL.

\subsubsection{The Burden of Proof}

At this point, the Swedish government has not assumed a particularly precautionary approach with regard to base stations. By relying on international standards and EU recommendations, it has effectively prevented itself from making its own risk assessment of the issue. The burden of showing risks stemming from base stations appears to rest firmly with the party making that claim. The courts have, so far, not found that an applicant has managed to fulfil this obligation, and thus no successful appeals regarding decisions to site base stations exist on health grounds. ${ }^{290}$ Courts have made firm demands on the scientific evidence needed for a successful appeal.

As mentioned above, the Environmental Appeal Court has, in one instancc, highlighted uncertainties in relation to base stations. ${ }^{291}$ However, this case related to whether the local government was obliged to check the compliance of an undertaking with the

${ }^{289}$ Översiktsplan 2003 Nyköpings kommun - Kommunens vilja och ambition, 50 and 88 . Available at http://www.nykoping.se/op2003/pdf/huvud.pdf.

290 Judgment of the Supreme Administrative Court in Case nr. 1163-2001; judgment of the Supreme Administrative Court in Case nr. 3635 and judgment of the Supreme Administrative Court in Case nr. 3650-1999. The latter was also reported in a note in the yearbook of the Swedish Supreme Administrative Court (RA 1999 not 217). See, also, judgments from lower environmental courts in, for example, M390-05 and M3123-04.

${ }^{291}$ Case M7485-04. 
radiation levels currently recommended in Sweden. By declaring that radiation from third generation mobile phone systems is, indeed, to be considered to be an environmentally hazardous activity, the court found this to be the casc. It is unlikely that the Environmental Court of Appeal would find the same scientific cvidence considered in the case to be sufficient to overturn the granting of a building permit of a base station which complied with the said recommendations. ${ }^{292}$ Previous case law unequivocally indicates that the guidelines issued by the SSI, which are, in turn, based on the ICNIRP recommendations, assure an adequatc level of protection. This clearly indicates that the burden of proof in cases relating to the risks stemming from base stations is firmly placed with the party claiming the health risk, at least in situations in which the recommended limits are abided by. This is the direct opposite of the situation in relation to pesticides, where uncertainties with regard to potential health risks explicitly mandate strict regulation.

\subsubsection{Cost/Benefit Analysis}

Nothing is mentioned in relation to cos/bencfit analysis in either the SSL or in the General Advice. However, the general "unreasonable-test" in Article 2:7 of the Environmental Code must be considered applicable also in the area of radiation, just like in the case of pesticides. As discussed above, the requirement enshrined in Article 2:7 of the Environmental Code is not a traditional cost/benefit or proportionality requirement. Instead, it aims to codify earlier Swedish practice which stated that actions to protect the environment should not be taken only in cases in which this was not "environmentally justified". Above, it was argued that it appears that such situations are those situations in which excessive costs are incurred and the result is only limited environmental benefits. Thus, the presumption is that measures should be taken. Only where they would be manifestly unreasonable should they not be taken.

In the Joint Statement, on the other hand, the role of economic considerations is strongly emphasised when it comes to regulating the risks from radiation. In the definition of the precautionary principle found there, it is emphasised that measures should be taken only if they incur "reasonable costs and other consequences". ${ }^{293}$ Through this, effectiveness considerations have been given a more pronounced place when contemplating precautionary measures in relation to radiation than is the case in relation to, for example, pesticides. That what is referred to is a bona fide cost/benefit analysis is clearly emphasised in the text of the

292 Ibid.

${ }^{293}$ Myndigheternas försiktighetsprincip om lăgfrekventa electriska och magnetiska fält- en vägledning fờr beslutsfattare, p. 2. 


\section{Joakim Zander}

Joint Statement, in which the suggested considerations are centred on the monelary costs of saving statistical lives. ${ }^{294}$ However, even though it clearly advocates a cost/benefil based approach to precautionary measures, the Joint Statement stops short of delining what would be a "reasonable" cost for saving one statistical life. This issue, it apparently leaves to the decision-makers in individual cases. On the whole, the role of cost/benefit considerations appears wholly different in instances of radiation than is the case with regard to pesticides, where officials at KemI held that the prospective costs of regulation play no role whatsoever. ${ }^{295}$

\subsubsection{Conclusion}

Three main legislative acts arc involved at different, but partly overlapping, levels when it comes to the regulation of base stations in Sweden. First, the Environmental Code establishes that all aspects of environment and health protection in Sweden should be guided by the precautionary principle. The content of the strict precautionary principle enshrined there has been discussed extensively in the previous chapters. The Environmental Code also establishes that both ionising and non-ionising radiation are to be considered as "environmentally hazardous activities" if they "may cause detriment to the surroundings". That this is the case for base stations has been established by the Supreme Environmental Court. However, so far, this finding has had little impact on how base stations are regulated in Sweden.

Second, instead of a centralised procedure, the placing of base stations is regulated as a general planning decision under Planning and Building Act. Such decisions are taken at local level by local govemments. The Planning and Building Act does not include a specific precautionary principle, but a study of preparatory work and the literature suggests that the Environmental Code version of the precautionary principle should be guiding planning decisions as well. However, the Swedish Agency for Social Affairs, which is mainly responsible for health issues, has, in no uncertain terms, indicated in a communication to local government that the precautionary principle should not be applied with regard to base stations at local level. This approach has been upheld by courts in the scarce case law existing in the area.

\footnotetext{
${ }^{294}$ Myndigheternas försiktighetsprincip om lågfrekventa electriska och magnetiska fălt- en vägledning för beslutsfattare, p 3, and p. 6-7.

295 Interview with officials at KemI, 09 September 2004.
} 
Third, the Radiation Protection Act lays down the framework for radiation protection in general. Radiation Protection Act concerns both ionising and non-ionising radiation, and, read in the light of the preparatory work, it includes a weak precautionary principle. It allows for the delegation of the issuing of standards and the control of the implementation of the said standards to a government agency. The agency that has been given these tasks is the SSI, which, in relation to base stations, has stopped short of issuing binding requirements on the emission of radiation from base stations. Instead, it has chosen to implement the EU Council Recommendation, which, in turn, is a direct implementation of the ICNIRP Recommendation, in the form of a General Advice. This General Advice has been relied on heavily by courts in a few cases. However, even if no strong precedents have, so far, been created, it must be assumed that the General Advice is a direct manifestation of the Swedish policy toward radiation from base-stations. Since the ICNIRP Recommendation is based solely upon scientifically-verified thermal effects in humans, it can hardly be perceived as incorporating a precautionary approach in the broad sense. Minority medical and epidemiological studies exist, which suggest the presence of risks which were not taken into account when the Recommendation was formulated. The scientific uncertainty in the area must be considered as being relatively great, and is generally acknowledged by scientists and decision-makers. This uncertainty is largely due to the lack of conclusive research, rather than due to conflicting evidence. This, however, is not recognised by the SSI, which, in its information material, repeatedly states that base stations are safe from a human health perspective.

The finding that the precautionary principle applied in cases of low frequency radiation is different and weaker than the remarkably strict approach found in the area of pesticides is supported by a joint communication from a number of Swedish agencies. In the communication, the precautionary principle in the area of low frequency radiation is understood as relative to the area in which it is being applied and directly contingent upon cost/benefit considerations.

Some facts make the leniency toward mobile telephony understandable. In Sweden, the government estimates that 9 out of every 10 people in the age group of 16-75 years of age use mobile phones, and Sweden's largest infrastructure project is the extension of third generation mobile telephony to the whole country. Information technology and telecommunications has rapidly become the most important sector of Swedish industry, and it 
Joakim Zander

currently employs directly almost 200,000 people. Telecommunications accounts for $20 \%$ of the overall industrial value of Sweden and $15 \%$ of total exports. ${ }^{296}$ The mobile phone systems manufacturer Ericsson undoubtedly accounts for a sizeable share of these figures.

When considering the political importance that the Swedish government has attached to full geographical mobile phone coverage, and the macro-cconomical importance of the Swedish telecom sector, downplaying the risks stemming from base stations makes political sense. However, if one values a rational agenda-setting based on public health protection, the setting of actual risk-levels, and consistency in the application of the law, this is an approach which is difficult to defend. When comparing the Swedish use of the precautionary principle in the area of pesticides with how it has been used in the arca of base stations, it appears that political and economic considerations are highly influential in determining how comparable risks should be treated. This is a far cry from the strict and absolute precautionary principle advocated in the Environmental Code. And, furthermore, it suggests that the precautionary principle in Sweden in its present form may often function as a political tool rather than as a legal instrument which is equally applicable in all similar situations.

${ }^{296}$ http://www.sweden.se/templates/cs/FactSheet [4931.aspx. 


\section{CHAPTER 6.}

\section{THE PRECAUTIONARY PRINCIPLE IN THE UNITED KINGDOM}

\subsection{The Development and Status of the Precautionary Principle in the UNITED KINGDOM}

\subsubsection{Introduction}

In Sweden, the precautionary principle has, in one way or another, been a basic clement of environmental and health protection for more than 30 years. It is firmly embedded in legislation and has been fleshed out, to a considerable degree, in preparatory works, casc law and guidance documents. In the UK, the story is very different. Even though precautionary decisions have, historically, been taken in various policy sectors in the UK, a more consistent approach, spanning across all policy areas, was not considered until the early 1990s. Lacking reference in statutory instruments, the precautionary principle has been dealt with in documents of policy nature. Following this development, the precautionary principle has tentatively been relied on before the UK courts. Since the precautionary principle has not been included in UK legislation, the sources for this chapter mainly include policy documents and relevant judgments of UK courts.

In this chapter, the background, development and status of the precautionary principle in the UK will be analysed and discussed. As in the previous chapters, constituent elements of the precautionary principle, such as risk assessment and management, the rolc of scientific evidence, and cost/benefit analysis are discussed separately.

\subsubsection{Background and Development}

Where the precautionary principle in Sweden can be traced back to, at least, the late 1960s, a general precautionary mechanism in the UK is a much more recent concept. This does not, however, mean that precautionary conccrns have not been influential in shaping policy. As the Australian judge Stein J. of the Land and Environment Court of New South Wales has stated: 
Joakim Zander

"[The precautionary principle] is a statement of common sense and has already been applied by decision-makers in appropriate circumstances prior to the principle being spelt out."

Even though the term "precautionary principle" is a recent concept, UK risk regulation can be traced back to 19th century and the first Smoke Abatement Law, which restricted the burning of coal in London. ${ }^{2}$ Other notable early pre-precautionary principle actions include the introduction of the Alkali Act of 1863, which was concerned with the regulation of heavy chemicals. ${ }^{3}$ These acts represent regulation undertaken in areas affected by varying, but significant, degrees of uncertainty. Thus, they can also be considered to have been issued on the basis of some basic precautionary considerations. Early developments such as those described above have little to do with a comprehensive, modern version of the precautionary principle, but are important examples of the fact that regulation in the face of varying degrees of uncertainty is hardly a new issue. The precautionary principle as an independent legal instrument, on the other hand, is.

Following the increasing international concern for environmental issues in the last two decades of the 20th century, UK government statements and publications tentatively began to recognise the precautionary principle in a broad sense in the late $1980 \mathrm{~s} .{ }^{4}$ In January 1988, the Minister of State for the Environment stated that the UK officially accepted the precautionary principle. ${ }^{5}$ However, in the UK as clsewhere, a more precise content of the principle was not elaborated on at this time.

Before UK courts, the precautionary principle was relied on as an independent legal ground in the Duddridge case of $1994 .{ }^{6}$ The case regarded an application for judicial review of a decision whereby the Secretary of State for Trade and Industry had declined to issue regulations restricting the electromagnetic fields created by electric cables. The application

1 Leatch $\mathrm{v}$ Director-General of National Parks \& Wildlife Service and Shoalhaven City Council [1993] NSWLEC 191 (23 November 1993) (Land and Environment Court of New South Wales) (No 10376 of 1993). Available at: http://www.elaw.org/resources/text.asp?id=2791.

2 Sec, for example, C. Flick, the Movement for Smoke Abatement in 19th-Century Britain, Technology and Culture, Vol. 21, No. 1, pp. 29-50.

3 See, for example, W.A. Damon, The alkali act: Its administration and relation to chemical industry, Journal of the Society of Chemical Industry, Volume 54, Issue 50, p. 1070-1075. Published online 29 May 2007.

4 For a summary of such examples see, N. Haigh, The Introduction of the Precautionary Principle into the UK, in T. O'Riordan \& J. Cameron (eds), Interpreting the Precautionary Principle, Earthscan, 1994, pp. 247-251.

5 Ibid., 247.

$6 \quad R \vee$ Secretary of State for Trade and Industry ex parte Duddridge and Others, Queen's Bench Division (Crown's office List), The Independent, 4 October 1994. 
was brought on behalf of three children living in an area in which the new National Grid was to be drawn. In the case, the ruling judge found that the precautionary principle was essentially designated for environmental protection, and that the only reference of potentially binding nature in the UK would be Article 174 of the EC Treaty. However, at EC level, the Court found the precautionary principle to be limited to the interpretation of EC legislation, and it thus has no relevance for the application or interpretation of strictly national legislation. ${ }^{7}$ The Court did not rule out the possibility of taking precautionary measures, but stated that it would be for the Secretary of State to use his discretion to decide whether to issue these or not. Thus, the Court did not find the precautionary principle to function independently or to bind the government positively to act in a precautionary manner. ${ }^{8}$ Below the judgment in Duddridge is discussed and compared to more recent case law and other developments, including, among other documents, the 2002 Report of the Inter-Departmental Liaison Group on Risk Assessment (hereinafter referred to as "the ILGRA Report")."

\subsubsection{The Current Context and Definition of the Precautionary Principle}

Early documents relating to the precautionary principle in the UK are mainly concerned with establishing that the UK accepts the concept, but do not flesh out the actual content of it. The most commonly referred to document in this regard is the 1990 White Paper "This Common Inheritance", which includes a passage on precaution. ${ }^{10}$ This section states that:

"Where there are significant risks of damage to the environment, the Government will be prepared to take precautionary action to limit the use of potentially dangerous materials or the spread of potentially dangerous pollutants, even where scientific knowledge is not conclusive, if the balance of likely costs and benefits justifies it. This precautionary principle applies particularly where there are good grounds for judging either that action taken promptly at comparatively low cost may avoid more costly damage later, or that irreversible cffects may follow if action is delayed."

Ibid.

Ibid.

9 The Precautionary Principle: Policy and Application, Report of the Inter-Departmental Liaison Group on Risk Assessment, 2002. Hereinafter referred to as "the ILGRA Report". Available at: http://www.hse.gov. uk/aboutus/meetings/ilgra/pnoa.htm

10 White Paper "This common Inheritance: Britain's Environmental Strategy", presented to Parliament, September 1990, HMSO, Cm 1200.

11 Ibid., 1.18 


\section{Joakim Zander}

In the following section of the White Paper, it is emphasised that precautionary action must be based on "sound science". 12 The definition contained in the White Paper appears to make any precautionary measures contingent upon cost/benefit analysis. Thus precautionary action should only be taken where the benefits of action outweigh the costs. Furthermore, it should be pointed out that the definition does not limit the precautionary principle to situations in which the potential damage associated with an activity are irreversible, but it does emphasise that precautionary measures in such situations may be particularly motivatcd.

After the adoption of the Rio Declaration in 1992, the UK definitions of the precautionary principle have centred on the version included in its Principle $15 .^{13}$ Increasingly, the principle appears to be defined in broad and general torms as an instrument which enables action at an early stage and aims to avoid "paralysis by analysis". ${ }^{14}$ Such broad statements have led some commentators to consider it "[...] a rather shambolic concept muddled in policy advice and subject to the whims of international diplomacy and the unpredictable public mood over the true costs of sustainable living". ${ }^{15}$ The case law has also failed to define the principle in a more concrete manner. Instead, it has been pointed out that "no comprehensive or authoritalive definition" exists in the UK. ${ }^{16}$ Courts have sometimes held that the definition and practice in relation to the precautionary principle which has developed at EC level should only bind the UK in as much as an EC legal act is being interpreted. ${ }^{17}$ However, in Turnbull, the court seemed to indicate that the precautionary principle as interpreted in Article 174 TEC could also have some influence in circumstances governed solcly by UK law. ${ }^{18}$ It was emphasised that this would have to be done on a caseby-case basis. That the precautionary principle as interpreted at $\mathrm{EC}$ level also has relevance in UK domestic affairs is further supported by the ILGRA Report. Here, it was held that:

"[a]pplying the precautionary principle is essentially a matter of making assumptions about consequences and likelihoods to establish credible scenarios, and then using

12 Ibid., 1.19 .

13 See, for example, the ILGRA Report.

14 Ibid, 5-6.

15 C. O'Riordan \& A. Jordan, The History and Contemporary Significance of the Precautionary Principle, in Interpreting the Precautionary Principle, Earthscan 1994, 23, and more recently quoted in J. Thornton \& S. Beckwith, Envrionmental Law, Swect \& Maxwell 2004, 15.

i6 $R$ Secretary of State for Trade and Industry ex parte Duddridge and Others, p. 3.

$17 \mathrm{Ibid}$, and $R$. v Derbyshire Country Council, ex parte, Queen's Bench Division (Administrative Court), 6 October 2000.

$18 R$ v Environment Agency ex parte Turnbull, Queen's Bench Division (Crown Office List), CO/4848/99, 12 January 2000. 
standard procedures of risk assessment and management to inform decisions on how to address the hazard or threat." 19

More recently, The Scicnce and Technology Committee of the House of Commons has expressed concern with regard to both the definition and the application of the precautionary principle in the UK. It stated that, due to the confusion surrounding the application of the principle and the different interpretations available, the principle has been "devalued and of little practical help". Pending further clarification with regard to scientific methodology, the Committee finds the principle to be unrealistic and impractical. Furthermore, it expressed its preference for using the term "precautionary approach" instead of "precautionary principle". Future work on the clarification of the principle or approach should be focussed on developing adequate "risk management theories" to be applied under uncertainty. ${ }^{20}$

Similar concerns have been expressed by the Sclect Committee on Economic Affairs in the Housc of Lords, which has stated that it finds the precautionary principle "ill-defined and ambiguous", and that it may lead to the assuming of an excessivcly cautious attitude to risk. $^{21}$

\subsubsection{Judicial Review}

Since the precautionary principle lacks an independent history in the UK, it has been held that a "true test" of its impact will be how it is received by the UK courts. ${ }^{22}$ Traditionally, judicial review in the UK is rather restrained. Not all measures, or aspects of measures, are subject to review by the courts. A few main issues in relation to judicial review are of interest here. First, high-level policy issues are deemed inappropriate for judicial review. As in the case of Sweden discussed above, the courts are prevented from "second-guessing" what are cminently political choices made by, or on behalf of, elected officials. ${ }^{23}$ As has been discussed in previous chapters, this has great significance for the precautionary principle since its application is generally decided on by the government or on behalf of the government with significant discretion.

19 Interdepartmental Group on Risk Assessment, The Precautionary Principle: Policy and Application, 2.

20 House of Commons Select Committee on Science and Technology, Scientific Advice, Risk and Evidence Based Policy Making, 7th Report of Session 2005-2006, Vol. I, Authority of the House of Commons, 2006, p. 82-83.

21 Select House of Lords Committee on Economic Affairs, Government Policy on the Management of Risk, 5th Report of Session 2005-2006, Vol. I, 25.

22 E. Fisher, Is the Precautionary Principle Justiciable?, J. of Env. Law, 13 (3), 2001, pp. 315-334.

23 E. Fisher, Is the Precautionary Principle Justiciable?, pp. 315-334. 


\section{Joakim Zander}

Second, courts defer to the discretion of bodies that have had decision-making powers delegated to them. In such cases, the courts will review the formal procedure under which the decisions were taken, but will only make a limited review of the substance of the case. This review is centred on the issue of whether the body acting with discretion has acted "unreasonably", and, if this is found to be the case, the measure can be quashed. The requirements for this to be the case are set very high. ${ }^{24}$ It has been held that this review is comparable to the limited review performed by the European Court of Justice. ${ }^{25}$ Such review is significantly more restrictive than the review performed by Swedish courts. ${ }^{26}$

Since the application of the precautionary principle is often highly political, and is used in cases of substantive uncertainty, often by bodies which have had decision-making powers delegated to them, it is not surprising that the UK courts have, to date, trod carefully in relying on the principle as an independent ground. In Alfred McAlpine Homes, the Secretary of State for the Environment applicd the precautionary principle as a statement of policy, and found explicit support for this before the Queen's Bench, and, even if it was not as explicit, on appeal before the Appeals Court. ${ }^{27}$ In Duddridge, the Court refrained from testing the substance of the case against the precautionary principle based on the fact that it considered its application to be within the scope of the discretion of the Secretary of State for the Environment. ${ }^{28}$ A similar approach was assumed by the Queen's Bench in Re Cullen. ${ }^{29}$ Similar for these cases is that they all uphold the decisions taken by the Minister using his discretion. This is the case in Alfred McAlpine and Re Cullen in which the precautionary principle was used to justify measures, but also in Duddridge, in which the principle was disregarded. Thus, it appears that the courts are reluctant to review measures taken with reference to the precautionary principle as well as measures taken disregarding it. Despite this, the courts have been inclined to perform a surprisingly material review of the scientific evidence placed before them. This issuc is returned to in the following.

24 P. Cane, Administrative Law, Oxford University Press, 2004, $250 \mathrm{et}$ seq.

25 E. Fisher, Is the Precautionary Principle Justiciable?, pp. 315-334.

26 In this regard, see, above, Section 5.4

27 Alfred McAlpine Homes (North) Ltd. v Secretary of State for the Environment and Another, Quecn's Bench Division (Crown's List), 5 April 1993 and Alfred McAlpine Homes (North) Ltd. v Secretary of State for the Environment and Another, Court of Appeal (Civil Division), 3 November 1994

$28 \quad R$ v Secretary of State for Trade and Industry ex parte Duddridge and Others.

29 Re Cullen, Queen's Bench Division, NIQB 9, 14 February 2005. 


\subsubsection{Risk Assessment and Risk Management}

No general explicit reference to formal requirements on decision-making in relation to risks is found in UK legislation. However, during the 1980s and 1990s, the understanding and use of analytical risk assessment increased markedly in the UK. ${ }^{30}$ The relevance of risk assessment in the respective sectors relevant here is returned to in the following chapters.

In 1995, the Department of the Environment published its first Guidelines outlining how it intended to make use of risk assessment, risk management and risk communication. ${ }^{31}$ This guide has since been updated and is available in its present form on the Department of the Environment webpage. ${ }^{32}$ In the Guidelines, the separation of risk assessment, risk management and risk communication is maintained, and each is elaborated on in a rather sophisticated fashion. When compared to, for example, the Commission Communication on the Precautionary Principle, ${ }^{33}$ the Guidclines appear nuanced and more overtly concerned with the process of decision-making. However, where one main feature of the Communication on the Precautionary Principle is the issue of how to obtain independent scientific advice and the fundamental importance of the separation of risk assessment and risk management, the Guidelines centre mainly on procedural issues of risk assessment and substantive issues of relevance for the risk management decision. This is exemplified by the organisation chart included, which prescribes rather detailed theoretical models for risk assessment, ${ }^{34}$ as well as the concern with risk trade-off analysis and cost/benefit analysis in the risk management phase. Less effort is spent on illuminating the border between what are risk assessment issues and what are management choices. Furthermore, little attention is given to the issue of how to make sure that as objective and independent scientific advice as possible is obtained.

In the ILGRA Report on the Precautionary Principle, it is not explicitly stated where in the process the precautionary measures should actually be decided on. However, considering that emphasis in the Report is put on the fact that the principle should be applied after a risk assessment has taken place with consideration of cost/bencfit analysis, it appears

30 E. Fisher, The Rise of the Risk Commonwealth and the Challenge for Administrative Law, Public Law, 2003, pp. $455-478$.

31 Department of the Environment, A Guide to Risk Assessment and Risk Management for Environmental Protection, HMSO 1995.

32 Department of Environment, Guidelines of Environmental Risk Assessment and Management, availablc at: httn:/www.defra.gov.uk/environment/risk/eramguide/ (hereinafter referred to as the Guidelines).

33 Communication from the Commission on the precautionary principle, COM 2000/1/Final.

34 Figure 2.1, available at: htp://www.defra.gov.uk/environment/risk/eranguide/03.htm. 
that the decision to issue precautionary measures is intended to be taken in the risk management phase. ${ }^{35}$

Given the lack of a clearer distinction between risk asscssment and risk management in cither legislation or in other government documents, it is hardly surprising that the courts have not touched upon the issue. However, considering what was stated above in relation to the deference of the courts to the discretion of the decision-maker, it could be presumed that they consider the application of the precautionary principle a management choice. Since management decisions are taken using the discretion that the relevant body has had delegated to it, the courts show significant deference in reviewing their substance.

\subsubsection{Scientific Evidence and the Level of Proof}

So far, this chapter has shown that the role of the precautionary principle as a generally applicable principle in the UK is rather weakly defined. The courts have proven as reluctant as the legislator to flesh out its content and application. Despite this, there is evidence that precautionary measures are applied in the UK in specific situations. The question, then, arises as to when and how such measures are invoked.

As mentioned above, scientific analysis and scientific proof were instrumental in setting the UK risk agenda during the 1980s and 1990s. It has been held that failure to act before full scientific proof was available contributed to, for example, the BSE crisis. ${ }^{36}$ The importance of scientific evidence also in cases of uncertainty is supported in UK government documents relating to the precautionary principle. The UK government's White Paper on its Environmental Strategy of 1990 held that precautionary measures should be considered cither "where there are good grounds for judging either that action taken promptly at comparatively low cost may avoid more costly damage later, or that irreversible effects may follow if action is delayed". 37 "Good grounds", here, appears to allude to the fact that some scientific basis needs to support the measure. Similar sentiments were voiced almost ten years later in the UK government's White Paper on Environmental Strategy of 1999. Although it was emphasised that action to protect the environment should not only be considered in situations of $100 \%$ certainty, it was stressed that "significant risk" of damage to the environment would

35 ILGRA Report, p. 6 and 10.

${ }^{36}$ Fisher, The Rise of the Risk Commonwealth and the Challenge for Administrative Law, p. 7 (in LEXIS NEXIS edition).

37 This Common Inheritance, Britain's Environmental Strategy, Cm 1200, HMSO, 1990, Section 1.18. 
have to be present. ${ }^{38}$ This indicates that, even if full scientific proof is not required, some degree of scientific evidence needs to support the decision.

In the ILGRA Report, scientific cvidence is further emphasised and elaborated on. Here, it is held that "good reason" to believe that harmful effects would occur necds to be:

"demonstrated by empirical evidence; by analogy with another activity, product or situation which has been shown to carry a substantial adverse risk or by showing that there is a sound theoretical explanation (tested as necessary by peer review) as to how harm might be caused $[. . .]^{\prime 3} .{ }^{39}$

Thus, it appears that "good reason" can be established by empirical studies as well as by theoretical modelling or through analogy with similar activities. Nothing is stated in relation to whether the scientific evidence relied upon must represent the majority of scientific opinion.

In Duddridge, the Court appears to have made a relatively material review of the scientific cvidence relevant for the case, only to conclude that a "significant risk" of cancer had not been shown to emanate from the electromagnetic ficlds at issue in the case. However, the Court did not rule out the fact that electromagnetic fields may still constitute a risk. In fact, it appears that the Court considered the EU definition of the precautionary principle to be wider than the more circumscribed version which it considers being in effect in the UK. It even conceded that, if the Court were to consider the EU version to be in effect in the UK (which it did not), then the Secretary of State would have been under an obligation to apply the precautionary principle ${ }^{40}$ This is interesting for three reasons. First, the Court considers the UK version of the precautionary principle to be different and less onerous on the regulator than that in effect at EU level. The Secretary of State in this case was explicitly allowed to determine the scope of the principle using its discretion and the courts would not challenge this. Second, the UK courts, if they follow the Duddridge model, will materially examine scientific evidence put before them in order to establish the level of risk. Third, if a "significant risk" is found to be present the regulator appears under an obligation to act in a precautionary manner provided that a cost/benefit analysis supports the measures. ${ }^{41}$ It is

38 Ibid., section 11

39 ILGRA Report, p. 6.

${ }_{41} R \mathrm{v}$ Secretary of State for Trade and Industry ex parte Duddridge and Others, p. 7 (in LEXIS NEXIS version). ${ }^{41}$ Ibid. 


\section{Joakim Zander}

important to observe that the term "significant risk" is not equivalent to any risk, but something needs to qualify it as significant.

In a more recent casc, which will be returned to in more detail below in relation to base stations, the Qucen's Bench generally upheld the approach established in Duddridge. The issue in Al-Fayed centred on the risks posed by base stations for mobile tclephones. ${ }^{42}$ The court held that the uncerlainty surrounding the health implications of radiation from base stations was not sufficient to justify a precautionary approach. The judge evaluated the available scientific evidence and failed to find any scientifically-supported allegation of risk. Thus, the court saw no reason to issue any type of precautionary measures on the side of the regulator. The judgment was upheld in this part on appeal. ${ }^{43}$

\subsubsection{The Burden of Proof}

In the ILGRA Report on the Precautionary Principle the burden of proof is dealt with under a separate sub-heading. ${ }^{44}$ Here, the issue of pre-authorisation regimes is primarily dealt with. It is in this area, the Report implies, that the reversed burden of proof plays its largest role. Pesticide regulation and the permitting regime for nuclear plants are given as examples. The Report points out that the burden of proof may be fashioned differently in different areas in which pre-authorisation regimes are in place. In pesticide regulation, the level of acceptable risk is decided on by the government. It is then the responsibility of the manufacturer of a pesticide to convince the decision-maker that its product meets this level in a concrete case. This is done by producing a risk assessment in favour of allowing the pesticide in question. As mentioned in previous chapters, the burden of proof may, in such cases, be conceived as being reversed. However, the initial burden of proof generally rests with the government to indicate a potential risk with a substance. This level of proof may, indeed, be low. Once it has been met, the onus is shifted on to the applicant to show that the assumption of risk is unfounded. ${ }^{45}$

Furthermore, it is made very clear in the ILGRA Report that the government wants to retain wide latitude to prescribe in greater detail where the burden of proof should be placed

42 R.v Tundridge D.C. and another, ex parte Al-Fayed, Queen's Bench Division Crown Office List) 79 P / CR 227, [1999] JPL 825, [1999] 1 PLR 104, The Times 28 January 1999, CO/3665/97, 14 January 1999.

43 R. v Tandridge D.C. and another, ex parte Al-Fayed.

44 ILGRA Rcport, p. 11.

45 Ibid. 
The Precautionary Principle in the UK

in different regimes. ${ }^{46}$ Thus, it appears that the burden of proof is not intended to be static in relation to the precautionary principle. Instead, it should be allowed to fluctuate to the intent of the legislator.

The above, in combination with the limited scope for judicial review that the courts have allowed themselves, makes it difficult to foresee a situation in which a challenge of a precautionary measure could be successful. In Duddridge, it was held that only when "significant proof" of harm is present would it be possible to demand regulation on the part of the regulator. ${ }^{47}$ However, following the Duddridge reasoning, nothing excludes that the regulator could use its discretion and regulate a risk before "significant proof" exists. Thus, "significant proof" does not represent a level of risk which the regulator needs to meet in order to act in a precautionary manner, but rather a level of proof in which it can be expected to act in a precautionary manner.

The limited review, or ultra vires, doctrine employed in the UK prescribes that, only if the regulator has acted in a formally incorrect manner, outside of its competences, or has acted "unreasonably", can a measure be quashed on substantive grounds. In relation to the substantive review of precautionary measures, the last of these options is most relevant. The unreasonableness test used in the UK emanates from the famous Associated Provincial Picture Houses Ltd $v$ Wednesbury Corporation. ${ }^{48}$ In this case, it was stated that a decision or rule must be "so unreasonable that no reasonable authority could ever have come to it" for it to be quashed by the courts. ${ }^{49}$ The bar for so-called "Wednesbury unreasonableness" is set high. It is not sufficient that the court does not agrce with the decision of a regulator, but it must be apparent that the measure is unreasonable. ${ }^{50}$

With regard to challenges to decisions involving the precautionary principle, this may have great relevance for the possibilities for effective redress. In areas surrounded by varying degrees of uncertainty, it is exceedingly difficult for a plaintiff to convince a court that the actions of a regulator were "Wednesbury unreasonable". Since high levels of uncertainty per definition are situations in which no clear course of action can be prescribed, it is nearly

46 lbid., p. 12.

$47 \quad R$ v Secretary of State for Trade and Industry Ex parte Duddridge and Others.

48 Associated Provincial Picture Houses Ltd v. Wednesbury Corporation [1948] 1 KB 223.

49 Ibid.

so P. Cane, Administrative Law, Oxford University Press, 2004, p. 250. 


\section{Jikatim Yamder}

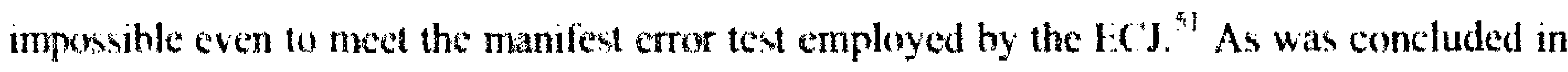
the chapter on EC law, a suecessful challenge of a precautionary measure before the ECJ would have to end the scientific uneertanty in order to prove the decision taken to be vitiated by a matnifest error. In the UK legal order, this may not even be enough. What needs to be shown is that mo reasonable person would have taken the decision at the time. However, if if is shoun that the decosion was ohjectively contrary to scientific evidence, but not unreasomable, the courts will not quash it. Ihus, the burden of proof, once reversed, appears to be even higher in the $\mathrm{UK}$ than at $\mathrm{I}$ ( ' level. This is further emphasised in a statement by in R v Ministry of Defence, ex parte Smith, in which it was held that:

\footnotetext{
"the greater the puldey content of a decinion, and the more remote the subject matter of the decision from ordinary judicial experience, the more hesitant the court must necessurily he in twlding a decision to be irrational.
}

Since this adequately describes the circumstances under which precautionary measures are likely to be taken, the already miniscule scope for effective redress appears even smaller.

\subsubsection{Cost/Benefit Analysis}

That costbenefit analysis can be one of the decisive elements for precautionary regulation was already indicated, but not elaborated on, in This Common Inheritance in 1990.53 in Duddridge, the court placed great weight on the performance of cosi/benefit analyses. In the case, it was indicated that the decision to introduce precautionary measures would have to depend on two major elements, the first of which was the risk assessment, and the second a costbenefit analysis. It was repeatedly stressed that a cost/benefit analysis would have to be carried out before precautionary measures could be issued. ${ }^{54}$ In the ILGRA Report on the Precautionary Principle the use of costbenefit analysis was also stressed, but not elaborated on in any detail. ${ }^{5 s}$

Since the Environment Act of 1995, it has been explicitly established that the Environment Agency must consider the costs and benelits of its aetions whenever it exercises

\footnotetext{
st For a discussion on the judicial review before the $\mathrm{IC}$ c courts, see, in particular, Section 4.3 .3 above.

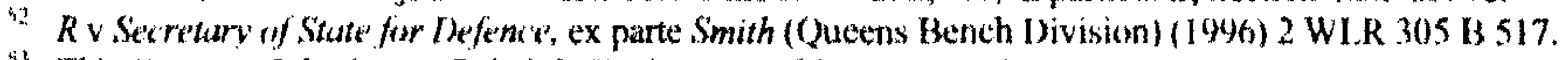

4t This Common Inheritance, Britain"s Environmental Strategy, p. 11.

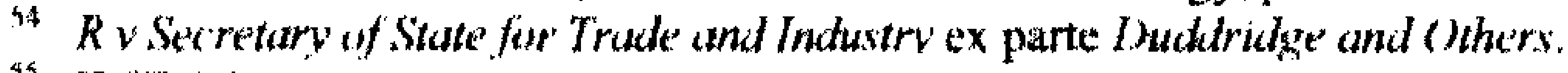

45 IICGRA Report, p 10.
} 
its powers. ${ }^{56}$ How the Agency is to go about this has been elaborated on in a Consultation Paper of 2003, ${ }^{57}$ and more recently in the document "Managing Risks to the Public: Appraisal Guidance" (Hercinafter referred to as "the Risk Appraisal Guide"). ${ }^{58}$ However, since the scope of the Environment Agency is limiled to issues not dealt with in any detail in this book (for example, pollution control and waste), the Risk Appraisal Guide will be dealt with in greater detail since its scope is not limited to certain arcas, but applied generally to health as well as to the environment.

The UK approach to the weighing of costs and benefits analysis is nuanced and, even though it is summarised in a brief form in the available documents, detailed. Distinction is made between cost/benefit analysis and cost-cffectiveness analysis, the former being a decision-making tool used to inform the decision-maker as to the desirability of a certain type of regulation, and the latter being an instrument to find the most effective way of carrying out a pre-determined piece of regulation. ${ }^{59}$ It is emphasised that in the absence of a market, surveys measuring the public's "willingness to pay" (WTP) and "willingness to accept" (WTA) can be used for input in the analysis. ${ }^{60}$ Benefits to health can also be measured in Quality Adjusted Life Years (QUALYs). This basic abstraction builds on the fact that one life year in full health equals 1.0 QUALY. This value is then adjusted downward depending on perceptions of the decrease in the quality of life with age. Perceptions are measured through the use of statistical surveys. Thus, the older a person becomes, the fewer QUALYs equal one life in real time. ${ }^{61}$ The values that the cost/benefit analysis generate should be adjusted for ethical or moral considerations connected to, for example, the willingness to provide higher levels of protection for children, or against particularly undesirable causes of loss in QUALYs. ${ }^{62}$ In general, it is emphasised that all considerations put into a cost/benefit analysis or cost/effectiveness analysis should be made explicit so that the sources of the equation can be readily understood. ${ }^{63}$ Uncertainties should be expressed and highlighted. ${ }^{64}$

56 Environment Act of 1995, Article 39.

57 The Green Paper, Appraisal and Evaluation in Central Government, IM Treasury 2003. Available at: httns://www.hm-treasury.gov.uk/d/4(4).pdf.

58 Managing Risks to the Public: Appraisal Guidance, IM Treasury, 2005. Available at: http://www.hmtreasury.gov.uk/d/managingrisks appraisal220705.pdf.

59 Ibid., 21 .

60 Ibid. For a general discussion on this in the context of the precautionary principle, see C. Sunstein, Laws of Fear, Cambridge University Press, 2005.

61 Managing Risks to the Public: Appraisal Guidance, p. 22-23.

62 Ibid., p. 28 .

63 Ibid., p. 24-25. 


\section{Joakim Zander}

The Risk Appraisal Guide provides an example of the importance that the UK government attaches to the use of CBA and CHA in risk regulation. It is also an unusually detailed outline of how it intends to make use of these instruments.

\subsubsection{The Targeting of Risks}

The order in which to target risks, or "risk prioritisation," is dealt with in a number of UK policy documents. In "(iuidelines for lnvironmental Risk Assessment and Management" it is stressed that ranking, rating and weighing risks objectively is fundamental to effective risk regulation. It is held that:

"All good policy decisions rely on the eflective analysis of alternative options. 'Therefore, a systematic appraisal is important to emure that the decision-maker is clear ahout the objectives and bow to decide where the balance lies between the benefits from the reduction of the risk and the implications for society of introducing potential control measures.",

The basis for tackling environmental risks in this fashion should be environmental impact assessments, strategic environmental assessments and cost benefit analyses. ${ }^{60}$

In the Risk Appraisal Guide, this approach is reinfored more generally in the area of risk regulation. The approach advocated here is more overtly of economic nature. It is held that WTP analysis can be used as an input in the ranking of risks in order to find a balance between the risk and the public willingness to protect itself from the risk. ${ }^{67}$ The ethical problems involved in comparing the saving of lives are emphasised. ${ }^{6.8}$ Interestingly, the issue of risk trade-offs is not discussed in any detail, even though the literature on the subject is included in the bibliography to the document. ${ }^{69}$

The commitment to a rational ranking of risks by using economic models such as cost/benefit analysis and cost/effectiveness analysis seems firm in the UK. However, the lack of the inclusion of the concepts in any binding documents may make it difficult for the UK courts to test decisions against this commitment due to the limited review generally

thid., 29.

6.5 Gujdelines for Fnvironmental Risk Assessment and Management, IIMSO 2000. Now updated and available at:

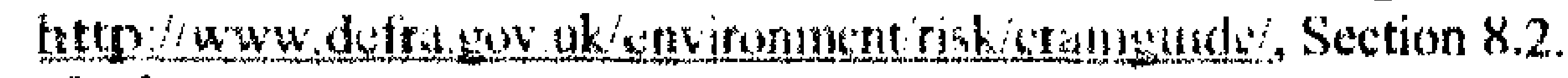

ho Ibid.

67 Managing risks to the public: appraisal guidance, p. 25-26.

thid, 28 .

t9 For example, J.B. Wiener \& J.D. Graham, Risk vs. Risk: Trouleffs in protecting health and the environment, Harvard University Press 1995. For a further diacussion on the issue of risk tradeoffs, see, above, Section 2.4 .2 .3 . 
performed. Thus, it would have to be considered that what has been discussed above in this section shows that an elaborated and rational approach is intended by UK decision-makers, but they can hardly be interpreted as legally binding requirements.

\subsubsection{Public Opinion}

As has been shown above, public opinion is taken into account in a sophisticated manner through the use of WTP, WTA and QUALYs. All of these mechanisms essentially build on public perception of how much one is willing to pay to avoid a risk, how big a risk one is willing to accept, or how one values decreasing life quality with age. Thus, public opinion in an abstract form is made an integral part of the essentially economic approach suggested by the UK government in the Risk Appraisal Guidance.

However, the issue is also dealt with as a separate topic under Appendix A, in which the emphasis is on understanding the causes and levels of public concern regarding a given risk. The public concern should be identified and given a number on a 5-point scale, where 1 represents the lowest level of concern, and 5 the highest. This scale is then used as input for the decision-maker when choosing between regulatory choices, communication strategies, etc. $^{70}$

The fact that the above-described methods of allowing public perception to influence economic considerations and dccision-making are not exclusive is suggested in the Guidelines for Environmental Risk Assessment and Management. Here, it is first emphasised that allowing the public to influence the procedure is important in order to enhance the legitimacy and trust in the process. ${ }^{71}$ Second, it is held that this can, perhaps, best be done through the involvement of stakeholders in risk regulation. ${ }^{72}$ Similar concerns are expressed in the UK Government's Strategy Report of 2002, ${ }^{73}$ although no concrete proposals are made as to how public participation is to be effectively carried out in particular policy areas. The involvement of the public, as well as stakeholder participation, appears to be entirely up to the discretion of the decision-maker in the individual cases.

70 Managing risks to the public: appraisal guidance, p. 34-35.

71 Guidelines for Environmental risk Assessment and Management, Scctions 3.2-3.5.

72 Ibid., 3.8.

73 Risk: Improving government's capability to handle risk and uncertainty, Strategy Unit Report, November 2002, pp. 74-92. Available at: http:/www.strategy.gov.uk/downloads/su/RISK/REPORT/pdf.htm. 


\section{Joakim Zander}

In practice, it has been predicted by Haigh that public opinion may count much more than any principle of precaution. ${ }^{74}$ In relation to this, the courls stated relatively clearly in $\mathrm{R} \mathrm{v}$ Tandridge District Council, ex parte Al Fayed that public concern can, possibly, be relied upon to compel the authorities to examine the matter further through a risk assessment. Whether the government allows public opinion to be decisive for the action it takes seems to lic entirely within its discretion. There appcars to be little in the way of documents, binding or not, which describe in any detail how the government should go about this. The only thing which appears to be clear is that continucd public opinion in opposition to a measure which was issued after a risk assessment, abiding by formal requirements, and not affected by Wednesbury unreasonableness, is not sufficient to override it. ${ }^{75}$

In conclusion, it is clcar that the involvement of the public in risk regulation is an issue that has received a fair amount of attention from the UK government, and is perceived to be of importance when deciding on issues involving uncertainty and precaution. However, involvement is carried out on an ad hoc basis and failure to take public opinion into account does not lead to a measure being challengeable before the courts. Despite this, it must be held that the emphasis on public opinion and rational communication is far greater in the UK than is the case in Sweden, where this issue is barely touched upon at all.

\subsubsection{Conclusion}

Precautionary decisions in areas of environmental and health protection in the UK are not a new feature of the UK legal order. It has been shown that such decisions have been a part of the UK legal order for centuries. However, the precautionary principle as an over-arching policy that is adopted consistently by the UK Government is a very recent feature. Not included in any statutory instruments, the principle has mainly been referred to in statements by UK ministers and policy documents, the most detailed of which being the ILGRA Report of 2002. In general, policy documents do little to flesh out the content of the precautionary principle and even less to discuss how it is intended to apply in the UK. During the 1990s, discussions rarely went further than re-iterating Principle 15 of the Rio Declaration. In the ILGRA Report, it was made clear that the precautionary principle should apply after a risk assessment has been performed and in conjunction with a cost/benefit analysis. This indicates that the principle is considered to be a tool to be applied by the risk manager. However, no

74 N. Haigh, The introduction of the Precautionary Principle into the UK, p. 240.

${ }^{75} R$ v Tandridge District Council, ex parte $A$ l Fayed, p. 7 (the page number follows version printed from LEXIS NEXIS). 
clear separation between risk assessment and risk management is maintained in the UK, so it is often unclear to which category a decision belongs. Furthermore, in the last couple of years, both the House of Commons and the House of Lords have expressed their concern with the unclear nature of the precautionary principle, and have recommended that the concept be better defined.

With regard to when the precautionary principle is to apply, not much guidance is given. In the ILGRA Report, as well as in other carlicr documents, it has been held that the principle should come into effect where there is "good reason" to believe that harmful effects may occur. Such good reason would be demonstrated by empirical studies, modelling, or analogy with a similar activity. This indicates that some form of scientific evidence lies at the heart of the application of the principle.

The UK courts have not proven any more helpful in interpreting the precautionary principle than the UK government. Usually considering themselves prevented from material review, they have allowed the UK government near total freedom in deciding on when and how to apply the precautionary principle. Due to the severely limited material review that the courts are allowed in administrative cases, they are content to review whether measures taken by, or on behalf of, the UK Government are reasonable. This is in stark contrast to the Swedish courts which do, at least in some cases, take an active part in reviewing also detailed scientific evidencc involved in a case. In Duddridge, the Court considered the precautionary principle in force at EU level through Article $174 \mathrm{EC}$ to be restricted to the application of EU rules and found that it could not be used to challenge national rules or decisions. The Court clearly indicated that the UK version of the precautionary principle was less onerous than the EU version, and that the UK government was afforded full discretion in deciding on how to make use of it. In Al Fayed, it was held that the government was under an obligation to act in a precautionary manner in cases of base stations for mobile telephones, but the Court could not find that any clear scientific evidence with which to support such a claim.

The lack of a definition or a more defined content of the precautionary principle, in combination with the extreme reluctance of the courts to review precautionary decision, has led to a situation in which the decision-maker enjoys unbridled discretion. Consequently, it is excessively difficult to foresee a situation in which a precautionary decision could be successfully challenged by the UK courts. In the chapter on the EU, it was shown that a successful challenge of a precautionary decision by the Council or the Commission bcfore the 


\section{Joakim Zander}

European Court of Justice would effectively have to end the scientific uncertainty in order to mect the high level of proof created through the manifest error doctrinc. However, in the UK, even this may not be enough. Since what needs to be shown is that the decision taken is "unreasonable", it may, in fact, be wrong, as long as a reasonable person could potentially have taken the decision. What needs to be shown, therefore, appears to border on showing that a decision was taken by negligence or was intentional. It is difficult to foresee how a more onerous burden for the plaintiff could be envisaged. The conclusion is that it is virtually impossible to challenge any decisions taken under the pretext of the precautionary principle in the UK.

It has been indicated in, for example, the ILGRA Report, that the application of the precautionary principle is contingent upon the carrying out of a cost/benefit analysis. This was also supported by the reasoning by the judge in Duddridgc. In a government Consultation Paper of 1993 as well as in the Risk Appraisal Guidance, the UK government has, in considerable detail, fleshed out how all government decisions in the areas of health and environmental protection should be preceded by the performance of cost/benefit analyses and risk trade-off analyses. Advanced models are suggested for making such comparisons. These include Willingness to Pay and Willingness to Accept calculations, as well as Quality Adjusted Life Years. Whether, and if so, how the UK Government has made use of these instruments in relation to the precautionary principle is unclear. The documents in which they are suggested are not binding, and no other rules indicate that the performance of a cost/benefit analysis would be a formal requirement. The courts have not tested the application of the principle against any formal requirements.

The role of public opinion is also emphasised in UK policy documents. Once again, no formal requirement has been created to safeguard this requirement. However, as is discussed in the chapter on base stations, perhaps public opinion in the end plays a larger role when opting for the issuing of precautionary measures than that of an independent and legally-binding precautionary principle.

In conclusion, it should once again be pointed out that the precautionary principle lacks independent legal status in the UK, at least outside the application of EU law. The decision to apply precautionary measures in individual cases is entirely in the hands of the UK government. The failure to issue any binding documents regarding its potential definition or application in combination with the reluctance of the courts to review matters 
substantively means that no formal rules for the application of the principle exist. Thus, if the UK government decides to use its discretion to issue precautionary measures, the scope for effective redress is very limited.

\subsection{The Application of the Prechutionary Principle in UK Pesticides REgulation}

\subsubsection{Introduction}

As in other EU countries, the regulation of pesticides in the UK is a bundle of national rules and EU directives, which is not always easy to straighten out. Unlike the situation in Sweden, where the Chemicals Agency reigns more or less supreme, a number of national bodies are involved in the regulation and oversight of pesticides in the UK. Their competences and scopes of power are not always readily discerned and their functions sometimes overlap. Risk assessments are largely performed by the Advisory Committee on Pesticides but other standing scientific committees are involved on an ad hoc basis.

In Sweden, the precautionary principle in relation to pesticides underlies all policy and has led to the adoption of the policy goal of a "Non-Toxic Environment" which effectively means that all man-made substances are to be eliminated from the environment by 2020. In the UK, on the other hand, the precautionary principle is not codified anywhere in statutes and has a significantly lesser impact on policy in relation to pesticides.

This chapter aims to explain how the precautionary principle has been expressed in the area of pesticides regulation, and how precautionary considerations have been used in practice in the UK. The chapter begins with an outline of the regulatory and institutional framework in the area, before the topic of the precautionary principle is discussed in detail. As in previous chapters, the precautionary principle is disseminated and dealt with in its constituent parts. Of particular importance, here, are the issues of risk assessment, the role of scientific evidence, and the burden of proof, as well as cost/benefit analysis, risk trade-off analysis and the role of public opinion.

\subsubsection{The Legal Framework}

In the UK, the legal basis for the control of pesticides consists of a number of provisions. The basic framework is made up of the Food and Environment Protection Act of 1985 Part III $\left(\right.$ FEPA) ${ }^{76}$ and the eight Control of Pesticides Regulations of 1986 (COPR). ${ }^{77}$ The aims of

76 Food and Environment Protection Act 1985, Chapter 48, s. 16.

77 Control of Pesticides Regulations, SI 1986/1510, s. 1-8. 
Joakim Zander

FEPA are to protect health, safeguard the environment, secure safe and effective methods of controlling pests, and to make information on pesticides available to the public. ${ }^{78}$ The Act is mainly of enabling nature, with the aim of authorising ministers to issue more detailed legislation and set up bodies for advising on the use of pesticides. ${ }^{79}$

In COPR, which was issued the year after FEPA, it is established that advertising or trade in pesticides is prohibited unless authorised by the ministers. ${ }^{80}$ In the Regulations following the prohibition, it is prescribed how ministers may issue approvals of pesticides and grant permission for the sales and advertising of the products. ${ }^{81}$ In schedules attached to the Regulations more specific requirements for approval and consent are established.

Since the early $1990 \mathrm{~s}$, pesticide regulation is mainly subjected to harmonised rules at EU level under Directive $91 / 414$ (hereinafter referred to as ("the Dircetive"). In the UK, the Directive was implemented in the Plant Protection Products Regulation of 1995 (PPPR). Anyone applying for a permit to use a new active substance has to request permission from the Secretary of State, and, furthermore, must submit the application to the Commission and the competent authorities of the other Member States of the EU. ${ }^{82}$ The decision regarding whether to include a substance in Annex $I$ of the Directive is then taken using a comitology procedure. $^{83}$

If the active substances in a pesticide have been duly included in Annex I of the Directive, the product still has to be approved by the Secretary of State. ${ }^{84}$ In practice, this task has been delegated to the Pesticide Safety Directorate, which functions as an Executive Agency of the Ministry of Agriculture, Fisheries and Food. ${ }^{85}$

\subsubsection{The Institutional Framework}

The task of regulating agricultural pesticides in the UK falls, in principle, to the Department of Environment, Food and Rural Affairs (DEFRA). Since 1993, this task was delegated by DEFRA to the Pesticide Safety Directorate (PSD). ${ }^{86}$ The PSD was established as an

78 FEPA, Article 1.

79 Ibid., Articles 2 and 7.

80 COPR, s. 4, Articles 1 and 2.

8I lbid., s. 5 and 6.

82 Plant Protection Products Regulations 2005, SI 1435, s. 4.

83 Sec, above, Section 5.2.2.

84 PPPR, s. 5, Article 1.

8s The Pesticides Safety Directorate's Framework Document, Article 2.3. Available at: hltp:/www.pesticides.gov.uk/corporate.asp?id-232.

86 Ibid., Article 1.1. 
Executive Agency in The Pesticides Safety Directorate's Framework Document (the Framework Document) in $1993 .{ }^{87}$ With regard to non-agricultural pesticides, the Health and Safety Executive, and its counter-parts in Scotland, Wales, and Northern Ireland, are the relevant bodies. ${ }^{88}$

The system of executive agencies in the UK was conceived in the late 1980s and came as a response to the realisation that government ministries were being increasingly overburdencd with implementation tasks. ${ }^{89}$ In the case of PSD, it has effectively taken over the overseeing and application of the legislative framework from DEFRA. Its principal objectives thus include maintaining and administcring the approval, reviewing and monitoring systems in place for pesticides, providing policy advice to DEFRA, and the promotion of the minimisation of pesticide use. ${ }^{90}$

The PSD is headed by a Chief Executive who is appointed by the Minister of the Environment, Food and Rural Affairs. ${ }^{91}$ The Ownership Board functions as a liaison between the Chief Executive and the Minister since its tasks are to advise the Minister on issues pertaining to the PSD, monitor the work of the PSD and, at the same time, provide advice and support to the Chief Executive. Furthermore, the Board functions as an arbiter between the PSD and the Ministry on certain issues. ${ }^{92}$ Its members are appointed by the Minister and the Chief Executive has to be onc of them. ${ }^{93}$

The general guidelines for the work of the PSD are drawn up by the Minister, ${ }^{94}$ but the Chief Executive may make changes to the organisational structure to ensure its efficiency and overall performance. ${ }^{95}$ In principle, the day-to-day management of affairs is performed by the PSD without interference from the government. However, no constitutional guarantee granting the agency independence in deciding on cases before it, such as the one in place in

87 Ibid. The above reference is to the Framework Document of 1996, which is an updated version of the Framework Document of 1993 and it is the one presently in force.

88 A Guide to Pesticide Regulation in the UK and the role of The Advisory Committee On Pesticides, 18.

89 Improving Management in Government: The Next Steps, A Report to the Prime Minister (Ibbs Report), HMSO 1988. Main points summarised on:

http:/www.civilservice.gov.uk/the future of the civil service/agencies and public bodics/cxecutive agencie s and non ministerial departments/background and development/index.asp

90 The Pesticides Safety Directorate's Framework Document, Articles 2.1 - 2.3.

91 Ibid., Articles $3.2 \& 4.4$.

92 lbid., Article 4.7.

93 Ibid., Article 4.6.

94 Ibid., Article 4.1.

95 Ibid., Article 3.3. 


\section{Joakim Zander}

Sweden, is to be found in the UK. ${ }^{96}$ Instead, it is explicitly held in the framework document that the PSD functions under the DEFRA, and that the Minister may, in exceptional circumstances, issue direct instructions to the Chiel Executive of the PSD. ${ }^{97}$ The budget for the PSD is granted by Parliament for cach budgetary year. However, the bids for the budget to be put before Parliament have to be agrced upon by the Chief Executive and the Minister. Parts of the budget are financed through the collection of fees. ${ }^{98}$

The Advisory Committee on Pesticides (ACP) was introduced in 1977 to give scientific advice to the Minister in relation to pesticides. ${ }^{99}$ In its present form it functions under section 16(7) of the FEPA. ${ }^{100}$ The ACP consists of as many members as the Minister sees fit. ${ }^{101}$ Currently there are 18 members, including the Chairman and the Deputy Chairman. ${ }^{102}$ The committee consists of eminent scientists and the importance of their independence from government as well as industry is strongly emphasised. ${ }^{103}$ The role of the committee is strictly advisory, and it does not have a regulatory function. ${ }^{104}$ Since the Ministcr is bound by FEPA to consult the relevant advisory body before taking any decision, the amount of work before the ACP is significant. ${ }^{105}$ In order to deal with this, the ACP applies a simplified procedure which allows it to review only novel products in detail. A system is in place to let the PSD and the HSE revicw issues which have already been evaluated by ACP. ${ }^{106}$

It should also be noted that other scientific committees are sometimes consulted by the PSD on an ad hoc basis. There is no statutory basis for this procedure but it takes place where the expertise of other committees are required for "obvious reasons". 107

In conclusion, the only truly independent organ involved in UK pesticide regulation is the ACP, which only has an advisory function. The PSD is, even though formally

96 For a Swedish comparison, see above, Section 5.2.3.

97 The Pesticides Safcty Directorate's Framework Document, Article 4.3.

98 Ibid., 6.3.

99 A Guide to Pesticide Regulation in the UK and the Role of the Advisory Committec on Pesticides, ACP 19 (311/2005), 20. Available at: http://www.pesticides.gov.uk/acp.asp.

${ }_{100}$ Control of Pesticides (Advisory Committee on Pesticides) Order 1985, SI No 1985 No. 1516.

101 Control of Pesticides ( $\Lambda$ dvisory Committee on Pesticides) Order 1985, SI No 1985 No. 1517, s. 2.

${ }_{102} \wedge$ Guide to Pesticide Regulation in the UK and the Role of the Advisory Committee on Pesticides, 20.

103 I bid and Control of Pesticides (Advisory Committee on Pesticides) Order 1985, SI No 1985 No. 1517, s. 2.

$104 \Lambda$ Guide to Pesticide Regulation in the UK and the Role of the Advisory Committee on Pesticides, p. 22

105 See FEPA, Section 16, Article 9.

106 A Guide to Pesticide Regulation in the UK and the Role of the Advisory Committee on Pesticides, p. 21.

107 The Queen on the Application of Avac Chemical UK Limitied v. Secretary of State for Environment, Food and Rural Affairs, Secretary of State for Transport, Local Government and Regions, Food Standards Agency, High Court of Justice, Queen's Bench Division (Administrative Court) 3 December, 2001, 2001 WL 1479891. 
independent when it comes to day-to-day issues, closely tied to the Ministry through its organisational structure, its financing, and the possibility of the Minister to take decisions actively in individual cases under exceptional circumstances.

\subsubsection{Risk Assessment and Risk Management}

No formal separation of risk assessment and risk management is established in UK legislation. However, as demonstrated in the previous section, in most cases, risk management decisions are ultimately taken by the Minister, after preparation by the authority to which this task has been delegated (in the case of pesticides, this means the PSD). This arrangement is supported in UK soft law instruments. ${ }^{108}$ The risk assessment is also performed by the PSD together with the Advisory Committee on Pesticides.

When requesting an authorisation, companies are requested to complete and submit an extensive package of scientific data, which forms the basis for the risk assessment. ${ }^{109}$ In this package, the applicant needs to account for the physico-chemical properties of the substance, the product's potential toxicity in humans, the tolerance of humans towards residues of the pesticide, how operators and bystanders may be affected by it, and the environmental and ecotoxicological behaviour of the product. ${ }^{110}$ If the active substance has been included in Annex I to Directive 91/414, it is held that "the government would be expected to draw upon the scientific assessment that had already been agreed [on the EU level]". "II Despite this fact, it is emphasised that the assessment and approval of pesticides is a decision to be taken at national level. ${ }^{112}$ It could be assumed that what is meant by this is that, if an active substance is included in Annex $\mathrm{I}$, the risk assessment with regard to the active substance has been carried out at EU level. However, the properties of the pesticide in which the active substance is included is to be assessed at national level. Since the coming into force of Annex I of Directive $91 / 414 / \mathrm{EC}$, the UK authorities, in practice, rely on the risk assessment performed at EU level. That this is the case was illustrated in, for example, British Agrochemicals Association Limited. which regarded the question of parallel importations of pesticides with similar characteristics to the substances included in Annex I. ${ }^{113}$ It does not appear that the UK government pursues its own risk assessment and management agenda in the way that Sweden

\footnotetext{
${ }^{108}$ Compare with discussion above in Section 6.2.5.

109 A Guide to Pesticide Regulation in the UK and the Role of the Advisory Committee on Pesticides, p. 8.

${ }^{110}$ Ibid., pp. 8-14.

111 Ibid., p. 6.

112 Ibid.

${ }^{113} R \vee$ Ministry of Agriculture, Fisheries and Food ex parte British Agrochemicals Association Ltd,. English Court of Appcal (Civil Division), 9 November 2001, [2002] 1 C.M.L.R. 8.
} 
Joakim Zander

does in the area of pesticides through the setting of far-reaching environmental quality objectives, the strict application of the precautionary principle, and the setting of cut-off criteria.

In cases before the UK judiciary, courts have proven reluctant to allow substantive review of the scientific evidence underlying a decision. ${ }^{114}$ With regard to the formal procedure, however, the Court in Inquinosa International clarified that the PSD is at the centre of the risk assessment procedure, and that it takes the decision on which scientific evidence is to be passed onto the ACP for evaluation. In this case, the claimant argued that the advicc given by the ACP was not complete duc to the fact that the ACP had not had access to the full scientific study carried out by the applicants. Parts of this study had been "filtered" by the PSD. The ACP report proved decisive for the decision by the Ministers to revoke the authorisation of the pesticide Lindane. The claimants held that since the report was not based on all the scientific evidence available, but rather a selection of it, the report was flawed. The Court did not agree. Instead it held that there is "nothing unusual, and nothing objectionable in the PSD acting as a filter in this way". ${ }^{115}$ It is interesting to note that the PSD, which is a branch subordinate to the Secrelary of the Environment, is explicitly allowed to control the material that is to be assessed by the only independent body in the UK pesticide regulatory regime, the ACP. Thus the risk manager can maintain control over the scientific material put before the risk assessor and thus it can potentially exert a very direct control of the outcome of the risk assessment.

\subsubsection{The Level of Proof and the Triggering of Precautionary Measures}

As shown in the previous chapter, the precautionary principle in the UK is not defined, and the decision of whether and how to apply precautionary measures lies entirely within the discretion of the risk manager. It is not even entirely clear that health risks could trigger precautionary action. In a Paper for the ACP Open Mecting of 2001, the former ACP Chairman, David Coggon, held that the precautionary principle "focuses only on environmental degradation". ${ }^{116}$ This statement was quoted by the Court in Amvac Chemical UK Limitied in order to limit the scope of the principle to issues of environmental

114 See, for example, $R$ v Minister for Agriculture ex parte Inquinosa International, Queen's Bench Division (Crown Office List), 17 January 2000.

${ }^{115} R v$. Minister for Agriculture ex parte Inquinosa International.

${ }^{116}$ D. Coggon, The Precautionary Principle and Pesticide Regulation, Chairman's Paper for ACP Open Mceting 2001. Available at: www.pesticides.gov.uk/acp.asp?id $=490$. 
protection. ${ }^{117}$ However, the Guide to Pesticide Regulation issucd jointly by DEFRA and the HSE in 2005, hold that:

"Effectively, the precautionary principle is applied as routine in the regulation of new pesticides. As has already been explained, now products are not authorised unless there is adequate scientific evidence that their use will not pose unacceptable risks to health and to the environment." 118

This indicates clearly that not only environmental concerns are considercd when deciding on whether to issue precautionary measures. Instead the precautionary principle is applied to ensure that "adequate scientific evidence" supports the fact that a product does not pose unacccptable risks. So far this construction has not been clarified further by the ministries or elaborated on by the courts, but it seems to indicate that the UK authorities concerned with pesticide regulation do not intend to restrict the use of the precautionary principle to solcly environmental issues. ${ }^{119}$

Having stated that, the issue of what lies in the concept "adequate scicntific evidence" arises. First, it should be noted that what needs to be shown is that a product does not pose unacceptable risks. Thus, the presumption with regard to pesticides seems to have changed, moving away from the regulator showing the risk inherent in a product, towards the applicant showing that it does not bring unacceptable risks. This has to be backed up with "adequate scientific evidence". What is meant by this is further qualified in the Guide:

"In other words, uncertainties in the risk assessment must have been sufficiently eliminated bcfore a new product is approved." 120

If the two statements are combined, the conclusion is can be drawn that "adequate scientific evidence" should have "sufficiently eliminated" uncertainties beforc a product is authorised. The fact that the phrase "sufficiently eliminated" does not mean that full scientific certainty regarding the hamlessness of a product is required appears relatively clear. It has been stated that requiring this "would be as unrealistic as requiring full scientific certainty of

117 The Queen on the Application of Avac Chemical UK Limited $v$ Secretary of State for the Environment, Food and Rural Affairs, Secretary of State for Transport, Local Government and Regions, Food Standards Agency, p. 79.

${ }_{118}$ A Guide to Pesticide Regulation in the UK and the role of The Advisory Committee on Pesticides, p. 15.

119 This issue has also been discussed in the area of base stations for mobile telephones, and is returncd to in relation to this below.

121) A Guide to Pesticide Regulation in the UK and the role of The Advisory Committee on Pesticides, p. 15. 


\section{Joakim Zander}

the existence of a hazard". ${ }^{21}$ Building on this explicit recognition of uncertainties, the precautionary principle in pesticide regulation has been elaborated on as a specific example of a gencral principle of risk management, which holds that uncertainties must bc appropriatcly taken into account. However, very little is stated in relation to the level of actual level of risk required for precautionary action. ${ }^{122}$ It can be assumed that new products will be approved in the UK following the result of risk assessments taken at EU level. In relation to this, it has been emphasised that the trend is progressively moving towards a more precautionary approach towards chemicals in general. ${ }^{123}$ A more complicated area, in which national risk management decisions still play a large role, is that of pesticides that werc originally approved before the EU regime came into effect.

One of the few, if not the only, cases that deal, in some detail, with the scientific evidence underlying a regulatory decision on a pesticide is Amvac Chemical UK Limited, in which the High Court of Justice was faced with a challenge regarding a revoked authorisation for the pesticide Dichlovoros. Dichlovoros had not been included in Annex I of Directive 91/414, but had been authorised in the UK before the coming into force of Annex I. ${ }^{124}$ The Court did not grant permission to challenge the substance of the decision, but only the issue of whether the decision had been taken according to formal requirements. Furthermore, the issue of whether the precautionary principle had been properly regarded was considered. ${ }^{125}$

Even if the substance of the case was not tried before the Court, the judgment proved to at least give some indication as to how the ACP and other scientific bodies advise the PSD and the impact their advice have on the outcome of decisions. In the case, the Committee on Mutagenicity of Chemicals in Food (COM) was consulted on an ad hoc basis, beside the mandatory consultation of the ACP. Interestingly enough, in its advice, the ACP deferred to the expertise of the COM. Instead of giving a material advice on the facts, it held that, if the COM found dichlovoros to possess in vivo mutagenic properties and it could not be excluded that the occurrence of tumours in animal tests were due to a genotoxic mechanism, the

${ }^{121}$ D. Coggon, The Precautionary Principle and Pesticide Regulation.

122 lbid.

12.3 Ibid.

124 The substance was originally approved in 1994, thus before Annex I of Directive 91/414/EC of 15 July 1991 concerning the placing of plant protection products on the market, OJ L 230/1 had come into effect. According to provisional measures in Article 8.2 of Directive 91/414/EC national administrations were allowed during a transitional period to authorise pesticides pending revicw of the Commission.

125 The Queen on the Application of Amvac Chemical UK Limited v Secretary of State for the Environment, Food and Rural Affairs, Secretary of State for Transport, Local Government and Regions, Food Standards Agency, $p$. 2 . 
authorisation for the substance should be revoked. ${ }^{126}$ This was the advice given, the ACP stated, despite the fact that the risk of carcinogenicity in humans must be regarded as very small. The COM subsequently declared that it found it "prudent to assume a genotoxic mechanism on the basis of the available data", and it concluded that:

"The Committee agreed that in the absence of appropriate mechanistic data a precautionary approach should be adopted and no threshold could be assumed for the mutagenic and carcinogenic effects of Dichlorvos." 127

The COM conclusions were based on a rather extensive study of the litcrature, which was summarised in a statement dated January $2002 .{ }^{128}$ In the statement, it appears that the risk of mutagenecity perceived by the COM is rather low, and it explicitly stated that "there was no evidence for systemic mutagenic effects". ${ }^{129}$ The uncertainty surrounding the issue seems to havc been due to the lack of adequatc scientific evidence, rather than conflicting opinions. ${ }^{130}$ Facing this situation, the COM advised that "until evidence was provided to the contrary and the absence of appropriate mechanistic data, a precautionary approach should be adopted [...]". ${ }^{131}$ The ACP also chose to recommend a suspension of the authorisation for Dichlorvos rather than the revocation of the substance, pending the resolution of the scientific uncertainty. $^{132}$

It appears clear that the decision taken in the case of Dichlorvos was based exclusively on scientific advice provided by the $\mathrm{COM}^{133}$ No mention is made of other concerns such as a weighing of the costs and benefits of regulation. As shown, it appears that the level of proof for the triggering of measures is low here. Little cvidence indicated that the substance might lead to mutagenicity, but even less evidence indicated that it would not. Thus, in the absence of convincing evidence in either direction, the UK authorities opted for a textbook precautionary approach and suspended the application of the product. It should be

\footnotetext{
126 Ibid., p. 47.

127 Ibid., p. 49.

${ }^{128}$ Mutagenicity of dichloros, COM statement COM/02/S2 - January 2002, available at: http://www.advisorybodies.doh.gov.uk/com/dichlorvos.htm.

129 The Queen on the Application of Avac Chemical UK Limitied v Secretary of State for the Environment, Food and Rural Affairs, Secretary of State for Transport, Local Government and Regions, Food Standards Agency, p. 23.

130 Ibid., p. $20 \& 21$

131 Ibid., p. 23.

132 Minutes of the 290th Meeting of the Advisory Committee on Pesticides (ACP on 4 March 2002, 1.5. Available at: http:/www.pesticides.gov.uk/acp.asp?id 269.

133 DEFRA News Releasc, 19 April 2002. Available at: hltn://www.defra.gov.uk/news/2002/020419a.htm.
} 
noted that, due to the high level of uncertainty, the UK authorities settled for and interim measure, rather than a permanent one, i.e., it suspended the authorisation rather than revoking it.

If the regulation of Ddichlorvos as highlighted in Amvac Chemical UK Limited is indicative of the process in the UK, it tells us a number of important things about UK pesticide regulation. First, the decision-maker, in these cases the Minister of the Environment and Health, relies heavily on the advice of scientific expertise. The advice in this case was provided by the COM and the ACP, which are both scientific agencies, formally independent from the government. Second, the threshold for invoking precautionary measures appears low here. The risk of cancer is, of course, serious, but the probability of the substance actually causing it, even if mutagenic effects are proven, is generally recognised as very low. Third, the scientific agencies will, in some cases of scientific uncertainty, activcly endorse the precautionary principle and base their advice on it. Fourth, and connected to this, in the judgment, the Court once again re-inforces the approach that the precautionary principle is a tool to be used at the full discretion of the UK government. It does not view it as a legal principle to be consistently applied in all cases, and no formal rules of risk assessment accompany it.

That the precautionary principle in the UK is not approached similarly in other instances of pesticide regulation in which the risks are similar or greater than in the case of Dichlorvos can be illustrated by the issue of Paraquat. As discussed in the chapter on Swedish pesticide regulation above, the pesticide Paraquat is acutely toxic even in small doses when ingested and possesses a number of other health risks of a more uncertain nature. ${ }^{134}$ As with Dichlorvos, Paraquat mainly poses a risk when handled. The risk from residues in food can be considered negligible at the doses normally employed. Paraquat has been described as "one of the absolutely most hazardous pesticides" there is. ${ }^{135}$ Despite this fact, the UK government chosen to defer to the risk assessment at EU level. ${ }^{136}$ Interestingly, the UK was the rapporteur Member State for Paraquat within the framework of Regulation 91/414, and its

\footnotetext{
134 See, above, Section 5.2.5.

135 Statement of the Swcdish Chemicals Agency (KemI), 6 September 2003. Available at: http://www.kemi.se/templates/News 3090,aspx.

136 Short Report of the Meeting of the Standing Committee on the Food Chain and Animal Health (Phytopharmaceuticals Section) held on 3 October 2003 in Brussels. SCFA 4/2003. p. 2. Available at: hitp:/europa.eu.int/comm/food/committees/regulatory/scfcah/phytopharmaceulicals/summary/6 en.pdI.
} 
recommendation was that Paraquat was sufficiently safe for professional use in the EU. ${ }^{137}$ Thus, the UK considered Paraquat, a pesticide with much more well-documented risks than Dichlorvos, to be sufficiently safe to be allowed on the UK and the EU markets, whereas Dichlorvos, a pesticide for which the magnitude of risk is low, and a great degree of uncertainty pertains to its actual existence, is forbidden, based on the "precautionary principle". From the documentation available for this research, it has been impossible to discern whether other than scientific facts have influenced the UK stance on the abovediscussed pesticides, and what such concerns may have entailed. Officials at the PSD declined to be interviewed for this book.

\subsubsection{The Burden of Proof}

In the case Amvac Chemical UK Limited, the Claimant argued that, since the precautionary principle was relied upon by DEFRA, it would be bound by some form of formal risk assessment. It held that, if this were not the case, the conclusion would be that the Claimant would have to prove the absence of risk to successfully challenge the decision. "Rarely," it held, "is it possible to prove a negative." 138 The Court, however, chosc not to deal with this plea, hiding behind the fact that a substantive review had not been granted in the case. Instead, it seemed to misunderstand slightly the plea put forth by Amvac as seeking to connect the precautionary principle to a formalistic type of risk assessment. ${ }^{139}$ The Court concluded:

"[M]y very firm conclusion is that there is - at least so far - no settled, specific or identifiable mechanism of risk assessment in the field of pesticide approval that the Claimant is entitled to rely on as part of the 'precautionary principle'." 140

This is a rather peculiar statement since, as was shown in the previous sections, an institutionalised system for risk assessment involving agencics is foreseen in UK legislation and was made use of in the case. What does not seem to exist is substantive guidelines for how the risk assessment is to be performed, against which a plea could be formally tried. However, this discussion seems to be missing the point made by the claimant. What was

${ }^{137}$ Review report for the active substance paraquat, 3 October 2003, SANCO/10382/2002 -final. Available at: http://ec.europa.eu/food/plant/protection/cvaluation/existactive/list paraquat.pdf.

${ }^{138}$ The Queen on the Application of Amvac Chemical UK Limited $\mathrm{v}$ Secretary of State for the Environment, Food and Rural Affairs, Secretary of State for Transport, Local Government and Regions, Food Standards Agency, p. 67.

139 Ibid., p. 68.

${ }^{140}$ Ibid., p. 84. 


\section{Joakim Zander}

actually argued was a repetition of the classic criticism of precautionary decisions taken under uncertainty, namely, that they force the parties challenging them to prove a negative, and, thus, render effective redress impossible. ${ }^{141}$ This issuc was not addressed by the Court at all.

As discussed above, when it comes to pesticide regulation, the presumption is reversed, and, instead of the regulator having to demonstrate harm, the applicant needs to demonstrate that "adequate scientific evidence" "sufficiently eliminates" uncertainties before a product is allowed. The fact that scientific certainty with regard to the harmlessness of the product "would be just as unrealistic as requiring full scientific certainty of the existence of hazard" has been emphasised by the ACP. ${ }^{142}$ The keyword is thus "sufficiently". It has previously been discussed that a change of presumption may, at first, be interpreted as a reversal of the burden of proof onto the applicant, but that this, in reality, is not the case. Instead, it has been held that this situation is one of a "false" burden of proof placed on the applicant. The real, initial, burden of proof still rests with the regulator, who must indicate what kind of harm it expects from the product, and this then needs to be refuted by the regulated party. The level of proof, which necds to be met by the regulator, can, in these instances, be very low. Once, however, it has been met, it changes onto the regulated party, and, subsequently, the level of proof that it nceds to meet can be set very high. ${ }^{143}$

It is, at present, unclear what the UK authorities would consider a sufficient elimination of uncertainties. Since the courts make use of the unreasonable test for substantive review of government decisions, not much help can be found in the case law. In Amvac Chemical UK Limited, Amvac presented scientific evidence to the ACP and the COM during the regulatory process. Some of the studies criticised the methodology and the conclusions drawn from the evidence initially relied on by the COM. ${ }^{144}$ This evidence was considered by COM, but it concluded that when viewing the available evidence as a whole, the remaining uncertainties were sufficient to warrant precautionary advice. However, when bearing the issue of Paraquat in mind, this conclusion appears inconsistent at best. Far more

${ }^{141}$ Ibid., p. 67.

${ }^{142}$ D. Coggon, The Precautionary Principle and Pesticide Regulation.

${ }^{143}$ Sec, above, Section 5.1.7, in particular, footnote 95.

${ }^{144}$ The Queen on the Application of Amvac Chemical UK Limited $\mathrm{v}$ Secretary of State for the Environment, Food and Rural Affairs, Secretary of State for Transport, Local Government and Regions, Food Standards Agency, p. 15-17. 
scientific evidence of risk exists in this case, but no action to counter these risks has been proposed.

\subsubsection{Cost/Benefit Analysis}

In the previous chapter, it was established that the issue of cost/benefit regulation in the area of UK risk regulation has received a fair amount of attention and has been assigned a great deal of importance. ${ }^{145}$ Statutory support for the carrying out of cost/benefit analyses in relation to environmental and health decision-making is, so far, only to be found with regard to the Environment Agencies set up in the Environment Act of $1995 .{ }^{146}$ How such analyses should be carried out was further clarified in $2003 .{ }^{147}$ That not only the Environment Agencies should be subject to a requirement to carry out cost/benefit analysis when carrying out regulation was indicated in the document "Managing Risks to the Public: Appraisal Guidance" (hereinafter referred to as "the Risk Appraisal Guide"). ${ }^{148}$ The Risk Appraisal Guide gives a detailed account of how the costs and bencfits of a regulation can be compared using monetary units and so called Quality Adjusted Life Years (QUALYs). In the Duddridge case, the Court placed great emphasis on the two constituent parts of the application of the precautionary principle, the first of which being the risk assessment, and the second being the performance of a cost/benefit analysis. ${ }^{149}$ The relevance of analysis of costs and benefits was further emphasised in R v Tandridge District Council, ex parte Al Fayed. ${ }^{150}$

In light of the lip service that has been paid to the importance of cost/benefit analysis in risk regulation in general, one would expect to find ample examples of it in the area of pesticide regulation. The bodies involved in the regulation of pesticides should be considered subject to, if not the Environment Act, then at least the Risk Appraisal Guide. However, if cost/benefit analyses are being performed in UK pesticide regulation, this is being carried out at an informal level. No formal requirements have been made on the prccautionary principle being contingent upon the comparison of costs and benefits. On the contrary, as was discussed above, the Court, in Amvac Chemical UK Limited, held that there was no settled mechanism in place for the application of the precautionary principle against which a risk

\footnotetext{
145 See, above, Section 6.1.8.

146 Environment Act of 1995, Article 39.

147 The Green Paper, Appraisal and Evaluation in Central Government, HM Treasury 2003. Available at: htth:/www.hm-treasury.gov.uk/media/785/27/Green Book 03.pdf.

148 Managing Risks to the Public: Appraisal Guidance, HM Treasury, 2005. Available at: http://xwww.hmtreasury.gov.uk/media/8^B/54/Managing risks to the public.pdt.

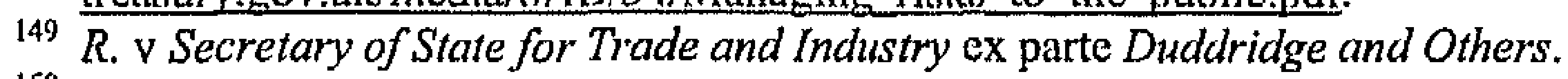

${ }^{150}$ R. v Tandridge District Council, ex parte Al Fayed, p. 7 (of the LEXIS NEXIS version).
} 


\section{Joakim Zander}

management choice could be tried. ${ }^{151}$ Thus, it appears oncc again that use of cost/benefit analysis that is made in the risk management phase lies solcly within the discretion of the UK government. It appears that, since no mechanism is in place for the use of the principle, the UK government can use the precautionary principle as it sees fit.

In the previous chapter, it was discussed that the issue of rational targeting of risks and risk trade-off analysis are concepts that have been elaborated on to a ccrtain degree by the UK government, ${ }^{152}$ but that no firm commitment has been made to such mechanisms in binding documents. In the area of pesticides regulation, the ACP has stated that it aims to takc, among other things, risk off-sets and risk substitutions into account when scientifically examining pesticides before it. When preparing advice, it will highlight such issues and emphasise the remaining uncertainties. ${ }^{153}$ In the case law, once again, the courts have left such considerations up to the exclusive discretion of the government.

\subsubsection{Conclusion}

Three main pieces of legislation lay down the legislative framework for pesticide regulation in the UK. The FEPA and the COPR were both issued before Directive 91/414/EC, which effectively harmonised the approval of active substances in pesticides at EU level. The Directive has been implemented in the UK in the Plant Products Regulations. The regulation of pesticides primarily falls under the competence of the Department of the Environment, Food and Rural Affairs, which is headed by a government minister. Non-agricultural pesticides arc regulated by the Health and Safety Executive. In practice, many tasks have been delcgated to the Pesticide Safety Directorate, which functions as an executive agency under the DEFRA. The PSD maintains strong ties with the DEFRA and cannot be said to function as an independent agency. The Advisory Committee on Pesticides mainly performs risk assessments in relation to pesticides. The role of the $\mathrm{ACP}$ is to function as an independent advisory group and its members consist of eminent experts. Even though the ACP is formally independent, the case law has illustrated that the PSD, in practice, can exert

151 The Queen on the Application of Amvac Chemical UK Limitied v Secretary of State for the Environment, Food and Rural Affairs, Secretary of State for Transport, Local Government and Regions, Food Standards Agency, pp. $84-86$.

152 See, for example, Guidelines for Environmental Risk Assessment and Management, HMSO 2000. Now updated and available at: http:/www.defra.gov.uk/environment/risk/eramguide/, Section 8.2.

153 A Guide to Pesticide Regulation in the UK and the role of The Advisory Committec on Pesticides, p. 16. 
control with regard to what information is actually put before the ACP. ${ }^{154}$ A strict separation of risk assessment and risk management is not upheld.

As discussed extensivcly in the previous chapter, UK courts have, in general, avoided pronouncing judgment on the merits of cases pertaining to the precautionary principle. This has led to a situation in which the UK government has a de facto unlimited discretion in deciding on issues involving scientific uncertainty. In the few cases involving the regulation of pesticides, this trend has been maintained. In Amvac Chemical UK Limited, the court refused to investigate the facts. Despite this, a few interesting conclusions can be drawn from the case. First, the recommendations of scientific bodies are instrumental for the decisions taken by the UK government in cases of uncertainty. Second, the level of potential risk does not have to be particularly high for measures to be invoked if they are recommended by scientific bodies. In Amvac Chemical UK Limited, all the parties agreed that the risk resulting from the use of the pesticide Lindane was very low even though it was demonstrated that it had mutagenic propertics. Despite this, a precautionary approach was taken. Third, even though the PSD did not refer to the precautionary principle in the case, it passively endorsed it, since its decisions were bascd on the opinions of the scientific bodies which were explicitly precautionary. Fourth, and most importantly, the three previous points do not establish any form of trend that can be relied upon for future reference. The use of the precautionary principle is entircly in the hands of the government. In the case of Lindane, a very small risk of cancer was allowed to justify precautionary action, but in the case of Paraquat, a pesticide with well-documented toxic properties, the UK government has taken no action. Instead it has, in the risk assessment carried out at the EU level, held that it considers it safe for normal use.

As discussed in the previous chapter, this apparently leads to a situation in which, in order to challenge a precautionary decision, one would first have to "eliminate sufficiently" the scientific uncertainty, and, second, show that it was unreasonable for the government to take the decision it has taken. Despite this, the ACP has stated that asking someone to show the harmlessness of a product is just as unrealistic as asking someone to prove the hazardousness of a product. However, this is exactly what the courts are doing under the

${ }^{154}$ See R. v Minister for Agriculture cx parte Inquinosa International where the court let the PSD "filter" information to be regarded by the ACP. 


\section{Joakim Zander}

current regime, and it may not even be sufficient to show that the product is harmless. One also has to show that no reasonable person would have taken the erroneous decision.

In the previous chapter, it was discussed extensively how the UK government emphasises the importance of cost/benefit analysis, and, to some degree, risk trade-off analysis. However, in relation to pesticides, no formal regime for taking such considerations into account is in place. If costs and benefits are compared and trade-offs considered, this is done in an informal manner. Here, too, the UK Government has avoided laying down formal requirements against which its decisions can be checked. The same is true for the role of public opinion.

The lack of formal requirements on the application of the precautionary principle and the ineffective judicial review in the UK system of pesticide regulation undoubtedly leaves the government much room to manoeuvre. The price of this leeway a limited??? judicial protection for undertakings and individuals. Possibilities of redress and foresecability are severely limited under the UK regime. Furthermore, it is difficult to obtain background material and reports on the basis of which decisions have been taken by the UK government. It should also be noted that requests to interview UK civil servants involved in the regulation of pesticides were turned down.

The fact that pesticide regulation nowadays is mainly carried out at EU level within the framework of Regulation 91/414 does little to remedy the situation. The risk assessment under the Regulation is, as shown above, Member State driven. It is Member States that are appointed rapporteurs for the risk assessments carried out and it is the Member States that recommend the actions to be taken. The fact that the Member States treat the issue of the precautionary principle inconsistently leads to problematical situations. One example of this is the evaluation of the pesticide Paraquat, in which the strict Swedish precautionary approach stands out in stark contrast to the more toned-down approach assumed by other Member States, in this case notably the UK. Different approaches to this issue will continue to lead to different assessments being made and a continuation of the friction and imbalance in the treatment of the same products in different Mcmber States. 


\subsection{The Application of the Precautionary Principle in the UK Regulation of BASE STATIONS}

\subsubsection{Introduction}

Unlike the Swedish example above, the UK does not employ a multitude of overlapping laws and regulations in the field of radiation in rclation to mobile telephony. However, this does not render the UK situation any less complicated or ambiguous. In the UK, no general statutory provision aiming to address the issue of radiation risks to the public exists. The only legal instruments that do exist in the area regard workers who come in contact with radiation when carrying out their duties. ${ }^{155}$ The issue of base stations siting is regulated through the use of general planning rules, where it is stipulated that basc station, in most cases, are exempt from planning permission. However, non-binding recommendations relating to non-ionising radiation issued at national level have proven important.

In contrast to the arca of pesticide regulation discussed above, the regulation of base stations has yielded an increasing body of case law. Primarily, issues before the courts have dealt with how public opinion should be taken into account, and how big a role it should be allowed to play in the outcome of decisions. Connected to this is the issue of whether local authorities are allowed to be more precautionary when deciding on the siting of base stations than what national guidelines would recommend.

This section, like sections above, deals with the constituent parts of the precautionary principle separately. First, an overview of the legislative and institutional framework is given. Then, the attention is turned towards issues of risk assessment and management, the role of scientific evidence, the burden of proof, and the role of cost/benefit and risk trade-off analyses. Finally, the issue of how public opinion at local level is allowed to influence the application of precautionary measures is addressed.

6.3.2. The Legal Framework

In Sweden, the Radiation Protection Agency has explicitly been given the statutory right to issue regulations and recommendations to cnsure effective protection from radiation. In the UK, no such framework is in effect. Instead, the only recommendations in place with regard to base stations for mobile phones have been issued by National Radiation Protection Board (NRPB). ${ }^{156}$ The institutional framework and the content of the recommendations are returned

155 Hcalth and Safety at Work, etc. Act of 1974 and the Management of Health and Safety at work Regulations of 1999.

${ }^{156}$ Available at: http:/www.hse.gov.uk/radiation/nonionising/hse.htm. 


\section{Joakim Zander}

to below. The lack of a legislative framework regarding radiation from base stations means that guidance with regard to the precautionary principle needs to be sought in planning law and in judgments from the courts.

Like other UK statutory instruments, the relevant planning law is silent on the issue of the precautionary principle. ${ }^{157}$ Instead, it explicitly states that the establishment of "telecommunications systems" is a permitted development, provided that a number of acsthetical requirements are met. ${ }^{158}$ These requirements are primarily concerned with the height of the proposed masts. Development ol base stations is subject to a procedure in which the local planning authority must decide if the project needs prior approval with regard to the siting and the appearance of the development. ${ }^{159}$ If the development does not exceed 2 cubic meters in size there is no need to consult the local planning authority. ${ }^{160}$ The request for prior approval has to be made in writing and has to be accompanied by plans and a description of the proposed development. ${ }^{\mid 61}$

\subsubsection{The Institutional Framework}

As was seen in the Swedish example, at least two institutional structures are involved in the regulation of radiation from base stations. ${ }^{162}$ The issue of setting safety standards in relation to the radiation from base stations is usually taken care of at national level, by a radiation protection agency. In the UK, the body responsible for this was the NRPB, but its authority was transferred onto the new Health Protection Agency (HPA) in the spring of $2005 .^{163}$ The actual siting of base stations falls under the authority of local governments and are subject to normal planning rules. ${ }^{164}$ Special rules for workers are the prime responsibility of the Health and Safety Executive, which will not be dealt with in any detail here. ${ }^{165}$

Without going into too much detail with regard to the NRPB, it should be pointed out that it was assisted by an group of experts which was set up by its Director in 1990. The group of experts still exists and reports to a sub-committee of the HPA. Its advice is not

\footnotetext{
157 The Town and Country Planning Order of 1995, Statutory Instrument 1995 No. 418.

${ }^{15 \times}$ Ibid., Part $24, \Lambda$ and $A .1$.

${ }^{159}$ Ibid., Part 24, $\Lambda .2$ (4) (b) (ii).

${ }^{160}$ Ibid., Part 24, A.2 (4) (b)

til Ihid., Part 24, A.2 (4) (b) (iii).

162 See, above, Section 5.3.3.

${ }^{163}$ Health Protection Agency Act of 2004, Article 3. Available at: httg/wwwopsi.gov.uk/acts/acts2004/20) 40017.hm.

164 The Town and Country Planning Order of 1995.

$16.5 \mathrm{http:} /$ /www.hse.gov.uk/radiation/nonionising/index.htm.
} 


\section{The Precautionary Principle in the UK}

binding but is regularly referred to by the HPA. ${ }^{166}$ The position of the HPA is that of an indepcndent agency. Unlike the Pesticide Safety Directorate discussed in the previous chapter, the HPA is formally independent from direct influence from the government. ${ }^{167}$ In this sense, it is more similar to the agencies discussed in the Swedish section. A chairman, who is appointed by the Secretary of State, heads the Agency. The Chairman, in turn, is seconded by a number of non-executive members, who also are appointed by the Secretary of State and by the representatives of the home countries. ${ }^{168}$ These serve on the board of the HPA together with executive members and the chief executive, who are all employed by the HPA or are seconded staff. ${ }^{169}$ The Chief Executive leads the day-to-day work of the Agency.

To assist it in its scientific work, the agency may appoint committees and subcommittees, which may consist of people not employed by the Agency. ${ }^{170}$ In 1990, the NRPB set up an advisory group, the Advisory Group on Non-Ionising Radiation (AGNIR), whose aim is to "to review work on the biological effects of non-ionising radiation relevant to human health and to advise on research priorities". ${ }^{171}$ The AGNIR consists of a number of scientists which were appointed by the NRPB. The Advisory Group now fulfils the same tasks, but answers to the HPA. It has no formal decision-making role, but functions as a strictly advisory body. ${ }^{172}$ Formal documents pertaining to its internal workings, as well as to its actual influence on UK policy, are difficult to come by. However, it appears that, in practice, its advice has been referred to as the official UK policy towards non-ionising radiation. ${ }^{173}$

Following widespread public concern regarding the use of mobile phones, an independent expert group was formed in 1999 following the recommendation of the House of Commons' Science and Technology Committee. ${ }^{174}$ Its official terms of reference were:

166 Available at: httn:/www.hpa org.uk/webw/HP Aweb\&Page\&HPAwebAutoListName/Page/1207821636407/p=:12078216364 07.

167 Health and Protection Agency Act of 2004, Schedule 1, Articles 5 and 6.

168 Ibid., Article 1 (1) - (3).

169 Ibid., Article I (4).

170 lbid., Article $11(1)-(3)$

171 Available at: http://www.hpa,org.uk/webw/HPAweb\&Page\&HPAwebAutoL istName/Page/1207821636407?p=12078216364 07.

172 Ibid.

173 Ibid. From this website, the reports so far issued by AGNIR can be downloaded.

174 House of Commmons, Science and Technology Committee Publications, Third Report, printed on 2 Septcmber 1999. Available at: http:/www parliament the-stationery- 


\section{Joakim Zander}

"To consider present concerns about the possible health effects from the use of mobile phones, base stations and transmitters, to conduct a rigorous assessment of existing research and to give advice based on the present state of knowledge. To make recommendations of further work that should be carried out to improve the basis for sound advice." 175

Professor Sir William Stewart was appointed to lead the work of the Independent Expert Group on Mobile Phones (IEGMP) as the group was called. Its conclusions were published in the form of a report on 11 May 2000 and have proven to be highly influential as a basis for the UK policy in relation to mobile phones. ${ }^{176}$ The report, which rccommended a precautionary approach to radiation from mobile phones and base stations, is widely referred to as "the Stewart Report" and is returned to in more detail below.

As mentioned above, the actual siting of base stations follows planning rules. Local Planning Authorities (LPAs) are responsible for revicwing planning requests and issuing planning permission where necessary. In the section which deals specifically with telecommunications, no reference to health concerns is made. Instead, the main focus is on aesthetic considerations. As already stated, for masts below the height of 15 meters no building permit is required. The Stewart Report made far-reaching recommendations to change UK planning rules in a more precautionary direction. These recommendations included the revocation and re-examination of all planning decisions for base stations, the introduction of clear templates of protocols to be used by LPAs, and the establishment of exclusion zones around base stations. ${ }^{177}$ Furthermore, it recommended that the ICNIRP standards, which also form the basis for the EU Council Recommendations in the area, ${ }^{178}$ be accepted as the UK standard for non-ionizing radiation as well. ${ }^{179}$

The UK government chose to adopt a significantly more moderate approach than what was advocated in the Stewart Report. The only modifications it chose to make to the planning

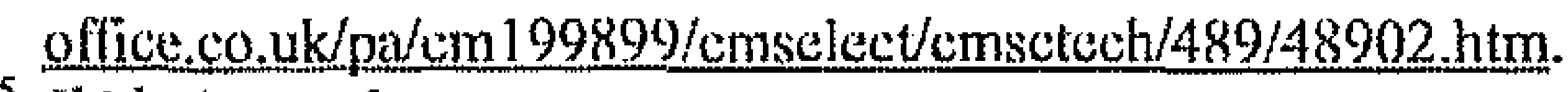

175 Ibid, Annex 2.

176 For a background to the work of the IEGMP and the report in full, see the homepage of IEGMP at: http://www.iegmp.org.uk/.

177 Independent Expert Group on Mobilc Phones, Mobile Phones and Health, May 11 2000, 1.30-1.48. Available at: http://www.iegmp.org. uk/repor/text.htm.

178 Council Recommendation 1999/519/EC of 12 July 1999 on the limitation of exposure of the general public to electromagnctic fields (0 Hz to $300 \mathrm{GHz}$ ). OJ L 199/59.

179 Independent Expert Group on Mobile Phones, Mobilc Phones and IIealth, Section 1.27. 
rules were to strengthen public consultation mechanisms, and increase time-limits and fees to allow for this. ${ }^{180}$

The issue of whether it is possible for LPAs to adopt a more precautionary approach than the ICNIRP standards allow, i.e., the establishment of radiation free zones and lower acceptable levels of radiation, was discussed by the UK Courts in Al Fayed. In the case, the Queen's Bench Division ruled that the LPAs should be bound by safety standards developed nationally, and should not be allowed to set their own, individual risk levels. ${ }^{181}$ However, on appeal, the Court of Appcal indicated that the issue might not be as clear-cut as this. Instead, it held that LPAs could be allowed to be more restrictive than the national policy would allow for in certain cases. ${ }^{182} \mathrm{~A}$ similar stance has been taken in some later cases. ${ }^{183}$ The details of these judgments are returned to below.

\subsubsection{Risk Assessment and Risk Management}

As has been shown in previous chapters, no formal separation between risk assessment and risk management is in place in the UK legislation. ${ }^{184}$ However, in practice, in the area of base stations, risk assessment is separated from risk management. In the area, the HSE, the HPA and the Local Planning Authorities share decision-making powers. The HSE and the HPA are the main risk managers since they are responsible for commissioning scientific research into issues of radiation, and have the formal powers to issue more specific guidance. The risk assessment is carried out by expert groups, for example, the AGNIR, which was set up by, and answers to, the HPA.

At present, the authoritative document relating to risks from base stations in the UK is the Stewart Report. The Report is, in effect, a risk assessment performed by a group of experts, and not a risk management decision based on scientific evidence. However, in the absence of binding rules, the Stewart Report has become the authoritative source in the field. Guidelines and recommendations by the HPA and other institutions endorse most of its scientific conclusions, if not all of its policy recommendations. Courts have proven willing to

${ }^{180}$ R. Ford, Planning For a New Telecommunications Network in the U.K., J.P.L. 2001, September, 1035.

181 R. v Tandridge Destrict Council, ex parte Al Fayed, Queens Bench Division (Crown Office List)79 P / CR 227, [1999] JPL 825, [1999] 1 PLR 104, The Times, 28 January 1999, CO/3665/97, 14 January 1999, p. 7 (of the LEXIS NEXIS version).

182 R. v Tandridge District Council and another, ex parte Al Fayed, Court of Appeal, p. 2 (of the LEXIS NEXIS version).

${ }^{183}$ Most notably in T-Mobile (UK) Ltd v First Secretary of State, Court of Appeal (Civil Division), [2005] Env. L.R. 18, C2 and C3.

184 See, above, Section 6.1.5. 


\section{Joakim Zander}

rely on the conclusions of the Stewart Report, at least as far as they have been reflected in government recommendations. ${ }^{185}$

The experts who took part in the Independent Expert Group for Mobile Telephones and in the writing of the Stewart Report were appointed by the NRPB upon a request by the Minister of Public Health. ${ }^{186}$ The Report constituted principally of a study of the literature in the area of non-ionising radiation. Preceding the commencement of the work of the group, a call for scientific evidence was made. Oral evidence regarded as valid by the committee is to be found on its website. ${ }^{187}$

The conclusions and recommendations of the expert group were far more precautionary in nature than had previously been the case in the UK. ${ }^{188}$ The basis for this is discussed in detail in the following sections. It is, however, important to point out, in relation to risk assessment and risk management, that the Stewart Report was the first governmentcommissioned research to recommend an adoption of the ICNIRP values in the UK.

\subsubsection{The Level of Proof and the Triggering of Precautionary Measures}

The risk assessment in the $\mathrm{UK}$ in relation to radiation from mobile telephony and base stations has traditionally been performed AGNIR and the HPA. However, as shown in the previous chapter, the most authoritative risk assessment since 1999 has been the Stewart Report. A closer look at this report is, therefore, warranted.

Up until 1999, AGNIR and the HPA had recommended maximum radiation levels from base stations that were considerably higher than those advised by the ICNIRP and in usc in other countries. ${ }^{189}$ The reason for this recommendation was that the AGNIR considered that ordinary citizens would not be exposed to radiation from base stations on a scale that would warrant the stricter approach reflected in the ICNIRP standards. For workers who

${ }^{185}$ Sec, for example, T-Mobile (UK) Ltd $\mathrm{v}$ First Secretary of State, Court of Appeal.

${ }^{186}$ Independent Export Group on Mobile Phones, Mobile Phones and Health, published on 11 May 2000 (The Stewart Report), available at http://www.icgmp.org.uk/completion.htm.

${ }_{187} \mathrm{http}: / / \mathrm{www}$.iegmp.org. uk/evidence/index.htm.

188 Compare with the reports published by AGNIR, which preceded the publishing of the Stewart Report. Apart from the obvious references to precaution in the Stewart Report, the exposure levels recommended in the AGNIR reports were significantly higher. AGNIR reports are available at: http://www.hpa.org.uk/radiation/advisory groups/agnir/.

${ }^{189}$ National Radiation Protection Board, Restrictions on human exposurc to static and time varying electromagnetic fields and radiation, Doc NRPB, 4(5) 1993 
would routinely be exposed to radiation, the AGNIR considered the UK approach to be in line with the ICNIRP guidelines. ${ }^{190}$

The Stewart Report, on the other hand, found that the ICNIRP guidelines would be better suited to take into account the special needs of those in the general public who might be "unusually susceptible" to the heating effects of radiation. ${ }^{191}$ Thus, it recommended that:

"as a precautionary approach, the ICNIRP guidelines for public exposure be adopted for use in the UK rather than the NRPB guidelines." 192

It is interesting to note that the Stewart Report explicitly views the implementation of the ICNIRP values as a precautionary measure. However, as has been discussed earlier, the standards are not necessarily precautionary in nature. The foundation for the ICNIRP values is the level at which thermal effects on humans are scientifically certain. Above, it was discussed that they are based on "scientific data alone", ${ }^{193}$ and, thus, can best be described as preventive, rather than precautionary, measures. ${ }^{194}$ It seems that what the Stewart Report finds to be precautionary in the ICNIRP recommendations is the fact that its values incorporate a reduction factor of five to ensure that the scientifically certain effects do not occur. ${ }^{195}$ This factor had previously been considered arbitrary by the AGNIR. ${ }^{196}$ However, such reduction factors are the rule, rather than the exception, in risk regulation. It could be argued that they are precautionary in nature since they recommend a safety margin that is not directly scientifically justifiable above or below a scientifically verified level in which harm ensues. If the exposure is set at $X$, a reduction factor of 5 may be used. This means that, at $X$, harmful effects are certain; consequently, the approved emission level is set at X divided by 5 in order to ensure that the harmful level is not approached. If the level was set exactly at the level of scientifically proven harm, the margin of error would be very small. By adding a safety margin around the exposure level, the margin of error is widened. This does not,

\footnotetext{
${ }^{190}$ National Radiation Proection Board, Advice on the 1998 ICNIRP guidelines for limiting exposure to timevarying electric, magnetic and electromagnetic fields (up to $300 \mathrm{GHz}$ ). Doc NRPB, 10(2), 1, 1999.

191 The Stewart Report, 6.34.

192 Ibid., 6.35.

193 International Commission on Non-Ionising Radiation Protection. Guidelines for Limiting Exposure to TimeVarying Electric, Magnetic, and Electromagnetic Fields (up to 300 GHZ). Health Physics. Vol 74. No. 4, 1998, p. 495.

194 See, above, Section 5.3.5.

195 The Stewart Report, Sections 6.32-6.35.

${ }^{196}$ National Radiation Protection Board, $\Lambda$ dvice on the 1998 ICNIRP guidelines for limiting exposure to timevarying electric, magnetic and electromagnetic fields (up to $300 \mathrm{GHz}$ ). Doc NRPB, Vol. 10 No. 21999.
} 


\section{Joakim Zander}

however, have to be viewed as a strictly precautionary decision, in that it does not necessarily aim to counter uncertainties in the data. Instead, it can be seen as a prudent, albeit arbitrary, way to establish a "fence" around the scientifically certain harm. In relation to the ICNIRP values, the aim of the reduction factor is thus not to take any of the significant and previously discussed uncertainties in relation to cxposure from radiation form base stations into account. ${ }^{197}$ Instead, the purpose is to ensure that a sufficient safety margin is maintained between the exposure levels at which harm undoubtedly ensues and actual exposure levels. The Stewart Report recommended that the ICNIRP values should not be incorporated in UK statutes, the reason for this being that it considered it likely that the emergence of more scientific information would make them liable to change over time. ${ }^{198}$

However, the Stewart Report did not limit itself to recommending the implementation of the ICNIRP values as a precautionary measure in the UK, it went on to state that scientific evidence suggests that thermal effects may not be the only hazard of mobile telephone systems. It also held that radiation may result in biological effects in humans. ${ }^{199}$ Since the ICNIRP guidelines focus solely on thermal effects, biological effects may present themselves even though the guidelines are abided by. Therefore, the Report concluded that:

\footnotetext{
"it is not possible at present to say that exposure to RF radiation, even at levels below national guidelines, is totally without potential adverse health effects, and that the gaps in knowledge are sufficient to justify a precautionary approach."200
}

The Group of Experts expressed that it seemed "highly unlikely" that the level of radiation normally emitted from base stations would lead to "significant, direct adverse effects on health" but that this "could not be ruled out with confidence". ${ }^{201}$ To address these uncertainties, a number of recommendations were made, for example, the establishment of a national register for base stations, ${ }^{202}$ the establishment of a protocol to be followed when establishing basc stations, ${ }^{203}$ and the mandatory cstablishment of clearly marked exclusion zones around every base station. ${ }^{204}$ It also made the far-reaching suggestion that all planning

\footnotetext{
197 See, above, Section 5.3.5.

${ }^{198}$ The Stewart Report, Section 6,36.

$199 \mathrm{Ibid}$., Section 1.18 and 6.38 .

${ }^{200} \mathrm{Ibid}$., Sections 1.19 and 6.39 .

$201 \mathrm{Ibid}$., Section 6.43 .

${ }^{202}$ Ibid., Section 6.48 .

${ }^{203}$ Ibid., Sections 6.54, 6.58 and 6.59.

204 Ibid., Section 6.50.
} 
decisions for base stations issucd at the time of the issuing of the Report should be revoked and re-examined. ${ }^{205}$ Furthermore, base stations near schools should be designed in a manner to minimise the radiation affecting the actual school grounds. ${ }^{206}$

If compared with the Swedish risk assessment of radiation from base stations, it is clear that the Stewart Report chose to emphasise uncertainties to a much larger extent than the Swedish Radiation Protection Agency. ${ }^{207}$ Where the Swedish Agency glossed over uncertainties and focuses upon what is scientifically verifiable, the Stewart Report emphasised the existing uncertainties and chose to recommend a far-reaching precautionary approach. It is particularly interesting that this is the case, given the fact that both the Swedish and the UK risk assessments are based upon essentially the same set of data.

The response from the UK government to the Stewart Report was widely positive. The ICNIRP values were not incorporated into statutes, but they have become the standard advocated by the government in policy documents. ${ }^{208}$ Following the publishing of the Report, a review of the UK planning system was put in place. The far-reaching proposal in the Report to revoke all planning decisions and re-evaluate them was not followed in practicc. However, Northern Ireland and Scotland have essentially implemented the recommendation to require full planning permission for all base station sites. The same rule has not been implemented in England and Wales. ${ }^{209}$ In addition, following the recommendations of the Stewart Report, a website was established where the general public can find information about where base stations are located. ${ }^{210}$ Furthermore, two documents with recommendations for how the siting process of base stations is to be carricd out have been issued. ${ }^{211}$ The primary focus of these documents is to provide an easy-to-access version of the relevant planning rules, but they also emphasise the importance of public participation. This is returned to below.

The courts have generally accepted the ICNIRP values as the standard to be used in assessing radiation from base stations. However, in some cases, it has been indicated that it is

205 Ibid., Section 6.57.

206 Ibid., Section 6.68 .

${ }^{207}$ For a discussion on the Swedish approach, see, above, Section 5.3.5.

${ }^{208}$ See, for example, Planning Policy Guidance 8, p. 95.

${ }^{209}$ Report by the Board of NRPB, Mobile Phones and Health, Doc. of the NRPB Vol. 15, Issuc 5, 2004. Interestingly, it thus appears that different precautionary decisions have been implemented also within the UK based on the same data.

$210 \mathrm{htp} / / \mathrm{ww}$ w.sitefinder.radio.gov.uk

211 Planning Policy Guidance 8 and code of Best Practice on Mobile Phone Network Development, Office of the Deputy Prime Minister, 2002. 


\section{Joakim Zander}

not impossible for local planning authorities to be allowed to act in a more precautionary manner, when deciding on the siting of base stations, than the national rules stipulate. ${ }^{212}$ This is in stark contrast to the UK government's own opinion that the general rules relating to the expansion of the telecommunications system is best decided at national level. ${ }^{213}$ The courts have pointed out that the guidance document only has limited value when interpreting legislation, and is not to function as a rule to "fetter" the judgment of the decision-maker. ${ }^{214}$ Thus, it would appcar that the Local Planning Authorities do, in fact, enjoy some discretion to apply the precautionary principle, at least in theory. When the issue of a more precautionary approach at local level has been brought before the courts, the justification for the more restrictive policy has generally been negative public opinion in relation to the siting of the base station in question. It, thus, seems that, in some cases in the UK, the precautionary principle is closely related to the public opinion. The issue is returned below.

\subsubsection{The Burden of Proof}

As in the case of Sweden discussed above, the UK has not adopted a particularly precautionary approach at national level. The ICNIRP standards which have been incorporated through policy documents and case law primarily offer protection against scientifically established risks and cannot be said to reflect the precautionary principle in the scnse discussed here. The Stewart Report included frequent references to the precautionary principle or approach, but stopped short of actually suggesting more restrictive measures than those which can be justified by preventive considerations. It is, therefore, difficult to say what would have to be shown in order to challenge a precautionary measure at national level in the UK, simply because a precautionary approach is not really in effect at the moment.

However, at local level, the issue is slightly different in the UK than in Sweden. Where the Swedish government and courts have made it clear that they do not consider the precautionary principle to be in effect when local authorities decide on planning matters, the matter is more complicated in the UK. As discussed briefly above, Planning Policy Guidance 8 , issued by the office of the Deputy Prime Minister, holds that, in relation to base stations,

${ }^{212}$ R. v Tandridge District Council and another, ex parte Al Fayed, Court of Appeal, and T-Mobile (UK) Ltd v First Secretary of State, Court of Appeal.

213 Planning Policy Guidance p. 8, $29 \& 30$.

${ }^{214} R$. (on the application of S) v Brent LBC [2002] E.W.C.A Civ 693; [2002] E.L.R 556, para. 15. As quoted in relation to Planning Guidance 8 in Trevett $v$ Secretary of State for Transport Local Government and the Regions and Others [2002] E.W.H.C. Admin 2696, 25 November, 2002, paras 23-24. 
the issue of health safeguards is best dealt with at a centralised level. ${ }^{215}$ However, the document is not binding, and courts have, albeit inconsistently, held that Local Planning Authorities may actually be allowed to act in a more precautionary manner than the relevant policy documents would seem to permit in certain cases. In practice, such precautionary measurcs are primarily based on public opinion that is opposed to the siting of base stations.

\subsubsection{Cost/benefit Analysis}

As has been held in previous chapters, the official commitment to cost/benefit analysis in the UK is firm. Different departments of the central UK government, as well as agencies, have issued non-binding guidelines and reports re-affirming both the importance and the usefulness of cost/benefit analysis. In official documents pertaining to the establishment of base stations, this issue is not elaborated on in any detail. The relevant planning regulations do not require a cost/benefit analysis to be carried oul, and no proportionality requirement appears to override the issue. The same can safely be said with regard to the analysis of risk trade-offs.

In Planning Policy Guidance 8, the emphasis is clcarly on the benefits of mobilc telephony and the importance of consumer choice. ${ }^{216}$ As has been discussed extensively above, the UK Government appears to consider the adherence to the ICNIRP guidelines to address the issue of potential risks of mobile phone technology effectively.

However, as is shown in the following section, the courts are increasingly allowing local authorities to act in a more precautionary manner than the ICNIRP standards stipulate when such action is supported by public opinion. It appears that the rudimentary mechanism that the courts have applied include a weighing of the public opposition towards base stations against the current scientific evidence and any other potential costs of not having adequate mobile phone coverage. ${ }^{217}$ What may develop out of this is a requirement of an informal cost/benefit analysis in the broad sense, without a firm theoretical basis. What such an analysis should entail and how it should be performed appears to have been adjudicated upon by courts on an ad hoc basis so far. That courts would also consider the proportionality of measures and risk trade-off analysis when conducting such a balancing secms likely

215 Planning Policy Guidance, para 30.

216 Planning Policy Guidance 8, paras 1-6.

217 Trevett $\vee$ Secretary of State for Transport Local Government and the Regions and Others, para. 25, and TMobile (UK) Ltd v First Secretary of State, Court of Appeal, para. 29. 
Joakim Zander

\subsubsection{Public Opinion}

Therc is no formal, statutory requirement in place to safeguard the consideration of public opinion in the UK. Generally, base stations are considered Class A developments and do not requirc a building permit. ${ }^{218}$ Only if the masts are above 15 meters in height or in any other way exceed the limits established in Section A.1 of Part 24 of the planning code must a formal building permit be applied for. In such cases, normal planning rules include a formal consultation procedure.

However, even though statutory requirements make relatively weak requirements on public involvement, the UK government stresses the importance of involving the "interested parties" in the process in policy documents. ${ }^{219}$ Furthermore, a system of "traffic lights" has been developed, whereby the public attitude can be gauged. ${ }^{220}$ The mobile phone operator carries out the assessment and is responsible for choosing the appropriate communication strategy based on its results. ${ }^{221}$ If the result of the survey is to be classified as green, the public opinion is deemed to be benign to the development, and normal planning rules can be relied on. If the result of the survey is red, the public opinion is considered hostile to the development, and a more thorough consultation procedure must take place. Such a procedure includes increased publicity around the planned development and a 14 day consultation period. $^{222}$

Even though a robust, albeit non-binding, public consultation procedure is foreseen and advocated by the UK government, it remains unclear what effects a consistently negative public opinion at local level may have on actual planning decisions. Planning Policy Guidance 8 stresses both that "health considerations and public concern can in principle be material considerations in determining application for planning permission and prior approval", ${ }^{223}$ and that "it is the governments firm view that the planning system is not the place for determining health safeguards". ${ }^{224}$ It has becn left to the courts to interpret this somewhat schizophrenic approach.

\footnotetext{
218 The Town and Country Planning Order 1995, Part 24, A.

219 See, for example, Planning Policy Guicance 8, para. 61.

${ }^{220}$ Code of Best Practice on Mobile Phone Network Development, paras. 38-48.

221 Ibid., para. 44.

222 Ibid, para. 45.

${ }^{223}$ Planning Policy Guidance 8, para. 97

224 lbid., para. 98.
} 
Unfortunately, the UK courts have not dcalt with the issue in a particularly consistent manner, either. In two planning cases stemming from the mid- and late-1990s, which respectively concerned dioxin emissions from a proposed development, ${ }^{225}$ and the perceived risks from a chemical waste treatment plant, ${ }^{226}$ the Court of Appeal reached what were, essentially, contradictory conclusions. In Gateshead, the Court held that public opinion without the firm support of scientific evidence cannot be allowed to function as a justification for disallowing development. If this were allowed, very little development at all would take place. $^{227}$ In Newport, on the other hand, the Court stated, in diametrical opposition to the above, that "public perception can [...] warrant refusal, even though the factual basis for that fear has no scientific or logical reason". 228

In successive case law dircctly concerning the siting of base stations, this inconsistency has been maintaincd. In Al Fayed, the Court of Appeal held that it was "common ground" between the parties that "objectively unjustified fears in the locality" are, in some cases, legitimate factors for the planning authority to consider. ${ }^{229}$ It has been pointed out that the fact that the point was conceded by both parties reduces the precedential value of this issue. ${ }^{230}$ In Phillips, the Queen's Bench ruled that, if two alternative sites with cqual properties exist, "as a matter of principle", the option to refuse approval for the site where public opposition to the development was strong could be justified. ${ }^{23 !}$ In Trevett, the Queen's Bench made an attempt to link the two contradictory statements in the Planning Policy Guidance 8 after it had stated that the Policy Guidance could not be considered to "fetter" the judgment of the court. ${ }^{232}$ The judgment in the case related to the refusal of a local council to issue planning permission for TETRA communications masts mainly due to public opposition to the establishment of the masts. Here, the court held that public opposition to a base station was not necessarily sufficient to justify a refusal. However, it also held that it would be equally erroneous to ignore pubic opinion, even if the public fears were not objectively justified. What the court suggests is that public opinion must be carefully weighed

${ }^{225}$ Gateshead MBC v Secretary of State for the Environment I P.L.R., 85. 1994.

${ }^{226}$ Newport CBC v Secretary of State for Wales, J,P.L, 377, 1998.

227 Gateshead $M B C$ v Secretary of State for the Environment, para. 95.

${ }^{228}$ Newport CBC v Secretary of State for Wales, 385.

229 R. v Tandridge District Council and another; ex parte Al Fayed.

${ }^{230} \mathrm{C}$. Hilson, Planning Law and Public Perceptions of Risk: Evidence of Concern or Concern Based on Evidence, J.P.L, Dec. 2004, 1641.

231 Phillips v First Secretary of State and others, Queens Bench Division (Administrative Court) [2003] EWHC 2415 , para. 41.

${ }^{232}$ Trevett $\mathrm{v}$ Secretary of State for Transport Local Government and the Regions and Others, paras. 23 and 24. 


\section{Joakim Zander}

against the current scientific evidence on a case-by-case basis. ${ }^{233}$ The inevitable conclusion of this must be that the court in Trevett did not find the ICNIRP guidelines to reign supreme, but that public opinion could, under certain circumstances, justify the refusal to grant planning permission even though the ICNIRP standards were met. In the case at hand, the court did not find reason to override the ICNIRP standards and thus it considered the local council's decision to have been flawed when it refused to grant planning permission. The Trevett judgment does little to resolve the tension built in to Planning Policy Guidance 8. Instead, it re-inforces its ambiguity. The samc can be said for the more recent T-Mobile judgment, in which the Court of Appeal held that:

\footnotetext{
"Health considerations and public concern can in principle be material considerations in determining applications for planning permission and prior approval. Whether such matters are material in a particular case is ultimately a matter for the courts." 234
}

Once again, the Court leaves the door open for the local authorities to take public opinion into account, and, interestingly, a more precautionary reading of potential health effects, than would be allowed were the ICNIRP values considered binding.

The role of public opinion in decision-making in relation to base stations is ambiguous at best. In recent case law, it appears that courts are increasingly becoming willing to accept public opposition to the establishment of base stations as a justification to deny planning permission at local level, even when such base stations are abiding by the national rules and standards. However, it appears that a weighing of the interests must precede such a decision.

\subsubsection{Conclusion}

The UK legal system lacks a direct statutory instrument which covers the area of non-ionising radiation. Instead, the National Radiation Protection Board was originally given the task of issuing recommendations in the field. Now, this task has been transferred to the Health Protection Agency, an independent agency, which does not answer directly to the ministry in the way that the PSD does in the field of pesticide regulation. The degree of autonomy is thus greater on the part of the HPA. To assist the HPA by performing the de facto risk assessments, the Advisory Group on Non-Ionising Radiation exists. However, with regard to

233 Ibid., para. 25.

${ }^{234}$ T-Mobile (UK) Ltd v First Secretary of State, Court of Appeal, para. 29. 
mobile telephony, the most authoritative report to date was published by the Independent Expert Group on Mobile Phoncs, a temporary advisory group charged with the task of providing scientific advice on mobile phones. The conclusions of the group were published in the Stewart Report.

The siting of base stations is subject to planning rules like all other installations. For base stations that do not exceed certain limitations in size, no planning permission is required. However, a request for establishment must be made to the relevant Local Planning Authority which has to reply that planning permission is not needed before construction can begin.

As has been stated repeatedly above, no formal separation of risk asscssment and risk management is in effect in UK lcgislation. The UK government has not turned the risk assessment included in the Stewart Report into binding regulations, but has broadly embraced its conclusions in policy documents. Thus, the Stewart Report's recommendation that the ICNIRP standards be adopted in the UK has been welcomed by the UK authorities. However, it has stopped short of implementing some of the more far-reaching planning recommendations made in the Report. The Stewart Report explicitly endorsed a precautionary approach to the regulation of base stations. Instead of glossing over the existing uncertainties, as, for example, the Swedish Radiation Protection Agency has done in its assessments, uncertainties were highlighted and discussed. It is thus clear from the Stewart Report that the health effects of radiation from mobile phones are far from certain.

When adopting the ICNIRP standards, the UK Government stated that it found health effects stemming from base stations to be regulated most effectively at national level. However, in Planning Policy Guidance 8, it left a door open for public opinion to be considered at local level. UK courts seem to have expanded this leeway for local governments. In Brent and Trevett, it was pointed out that the govermment documents in the area of planning for base stations are not binding and therefore cannot be considered to "fetter" the judgment of the courts. This would seem to allow some room for manoeuvre on the side of the local authorities when applying the precautionary principle and taking public opinion into account. The issue of whether, and, if so, how much, scientific evidence must underlic a precautionary decision by the local authorities has received very contradictory treatment by the courts. In Gateshead, the Court of Appeal held that public opinion could be relied on, but only if strong support for the views of public opinion was to be found in science. In Newport, the court held that public opinion can warrant a more restrictive policy 


\section{Joakim Zander}

even if its factual basis "has no scientific or logical reason". Successive case law has done little to resolve this conllict. The Court of Appeal concluded in Al Fayed that it can sometimes be legitimate for "objectively justified fears" to be taken into consideration by planning authorities when deciding on matters relating to base stations. However, the precedential value of the case was undermined by the fact that both parties had apparently conceded this point at the outset of the proceedings. The court, in Phillips, ruled that, in cases where two alternative, but equal, sites were available for base station, the one with the lesser public resistance could be chosen. In Trevett, the Queen's Bench aimed to negotiate the contradictory statements in Planning Policy Guicance 8. It essentially concluded that public opinion without a scientific basis to justify its fears was not sufficient to refusc the establishment of the site in question. Simultaneously, it held that the fact that no scientific basis for fears existed, but that public opinion was still negative, did not necessarily mean that a base station should be allowed. It is difficult to imagine how the court could have offered any less guidance on how actually to carry out this balancing act. The only thing that it does is re-inforce the ambiguity of Planning Policy Guidance 8 and the previous case law. The same thing can be said for T-Mobile, where the court held that "public concern can in principle be material considerations" when deciding on planning issues relating to base stations.

In conclusion, it can be said that health and safety concerns stemming from radiation from base stations are, in principle, only addressed by the recommended ICNIRP standards in the UK. Expert groups, the UK Government, Local Planning Authorities and courts have generally agreed upon this. So far, the regulation in the UK resembles that of Sweden. However, whereas, in Sweden, the Government and courts have clearly established that local governments are prevented from taking a more precautionary stance, the UK situation is open to this, provided that the public opinion is opposed to the establishment of base stations. Since Local Planning Authorities are not directly bound by regulations in the area of nonionising radiation, they should not be fettered by the recommendations made by the UK Government. In Duddridge, the court pointed out that local authorities were not the place to consider precautionary measures. However, as can be seen from the case law in this chapter, public opinion clearly can play an, as of yet, undefined role in influencing planning decisions. In the case law, public opinion often is treated as an independent ground, not included in the precautionary principle. This development indicates that, in the area of base stations, public opinion may be as important as that of any legally-binding precautionary principle. This 
would be in line with Haigh stated already in 1994 in relation to the general implementation of the precautionary principle in the UK:

"When it comes to political action, public pressure is as likely to count as much as, or more than, principle."235

${ }^{235}$ N. Haigh, The Introduction of the Precautionary Principle into the UK, in: T, O'Riordan \& J. Cameron, Interpreting the Precautionary Principle, Earthscan, 1994. 


\section{CHAPTER 7.}

\section{THE DEVELOPMENT AND STATUS OF THE PRECAUTIONARY PRINCIPLE IN}

THE UNITED STATES

\subsection{The Development and Status of the Precautionary Principle in the UNITED STATES}

\subsubsection{Introduction}

That the U.S. view of the precautionary principle differs significantly from the view advocated by the EU is apparent from recent international trade conflicts, ${ }^{1}$ as well as from the official rhetoric from both sides of the Atlantic. ${ }^{2}$ The American authorities tend to argue that the EU version ${ }^{3}$ of the precautionary principle slows down scientific and technological development and hinders international trade. Where the EU is seen as risk averse, the U.S. appears to require firm scientific evidence of harm before recognising the need for regulation. Babich has held that the American mentality is not pre-disposed to precautionary considerations:

"U.S. culture embraces change and risk. Our heroes look forward - entrepreneurs and inventors that create what we have barely imagined, athletes who break physical boundaries, and stars of music and film who transcend behavioral conventions. The precautionary principle is not at the core of our national character [...]".

In the same vein, the New York Times held in 2003 that "precaution is for Europeans". 5

However, the facts do not seem to match the rhetoric. In fact, historically, the U.S. has acted in as precautionary a manner as the EU, if not more so. ${ }^{6}$ U.S. environmental legislation of the 1970s went a long way to establishing a form of the precautionary principle in many

See, above, Section 3.3.2.

See, for example, J.D. Graham, The Perils of the Precautionary Principle: Lessons from the American and European Experience, Speech before the Heritage Foundation, Washington D.C., 20 October 2003. Available at: http://www. whitchouse.gov/OMB/inforeg/specches/031020)graham,pdf.

3 For a discussion on the problems with considering one EU version of the precautionary principle to exist, see previous sections of this book.

4 A. Babich, Too Much Science in Environmental Law, 28 Colum. J. Envl. L., 119, 2003, p. 182-183.

5 S. Loewenberg, Precaution is for Europeans, New York Times, 18 May 2003, Section 4, p. 14.

6 Sce, for example, R.E. Löfstedt, The Changing Character of Regulation: A Comparison of Europe and the United States, Risk Analysis, Vol 21, No. 3, 2001, pp. 399-405. 


\section{Joakim Zander}

areas. Agencies and Courts have interpreted statutes in order to afford precautionary considerations even grealer weight. Applegate has held that:

"[p]recaution is clcarly one of the principal goals of congress in drafting and of the Environmental Protection Agency (EPA) in administering environmental legislation."7

This chapter aims to look beyond the rhetoric and give a brief overview of the development of what some have called a "precautionary preference" in U.S. legislation. ${ }^{8}$ Even if this preference does not amount to an all-encompassing precautionary principle, like the one found, for example, in Sweden, it is argued here that it is definitely comparable to how precaution is used in the EU. In order to facilitate this comparison, the precautionary principle is broken down into its constituent parts and dealt with separately as in the previous chapters. In the following sections, it is discussed whether, and, if so, how the precautionary principle, or something resembling the precautionary principle, has influenced regulation in the fields of the regulation of base stations for mobile telephones and pesticides.

\subsubsection{Background and Development}

The precautionary principle as an independent legal concept is not applied in the United States. The U.S. Constitution does not refer to the principle, and neither do representative state constitutions. ${ }^{9}$ The U.S. Supreme Court has never referred to the concept, and only one federal appellate court has ever referred to it. ${ }^{10}$ Moreover, reference to the precautionary principle in legal doctrine is scarce. ${ }^{11}$

However, even though the precautionary principle as a general, legal principle certainly does not feature prominently in the U.S. legal system, there is little doubt that precautionary considerations have played a significant part in U.S. regulatory history. ${ }^{12}$ One

7 J.S. Applegate, The Precautionary Preference: An American Perspective on the Precautionary Principle, Human and Ecological Risk Assessment, Vol. 6, No. 3, p. 420.

8 J.S. Applegate, The Precautionary Preference: An American Perspective on the Precautionary Principle.

9 This conclusion is based on the study of the state constitutions of California, Florida, Iowa, Illinois, Massachusetts, Michigan, New York, Oregon, Texas and Utah, which was carried out by Wood et al., and prescnted in S.G. Wood, S.Q. Wood \& R.A. Wood, The Precautionary Principle? An American Assessment, in: M. Paques, Le Principe de precaulion en droit administratif / Precautionary Principle and Administrative Law, National and International Reports, International Academy of Comparative Law, Bnylant, 2007, p. 247.

$10 \mathrm{Ibid}$, p. 248. However, the case in which the federal court in question made the reference to the precautionary principle related to international torts, and not to U.S. domestic affairs. It should also be mentioned that the 5th Circuit in the case did not find that the precautionary principle rose "to the level of an international tort". Bunal v Freeport-McMoran, Inc, 197 F 3d 161 (5th Cir. 1999).

1 Ibid., p. 248-249.

12 See, for example, J.B. Wiener, Precaution in a Multi-Risk World, Duke Law School Public Law and Legal 
commentator has cven stated that "the precautionary principle has found its way into United States environmental laws, regulations, and policics". ${ }^{13}$ Vogel has pointed out that, over the last thirty years, it appears that the EU and the U.S. have traded places when it comes to being risk averse and precautionary. ${ }^{14}$ Together with Löfstedt, Vogel has also argued that some of the regulatory policics in place in the EU have originally been borrowed from the U.S., and vice versa. ${ }^{15}$ Already from the outset, it can thus be noted that historically the regulatory similarities between the EU and the U.S. are greater than they are often credited with.

One example of early precautionary legislative instruments in the U.S. is the Endangered Species Act of 1973. The Act states that its purpose is the "conservation"16 of "endangered", 17 "threatened", 18 and "jeopardised"19 species. The fact that this not only includes scientifically certain risks of extinction is clarified by the fact that species "likely to become so within the foreseeable future" should also be protected..$^{20}$ In the highly commented on Snail Darter case of 1978, the U.S. Supreme Court, citing the legislative history, held that the Endangered Species Act constituted an expression of "institutionalized caution"." Interestingly, the Court here seems to have acknowledged and afforded weight to the existence of uncertainty in relation to endangered species. However, in Snail Darter, the Court did not primarily consider uncertainty in relation to whether the species may be extinct, but, instead, considered how it may benefit humanity in the future. The Court concluded that, since the benefits of the Snail Darter in the future are uncertain, it should be prevented from extinction. Thus, potential benefits from the species to humanity will be safeguarded. On the

Theory Working Paper Series, No. 23, 2001, p. 1-2, J.S. Applegate, The Precautionary Preference: An American Perspective on the Precautionary Principlc; B.D. Goldstein \& R.S. Carruth, Science in the Regulatory Process: Implications of the Precautionary Principle for Environmetal Regulation in the United States: Examples from the Control of Hazardous Air Pollutants in the 1990 Clean Air Act Amendments, 66 Law \& Contemp. Prob. 247, 2003, and S.G. Wood, S.Q. Wood \& R.A. Wood, The Precautionary Principle? An American Assessment, p. 250.

13 P.M. Kannan, The Precautionary Principle: More than a Cameo Appearance in United States Environmental Law, $31 \mathrm{Wm}$. \& Mary Envtl. L \& Pol'y Rev. 409, 2007, p. 456.

14 D. Vogel, Ships Passing in the Night: GMOs and the Politics of Risk Rgulation in Europe and the United States, EUI Working Paper, No. 2001/16.

15 R.E. Löfstedt, The Changing Character of Regulation: A Comparison of Europe and the United States, Risk Analysis.

16 The term is used throughout the Act; see, for example, Endangered Species Act of 1973, 16 U.S.C. 1531-1544, Sect. 4 (B) and (D).

17 Ibid., Section 4

18 Ibid., Section 4.

19 Ibid., Section 7 (A) (4).

20 Ibid., Section 4 (B) (1) (a) ii

21 Tennessee Valley Authority (TVA) v Hill, 437 U.S. 153 (1978). 


\section{Joakim Zander}

face of it, this does not seem directly similar to the precautionary principle, as it has been discussed in the previous chapters in this book. Despite this, Applegate has held that the expression of the Supreme Court in Snail Darter is a "fair paraphrase of the precautionary principle".22

Other early legislative instruments in the U.S. that were based on basic precautionary assumptions include The Clean Air Act of $1970^{2324}$ and the Clean Water Act of $1972 .^{2526}$ The precautionary nature of The Clean Air Act was re-inforced and claborated on in quite some detail in the influential Ethyl Corp. case. ${ }^{27}$ Furthermore, in Reserve Mining Co. v EPA, the U.S. Supreme Court once again stated that the term "endangering", this time in the context of the Clean Water Act, signifies that not only scientifically certain hazards may be regulated, but also that precautionary action may be taken by administrators. ${ }^{28}$ This was also established in Lead Indus. Ass'n, Inc. v EPA, in which the D.C. Circuit Court held that, in the Clean Air Act, Congress had "directed the Administrator to err on the side of caution in making the necessary decisions". 29

The most overt example of the use of a precautionary principle or approach in the U.S. is found in food regulation. The (in)famous Delaney Clause imposed zero tolerance for residues which may cause cancer in food, regardless of how small the actual risk would bc. ${ }^{30}$ In Public Citizen y Young, the D.C District Court established that the apparent absolutism in the clause was intended by Congress, and should, therefore, be upheld in the application of the statute. ${ }^{31}$ The Delaney Clause has since been revoked, but its influence on U.S. pesticide regulation is returned to in detail in the section on pesticides below. ${ }^{32}$

It is no coincidence that most of the above examples of precautionary action by U.S. Congress and courts relate to legislation passed in the 1970s, a time when the environmental

22 J.S. Applegate, The Precautionary Preference: An American Perspective on the Precautionary Principle, Human and Ecological Risk Assessment, p. 420.

23 The Clean Air Act of 1970, 42 U.S.C. 7401.

24 D. Vogel, Ships Passing in the Night: GMOs and the Politics of Risk Rgulation in Europe and the United States, p. 3.

25 Federal Water Pollution Control Act (Clean Water Act), 33 U.S.C. 1251.

26 J. Tickner \& C. Raffensberger, The Precautionary Principle in Action: A Handbook, Science and Environmental Health Network, 1999, 3. Available at http:/www.sehm.org/rtfdocs/handbook-rtt.rtf.

27 Ethyl Corp. v EPA, 598 F.22d 91 (D.C. Cir. 1979). The Case is returned to in detail below.

28 Reserve Mining Co. v EPA, 514 F.2d 492 (8th Cir. 1975), 528.

29 Lead Indus. Ass' $n$, Inc. v EPA, 647 F.2d 1130 (D.C. Cir. 1976), 1155

30 Federal Food, Drug and Cosmetic Act of 1958, 21 U.S.C. 348, Section 408 and 409.

31 Public Citizen v Young, 831 F.2d 1008 (D.C. Cir. 1987).

32 See, also, P.M. Kannan, The Precautionary Principle: More than a Cameo Appearance in United States Environmental Law, pp. 438-440. 
movement was growing strong. During the presidency of Ronald Reagan (1981-1988), the impetus for environmental regulation in general was weakened. This trend was continued during the Republican Control of Congress in the 1990s and 2000s (1994-2007). It has been argued that, during this time, environmental groups have been largely concerned with (successfully) maintaining the status quo of environmental regulation, rather than trying to break new ground. ${ }^{33}$ Since the coming into force of the Data Quality Act in October of 2002, this balance might finally be conclusively shifted away from precautionary considerations and towards the strict requirements of scientific evidence for regulation. ${ }^{34}$ The concrete implications of this issue is returned to in detail below in this chapter.

\subsubsection{The Current Context and Definition of the Precautionary Principle}

In the absence of any explicit, or even implied, reference to a generally applicable precautionary principle in U.S. legislation, the content of precautionary measures, and the circumstances under which they may be taken, have been dealt with primarily by the U.S. courts. ${ }^{35}$ Following the introduction of the National Environmental Policy Act of 1969 (NEPA), U.S. courts became a battleground for "competing environmental ideologies". ${ }^{36}$ On one side, the newly established environmental movement argued for a wide introduction of environmental concerns in U.S. regulation, and, on the other side, industry fought to maintain the status quo. In this environment, even though not relying particularly on the NEPA, activist U.S. courts started carefully to define a precautionary principle of sorts in certain policy areas.

As outlined briefly above, two cases in the mid-1970s became central for the inclusion of precautionary considerations in the United States. The Clean Air Act and the Federal Water Pollution Control Act, which were the statutes at issue in the respective cascs, lacked any direct reference to precautionary measures. However, this did not stop the courts in the mid-1970s from allowing precautionary measures taken by the Environmental Protection Agency (EPA) under these acts. The vessel used to facilitate this development was the term "cndanger", which was included in both statutes. ${ }^{37}$

33 D. Vogel, Ships Passing in the Night: GMOs and the Politics of Risk Regulation in Europe and the United States, p. 32.

34 For an interesting account of this development, see C. Mooney, The Republican War on Science, Basic Books, 2005, pp. 102-120.

35 S. Jasanoff, Science at the Bar, Marvard University Press, 1995, 36 et seq.

36 Ibid., p. 37.

37 As regards the Clean Air Act, see Section 211(c)(1)(A) which authorises the Administrator of EPA to regulate 


\section{Joakim Zander}

In Reserve Mining, the U.S. Court of Appeals for the Eighth Circuit needed to assess if low-grade iron ore cmissions from a mining operation was a sufficicnt thrcat to public health to warrant regulatory intervention. The evidence regarding the emissions was not conclusive and the issue was surrounded by a great deal of uncertainty. As mentioned above, the relevant statute, the Federal Water Pollution Control Act, held that substances that "endanger" human health should be regulated. No more guidance as to how to interpret the term "endanger" was to be found in the statute, nor had the U.S. Supreme Court at that time made any rulings on how the term was to be interpreted. ${ }^{38}$ Thus, the Court had some discretion with regard to whether to interpret the term narrowly and demand firm scientific evidence of harm before action, ${ }^{39}$ or to expand the term to incorporate situations fraught with scientific uncertainty. Relying on a dissenting opinion in the first Ethyl Corp. $\vee$ EPA, ${ }^{40}$ the Eighth Circuit decided to opt for the latter. ${ }^{41}$ It stated:

\footnotetext{
"In the context of this environmental legislation, we believe that Congress used the term 'endangering' in a precautionary or preventive sense, and, therefore, evidence of potential harm as well as actual harm comes within the purview of that term". ${ }^{42}$
}

Interestingly, it found further support for this reading of the statute in a 1966 casc from the U.S. Supreme Court in which the importance of "common sense" interpretations of environmental statutes was emphasised. ${ }^{43}$ Thus, it appears that the issuing of precautionary measures in this case was considered to be common sense by the court. This interpretation of the term "endangering" must be considered a relatively strong endorsement of a form of the precautionary principle. This is particularly the case when it is considered that the Federal Water Pollution Control Act and the Clean Air Act "together constitute the bulk of this

gasoline additives whose emission products "will endanger the public health or welfare". With regard to the Federal Water Pollution Control Act, see Section 11, which holds that regulation should be enacted with regard to substances "endangering the health or welfare of persons".

38 Reserve Mining v EPA, 90-91.

39 This was the traditional common law approach in situations of scientific uncertainty up until the 1970s, as exemplificd by for example Fletcher $v$ Bealey 28 Ch.D. pp. 688-700. For a more detailed discussion on this, see S. Jasanoff, Science at the Bar, p. 36.

40 The Court here referred to the first of two identical cases brought by Ethyl Corp. before the U.S. Court of $\Lambda$ ppeals for the D.C Circuit. In this case, the majority found in favour of the plaintiff and quashed the precautionary action by the EPA. However, as is shown below, the case was referred back to the Court for an en bank decision before long and the verdict was reversed.

41 Reserve Mining v EPA, pp. 89-90.

42 Ibid. 89.

43. Ibid., 91 . 
nation's substantive environmental protection legislation" at the time of the Reserve Mining and Ethyl Corp. rulings. ${ }^{44}$

As was mentioned above, the majority of the Court in the first Ethyl Corp. case had rejected the expansive reading of the term "will endanger" in the Clean Air Act. ${ }^{45}$ Instead, the Reserve Mining case was constructed on the basis of the minority opinion of Judge Wright in the same case. However, the Ethyl Corp. case was referred back to the D.C Circuit Court, this time for an en bank decision. And, this time, Judge Wright's stance was supportcd by the majority of the Court, which stated in conclusion:

"In sum, based on the plain meaning of the statute, the juxtaposition of Section 211 with Sections 108 and 202, and the Reserve Mining precedent, we conclude that the 'will endanger' standard is precautionary in nature and does not require proof of actual harm before regulation is appropriate." 46

In a few other cases, stemming from around the same time as Reserve Mining and Ethyl Corp., courts continued to hold that, in areas that are "particularly sensitive and fright laden", ${ }^{47}$ regulation on the based on "lower standards of proof than otherwise applicable"48 could be allowed. ${ }^{49}$

If the judgments of the appcllate courts in Reserve Mining and Ethyl Corp. seemed to establish a precautionary principle of sorts in the U.S, as well as to go somc way towards defining it, subsequent case law was to put a serious dent in this development. The National Environmental Protection Act of 1969 (NEPA) established the use of Environmental Impact Statements in the U.S. and has bcen considered by some to be an embodiment of the precautionary principle in U.S legislation. ${ }^{50}$ Others have held that, even though it has precautionary elements, it lacks "the substantive teeth" that can be expected from an

44 Ethyl Corp. $\mathrm{v}$ EPA, 37.

45 The relevant provision, Section 211 (c) (1) (a) of the Clean Air Act of 1970, holds that the regulator may "control or prohibit the manufacture, introduction into commerce, offering for sale, or sale of any fuel or fuel additive for use in a motor vehicle or motor vehicle engine $(A)$ if any emission products of such fuel or fuel additive will endanger the public health or welfare". Highlighting added by this author.

46 Ethyl Corp. v EPA, 39.

47 Environmental Defence Fund v. EPA, 465 F.2.d 528 (D.C. Cir. 1972).

48 Certified Color Manufacturers Association et al., v. David Mathews, Secretary of the Department of HEW et al,, 465 F.2d 528 (D.C. Cir. 1976), 297-298.

49 For a similar discussion on this, sce S. Jasanoff, The Fifth Branch: Science Advisers as Policymakers, Harvard University Press 1994, p. 51.

so See, for example, the position of the Science and Environmental Health Nctwork (SEHN) at: hilp://www.sehn.org/ppfaqs.himl. 


\section{Joakim Zander}

instrument which truly reflects the precautionary principle. ${ }^{51}$ This is supported by the fact that the U.S. Supreme Court explicitly stated that the NEPA does not assign any particular weight to environmental considerations. ${ }^{52}$ Furthermore, there is no effective obligation under the NEPA that mandates the EPA to mitigate harms which may bc identified in the Environmental Impact Statement. ${ }^{53}$ Even if it is contemporary to the Clean Air Act and the Federal Water Pollution Control Act, the precautionary element in the NEPA must be considered to be significantly less pronounced.

In the Benzene case of 1980 , the U.S. Supreme Court confirmed that precautionary regulatory action could be taken under the Occupational Hcalth and Safety Act, but that such action would have to be backed up by a certain amount of scientific evidence. ${ }^{54}$ The case marked the beginning of a new era in U.S. risk regulation under the Reagan administration. Regulatory decisions would, from now on, have to be based on detailed risk assessments, rather than on more sweeping precautionary considerations. ${ }^{55}$ The fact that the increased scope of courts' judicial review was instrumental to this development is discussed in the following.

\subsubsection{Judicial Review}

While the judicial review in the national legal orders previously discussed here can best bc described as narrowly confined, ${ }^{56}$ the situation in the U.S. is rather different. The scope of judicial review of administrative action in the U.S. is partly defined in a statutory instrument. ${ }^{57}$ The Administrative Procedure Act (APA) holds that administrative decisions should be overturned if they are "arbitrary, capricious, an abuse of discretion, or otherwise not in accordance with law", 58 or if they arc not based on "reliable, probative, and substantial

51 J. Applegate, The Precautionary Preference, 429.

52 Marsh v Oregon Natural Resources Council 490 U.S. 332 (1989).

53 J. Applegate, The Prccautionary Preference, 429.

54 Industrial Union Department, AFL-CIO v American Petroleum Institute, 448 U.S. 607 (1980).

55 J. Wiener, Precaution in a Multi-Risk World, p. 2.

56 This, in practice, is also the case in Sweden, even if, as was shown above, the actual legal scope for judicial review leaves a rather wide leeway for the courts. However, traditionally courts have made very limited use of this possibility. Potentially, this is changing with the expanded use of scientific expertise in the courts' composition within the framework of the newly cstablished environmental courts. For a detailed discussion, see, above, Section 5.1.4.

57 Section 704 of the Administrative Procedure Act of 1974, 5 U.S.C. 551 (APA).

58 Ibid., Scction 706(2)(A). For a consise discussion on jucdicial review under the APA, see F. Anderson, M,A. Chirba-Martin, D.D. Elliott, C. Farina, E. Gellhorn, J.D. Graham, C. Boyden Gray, J. Holmstead, R.M. Levin, L. Noah, K. Rhyne \& J.B. Wiener, Regulatory Improvement Legislation: Risk Assessment, Cost-Benefit Analyis, and Judicial Review, 11 Duke Environmental Law and Policy Forum 89, 2000. 
evidence" ${ }^{59}$ Howcver, the interpretation of this provision has not been consistently upheld in the case law, as is the case in the UK, where the "reasonableness" lest, as developed by the courts, is a veritable judicial axiom. ${ }^{60}$ Instead, the U.S. courts' willingness to review administrative decisions concerning scientific assessments has varied over time, secmingly in unison with the reigning political paradigm. ${ }^{61}$

The fact that agency actions in the U.S. are subjected to judicial review is thus established by federal statute. The APA allows for judicial review of all actions for which there is no other adequate remedy, where such review has not been precluded by statute, or wherc agency discretion is commanded by law. ${ }^{62}$ The exceptions to judicial review have been narrowly defined in the case law, and the prevailing legislative intent of the APA is that agency action should be open to review by the courts. ${ }^{63}$

Jasanoff has discussed a number of different schools of judicial review which have been applied by the courts in relation to scientific evidence since the $1970 \mathrm{~s}^{64}$ The first school, which has, to a ccrtain extent, been discussed above, occurred in the 1970s, when activist federal courts went a long way to use expansive rcadings of environmental legislation in order to usher through precautionary decisions. A famous example of this stance of the courts is the Ethyl Corp. decision, which was touched upon above. A methodology central to this development was the so-called "hard look doctrine", developed primarily by the D.C. Circuit Court. The hard look doctrine aimed to ensure that agencies had, indeed, reviewed the relevant scientific evidence underpinning an issue and understood it. The method has been defined in the following manner:

\footnotetext{
"Assumptions must be spelled out, inconsistencies explained, methodologies disclosed, contradictory evidence rebutted, record references solidly grounded, guesswork eliminated and conclusions solidly supported 'in a manner capable of judicial understanding, ${ }^{2}$ "65
}

59 Ibid., Section 706(2)(E).

60 See, above, Section 6.1.6

S. Jasanoff, Science at the Bar, p. 70-71.

62 Ibid., Sections 701(a)(1) and 701(a)(2), respectively.

63 See, for example, M. Pak, Note \& Comment: An IQ Test for Federal Agencies? Judicial Review of the Information and Quality Act Under the APA, 80 Wash. L. Rev. 731, 2005, 743-751.

64 S. Jasanoff, Science at the Bar, pp. 69-72.

65 EI DuPont de Nemours and Co. v Train, 541 F.2d 1018 (4th Cir. 1976). 


\section{Joakim Zander}

However reasonable the review described appears to be in theory, in practice, it proved very difficult to strike the required balance. ${ }^{66}$ These difficulties led to a resort to proceduralism by the courts, and, in order to facilitate this development, they even began to invent formal procedures against which agency decisions were measured. ${ }^{67}$ However, in Vermont Yankee, the U.S. Supreme Court curtailed this practice and held that courtprescribed procedures would only exaggerate the uncertainties inherent in the judicial process. ${ }^{68}$ At the same time, Vermont Yankee explicitly allowed courts to substantially review the data on which decisions were made.

In the 1980 s, the courts, following a number of precedents from the U.S. Supreme Court, began to offer more deference to the interpretation of scientific evidence by agencies. ${ }^{69}$ However, the hard look doctrine was, in principle, maintained and solidified by the Supreme Court in State Farm. In the case, the Court famously held that:

"the agency has relied on factors which Congress has not intended it to consider, entirely failed to consider an important aspect of the problem, offered an explanation for its decision that runs counter to the evidence before the agency, or is so implausible that it could not be ascribed to a difference in view or the product of agency expertise".

However, in Baltimore Gas, the U.S. Supreme Court elaborated on the limits to the hard look doctrine and held that a court "must generally be at its most deferential" when it is reviewing assessments made at the "frontiers of science", thus indicating that the scope of the courts' review should be more limited in cases of scientific uncertainty. ${ }^{70}$ In Sierra Club v Costle, the D.C. Circuit Court concluded that agency "informal rule-making" was not only a technocratic process, but that it must also be allowed to include political considerations. Thereby, the Court seemed to indicate that a certain leeway should be afforded to agencies to enable them to consider aspects of regulation other than those strictly based in science. ${ }^{71}$

A few other cases, dating from the early 1980s, indicate that the change in the evolving character of judicial review, perhaps, had more to do with curtailing the substantive

\footnotetext{
66. S. Jasanoff, Science at the Bar, p. 76.

67 Ibid., p. 77.

6 Vermont Yankee Nuclear Power corp. v Natural Resources Defense Council, 435 U.S. 519 (1978), 547.

69 S. Jasanoff, The Fifth Branch: Science Advisers as Policymakers, p. 56.

70 Baltimore Gas and Electric Co. v Natural Resources Defence Council, 462 U.S. 87 (1983), 103.

71 Sierra Club v Costle, 657 F.2.d 298 (D.C. Cir. 1981), p. 408.
} 
environmental activism on the part of some U.S. federal courts than any genuine procedural issues of judicial review. Where the courts in cases such as Ethyl Corp. and Reserve Mining had effectively reversed the burden of proof onto the regulated parly, the Benzene case showed that the Supreme Court wished it to remain with the agency. In order to do so, it substantively reviewed the data which underlay the decision to regulate benzene emissions and found it insufficient to warrant regulation. ${ }^{72}$ This trend is also visible in Gulf South Insulation. ${ }^{73}$ The issue of the allocation of the burden of proof is returned to in greater detail below. Here, it is sufficient to point out that courts in the 1980s started to break up the activist partnership that had formed between agencies and courts in the 1970s. This task was further facilitated by the fact that Congress began to issue narrower and more detailed rules in the field of the environment, thus further limiting the possibilities of wide interpretation by agencies that previous legislation had allowed for. ${ }^{74}$

In Chevron, the Supreme Court attempted to clarify the scope of agency discretion by introducing a two-pronged test. This test meant that courts should first ask themselves whether "Congress has directly spoken to the precise question at issue" in the case. If so, the court had to "give effect to the unambiguously expressed intent of Congress". ${ }^{75}$ Thus, the discretion of the agency in question was strictly limited. However, if Congress has not directly addressed the issue, courts can only consider whether the agency's interpretation is "is based on a permissible construction of the statute". ${ }^{76}$ If this is the case, the court can do nothing but defer to the interpretation of the agency. ${ }^{77}$ In short, the Court's reasoning meant that, unless Congress has addressed an issue unambiguously, it is for the relevant agency to interpret the statute, and this interpretation is only subject to a limited review by the courts. It has been held that this doctrine distorts the system of checks and balances at the expense of the judiciary. ${ }^{78}$

In the more recent case Texas Oil \& Gas Ass'n v EPA, which dealt with discharge limits established by the EPA, the 5th Circuit Court reconfirmed that the judicial revicw of

${ }^{72}$ Industrial Union Department v American Petroleum Institute, 448 U.S. 607 (1980).

73 Gulf South Insulation v Consumer Product Safety Commission, 701 F.2d 1137 (5th Cir. 1983).

74 S. Shapiro \& R.L. Glicksman, Congress, The Supreme Court and the Quiet Revolution in Administrative Law, Duke L. J. 819, 1988, 819.820.

75 Chevron U.S.A. Inc. v Natural Resources Defence Council, 467 U.S. 87 (1984), pp. 842-843.

76 Ibid., p. 843

77 Ibid.

78 S. Shapiro \& R.L. Glicksman, Congress, The Supreme Court, and the Quiet Revolution in Administrative Law, 862. 
agency decisions must respect a great margin of deference when "the agency's decision rests on an evaluation of complex scicntific data within the agency's technical expertise". ${ }^{79}$

Following the highly publicised Daubert v Mcrrel Dow Pharmaceuticals ${ }^{80}$ in 1993, in which the U.S. Supreme Court explicitly allowed lederal judges to reject irrelevant or unreliable scientific evidence, voices have been raised in favour of courts implementing the Daubert approach in the review of agency decisions. ${ }^{81}$ In Daubert, the Supreme Court established a number of methods or principles regarding how courts should treat scientific evidence. Among other things, it held that courts must exercise an element of screening when deciding on what scientific evidence to consider. The aim of this would be to ensure that only "relevant" and "reliable" evidence is relied upon in court proceedings. ${ }^{82}$ However, the Supreme Court also prohibited judges from drawing their own conclusions on the basis of the scientific evidence presented. Instcad, they should evaluate and criticise the "principles and methodology, not $[\ldots]$ the conclusions they generate". ${ }^{83}$ Since this judgment, courts have expressly rejected the extension of the Daubert approach to agency decisions. ${ }^{84}$ However, some commentators have vigorously supported its application in administrative cases. ${ }^{85}$ Other commentators have found that deep substantive review possibilities, including the hard look doctrine, have led to Courts splitting separating according to partisan lines when deciding on the outcome of cases. ${ }^{86}$

On the whole, judicial review by U.S. courts has remained as it was developed by the U.S. Supreme Court during the 1980s. This means that the activist approach by courts in Ethyl Corp and Reserve Mining has, to a large extent, been abandoned in favour of a more deferential review, although the hard look doctrine still remains in force. However, stronger demands for scientific evidence and the reasoning of agencies before regulatory action is

79 Texas Oil \& Gas Ass' $n$ v EPA, 161 F.3d 923 (5th Cir. 1998), 933-934.

80 Daubert v Merrel Dow Pharmaceuticals, 509 U.S. 579 (1993).

${ }^{81}$ See, for example, A.C. Raul \& J.Z. Dwyer, Science in the Regulatory Process: "Regulatory Daubert": $\Lambda$ Proposal to Enhance Judicial Review of Agency Science by Incorporating Daubert Principles into Administrative Law, 66 Law \& Contemp. Prob. 7, 2003.

82 Daubert v Merrel Dow Pharmaceuticals, p. 589.

${ }^{83}$ Ibid., p. 595.

84 See Sierra Club v Marita, 46 F.3d 606 (7th Cir. 1995), p. 622.

85 Sce, for example, A.C. Raul \& J.Z. Dwyer, Science in the Regulatory Process: "Regulatory Daubert": A Proposal to Enhance Judicial Review of Agency Science by Incorporating Daubert Principles into Administrative Law, 66 Law \& Contemp. Prob. 7, 2003.

86 T.J. Miles \& C.R. Sunstein, The Real World of Arbitrariness Review, John M. Olin Law \& Economics Working Paper No, 368, November 2007. 
taken have progressively been made. ${ }^{87}$ What this means for the application of the precautionary principle with regard to scientific evidence, burden of proof and cost/benefit analysis is discussed below.

Finally, it should be mentioned that in the recent case Massachusetts $v$ EPA, a split Supreme Court found that Massachusetts should be awarded standing to challenge the decision of the EPA not to regulate greenhouse gas emissions from mobile sources. ${ }^{88}$ Even though the Court treated the link between greenhouse gas emissions and global warming as, more or less, scientifically certain, the case provides an interesting move towards opening a theoretical possibility for claimants to gain access to the court system for challenges of agency decisions based on the precautionary principle. Some commentators have held that the Supreme Court missed an opportunity to make a strong endorsement of "precautionary standing" in U.S. courts in the case. ${ }^{89}$ However, others have stated that the case was an example of undue judicial activism on the part of the Supreme Court. ${ }^{90}$

\subsubsection{Risk Assessment and Risk Management}

As has been elaborated on here in the previous sections, U.S. risk regulation during the $1970 \mathrm{~s}$ was often precautionary, although strict requirements on risk assessment before issuing regulation were not always made. However, in 1980, a divided U.S. Supreme Court in the Benzene decision stated that the Occupational Safety and Health Administration (OSHA) needed to base its decision to regulate benzene emissions on scientific evidence. The judgment marked a clear shift away from the environmentalist "partnership" government agencies and courts that had emerged during the 1970s, which had allowed for precautionary interpretations of environmental statutes. In only a few years after Benzene, the use of risk assessment in the U.S. regulatory regime became "almost routine" when taking decisions on chemicals and physical agents. ${ }^{2}$

In 1983, the U.S. National Research Council issued an influential report which set out to define some of the technical aspects of risk assessment. ${ }^{93}$ It also included a section which

87 A.C. Raul \& J.Z. Dwyer, Science in the Regulatory Process: "Regulatory Daubert": A Proposal to Enhance Judicial Review of Agency Science by Incorporating Daubert Principles into Administrative Law.

88 Massachusetts v EPA, 127 S. Ct. 1438 (2007).

89 J.R. Nash, Standing and the Precautionary Principle, 108 Colum. L. Rev. p. 494, 2008.

Editorial, Jolly Green Justices, Wall St. J., 3 April 2007, at A14.

91 S. Jasanoff, Science at the Bar, p. 88-89.

92 B.D. Goldstein, The Interface Between Science and Law, 14 Colum. J. Envtl. L., 343, 1989, p. 355.

93 National Research Council, Risk Assessment in the Federal Government: Managing the Process, National Academy Press, 1983. 


\section{Joakim Zander}

recommended that the assessment of risks be kept separate from the decision of how to manage the risk. ${ }^{94}$ During the 1990 s, the Republican majority in the U.S. Congress sought to pass legislative measures which would lay down detailed requirements on risk assessment, including, in some cases, methods and procedural requirements. However, this cffort was not successful and the use of risk assessment in environmental and health regulation has not been cffectivcly included in binding legislation. ${ }^{95}$ It is thus largely within the discretion of the respective agencies entrusted with risk management tasks to decide on how to carry out risk assessments in the relevant cases, unless more detailed formal requirements on the use of scientific committees, etc., have been laid down by the U.S. Congress. ${ }^{96}$ However, the performance of risk assessments can be described as a "quasi-procedural requirement", ${ }^{97}$ and the courts have, at least in some cases, proven willing to check in which manner the risk assessment has been performed.

The issue of the separation of risk assessment and risk management has received surprisingly little attention in the U.S. ${ }^{98}$ In a seminal report issued by The Presidential/Congressional Commission on Risk Assessment and Risk Management in 1997, the issue was not dealt with in any greater detail, but it can be concluded both from the graphs and the general discussion that a separation of risk assessment and risk management is, in fact, fundamental. ${ }^{99}$ It also concluded that:

"Failure to achieve a clear separation of scientific evidence from policy considerations has negative implications beyond impaired credibility: it inevitably obscures the overall level of uncertainty in the assessment and will influence consideration of societal trade-offs and ultimate decision making." ${ }^{100}$

However, the EPA has stated that, in practice, a formal, institutional separation of the risk assessment and risk management is not upheld. On the contrary, the EPA considers it important that the two processes take place side by side, in order for the risk manager to be

94 Ibid., p.152.

95 L.-J. Schierow, Environmental Risk and Cost-Benefit Analysis: A Review of Proposed Legislative Mandates, 1993-1998, CRS Report for Congress, 22 January 1999.

96 This issue is returned to in detail in the respective case studies below.

97 J.S. Applegate, A Beginning And Not An End In Itself: The Role Of Risk Assessment In Environmental Decision-Making, 63 U. Cin. L. Rev. 1643, 1994/1995, p. 1651.

98 R.M. Sedman \& P.W. Hadley, Risk Assessment and Risk Management: Mending the Schism, 3 Risk - Issues in Health \& Safety 189,1992, p. 189-190.

99 The Presidential/Congressional Commission on Risk Assessment and Risk Management, Risk Assessment and Risk Management in Regulatory Decision-making, Final Report Vol. 2, 1997, 2 and 3.

${ }^{100}$ lbid., p. 192. 
adequately informed on how the process of risk assessment has been conducted. It is, however, emphasised that the respective roles of risk assessor and managers are different. Risk assessors analyse the scientific material, and risk managers take the decisions based on this scientific evaluation. ${ }^{101}$

Reccntly, it would seem that the importance of risk assessments is increasing even further. With the passing of the Data Quality Act in 2000, all government decisions can be subject to "correction" if they do not meet strict requirements established in relevant guidelines. ${ }^{102}$ In 2002, the Office of Management and Budget issued detailed guidance on the scientific data to be used for regulatory purposes by federal authorities. ${ }^{103}$

The increased demand for dccisions to be based on scientific evidence from the early 1980s onwards means that risk assessments are at the core of U.S. risk regulation. Courts will mandate the performance of a risk assessment and may penalise a government body that has failed to perform it. Furthermore, it appears that risk assessment is, in principle, considered a scientific process which is to be kept scparate from risk management, which is the process of taking decisions upon the basis of the risk assessment. It has been emphasised that these processes, even if separated, should take place side by side in order for the best decisions to be taken. How this is done in practicc, and how it influences the decisions taken is dealt with in the following section.

\subsubsection{Scientific Evidence and the Level of Proof}

With the ruling in the Benzene case, and the subsequent development of a strict rcliance on risk assessment during the 1980s, the importance of scientific evidence when regulating risks in the U.S. has been strongly emphasised. As has been shown above, the demands on scientific evidence required for regulation during the 1970s had been low. Agencies had often used scientific uncertainty as sufficient proof of risk to warrant regulation, ${ }^{104}$ and the courts, content with the fact that the agencies had had a "hard look" at the scientific evidence brought before them, would generally allow for this. However, in the Benzene ruling, the U.S. Supreme Court mandated, with the thinnest margin possible, that agencies base their

101 U.S. Environmental Protection Agency, An Evaluation of EPA Risk Assessment Principles and Practices, Staff Paper Prepared for the U.S. Environmental Protection Agency by mombers of the Risk Assessment Task Force EPA/100/B-04/001, p. 22-23.

102 Data Quality Act, Amendment to the Paperwork Reduction Act, 4 U.S.C. 3501.

${ }^{103}$ Office of Management and Budget, Guidelines for Ensuring and Maximizing the Quality, Objectivity, Utility, and Integrity of Information Disseminated by Federal Agencies; Notice; Republication, Federal Register / Vol. 67 , No. $36 / 22$ February 2002. This is discussed in more detail below in the section on scientific evidence.

104 See the discussion on Ethyl Corp., and Reserve Mining, above. 


\section{Joakim Zander}

actions on some form of scientific evidence of risk. The majority held that bcfore "any permanent health or safety standard" can be required, "a threshold finding [...] that significant risks are present and can be eliminated or lessened by a change in practices" must be established. ${ }^{105}$ However, it was not possible for the justices in Benzene to agree on a more defined and generally applicable allocation of the scientific cvidence which would be required to establish the "significant risk". Three of the judges in the case thought it prudent to call for regulatory action in situations in which it would be "more likely than not" that the rclevant activity would lead to the realisation of the suspected risk. ${ }^{106}$ However, this assertion was not supported by the majority.

The majority in the Benzene case established that a "significant risk" triggers regulatory action, but proved hesitant to lay down any more precise indications of how much, or what kind of, scicntific cvidence this would require. At the same time, it did make it clear that the scientific evidence would not need to represent "anything approaching scientific certainty". ${ }^{107}$ Thus, it appears that:

"[the agency] may use conservative assumptions in interpreting data, thus erring on the side of overprotection, so long as its decision is supported by a body of reputable scientific thought." 108

However, the Benzene case did not put an ond to precautionary considerations by U.S. authorities. On the contrary, it explicitly stated that "policy considerations" play an important role when deciding on regulatory action under conditions of uncertainty. ${ }^{109}$ However, il did make it clear that scientific uncertainty alone cannot justify regulatory action. The absence of scientifically certain evidence in support of the harmlessness of a product or an activity is not sufficient to warrant regulation. Some, but not necessarily conclusive, evidence of a risk is required for a measure to stand.

"Significant risk", as it was dealt with in the Benzene ruling, has not been defined in any detail. The general deference of the courts, when it comes to dealing with scientific uncertainty, allows the regulator considerable freedom in deciding on what measures to take

\footnotetext{
${ }^{105}$ Industrial Union Department, AFL-CIO v. American Petroleum Institute èt al., 448 U.S. 607 (1980), p. 408.

${ }^{106}$ Ibid., 653.

${ }^{107}$ Ibid., 656.

108 J.C. McElveen \& C. Amatea, Risk Symposium: Legislating Risk Assessment, 63 U. Cin. L. Rev. 1553, p. 1568.

${ }^{109}$ Industrial Union Department, AFL-CIO v. American Petroleum Institute et al., 448 U.S. 607 (1980), p. 656.
} 
based on the scientific evidence in each individual case. ${ }^{110}$ However, since the passing of the controversial Data Quality Act in 2000, the requircments on scientific evidence have been elevated further. The purpose of the Act is to ensure that government agencies rely on "good science" when issuing regulations. The Act mandates the Office of Management and Budget (OMB) to issue guidelines on how data quality can be ensured, ${ }^{111}$ and more detailed and agency-specific requirements have been issued by individual agencies. ${ }^{112}$ In short, four principles are identified as fundamental for the information relied upon by regulators: quality, utility, objectivity, and integrity. ${ }^{113}$ If data held by an agency does not meet the standards laid down in the OMB or agency-specific guidelines, a "correction" of this data can be sought by application to the relevant agency holding the data. ${ }^{114}$

The aim of the Act is to force agencies to rely on accurate and established information, when issuing regulation. However, many commentators have held that the Act leads to a situation in which all science-based regulations can be effectively challenged, since few scicntific findings would meet a strict application of the requirements. Some level of uncertainty always remains, and this can be exploited by parties that wish to challenge legislation by "manufacturing uncertainty". 115 Even though frequent use appears to be made of the possibility of having agencies "correct" the data held by them, primarily by industry, courts have so far proven reluctant to afford any type of judicial review of the Act or the guidelines. The fact remains that a strict application of the Data Quality Act, and the guidelines based on it, could potentially lead to a siluation in which the regulator can base decisions solely on established scientific facts. If this is the case, the possibility of regulatory action under uncertainty would effectively disappcar, and only scientifically proven risks could be regulated.

110 See, for example, Chevron and Texas Oil \& Gas Ass' $n$ v. EPA, discussed above.

111 Office of Management and Budget, Guidelines for Ensuring and Maximizing the Quality, Objectivity, Utility, and Integrity of Information Disseminated by Federal $\Lambda$ gencies; Noticc; Republication, Federal Register, Vol. 67, No. 36,8452 .

112 In relation to the EPA, see United Stated Environmental Protection Authority, Guidelines for Ensuring and Maximizing the Quality, Objectivity, Utility, and Integrity of Information Disseminated by the Environmental Protection Agency, EPA/260R-02-008.

113 Ibid.

114 Ibid., p. 12.

115 See, for example, R. Weiss, Law is Nemesis of Regulation, Washington Post, 16 August 2004, p. A01, and C. Mooney, The Republican War on Science. 


\subsubsection{The Burden of Proof}

As has been seen in the previous chapters, precautionary decision-making rarely, if ever, entails an initial reversal of the burden of proof. ${ }^{116}$ Instead, the initial burden of proof generally rests with the regulator. ${ }^{117}$ However, the initial level of proof may, in some cases, be very low, and thereby create the illusion that the burden of proof is originally placed on the regulated party. In administrative cases in the U.S., the burden of proof explicitly rests with the proponent of a rule or an order. Thus, it is for an agency wishing to regulate a product to demonstrate that the risk associated with it warrants regulation. In the previous section here, it was shown that the level of proof needed to be met for regulation seems to have changed over time. For courts in the $1970 \mathrm{~s}$, mere scientific uncertainty was sufficient for regulation. However, after the Benzene case, some evidence of risk is required, even if it does not have to meet the $50 \%$ likelihood requirement, which is in effect in civil litigation. ${ }^{118}$ Once this level of proof has been met, the burden of proving the agency's conclusions wrong shifts onto the regulated party.

Successful challenges against agency decisions under varying degrecs of uncertainty appcar mainly to relate to situations in which the relevant agency has failed to explain adequately how and why it has made use of scientific evidence. ${ }^{119}$ In State Farm, the U.S. Supreme Court found that the National Highway Traffic Safety Administration had failed to explain why it had made a requirement for new vehicles to be equipped with passive restraints, and therefore the decision was vacated?/annulled. ${ }^{120}$ Similarly, in National Mining Association $v$ Babbitt, the D.C. Circuit Court found that the Office of Surface Mining Reclamation and Enforcement had failed to justify the presumptions underlying its decision and, consequently, it came to the conclusion that the decision of the agency was not based upon scientific evidence. ${ }^{121}$ Furthermore, in Midwater Trawlers Cooperative v Department of Commerce, the Ninth Circuit Court struck down a measure that it found to be "a product of pure political compromise, not reasoned scientific endeavour". ${ }^{122}$ In these cases, the courts

\footnotetext{
${ }^{116}$ See, above, in relation to Sweden, Section 5.1.4 and in relation to the UK, Section 6.1.4.

117 An exception to this may be pre-authorisation systems, for example for pesticides, where a risk level has been established and must be met by a party wishing to have its product authorised.

${ }^{118}$ S. Jasanoff, Science at the Bar, p. 10.

119 A.C. Raul \& J.Z. Dwyer, Science in the Regulatory Process: "Regulatory Daubert": A Proposal to Enhance Judicial Review of Agency Science by Incorporating Daubert Principles into Administrative Law, p. 22-24.

${ }_{20}$ Motor Vehicle Manufacturers Association v State Farm Mutual Auto Insurance, Co., 463 U.S. 29 (1983)

121 National Mining Associationn v Babbitt, 172 F.3d 906 (D.C. Cir. 1999).

${ }^{122}$ Midwater Trawlers Cooperative v Department of Commerce, 282 F.3d 710 (9th Cir. 2002), p. 720.
} 
have generally considered the measures to be arbitrary and capricious in accordance with the APA. ${ }^{123}$

None of the above cases regarded a situation in which an agcncy had acted flawlessly and a challenging party had successfully challenged the decision on its merits. Instead, they dealt with cases in which the challenging party had successfully shown arbitrariness and capriciousness on the side of the regulator, a bar that is, perhaps, comparable to the "manifest error" doctrine employed by the European Court of Justice (ECJ). As in cases before the ECJ, U.S. courts, to a great extent, defer to the judgments of the agencies. However, the "hard look" doctrine still shines through before the U.S. courts, and they often appear to assess the validily of the scientific evidence put before them, if only to assess whether the agencies have taken it into account in an appropriate fashion when issuing decisions. ${ }^{124}$

With the implementation of the Data Quality Act, the requirements on scientific data have been raised furthcr in the U.S. This may lead to an incrcased scope for challenges made against regulatory decisions on the basis that the scientific data uscd by the regulator is not adequate. However, so far, U.S. courts have proven reluctant to test decisions against the Act.

\subsubsection{Cost/Benefit Analysis}

The history of institutional cost-benefit analysis in the U.S. regulatory systcm dates back to the time of the Quality of Life Reviews introduced by President Nixon (1969-1974) in the early 1970 s. ${ }^{125}$ Since then, the use of cost/benefit analysis has continued to be mandated in Executive Orders issued by U.S. Presidents, Republican as well as Democrat. ${ }^{126}$ It has been held by some influential commentators that "cost-benefit balancing is now the official creed of the executive branch". 127

${ }^{123}$ See, above, Section 7.1.4.

${ }^{124}$ However, as was shown in the section on the precautionary principle in the EU above, also the ECJ does assess scientific evidence in quite some detail in order to establish that scientific uncertainty is at hand. Compare, for example, with the ECJ in the Pfizer case; see above, Sections 4.3.3.-4.3.5.

125 C. Sunstein, The Cost-Benefit State, Chicago Working Paper in Law \& Economics, No. 039, 05/1996, 24. Available at: http://www.law.uchicago.edu/Lawecon/wpl-50.html.

126 The famous Executive Order No. 12,291, 3 C.F.R. 127(1982) issued by Republican President Reagan in 1982, which became a strong incentive for making agency action contingent upon the performance of cost/benefit balancing, was heavily criticised by democrats, but its general content has been upheld by consecutive presidents, including the Democratic President Clinton (Executive Order 12,866 , 3 C.F.R. 638 (1994).

${ }_{127}$ R.W. Hahn \& C.R. Sunstein, A New Executive Order for Improving Federal Regulation? Deeper and Wider Cost-Benefit Analysis, Chicago Working Paper in Law \& Economics, No. 150, 04/2002, p. 1. Available at: http://www.law.uchicago.edu/Lawecon/wp1-50.html. 


\section{Joakim Zander}

Recent Executive Orders instruct agencies to perform regulatory impact assessments (RIA) before issuing regulations. ${ }^{128}$ Such analyses include the carrying out of cost/bencfit analysis, but also include a statement rclating to the necd for the proposed action by the agency, as well as an examination of altemative approaches. ${ }^{129}$ Through the use of RIAs, the executive branch obliges agencies to consider the wider implications of issuing regulation. However, it is important to note that this also creates a mechanism whereby the independence of agencies is made contingent on control by the executive branch. The actual executive oversight is carried out by the Office of Management and Budget (OMB), which is itself an entity with the Executive Office of the President (EOP). ${ }^{130}$ Within the OMB, the Office of Information and Regulatory Affairs (OIRA) is responsible for the oversight of agency regulations. ${ }^{131}$

The rules prescribed in Executive Orders are not formally subject to judicial review, and, thus, the failure of agencies to pcrform a cost/benefit analysis adequately should, for the most part, be beyond the reach of the courts, unless statutes passed by Congress prescribe their performance. ${ }^{132}$ It has been pointed out that some statutes do include independent requirements of some kind of balancing. ${ }^{133}$ On the other hand, other statutes actually prohibit the regulator from comparing costs and benefits. 134

Even though, in most cases, the courts do not uphold requirements to perform cost/benefit analysis, the influence of the OIRA in upholding the meaning of the Executive Orders should not be underestimated. In 2001 and 2002, the United States Gencral Accounting Office investigated how a number of draft regulations had faired in review by the

${ }^{128}$ Sce, for example, Executive Order 12,866.

${ }^{129}$ Office of Management and Budget, Retulatory Analysis, Circular A-4 To the Heads of Executive Agencies and Establishments, 17 September 2003, p. 2.

130 See, for cxample, E. Kagan, Presidential Administration, 114 Harv. L. Rev., 2245, 2001. p. 2247. For a recent discussion on the influence of $\mathrm{OMB}$ in a number of agency decisions, see J.D. Graham, The Evolving Regulatory Role of the U.S. Office of Management and Budget, Review of Environmental Economics and Policy, Vol. 1, Issue 2, 2007, pp. 171-191.

131 For a detailed summary of how the OMB and the OIRA surveys agency rulc-making, see United Stated General Accounting Office, OMB's Role in Reviews of Agency's Draft Rules and the Transparency of Those Reviews, GAO-03-929, 2003. Available at: httn://www.gelo.gov/new items/d03929.pdf. For a critical analysis of the impact of OMB review on Agencies' performance of cost/benefit analysis, see J.C. Johnston, A Game Theoretic Analysis of Alternative Institutions for Regulatory Cost-Benefit Analyis, University of Pennsylvania Law Review Vol. 150: 5 2002, p. 1343-1411.

132 Sunstein, for one, has held that the courts have played a "limited role" in making agencies implement cost/benefit analysis; see C. Sunstein, The Cost-Benefit State, p. 23.

133 For example the Toxic Substances Control Act, 7 USC, 136-136y and the Fungicide, Insecticide, and Pesticide Act, 15 USC, 2601-2692. See C. Sunstein, The Cost-Benefit State, p. 3. These provisions are dealt with in morc detail below in the section on pesticides.

${ }^{134}$ For example the Clear Air Act, the Clean Water Act, and the Delaney Clausc. 
OIRA, and it concluded that, out of a total number of 85 measures investigated, 25 had been significantly modilied. Often, the modifications related to how costs and benefits had been compared by the relevant agency. ${ }^{135}$ It should be noted that, in consecutive Executive Orders, it has been held that the OIRA's review is to focus on "particularly important" agency rulemaking. ${ }^{136}$ Furthermore, it should be pointed out that the OIRA's influence is not limited to the formal review. Informal contacts between agencies and the OIRA during the drafting process appears to be a common occurrence. ${ }^{137}$

In its Circular A-4 of 2003, the OMB went to considerable lengths to define how regulatory impact analysis in general, and cost/benefit (or benefit/cost analysis as it is called in the document) in particular, is to be carried out by agencies. ${ }^{138}$ Unlike the cases of Sweden and the UK, where the performance of cost/benefit analysis falls to the discretion of the regulator, the $\mathrm{OMB}$ gives a detailed account for how balancing is expected to be carried out by agencies. It also discusses the usefulness of Cost-Effectiveness Analysis (CEA), which is defined as being "designed to compare a set of regulatory actions with the same primary outcome $[\ldots]$ or multiple outcomes that can be integrated into a single numerical index". ${ }^{139}$

The OMB makes it clear that costs as well as benefits are to be measured in "opportunity costs", using calculations based upon Willingness to Pay (WTP) or Willingness to Accept (WTA) assumptions. ${ }^{140}$ All values should, as far as possible, be quantified in monetary terms. ${ }^{141}$ However, the Circular recognises that it may not be possible to express all the relevant factors in quantitative terms, and that, in such cases, qualitative considerations may be included, as long as they are clearly identified and motivated. ${ }^{142}$ Thus, the OMB does not necessarily translate all benefits of regulation to numerical values, but may also accept rules that are "proposed on philosophic grounds that have nothing to do with economic

${ }^{135}$ United Stated General Accounting Office, OMB's Role in Reviews of Agency's Draft Rules and the Transparency of Those Reviews, p. 5.

136 S. Croley, White House Review of Agency Rulemaking: An Empirical Investigation, 70 U. Chi. L. Rev. 821, 2003, p. 882.

${ }^{137}$ For detailed accounts of the influence of the executive branch on agency rule making, see United Stated General Accounting Office, OMB's Role in Reviews of Agency's Draft Rules and the Transparency of Those Reviews, 5; E. Kagan, Presidential Administration; and S. Croley, White House Review of Agency Rulemaking: An Empirical Investigation.

138 Office of Management and Budget, Retulatory Analysis, Circular A-4 To the Heads of Executive Agencies and Establishments.

${ }^{139}$ Ibid., p. 11.

${ }^{140}$ Ibid., p. 18

${ }^{141}$ Ibid., p. 10

142 Ibid., p. 27. 


\section{Joakim Zander}

efficiency". ${ }^{143}$ Furthermore, it is explicitly stated that issues surrounded by varying degrees of uncertainty should also be quantified and assigned economic values. It is stressed that transparency and openness with regard to the models underlying the assumptions essential. Worst-case scenarios and conservative estimates should be avoided when analysing the material in question, and the regulator should consider whether regulation could be postponed until a clearer picture has emerged. ${ }^{144}$ This would imply that precautionary considerations do not play a prominent role when carrying out the cost/benefit analysis. This is understandable when one considers that the result of the regulatory impact assessment does not necessarily mandate the degree of regulation, but, instead, aims to put all costs and benefits "on screcn". ${ }^{145}$ However, one could be forgiven for thinking that conscrvative estimates could also help balance the assessment, at least as a complement to realistic estimates in cases of uncertainty.

The U.S. approach to cost/benefit analysis is the most developed of the systems investigated here. In the last five years, the Commission has begun to work more concretely by estimating the costs of all proposed regulation in the EU. However, so far, the EU approach appears to be based mainly on the participation of the stakeholders. There is still a wide gap between this and the firm use of economic modelling and the strong and independent role of the OMB in the U.S.

\subsubsection{The Targeting of Risks}

Like the performance of cost/benefit analyses discussed above, no generally applicable statute dictates that countervailing risks or risk offsets have to be considered by the regulator when issuing measures. ${ }^{146}$ In fact, and also as in the case of cost/benefit analyses, some statutes actively appear to prohibit the regulator from considering risk trade-offs, while others require the regulator to perform them. ${ }^{147}$

143 J.D. Graham, The Evolving Regulatory Role of the U.S. Office of Management and Budget, p. 172-173.

144 Ibid., pp. $28-29$.

145 As has been argued by, for example, Sunstein, in C. Sunstein, Risk and Reason, Cambridge University Press, 2002, p. 8 and 29. See, also, Section 2.3.2. above.

${ }^{146}$ However, attempts were made by the 105th Congress to make the consideration of "substitution risks" mandatory for regulators through the unsuccessful introduction of the Regulatory Improvement Act of 1998, S. 981, 105th Congress, 627 (1998). See, in this regard, F. Anderson, M.A. Chirba-Martin, D.D. Elliott, C. Farina, E. Gellhorn, J.D. Graham, C. Boyden Gray, J. Holmstead, R.M. Levin, L. Noah, K. Rhyne \& J.B. Wiener, Regulatory Improvement Legislation: Risk Assessment, Cost-Benefit Analyis, and Judicial Review. For a general discussion on risk trade-offs, targeting and ranking of risks, see, above, Section 2.3.3.

147 See, for example, C. Sunstein, Cost/benefit Default Principles, p. 15. 
In its Circular A-4 on Regulatory Analysis, the OMB clearly stated that agencies "should look beyond the direct benefits and direct costs of [...] rulemaking and consider any important ancillary benefits and countervailing risks". ${ }^{148}$ When doing this, agencies are instructed to monetise the valucs that expected trade-offs may bring and compare them to the proposed regulation. It is also suggested that agencies should include risk trade-off data in the cost/benefit analysis if they wish. This must be made in a transparent fashion. ${ }^{149}$

The OMB Circular A-4, which aims to clarify the Executive Order relating to the analyses of risks, is not legally-binding, as was discussed above. However, the courts have, in some cases, proven willing to allow agencies to base the issuing of regulatory measures upon the analysis of risk trade-offs. ${ }^{150}$ For example, in Corrosion Proof Fittings, the 5 th Circuit Court held, in relation to asbestos, that the responsible agency could not solely concentrate on one substance, but would have to consider the risks of other materials that would substitute the risks associated with the asbestos. ${ }^{151}$

Sunstein has summarised the current status of trade-off analysis along the following lines:

"Agencies ought generally to be required to show that they are doing more good than harm. This does not mean that courts should engage in independent review of agency judgments on this score. But it does mean that courts should take a "hard look" at agency decisions failing to undertake health-health comparisons." 152

However, even if such analysis is, in practice, performed by agencies following the OMB guidance, there is no strong, legally enforceable mandate for them to do so. How tradeoffs are considered in practice is returned to below in the sections on pesticides and on base stations.

During the 1990s, the issue of clearly prioritising risk regulation and ranking the order of dealing with risks bccame a major issue. ${ }^{153}$ Applegate has held that a lack of growth in

148 Office of Management and Budget, Retulatory Analysis, Circular A-4 To the Heads of Executive Agencies and Establishments, p. 26.

149 Ibid.

${ }^{150}$ C. Sunstein, Cost/Benefit Default Principles, p. 38.

151 Corrosion Proof Fittings. v EPA, 247 F.2d 12 1 (5th Cir. 1991).

152 C. Sunstein, Health Health Tradeoffs, p. 28.

153 See, for example S. Brcyer, Breaking the Vicious Circle: Toward Effective Risk Regulation, Harvard University Press, 1993; A.M. Finkel \& D. Golding, Worst Things First? The Debate over Risk-Based National Environmental Priorities, Recources for the Future, 1994; and C. Sunstein, Risk and Reason. 


\section{Joakim Zander}

agency budgets spurred on the development towards a greater emphasis on priorily setting with regard to environmental and health risks. ${ }^{154}$ In a situation in which resources were limited, the ranking of prioritics became a necessity:

"The agency's first task, upon which the overall efficacy and efficiency of the rest of the process depends, is the allocation of resources among potential regulatory efforts.

Agencies must set priorities among the risks within thcir purvicw." 155

The performance of risk assessment, cost/benefit analysis, and risk trade-off analysis can be used to yield the data needed to establish a rational agenda for the reduction of risks. Such input can be used to measure the impact of precautionary measures and to make sure that the measures issued do, in fact, lower the overall risk level.

The method used for priority setting in relation to risks has been called Comparative Risk Analysis (CRA). ${ }^{156}$ Originally influenced by the EPA Report entitled Unfinished Business, ${ }^{157}$ CRA aims to "compare the relative magnitudes of threat posed by environmental factors under EPA jurisdiction with the agency staff, budget, and attention allocated to each factor". ${ }^{158}$ Unfinished Business identified and analysed a large number of risks according to four categories: Cancer risks, non-cancer health risks, ecological effects, and welfare effects. The risks were then ranked according to how they scorcd in the different categories. No risks scored high in all categories, but risks that scored at least medium in at least three categories were recommended to be tackled first. The Report laid the groundwork for the systematic approach assumed by the EPA in the years to come. ${ }^{159}$ Its conclusions were broadly supported in a Review published by the Science Advisory Board in 1990, which urged the EPA to continue its prioritisation of risks. ${ }^{160}$

154 J. S. Applegate, Worst Things First? Risk, Information, and Regulatory Structure in Toxic Substances Control, 9 Yale J. on Reg 277, 279-280.

155 J. S. Applegate, Worst Things First? Risk, Information, and Regulatory Structure in Toxic Substances Control, p. 288.

156 For an overview of the development of this concept see for example C. W. Kent and F. W. Allen, An Overview of Risk-Based Priority Setting at EPA, in A. M. Finkel and D. Golding, Worst Things First? The Debate Over Risk-Based National Environmental Priorities.

157 The Environmental Protection Agency, Unfinished Business: A Comparative Assessment of Environmental Problems, Fcbruary 1987.

158 J. K. Hammitt, Improving Comparative Risk Analysis, 8 Duke Envtl. L. \& Pol'y F, 81

159 C.W. Kent \& F.W. Allen, An Overview of Risk-Based Priority Setting at EPA, p. 51.

160 The Environmental Protection Agency, Reducing Risk: Setting Priorities and Strategies for Environmental Protection, September 1990. 
During the 1990s, the issue of ranking and prioritising risks was a topic of great importance for U.S. agencies (most notably the EPA), and was, together with CBA and RIA, intensely discussed in the literature. ${ }^{161}$ Principally, this discussion centred on how the EPA should carry out assessments and rankings. However, in the absence of binding rules or guidelines, it appears that no standardised procedure or strategy for the targeting of risks exists.

\subsubsection{Public Opinion}

That the general public is to be given an opportunity to voicc its opinions on proposed administrative decision-making is established in the APA, and called "notice-and-comment rule-making". ${ }^{162}$ In general, there are two stages in the decision-making process where the public and stakeholders may influence its outcome. First, organised stakcholders with whom a public administration has an established relationship may be consulted during the drafting of a measure. Second, once a full draft measure has been established, it is formally announced and public comments are requested. These comments should be considered by the relevant public body beforc the measure is formally adopted and included in the Federal Register. ${ }^{163}$

In the above discussed Vermont Yankee case, a number of public interest interveners held that the system of notice-and-comment was too weak to allow for efficient participation, and that it thereby "denied them a meaningful opportunity to participate in the proceedings". ${ }^{164}$ The D.C. Circuit Court agreed with the interveners without specifying in any detail what more could be required by the regulator. ${ }^{165}$ However, on appeal, the U.S. Supreme Court held that the approach advocated by the D.C. Circuit would amount to a procedural requirement not mandated by Congress, and thus considered the limited public consultation provided in the notice-and-comment procedure to be sufficient. ${ }^{166}$

However, as has been pointed out by Applegate, the court did not preclude that agencies could imposc voluntary arrangements pertaining to public involvement. What the

161 See, for example, A.M. Finkel \& D. Golding, Worst Things First? The Debate Over Risk-Based National Environmental Priorities.

I62 APA 5 U.S.C. 553 (1994).

163 J. Applegate, Beyond the Usual Suspects: The Use of Citizens Advisory Boards in Environmental Decisionmaking, 73 Ind. L.J. 901, 1998, p. 907.

164 Vermont Yankee, p. 643

${ }^{165}$ Natural Resources Defense Council, Inc. v United States Nuclear Regulatory Comm'n, 547 F.2d 633, (D.C. Cir. 1976), p. 654.

166 Vermont Yankee, pp. 543-548. 


\section{Joakim Zander}

Supreme Court stated in Vermont Yankee was merely that the review of the courts could not stretch as far as to invent such requirements. ${ }^{167}$ The EPA, for example, issued a set of general guidelines for public participation in relation to waste disposal in $1981 .{ }^{168}$ In 2003 , the EPA issued general guidelines for public participation within the agency's sphere of regulation, ${ }^{169}$ which specified that sectoral arrangements, such as those included in the 1981 guidelines on waste regulation, provided minimum requirements for the agency when regulating topics covered by them. ${ }^{170}$ The 2003 Guidelines emphasise that, in order for the involvement of both the public and the stakeholders to be meaningful, information must be sharcd between the EPA and the affected parties. The EPA should establish a budget for each public involvement enterprise, and should, as far as possible, try to accommodate involvement through the sctting up of meetings and panels, and even provide funding and resources for the public and stakeholders. ${ }^{17 t}$ The outcome of the public involvement can range from providing information to conducling binding agreements with stakeholders. ${ }^{172}$ Even if the guidelines are not formally binding before the courts, they go some way towards showing the intention of the EPA to take the views of interested partics seriously. However, to date, concrete examples of deep and far-reaching public involvement can, mainly be found at local and regional levels. ${ }^{173}$ Thus, no formal rolc is foreseen for the public to influence decisionmaking prompted by precautionary considerations. However, it is shown bclow that the opinion of the public may, possibly, be an important factor when issuing precautionary measures in specific cases. ${ }^{174}$

Finally, it should be pointed out that it remains to be seen whether the passing of the Data Quality Act in 2000 makes it more difficult for the concerns of stakeholders and the general public to be relied upon if such concerns are not based on scientifically certain data.

167 J. Applegate, Beyond the Usual Suspects: The Use of Citizens Advisory Boards in Environmental Decisionmaking, p. 909 , note 31 .

168 Environmental Protection Agency, RCRA Public Participation Policy, 1981.

169 Environmental Protection Agency, Public Involvement Policy of the Environmental Protection Agency, May 2003. Available at: http://www.epa.gov/publicinvolvement/pdt/policy2003.ndf.

170 Ibid., p. 1.

171 Ibid., Appendix 1.

172 Ibid.

${ }^{173}$ See, for example, J. Applegate, Beyond the Usual Suspects: The Use of Citizens Advisory Boards in Environmental Decision-making.

174 See, below, Section 7.3. 


\subsubsection{Conclusion}

The precautionary principle, as such, lacks explicit endorsement in U.S. legislation and policy. Despite this fact, activist U.S. courts in the 1970s went to some lengths to carve out a space for precautionary considerations in U.S. regulation. This never amounted to an cffective endorsement of a generally applicable precautionary principle, but judgments such as Ethyl Corp. and Reserve Mining allowed U.S. agencies to act in a precautionary manner without an explicit basis in scientific evidence. Even though this far-reaching development was effectively curtailed by the Benzene case and the subsequent emphasis on risk assessment by the executive branch and Congress during the Reagan administration, the possibility of basing decisions on precautionary considerations did not disappear.

The "hard look" doctrine which was developed by the D.C. Circuil Court in the 1970s continues to influence the scope of the judicial review, even as the procedure-based approach applicd by courts in the 1970 s was denounced. For precautionary measures to be enacted, a threshold finding of "significant risk" must be present. Precisely what is required for this to be the case is unclcar, but it appears that mere scientific uncertainty is not sufficient. This means that, when a precautionary measure is challenged, U.S. courts will analyse the scientific evidence brought before them, in order to establish whether or not a risk exists. Here, U.S. courts differ in their approach when compared to the other jurisdictions described above, in which the courts generally allow for a near total deference on the side of the regulator, and the mere existence of scientific uncertainty is generally sufficient to warrant regulation. However, this does not mean that U.S. courts require scientific certainty for regulation to be legal. Instead, it appears that the approach is more akin to that of the interpretation of the SPS Agreement advanced in the WTO Dispute Settlement Body. ${ }^{175}$ Like the WTO panels and the Appellate Body, U.S. courts require a threshold finding of a plausible risk before regulation is permitted. This implicitly mandates the performance of risk assessments to establish whether such a threshold has been met before any regulation can be issued.

In some cases, where measures have been taken under varying degrees of uncertainty, claimants have managed to challenge them successfully before the courts. Often, such cases are based on the performance of flawed risk assessments or formal errors on the part of the

175 Outside of the scope of Article 5.7 of the SPS Agreement, where precautionary measures arc explicitly authorised when the scientific material is so inconclusive that it renders the performance of a risk assessment impossible. 


\section{Joakim Zander}

regulator. However, it appears that it is technically possible to challenge a decision on the merits before U.S. courts. At the very least, it can be said that the scope for such review must be considered greater than in the other legal systems here investigated.

US. regulatory measures are preceded hy Regulatory Impact Assessments. RIAs include not only the perfirmance of risk assessment and costhenefit analysis, but also a statement relating to the need for the proposed ation by the agency, as well as an examınation of altemative approaches. Risk trade-ofls should be considered, and there is a strong impetus for ranking risks in order of priority. The executive branch, through its Office of Management and Budget, oversees the rationality and consistenty of regulatory proposals. both formally and informally. When the OMB does not agree with the assessment performed by an agency, the measure is sent back for revision. The importance and influence of the OMB is on the rise. The notorious Data Quality Act gives the affected parties an opportunity to lile for a "correction" of the scientific data held by agencies with the OMB. However, to date. the courts have proven reluctant to test the performance of cost/benefit analysis and RIAs in any detail, but have, instead. left its performance up to the execulive branch. The same goes for the challenges against regulatory decisions based on the Data Quality Act.

The precautionary principle does not exist as an independent concept in the U.S. legal system. However, this does not mean that precautionary considerations do not play a significant role in U.S. regulation. Compared to Sweden and the UK, risk regulation in the U.S. is more firmly based on rational concepts such as risk assessment and cost/benefit analysis. Decisions that are not adequately supported by scientific evidence may be overturned by U.S. courts. Thus, the hands of the U.S. regulator are more tied than in Sweden, the UK, or the EU, unless Congress has specifically mandated that risks do not need to be established scientifically. At present, it would be difficult for the U.S. regulator to base decisions solely on public opposition to a certain activity. The discretion of the regulator simply does not stretch that far. Instead, it has been bound by scientific evidence and rational reasoning. In Sweden, the UK, and the EU, on the other hand, the regulator is seen as acting on a broader mandate of the parliament (or the parliament and the Member States in the case of the EU). Consequently, courts are reluctant to overturn decisions taken using this broad discretion.

Contrary to the discussion in Europe, which tends to centre on the increased involvement of stakeholders and the public in precautionary decision-making, many U.S. 
commentators argue in favour of an increased use of science and procedural requirements. It remains to be seen if the highly controversial Data Quality Act and cases like Daubert will move the U.S. system further towards the strict use of scientifically verified data as a basis for regulation. This would inevitably further limit the scope that precautionary considerations play in risk regulation.

\subsection{The Application of the Precautionary Principle in US Pesticides REgulation}

\subsubsection{Introduction}

Pesticides have been regulated at federal level in the U.S. since the early 1900 s, and within its current legislative structure since late 1940s. Naturally, the content of the legislation has changed somewhat over the years as the means to assess risks have become more sophisticated, and societal concerns have evolved. However, contrary to public belief, U.S. pesticide regulation has a history that is far more precautionary in nature than most European countries. In the main, this is due to the strict pre-authorisation regime set up by statute in combination with the controversial Delaney Clause of 1958 . Effectively barring all pesticides with even microscopic carcinogenic properties from authorisation, the Delaney Clause meant that the U.S. did, in fact, have a zero-risk approach in place for most pesticides for around 40 years, until the Delaney Clause was revoked in the mid-1990s. Since the Clause was repealed, the Environmental Protection Agency (EPA) has enjoyed greatcr discretion to carry out a more nuanced assessment of pesticides, weighing risk assessment results against the potential benefits of authorising a pesticide. To assist the EPA in its tasks, there is a developed structure of scientific bodies, which carry out risk assessments and give general, as well as specific, advice.

The legal and institutional structure of pesticide regulation in the U.S. is outlined and discussed below. As in previous sections, the focus is on whether, and, if so, how, precautionary considerations function as a basis for regulation. Important issues in this regard are not only the treatment of scientific evidence and the level of proof for regulation, in cases of authorisation, but also the instances in which pesticides are withdrawn from the market. The issue of the costs and benefits of regulation is an important aspect when considering pesticide regulation in the U.S., and this is discussed in some detail. 


\subsubsection{The I equal framework}

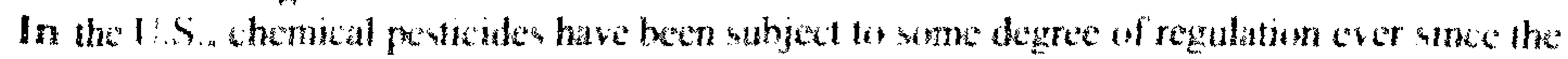
Insecticule Aat of 1910." Today. the federal Insecticude. Fungude and Rinknticide Act

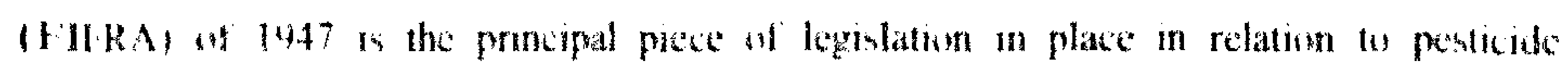

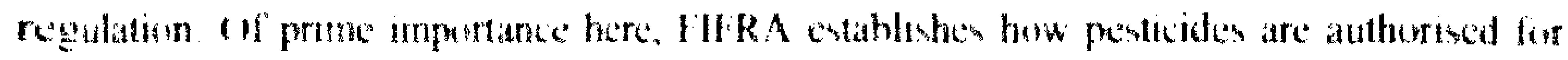
use on the U.S. masket, and how, and under whoh cercumetances, authorisations can be suspended and revoked" " ther statutes help complete the picture by dealing specifically with thates of pesticide residues in human firel and anmal leed. ${ }^{1 / 4}$

Pesticules cannen be used of marketed in the Us. unless they have hecn regustered following the provinions on FIFKA. The hurden of information in HFRA is put squarely on the registrant. who has fo provude evidence to support the assertion that the pesticide does not entail "urreasonahle adverse effects on the environment". " What it is that needs to be registered is not enturely unambigueus. As Miller has pointed out, the term "pesticte" has besen interpreted to mean both an active substance and a product containing one or more active substances. ${ }^{\text {lst }}$ All authorisations, or registrations as they are known in FIF RA, are given for a limited period of time and have to be renewed when they expire. ${ }^{1 \times 2}$ Conditional registrations can be issued by the EPA in some cases where information regarding a substance is temporarily lacking. This may primarily be the case when the substance in question. and the risks associated with it, are known to the LPA. ${ }^{183}$ The process may not be initiated in relation to pesticides for which suspected risks have led to the initiation of a special review process. ${ }^{\text {int }}$

HIFRA also provides for the revoking of registration. It makes a separation between instances of "cancellation" and "suspension", where the latter constitutes an immediate

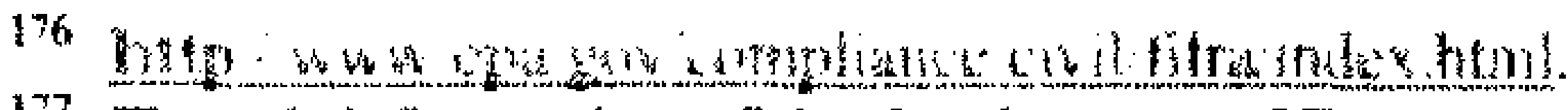

17 For abrief werview of the development of FIFRA, see B.L. Johnston, Envirommental Pollov and Public Health. CRC Prest, 2007, pp. 262-265.

178 Food (Quality Protection Act of 1996 (FPQA). Pub 1. 104-170) and Federal Food, Drug and Cosmetic Act of 1996 (FFDC A), 21 U.S. 19

1) FIFRA, 7 U.S.C. 136 ala

iso FIFRA, 7 USC \$ 136 (c) (9) (B) (i) (1), FIFRA; 7 U.S.C. 136a (c) (5)(C), FIFRA, 7 US.C. $136 a(\mathrm{c})(7)$ (a). The term "unireasionuble adverse effects on the environment" is defined elsewhere in FIFRA and this is returned to in detall under the sections on level and burden of prosf

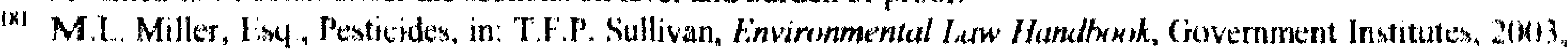
p. $052-653$

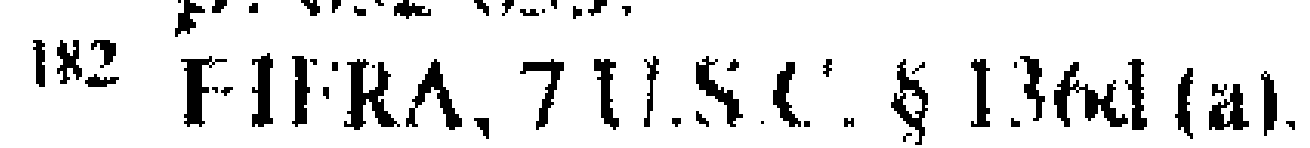

183 FIFRA, 7 USSC: 136alc) 7.

t\$4 M.I. Miller, Esy. Pesticides, p. 6,55
} 
revocation in a situation in which a product is deemed to pose an "imminent hazard". 185 Where a "cancellation" is considered, a product remains on the market until it is clarified whether or not it poses "unreasonable adverse effects on the environment". ${ }^{186}$ Moreover, a product can be suspended during the time that the cancellation procedure is in place. In the following, what may trigger these procedures is investigated in detail.

\subsubsection{The Institutional Framework}

The EPA is responsible for implementing and administering FIFRA. This means that the EPA administrators are responsible for receiving and making decisions on the registrations of pesticides, as well as for deciding on whether to initiate and carry out cancellation and suspension procedures. ${ }^{187}$ Within the EPA, the task of regulating pesticides belongs to the Assistant Administrator for Prevention, Pesticides, and Toxic Substances. ${ }^{188}$ The Assistant Administrator functions as the Head of the Office of Prevention, Pesticides, and Toxic Substances (OPPS). ${ }^{189}$

The EPA is officially an "independent agency" with its own staff, budget and internal rules. However, it is set up by, and functions under, the executive branch of the U.S. government, and the U.S. president maintains important possibilities of control of the agency. ${ }^{190}$ Examples of such measures of control include the power of appointments and the issuing of the budget. In both cases, the U.S. Congress needs to concur with the decisions of the president. ${ }^{191}$

In its work, the EPA is assisted by an expert Scientific Advisory Panel (SAP), in all cases relating to the cancellation/suspension, or the issuing of other regulations. ${ }^{192}$ Notably, the SAP does not need to be consulted when issues of registration are considered. ${ }^{193}$ It consists of a total of seven scientific experts, who are selected and appointed by the EPA Administrator from a list of twelve nominees, six nominated by the National Institutes of

185 FIFRA, 7 U.S.C. $\$ 136 \mathrm{~d}$ (b) and (c).

${ }^{186}$ The definition of this term is returned to in detail in the following.

187 See for example FIFRA, 7 U.S.C. $\$ 136 \mathrm{a}$ and d respectively, as well as the EPA FIFRA website at: http:/www.epa.gov/pesticides/.

188 See EPA Organizational Structure at http://www.cpa.gov/epahome/organization.htm.

189 See about OPPS at http://www.cpa.gov/oppts/pubs/aboppts.htm.

190 Reorganisation Plan No. 3 of 1970 , Spccial Message from the President to the Congress About Reorganization Plans to Establish the Environmental Protection Agency and the National Oceanic and Atmospheric Administration, 9 July 1970. Available at: www.epa.gov/history/org/origins/rorg,htm.

191 Reorganisation Plan No. 3 of 1970, Section 1

192 FIFRA, 7 U.S.C. $\S 136 \mathrm{w}$ (d).

193 For some of the implications of this, see S. Jasanoff, The Fifth Branch: Science Advisers as Policymakers, p. 151 , note 40 . 


\section{Joakim Zander}

Health and six by the National Science Foundation. It is laid down that the members of the SAP should be selected based on "professional qualifications to assess the effects of the impact of pesticides on health and the environment". As far as possible, the panel should entail members with expertise in the fields of toxicology, pathology, environmental biology, and related sciences. ${ }^{194}$ Within the framework of the SAP, sub-panels for specific topics and areas of expertise may be established. Sub-panels can consist of members of the SAP, but outside scientists can be appointed by the SAP if this is needed. U.S. Advisory Committees are subject to the Federal Advisory Committec Act (FAC $A)^{195}$ which establishes congressional oversight over the activities and functions of each advisory committec, the SAP included. The FACA, furthermore, holds that experts serving on committees should be "fairly balanced in terms of the points of view represented", and that they should not be "inappropriately influenced" by either the authority under which it serves, or outside interests. ${ }^{196}$ It thus appears that Congress is intent to saleguard the independence of U.S. expert committees, as well as the representation of differing interests and viewpoints on the committces themselves. Here, the U.S. system here goes further towards establishing such requirements than the other national systems investigated here. In both Sweden and the UK, the selection of experts mainly falls to the sole discretion of the government or the agency which has had powers delegated to it. Objective criteria like those included in FACA are rare. In this regard, the U.S. system is more similar to the EU system of institutionalised scientific advice. $^{197}$

As stated above, the role of the SAP is, according to FIFRA, to advise the decisionmaker on scientific aspects of proposed regulation. The courts have rejected the possibility that the EPA Administrator be bound by the conclusions of the expert committcc. Instcad, they have held that the Administrator is free to disregard the advice given, provided that there is "justifiable" reason to do so. ${ }^{198}$ The issue is returned to in more detail below in relation to the distinction between risk assessment and risk management.

194 Ibid.

195 Public Law 92-463, 5 U.S.C. App. 1

$196 \mathrm{Ibid}$, Section 5, (a) (2) and (3)

197 For a comparative discussion on the use of scientific bodies in evaluating data relating to pesticides in the U.S and Europe, see R. Brickman, S. Jasanoff \& T. Ilgen, Controlling Chemitals: The Politics of Regulation in Europe and the United States, Cornell University Press, 1985, pp. 174-18().

198 M.L. Miller, Esq., Pesticides, p. 677. 
Another interesting aspect of FIFRA is that it explicitly demands that all "major scientific studies" conducted by the EPA should be subjected to peer review by the SAP. ${ }^{199}$ This means that the advisory committee is not only limited to influencing the outcome of concrete decisions, but it also holds a supervisory role in relation to all scientific work of "major" importance conducted at the EPA.

\subsubsection{Risk Assessment and Risk Management}

As stated in the previous chapter, the use of risk assessment has increased in the U.S. in the last 25 years. However, the issue of how the process of risk assessment relates to risk management has received surprisingly little attention. ${ }^{200}$ In policy documents, it is held that even though the roles of the risk assessor and the risk manager are different, it is important that they perform their duties in co-operation. ${ }^{201}$ Even though the EPA has held that it considers risk assessment and risk management "not necessarily separate", ${ }^{202}$ it appears in other documents that they are subject to the traditional separation discussed elsewhere in this book. ${ }^{203}$

With regard to pesticide regulation, the risk assessment is mainly performed by the SAP. As discussed in the previous section, referral to the SAP for advice is mandatory in FIFRA during cancellations procedures. However, the advice given by the SAP is not binding on the EPA Administrator, who may disrcgard it provided that reasons are stated for this. In Dow $v$ Ruckelshaus, which involved the cancellation of the pesticide 2,4,5-T, the EPA cancelled the pesticide despite advice from the scientific committee which had maintained that it should be allowed on the market. ${ }^{204}$ The 8th Circuit Court held that the Administrator had acted within his discretion when he came to a different conclusion than that of the scientific committee. "[The Administrator] was not required to adopt the Advisory Committee findings", the 8th Circuit Court stated unambiguously. ${ }^{205}$ It is also important to

199 FIFRA, 7 U.S.C. $\$ 136 \mathrm{w}(\mathrm{e})$.

${ }^{200}$ See, above, Section 7.1.5.

201 See Environmental Protection Agency, An Evaluation of EPA Risk Assessment Principles and Practices, Staff Paper Prepared for the U.S. Environmental Protection Agency by members of the Risk Asscssment Task Force, March 2004, available at: http://www.epa.gov/osa/pdfs/ratf-final.pdf, and U.S. Environmental Protection Agency, Risk Characterization Handbook, December 2000, pp. 20-23, available at: http://www.epa,gov/OSA/spc/pdfs/rchandbk.pdf.

202 U.S. Environmental Protection Agency, An Evaluation of EPA Risk Assessment Principles and Practices, p. 22.

${ }^{203}$ See, for example, National Research Council, Risk Assessment in the Federal Govemment: Managing the Process, 18-20. Scc, also, Section 2.3. above.

204 The Dow Chemical Company v William D. Ruckelshaus, Administrator Environmental Protection Agency 205 Ibid. Defendant-Appellant, (8th Circuit 1973) 477 F2.d 1317. 
Joakim Zander

note here that the Administrator had issued a number of statements outlining ten reasons for not following the SAP recommendations. Thus, the courts have held that the risk manager, the EPA Administrator in cases regarding pesticides, is not bound by the recommendations of the risk assessor. This emphasises the notion of the difference and separation of tasks between the two levels within the risk regulation framework.

\subsubsection{The Level of Proof and the Triggering of Precautionary Measures}

In the previous chapters, it was shown that, since the 1980s, the requirements on the legislator to provide scientific evidence in support of a risk stemming from a product before regulating it have been increasing. ${ }^{206}$ The regulation of pesticides, however, provides an important example of an exception to this development. This issue has been particularly publicised with regard to pesticide residues in food. According to the Dclaney Clause, which was a 1958 amendment to the Food, Drug, and Cosmetic Act (FDCA), any cancer-causing food additives were barred from appearing in foods regardless of the magnitude of the risk. ${ }^{207}$ This zero-risk approach was upheld by courts, ${ }^{208}$ but was heavily criticised and difficult for the EPA to uphold in practice. ${ }^{209}$ In 1996, Congress decided to revisit the matter and revise the zero-risk approach. The resulting Food Quality Protection Act (FQPA) established that all pesticide residues in food are deemed unlawful, unless the EPA has set a tolerance level for them and the pesticides in question comply with these levels. This meant that the EPA was allowed to decide on where to set the level of regulation, and that it was within its discretion not to regulate pesticides with negligible carcinogenic propertics. The "safety level" established by the FQPA was set at "reasonable certainty" of no harm. ${ }^{210}$

With regard to the allowing of pesticides on the U.S. market, it is useful to separate the issues of registration on the onc hand, and suspension and cancellation on the other. As mentioned above, in relation to registration of pesticides, the burden of information is put squarely on the applicant to provide data to support the fact that the pesticide in question does not bring "unreasonable adverse effects on the environment". ${ }^{211}$ When determining what

${ }^{206}$ See, above, Section 7.1.4.

${ }^{207}$ M.L. Millor, Esq., Pesticides, p. 693

${ }^{208}$ See, for example Lee v Reilly 968 F. 2d 985 (9th Cir. 1992), p. 988, where the court held that EPA had no discretion to permit carcinogenic foods, regardless of the minimal degree of risk posed by them.

209 E. Dunkelberger \& R.A. Merrill, The Delaney Paradox Re-examined: Regulating Pesticides in Processed Foods, 48 Food \& Drug L. J., p. 411, 1993, and A. Montemarano, The Delaney Paradox Resurfaces: Regulating Pesticides as Food Additives Under Federal Law, 25 Rutgers L.J. 433, 1993/1994.

${ }^{210}$ FQPA, Sec. 405.

211 FIFRA, 7 U.S.C. § 136a (a). 
constitutes "unreasonable effects on the environment", the EPA should not only consider risks to human health and the environment, but must also take "into account the economic, social, and environmental costs and benefits" the proposed pesticide brings. ${ }^{212}$ This level has been described as a non-zero risk level, which allows the EPA to decide on registrations on an ad hoc basis, taking risk assessment factors into account, but balancing these with a wider socio-economic analysis. ${ }^{213}$ The EPA does not have to wait until scientific uncertainty materialises, but can reject a request for registration as a precautionary measure under conditions of uncertainty, as long as this does not aim to set a zero-risk level. ${ }^{214}$ This has bcen emphasised by courts, which have rejected regulation of de minimis toxic risks. ${ }^{215}$ In practice, it has been pointed out, time-constraints and lack of resources may lead to situations in which the EPA is more likely to approve a registration under uncertainty than arguing that the uncertain risk is "unreasonable". ${ }^{216}$ However, the EPA emphasises in its own reports the importance of identifying and classifying uncertainty during the risk analysis process, ${ }^{217}$ and it has stated that it aims "to use all information available in an objective, realistic, scientifically balanced way to make decisions". 218

When it comes to cancelling and suspending pesticides, the leeway for the EPA is somewhat different. First, as mentioned above, the SAP needs to be consulted when cancellations are prepared, and, even if its verdict is in no way decisive, it highlights the emphasis of scientific advice in this situation. Second, the burden of proof is put more explicitly on the EPA. This is returned to in the following section. If the Administrator finds that a registered pesticide no longer conforms to the requirements in FIFRA, on which its registration was based, and that the product poses a "substantive question of safety", 219 the registration may be cancelled. ${ }^{220}$ In EDF v Ruckelshaus, the D.C. Circuit left it to the general

${ }^{212}$ FIFRA 7 U.S.C. $\$ 136(\mathrm{bb})$.

213 J.S. Applegate, The Perils of Unreasonable Risk: Information, Regulatory Policy and Toxic Substances Control, 91 Colum. L. Rev. 261, 1991, p. 268.

${ }^{214}$ See, for example, Ciba-Geigy Corp. v EPA, 874 F.2d 277, 1989 (5th Cir.), 280, where the court held that FIFRA allows for regulation without the EPA having to show "actual adverse consequences".

215 J.S. Applegate, The Perils of Unreasonable Risk: Information, Regulatory Policy and Toxic Substances Control, p. 267 and note 68.

${ }^{216}$ M.W. Graf, Regulating Pesticide Pollution in California Under the 1986 Safe Drinking Water and Toxic Exposure Act (Proposition 65), 28 Ecology L.Q. 663, 2001, p. 694.

${ }^{217}$ U.S. Environmental Protection Agency, An Evaluation of EPA Risk Assessment Principles and Practices, pp. $30-51$.

${ }^{218}$ Ibid., p. 139.

219 This term the D.C. Circuit found support for in the legislative history to FIFRA, see EDF $\vee$ Ruckelshaus, (D.C. Circuit, 1971) 439 F. 2d 584, pp. 593-595.

${ }^{220}$ FIFRA, 7 U.S.C. $\$ 136 \mathrm{~d}(\mathrm{~b})$. 
discretion of the Administrator to decide when a "substantive question of safely" was present. In the case, which regarded the prohibition of the pesticide DDT, the court recognised that the data relied upon by the Administrator was uncertain in nature, but did not review it in any detail. $^{221}$

The intention to cancel a product has been described as "a determination [...] that adjudicatory procecdings will commence". ${ }^{222}$ However, during such procedures, which may be lengthy, the product in question remains on the market. In order to provide the EPA with a possibility of removing products from the market at an earlier stage, the possibility of suspension has becn included in FIFRA. ${ }^{223}$ A suspension of a registration can be ordered when it "is necessary to prevent an imminent hazard". ${ }^{224}$ Normally, a suspension is issued after a hearing has been held, but it can also be issued in advance of notification to the affected parties in the form of an emergency order. ${ }^{225}$ When it comes to the issuing of suspension orders, courts have held that a higher level of evidence must be met by the EPA than is the case for cancellations. ${ }^{226}$ The D.C. Circuit has held that the level of proof that would have to be met by the Administrator should correspond to a "likelihood"-requirement, i.e., the expected risk from a pesticide would have to be likely to be realised, instead of just pose a "substantial question of safety". 227

As can be deducted from the above, FIFRA does not set any explicit exposure limits which bind the regulator. Instead, every instance of regulation is judged on a case-by-case basis. Precautionary action can be taken under conditions of scientific uncertainty, but the occurrence of scientific uncertainty does not mandate regulatory action on the part of the EPA. ${ }^{228}$ Courts have interpreted FIFRA to entail different demands on scientific evidence, depending on which type of action is considered. The level of proof is the highest in cases of cmergency suspensions. ${ }^{229}$ It should also be pointed out that, in practice, the FQPA requires the EPA to set "safe" exposure levels for pesticide residues in food. Due to the fact that cost-

221 EDF $\vee$ Ruckelshaus, 594.

${ }^{222}$ FTC v Standard Oil Co., 449 U.S. 232 (1980).

${ }^{223}$ FIFRA, 7 U.S.C. $\$ 136 \mathrm{~d}$ (c). A suspension is a temporary prohibition of the marketing of a product, pending the results of cancellation procedures.

224 FIFRA, 7 U.S.C. $\$ 136 \mathrm{~d}$ (c) (1).

${ }^{225}$ FIFRA, 7 U.S.C. \& $136 \mathrm{~d}$ (c) (3).

${ }^{226}$ ni National Coalition Against the Misuse of Peticides, et al., v EPA, (D.C. Circuit, 1989) 867 F.2d 636, p. 644.

227 Ibid., where the Court described the requirement a risk having to be "likely to result" in harm. The Court had similarly held in $E D F \vee E P A$ that "substantial likelihood" of the realisation of harm would trigger regulation. $E D F$ v EPA, (D.C. Circuit 1976) 548 F.2d 998, p. 1005.

${ }^{228}$ National Coalition Against the Misuse of Peticides, et al., v EPA, p. 644-645.

${ }^{229}$ Ibid., p. 644. 
benefit balancing is morc restricted under FQPA, precautionary regulation and the reliance on uncertain information may be more widespread in such cases. ${ }^{230}$ Interestingly, the FQPA introduced the ubiquitous "10x factor", which means that a 10-fold safety factor for infants and children is maintained. ${ }^{231}$ In practice, this means that, when a "safe" exposure level has been identified, this has to be multiplied by ten in relation to substances that may be consumed by infants and children. Thus, the " $10 \mathrm{x}$ factor" is a far-reaching precautionary measure. Interestingly, it is not based on scientific evidence, but, instead, it aims to increase the margin of safety for children even though a risk assessment has established that a product is virtually risk free.

The introduction of the FQPA has also meant a development of the risk assessment techniques employed by the EPA. After its introduction, the EPA routinely includes, for example, aggregate exposure and cumulative effects in its assessments of risks. ${ }^{232}$

\subsubsection{The Burden of Proof}

As in the case of the EU regulation of pesticides, as also reflected in the Swedish and UK systems, FIFRA appears to put the onus with regard to pesticides registration on the applicant. ${ }^{233}$ Instead of the regulator needing to demonstrate the risk, it is for the regulated party to show that the product is without "unreasonable risk". ${ }^{234}$ However, it could be argued that the burden borne here by the applicant is a "false" burden of proof, ${ }^{235}$ or at least, that the burden is shared between the applicant and EPA. It is clcar that the applicant bears the burden of information. This is the typical situation in relation to pre-authorisation schemes, since the applicant is the parly in possession of the scientific evidence on which the registration is to be based. It is also clear that this information forms the basis on which the decision that no "unreasonable risk" stems from the pesticide must be deduced. However, it is the responsibility of the EPA to identify an "unreasonablc risk" during the registration procedures in order to bar the product from being marketed. If the EPA does not meet this requirement, the pesticide should be registered and allowed to enter the market. If the EPA

${ }^{230}$ M.W. Graf, Regulating Pesticide Pollution in California Under the 1986 Safe Drinking Water and Toxic Exposure Act (Proposition 65), 687, note 100. This issue is returned to in more detail below under the section on cost/benefit analysis.

231 EPA Evaluation Report, Changes Needed to Improve Public Confidence in EPA's Implementation of the Food Quality Protection Act, Report No. 2006-P-00003, 19 October 2005, p. 5-6.

232 Ibid.

${ }^{233}$ See, above, Sections 5.2.6 and 6.2.6, respectively.

${ }^{234}$ FIFRA, 7 U.S.C. $\$ 136 \mathrm{a}$ (a).

${ }^{235}$ See, above, Section 5.1.7. 
Inakim Zander

identifies a risk in an application for registration, the burden falls on the applicant to show that this risk is net unreasmable. ${ }^{3 \text { to }}$ Thus, the initial burden of prewf rests with the HPA, but the meeting of a relatively low level of profips the burden onto the applicant.

In contrast to this, the onus is clearly on the $1 P A$ to show that a pesticide poses a "substantial question of saltety" when it intends to initiate cancellation or suspension proceedings. This has also betn upheld by courts." In fIDf $v$ Rucketshaus, the court held that:

\footnotetext{
"The leguslative histury supports the conclusion that (ongress intended any subutantial question of salety to trigger the issuance of cancellation movices, shilting to the mamulacturer the barden of proving the safety of his product., ${ }^{2}$ ix
}

\subsubsection{Cost/Benefit Analysis}

One of the main differences with regard to pesticide regulation in the EU, Sweden and the UK, on the one hand, and, the U.S., on the other, is the firm demand on, and significance of', the balancing of costs and benefits in the latter. ${ }^{24}$ When determining whether a risk is "unreasonable" or not during the registration procedure, the costs and benefits of the product appear to be as impurtant to the outcome as that of the nature and magnitude of the product's inherent risk. ${ }^{241}$ Applegate has held that cost/benefit analysis is a necessary part of pesticide regulation, since it is only the estimate bencits of a product that can motivate anything but a zero-risk approach. ${ }^{241}$ If a risk to health or to the environment is not perceived as bringing anything beneficial, why then take the risk at all? This insight may seem trivial, but it helps to explain how Swedish chemicals regulation has become so radical. Since the costs and benefits of products are not considered, even de minimis risks are considered sufficient to warrant regulation. Since the Swedish Chemicals Inspectorate (KemI) has confined itself to considering risks alone, and not juxtaposing them with corresponding expected costs and benefits incurred when regulating risks, it also narrows its flexibility. If a risk is found, the product should not be allowed. The flexibility of the EPA, on the other hand, is considerably

23 The level of prof needed to be met by FPA here is low, as was discussed in the previous section. The requirements become progressively higher for cantellations and suspensions.

23. Ste, for example, National Coulition Against the Misuse of Festicides, et al., v FPA, p. 642

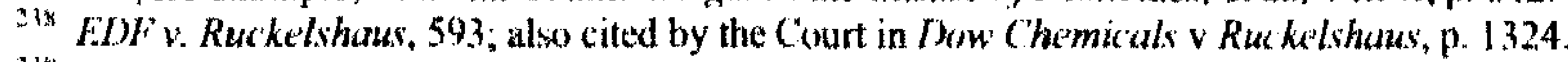

214 See, above, Section 7.1.7.

24t) FIFRA, 7 US.C. \$136hb, where "unreasomable risk" is defined as being contingent upx the "taking intw account the econoric, social, and environmental costs and benefits of [the pesticide's] use".

241 J.S. Applegate, The Perils of Unreasonable Risk: Information, Regulatory Policy and 'Toxic Substances ('ontrol, p. $274-275$. 
greater. By balancing the risks, costs, and benefits on a case-by-case basis, it has a substantial margin of manoeuvre. ${ }^{242}$ Applegate has summarised the issue in the following fashion:

"Likewise, the unreasonable lcvel of risk floats somewhere between harm that is not certain and risk that is not de minimis. Acceptance of non-absolute or relative safety therefore begs the question, how safe? This is where cost enters the risk formula. The unreasonable risk standard expressly incorporates cost-risk-benefit balancing to answer the question raised by relative safety. EPA may not take action without considering the degree of risk involved, the costs associated with regulation, and the benefits that may be achicved by the proposed regulation." 243

This, however, has not always been the case. Until the Delaney clause was revoked in the mid-1990s, the EPA was effectively prohibited from taking other considerations than risk into account when deciding on pesticides which might have resulted in residues in food. ${ }^{244}$

The margin of manoeuvre enjoyed by the EPA functions within the confines of what U.S. courts have stipulated. In National Coalition Against Misuse of Pesticides v EPA, the D.C. Circuit held that scientifically uncertain risks may, indeed, be offset by the costs incurred by regulation. ${ }^{245}$ In Love v Thomas, which regarded the EPA emergency suspension of the pesticide Dinoseb, the 9th Circuit Court referred to the definition of "imminent hazard" in FIFRA, and held that, before a suspension can be issued, costs as well as benefits have to be carefully balanced. ${ }^{246}$ The Court evaluated the cost/benefit analysis performed by the EPA in relation to Dinoseb in detail, and found it to have seriously undervalued the costs for local farmers. It stated:

"With all due respect to the EPA and its overworked staff, such insensitivity to the local economic problems caused by its decision is unbecoming and inappropriate. ${ }^{247}$

However, the Court continued, the EPA could still have been entilled to issue the emergency suspension if a true emergency had been at hand. In the case of emergency

\footnotetext{
242 Ibid., p. 276-277.

243 Ibid., p. 274-275.

244 See, above, Sections 7.1.2 \& 7.2.1.

245 "[The EPA] might determine after an administrative hearing [...] that scientific uncertainty as to the danger of a specific pesticide (combined perhaps with the economic impact of cancellation on "agricultural commodities, retail food prices and the [] agricultural economy" 7 U.S.C. $\$ 136 \mathrm{~d}(\mathrm{~b})(1982)$ ) indicates that the registration should not be cancelled". National Coalition Against Misuse of Pesticides v EPA, p. 642.

246 Love v Thomas, (9th Cir. 1988) 858 F.2d 1347, p. 1357.

${ }^{247}$ Ibid., 1361.
} 
suspensions, a balancing of conts and benefits is nut required. ${ }^{24 x}$ However, since Dinoseb was unlikely to he used by farmers until the next spraying of the putato crop. some six months after the HPA decision, an emereney was mot present aceurding to the court. and therefore the decision appeared "entirely arhitrary". 24

I.we v Thomas provides an interesting example of how the courts are nut content only to consider whether the IPA has taken athard lowk" at the costs and benefits, but also take a clome lexk at the details of the halancing as well as the data reviewed. This illustrates how the reliance on costhenefit analysis on U.S. pesticide regulation is far more advanced than is the case in the other legal systems compared here. It should be pointed out that, even after the demise of the Delaney clause, courts have suggested that the halancing might be skewed in favour of health protection in cases where cancer is the suspected risk. In HDF $v$ Ruckelshaus, the court held that the law "places a heavy burden on any administrative officer to explain the hasis for his decision to permit the continued use of a chemical known to produce canker in experimental animals". ${ }^{5}$.

That a "safer" or similar product already exists on the U.S. market should not lead the EPA to deny an application for registration. However, the fact that this is the case can be factored into the cost/benefit analysis, and, in this way, be taken into account in determining the "unreasonable" nature of a given risk." Thus, the substitution principle, or product choice principle, is not in effect in the U.S., but issues that are similar to it can be factored into the cost benefit balancing. ${ }^{252}$

\subsubsection{Conclusion}

As already mentioned in the introduction, the U.S. has a long history of precautionary regulation in the area of pesticides. Even though the precautionary principle, as such, is not used, specific provisions, such as the Delaney Clause, and the "10x factor" for carcinogenic properties in products intended for consumption by children, are precautionary in nature. Interestingly, these precautionary measures focus on the risk of cancer, while other risks, such as toxicity, are not necessarily treated as harshly. Thus, a choice appears to have been made to target products that may give rise to cancer in particular. With the revocation of the

${ }^{240}$ M.L. Miller, Fsq., Pesticides, p. 674

249 Ihat, p. 1362.

56) EI) F v Ruckelshons, p. 596

$\therefore$ See, for example, EDF $\vee$ EPA, (I) C. ("ircuit 1972) 465 r.2d 52X, p. 539.

24. Compare with the situation in Sweden, where the substitution principle is strictly interpreted and closely connected to the precautionary principle. See, for example, Section 5.2.5. above. 
Delaney (lause in the 1990s, the EPA has been given an increased mandate to take other issues than the risk of cancer into account when deciding on the treatment of pesticides.

FIHRA functions as the legislative framework for pesticide regulation in the U.S. It is. in many ways, smilar to Directive $91 / 414 / \mathrm{k}:$ in place in the $111^{253}$ in that it places the burden of information squarely on the applicant and makes explicit use of scientific bedies to examine and advise the bureaucratic body empowered to take decisions, (onuts have clarified that the LPA is not bound by the advice issued by secentific bodics, but it appears that it has to give its reasons for why it chooses to derogate. At first sight, it appears that the burden of proof in the HIR $\Lambda$ is reversed, and thus placed on the applicant. However, it is argued here that this construction constitutes a "false" burden of proof," and that the actual burden still rests with the EPA to demonstrate that an "unreasonable risk" is present during the registration procedure. The level of proof is low, and, once it is met, the burden is switched onto the applicant to show that no "unreasonable risk" is present. The level of proof is higher when switched onto the applicant.

Since the revocation of the Delaney Clause, risk is only one among many clements that need to be considered by the EPA when taking decisions under VIFRA. The process of authorising or cancelling authorisations in the U.S. is often described as a balancing exercise, which indicates that several competing interests must be considered together. Applegate holds that this is a necessary starting point, because, if positive aspects of a product were not considered, there would be nothing to justify anything but a zero-risk approach. Here, it is interesting to compare this with the situation in Sweden, in which the precautionary regulation of pesticides is very far-reaching. This is made possible by the fact that, as Swedish oflicials have stated, no economic considerations are taken into account when formulating decisions in relation to pesticides.

The U.S. system allows for a more nuanced way of taking decisions. In fact, it requires a more nuanced decision-making process, because it is costbenefit balancing that will answer the question of whether a product poses an "unreasonable" risk or not. Furthermore, courts have indicated that they find it within their remit to "second-guess" the balancing performed by the EPA, at least in cases where they find that cost/benefit analysis is significantly flawed. In Love $v$ Thomas, the court investigated the details of the EPA

"Or rather, Directive $91 / 414 / 1 \mathrm{C}$ ' is reminisent of FIIRA, sine preceded the Directive by some 45 years. 
cost/benefit analysis, beforc it decided to overturn it. Some cases have indicated that the cost/benefit analysis may be skewed in favour of health protection, at least in cases where cancer is the suspected risk. In EDF $v$ Ruckelshaus, the court stated that the EPA had a "heavy burden" to explain why it allowed a pesticide when it had been shown to have carcinogenic properties in animal testing. Finally, in rclation to cost/benefit balancing, it should be pointed out that even though the substitution principle is not formally in effect in the U.S., the issue of whether a comparable, but less risky, pesticide is already on the market should be allowed to influence the outcome of the balancing. Thus, issues similar to the substitution principle can be considered under FIFRA.

\subsection{The Application of the Precautionary Principle in the US Regulation of BASE STATIONS}

\subsubsection{Introduction}

In the chapters on Sweden and the UK, it was shown that the public is increasingly concerned with radiation from mobile telephones and base stations. However, in the U.S., the concern with health risks from radio-frequency radiation is not as widespread or high profile as it is in, for example, the UK. It has been held that the media coverage in the U.S., with regard to these issues, is relatively subdued in comparison with some European countries, and that a well-organised, national network championing health concerns from mobile phones has failed to materialise, at least, as of yct. ${ }^{254}$ Thus, the U.S. emissions guidelines in place, as well as the statutory instrument which pre-empts state and local authorities from making thcir own health risk assessments, has received relatively little attention, both in mainstream media and in specialist literature.

The regulation of base stations for mobile telephones is a relatively complicated area, due to the fact that national rules function together with decisions taken at local level during the planning process. The desire for the rapid expansion of mobile phone coverage is often counter-balanced by local planning concerns, including aesthetic, as well as health, considerations. In this section, as in the previous sections, a structure which aims to deal with the constituent parts of the precautionary principle is maintained. Thus, two sections outline the legal and institutional structure in the arca, before substantive issues of whether, and, if so, how, and by whom, precautionary considerations can be taken during the process. The ${ }^{254}$ A. Burgess, Cellular Phones, Public Fears, And a Culture of Precaution, Cambridge University Press, 2004, p.
178-180. 
central topics here are, of course, not only the issues relating to the level and burden of proof needed for the regulation of base stations, but also the issue of public opinion, which is of central importance to this chapter/section.

\subsubsection{The Legal Framework}

In the U.S., as in the other legal systems discussed above, several laws and regulations, at national, as well as at local, level, are concerned with the regulation of base stations. At U.S. federal level, the National Environmental Protection Act (NEPA), ${ }^{255}$ the Radiation Control for Health and Safety Act (RCHSA), ${ }^{256}$ and the Tclecommunications $\mathrm{Act}^{257}$ make up the legislative framework. At local level, the actual placement of base stations, or cell towers as they are frequently referred to in the U.S., is subject to local planning, or "zoning", rules.

The most relevant government body in the area of mobile telephony is the Fedcral Communications Commission (FCC), which was already established by the Communications Act in $1934 .{ }^{258}$ The role of the FCC is to regulate the U.S. radio spectrum, which includes the considering of whether communication equipment significantly affects the quality of the human environment. ${ }^{259}$ The institutional structure and tasks of the FCC are dealt with in detail in the following section.

The most significant single piece of legislation in relation to base stations is the Telecommunications Act of 1996. It was adopted by Congress, after heavy lobbying, ${ }^{260}$ to facilitate the expansion of the U.S. mobile phone network, and to secure a competitive environment for the benefit of consumers. ${ }^{261}$ In order to prevent local governments from evaluating environmental and health concerns within the framework of zoning procedures, the Act included a provision which holds that:

"No State or local government or instrumentality thereof may regulate the placement, construction, and modification of personal wireless scrvicc facilities on the basis of

${ }^{255}$ National Environmental Protection Act, 42 U.S.C. 4321.

256 Radiation Control for Health and Safety Act of 1968,42 U.S.C. $263 \mathrm{f}$.

257 Telecommunications Act of 1996, Pub. L. No. 104-104, 110 Stat. 56.

${ }^{258}$ The Communications Act of 1934 preceded the Telecommunications Act which amended it in 1996.

259 According to NEPA this is a requirement on all federal agencies to take into account when issuing regulations. See NEPA Sec. 102, 42 U.S.C 4332 (c). The fact that FCC is essentially is not designed to make health assessments is returned to in the following section.

260 For a critical parallel between alleged campaign contributions to members of Congress from telecom actors and the hasty passing of the bill, see N. Tinari, Cell Phone Towers in Residential Areas: Did Congress Let the Pig in the Parlor with the Telecommunication Act of 1996?, 73 Temp. L. Rev. 269, 2000.

261 S. Lorde Martin, Communication Tower Sitings: the Telecommunications Act of 1996 and the Battle for Community Control, 12 B.T.L.J. 1, 1997, Available at: httn://www.law.burkeley.edu/journals/buljarticles/vol 12/index.htm. 
Joakim Zander

the environmental effects of radio frequency emissions to the extent that such facilities comply with the [Federal Communications] Commission's regulations concerning such emissions." 262

The provision explicitly pre-empts local governments from imposing thei assessments, and makes environmental and health considerations a matter for the government. ${ }^{263}$ In apparent contradiction to this, the Act also authorises states to "in measures which are necessary to "protect the public safely and welfare". ${ }^{264}$ Howe $_{v_{f}}$ statement is subjected to the possibility of pre-emption by the Federal Commun Committee. ${ }^{265}$ It has been held that, after the Telecommunications Act came into for prospects for local authorities to impose their own assessments with regard to enviro considerations has indeed, become bleak. ${ }^{266}$ In comparison with Sweden and the U U.S. legislation is strict on this point, where the former two are more ambiguous.

\subsubsection{The Institutional Framework}

Since state and local authorities are effectively precluded from establishing hea environmental standards for emissions from base stations, the most important actors U.S. are found at federal level. A number of agencies have a stake in the process, 1 "spider in the web" is the FCC, which has the statutory power to regulate the However, since the FCC has admitted that it lacks the expertise to formulate reg guidelines for health and environmental exposure to radiation from mobile telephony, $\mathrm{i}$ heavily on other public and private bodies for scientific input. ${ }^{268}$

The Food and Drug Administration is the government agency that has the responsibility for regulating radiation emissions from electric products. However, to has declined to make real use of its powers in the arca of mobile telephony, referring

\footnotetext{
${ }^{262}$ Telecommunications Act of 1996, Sec. 704 (B) (iv).

${ }^{263}$ Howcver, in Sprint pectrum L.P. v Mills the 2nd Circuit Court opened up for more stringent measur prescribed by local governments where these act as "proprietors" rather than "regulators". In the govcrnment owned school building was subjected to more stringent demands on radiation emissions it agreement. Since the agreement was not considered to be a regulatory act, the arrangement was deeme court to fall outside of the Telecommunications Act, and thus be within the discretion of the local gov' See Sprint Spectrum L.P. v Mills, (2nd Cir. 2002) 283 F.3d 404, p. 417-420.

264 Telecommunications Act, Sec. 253 (b).

265 Ibid., Sec. 253 (d)

${ }^{266}$ B.M. Gerber, Case Comment: City of Rancho Palos Verdes, California v Abrams, 30 Harv. Envtl. L., 2006, p. 302.

267 Telecommunications Act, Sec. 704 (b).

268 Rescarch and Regulatory Efforts on Mobile Phone Health Issues, Report to Congressional Requesters States General Accounting Office, May 2001, AO-01-545, p. 20.
} 
to the lack of scientific certainty with regard to the possible health effects stemming from mobile phone use. It has, however, worked together with industry to seek ways in which the exposure to radio-frequency radiation can be minimised. ${ }^{269}$

The Environmental Protection Agency (EPA) also plays a part in the institutional framework for radiation protection and control. Under Reorganisation Plan No. 3 of 1970, it is responsible for advising the President and providing guidance to all federal agencies on matters relating to protective standards for radiation exposure. ${ }^{270}$

In relation to workers, the National Institute for Occupational Safety and Health (NIOSH) and the Occupational Safety and Health Administration (OSHA) have been involved in monitoring and investigating issues relating to exposure to radio-frequency. ${ }^{271}$

The FCC is the only agency that has issued exposure guidelines for radiation from mobilc phones. This was done in the form of a non-binding document in the late summer of $1999 .{ }^{272}$ The details of these recommendations are returned to in the following sections. The FCC is a federal agency founded in 1934 whose role it is to regulate "interstate and international communications by radio, tclcvision, wire, satellite and cable" ${ }^{273}$ Answering directly to the U.S. Congress, the FCC is directed by five Commissioners, who are appointed by the President. One of them is designated as the Chair-person, and only three of them can be from the same political party. ${ }^{274}$ The agency is divided into six different bureaus and ten offices, where the Office of Engineering and Technology (OET) is the unit which has issued the above-mentioned exposure guidelines. The office has little practical expertise in the area of health and safety regulation, ${ }^{275}$ and is generally responsible for advising the Commission on all "engineering matters". 276 The fact that health and safety regulation is not the prime focus of the OET can also be deduced from the FCC organisation outline, in which no one seems to be specifically mandated to cover health and safety issues. ${ }^{277}$ This is further

${ }^{269}$ L. Grasso, Cellular Telephones and the Potential Hazards of RF Radiation: Responses to the Fear and Controversy, $3 \mathrm{Va}$.J.L. \& Tech. 2, 1998.

${ }^{270}$ Research and Regulatory Efforts on Mobile Phone Health Issues, p. 9.

271 Questions and Answers about Biological Effects and Potential Hazards of Radiofrequency Electromagnetic Fields, OET Bulletin 56, Fourth Edition, August 1999, p. 10.

272 Questions and Answers about Biological Effects and Potential Hazards of Radiofrequency Electromagnetic Fields.

273 www. fcc.gov/aboutus.html

274 Ibid.

275 Research and Regulatory Efforts on Mobile Phone Health Issues.

276 www fcc.gov/oet!

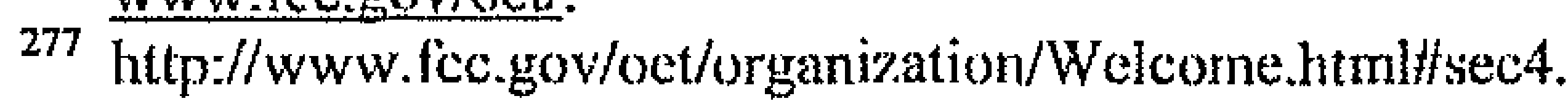




\section{Joakim Zander}

underscored by the fact that none of the FCC's advisory committees, established under the Federal Advisory Committee Act, are directly concerned with providing scientific input to the Committec. ${ }^{278}$ As mentioned above, and as is discussed in more detail below, this has led to the FCC being heavily reliant upon other bodies when issuing its advice.

\subsubsection{Risk Assessment and Risk Management}

It was shown above that the reliance on risk assessment as a foundation for U.S. risk regulation has been increasing since the $1980 \mathrm{~s}^{279}$ In the area of pesticide regulation, the institutional structure and separation of the two stages is generally relatively straightforward. In U.S. pesticide regulation an advisory panel is influential in the risk assessment stage and decisions are ullimately taken by the EPA Administrator. ${ }^{280}$

However, the situation in the area of base stations is slightly different, since several institutions have a stake in the regulation, at local level as well as at national level. In the U.S., the FCC is the institution that has the statutory task of issuing regulations in relation to radiation from basc stations. Thus, the FCC is the agency which it is most accurate to associate with risk management tasks in relation to base stations. However, due to the lack of a clear institutional structure, the FCC also has to analyse the scientific evidence, a task more readily associated with the tasks of a risk assessor than a risk manager. This is a task that FCC itself has stated that it feels uncomfortable with, duc to the lack of in-house scientific expertise that the agency possesses. ${ }^{281}$ Despite this, the FCC has issued recommendations on the basis of its own gathering of data from various other institutions, both public and private. ${ }^{282}$ These recommendations are the most authoritative source in place in relation to exposure to radiation stemming from base stations. ${ }^{283}$ The FCC guidelines were also largely endorsed in the independent study carried out by the General Accounting Office (GAO). ${ }^{284}$

${ }^{278}$ Federal Advisory Committees Follow Requirements, but FCC Should Improve Its Process for Appointing Committee Members, Report to the Chairman, Committee on Government Reform, House of Representatives, General Accounting Office, GAO-05-36, 2004. The Intergovernmental Advisory Committce advises the FCC on public health issues, but does not consist of scientific experts. It is returned to in the section on public opinion.

279 Scc, above, Section 7.1.4.

280 See, above, Section 7.2.4.

281 In relation to exposure guidance and testing of handheld devices the FCC has relied on "one staff specialist in radiofrequency exposure issucs" to review test results. This appears a long way from a systematic framework of risk asscssment and scientific advice. See United States General Accounting Office, Research and Regulatory Efforts on Mobile Phone Health Issues, p. 4.

${ }^{282}$ For a discussion of the content of this advise, see the following section.

${ }^{283}$ Questions and Answers about Biological Effects and Potential Hazards of Radiofrequency Electromagnetic Fields.

${ }^{284}$ See Research and Regulatory Efforts on Mobile Phone Health Issues, Report to Congressional Requesters. 
The lack of a clear institutional structure and separation of risk assessment and risk management in the area of regulation of base stations is not unique for the U.S. As has been seen above, both in Sweden and the U.K. the frameworks are stricter in rclation to pesticide regulation than in relation to base stations.

\subsubsection{The Level of Proof and the Triggering of Precautionary Measures}

Two main documents outline the FCC recommendations in relation to the regulation of radiation from base station. The first one, Bulletin 65 , deals primarily with exposure from handsets. It establishes that an exposure threshold of 4 SAR should be set as the limit for humans, above which "potentially hazardous exposure may occur". ${ }^{285}$ This, the Bulletin holds, is in line with what "expert organisations" recommend. ${ }^{286}$ The limil, which is similar to that recommended by the International Commission for Non-Ionising Radiation Protection (ICNIRP) and is subsequently in force in Sweden and the United Kingdom as discussed above, offers a slightly stricter level of protection than was the case in earlier recommendations issued by the FCC in 1985. However, this is not to signify that any new scientific evidence has come to light, according to the FCC. Instead, it aims to express a "precautionary desire to protect sub-groups of the general population who, potentially, may be more at risk". ${ }^{287}$ This appears to be similar to the reasoning provided by the U.K. authorities when they incorporated the ICNIRP values. The ICNIRP recommendations consist of a SAR value, which is based upon an arbitrary, built-in "safety margin" around the value at which detrimental effects are identified. ${ }^{288}$ Even though the recommendations coincide, Bulletin 65 does not refer to ICNIRP. Instead, the values are based on the conclusions of the National Council on Radiation Protection and Measurement (NCRP), the Institute of Electrical and Electronics Engineers, Inc. (IEEE), and the American National Standards Institute (ANSI). ${ }^{289}$ Thus, the FCC draws on scientific advice formulated by

${ }^{285}$ Evaluating Compliance with FCC Guidelines for Human Exposure to Radiofrequency Electromagnetic Ficlds, OET Bulletin 65, Edition 97-01, August 1997, p. 8.

${ }^{286}$ Ibid. As has been discussed above, the FCC does not consider itself an expert organisation when it comes to environmental and health protection.

287 Ibid.

288 See, above, Sections 5.3.4 \& 5.3.5.

${ }^{289}$ Evaluating Compliance with FCC Guidelines for Human Exposure to Radiofrequency Electromagnetic Fields, p. 7. 


\section{Joakim Zander}

government bodies (the $\mathrm{NCRP}^{290}$ ), as well as branch organisations (IEEE ${ }^{291}$ ) and voluntary standard setting bodies (ANSI ${ }^{292}$ ) for inspiration.

In August of 1999, the FCC responded to the task it had been given by the Telecommunications Act and issued OET Bulletin 56 with guidelines for maximum cxposure limits from base stations. ${ }^{293}$ These recommendations are built largely on the same conclusions as Bulletin 65 , with the difference that the exposure limits are set as maximum field exposure, rather than SAR values. ${ }^{294}$ The document was preceded by an extensive consultation procedure with relevant U.S. agencies, such as the FDA, the OSHA, and the EPA. All the consulted agencies supported the NCRP and ANSI/IEEE guidelines upon which the FCC based their recommendations. ${ }^{295}$

The FCC guidelines separate occupational (or "controlled") exposure from exposure to which the general public may be subject ("uncontrolled exposure"). The occupational exposure limits are set higher than those established for the general public. ${ }^{296}$ Like Bulletin 65 and the ICNIRP guidelines, the FCC recommendations are based on the presumption that scientifically-established health risks are a fact at a degrec of exposure exceeding a SAR threshold of $4 \mathrm{~W} / \mathrm{kg} .{ }^{297}$ Howcver, ICNIRP recommends different exposure levels in the lower and upper frequency ranges and for localised exposure from certain products such as handheld wireless telephones. ${ }^{298}$ This difference is marginal, and appears to be due to the use of different physics models. ${ }^{299}$

In 2001, U.S. Senators Licbcrman and Markey requested the U.S. General Accounting Office (GAO) to conduct an independent survey of mobile phone health issues. This initiative is similar to the U.K. approach, in which an independent expert group was asked to conduct an investigation into the same matter, outside of the regular institutional structure. ${ }^{300}$ Where, the U.K. investigation was mainly motivated by the growing public discomfort with rapid

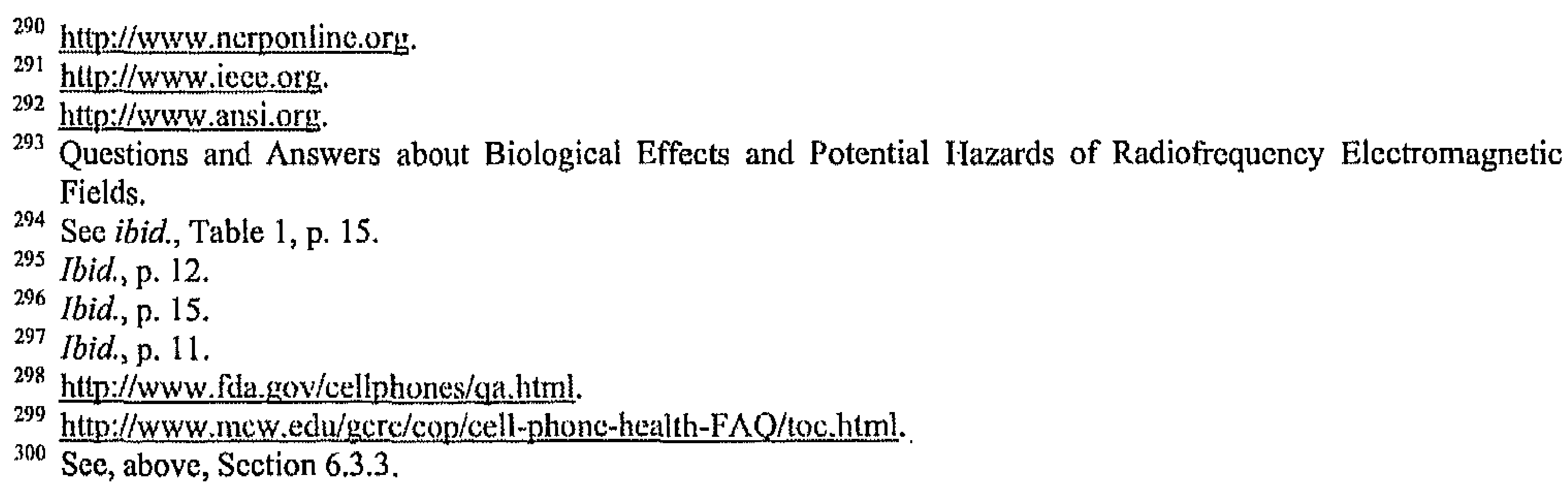


mobile phone technology expansion, the U.S. counterpart appears to have aimed more as a general clarification of the seienes and legistation affecting the area." The evidence considered in the Report consists of seientific reports issued by international bodtes such as the World Health Organisation, as well as by "expert panels" in the U.K.. Canada, and Australia. which have considered the per-reviewed scientific assessments in the area. ${ }^{37}$ It thus appears that, when drafting the report, the (iAr) only considered the seientific evidence that had already been considered by other, internatonal and national, bodies.

The conclusion of the (iA ) Report is that the evidence does not support the assertion that radiation, within the recommended limits, from handsets or base stations would have any adverse health eflects. However. like the Sitewart Report in the U.K., it emphasises that the evidence existing at this point is not conclusive, and that more research is required to understand the effects of radiation from mobile telephones fully. ${ }^{3 / 4}$ Unlike the Stewart Report, the (BAO Report does not recommend any precautionary measures, although it does go further than the Swedish government assessments in that it highlights the uncertaintics inherent in the data in the area. ${ }^{316}$ As a response to the uncertainty, the GAO Report recommends increased efforts to carry out research into health effects, both within the framework of the U.S. regulatory structure in the area, and in partnership with industry. ${ }^{317}$

It thus appears that, in the area of mobile phones, mere uncertainty as to health effects is not sufficient for the U.S. govermment to issue precautionary measures. Some positive scientific evidence of a risk needs to be at hand. In this context, it should be pointed out that some studies, which indicate potential biological effects from extended exposure to low levels of radio frequency. ${ }^{3 / x}$ had not yet been carried out when the U.S. regulatory bodies

Ibid.

Research and Regulatory Efforts on Mobile Phone Health Issues, p. 2

Itid. pp. 9.12 .

Ihit., p. 8-9.

As was discussed above, the Stewart Report recommended relatively far-reaching precautionary measures as a response to the uncertainty in relation to base station. This response included a revocation of approval for base stations and a renewed procedure. It also recommended restrictive siting of base stations in the neighbourhood of schools. See, above, Section 6.3.5.

3ik The Swedish government has instead opted to play down uncertainties in relation to mobile telephony, and has emphasised that radiation stemming from mobile telephone systems is essentially harmless for humans. See, abuve, Section 5.3 .

307 United Statex (ienctal Accounting (Iffice, Research and Regulatory I:fforts on Mobile Phone Health Issues, 1218.

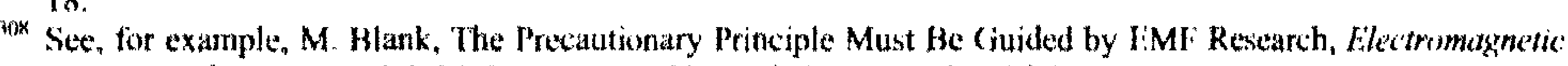
Biolign and Mtdis one, Vol. 25,200k, p. 203-20x, and above, Section 5.3.5. 
Joakim Zander

issued the bulk of their recommendations. However, no measures have been taken since, either.

In a 1999 challenge before the 2nd Circuit Appeals Court, petitioners argucd that the FCC had not adequately considered the unccrtain risks of mobile phone radiation when issuing its guidelines. ${ }^{309}$ Among other things, the petitioners held that the FCC should have paid more attention to some scientific advice which clearly emphasised potential, but highly uncertain, risks. Furthermore, they held that the FCC was under an obligation developed by the Nuclear Regulatory Commission to keep radiation levels "as low as reasonably possible". The Court did not agree with this. Ciling earlier case law, it began by stating that the judicial review under the APA had been interpreted to be deferential in nature:

"The agency's action should only be set aside where it relied on factors which Congress has not intended it to consider, entirely failed to consider an important aspect of the problem, offered an explanation for its decision that runs counter to the evidence before the agency, or is so implausible that it could not be ascribed to a difference in view or the products of experts." 310

Having thus held that it considered its margin for review narrowly confined, the Court examined the scientific evidence provided by the applicants. It concluded that the evidence in question was not conclusive, and had this had been considered by the FCC when drafting its guidelines. That it had chosen not to act in a more precautionary manner and had based its recommendations on the existing uncertaintics, the Court did not find to be problematical. It concluded:

"[t]he argument that the FCC should create greater safety margins in its guidelines to account for uncertain data is a policy question, not a legal one."311

Thus, it appears that the Court considers it possible for the FCC to rely on the uncertainty if it so wishes, but that such a choice is within its discretion. Here, the situation appears to be similar to the UK situation in which the courts leave precautionary decisions entirely up to the consideration of the relevant government authorities. ${ }^{312}$ However, as

${ }^{309}$ Cellular Phone Task Force, ct al., v FCC, (2nd Cir. 2000) 205 F.3d 82.

310 Ibid.

311 Ibid.

${ }^{312}$ See, above, Section 6. 
discussed above, other US cases in relation to other statutes suggest that courts will review, and, in some cases, overturn, decisions taken upon the basis of scientifically uncertain evidence. $^{313}$

In some cases, local governments have wished to maintain a stricter application of radiation levels than is provided for in the FCC guidelines. Sometimes zoning permits for base stations have been denied on this basis. In order to impose any restrictions on base stations, the action on the part of the state or local government has to be supported by "substantial evidence". 314 This does not mean that the evidence needs to be conclusive, but the mere existence of scientific uncertainty is apparently not sufficient. The term "substantial evidence" has "a long-standing meaning in federal law" Fourth Circuit Court as meaning "more than a mere scintilla of evidence", but "less than a preponderance". ${ }^{316}$ The First Circuit Court has held that:

"[s]ubstantial evidence is such relevant cvidence as a reasonable mind might accept as adcquate to support a conclusion." 317

However, the 4th Cicuit Court held in AT\&T Wireless PCS, Inc. v City Council of Virginia Beach that health concerns are effectively precluded from consideration by local and state authorities since the Telecommunications Act. ${ }^{318}$ Thus, the substantial evidence brought by state or local governments must generally regard issues other than health risks. This topic is returned to in the context of public participation below.

\subsubsection{The Burden of Proof}

As in the previous studies conducted here, the burden of proof is not reversed in the U.S. with regard to the regulation of base stations. As has been shown above, the guidelines issued by the FCC incorporate safety margins in a way that is similar to the ICNIRP values, which are effectively in use in Sweden and in the U.K. However, these safety margins do not appear to be precautionary as such; instead, they aim to establish a "fence" around the emissions levels at which adverse effects in humans are scientifically proven to appear in order to avoid them being breached accidentally. Since the regulated parties, the providers of mobile phone

\footnotetext{
313 Scc, above, 7.1.5.

314 Telecommunications Act, Sec. 704 (7) (B) (3) and Ibid.

315 Petersburg Cellular Partnership v Boards of Supervisors of Nottoway County, 205 F.3d 688 (4th Cir. 2000), 694.

316 AT\&T Wireless PCS, Inc. v City Council of Virginia Beach, p. 430.

317 In Associated Fisheries of Maine, Inc. v Daley, (1st Cir. 1997) 127 F.3d 104, p. 109.

318 AT\&T Wireless PCS, Inc. v City Council of Virginia Beach, (4th Cir. 1998) 155 F.3d 423, p. 431.
} 


\section{Joakim Zander}

systems, have not been inclined to challenge the FCC guidelines or their application by state or federal governments, it is difficult to speculate on how these levels could be successfully challenged by the regulated partics. To date, the case law has only concerned instances in which a more precautionary approach than the FCC guidelines has been argued by parties.

\subsubsection{Cost/benefit Analysis}

The Telecommunications Act of 1996 is not primarily an instrument for health protection. Instead, its focus is clearly on removing barriers to trade ${ }^{319}$ in telecommunications services in order to pave the way for "competitive markets". ${ }^{320}$ It has been pointed out that "[c]ongress enacted the Telecommunications Act of 1996 to meet society's communication demands", 321 rather than as a means to address the issue of radiation from base stations. In the light of this, it would be fair to say that the act is clearly motivated by economic considerations, rather than by a wish to create a radiation safe environment. Thus, the main focus of the Telecommunications Act is to allow for increased competition between actors on the telecommunications market, and an increasing quality of services and better prices for consumers. This is further emphasised by the fact that the FCC has been given the task of overseeing the $\mathrm{Acl}$. Asit has, itself, pointed out, it lacks the competence to formulate radiation protection guidelines on its own. ${ }^{322}$ When considering the background and purpose of the Telecommunications Act, it appears that risk considerations play a rather small role in the grand scheme. Thus, it would seem that the scales were already tipped from the outset in favour of the benefits of rapid mobile phone expansion.

When considering the guidelines established by the FCC, and the documents which relate to it, such as Bulletin 65 and the Lieberman/Markey Report, references to cost/benefit analysis are lacking in their entirety. Instead, the guidelines are based solely on risk considerations, even though they are based upon scientifically certain effects, rather than on precautionary considerations. ${ }^{323}$ Neither risk nor risk trade-offs are dealt with in the guidelines and related documents. This is probably due to the fact that no risk appears to be present, provided that the guidelines are abided by. If cost/benefit or trade-off analyses had

319 Telecommunications Act, Section 253.

320 lbid., Part II.

${ }^{321}$ T.L. Gustin, The Perpetual Growth and Controversy of the Cellular Superhighway: Cellular Tower Siting and the Telecommunications Act of 1969, 23 Wm. Mitchell L. Rev. 1001, 1997, p. 1004.

322 United States General Accounting Office, Research and Regulatory Efforts on Mobile Phone Health Issues, p. 20.

${ }^{323}$ Questions and Answers about Biological Effects and Potential Hazards of Radiofrequency Electromagnetic Fields, pp. $9 m 16$. 
been carried out when drafting the legislation or the advice mandated by the legislation, these appear informal and almost intuitive in nature.

At both state level and local level, the Telecommunications Act effectively pre-empts state and local governments from making other assessments than thuse suggested in the $\mathrm{fCC}$ guidelines. This means that they are prevented from making their own assessments of risk levels. Thus, independent assessments of the costs and benefits, as well as of trade-olfs inherent in potential regulation, are also beyond their reach. Only if "suhsiantial evidence" is presented can they act more restrictively than has heen prescribed by the federal government. ${ }^{3 / 4}$

\subsubsection{Public Opinion}

As has been stated repeatedly above, the FCC guidelines in place in the U.S. are based solely on seientifically proven risks. When establishing these limits, no record shows that attention was paid to any potential opposition to mobile phone technology or radiation on the part of the public. In relation to this, it has been prointed out that public opposition to mobile phone technolugy in the U.S. is at a significantly lower level than. for example, in the U.K., where public interest groups are well-organised and rocal. ${ }^{35}$ Since the Telecommunicalions Act pre-empts local and state governments from taking more precautionary decisions than is provided for in the FCC guidelines, the role of the public opinion at local and state level is also severely limited. However, the possibilities that do exist for local citizens to oppose the establishment of base stations in their vicinity will be dealt with in some detail here.

While the opposition to base station development in some other countries is more centrally organised and often based on health concerns, ${ }^{32 t}$ public opposition in the U,S. seems to be ad hoc, and based upon what has been described as a "NIMBY" (not in my back yard) mentality. ${ }^{327}$ Often, the main reason for opposition to the development of base stations is not the uncertain health risks associated with them, but, instead, the effect that the establishment of them may have on property values. Here, aesthetic concerns are likely to be more prominent than the potential risks, ${ }^{328}$ and they are not regulated in any detail in the

324 Telecommunications Act, Sec. 704 (B) (II) (iii)

s: Aurgess, Cellular Phomes. Public Fe'ars, And a Culture' of Precaution, p. 178-180

326 Ihid.

27) "Not In My Backyard". See T.I. (iustin, The Perpetual Growth and Controversy of the Cellular Superhighway: Cellular Tower Siting and the Telecommunications Act of 1969,1006.11007

is See, for example, K. Hafner, First ('ome ('ellphone Towers, Then the Babel, NYT' 1 atte lidition Final, Section 1, Page 1, Column 3, May 12005. 


\section{Joakim Zander}

Telecommunications Act, although it appcars that, in order for such concerns to constitute a basis for a denial of a zoning application, "a local zoning board's aesthetic judgment must be grounded in the specifics of the case". ${ }^{329}$ Thus, general bans on the establishment of base stations seem to be impossible to maintain even when they are based on an aesthetic rationale.

In the case Cellular Telephone Co. $v$ The Town Board of Oyster Bay, the issue of what weight can be given to public concerns with health risks from base stations when taking zoning decisions was dealt with in some detail. ${ }^{330}$ When deciding on the placement of mobile phone towers, the Town Board of Oyster Bay in New York held public hearings in order for the citizens of the town to have input in the process. At the hearings, AT\&T presented evidence as to the need for the development in order to safeguard uninterrupted mobile phone coverage in the area. It also presented scientific evidence with regard to the radio frequency cmissions that the development would give rise to in order to mitigate the fears of adverse health effects. ${ }^{331}$ Representatives of the citizens of Oyster Bay spoke out against the proposed developments and cited, primarily, the risks of adverse health effects, including cancer, as their reason for opposing the plans. In February of 1997, the Town Board denied the applicanl's request for zoning permission, and primarily cited "safety reasons" as the basis for its decision. In addition to this, the Board also furnished a number of other reasons, including the failure to provide parking, the need for a full environmental impact assessment, and aesthetic concerns. ${ }^{332}$

With regard to the health concerns, the Court held that previous case law had established that "generalised health concerns of citizens are insufficient to rise to the level of substantial evidence", 333 and that the Telecommunications Act precludes "health concerns from radio emissions". ${ }^{334}$ However, the Court held that aesthetic considerations could, potentially, be grounds for denying a planning permission, even though, in this case, it found the referral in question to be unsupported by evidence. Furthermore, and interestingly, it also touched upon the issue of whether declining property values can function as grounds for

\footnotetext{
${ }^{329}$ Southwestern Bell Mobile Sys. v Todd, (1st Cir. 2001) 244 F.3d 51, p. 61.

${ }^{330}$ Cellular Telephone Co. $\mathrm{v}$ The Town Board of Oyster Bay, (2nd Cir 1999) 166 F.3d 490.

${ }^{331}$ Ibid.

${ }_{332}$ Ibid.

${ }^{333} \mathrm{Ibid}$. Here, the Court cited the judgment in Illinois RSA No. 3, Inc. v County of Peoria, $963 \mathrm{~F}$. Supp. 732 , (C.D.IIl. 1997), p. 745

334 Ibid. Here, the Court cited the judgment in AT\&T Wireless PCS, Inc. v City Council of Virginia Beach, p. 431 note 6 .
} 
denying a permit. In the end, it declined to give a clear ruling on the interesting issue of whether declining property values as a result of the fear of health risks from base stations would be permissible under the Telecommunications Act. AT\&T held that allowing for such reasoning would only function as a proxy to usher in reasoning based upon health considerations which are not allowed. In the end, the Court found the reasoning of citizens in the public hearings to be too general in nature to fulfil the substantive evidence requirement and did not rule on the issue as such. ${ }^{335}$

In summary, the Court in AT\&T Wireless Servics v The Town Board of Oyster Bay did not exclude that public concerns could potentially be taken into account. But it did clearly state that such considerations would have to be supported by a significant body of evidence in order for it to "rise to the level of "substantial". ${ }^{336}$ It also appears that concerns other than health risks are more likely to be effective when challenging a zoning decision since the Telecommunications Act explicitly authorises the FCC to issue advicc on this. ${ }^{337}$ Thus, the situation in the U.S. is somewhat different to that in the U.K., where public fears appear to be increasingly considered. Instead, it is closer to the Swedish situation, in which the centrally established guidelines are upheld consistently by courts even in the face of public resistance.

In a more recent case from the Sccond Circuit Court, it is highlighted that the applicant bears the burden of showing that the establishment of a base station is necessary, at least, in the face of public opposition. In the case, the applicant had failed to show why the proposed establishment of a base station would be necessary in order to maintain full mobile phone coverage in the area. The Court placed weight on the fact that other service providers managed to afford this without building on the contested site. ${ }^{338}$ It is interesting to note that courts are seemingly expanding the possibilitics of opposing the establishment of base stations, but only provided that the reasons for the opposition is not one of health concerns.

\subsubsection{Conclusion}

The regulation of base stations in the U.S. is an example of the conflict that arises between the desire at federal level to push through the rapid expansion of mobile phone technology while maintaining the responsibility for planning decisions at state and local levels. This is a

\footnotetext{
335 Ibid.

336 Ibid.

${ }^{337}$ See, for example, AT\&T Wireless PCS, Inc. v City Council of Virginia Beach, p. 431 note 6, where the Fourth Circuit Court had to work around the health concerns issue in order to find a way to allow for the public opposition to influence the City Council.

338 Omnipoint Communications Inc. v The City of White Plains, (2nd Cir. 2005) 430 F.3d 529, p. 536.
} 
situation that is familiar from the previous case studies presented above. The U.S. example, however, distinguishes itself in that a statutory instrument explicitly pre-empts local governments from laking a more precautionary stance than that presented by the FCC in the national guidelines. In Sweden, the de facto situation is similar, due to the fact that the Radiation Protection Agency has issued, in itself non-binding, advice, which has consistently been upheld in the Swedish courts. In the U.K., it appears that local governments in may have somewhat more of a possibility of maintaining more stringent regulation based on public opinion.

The Telecommunications Act of 1996 was the instrument which gave the $\mathrm{FCC}$ the task of developing national emissions guidelines for mobile phones. This, the FCC has done in two Bulletins, also issued in the late $1990 \mathrm{~s}$. The content of the guidelines are almost identical to the guidelines issued by ICNIRP, which are in place in Sweden and in the U.K. Both the FCC and the ICNIRP guidelines are based solely on scientifically-proven adverse effects in humans. The brcak-off point in both sets of guidelines is 4 SAR. With regard to what levels of frequency can be permitted to be emitted from base stations in order for this level to be avoided, the ICNIRP guidelines are marginally stricter in some frequency ranges due to the use of different physics models.

The FCC has repeatedly held that it fecls uncomfortable with the task of issuing health and safety guidelines, since it is not primarily a health and safety agency, and thus lacks the necessary expertise. When studying the organisation of the Office of Engineering and Technology, which is responsible for drafting the guidelines within the FCC, the lack of expertise is striking. Due to this fact, the FCC has relied on other government agencies, such as the FDA and branch organisations, when formulating its advice. Interestingly, it has not referred to the ICNIRP, the internationally recognised body which is active in the area. Like in the U.K., an independent report commissioned by a branch of the government (the U.S. Congress and a ministry in the U.K. respectively) has evaluated the current state of the scientific research. Both reports highlighted the uncertainties regarding the radiation fron mobile phones. However, the U.S. report stopped short of recommending any precautionary measures, while the U.K. equivalent went to great lengths to advocate a precautionary approach based on the same set of data. In Sweden, no such independent report has beer commissioned. The advice present in Sweden is drafted solely by the Radiation Protectior Agency. 
With regard to the content of the guidelines in place at national level in the U.S. it can be concluded that they are similar to those recommended by the ICNIRP and in place in most EU countries, including Sweden and the U.K. discussed earlier. Like the ICNIRP guidelines, they cannot be considered to be based on the precautionary principle, since they do not aim to address the uncertainties in the scientific material on which they are based. Instead, they focus solely on protecting the public against the scientifically-verified risks from radiofrequency emissions. It is true that they, like the ICNIRP values, recommend a "safety margin" around the scientifically-certain risks. However, the purpose of this does not appear to be to take the uncertain nature of the data in question into account, but, instead, to function as a "fence" so that the risks do not accidentally matcrialisc.

As already mentioned, federal statute pre-empts state and local governments from opposing the establishment of base stations based on health concerns. This approach has been upheld in the case law. However, some cases indicate that courts may permit a relatively farreaching consideration of aesthetic concerns and the effects of the establishment of base stations on property values by local governments. This could lead to a situation in which an active public opposed to the establishment of base stations could successfully challenge mobile phone providers on such grounds. So far, the courts have avoided ruling on the sensitive issue of how dwindling property values based on the fear, rational or not, of radiation from base stations may be a valid basis on which to oppose developments. If this is, indeed, deemed to be a valid ground, it opens a significant "back door" for local governments to take precautionary considerations into account when making zoning decisions. Courts have already stated that the burden of proof is on the mobile phone service providers to show the necessity of the establishment of base stations for continuous mobile phone coverage, at least when the establishment of the base stations is faced with public opposition. On the wholc, the case law indicates that the courts are inclined to afford local governments at lcast some leeway to oppose the establishment of base stations. Here, the U.S. situation is closer to how the U.K. courts have dealt with the issue than to the Swedish situation, in which it is excessively difficult for local governments to oppose the expansion of mobile phone services.

In conclusion, the regulation of base stations in the U.S. is not explicitly based on the precautionary principle. The exposure limits in the U.S. are comparable to the ICNIRP guidelines, which have been endorsed in the EU, the UK and Sweden. These limit values are not precautionary in nature, but are based only on scientifically certain effects. However, 


\section{Joakim Zander}

local governments may have possibility of issuing more precautionary planning decision based upon public opposition to base stations. This would be similar to the situation in the UK, but is in contrast to the Swedish situation, in which the national guidelines must be abided by and local governments appear more limited in their power to refuse the establishment of base stations. 


\section{CHAPTHK $X$}

\section{conclestons}

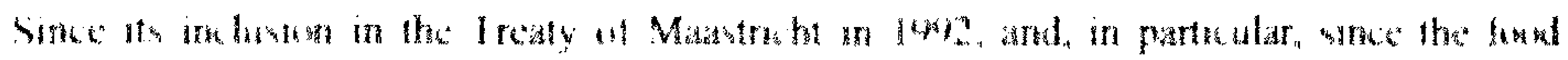

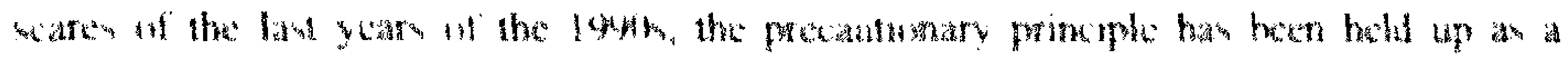

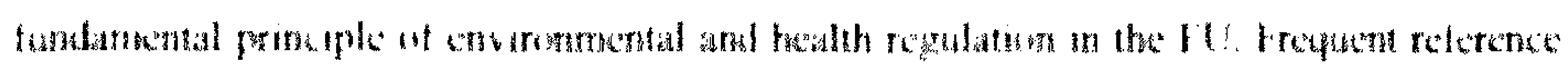

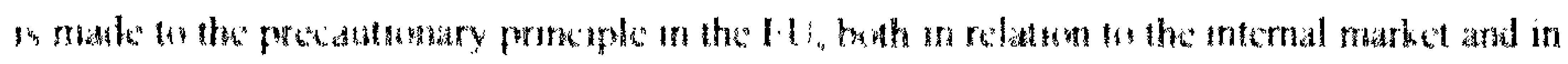

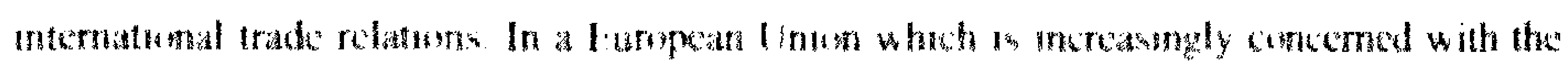

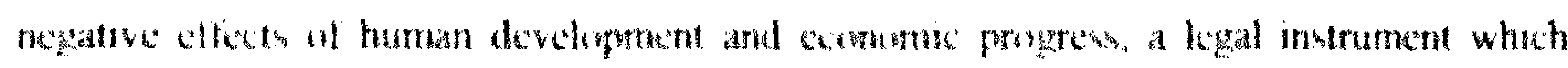

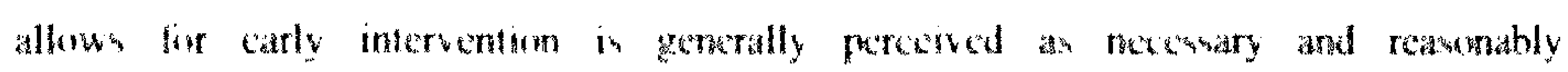
unsontroverstal

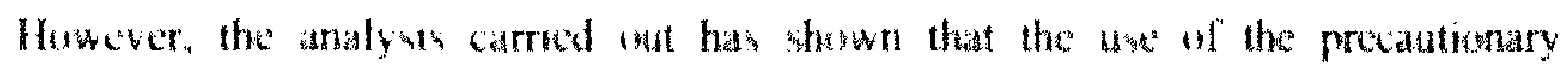

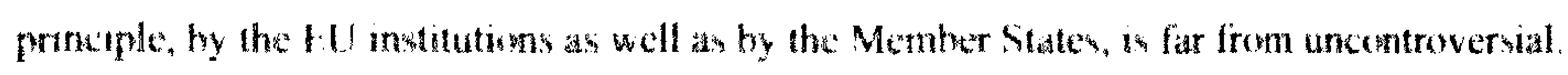
Simular situtions arc nu trated in amparable fahwo, which makes it incrasingly

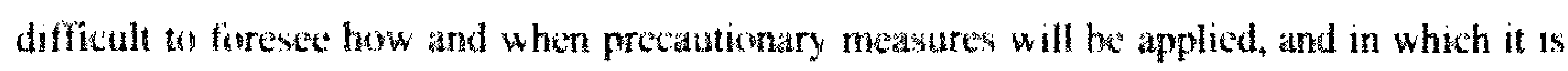

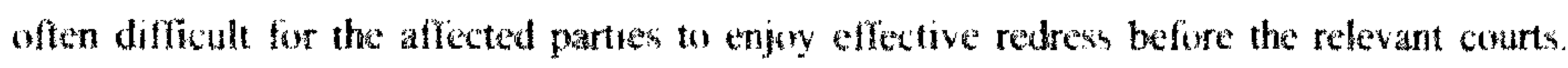
Furthermore, 1/ Member State increasingly justify derogation not only from harmonised rules bat also from the basic free movement prow isions with the precantionary principle. This pretice runs the risk of undermining the careful compromises and agreements which underlie tha LU. and. As a consequence* a frammentation of the internal market.

This book has analysed whether it is poswible to discern a definition of the precautionary principle, as well as whether there are systematic and coherent elements behind the issung of precautionary measures at international, European and national levels. In so doing a number of factors have been identified as heing instrumental for the outcome of precautionary decision-making. These factors have been studied separately in each chapter, and they incluate the definition of the precautwary principle in each particular legal system. and in the particular policy area stidied, the scope of judicial review, the separation of risk assessment and risk management, the role of scientific evidence, the placement of the burden of proof, the roke of cost /benefit analysis, risk trade-off analysis, and the ranking of risks. Where it has appeared to have been influential for the application of the precautionary primiple, the role of the public in decision-making has also been considered. 


\subsection{IN'TERNATIONAL LAW}

\subsubsection{International Environmental Law}

In international law, the precautionary principle is still a reasonably new and unclear concept. Even though reference to a "precautionary principle" or a "precautionary approach" has been included in a number of, primarily, sectoral international agreements in the area of the environment, the International Court of Justice (ICJ) and other international tribunals have proven reluctant to acknowledge it any legal effects except in specific agreements. Principally, it has been pointed out that, to date, it has been difficult to identify the consistent practice and opinio juris, which are necessary for a concept to assume the status of international custom. De Sadeleer has argued that the precautionary principle could be considered to be an "emerging principle" of international law. However, the role and status of such a concept remains uncertain.

Even if the status of the precautionary principle in international law must be considered weak from a legal point of view, from a political viewpoint, the inclusion of precautionary considerations in international agreements has been of great importance. Most prominently, the triple negative definition of the precautionary principle included in Principle 15 of the Rio Declaration is the definition of the principle most frequently referred to by most commentators and decision-makers.

\subsubsection{WTO law}

As in "traditional" international law, both the panels and the Appellate Body of the World Trade Organisation (WTO) have proven reluctant to afford the precautionary principle any weight as an independent legal concept. Instead, they have consistently held that the precautionary principle finds reflection in Article 5.7 of the SPS Agreement, which allows Members to issue protective measures without basing them on risk assessments in instances where the scientific data are insufficient to perform a risk assessment. In all other instances, the requirement laid down in Articlc 5.1 of the SPS Agreement to base measures on risk assessments is absolute.

Despite this, when studying the panel and Appellate Body reports in detail, it appears that the above does not exhaust the possibilities of taking precautionary measurcs under the SPS Agreement. Article 5.7 merely functions as a last resort when the scientific evidence is so incomplete that a meaningful risk assessment would be impossible to perform. The Appellate Body stated in EC-Hormones that minority scientific opinions may be relied upon in order to justify precautionary measures, provided that they come from reputable sources. 
Thus, in instances of conflicting scientific evidence, a member does not need to follow the majority scientific opinion, but is free to rely on scientific cvidence which suggests a more precautionary approach. The WTO panels will scrutinise the scientific evidence put before them. In fact, the review performed by WTO panels is the deepest carried out by any judicial body in the legal systems investigated in this book.

As demonstrated in, for example, Japan-Apples, the panels will look for "sufficient scientific evidence" in order to support a trade restrictive measure issued by a member. In order to establish whether this level has been met, panels will make a detailed study of the scientific evidence presented to them, and, in some cases, even procure their own scientific evaluation of it ex officio. A scientifically credible chain between a product or an activity and the argued risk in question needs to be established, even if it cannot be scientifically proven. This chain will be examined in detail by the WTO pancls. On appeal, the Appellate Body is restricted to considering formal issues and will not "second-guess" the scientific assessment performed by the panels.

When considering the above, the scope for WTO Members to act in a precautionary manner is greater than is generally assumed. It is indeed possible for Members to take measures based on inconclusive evidence and still abide by WTO rules. But it is not sufficient to base a measure upon mere suspicion or fear. A scientific link needs to be presented in order for the measures to stand. This link does not have to be scientifically proven, and it does not nced to represent the majority scientific view. In EC-Hormones, it was made clear that the scientific evidence needed to be specific to the risk from which the Member aimed to protect itself. So far, no Member has successfully managed to maintain precautionary measures, but it should also be pointed out that, so far, only a very limited amount of cases relating to the precautionary principle have been considered by the WTO Dispute Settlement Body.

\subsection{EU LAW}

The application of the precautionary principle in the EU is a highly complex issue. To begin with, the principle is codified in Article 174 of the EC Treaty. As a consequence, it is to function as a principle which underpins all environmental policy in the EU. In its case law, the European Court of Justicc (ECJ) has extended its scope to include issues of human health protection. There are abundant examples of how the precautionary principle influences EC legislation. Some highly publicised examples are the regulation of genetically modified 


\section{Joakim Zander}

organisms (GMOs) and the comprehensive package for the regulation of chemicals (REACH). In these instances, the precautionary principle has led to the adoption of legislative frameworks which rely on systems of pre-authorisation and ex ante controls.

In a Communication of 2000 , the Commission intended to clarify the application of the precautionary principle in the EU. It emphasised that scientific evidence and expertise should be the basis for regulation. Furthermore, it held that a weighing of costs and benefits should precede regulation, and that the burden of proof could be allowed to be reversed on a case-by-case basis. However, the non-binding document does not propose a comprehensive framework to be applicd when precautionary decisions are considered, and it did not touch upon the issue of how to approach situations in which Member States wish to rely on the precautionary principle in order to avoid harmonising measures.

In its case law, the EU courts have adopted a deferential approach to issues surrounded by scientific uncertainty. In most cases, it affords scemingly unlimited discretion to the EU institutions to which the tasks of regulation or implementation have been given. In the voluminous and sometimes contradictory Pfizer judgment, the Court of First Instance (CFI) aimed to follow the vague framework established by the Commission Communication on the Precautionary Principle. It highlighted the importance of risk assessment and cost/benefit analysis, but stopped short of establishing any binding tests against which such requirements could be tested. Instead, it held that, in order to avoid regulation, a challenging party would have to "prove conclusively" that the risk suggested by a Community body entrusted with a regulatory task was unlikely to materialise. By requiring the challenging party to show the non-existence of a risk, the CFI raised the level of proof to the impossible. It follows logically from the concept of scientific uncertainty that it is not possible to demonstrate conclusively the existence or non-existence of a risk. If it were possible to prove conclusively the existence of the risk, it would not be uncertain. In fact, it is widely recognised that it is impossible to show any fact conclusively since every scientific observation is surrounded by varying degrees of uncertainty. Therefore, the conclusion of the Pfizer judgment leads to a situation in which an EU institution can adopt any decision it sees fit in cases of scientific uncertainty, as long as it acts within the margins of its discretion. The EU courts, if they uphold the conclusions established in the judgment, refuse to make any qualitative requirements on decisions taken under scientific uncertainty. It should be mentioned that, in its recent judgment in Sweden $v$ Commission, the CFI disregarded its 
limited review in order to overtum a Commission decision to authorise the pesticide paraquat based on a different interpretation of scientific evidence. This is a surprising and paradoxical approach considering the previous consistent case law of the ECJ and the CFI in relation to judicial review. So far, this is the only case in which the limited review doctrine has been disregarded by the European Courts. It remains to be seen if the case signals a deliberate and consistent shift in the policy of the ECJ and the CFI.

The limited review doctrine creates a situation in which the original burden of proof is indeed on the EU institutions to support precautionary measures. However, what needs to be shown is that the issuc in question is surrounded by scientific uncertainty. Since, to date, the EU courts have not shown an inclination to examine scientific evidence in any detail, little is required in terms of evidence to demonstrate the presence of scientific uncertainty. Thus, the level of proof to be met is very low. When scientific uncertainty has been established, the courts do not investigate whether cost/benefit and risk trade-off analyses have been taken into account. Instead, the usc of such instruments remains completely at the discretion of the relevant institutions. There is no specific requirement for the decisions taken to be efficient or effective.

The worrying conclusion of the EU case law, so far, is that effective redress is virtually impossible for individuals or undertakings affected by precautionary decisions emanating from the European institutions. In order to remedy this, the CFI and the ECJ need to step out of the shadow of their limited review and establish a system against which precautionary measures can be tested. If they fail to do so, the application of the precautionary principle risks will remain arbitrary and impossible to challenge. In order to establish a more foreseeable, effective and efficient system of precautionary regulation, some lessons can be learned from the US system. This issue is returned to below.

A further problem of the application of the precautionary principle in the EU is the issue of how the Member States are allowed to make use of the principle as a "shield" against harmonisation measures. In harmonised areas, Member States are increasingly making use of the "safeguard clauses" built into harmonising measures, and in non-harmonised areas Member States often successfully base their justifications for derogation from the basic free movement provision in Article $28 \mathrm{EC}$ on a precautionary interpretation of facts under Article $30 \mathrm{EC}$ or the mandatory requirements established in the case law of the ECJ. In these instances, the ECJ has also proven deferential when it comes to challenges of Member State 
Joakim Zander

practice by the Commission. In principle, the burden of proof is on the Member States when they wish to derogate from treaty provisions or harmonising measures. However, since the ECJ rests when scientific uncertainty has been established, the level of proof required by the Member States is very low. This leads to a situation in which it is relatively easy for Member States to maintain or introduce national rules which hinder intra-community trade. As stated above, a continuation of this practice will inevitably lead to a fragmentation of the internal market.

The precautionary principle clearly enjoys the status of a legal principle in the EU. It has been interpreted by the EU courts to allow for regulation under conditions of scientific uncertainty. An in-depth analysis of the relcvant casc law indicates that EU institutions or Member States are not obliged to use the precautionary principle under scientific uncertainty. Rather it is of an enabling character, i.c., once scientific uncertainty is present, the precautionary principle may be invoked. ${ }^{1}$ No qualitative requirements are made on precautionary decisions. Instead, it appcars to establish that, in the absence of scientific certainty, any decision may be justified.

\subsection{THE CASE STUDIES}

The three case studies on the use of the precautionary principle by Sweden, the UK, and the US, in the regulation of pesticides and base stations for mobile telephones illustrate that most states are unlikely to use the principle as a rational instrument for reducing the overall risk level of their society. Instead, precautionary considerations are sometimes used to justify predetermined policy choices which do not always aim toward overall risk reduction, but appear to be motivated by macro-economic interests and public and media pressure.

The states which have been investigated were chosen to give as broad as possiblc a scope of how the precautionary principle is being applied. Sweden and the UK are interesting since they are both Member States of the EU which have a different approach to the precautionary principle, and thus serve to illustrate the conflicts between different approaches within the EU. The US was chosen since it is not a member of the EU, and is often in open opposition to the EU approach to the precautionary principle, as well as the use of it as a legal

I However, in the recent Sweden v Commission, the CFI overturned a decision where it considered the Commission not to have acted precautionary enough when granting an authorisation of the pesticide paraquat. It remains to be seen if this judgment is relevant outside of Directive 91/414/EC on plant protection products, as well as if the approach will be upheld in the future case law of the European Courts. 
principle. However, when one goes beyond the rhetoric, it is clear that the US also allows for precautionary decision-making, and, in some instances, goes further than the EU and its Member States.

The policy areas investigated were chosen because both pesticides and base stations are examples of involuntary, uncertain risks which are subject to regulation in one way or another. Of particular intercst is the fact that precautionary considerations, or the precautionary principle, have been used in fundamentally different ways in relation to similar risks in different policy areas within the same states, as well as in relation to the same policy areas in different states.

With regard to the authorisation of pesticides in the EU, the area is harmonised within the framework of Directive $91 / 414 / \mathrm{EC}$. The Directive does not make any reference to the precautionary principle or precautionary considerations in general. Instcad, a pesticide should be allowed on the market if it is considered that its "normal use" does not produce "harmful" effects on human health or "unacccptable influence" on the environment. The approach to pesticides by individual Member States is of pivotal importance in EU pesticide regulation since the risk assessment as well as the authorisation of pesticides is Member State driven through the use of comitology procedures under Decision 1999/468/EC. Thus, although the area is harmonised at EU level, Member States are highly influential when deciding on whether to allow a specific pesticide or not. If Member States apply the precautionary principle differently in their internal policies towards pesticides, this is likely to create conflicts when evaluating pesticides at EU level.

There is no comprehensive Community policy in place in relation to base stations for mobile telephony, but Council Recommendation 1999/519/EC suggested that Member States apply the internationally agreed upon ICNIRP standard as an appropriate level of protection from low frequency radiation. However, in practice, the area is not harmonised and Member States are free to apply whichever policies they see fit in relation to radiation from mobile phones and base stations.

\subsubsection{Sweden}

In Sweden, the precautionary principle is codified in the Swedish Environmental Code and is supposed to underpin all government regulation in the areas of environment and health. It is not more closely-defined, but can best be described as a broad principle which establishes a wide duty of care, rather than only aiming to allow for regulation in the face of uncertainty. 
Joakim Zander

Connected to the precautionary principle is the substitution principle which entails an individual responsibility to opt always for the use of a less hazardous product when one is available. Due to the strict and mandatory nature of the precautionary principle included in the Swedish Environment Code, on paper, it is one of the most far-reaching versions of the principle in place in any legal system.

When considering the reasoning in the relevant preparatory works, judicial review by courts in administrative cases in Sweden appears to be deeper than in the EU and in many other Europcan countries. Courts are not formally hindered from reviewing the facts of a case under revicw and no "reasonableness" or "manifest error" threshold needs to be met in order for the courts to overturn an administrative decision. However, in practice courts have proven reluctant to review the substance of decisions taken by agencies and the government using their discretion. However, it is possible that the recent system of environmental courts in Sweden may increase the depth of review. The courts incorporate scientific and technical expertise in the tribunals, and there is some indication that they intend, at least in some cases, to make full use of the possibilities of judicial review.

Sweden does not conduct a clear separation of risk assessment and risk management. In cases in which agencies have had decision-making powers delegated to them, the scientific analyses and the management decisions are often taken by the same people. "Common sense" plays a large role in the decision-making. The applicant must, in most cases, carry out the scientific assessment in order to have product authorised.

When issuing a precautionary measure, the initial burden of proof rests with the regulator. The level of proof required is low, and some support exists for the notion that a decision not to allow a product must be based on scientific evidence and may not be theoretical. Once this low level of proof has been met by the regulator, it shifts on to the party facing regulation and is subsequently high. Commentators have held that what is required is to disprove the chain of evidence provided by the regulator, rather than proving that the activity or the product in question is safe. This seems to lead to a situation in which the level of proof required is slightly lower than that required by the ECJ.

According to the Swedish Environmental Code, all measures issued must be "reasonable". The article seems to encompass what the courts previously referred to as the requirement that measures must be "environmentally justifiable", as well as meet some form of proportionality requirement. The term "environmentally justifiable" functioned as a form 
of cost/benefil requirement which aimed to hinder measures to improve the environment for which the benefits were so small that they could not justify the high costs associated with them. It is important to note that this was not developed as a traditional cost-cfficiency requirement, but was, instcad, used to prevent cases of extreme differences between costs and bencfits. The reasonableness requirement too is not based on cost-efficiency reasoning. Instead, it appears to aim to focus on the regulated party and its economic ability to sustain regulation. Thus, economically successful undertakings have been deemed to be ablc to accept stricter regulation than weaker ones.

Swedish policy on environment and health regulation is laid down in 15 broad environmental quality objectives, which have been adopted by the Swedish Parliament. These goals are to be reached within one generation. The environmental quality objectives are, in turn, divided into partial goals, which have been given deadlines for completion. This system provides for a broad, but relatively detailed, system of prioritising risks. The prioritisation is not based on rational concepts such as risk assessment and cost/benefit analysis, but appears to be political in nature.

In the area of pesticide regulation, the version of the precautionary principle oullined in the Environmental Code is used to its full extent. Swedish chemicals policy is highly restrictive, and an environmental policy goal established by the Swedish parliament holds that all man-made substances which may have detrimental effects should be phased out of the natural environment by 2020 . This is a remarkably absolute version of the principle.

The Swedish Chemicals Agency (KcmI) is the agency entrusted with issuing authorisations and detailed rules regarding pesticides. No formal separation of risk assessment and risk management is in effect; instead, decisions are often taken in informal deliberations between the civil servants in the agency.

In its assessments of pesticides, Keml considers the risk of the intrinsic properties of each substance, and not the risk posed by the substance in normal use. This leads to a situation in which a substance with which a risk is associated is not deemed fit for use even if it is abundantly clear that the substance does not pose a risk under normal conditions of use. The strict application of the precautionary principle has caused Sweden significant problems with complying with EU risk assessments, which tend to be based on the normal use of substances. As an example, in one case, the plaintiff argued that it would be unreasonable to have to show that the substance in question (mancozeb) was safe for use at high doses, since 


\section{Joakim Zander}

the normal use of the product would only concern significantly lower doses. Keml and the Swedish courts were unmoved by thesc pleas. They reasoned that it was not sufficient to show that a pesticide was without risk when used under normal circumstances. Instead, each of the substances which are contained in the pesticide must be shown to be risk free. Such reasoning ultimately leads to a situation where only zero-risk products are tolerated.

Furthermore, the substitution principle, in practice, constitutes a particular manifestation of the precautionary principle, since it means that if "safer" pesticides of equal effect as the one in question exist on the market, the pesticide in question should not be allowed. Thus, it establishes comparative assessments, instead of absolute requirements with regard to what level of risk should be tolerated. Such moving targets are difficult to comply with, and may lead to situations of considcrable legal uncertainty.

With regard to cost/benefit balancing in Swedish law; it appears that, when evaluating substances, KemI only considers the risk and not benefits associated with the products in question. This enables it to apply a very restrictive policy towards pesticides. If the benefits of a product are not considered, it is virtually impossible to justify anything but a zero-risk strategy. Thus, the proportionality requirement in Swcdish environmental regulation is reserved for situations in which it is not "environmentally motivated" to prohibit a certain product or activity. The requirements, for this to be the case, are very high.

The area of base stations in Sweden is regulated in a number of different statutes, comprising the Environmental Code, the Radiation Protection Act, and the Planning and Building Act. As was stated above, all areas relating to environmental and health protection in Sweden are covered by the precautionary principle included in the Environmental Code. According to the Radiation Protection Act, the Radiation Protection Agency is responsible for drawing up detailed rules for protection from radiation, and these rules should incorporate precautionary considerations. Finally, the siting of base stations is decided on by local authorities according to the Planning and Building Act.

The Radiation Protection Agency has issued a General Advice which outlines the Swedish position on protection from radiation from base stations. The General Advice is based on the EU Council Recommendation of 1999, which, in turn, incorporates the Gguidelines of the International Commission for Non-Ionising Radiation Protection (ICNIRP). The ICNIRP guidelines are not precautionary in nature, but are based upon the scientifically verifiable thermal effects of radiation. They do not consider scientifically 
uncertain issues such as biological and non-thermal effects of radiation. Thus, the Swedish approach to radiation from base stations cannot be said to be precautionary in nature.

In a communication to local governments, a Swedish agency has unequivocally stated that the precautionary principle should not be applied with regard to base stations at local level. Thus, local govcrnment is prevented from assuming a more precautionary slance than that decided at national level. This approach has been upheld by the courts in the scarce case law existing in the area. To date, the courts have not been inclined to investigate the scientific evidence underlying challenges of the system currently in place. Instead, they have afforded full discretion to the Swedish Radiation Protection Agency in deciding on the appropriate level of protection. Cost/benefit considerations do not play a formal role in the regulation of base stations.

Thus, the non-precautionary approach assumed in relation base stations appears to be the inverse of the precautionary approach assumed in relation to pesticides. The reasons for this may include a long history in Sweden of strict regulation of chemicals, and a possibly exaggerated awareness of the risks of chemicals in the Swedish population. However, it is impossible to overlook the economic implications of the regulation of the two respective policy areas. Sweden has a very small chemical industry and a small agricultural sector which is not highly dependent on pesticides. On the other hand, the Swedish telecoms sector is at the core of Swedish economic growth. Full mobile phone coverage is a highly publicised goal of the Swedish government and Ericsson is a world leader in mobile phone technology and a symbol of Swedish industry in the 21st century. Consequently, it is understandable that the regulation of pesticides is likely to be significantly easier and more susceptible to the acceptance of the public and industry than the regulation of base stations. However, the result of the above is that national economic interests lead to a different approach in relation to comparable risks. This reliance on "the precautionary principle" to justify the regulation of one type of risk but to ignore a comparable one raises several concerns. Among the most serious is the result that the precautionary principle can be used as a general clause to justify any type of regulation that the government sees fit to enact. Connected to this are concerns relating to the effective redress of affected parties, as well as the lack of efficiency in the government's risk agenda. 


\subsubsection{The UK}

In the UK, the precautionary principle is not codified in any general statute like in Sweden. It is only recently that the UK government in policy documents has begun to give importance to the precautionary principle. However, these documents do little to clarify the content and scope of the principle.

The strictly limited review afforded to UK courts in administrative cases means that little guidance can be found in the case law. Some early cases which dealt with precautionary considerations considered that, as far as the principle was applicable in the UK, it would be restricted to interpreting measures laken to comply with EU law. This stance was due to the fact that Article 174 of the EC Treaty was the only legal instrument in which UK courts could find the principle mentioned. However, in more recent cases, the UK government has invoked the precautionary principle, and, when challenged, UK courts have invariably found this practice to be within the government's discretion.

In policy documents, it has been held that, even if the application of the precautionary principle is within the discretion of the government, decisions based on it should be taken following the performance of cost/benefit and risk trade-off analyses. Some support for this can also be found in the case law. Advanced models are suggested for making such comparisons. These include "Willingness to Pay" and "Willingness to Accept" calculations, as well as "Quality Adjusted Life Years". Whether, and, if so, how, the UK Government has made use of these instruments in rclation to the precautionary principle is unclear. The documents in which they are suggested are not binding and no other rules indicate that the performance of a cost/benefit analysis would be a formal requirement. The courts have not tested the application of the principle against any formal requirements. The same is true with regard to public involvement in the decision-making: its role is emphasised in policy documents, but is not made legally-binding.

Following this approach, no general statute obliges the UK government, or the agencies entrusted with regulatory tasks, to act in a precautionary manner in cases of uncertainty in the area of pesticide regulation. However, there is nothing to prevent them from taking precautionary measures when they see fit. In practice, it appears that different decisions may be taken regarding different pesticides with comparable risks. For example, the pesticide Lindane, whose carcinogenous properties are widely accepted as being highly 
uncertain, was subject to precautionary action, whereas paraquat, with its well-documented toxic propertics, was declared safe for use.

The agency responsible for pesticide regulation in the UK is the Pesticide Safety Directorate (PSD), which, in practice, has strong ties with the Department for Environment, Food and Rural Affairs (DEFRA). Scientific advice is usually given by the Advisory Committee on Pesticides, but is not binding on the PSD or the DEFRA. Interestingly, the case law has shown that the PSD can principally control the scope and scientific material to be assessed by the advisory committee. As a result, it cannot be established that a strict institutional separation of risk management and risk assessment is upheld in practice.

Above, it was held that the UK government has emphasised the usefulness and importance of cost/benefit and risk trade-off analyses, as well as the involvement of the general public in the decision-making. However, if these issues, indeed, are considered, this is done in an informal manner. In addition, in the area of pesticide regulation, the UK Government has avoided laying down formal requirements against which its decisions can be checked.

With regard to base stations, the general framework is broadly similar to that in place in Sweden. At national level, the Health Protection Agency (HPA) functions as an independent agency, which does not answer directly to the ministry in the way that the PSD does in the field of pesticide regulation. The HPA issues recommendations with regard to protection from non-ionising radiation. It is assisted in this task by the Advisory Group on Non-Ionising Radiation. However, the most influential document in the area to date is the "Stewart Report", which was drafted by the Expert Group on Mobile Phones. In the Stewart Report, independent experts commissioned by the government recommended that farreaching precautionary measures be issued in relation to base stations. Even though the UK government did not endorse fúlly these recommendations, government policy has proven more open to discussions on the possiblc ncgative health effects of radiation from base stations than the Swedish categorical refusal to categorise the issue as surrounded by uncertainty at all. The recommendations of the ICNIRP are currently the standard applied in relation to protection from non-ionising radiation in the UK, as it is in Sweden.

Furthermore, and also as in Sweden, concrete decisions regarding the actual siting of base stations are taken at local level by local planning boards. However, and unlike the situation in Sweden, it appears that local governments have the possibility of making use of 
Joakim Zander

some degree of independence in relation to the level of protection chosen at local level. Where Swedish planning boards are explicitly bound to respect the national radiation guidelines, the meagre and largely contradictory case law existing in this area in the UK, suggests that local planning boards may issue more precautionary measures than what has been established nationally. It is still unclear exactly what UK local planning boards need to show in order to issue such precautionary measures, but it appears that public opinion plays a an important role in establishing whether base stations should be restricted to local level. In some cascs, it has been emphasised that even public opinion which "has no scientific or logical reason" can function as material considerations for a local planning board when taking a decision on whether to allow a base station. However, no requirements are made on the formal weighing of the costs and benefits or the risk trade-off analyses, and it is unclear what role such considerations play in practice.

\subsubsection{The US}

The US is gencrally viewed as being a staunch opponent of the precautionary principle. The principle lacks a place in US statutes, and, in recent years, increased demands on scientific evidence and the imporlance of cost/benefit analysis have given the impression that precaution is not part of the US regulatory agenda. Some commentators have argued that precaution is not a part of the US mindset, and the New York Times asked itself the question of whether precaution, after all, is not just something for Europeans?

However, in reality, precautionary decision-making has an interesting and developed history in US regulation. Some commentators have even stated that the US Congress has a clear "precautionary preference" when issuing regulation in relation to health and environmental protection. In the 1970s, groundbreaking pieces of environmental legislation like the Clean Air Act were broadly interpreted by activist US courts to entail strongly precautionary elements.

One highly influential aspect of the US system in the field of risk regulation is the comparably extensive review of regulatory measures performed by US courts. In the 1970s, activist U.S. courts went to some lengths to carve out a space for precautionary considerations in U.S. regulation. This never amounted to an effective endorsement of a generally applicable precautionary principle, but judgments such as Ethyl Corp. and Reserve Mining allowed U.S. agencies to act in a precautionary manner without explicit basis in scientific evidence. Even though the "hard look" doctrine developed by the D.C. Circuit 
Court in the 1970s was curtailed by the change in the regulatory agenda brought about by the Reagan administration in the early 1980s, it still continues to influence the scope of the judicial review.

For precautionary measures to be enacted, a threshold finding of "significant risk" must be present. Exactly what is required for this to be the case is unclear, but it appears that mere scientific uncertainty is not sufficient to justify regulation. This means that U.S. courts must analyse the scientific evidence brought before them, in order to establish whether a risk actually exists. Here, the U.S. courts differ in their approach when compared to the other jurisdictions described above, in which courts generally allow for a near total deference on the side of the regulator, and the mere existence of scientific uncertainty is generally sufficient to warrant regulation. However, this does not mean that U.S. courts require scientific ccrtainty for regulation to be legal. Instead, it appears that the approach is more akin to that of the interpretation of the SPS Agreement advanced in WTO dispute settlement. Courts will actively investigate the risk assessment performed by the relevant agencies to discern whether it has been carried out in an objective and rational fashion, or whether other formal errors have been committed. This leads to a situation in which it is, at least, plausible that an affected party could substantively challenge a regulatory measure taken under conditions of uncertainty.

U.S. regulatory measures should be preceded by Regulatory Impact Assessments (RIAs). RIAs include the performance of risk assessment and cost/benefit analysis, but also a statement relating to the need for the proposed action by the agency, as well as an examination of alternative approaches. Risk trade-offs should be considered, and there is a strong impetus for ranking risks in order of priority.

The executive branch of the US government retains important powers of control through the Office of Management and Budget (OMB), which can ask agencies to review assessments with which it does not agree. The powers of the OMB have been increased further with the introduction of the highly criticised Data Quality Act, which allows for the possibilities for citizens to demand the "correction" of data held by government which is not scientifically "sound".

Pesticides regulation is one area of US legislation in which the influence of, if not a coherent precautionary principle, then at least precautionary considerations, in the broad sense, is particularly clear. For decades, the Delaney Clause meant that a zero-risk approach 


\section{Joakim Zander}

was taken towards the residues of carcinogenic properties food. In practice, this meant that a remarkably precautionary approach was introduced in relation to pesticides. Interestingly enough, this approach focused solely on the risks of cancer, other risks, such as toxicity, werc treated in a morc lenient fashion.

Since the Delaney Clause was revoked in the 1990s, the US approach to pesticides regulation has become more nuanced. Cancer risks arc no longer explicitly treated in a more restrictive manner than other risks such as toxicity, for example.

The Federal Insecticide, Fungicide and Rodenticide Act (FIFRA) functions as the legislative framework for pesticide regulation in the U.S. It is, in many ways, similar to Directive $91 / 414$ in place in the EU, in that it places the burden of information squarely on the applicant, and makes explicit use of scientific bodies to examine and advise the bureaucratic body empowered to take decisions. Courts have clarified that the EPA is not bound by the advice issued by scientific bodies.

Under the FIFRA, pesticides with "unreasonable risks" should not be permitted. This means that several competing interests must be considered together when taking decision on authorising or cancelling authorisations under the FIFRA. This includes risks, but also the economic impact of regulation. It has been pointed out that this is a necessary starting point, because, if positive aspects of a product were not considered, there would be nothing to justify anything but a zero-risk approach. It is interesting, here, to compare this with the situation in Sweden, where the precautionary regulation of pesticides is very far-reaching. This is made possible by the fact that, as Swedish officials have stated, no economic considerations are taken into account when formulating decisions in relation to pesticides.

The FIFRA requires a more nuanced decision-making process, because it is a cost/benefit balance that will answer the question of whether a product poses an "unreasonable" risk or not. Furthermore, courts have indicated that they find it within their remit to "second-guess" the balancing performed by the EPA, at least in cases in which they find that cost/benefit analysis is significantly flawed. In Love $v$ Thomas, the court investigated the details of the EPA cost/benefit analysis, before it decided to overturn it. Some cases have indicated that the cost/benefit analysis may be skewed in favour of health protection, at least in cases in which cancer is the suspected risk. In EDF $\vee$ Ruckelshaus, the court stated that the EPA has a "heavy burden" to explain why it allows a pesticide if it has been shown to have carcinogenic properties in animal testing. Finally, in relation to 
cost/benefit balancing, it should be pointed out that, even if the substitution principle is not formally in effect in the U.S., the issue of whether a comparable but less risky pesticide is already on the market should be allowed to influence the outcome of the balancing. Thus, issues comparable to the substitution principle can be considered under the FIFRA. The possibilities for public participation in the regulation of pesticides are limited in the US, just as in the cases discussed above.

In the US, as in other states investigated here, particularly Sweden, a conflict exists bctween the wish to expand mobile phone coverage as quickly as possible, while, at the same time, respecting local planning rules and the concerns of individuals. The U.S. example, however, distinguishes itself, in that a statutory instrument explicitly pre-empts local government from taking a more precautionary stance than that presented by the relevant government body, the Federal Communications Commission (FCC) in the national guidelines. In Sweden, the situation is similar, due to the fact that the Radiation Protection Agency has issued advice, albcit in itself non-binding, advice, which has been upheld consistently in the Swedish courts. In the U.K., it appears that local governments may have a somewhat greater possibility of maintaining more stringent regulation based on public opinion.

The Telecommunications Act of 1996 is the instrument which gave the FCC the task of developing national emissions guidelines for mobile phones. This, the FCC has donc in two Bulletins, also issued in the late 1990s. The content of the guidelines are almost identical to the guidelines issued by ICNIRP, which are in place in Sweden and the U.K. Both the FCC and the ICNIRP guidelines are based solely on scientifically-proven adverse effects in humans.

Interestingly, the FCC has repeatedly stated that it feels uncomfortable with the task of issuing health and safety guidance, since it lacks the appropriate expertise to do so. In practice, it relies heavily on other government agencies when formulating advice in this regard. As in the U.K., an independent report commissioned by a branch of the government (the U.S. Congress and a ministry in the U.K. respectively) has evaluated the current state of the scientific research in the area of non-ionising radiation. Both reports highlighted the uncertainties with regard to radiation from mobile phones. However, the U.S. report stopped short of recommending any precautionary measures, whereas the U.K. equivalent went to 


\section{Joakim Zander}

great lengths to advocate a precautionary approach based on the same set of data. In Sweden, no such independent report has been commissioned.

Even if local governments are prevented by statute from assuming a more precautionary approach than that suggested by the FCC, some cases indicate that courts may permit a relatively far-reaching consideration of aesthetic concerns and the effects of the establishment of base stations on property values by local governments. This could lead to a situation in which an active public opposed to the establishment of base stations could successfully challenge mobile phone providers on such grounds. So far, courts have avoided to rule on whether the sensitive issue of how dwindling property values based on the fear, be it rational or not, of radiation from base stations may be a valid basis upon which to oppose developments. If this is, indeed, deemed to be a valid ground, it opens a significant "back door" for local governments to take precautionary considerations into account when making zoning-decisions. Courts have alrcady stated that the burden of proof is on mobile phone service providers to show the necessity of the establishment of base stations for continuous mobile phone coverage, at least when the establishment of the base station is faced with public opposition.

\subsection{The Different Types of the Precautionary Principle}

In summary, there are at least three different ways in which the precautionary principle is currently applied. First, the principle may be viewed as a fundamental principle which obliges governments to act in a precautionary manner. This is the version which can be found in the Swedish Environmental Code. It is prima facie strict in application and places a low level of proof on the party wishing to invoke the principle. Generally, this version of the principle pre-supposes a deferential approach taken by the relevant courts, and the level of proof needed to be met to challenge precautionary measures is very high.

Second, the precautionary principle can be viewed as enabling governments to act in a precautionary manner. In, for example, the UK system, it is for the government to use its virtually unlimited discretion to issue precautionary measures where it sees fit. The courts, in such systems, are extremely deferential and a successful challenge of a precautionary measure is very difficult. The application of the precautionary principle in the EU to date has, in the main, resembled this version.

Third, the US and the WTO systems are examples of systems in which the precautionary principle can only be applied after procedural steps have been taken. These 
include the establishment of a risk, which does not need to be certain, but must, at least, be feasible, and the balancing of the costs and benefits of regulation. Courts acting within this version will take a "hard look" at the decisions taken to establish that the decision-maker has, indeed, taken the relevant information into account when issuing regulation. If not, the decision can be overturned.

As has been shown in this book, none of the systems described are upheld consistently in practice. In the end, the precautionary principle appears to be applied differently in different situations. In systems in which a procedural framework is lacking, it appears that the precautionary principle may, in some cases, be used to further socioeconomic goals, rather than to aim at rational overall risk reduction. Precautionary measures, in the EU, Sweden and the UK, are not issued on the basis of rational criteria of overall risk prevention and efficiency. There is no obligation to compare similar risks with each other, or to enact effective and efficient regulation. Such systems are open to a number of criticisms. First, by nol subjecting the issuing of precautionary measures to rational criteria such as cost/benefit and risk tradc-off analyses, public money risks being wasted and citizens may not be protected adequately against real risks. Second, decisions taken under conditions of uncertainty are often extremely difficult to challenge effectively in practice before the courts. Thus, the affected parties do not have access to effective redress. The unfortunate result of the above is that the precautionary principle as applied in the EU and the Member States investigated here can be used as a vessel with which to usher through virtually any regulation deemed necessary on subjective grounds.

\subsection{WhICH WAY FORWARD?}

In order to remedy the unsatisfactory situation outlined above, the EU and its Member States should glance across the Atlantic. Even though the US system of risk regulation is far from perfect, it offers a more rational alternative to the lack of a system currently in place in the $\mathrm{EU}$ and some of its Member States. By subjecting the issuing of precautionary measures to strict and objective Regulatory Impact Assessments, a balancing of the pros and cons of regulation can be carried out, and more effective and efficient risk reducing choices can be made.

Choosing the appropriate level of protection is an eminently political choice, which is, and should be, influenced by socictal values and ethics. However, since public funds are limited even when it comes to reducing risks to both the public and the environment, citizens 


\section{Joukim Zamber}

should expect and requre that government pulicies be amed at purchasing the highest level of protection for the money andalable

Ihs can be done by the 1:U and the Member State governments issuing formal. legally-hinding, graddines on bow the precautonary principle should be used. Such gendelines stwald fikus on the mpertance of independent scientific advice showing at least at threshold finding of a plawsblt: link between an activity and a risk. Such a link should not have to be scientifically certain , but need to be assessed in each individual case. Thus, the initial burden of prowl in order to issue precationary measures necessarily rests with the party whing to inveke restrictive measures. As has been detnonstrated above, this is not different from the allocation of the burden of prosel currently in place in all systems investigated here. What is different is that a regulating party should have to show that a risk is plausible by taking the relevant scientific advice into account before the activity is regulated. Consequently, a party wishing to challenge the precautionary measures should not have to "show conclusively" that the risk will not materialise. Such a high level of proof is impossible for the regulated party to meet. Instead, it should be suflicient to show that the risk is not plausible in order for courts to overturn the decision.

Furthermore, before issuing a precautionary measure, the regulating party should be formally bound to consider the costs and benefits associated with regulation. If such a balance is not carried out, it is impussible for the regulator to know if the intended regulation will, indeed, be efficient. Connected to this is the importance of analysing the trade-offs involved in a regulatory measure. By regulating one product, the market may, indeed, be opened up for other products which may pose even greater risks than the regulated product. If this is the case, the proposed regulation is meaningless at best, and may even increase the overall level of risk in a society. Following the outeome of cost/benefit analyses should not be binding for the regulator, but it would be reasonable to require the regulator to state its reasons for choosing to disregard rational criteria when issuing regulation.

Once a choice has been made on which risks to regulate, they should be ranked in order of importance. Such a ranking should include the respective costs and benefits brought about by regulation as well by lack of regulation. The ranking of risks allows the regulator to compare regulatory choices, but it is also a powerful communication tool. By summarising the information available and the regulatory choices decided on, measures can be presented to citizens in a coherent and transparent fashion. This is likely to provide a good incentive for 
the public debate and increased understanding for regulatory choices in the general public. In addition, it would be reasonable for the regulator to provide an explanation if it chooses not to follow the established ranking when targeting risks.

Finally, by creating legally-binding, formal requirements such as the ones briclly outlined above, it becomes possible for parties that are affected by precautionary regulation to foresee the decisions of governments. This creates a necessary minimum of legal certainly in the application of the law in this field. Furthermore, it becomes effectively possible for affected parties to challenge precautionary measures which are not taken in conformity with the requirements.

Good decision-making is decision-making that is based on as complete an understanding of both the facts and the consequences of the proposed decisions as is possible Under conditions of scientific uncertainty, it is clear that a complete understanding of the scientific facts is not possible. However, the scientific facts are only one aspect of the decision. The issues of the efficiency and the effectiveness of the proposed regulation based on different scenarios must still be performed, and are of comparable importance to the science underlying the decision.

In summary, only when all the available information is put on the table can good decisions be taken. In relation to the precautionary principle, fundamental information includes scientific evidence, knowledge of costs and benefits of the regulation in question, and knowledge of the risk trade-offs involved in the regulation in question. Such information should always be gathered and should also be made available to the public in order for the best decisions to be formulated, and to enable the citizens to be informed and be given the opportunity to make their opinions heard with regard to the regulatory choices made.

Furthermore, to act "precautionary" cannot mean that one specific risk is targeted whilc other more hazardous options are left unregulated. Instead, in order to act in a truly precautionary manner, risks need to be considered together, as a whole. A "truly precautionary" decision is one that decreases the overall level of risk in society, not one that targets an individual risk without considering other risks. Thus, in order to act in a "iruly precautionary" manner, it is not sufficient to focus on one single risk, but the full spectrum of risks needs to be considered at every instance when regulation is considered. Risks should be targeted in such a manner that the worst risks are tackled first in the most economically efficient manner. 


\section{Joakim Zander}

Finally, and perhaps most importantly, in a world of globalised markets, individual states are continuously going to be required to justify trade restrictive measures. If individual states are allowed to apply the precautionary principle to justify economic policy choices, it will undermine the system of European and international trade which has become fundamental both to our continuing economic growth and to the world as we know it. Therefore, not only national governments, but also the EU institutions, and the ECJ in particular, as well as the WTO, need to be able to check national regulations against the same formal rules, as outlined above. Failure by Member States to show why regulation is necessary and proportional, as well as effective and efficient, should lead to the measures being revoked.

The precautionary principle does, indeed, have its place in the EU as well as at international level. But it must be a principle which is applied in a coherent, predictable, efficient and effective fashion.

It has been shown above that precautionary measures are issued by responsible governments in certain cases regardless of whether they subscribe to a "precautionary principle" or not. Further codification of the precautionary principle, in the EU as well as internationally and nationally, should focus on the procedural application of the principle as outlined above, rather than on its definition. 


\section{NEDERLANDSE SAMENVATTING}

\section{INLEIDING}

Sinds haar opname in het Verdrag van Maastricht in 1992, en in het bijzonder sinds de voedselschandalen van de laatste jaren van de jaren 1990, wordt het voorzorgsbeginsel gezien als een fundamenteel beginsel voor milicu- en gezondheidsregelgeving in de EU. Zowel met betrekking tot de interne markt alsmede in internationale handelsbetrekkingen, wordt veelvuldig verwezen naar het voorzorgsbcginsel in de EU. In een Europese Unie die zich steeds meer bezighoudt met de negatieve effecten van menselijke ontwikkeling en economische vooruitgang, is een juridisch instrument dat vroegtijdige interventie toestaat gezien als noodzakelijk en redelijk onomstreden.

Dit boek heeft onderzocht of het mogelijk is een definitie van het voorzorgsbeginsel te onderscheiden, evenals of er sprake is van systematische en coherente elementen achter do afgifte van preventieve maatregelen op internationaal, Europees en nationaal niveau. Daarbij is een aantal factoren geïdentificecrd als zijnde instrumenteel voor de uitkomst van preventieve besluitvorming. Deze factoren zijn afzonderlijk bestudeerd in elk hoofdstuk, en ze bestaan onder andere uit de definitie van het voorzorgsbeginsel in clk rechtstelsel en, in het specifiek onderzochte beleidsterrein, de scheiding van risicoanalyse en risicomanagement, de rol van wetenschappelijk beleid, de plaatsing van de bewijslast, de rol van kostenbatenanalyse, risico inruil analyse, en de rangschikking van risico's. Waar het invloedrijk is gebleken voor de toepassing van het voorzorgsbeginsel, is de rol van de samenleving in het besluitvormingsproces ook in rekening genomen.

De staten die zijn opgenomen in de vergelijkende analyse op het nationale niveau zijn voornamelijk gekozen vanwege het feit dat ze in veel opzichten fundamentele verschillen representeren in hun benadering van het voorzorgsbeginsel. Zweden wordt in het algemeen beschouwd als cen sterk voorstander van vroege voorzorgsmaatregelen, in het bijzonder met betrekking tot chemicaliën. In het Verenigd Koninkrijk heeft het voorzorgsbcginsel, aan de andere kant, niet een zodanig prominente rol en is de regelgeving voor chemicaliën veel minder streng dan 
die van Zweden. De Verenigde Staten, ten slotte, heeft zich ontplooid op het internationale toneel als een uitdrukkelijke tegenstander van het voorzorgsbeginscl.

De beleidsterreinen die zijn vergeleken op het nationale niveau, zijn gekozen omdat ze in meerdere gevallen duidelijke verschillen in de toepassing van het voorzorgsbeginsel tonen. Het kan zijn dat staten die op cen stcrke variant van het voorzorgsbeginsel vertrouwen bij het reguleren van pesticiden, dat niet doen op het gebied van straling van zendmasten voor mobiele telefoons. Dit betekent dat een bepaald beleidsgebied onderhevig kan zijn aan strengere regulering dan andere beleidsgebieden, ook al zijn de gezondheidsrisico's vergelijkbaar.

\section{HET VOORZORGSBEGINSEL IN INTERNATIONAAL RECHT}

In internationaal recht is het voorzorgsbeginsel een nog redelijk nieuw en onduidelijk concept. Hoewel de verwijzing naar een "voorzorgsbeginsel" of een "preventieve aanpak" is opgenomen in een aantal, hoofdzakclijk, sectorale internationale overeenkomsten op het gebied van milieu, hebben het Intcrnationaal Gerechtshof en andere internationalc tribunalen bewezen terughoudend te zijn legenover de erkenning van welke juridische effecten dan ook, met uitzondering van specifieke overeenkomsten. Tot op heden is er voornamelijk op gewezen dat het moeilijk was een samenhangende praktijk en opinio juris te onderschciden, welke noodzakelijk zijn voor een concept om de status van internationaal gebruik aan te nemen. Hoewel de juridische implicaties van het voorzorgsbeginsel in internationaal recht niet altijd even solide mogen zijn, was het belang van de integratie van het beginsel in internationale overeenkomsten groot. De definitie van het voorzorgsbcginsel dat is opgenomen in Beginsel 15 van de Rio Verklaring, bijvoorbeeld, is de definitie van het beginsel waarnaar het meest frequent door commentatoren en besluitnemers wordt verwezen.

WTO panels en de Beroepsinstantie hebben steeds gesteld dat het voorzorgsbeginsel zijn weerspiegeling vindt in Artikel 5.7 van de SPS-Overeenkomst, die Leden toestaat beschermende maatregelen uit te vaardigen zonder ze te baseren op risicoanalyses in geval daar onvoldoende wetenschappelijk bewijs voor bestaat. In alle andere gevallen is de voorwaarde in Artikel 5.1 van de SPS-Overeenkomst om maatregelen te baseren op risicoanalyses absoluut.

Desondanks, lijkt het bij het gedetailleerd bestuderen van de panel- en Beroepsinstantierapporten crop dat het bovengenoemde niet alle mogelijkheden tot 
Ien van preventieve maatregelen onder de SPS-Overeenkomst bevat. Artikel jeert slechts als laatste redmiddel voor gevallen waar wetenschappelijk bewijs lledig is dat cen zinvolle risicoanalyse onmogelijk uit te voeren zou zijn. De ;instantie heeft verklaard dat wetenschappelijke adviczen die door een teid worden ondersteund kunnen worden aangevoerd ter rechtvaardiging van ieve maatregelen, mits ze afkomstig zijn van betrouwbare bronnen. De WTOzullen het wetenschappelijk bewijs in casu nauwkeurig bestuderen. De e uitgevoerd door WTO-panels is in feite de nauwgezetste uitgevoerd door crechtelijke instantie van de in dit boek opgenomen rechtstelsels ook.

Zoals in sommige zaken is gedemonstreerd zullen panels bekijken of er nde wetenschappelijk bewijs" is om een handelsbeperkende maatregel van een Idersteunen. Een wetenschappelijk geloofwaardig verband tussen een product letiviteit en het beargumenteerde risico in casu moet worden vastgesteld, zelfs liet wetenschappelijk bewezen kan worden. Een dergelijk verband zal in detail bestudeerd door het WTO-panel.

Als men het bovengestelde in rekening neemt is ruimte voor WTO-leden te $\mathrm{n}$ op een preventieve wijze groter dan in het algemeen wordt aangenomen. Het Jaad mogelijk voor Leden om maatregelen te nemen die zijn gebaseerd op niet sf bewijs en zich nog steeds houden aan WTO-rcgels.

\section{Het Voorzorgsbeginsel in Europees Recht}

assing van het voorzorgsbeginsel in de EU is een zeer complex probleem. Het 1 is, om te beginnen, gecodificeerd in Artikel 174 van het EG-Verdrag. Als daarvan is het een beginsel dat ten grondslag ligt aan elk milieubeleid in de I zijn rechtspraak heeft het Europees Hof van Justitie (EHvJ) zijn ingsgebied uitgebreid tot kwesties van volksgezondheidbescherming. Er is een ed aan voorbeelden van hoe het voorzorgsbeginsel EG recht beïnvloedt. dig gepubliceerde voorbeelden zijn de regelgeving voor genetisch ficeerde organismen (GGO's) en het uitgebreide pakket voor de regulering van the stoffen (REACH). De Europese Commissie heeft in 2000 een mededeling ardigd die ernaar streefde de toepassing van het voorzorgsbeginsel in de EU te eren. Het niet-bindende document stelt echter geen alomvaltend kader voor dat st kan worden bij het beschouwen van het voorzorgsbeginsel. 
Joakim Zander

In zijn jurisprudentie hebben de EU rechtbanken een passicve houding aangenomen ten aanzien van problemen die omgeven zijn van wetenschappelijke onzekerheid. In de meeste gevallen biedt het een schijnbaar onbeperkte handelingsvrijheid aan de EU-instellingen waaraan de taken van regelgeving of uitvoering zijn gegeven. Dienovereenkomstig hebben de rechtbanken een grote discretie toegekend aan Lidstaten in gevallen waar preventieve maatregelen zijn genomen op basis van wetenschappelijke onzckerhcid.

In sommige gevallen hebben het EHvJ en het Gerecht van Eerste Aanleg (GEA) gewezen op het belang van risicoanalyse en kosten-batenanalyse maar stelde geen bindende test vast waartegen dergelijke vereisten getest konden worden. Het GEA heeft daarentegen geoordeeld dat om regelgeving te voorkomen een eiser aan zou moeten tonen dat het risico, dat is gesteld door een Communautair orgaan belast met een regelgevende taak, onwaarschijnlijk zou materialiseren. Door het aantonen van het niet-bestaan van een risico te vereisen heeft het hof de bewijslast onmogelijk groot gemaakt. In een recente zaak heeft het GEO zijn passieve toetsing terzijde gezet en heeft geoordeeld over de gegrondheid van een zaak betreffende het pesticide paraquat. Het is onduidelijk of deze aanpak in de toekomst zal worden gehandhaafd.

Het voorzorgsbeginsel geniet duidelijk de status van een wettelijk beginsel in de EU. De EU-rechtbanken hebben het gë̈nterpreteerd als legitimatie voor het reguleren onder omstandigheden van wetenschappelijke onzekerheid. Een diepgaande analyse van de relevante jurisprudentie toont dat EU-instellingen of Lidstaten niet verplicht zijn hot voorzorgsbeginsel te gebruiken onder omstandigheden van wetenschappelijke onzekerheid. Het is veclecr van ecn autoriserend aard, d.w.z. men kan op het voorzorgsbeginsel een beroep doen als sprake is van wetenschappelijke onzekerheid. Geen kwalitatieve vereisten zijn gesteld aan preventieve besluiten. In tegenstelling, het lijkt er op dat welke beslissing dan ook gerechtvaardigd kan worden in afwezigheid van wetenschappclijke zekerheid.

\section{HET VOORZORGSBEGINSEL IN ZWEDEN}

In Zweden is het voorzorgsbeginsel gecodificeerd in het Zweedse Milieu Wetboek en wordt verondersteld aan de basis te staan van alle gouvernementele regelgeving op het gebied van milieu en volksgezondheid. Het is niet nader gedefinieerd, maar kan het best worden beschreven als een algemeen principe dat een brede zorgplicht vestigt, in 
tegenstelling tot het slechts trachten regelgeving toe te staan in geval van onzekerheid. In samcnhang met het voorzorgsbeginsel, is het substitutiebeginsel, dat een individuele verantwoordelijkheid oplegt altijd het minst gevaarlijkc product te kiezen indien voorhanden. Vanwege het strikte en verplichtende karakter van het voorzorgsbeginsel, zoals het is opgenomen in het Zweedse Milieu Wetbock, is het een van de verregaandste versies van het beginsel in kracht, in welk rechtstclsel dan ook.

De versie van het voorzorgsbeginsel dat van kracht is op het gebied van bestrijdingsmiddelregelgeving, wordt gebruikt in zijn volle omgang. Het Zwcedse chemicaliënbeleid is uiterst restrictief en cen milieubeleiddoelstelling van het Zweedse parlement stelt dat alle kunstmatige stoffen met potentieel schadelijke gevolgen uit de natuur moeten worden verwijderd voor 2020. Dit is een opmerkelijk absolute versie van het beginsel, dat in de praktijk uitgevoerd lijkt te worden door he Zweedse Agentschap voor Chcmicaliën (KemI). Tevens interessant, is dat KemI geen scheiding tussen risicoanalyse en risicomanagement handhaaft en dat het regelgeving niet door kosten laat beïnvloeden.

Het Zweedse Agentschap voor Stralingbescherming heeft een Algemeen Advies uitgevaardigd dat het $Z$ weedse standpunt betreffende straling van zendmasten samenvat. Het Algemene Advies is gebaseerd op een EU-aanbeveling van de Raad van 1999, die, op zijn beurt, de Richtlijnen van de Internationale Commissic voor bescherming tegen niet-ioniserende straling (ICNIRP) omvat. De ICNIRP richtlijnen zijn niet van nature gebaseerd op het voorzorgsbeginsel, maar zijn gebaseerd op wetenschappelijk verifieerbare thermische effecten van straling. Lokale overheden zijn nadrukkelijk verboden om regelgeving uit te vaardigen dat preventiever is dan die in plaats op het nationale niveau. Zo kan de Zweedse aanpak van zendmaststraling niet van nature beschouwd worden als zijnde geïnspireerd op het voorzorgsbeginsel.

\section{HET VerenIGD KoNINKRIJK}

In het Verenigd Koninkrijk is het voorzorgsbeginsel niet vastgelegd in welke algemene wet dan ook zoals dat het geval is in Zweden. Pas recentelijk is de Britse regering in beleidsdocumenten begonnen belang te schenken aan het voorzorgsbeginsel. Vanwege de strenge beperking van herziening van administratieve zaken kan weinig hulp ontleend worden aan jurisprudentie. Een aantal vroege zaken met betrekking tot overwegingen betreffende het voorzorgsbeginsel waren van 


\section{Joakim Zander}

oordeel dat het beginsel, tot zo ver het van toepassing was in het Verenigd Koninkrijk, zich beperkte tot de interpretatie van maatregelen genomen om te voldoen aan EUwetgeving. In meer recente zaken, heeft de Britsc regering zich echter beroepen op het voorzorgsbeginsel en Britse rechters hebben, wanneer betwist, altijd geoordeeld dat deze handelswijze binnen de beslissingsvrijheid van de regering viel. Belcidsdocumenten beklemtonen dat voorzorgsmaatregelen aan een kostenbatcnanalyse en een risico inruil analyse onderworpen dienen te worden.

Het agentschap verantwoordelijk voor bestrijdingsmiddelregelgeving in het Verenigd Koninkrijk is het Pesticide Veiligheidsdirectoraat (Pesticide Safety Directorate, PSD), dat, in de praktijk, sterke banden onderhoudt met het Ministerie voor Milieu-, Voedsel- en Plattelandzaken (Department for Environmenl, Food and Rural Affairs, DEFRA). In haar toepassing lijkt de Britse bestrijdingsmiddelregelgeving gevoeliger voor kosten dan de Zweedse regelgeving ook al zijn er slechts enkele formele eisen vastgesteld. In de praktijk geniet het PSD verregaande discretionaire bevoegdheid bij de afgifte van regelgeving.

Met betrekking tot zendmasten is het algemene kader in de grote lijnen vergelijkbaar met dat in Zweden. Tot op heden is het invloedrijkste rapport op dit gebied het "Stewart Rapport", dat werd opgesteld door de Deskundigengroep voor Mobiele Telefoons (Expert Group on Mobile Phones). In het Stewart Rapport hebben onafhankelijke deskundigen in opdracht van de regering advies gegeven verregaande voorzorgsmaatregelen te nemen met betrekking tot zendmasten. Ook al heeft het Verenigd Koninkrijk deze aanbevelingen niet volledig onderschreven, regeringsbeleid is meer open voor debat gebleken over de potentieel schadelijke gevolgen van straling van zendmasten dan de Zweedse categorische weigering de kwestie te classificeren als zijnde omgeven door onzekerheid. Dit komt ook tot uiting op het lokale niveau, waar de magere en soms tegenstrijdige jurisprudentie stelt dat comités voor ruimtelijke ordening meer preventicve maatregelen zouden kunnen nemen dan nationaal zijn vastgesteld.

\section{HET VOORZORGSBEGINSEL IN DE VS}

De VS wordt algemeen gezien als zijnde een fervent tegenstander van het voorzorgsbeginsel. Het ontbreekt het beginsel aan een plaats in de Amerikaanse statuten en de recente toename van vraag aan wetenschappelijk bcwijs en het belang 
van kosten-batenanalyse geven de indruk dat het nict op de Amerikaanse regelgevingagenda staat. In wcrkelijkheid heeft preventieve besluitvorming een interessante en ontwikkelde geschiedenis in Amerikaanse wetgeving. Sommige commentatoren hebben zelfs gesteld dat het Amerikaanse Congres een duidelijke "voorkeur voor voorzorg" heeft bij het uitvaardigen van regelgeving met betrekking tot volkgezondheid- en milieubescherming. Amerikaanse regelgeving is sterk beïnvloed door het afwegen van kosten on baten van interventie.

De Federale wct op Insecticide, Schimmelbestrijdingsmiddelen, en Ongediertebestrijding (Federal Insecticide, Fungicide and Rodenticide Act, FIFRA) is het wettelijke kader voor de regulering van bestrijdingsmiddelen in de VS. De FIFRA staat pesticiden met een "onredelijk risico" niet toe het en vereist een genuanceerder besluitvormingsproces, omdat het uiteindelijk een kosten-batenanalyse is dat bepaalt of een risico al dan niet cen "onredelijk" risico vormt. Amerikaanse rechters hebben geoordeeld dat het Agentschap voor Milieubescherming (Environmental Protection Agency) een "zware last" heeft bij het verklaren waarom het überhaupt een pesticide toestaat waarvan is aangetoond dat het kankerverwekkende eigenschappen heeft.

De aanbevolen maximale hoeveelheid straling van zendmasten in de VS is vergelijkbaar met aanbevelingen in de EU. De Federale Communicatie Commissie (Federal Communications Commission, FCC) is verantwoordelijk voor het ontwikkelen van beleid ten aanzien van straling van mobiele telefoons. De FCC heeft echter herhaaldelijk gesteld dat het zichzelf nict geschikt vindt om gezondheid- en veiligheidsadviezen te geven, aangezien het daarvoor niet de juiste expertise heeft. In de praktijk vertrouwt het sterk op andere overheidsagentschappen bij het formuleren van aanbevelingen. Net als in het Verenigd Koninkrijk heeft een onafhankelijk rapport in opdracht van de regering gewezen op onzekerheden omtrent straling van zendmasten. Tot op heden zijn dergelijke onzckerheden echter niet opgevat als rechtvaardiging voor een aanpak die meer is geinspireerd door het voorzorgsbeginsel dan in de andere onderzochte landen.

\section{Conclusie}

Dit proefschrift laat zien dat voorzorgsmaatregelen in bepaalde gevallen worden genomen door verantwoordelijke regering, ongeacht of zij het "voorzorgsbeginsel" onderschrijven. In de hier onderzochte landen wordt het voorzorgsbeginsel op ten 
Joakim Zander

minste drie verschillende manieren toegepast. Het beginsel kan ten eerste worden gezien als een fundamenteel principe dat regeringen verplicht te handelen op een wijze die in lijn is met het voorzorgsbeginsel. Dil is de versie die gevonden kan worden in het Zweedse Milicu Wetboek. Het beginsel kan ten tweede worden gezien als een principe dat regeringen tocstaat te handelen in lijn met het voorzorgsbeginsel. In, bijvoorbeeld, het Britse systeem kan de regering haar vrijwel onbeperkte discretionaire bevoegdheid gebruiken om maatregelen te nemen op basis van het voorzorgsbeginsel. Dit is ook hoc het voorzorgsbeginsel hoofdzakelijk wordt toegepast in de EU. Ten derde, zijn de VS en WTO systemen voorbeelden van stelsels waarin het voorzorgsbeginsel slechts kan worden toegepast nadat procedurele stappen zijn genomen. Het is echter ook aangetoond dat in de praktijk geen deze systemen consistent worden toegepast.

Het lijkt vaak erop dat dezelfde staat het voorzorgsbeginsel in verschillende situaties anders toepast. In stelsels waar een procedurecl kader ontbreekt, kan in sommige gevallen het voorzorgsbeginsel worden gebruikt voor socio-economische doeleinden in plaats van het rationeel streven naar een algchele risicovermindering. In de EU, Zweden en het Verenigd Koninkrijk ligt het voorzorgsbeginsel niet aan de basis van rationele criteria voor algehele risicopreventic en efficiëntie. Er is geen verplichting om soortgelijke risico's met elkaar te vergelijken of om doeltreffende en efficiënte regelgeving op te stellen.

In de VS en de WTO, helpen procedurele stappen zoals kosten-batenanalyse en risico inruil analyse bij te dragen aan meer samenhangende aanpak bij het nemen van maatregelen op basis van het voorzorgsbeginsel. Toekomstig werk over het voorzorgsbeginsel moet zich richten op het uitwerken van een procedureel kader van het beginsel, in plaats van zijn definitie. 


\section{TABLE OF CASES}

\section{International Court of Justice and other International Tribunals}

Gabcikovo-Nagymaros Project (Hungry/ Slovakia), Judgment, ICJ Reports 1997, p. 7

Request for an Examination of the Situation in Accordance with Paragraph 63 of the Court's Judgement of 20 December 1974 in the Nuclear Tests (New Zcaland V. France), ICJ Reports 1995, p. 288

The MOX Plant Case (Ireland v U.K.) (Provisional measures), (ITLOS), Order of 3 December 2001

Southern Bluefin Tuna Cases (New Zcaland v Japan; Australia $v$ Japan (Joined Cases)), ITLOS, Order of August 271999

\section{WTO Appellate Body Reports}

Report of the Appellate Body. Japan-Measures Affecting Agricultural Products. WT/DS76/AB/R (Japan Agricultural Products II).

Report of the Appellatc Body. Japan - Measures Affecting the Importation of Apples. WT/DS245/AB/R (Japan-Apples).

Report of the Appellate Body, EC - Sardines. Appellate Body Report, European Communities - Trade Description of Sardines, W'T/DS231/AB/R (EC-Sardines)

Report of the Appellate Body, Australia - Measures Affecting the Importation of Salmon WT/DS18/AB/R (Australia-Salmon).

Report of the Appellate Body, European Communities - Measures Affecting Asbestos and Asbestos-Containing Products. WT/DS135/AB/R (EC-Asbestos).

Report of the Appellate Body. United States -Measure Affecting Imports of Woven Wool Shirts and Blouses From India. WT/DS33/AB/R (US - Shirts and Blouses)

The Report of the Appellate Body, EC Measures Concerning Meat and Meat Products WT/DS26/AB/R (EC-Hormones).

\section{WTO Panel Reports}

Pancl Report, European Communities-Measures Affecting the Approval and Marketing of Biotech Products, WT/DS291/R, WT/DS292/R WT/DS293/R (ECApproval and Marketing of Biotech Products). 
Joakim Zander

Panel Report, EC Measures Concerning Meat and Meat Products (Hormones) (US) WT/DS26/R (Panel Report, EC-Hormones (US)).

Panel Report, EC Measures Concerning Meat and Meat Products (Hormones) (Canada), WT/DS48/R (Panel Report, EC-Hormones (Canada)).

Panel Report, European Communities-Measures Affecting the Approval and Marketing of Biotech Products, WT/DS291/R, WT/DS292/R WT/DS293/R (ECBiotech Products).

Panel Report, Japan - Measures Affecting the Importation of Apples, WT/DS245/R (Panel Report, Japan-Apples)

Panel Report, US-Continued Suspension of Obligations-EC Hormones, WT/DS320/R

\section{European Community}

\section{ECJ}

Case 120/78 Rewe v. Bundesmonopolverwaltung ("Cassis de Dijon") [1979] ECR 649

Case 174/82 Sandoz BV [1983] ECR 2445

Case 227/82 Van Bennekom [1983] ECR 3883

Case 94/83 Heijn [1984] ECR 3263.

Case 97/83 Melkunie [1984] ECR 2367

Case 240-83 Waste Oils [1985] ECR 531

Case 54/85 Mirepoix [1986] ECR 1067

Case 331/88 Fedesa and others [1990] ECR I-4023.

Case C-405/92 Etablissement Armand Mondiet SA v. Amement Ijslais SARL [1993] $\mathrm{I}-6133$.

Case C-320/93 Ortscheit [1994] ECR I-5243

Case C-341/95 Gianni Bettati v. Safety Hi-Tcch [1998] ECR I-4335

Cases C-157/96 The Queen v Ministry of Agriculture, Fisheries and Food, ex parte National Farmers' Union et al. [1998] ECR 1-2211

Case C-180/96 United Kingdom v. Commission [1998] ECR I-2265

Case C-120/97 Upjohn [1999] ECR I-223

Case C-473/98 Kemikalieinspektionen v. Toolex [2000] ECR 1-5681 
Case C-6/99 Association Greenpeace France and Others v. Ministere de'lAgriculture e de la Peche and Others [2000] ECR I-1651

Case C-248/99, France v. Monsanto [2002] ECR I-1

Case 512/99 Germany v. Commission [2003] ECR I-845

Case C-3/00 Denmark v. Commission [2003] ECR I-02643.

Case C-24/00 Commission v. France

Case C-192/01 Commission v. Denmark [2003] ECR I-9693

Case C-236/01 Monsanto Agricoltura Italia and Others [2003] ECR I-8105

C-41/02 Commission v Netherlands [2004] ECR I-11375

Case 132/03 Codacons and Federconsumatori, [2005] ECR 1-4167

Cases C-434/02 Arnold André GmbH \& Co. KG v Landrat des Kresies Herford [2004] ECR I-11825

C-210/03 Swedish Match AB and Swedish Match AB UK Ltd v Secretary of State for Health [2004] ECR I-11893

Joined Cases C-15/06 and C-295/06 European Parliament v Commission, judgment of 1 April 2008, not yet reported

CFI

Case T-120/96 Lilly Industries v Commission [1998] ECR II-2571

Case T-199/96 Laboratoires pharmaceutiques Bergaderm SA and Goupil v Commission [1998] ECR II-2805.

Case T-112/97 Monsanto v Commission.

Case T-13/99 Pfizer Animal Health SA v Council of the European Union [2002] ECR II-03305.

Case T-70/99 Alpharma Inc. v Council of the European Union [2002] ECR II-3495.

Case T-74/00 Artegodan.

Case T-177/02 Malagutti-Vezinhet v Commission [2004] ECR II-827.

Joined Cases T-366/03 and T-235/04 Austria v Austria [2005] ECR II-4005.

Case T-229/04 Sweden v Commission, Judgment of 11 July 2007, not yet reported.

\section{EFTA COUR'T}

Case E-3/00 EFTA Surveillance Authority v Norway [2000-2001] EFTA Court Reports. 


\section{United Kingdom}

Alfred McAlpine Homes (North) L.td. v Secretary of State for the Environment and Another, Queen's Bench Division (Crown's List). 5 April 1993.

Alfred McAlpine Homes (North) L.td. v Secretary of State for the Environment and Another, Court of Appeal (Civil Division), 3 November 1994.

Associated Provincial Picture Houses I.td. 、 Wednesbury Corporation [194X] 1 KB 223.

Gateshead MBC v Secretary of State for the Enviromment I P.L.R., 85. 1994.

Leatch v. Director-Creneral of National Parks \& Wildlife Service and Shoalhaven (ity (ouncil [1993] NSWLEC 191 (23 November 1993) (L and and linvironment court of New South Wales) (No 10376 of 1993 ).

Newport ('BC v Secretary of State for Wales, J.P.L. 377, 1998.

Phillips v First Secretary of State and others, Queens Bench Division (Administrative ('ourt) [2003] EWHC' 2415.

The Queen on the Application of Avac Chemical UK Limited v Secretary of State for Environment. Food and Rural Affairs, Secretary of State for Transport, Local Government and Regions, Food Standards Agency, High Court of Justice, Queen's Bench Division (Administrative Court) 3 December, 2001, 2001 WL 1479891

R. (on the application of S) v Brent L.BC [2002] E.W.C.A Civ 693; [2002] E.L.R 556.

R. v Derbyshire Country Council, ex parte, Queen"s Bench Division (Administrative Court), 6 Oetober 2000 .

R v Environment Agency ex parte Turnbull, Queen's Bench Division (Crown Office List), CO/4848/99, 12 January 2000.

$\mathrm{R}$ v Minister for Agriculture ex parte Inquinosa International, Queen's Bench Division (Crown Office List), 17 January 2000.

R v Ministry of Agriculture, Fisheries and Food ex parte British Agrochemicals Association Ltd., English Court of Appeal (Civil Division), 9 November 2001, [2002] 1 C.M.L.R. 8.

R v Secretary of State for Defence, ex parte Smith (Queens Bench Division) (1996) 2 WLR 305 B 517.

$\mathrm{R}$ v Secretary of State for Trade and Industry ex parte Duddridge and Others, Queen's Bench Division (Crown's office List), The Independent, 4 October 1994.

R. $\vee$ Tandridge D.C and another, ex parte. Al-Fayed, Queen's Bench Division (Crown's Office List) 79 P / CR 227, [1999] JPL. 825, [1999] 1 PL.R 104, The Times 28 January 1999, CO/3665/97, 14 January 1999. 
T-Mobile (UK) Ltd v First Secretary of State, Court of Appeal (Civil Division), [2005] Env. L.R. 18, C2 and C3

Trevett v. Secretary of State for Transport Local Government and the Regions and Others [2002] E.W.H.C. Admin 2696, November 25, 2002.

\section{United States of America}

Associated Fisheries of Maine, Inc. v. Daley, (1st Cir. 1997) 127 F.3d 104, p. 109.

AT\&T Wireless PCS, Inc. v. City Council of Virginia Beach, (4th Cir. 1998) 155 F.3d 423

Baltimore Gas and Electric Co. v Natural Resources Defence Council, 462 U.S. 87 (1983).

Banal v. Frceport-McMoran, Inc. (5th Cir. 1999) 197 F 3d 161.

Industrial Union Department, AFL-CIO v American Petroleum Institute et al. 448 U.S. 607 (1980).

Cellular Phone Task Force et al., v FCC, (2d Cir. 2000) 205 F.3d 82.

Cellular Telephone Co. v The Town Board of Oyster Bay, (2nd Cir 1999) 166 F.3d 490.

Certified Color Manufacturers Association et al. v. David Mathews, Secretary of the Department of HEW et al., (D.C. Cir. 1976) 465 F.2d 528.

Chevron U.S.A. Inc. v Natural Resources Defence Council, 467 U.S. 87 (1984).

Ciba-Geigy Corp. v EPA, (5th Cir. 1989) 874 F.2d 277.

Corrosion Proof Fittings v EPA, (5th Cir. 1991) 247 F.2d 12-1.

Daubert v Merrel Dow Pharmaceuticals, 509 U.S. 579 (1993).

The Dow Chemical Company $v$ William D. Ruckelshaus, Administrator Environmental Protection Agency Defendant-Appellant, (8th Circuit 1973) 477 F2.d 1317.

EDF v EPA, (D.C. Circuit 1976) 548 F.2d 998.

EDF v EPA, (D.C. Circuit 1972) 465 F.2d 528.

EDF v Ruckelshaus, (D.C. Circuit, 1971) 439 F. 2 d 584.

EI DuPont de Nemours and Co. v Train, 541 F.2d 1018 (4th Cir. 1976).

Environmental Defence Fund v EPA, 465 F.2.d 528 (D.C. Cir. 1972). 
Joakim Zander

Ethyl Corp. v EPA, 598 F.22d 91 (D.C. Cir. 1979).

Fletcher v Bealcy 28 Ch.D. 688-700.

FTC v. Standard Oil Co., 449 U.S. 232 (1980).

Gulf South Insulation v Consumer Product Safety Commission, $\left(5^{\text {th }}\right.$ Cir. 1983) 701 F.2d 1137 .

Illinois RSA No. 3, Inc. v County of Peoria, 963 F. Supp. 732, (C.D.Ill. 1997), 745.

Industrial Union Department, AFL-CIO v American Petroleum Institute, 448 U.S. 607 (1980).

Lead Indus. Ass'n, Inc. v EPA, (D.C. Cir., 1976) 647 F.2d 1130.

Lee v Reilly (9th Cir. 1992) 968 F. 2d 985.

Love v Thomas, (9th Cir. 1988) 858 F.2d 1347.

Marsh v Oregon Natural Resources Council 490 U.S. 332 (1989).

Massachusetts v EPA, 127 U.S. 1438 (2007).

Midwater Trawlers Cooperative v Department of Commerce, 282 F.3d 710 (9th Cir. 2002), p. 720.

Motor Vehicle Manufacturers Association v. State Farm Mutual Auto Insurance, Co, 463 U.S. 29 (1983)

National Coalition Against the Misuse of Pesticides et al v EPA, (D.C. Cir. 1989) 867 F.2d 636, p. 644 .

National Mining Association v Babbitt, 172 F.3d 906 (D.C. Cir. 1999).

Natural Resources Defense Council, Inc. V United States Nuclear Regulatory Comm'n, (D.C. Cir. 1976) 547 F.2d 633.

Omnipoint Communications Inc. v The City of White Plains, (2nd Cir. 2005) 430 F.3d.

Petersburg Cellular Partnership v Boards of Supervisors of Nottoway County, 205 F.3d 688 (4th Cir. 2000).

Public Citizen v. Young, (D.C. Cir. 1987) 831 F.2d 1008.

Reserve Mining Co. v EPA, (8th Cir. 1975) 514 F.2d 492.

Sierra Club v Costle, (D.C. Cir. 1981) 657 F.2.d 298.

Sierra Club v. Marita, (7th Cir. 1995) 46 F.3d 606.

Sprint Spectrum L.P. v Mills, (2nd Cir. 2002) 283 F.3d 404. 
Southwestern Bell Mobile Sys. v Todd, (1st Cir. 2001) 244 F.3d 51.

Tennessee Valley Authority (TVA) v Hill, 437 U.S. 153 (1978).

Texas Oil \& Gas Ass'n v EPA, (5th Cir. 1998) 161 F.3d 923

Vermont Yankce Nuclear Power Corp. v Natural Resources Defense Council, 435 U.S. 519 (1978), 547.

\section{Sweden}

Judgment of the Supreme Court in NJA 2004 s. 590.

Judgment of the Supreme Court in NJA 2006 s. 188.

Judgment of the Supreme Administrative Court in case RA 1996 Ref. 51.

Judgment of the Supreme Administrative Court in RA 1998 Ref. 56.

Judgment of the Supreme Administrative Court in RA 1999 Ref. 76.

Judgment of the Supreme Administrative Court in Case nr. 3635-1999 delivered on 14 October 1999 (not reported).

Judgment of the Supreme Administrative Court in Case nr. 3650-1999 delivered on 14 October 1999, summarised in RA 1999 not 217.

Judgment of the Supreme Administrative Court in R $\AA 2001$ Not 6.

Judgment of the Supreme Administrative Court in Case nr. 1163-2001 delivered on 12 July 2001 (not reported in RA).

Judgment of the Supreme Administrative Court in RA 2003 Ref 43.

Judgment of the Supreme Administrativc Court in RÅ 2004 Ref. 14.

Judgment of the Supreme Administrative Court in RA 2005 Ref. 2, 6, 7.

Judgment of the Environmental Court of Appeals of 17 October 2003, case nr. M 1894-03 (MÖD 2003:100).

Judgment of the Environmental Court of Appeal of 9 February 2005 in case nr. M 293-04 (MÖD 2005:9).

Judgment of the Environmental Court of Appeals of 30 March 2005 in case nr. M 9408-03 (not reported in MÖD).

Judgment of the Environmental Court of Appeals of 12 May 2005, case nr. M 322504 (not reported in MÖD). 


\section{Joakim Zander}

Judgment of the Environmental Court of Appeal of 12 October 2005 in case $\mathrm{nr}$. M7485-04 (MÖD 2005:55).

Judgment of he Environmental Court at Växjö Tingsrätt.of 14 February 2002, case $n_{0}$. M 13/99.

Judgment of Östersunds Tingsrätt of 12 January 2005, case no. M 3123-04.

Judgement of Växjö Tingsrätt of 3 October 2005, case no. M 390-05. 


\section{LIST OF SOURCES}

\section{BIBLIOGRAPHY}

\section{A}

Ackerman F., and L. Heinzerling. Priceless: On Knowing the Price of Everything and the Value of Nothing, The New Press, 2004.

Advisory Committee on Pesticides. A Guide to Pesticide Regulation in the UK and the Role of the Advisory Committee on Pesticides, ACP 19 (311/2005), p. 6, 8-15 and 20-22. Available at: http://www.pesticides.gov.uk/acp.asp.

Advisory Committee on Pesticides. Minutes of the 290th Mceting of the Advisory Committee on Pesticides (ACP) on 4th March 2002, 1.5. Available at:

hitp://www.pesticides.gov.uk/acp.asp?id=269.

Applcgate, J.S., Worst Things First: Risk, Information, and Regulatory Structure in Toxic Substances Control, 9 Yale J. on Reg. 277, 1992, 294-295.

Applegate, J.S., A Beginning And Not An End In Itself: The Role Of Risk Assessment In Environmental Decision-Making, 63 U. Cin. L. Rev. 1643, 1994/1995, p. 1651 .

Applegate, J.S., Beyond the Usual Suspects: The Use of Citizens Advisory Boards in Environmental Decision-making, 73 Ind. L.J. 901, 1998, p. 907, 909 and note 31.

Applegate, J.S., The Precautionary Preference: An American Perspective on the Precautionary Principle, Human and Ecological Risk Assessment, Vol. 6, No. 3, p. $420,429$.

Applegate, J.S., The Perils of Unreasonable Risk: Information, Regulatory Policy and Toxic Substances Control, p. 274-277.

Anderson, E., Value in Ethics and Economics, Harvard University Press 1993.

Anderson, F., and M.A. Chirba-Martin, E.D. Elliott, C. Farina, E. Gellhorn, J.D. Graham, C. Boyden Gray, J. Holmstead, R.M. Levin, L. Noah, K. Rhyne, J.B. Wiener. Regulatory Improvement Legislation: Risk Assessment, Cost-Benefit Analysis, and Judicial Review, 11 Duke Environmental Law and Policy Forum 89, 2000 .

Antonopolou, L., and P. van Meurs. The precautionary principle within European Union public health policy; The implementation of the principle under conditions of supranationality and citizenship, Health Policy 66 (2003) p. 185-189.

Arrow, K.I., Know a Hawk from a Handsaw In: Szenberg, M. (ed.), Eminent Economists: Their Life and Philosophies, Cambridge University Press 1992. 
Atik, J., and D.A. Wirth. Science and International Trade - Third Generation Scholarship, 26 B.C Int'1 \& Comp. L. Rev. 171, 2003. Sce also C. R. Kelly, Power, Linkage and Accommodation: The WTO as an International Actor and Its Influence on Other Actors and Regimes, 24 Berkely J. Int'l L. 79, 2006, 110 and note 220.

\section{B}

Babich, A., Too Much Science in Environmental Law, 28 Colum. J. Envl. L., 119, 2003, p. 182-183.

Beck, U., Risk Society: Towards a New Modernity, Sage Publishers, 1992.

Beck, U., World Risk Society. Blackwell Publishers Ltd 1999. P. 75, 88.

Bengtsson, B., Speciell fastighetsrätt, lustus 1999, p. 20.

Bengtsson, B., Miljöbalkens återverkningar, Norstedts 2001. p. 70-71.

Bergkamp, L. Understanding the Precautionary Principle (parts I and II), Env. Liability Vol. 10, 2002, p. 18-30 and 67-82.

Bergkvist, P., PM inför beslut om fortsatt godkännande för EBDC-medel, p. 2.

Bergqvist, U. et al., Exponering för radiofrekventa fält och mobiltelefoni, SSE rapport: 2001:09 (April 2001). p. 32-33.

Bernasconi-Osterwalder, N. et al., Environment and Trade: A Guide to WTO Jurisprudence, Earthscan 2006, p. 149-201, 256-264, 268-278 and 288-291.

Bernstein, P.L., Against the Gods: The remarkable story of risk, John Wiley \& Sons Inc. 1996, p. 11, 97f, 280.

Bisgaard, C., Assessing the Standard of Review for Trade-Restrictive Measures in the Sanitary and Phytosanitary Agreement, In: E. Brown Weiss and J. H. Jackson, Reconciling Environment and Trade, Transnational Publishers, 2001, p. 367.

Blank, M. The Precautionary Principle Must Be Guided by EMF Research, Elcctromagnetic Biology and Medicine, Vol. 25, 2006, p. 203-208.

Bodansky, D., Scientific Uncertainty and the Precautionary Principle, Environment 33, 1991, 4-5.

Bodansky, D., Commentary: The Precautionary Principle, Environment 34, 1992, p. 4-5.

Bohanes, J., Risk Regulation in WTO Law: A Procedure-based Approach to the Precautionary Principlc, 40 Colum. J. Transnat. L. 323, 2001-2002, p. 341, 338-339 and 345-346.

Breyer, S., Breaking the Vicious Circle: Towards Effective Risk Regulation, Harvard University Press 1993. p. 11-12, 21, 50-51, Table 4. 
Brickman, R., and S. Jasanoff, T. Ilgen. Controlling Chemicals: The Politics of Regulation in Europe and the United States, Comcll University Press, 1985, 174-180.

Burgess, A., Cellular Phones, Public Fears, And a Culture of Precaution, Cambridge University Press 2004, p. 178-180.

Button, C., The Power to Protect: Trade, health and uncertainty in the WTO, Hart 2004, p. 9-43, 114, 120-122, 163-191 and Chapters 5-7.

\section{$\mathbf{C}$}

Cameron D., and J. Abouchar. The Status of the Precautionary Principle in International Law, In D. Freestone and E. Hey (eds), The Precautionary Principle in International Law: The Challenge of Implementation, Kluwer Law International 1996, p. 29.

Cameron, J, The Precautionary Principle in International Law, in: Reinterpreting the Precautionary Principle, Cameron May, 2001. p. 129.

Cane, P., Administrative Law, Oxford University Press, 2004, $250 \mathrm{f}$.

Carson, R., Silent Spring, 104th edition, Marncr Books, 2002.

Cecot, C. and R. Hahn, A. Renda, L. Schrefler. An Evaluation of the Quality of Impact Assessment in the European Union with Lessons for the U.S. and the EU, AEI-Brookings Joint Center for Regulatory Studies, Working Paper, Dccember 2007, $11-12$.

Chittenden, F., and T. Ambler, D. Xiao. Impact Assessment in the EU, in: S. Weatherill, Better Regulation, Hart Publishing 2007, p. 271-286.

Christoforou, T. Science, Law and Precaution in Dispute Resolutions on Health and Environmental Protection: What Role for Scientific Experts?, in J. Bourrinet and S. Maljean-Dubois, Le commerce international des organismes génétiquement modifies, Aix-Marseilles/Paris 2002, p. 217-219 and 232.

Coggon, D., The Precautionary Principle and Pesticide Regulation, Chairman's Paper for ACP Open Meeting 2001. Available at: www.pesticides.gov.uk/acp.asp?id=490.

Covello, V.T., Risk Communication, in: P. Calow, Handbook of Environmental Risk Assessment and Management, p. 520.

Cranor, C.F., Asymmetric Information, the Precautionary Principle, and Burdens of Proof, in: C. Raffensperger and J. Tickner (eds.), Protecting Public Health and the Environment: Implementing the Precautionary Principle, pp. 74-99.

Croley P., and J.H. Jackson. WTO Dispute Procedures, Standard of Review and Deference to National Governments, 90 AM. J. Int'l L. 193, p. 211.

Croley, S., White House Review of Agency Rulemaking: An Empirical Investigation, 70 U. Chi. L. Rev. 821, 2003, 882. 
Damon, W.A., The alkali act: Its administration and relation to chemical industry, Joumal of the Society of Chemical Industry, Volume 54, Issue 50, p. 1070-1075. Published online May 292007.

Danish Environmental Assessment Institute, Getting Proportions Right: How far should the EU impact assessments go?, Environmental Assessment Institute, 2006

De Sadeleer, N., Environmental Principles: From Political Slogans to Legal Rules, Oxford University Press, 2002, p. 237.

De Sadeleer, N., "Procedures for derogations from the principle of approximation of laws under article 95 EC" (2003) 40 CMLRev 889. p. 890.

De Sadeleer, N., The Precautionary Principle in European Community Hcalth and Environmental Law: Sword or Shicld in the Nordic Countries?, Vol. 12 ELJ No. 2, 2006, p. 12-15, 20, 26-41, 139-172.

Dc Sadeleer, N., Implementing the Precautionary Principle: Approaches from the Nordic Countries, the EU and the USA, Earthscan 2007, p. 10-59, 295-313.

Department for Environment: Food and Rural Affairs UK. News Release, April 19, 2002. Available at: hitp://www.defra.gov.uk/news/2002/020419a.htm.

Department for Environment, Food and Rural Affairs UK. Figure 2.1. Available at: http://www.defra.gov.uk/environment/risk/eramguide/03.htm.

Department for Environment, Food and Rural Affairs UK. Guidelines for Environmental Risk Assessment and Management and A Guide to Risk Asscssment and Risk Management for Environmental Protection. Available at:

http://www.defra.gov.uk/environment/risk/cramguide/

Dinham, B., Why Paraquat Should Be Banned. Outlook on Pest Management, December 2004. p. 269.

Douma, W., The Precautionary Principle; Its Application in International, European and Dutch Law. Proefshchrift Rijksuniversiteit Groningen 6 Jan. 2003, p. 77-84, 172, 191-254 and 258-259.

Dunkelberger, E., and R.A. Merrill. The Delaney Paradox Re-examined: Regulating Pesticides in Processed Foods, 48 Food \& Drug L. J., 41 1, 1993.

Duriodé, B., The True Cost of Precautionary Chemicals Regulation, Risk Analysis. Vo. 23. No. 2, 2003. p. 395.

Duriodé, B., Plastic Panics: European risk regulation in the aftermath of BSE, in: J. Morris (ed), Rethinking Risk and the Precautionary Principle, ButterworthHeinemann, 2000, pp. 140-167.

Dworkin, R., A Matter of Principle, Harvard University Press 1985, p. 43-46. 
Ehlerman, C.-D., "The Internal Market Following the Single European Act" (1987) 24 CMLRev 9.

Ehrlich P. R., and A. Ehrlich, The End of Affluence: A blueprint for your future, Ballantine Books, 1974.

Ellis, E., (ed) The Principle of Proportionality in the Laws of Europe, Oxford University Press 1999.

The Environmental Protection Agency, RCRA Public Participation Policy, 1981.

The Environmental Protection Agency, Unfinished Business: A Comparative Assessment of Environmental Problems, February 1987.

The Environmental Protection Agency, Reducing Risk: Setting Priorities and Strategies for Environmental Protection, September 1990.

The Environmental Protection Agency, Public Involvement Policy of the Environmental Protection Agency, May 2003. p. 1 and Appendix 1. Available at: hitp://www.epa.gov/publicinvolvementpdf/policy2003.pdf.

The Environmental Protection Agency, An Evaluation of EPA Risk Assessment Principles and Practices, Staff Paper Prepared for the U.S. Environmental Protection Agency by members of the Risk Assessment Task Force, March 2004, available at: http://www.epa.gov/osa/pdfs/ratf-final.pdf.

The Environmental Protection Agency, Changes Needed to Improve Public Confidence in EPA's Implementation of the Food Quality Protection Act, Report No. 2006-P-00003, 19 October 2005, p. 5-6.

Eriksson, M. Band. Placera masten rätt: Miljö och naturskyddskrav på 3Gutbyggnaden, Svenska Naturskyddsföreningen Rapport, (Svenska Natuskyddsföreningen 2003), p. 10.

The European Environment Agency. Late Lessons From Early Warnings: The precautionary principle 1896-2000, Environmental issue Report No. 22, 2002. Available at: hitp://reports.eea.curopa.cu/envirommental issue report $200122 / \mathrm{en}$.

$\mathbf{F}$

Fidler, D.P., International Law and Public Health, Transnational Publishers Inc. 2000

Finkel, A. M., and D. Golding. Worst Things First? The Debate over Risk-Based National Environmental Priorities, Resources for the Future, 1994

Fischoff, B. Risk Perception and Communication Unplugged: Twenty Years of Process, in: R. Löfstedt and L. Frewer, The Earthscan Reader in Risk and Modern Society, 133-145. 


\section{Joakim Zander}

Fisher, E., Risk Regulation and Administrative Constitutionalism, Hart Publishing 2007, p. 212, 218-243.

Fisher, E., "Is the Precautionary Principle Justiciable?" in Journal of Environmental Law 13(3), 2001, p. 315-334.

Fisher, E., The Rise of the Risk Commonwealth and the Challenge for Administrative Law, Public Law 2003, p. 7, 455-478.

Fisher, E., et al., Implementing the Precautionary Principle, Edward Elgar Publishing 2006; A. Trouwborst, The Precautionary Principle in General International Law: Combating the Babylonian Confusion, 16 Review of European Community and International Environmental Law (RECIEL), nr. 2, 2007, pp. 185-195.

Flick, C., The Movement for Smoke Abatement in 19th-Century Britain, Technology and Culture, Vol. 21, No. 1, p. 29-50.

Ford, R., Planning For a New Telecommunications Network in the U.K., J.P.L. 2001, September, 1035.

Frecstone, D., and E. Hey (eds), The Precautionary Principle in International Law: The Challenge of Implementation, Kluwer Law International 1996.

Funtowicz, S.O., and J.R. Ravetz. Uncertainty and Quality in Science for Policy. Kluwer 1990.

Funtowicz, S.O. and J.R. Ravelz. Science fort he Post-Normal Age, Futures, Vol. 25, Issuc 2, 1993, p. 749-752.

\section{G}

Geiser, K., Establish a General Duty of Precaution in Environmental Protection Policies in the United States: A Proposal, in: C. Raffensperger and J. Tickner (eds), Protecting Public Health and the Environment: Implementing the Precautionary Principle, Island Press 1999, xxi and xxiv.

Gerber, B.M., Case Comment: City of Rancho Palos Verdes, California v. Abrams, 30 Harv. Envtl. L. Rev. 295, 2006, p. 302.

Gocha, N. Rohm and Haas Comments on DeZäta Granulat Registration Withdrawal by KemI, 18 January 1995.

Goldstein, B.D., The Interface Between Science and Law, 14 Colum. J. Envtl. L., 343, 1989 , p. 355.

Goldstein, B. D. and R.S. Carruth. Science in the Regulatory Process: Implications of the Precautionary Principle for Environmental Regulation in the United States: Examples from the Control of Hazardous Air Pollutants in the 1990 Clean Air Act Amendments, 66 Law \& Contemp. Prob. 247, 2003 
Graf, M.W. Regulating Pesticide Pollution in California Under the 1986 Safe Drinking Water and Toxic Exposure Act (Proposition 65), 28 Ecology L.Q. 663, 2001 , p. 687,694 and note 100 .

Graham, J. D. Legislative Approaches to Achieving More Protection Against Risk at Less Cost, U Chi L F 13, 1997. p. 7, 20-22, and 49-57.

Graham, J. D. The Perils of the Precautionary Principle: Lessons from the American and European Experience, Spcech before the Heritage Foundation, Washington D.C., October 20, 2003. Available at:

http:/www. whitehouse.gov/OMB/inforeg/speeches/031020graham.pdf.

Graham, J.D. The Evolving Regulatory Role of the U.S. Office of Management and Budget, Review of Environmental Economics and Policy, Vol. 1, Issue 2, 2007, 171 191.

Graham, J.D. and J.K. Hartwell. The risk management approach, in: J. D. Graham and J. K. Hartwell (eds.), The Greening of Industry, Harvard University Press, 1997, p. 12.

Graham, J.D., and S. Hsia. Europe's Precautionary Principle: Promise and Pitfalls, Journal of Risk Research 5:4, 2002, 371-390.

Graham, J.D., and J.B. Wiener. Risk versus Risk: Tradeoffs in Prolecting Health and the Environment, Harvard University Press 1995. p. 23 and 25.

Grando, M. T. Allocating the Burden of Proof in WTO Disputes: A Critical Analysis, Journal of International Economic Law Vol. 9, Edition 3, 2006, p. 615-658.

Grasso, L. Cellular Telephones and the Potential Hazards of RF Radiation: Responses to the Fear and Controversy, 3 Va. J.L. \& Tech. 2, 1998.

Grimeaud, D. Hoofdstuk II. The Precautionary Principle in International Environmental and Trade Law. in: Faure, M. and Vos E. (eds), Juridische afbakening van het voorzorgbeginsel: mogelijkheden en grenzen, Achtergrondstudie voor de Nederlandse Gezondheidsraad, No. A03/03 2003.

Gustin, T. L. The Perpetual Growth and Controversy of the Cellular Superhighway: Cellular Tower Siting and the Telecommunications Act of 1969, $23 \mathrm{Wm}$. Mitchell L. Rev. 1001, 1997, p. 1004, 1106-1007.

\section{H}

Hafner, K. First Come Cellphone Towers, Then the Babel, NYT, Late Edition-Final, Scction 1, Page 1, Column 3, May 12005.

Hahn R.W. and J.A. Hird. The Costs and Benefits of Regulation: Revicw and Synthesis, 8 Yale J. on Reg. 233, 1991. p. 259.

Hahn, R. W. and C. R. Sunstein, A New Executive Order for Improving Federal Regulation? Deeper and Wider Cost-Benefit Analysis, Chicago Working Paper in 


\section{Joakim Zander}

Law \& Economics, No. 150, 04/2002, p. 1. Available at: http://www.law.uchicago.edu/Lawecon/wpl-50.himl.

Haigh, N. The Introduction of the Precautionary Principle into the UK, in $T$. O'Riordan and J. Cameron (eds.), Interpreting the Precautionary Principle, Earthscan, 1994. p. 240 and $247-251$.

Hajer, M. Environmental Discourse, Clarendon Press, 1995.

Hammitt, J. K. Improving Comparative Risk Analysis, 8 Duke Envtl. L. \& Pol'y F, 81.

Hart, H.L.A. The Concept of Law, Oxford Clarendon Press, 1961.

Health Protection Agency. AGNIR reports. Available at: http://www.hpa.org.uk/radiation/advisory groups/agnir/.

Heinzerling, L. Regulatory Costs of Mythic Proportions. Yale Law Journal, Vol. 107 1981. p. 2069.

Hilson, C. Planning Law and Public Perceptions of Risk: Evidence of Concern or Concern Based on Evidence, J.P.L, Dec. 2004, 1641.

HM Treasury. The Green Book, Appraisal and Evaluation in Central Government, 2003. Available at: htlp://www.hmtreasury.gov.uk/media/785/27/Green Book_03.pdf.

HM Treasury. Managing Risks to the Public: Appraisal Guidance, 2005. p. 21-26, 2829, and 34-35. Available at:

htıp:/www.hm-treasury.gov.uk/media/8AB/54/Managing risks to the public.pdf.

House of Commons, Science and Technology Committee Publications, Third Report, printed on 2 September 1999, Annex 2. Available at: http:/www.parliament thestationery-office.co.uk/pa/cml $99899 / \mathrm{cmselect} / \mathrm{cmsctech} / 489 / 48902 \mathrm{htm}$.

House of Commons Select Committee on Science and Technology, Scientific Advice, Risk and Evidence Based Policy Making, $7^{\text {th }}$ Report of Session 2005-2006, Vol. I, Authority of the House of Commons, 2006, para. 82-83 and 166. Available at: http://www.publications.parliamont.uk/pa/cin200506/cmselect/cmsctech/900/900i.pdf.

House of Lords Select Committee on Economic Affairs. Select Committee on Economic Affairs, Government Policy on the Management of Risk, $5^{\text {th }}$ Report of Session 2005-2006, Vol. I and II: Minutes of Evidence, Authority of the House of Lords, 2006, para. 73 and 217-218. Available at: hltp://www.publications.parliament.uk/pa/ld200506/ldsclect/ldeconal/183/183ii.pdf.

Howse, R. Democracy, Science, and Free Trade: Risk Regulation on Trial at the World Trade Organization, 98 Mich. L. Rev. 2329, 2000, p. 2333-2338. 
Independent Expert Group on Mobile Phones. Homepage. Available at: htp://www.icgmp.org.uk.

Independent Expert Group on Mobile Phones. Mobile Phones and Health, 11 May 2000, 1.30-1.48. Available at: htlp://www.iegnmp.org.uk/report/text.him.

International Commission on Non-Ionizing Radiation Protection, Guidelines for Limiting Exposure to Time-Varying Electric, Magnetic, and Electromagnetic Fields (up to $300 \mathrm{GHZ)}$ ). Health Physics. Vol 74. No. 4, 1998, p. 494-522.

International Program on Chemical Safety (INCHEM) Poison Information Monograph (PIM) Nr. 399. Available at:

http://www.inchem.org/documents/pims/chemical/pim399.h1m;

$\mathbf{J}$

Jaeger, C. C. and O. Renn, E. A. Rosa and T. Webler, Risk, Uncertainty and Rational Action, Earthscan, 2001, p. 17, 213-221.

Jans, J. Proportionality Revisited. Legal Issues of Economic Integration. Vol. 27. Issue 3, 2000. pp. 239-265.

Jasanoff, S. The Fifth Branch: Science Advisors as Policymakers, Harvard University Press 1990. p.12-15, and 51.

Jasanoff, S. Science at the Bar. Harvard University Press 1995. p. 13 and

Johnston, B. L. Environmental Policy and Public Health, CRC Press, 2007, 262-265.

Johnston, J. C. A Game Theoretic Analysis of Alternative Institutions for Regulatory Cost-Benefit Analysis, University of Pcnnsylvania Law Review Vol. 150: 5 2002, p. 1343-1411.

Johnston, J. C. Paradoxes of the Safe Society: A Rational Actor Approach to the Reconceptualization of Risk and the Reformation of Risk Regulation, University of Pennsylvania Law Review Vol. 151: 747 2003, p. 747-784.

Jolly Green Justices, Editorial, Wall St. J., April 3, 2007, at A14.

Jordan, A. The Precautionary Principle in the European Union, in: J. Cameron et al, Reinterpreting the Precautionary Principle, Cameron May, 2001.

Jowell, J. "Of Vires and Vacuums: The Constitutional Context of Judicial Review", in: C. Forsyth (ed), Judicial Review and the Constitution, Hart Publishing 2000, pp. 329-334.

\section{$\mathbf{K}$}

Kagan, E. Presidential Administration, 114 Harv. L. Rev., 2245, 2001. p. 2247. 
Kahneman D. and A. Tversky, Prospect Theory: An Analysis of Decision under Risk. Econometrica, Vol. 47, Number 2, 1979.

Kannan, P. M. The Precautionary Principle: More than a Cameo Appearance in United States Environmental Law, 31 Wm. \& Mary Envtl. L \& Pol'y Rev. 409, 2007, p. $438-440,456$.

Karlsson, M. The Precautionary Principle, Swedish Chemicals Policy and Sustainable Development, Journal of Risk Research Vol. 9, No. 4, 2006, 341-348, 352-353, 661.

KEMI Swedish Chemicals Agency. Account of the compositions and tasks of the Toxicological Council. Available at: http:/www.kcmi.se/templates/Page 2988.aspx.

KEMI Swedish Chemicals Agency. Principles for Identifying Unacceptable Pesticides, KemI Report, No. 4/ 92, (National Swedish Chemical Inspectorate, 1992).

KEMI Swedish Chemicals Agency. List of Current Board Members. Available at: http:/kemi.se/templates/Pagc 3137.aspx.

KEMI Swedish Chemicals Agency. Statement of 16 September 2003. Available at: http:/www.kemi.sc/templates/News 3090.aspx.

Kent, C. W. and F. W. Allen. An Overview of Risk-Based Priority Setting at EPA, in: A. M. Finkel and D. Golding, Worst Things First? The Debate Over Risk-Based National Environmental Priorities. p. 51.

Keynes, J. M. The General Theory of Employment, The Quarterly Journal of Economics, Vol. 51, p. 213.

King, J. Application of Risk Assessment in Policy and legislation in the European Union and in the United Kingdom,in: P. Calow., Handbook of Environmental Risk Assessment and Management. Blackwell Science 1998. p. $249 \mathrm{f}$.

Kiss, A. C. and D. Shelton. International Environmental Law, Transnational Publishers 1994.

Knight, F. Risk, Uncertainty and Profit. Houghton Mifflin Co. 1933.

Krämer, L. EC Environmental Law, Sweet and Maxwell 2000, p. 75f, 78, 98 and 103.

Kuhn, T. The Structure of Scientific Revolutions, University of Chicago Press 1962.

\section{L}

Ladeur, K.-H. The Introduction of the Precautionary Principle into EU Law: A Pymhic Victory for Environmental and Public Health Law? Decision-making Under Conditions of Complexity in Multi-level Political Systems, 40 CMLR 6, 2003, 1455.

Lehrberg, B. Praktisk juridisk metod. Iustus Förlag, 2001. 
ons, J. and K. Schrader-Frechette, C. Cranor. The Precautionary Principle: atific Uncertainty and Type I and Type II Errors. Foundations of Science Issue 2, $\therefore$ p. 211.

blom, P. H. Miljöprocess Del II, Iustus 2002, p. 493-499.

venberg, S. Precaution is for Europeans, New York Times, May 18, 2003, on 4, p. 14.

tedt, R. Risk Communication and Management in the Twenty-First Century, national Public Management Journal, Vol. 7, Issue 3, 2004, pp. 335-346.

tedt, R. E. The Changing Character of Regulation: A Comparison of Europe and Jnited States, Risk Analysis.

tedt, R. The Swing of the Regulatory Pendulum in Europe: From Precautionary siple to (Regulatory) Impact Analysis, Journal of Risk and Uncertainty, Vol. 28, :2, 2004, pp. 237-260.

tedt, R. Risk Management in Post-Trust Societies, Palgrave Macmillan, 2005, p. .

Ledt, R. The Plateau-ing of the European Better Regulation Agenda: An analysis ctivities Carried out by the Barroso Commission, Journal of Risk Research, Vol. ssue 4, 2007, p. 423-447.

Ledt R. and Vogel, D. The Changing Character of Consumer and Environmental lation: A comparison of Europe and the United States, Risk Analysis, Vol. 21, 3, 2001, p. 399-405.

e Martin, S. Communication Tower Sitings: the Telecommunications Act of and the Battle for Community Control, 12 B.T.L.J. 1, 1997, Available at: /www.law.berkeley.edu/journals/bulj/articles/voll2/index.him.

Jormack, G. Scandinavian Realism, The Juridical Review, 1970, p. 33-55.

sley, J. Paraquat - Syngenta's controversial herbicide, SSNC Report 2002. p. 10ıvailable at hilp://www.snf.se/pdl/rap-inter-syngenta-paraquat.pdl

Ine, G. The Precautionary Principle and Regulatory Impact Analysis. Paper :nted at the International Seminar on Regulatory Impact Analysis. Rome 15 June ,p. 9 .

:hant, G. E. and K.L. Mossman. Arbitrary and Capricious: The Precautionary :iple in the European Union Courts, American Enterprise Institute Press, 2004. lable at: http://www.policynetwork.net/uploaded/pdf/Arbitrary-web.pdf.

, S. The Precautionary Principle in the Law of the Sea: Modern Decision Making sernational Law, Martinus Nijhoff Publishers, 2003 
McElveen, J.C. and C. Amatea. Risk Symposium: Legislating Risk Assessment, 63 U. Cin. L. Rev. 1553, p. 1568.

McNelis, N. EU Communication on the Precautionary Principle, Journal of Intemational Economic Law (2000) p. 550.

Meadows, D. ct al., The Limits to Growth: A report for the Club of Rome's project on the predicament of mankind, Universe Books, 1974.

Meddelandcblad från Socialstyrclsen till kommunala miljö- och hälsoskyddsnämnder, länsstyrelser och andra berörda myndigheter, June 2005. Available at:

http:/www.ssi.se/ickejoniserande stralning/Magnetfaelt/Forsiktighctspincip.html.

Meuwese, A. C. M. Inter-institutionalising EU Impact Assessment, in S. Weatherill, Better Regulation, Hart Publishing 2007, p. 287-309.

Michanek, G. Att väga säkert och vikten av att säkra. In: E.M. Bassc, ct al. (eds.), Fågelperspektiv på rältsordningen: Vänbok till Staffan Westerlund, lustus Förlag 2002, p. 74-76 and note 23.

Michanek, G. Chapter 7: Sweden, in N. de Sadeleer, Implementing the Precautionary Principle: Approaches form the Nordic Countries, EU and USA, Earthscan 2007, p. 121-123 and 128-130, 133-134.

Miles, T. J. and C. R. Sunstein. The Real World of Arbitrariness Review, John M. Olin Law \& Economics Working Paper No. 368, November 2007.

Miljömål: Environmental Objectives Portal. Summary of environmental policy goals. Available at: http:/www.miljomal.nu/index.php

Miljøstyrelsen, Vedrørende Dithane DG, 9 June 1993 (Available with author)

Miller, M. L. Esq., Pesticides, In: T.F.P. Sullivan, Environmental Law Handbook, Government Institutes, 2003, 652-653 and 655.

Montemarano, A. The Delaney Paradox Resurfaces: Regulating Pesticides as Food Additives Under Federal Law, 25 Rutgers L.J. 433, 1993/1994.

Mooney, C. The Republican War on Science, Basic Books, 2005, p.102-120.

Morris, J. Rethinking Risk and the Precautionary Principle, Butterworth-Heinemann, 2000.

Moss, D. A. When All Else Fails: Government as the Ultimate Risk Manager, Harvard University Press 2002 p. $22 \mathrm{f}$.

\section{$\mathbf{N}$}

Nash, J. R. Standing and the Precautionary Principle, 108 Colum. L. Rev. 494, 2008.

National Radiological Protection Board. Report by the Board of NRPB, Mobile Phones and Health, Doc. of the NRPB Vol. 15, Issue 5, 2004. 
National Research Council, Risk Assessment in the Federal Government: Managing the Process, National Academy Press, 1983, p. 17-20.

The New Oxford Dictionary, Oxford University Press 1998.

Newsweek. The Battle Over Caution, Newsweek, December 13, 2003. Available at: http://www.newsweek.com/id/60863.

Nilsson, A. Att byta ut kemikalicr, Nerenius och Santerus 1997. p. 137, 258, 271, 272 and 302 .

Nilsson, R. Science and Politics in the Regulation of Chemicals in Sweden, In: M. Gough (ed.), Politicizing Science: The Alchemy of Policymaking, Hoover Institutions Press, 2003, p. 227-259.

\section{$\mathbf{O}$}

O'Brien, M. Making Better Environmental Decisions: An alternative to Risk Assessment, MIT Press, 2000.

O'Riordan, C. and A. Jordan. The History and Contemporary Significance of the Precautionary Principle, in Interpreting the Precautionary Principlc, Earthscan 1994, p. 23.

Organisation for Economic Co-operation and Devclopment. Council Recommendation $\mathrm{C}(90) 164$ on Integrated Pollution Prevention and Control, 31 January 1991.

\section{$\mathbf{P}$}

Pak, M. Note \& Comment: An IQ Test for Federal Agencies? Judicial Review of the Information and Quality Act Under the APA, 80 Wash. L. Rev. 731, 2005, 743-751.

Palmeter, D. The WTO Standard of Review in Health and Safety, in: G. A. Bermann and P. C. Mavroidis, Trade and Human Health and Safety, Cambridge University Press, 2006, p. 224-235.

Pauwelyn, J. The WTO Agreement on Sanitary and Phytosanitary (SPS) Measures As Applied in the First Three SPS Disputes, JIEL Vol. 2(4), 641, 1999, p. 654.

Pauwelyn, J. The Use of Experts in WTO Dispute Settlement, ICLQ, Vol. 51, 325, 2002, p. 328-329, 360 and 363-364.

Pauwelyn, J. Expert Advice in WTO Dispute Settlement, in G. A. Bermann and P. C. Mavroidis, Trade and Human Health and Safety, Cambridge University Press, 2006, pp. 235-256.

Peng, J. et. al., The Herbicide Paraquat Induces Dopaminergic Nigral Paoptosis through Sustained Activation of the JNK Pathway, J. Bio. Chem., Vol. 279, Issue 31, 2004, p. 32626-62632. 
Peweatore, P. "Some crtical remarks on the "Single European Act" (1987) 24 (MIRev p. 9.

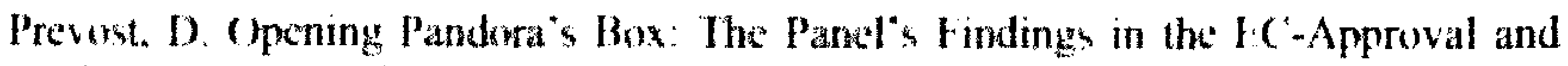
Marketing of Biotech Products Dispute. Legal lsoues of Economic Integration. Vol. 34. 1swere $1,2(6) 7$, p. $73.7 \times$ and 83.84

Prevent. D. and wan den Bosuche, P. The Agresment on the Application of Sanitary and Phyto-sanitary Measures, In P. Merory, A. Appleton and M. Plummer (eds.), The World Trade Organication: legal, Fonomic and Political Analysis, Springer 2005, p. 231.270.

\section{$\mathbf{R}$}

Raul, A. C. and J. Z. Dwyer. Sicience in the Regulatory Process: "Regulatory Daubert": A Proposal to lenhance Judicial Review of Agency Science by Incorporating Dauhert Principles into Administrative law, of law \& Contemp. Prob.7,2003

Regeringskansliet. Official English Translations of the Fnvironmental cinde.

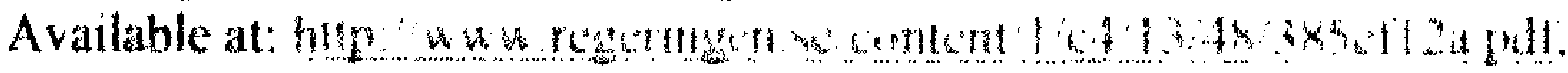

Regeringskansliet. The Swedish Judicial System -.. A Brief Presentation, published by the Swedish Ministry of Justice, available at:

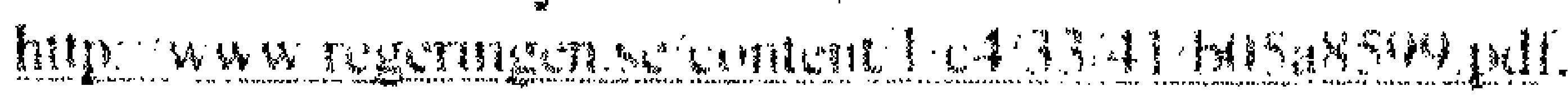

Renda, A. Impact Assessment in the EU: State of the Art an the Art of the State, Center for European Policy Studies, 2006.

Rohrmann, B. and (). Renn. Risk perception research ... An introduction, in: O. Renn and B. Rohrman, Cross-cultural Risk Perception: A Survey of Empirical Studies, Kluwer, 2000 , p. 14 and $31-38$.

Rotmans, J. and van Asselt. M.B.A. Uncertainty Management in Integrated Assessment Modeling: Towards a Pluralistic Approach. Environmental Monitoring and Assessment. Issue 69, 2001, p. 113.

Rotterdam Convention on the Prior Informed Consent Procedure for Certain Hazardous Chemicals and Pesticides in International Trade, Rotterdam, 10 September 1998. Available at: hin www pic inten Vien Paze asp'id 104.

The Royal Society, Risk: Analysis, Perception, Management, The Royal Society 1992, p. 2-3.

Rozin, P. Technological Stigma: Some Perspectives from the Study of Contagion, In: J. Flynn, P Slovic, and H. Kunverther (eds.), Risk, Media, and Stigma: Understanding Public Challenges to Modern Science and Technology, Karthscan, 2001, p. 38.

Ruessmann, L. A. Reflections on the WTO Doha Ministerial Conference: Putting the Precautionary Principle in its Place: Parameters for the Proper Application of a Precautionary Approach and the Implications for Developing Countries in Light of the 
Doha WTO Ministerial, 17 Am. U. Int'l L. Rev. $905-949$ (2002), p. 925-926 and 933935.

Sandin, P. Dimensions of the Precautionary Principle, Hum. and Ecological Risk Assessment, 5, 889, 1999.

Sandin, P. A Paradox Out of Context: Harris and Holm on the Precautionary Principle, Cambridge Quarterly of Healthcare Ethics, 15, 175 (2006), 175, 177.

Sandin, P. and M. Peterson, S-O Hansson, C. Rudén, A. Juthe. Five Charges Against the Precautionary Principle, Journal of Risk Research, 5: 4, 2002, 288-299.

Schicrow, L-J. Environmental Risk and Cost-Benefit Analysis: A Review of Proposed Legislative Mandates, 1993-1998, CRS Report for Congress, 22 January 1999.

The Science and Environmental Health Network (SEHN). Precautionary Principle FAQs. Available at: hitp://www.sehn.org/pp/aqs.html.

The Scientific Committee for Animal Nutrition (SCAN). Opinion on the immediate and longer-term risk to the value of Strcptogramins in Human Medicine posed by the use of Virginiamycin as an animal growth promoter of 10 July 1998.

Scott, J. The European Regulation of GMOs and the WTO, 9 Colum. J. Eur. L., 213, 2003, p. 230-231.

Scott, J. The WTO Agreement on Sanitary and Phytosanitary Measures, Oxford University Press, 2007. p. 84-91, 94, 104-110, 114-115, 127-128 and 243-280.

Scott, J. Of Kith and Kine (and crustaceans): Trade and Environment in the EU and WTO, available at: htlp://www.jeanmonnetprogram.org/papers/99/990307.html.

Scott, J. and E. Vos, The Juridification of Uncertainty: Observations on the Ambivalence of the Precautionary Principle with the EU and the WTO. In Joerges and Dehousse, R. (eds.), Good Governance in Europe's Integrated Market, Oxford University Press 2002. p. 253-286.

Sedman, R. M. and Hadley, P. W. Risk Assessment and Risk Management: Mending the Schism, 3 Risk - Issues in Hcalth \& Safety 189, 1992, p. 189-190.

Shapiro, S. and R. L. Glicksman. Congress, The Supreme Court and the Quiet Revolution in Administrative Law, Duke L. J. 819, 1988, p. 819-820 and 862.

Shrader-Frechette, K. Scientific Method, Anti-Foundationalism and Public Decision, in: E. Löfstedt and L. Frewer, The Earthscan Reader in Risk and Modern Society, Earthscan, 1998, p. 45-57.

Slovic, P. Informing and Educaling the Public about Risk, In: P. Slovic, The Perception of Risk, p. 183-191. 
Slovic, P. Perceived Risk, Trust and Democracy, In: P. Slovic, The Pcrception of Risk, p. 122, 124 and 317-318.

Slovic, P. and B. Fischoff, S. Lichtenstein. Facts and Fears: Understanding Perceived Risk, In: P. Slovic, The Pcrception of Risk, Earthscan, 2000, 146-148. P. Slovic., The Perception of Risk, p. 199, 136-153 and 264-275.

SSI Information, Strålning från basstationer för mobiltelefoni, i 2001:3, (August 2001), p. 2.

Starr, C. Social benefit versus technological risk, Science, 1969, p. 165, 1232-1238.

Statskontoret. Swedish Agency for Public Management. Available at: http://www.statskontoret.se/ StatskontoreU/Templates/NewsPage 2875.aspx

Stirling, A. On Science and Precautionary in the Management of Technological Risk, An Esto Project, Prepared for the Europcan Commission - JRC Institute Prospective Technological Studies Seville, May 1999. p. 40.

Strategy Unit Report. Risk: Improving government's capability to handle risk and uncertainty, November 2002, p. 74-92. Available at: http://www.stralegy.gov.uk/downloads/su/RISK/REPORT/pdf.htm.

Sunstein, C. After the Rights Revolution: Reconceiving the Regulatory State, Harvard University Press, 1990, p. 90.

Sunstein, C. The Cost-Benefit State, Chicago Working Paper in Law \& Economics, No. 039, 05/1996, 24. Available at http://www.law.uchicago.edu/Lawecon/wpl50.html.

Sunstein, C. Risk and Reason: Safety, Law and the Environment, Cambridge University Press, 2004, p. 6, 8, 29, 36, 72, 92, and 104-106.

Sunstein, C. The Laws of Fear: Beyond the precautionary principle, Cambridge University Press, 2005, p. 44.

Sunstein, C. Health-Health Tradeoffs, 63 U. Chi. L. Rev. 1533, 1996, p. 28.

Svärd, S.O. and T. Rahm. Prövning enligt miljöskyddslagen, Gebers Förlag 1975. p. 166.

Swedish Ministry for Foreign Affairs (EU Legal Secretariat), Letter To the Registrar at the Court of Justice of the European Communities, February 26, 2004, 2 and 19 (Available with Author). p. 20, 34-35, and 27.

Swedish Radiation Safety Authority. FAQ on basestations and masts. Frågor och svar om basstationer och master. Available at: www.ssi.se/ickejoniserande stralning/mobiltele/FAQ/FAQ2 bas master.html.

Swedish Radiation Safety Authority. List of regulations issued by SSI which have been translated to English. Available at: htp://www.ssi.se/forfattning/Eng ForfattLista.html. 
Thiruchelvam, M. et al. The Nigrostriatal Dopaminergic System as a Prefertial Target of Repeated Exposures to Combined Paraquat and Maneb: Implications for Parkinson's Disease, The Journal of Neuroscience, Vol. 20, No. 24, 2000. p. $9207-$ 9214.

Thiruchelvam, M. et. al., Overexpression of Superoxide Dismute or Glutathione Peroxidase Protects against the Paraquat + Maneb-induced Parkinson Disease Phenotype, J. Biol. Chem. ,Vol. 280, Issue 23, 2005, p. 22530-22539.

Thornton, J. and S. Beckwith. Environmental Law, Sweet \& Maxwell 2004, 15.

Tickner, J and C. Raffensberger. The Precautionary Principle in Action: A Handbook, Science and Environmental Health Network, 13. Available at: http://www.mindlully.org/Precaution/Precaution-In-Action-Handbook.pdf.

Tinari, N. Cell Phone Towers in Residential Areas: Did Congress Let the Pig in the Parlor with the Telecommunication Act of 1996?, 73 Temp. L. Rev. 269, 2000.

Tengs, T.O and M.E. Adams, J.S. Pliskin, D.G. Safran, J.E. Siegel, M.C. Weinstcin, J.D. Graham. Five-hundred life-saving interventions and their cost-effectiveness, Risk Analysis, Vol. 13, 1995, 369-390.

Trouwborst, A. Evolution and Status of the Precautionary Principle in International Law, Aspen Publishers 2002, p. 63f, 112-156, and 171-174.

Trouwborst, A. The Precautionary Principle in General International Law: Combating the Babylonian Confusion, 16 Review of European Community and International Environmental Law (RECIEL), nr. 2, 2007, pp. 185-195.

$\mathbf{U}$

United States Environmental Protection Agency, An Evaluation of EPA Risk Assessment Principles and Practices, Staff Paper Prepared for the U.S. Environmental Protection Agency by members of the Risk Assessment Task Force, EPA/100/B04/001, p. 22-23, 30-51 and 139.

United States Environmental Protection Agency, Reorganisation Plan No. 3 of 1970, Special Message from the President to the Congress About Reorganization Plans to Establish the Environmental Protection Agency and the National Oceanic and Atmospheric Administration, July 9, 1970. Available at: www.epa.gov/history/org/origins/rorg.htm.

United States Environmental Protection Authority, Guidelines for Ensuring and Maximizing the Quality, Objectivity, Utility, and Integrity of Information Disseminated by the Environmental Protection Agency, EPA/260R-02-008.

United States Environmental Protection Agency, Risk Characterization Handbook, December 2000, p. 20-23, available at http://www.epa.gov/OSA/spc/pdfs/rchandbk.pdf. 


\begin{abstract}
Joakim Zander
United States General Accounting Office. Research and Regulatory Efforts on Mobile Phone Health Issues, Report to Congressional Requesters, May 2001, AO-01-545, p. $2,4,8-18$ and 20 .

United States General Accounting Office, OMB's Role in Revicws of Agency's Draft Rulcs and the Transparency of Those Reviews, GAO-03-929, 2003. Available at: hutp:/www.ga0.gov/new.items/d03929.pdl.
\end{abstract}

\title{
V
}

van Asselt, M.B.A. Perspectives on Uncertainty and Risk: The PRIMA Approach to Decision Support. Kluwer 2000. p. 82-92.

van Asselt, M. B. A. and E. Vos, The Precautionary Principlc and the Uncertainty Paradox, 9 Journal of Risk Research 4, 2006.

van Calster, G. International and EU Trade Law: The environmental challenge. Cameron/May 2000, p. 398.

van den Bossche, P. The Law and Policy of the World Trade Organization, 2nd edition, Cambridge University Press, (forthcoming), p. 250-252, 460 and 463.

van den Bossche, P. and D. Prevost. The Agreement on the Application of Sanitary and Phylo-sanitary Measures, in P. Mcrory, A. Appleton and M. Plummer (cds.), The World Trade Organisation: Legal, Economic and Political Analysis, Springer 2005, p. $231-270$

Viscusi, K. Rational Risk Policy, Oxford University Press, 1998, 11-14, 25, 84-88, 99.

Viscusi, K. Monetizing the Benefits of Risk and Environmental Regulation, 33 Fordham Urb. L. J. 1003, 2006, 1003-10004.

Vogel, D. Ships passing in the night: GMOs and the Politics of Risk Regulation in Europe and the United States, Working Paper No 2001/16, Robert Schuman Centre for Advanced Studies, European University Institute, 2001.

von Moltke, K. The Vorsorgeprinzip In West German Environmental Policy, In: Royal Commission On Environmental Pollution, Twclfth Report: Best Practicable Environmental Option, Cmnd 310, HMSO: London.

Vos, E. EU Food Safety Regulation in the Aftermath of the BSE Crisis, Journal of Consumer Policy 23 2000, p. 231-234, 248-249.

Vos, E. Antibiotics, the Precautionary Principle and the Court of First Instance, Maastricht Journal Vol. 11, Issue 22004 p. 1, 3-7.

\section{W}

Wahlström, B. The Precautionary Approach to Chemicals Management: A Swedish Perspective, In: C. Raffensperger and J. Tickner (eds.), Protecting Public Hcalth and the Environment: Implementing the Precautionary Principle, 52-54. 
Walker, W.E. Harremoes, P. Rotman, J. van der Sluijs, J.P van Asselt, M.B.A. Janssen, P. and Krayer von Krauss, M.P. Defining Uncertainty: A Conceptual Basis for Uncertainty Managcment in Model-Based Decision Support, Integrated Assessment Vol. 4. No. 1 2003. p. 8 and 12.

Weale, A. Ecological Modernisation and the Integration of European Environmental Policy, in: J.D. Liffcrink, European Integration and Environmental Policy, Belhaven Press, 1993.

Weber, M. The Theory of Social and Economic Organization, Henderson and Parson, 1947 , p. 335.

Weiss, R. Law is Nemesis of Regulation, Washington Post, 16 August 2004, p. A01.

Westerlund, S. Lag om kemiska produkter: Kommentar, CE Fritzes Förlag 1985. p. 179.

Westerlund, S. Miljöskyddslagen: En analytisk lagkommentar, Åmyra Förlag. 1990. Section 7.21,

Wiener, J. Precaution in a Multi-Risk World, Duke Law School Public Law and Legal Theory Working Paper No. 23, December 2001. p. 1-4.

Wiener, J. Comparing precaution in the United States and Europe, Journal of Risk Research, Vol. 5 2002, p. 317 and 320-321.

Wiener, J. and Rogers, M.D. Comparing Precaution in the US and Europe, Journal of Risk Rescarch 5 2001. p. 340-342.

Wildawsky, A. Trial and Error versus Trial Without Error, in: J. Morris, Rethinking Risk and the Precautionary Principle, Butterworth-Heinemann, 2000, pp. 22-46.

Winickoff, D. et al., Adjudicating the GM Food Wars: Science, Risk, and Democracy in World Trade Law, 30 Yale J. Int'l Law 81, 2005, p. 113-114, footnote 173.

Wood, S. G. and S.Q. Wood, R.A. Wood. The Precautionary Principle? An American Assessment, in: M. Paques, Le Principe de precaution en droit administratif / Precautionary Principle and Administrative Law, National and International Reports, International Academy of Comparative Law, Bruylant, 2007, p. 247-250.

$\mathbf{Z}$

Zander, J. The Green Guarantee in Article 95 of the EC Treaty: Two recent cases, 16 Journal of Environmental Law 1, 65, 2004.

Zwanenberg, P. and E. Millstone. 'Mad cow disease' 1980s-2000: how reassurances undermined precaution, In: Late Lessons From Early Warnings: The precautionary principle 1896-2000, Environmental issue Report No. 22, 2002. Available at: http://reports.cea.europa.eu/environmental issue report $200122 / \mathrm{en} /$. 
Joakim Zander

\section{Other Sources}

\section{INTERNATIONAL AGREEMENTS}

African Convention on the Conservation of Nature and Natural Resources, Algiers, 1968.

The 1985 Convention for the Protection of the Ozone Layer: on Substances that Deplete the Ozone Layer, Vienna 1985.

The Agreement for the Implementation of the Provisions of the 1982 UNCLOS Relating to the Conservation and Management of Straddling Fish Stocks and Highly Migratory Fish Stocks, New York 1995

The Convention Concerning the Protection of the World Cultural and Natural Heritage, Paris 1972.

The Convention on International Trade in Endangered Species of Wild Fauna and Flora, Washington D.C 1973.

The Convention on the Ban on Import into Africa and the Control of Transboundary Movement and Management of Hazardous Wastes Within Africa, Bamako 1991.

The Convention on Wetlands, Ramsar 1971.

General Agreement on Tariffs and Trade, Geneva, 1947.

Marrakesh Agreement Establishing the World Trade Organization, Marrakesh 1994.

The Protocol to the 1992 Convention on Biological Diversity on Biosafety, Cartagena de Indias 2000.

The Protocol to the 1992 Framework Convention on Climate Change, Kyoto 1997.

The United Nations Convention on the Law of the Sea, Montego Bay 1982.

The United Nations Framework Convention on Climate Change, New York 1992, Article 3(3).

WTO Agreement on Technical Barriers to Trade (TBT Agreement). Marrakesh 1994.

WTO Agreement on the Application of Sanitary and Phytosanitary Measures. (SPS Agreement), Marrakesh 1994.

WTO Dispute Settlement Understanding, Marrakesh 1994.

InTERNATIONAL RESOlutions, DEClaRATIONS AND GUIDELINES

Declaration of the United Nations Conference on Environment and Development, Rio de Janeiro 1992.

Declaration of the United Nations Conference on the Human Environment, Stockholm, 1972. 
The International Commission on Non-Ionizing Radiation Protection, Guidelines for Limiting Exposure to Time-Varying Electric, Magnetic, and Electromagnetic Fields (up to $300 \mathrm{GHz}$ ) (ICNIRP Guidelines). Available at:

http://www.icnirp.de/documents/enfgdl.pde.

Ministerial Declaration on Sustainable Development in the ECE Region, Bergen 1990

The United Nations General Assembly Resolution 37/7 and Annex: World Charter for Nature, 28 October 1982.

\section{EU LEGISLATION AND SOFT LAW}

\section{Treaties}

Consolidated Versions of the Treaty on the European Union and of the Treaty Establishing the European Community, OJ 2002 C 325/1

\section{Regulations}

Council Regulation (EEC) No 2377/90 of 26 June 1990 laying down a Community procedure for the establishment of maximum residue limits for veterinary medicinal products in foodstuffs of animal origin, OJ L 224/1

Council Regulation 2821/98 amending, as regards withdrawal of the authorisation of certain antibiotics, Directive 70/524/EEC concerning additives in feedingstuffs [1998] OJ L 351/4.

Council Regulation 2821/98/EC amending as regards withdrawal of the authorization of certain antibiotics, Directive 70/524/EEC (1998) OJ L351/4.

Regulation (EC) No 178/2002 of the European Parliament and of the Council of 28 January 2002 laying down the general principles and requircments of food law, establishing the European food Safety Authority and laying down procedures in matters of food safety, OJ L $31 / 1$

Regulation (EC) No 1829/2003 of the European Parliament and of the Council of 22 September 2003 on genetically modified food and feed, OJ L 268/1

Regulation (EC) No 1907/2006 of the European Parliament and of the Council of 18 December 2006 concerning the Registration, Evaluation, Authorisation and Registration of Chemicals (REACH), establishing a European Chemicals Agency, OJ L 396/1

\section{Directives}

Directive 65/65/EEC of 26 January 1965 on the approximation of provisions laid down by Law, Regulation or Administrative Action relating to proprietary medicinal products, OJ 1965 L 22/369.

Directive 67/548/EEC of 27 June 1967 on the Approximation of the Laws, Regulations, and Administrative Provisions of the Member States Relating to the Classification, Packaging, and Labeling of Dangerous Substances, OJ 1967 L 196/1.

Directive 70/524/EEC of 23 November 1970 conccrning additives in feeding-stuffs, OJ 1970 L $270 / 1$. 
Joakim Zander

Directive 75/319/EEC of 20 May 1975 on the approximation of provisions laid down by Law, Regulation or Administrative Action relating to proprietary medicinal products , OJ $1975 \mathrm{~L} 147 / 13$

Directive $75 / 442 /$ EEC of 15 July 1975 on waste OJ 1975 L 194/39.

Directive 79/409/EEC of 2 April 1979 on the conservation of wild birds, OJ $1979 \mathrm{~L}$ 103.

Directive 79/831/EEC of 18 Scptember 197, OJ L 183/22.

Directive 90/219/EEC of 23 April 1990 on the contained use of genetically modified micro-organisms, OJ 1990/17.

Directive $90 / 220$ of 23 April 1990 on the deliberate release into the cnvironment of genetically modified organisms, OJ 1990, L 117/15.

Directive 90/220/EEC of 23 April 1990 on the deliberate release into the cnvironment of genetically modified organisms, OJ L 117/15.

Directive 91/414/EC of 15 July 1991 conccrning the placing of plant protection products on the market, OJ L 230/1.

Directive 94/67 of 16 December 1994 on the incineration of hazardous waste, OJ 1994 L 365/34.

Directive 96/51/EC of 23 July 1996, amending Direclive 70/524/EEC concerning additives in feeding-stuffs (1996) OJ L235/39.

Directive $96 / 61$ of 24 September 1996 on integrated pollution prevention and control, OJ 1996 C 137/20.

Directive 2001/18/EC of the European Parliament and of the Council of 12 March 2001 on the deliberate release into the environment of genetically modified organisms and repealing Council Directive 90/220/EEC, OJ L 106/1.

\section{Decisions}

Council Decision 90/218/EEC of 25 April 1990 concerning the administration of Bovine Somatotrophin (BST) OJ L 116/1.

Council Decision 94/936 of 20 December 1994 amending Decision 90/218/EEC concerning the placing on the market and administration of bovine somatotrophin, OL L 366/19.

Council Decision 96/239/EC of 11 June 1996 on emergency measures to protect against bovine spongiform encephalopathy, OJ L 078/9.

Council Decision 1999/468 of 28 June 1999 laying down the procedures for the excrcise of implementing powers conferred on the Commission. OJ L 184/ 23. 


\section{Communications of the Commission}

Communication of the Commission on Consumer Health and Food Safety, COM/97/83/Final

Communication from the Commission of 2 February 2002 on the Precautionary Principle, COM/2001/1/Final

Communication from the Commission on Impact Assessment, COM/2002/726, adopted 5 June 2002 .

Communication from the Commission to the Council and the European Parliament, Better Regulation for Growth and Jobs in the European Union, COM/2005/97 adopted 16 March 2005.

\section{Other}

Bulletin EC 6-1990, Conclusions of the Presidency, Point 1.14 and Annex II.

EU Bulletin 12-2000, Chapter 10 Community institutions, point 1.4.75.

Conclusions of the Presidency, European Council at Nice 7-10 December 2000, Annex III, Point $1 . \quad$ Available at: http://www.curoparl.curopa.cu/summits/nicel_en.htm.

Council Recommendation 1999/519/EC of 12 July 1999 on the limitation of exposure of the general public to electromagnetic fields ( $0 \mathrm{~Hz}$ to $300 \mathrm{GHz})$. OJ L 199/59.

Declaration of the Council of the European Communities and of the Representatives of the Governments of the Member States, meeting in the Council on the Programme of action of the European Communities on the Environment, OJ 1973, C112/1, p. 33 and 49.

Impact Assessment Guidelines, SEC/2005/791 adopted 15 June 2005.

Opinion of the Scientific Committee on Plants on Specific Questions from the Commission Regarding the Evaluation of Paraquat in the Context of Council Directive 91/414/EEC, SCP/PARAQ/002-Final, 16 January 2002

Short Report of the Meeting of the Standing Committee on the Food Chain and Animal Health (Phytopharmaceuticals Section) Held on 3 October 2003 in Brussels. SCFA 4/2003. p. 2. Available at:

hltp:/curopa.cu.int/comm/food/committecs/regulatory/sefcah/phytopharmaceuticals/s ummaryl 6 en.pdf.

Resolution of the Council and Representatives of the Governments of the Member States, meeting within the Council on the continuation and implementation of an EC policy and action programme on the environment (1987-1992), OJ 1987, C328/1.

Review report for the active substance paraquat, 3 October 2003, SANCO/10382/2002 -final. Available at:

http://ec.europa.eu/food/plan//protection/evaluation/existactive/list paraquat.pdf. 
SWEDISH LEGISLATION, PREPARATORY WORK, ETC.

Legislative Acts

Miljöskyddslag (SFS 1969: 387).

Förvaltningsprocesslag (SFS 1971:291).

Arbetsmiljölag (SFS 1977:1160).

Förvaltningslag (SFS 1986: 223).

Plan- och Bygglag (SFS 1987:10).

Lag (SFS 1988:205) om rättsprövning av vissa förvaltningsbeslut.

Strålskyddslagen (SFS 1988:220).

Lag (SFS 1991:639) om förhandsgranskning av biologiska bekämpningsmedel.

Kommunallagen (SFS 1991:900).

Lag (SFS 1998: 808) om införande av miljöbalken.

\section{Decrees}

Förordning (SFS 1985:643) med instruktion för kemikalieinspektionen, Article 2.

Förordning (SFS 1985:836).om bekämpningsmedel (SFS 1985:836).

Förordning (SFS 1988:295) med instruktion för Statens strålskyddsinsititut.

Förordning (SFS 1988:525) med instruktion för Kemikalieinspektionen and Förordning (2006: 524) med instruktion för Statens strålskyddsinstitut.

Förordning (SFS 1995:1322) med instruktion för Statens strålkskyddsinstitut.

Förordning (SFS 1998:947) om bekämpningsmedel.

Förordning (SFS 2006:1010) om växtskyddsmedel, Articles 4, 5, 17-19 and 53.

\section{Preparatory Works}

Proposition 1969: 28.

Proposition 1973:17.

Proposition 1987/88:69.

Proposition 1994/95:230

Proposition 1997/98:

Proposition 2000/01:130

SOU 1996:103 Del 1. Miljöbalken: En skärpt och samordnad miljölagstiftning för en hållbar utveckling. p. 239 
SOU 1993:27 Miljöbalk - förslag till åtgärder för ett framtida miljöskyddsarbete

SOU 1996:103 Miljöbalken - Del 1

\section{Other}

Interview with case handler at the Swedish Ministry of Environment, 8 September 2004.

Interview with officials at KemI, 9 September 2004.

KemI Memo (P. Bergkvist), PM inför beslut om fortsatt godkännande för EBDCmedel. 1994-11-08 (Not published, but available with author), p. 2

KemI Memo (P. Bergkvist), Yttrande over komplettcrand material från Rohm and Haas och Elf Atochem Agri angående överklagandena av Kemikalieinspektionens beslut den 9 november 1994 i fråga om bekämpningsmedel innehăllande EBDC, 23 August 1995 (Not published, but available with author), p. 1-4.

Kommentarer till Statens strålskyddsinstituts allmänna råd (SSI FS 2003:3) om begränsning av allmänhetens exponering för clektromagnetiska fält. (Translation by author), p. 2. Available at: http://www.ssi.sc/for/attning/pd//2002 3Komment.pdl.

Kommentarer till Statens strålskyddsinstituts allmänna råd (SSI FS 2003:3) om begränsning av allmänhetens exponering för elektromagnetiska fält.

Myndigheternas försiktighetsprincip om lågfrekventa electriska och magnetiska fälten vägledning för beslutsfattare, available at:

http://www.av.se/dokument/publikationer/adi/adi 477.pdf.

Statement by Swedish Foreign Office official Anders Kruse, quoted in Swedish daily newspaper Svenska Dagbladet, August 24, 2004. Available at:

hitp://www.svd.se/dynamiskt/inrikes/did 8027374.asp.

Statens strålskyddsinstituts föreskrift SSI FS 2002:3, Allmänna råd om begränsning av allmänhetens exponering för elektromagnetiska fält (General Advice on Limiting the Public's Exposure to Electomagnetic Fields (hereinafter referred to as "the General Advice").

Översiktsplan 2003 Nyköpings kommun - Kommunens vilja och ambition, 50 and 88 . Available at hitp://www.nykoping.se/op2003/pd//huvud.pdf.

\section{UNITED KINGDOM}

\section{Legislative Acts}

Health and Safety at Work etc. Act of 1974

Food and Environment Protection Act of 1985

Environment Act of 1995

Health Protection Agency Act of 2004, available at: htip:/www.opsi.gov.uk/acts/acts2004/20040017.htm. 
Joakim Zander

\section{Regulations and Orders}

Control of Pesticides Regulations, SI 1986/1510

Control of Pesticides (Advisory Committec on Pesticides) Order 1985, SI No 1985 No. 1516,1517

The Town and Country Planning Order of 1995, Statulory Instrument 1995 No. 418

The Management of Health and Safety at Work Regulations of 1999

Plant Protection Products Regulations 2005, SI 1435, s. 4, 5

\section{Other}

Code of Best Practice on Mobile Phone Network Development, Office of the Deputy Prime Minister, 2002

Guidelines for Environmental Risk Assessment and Management, HMSO 2000. Now updated and available at: http://www.defra.gov.uk/environment/risk/cramguide/, Sections 3.2-3.5, 3.8, 8.2.

Ibbs Report: Improving Management in Government: The Next Steps, A Report to the Prime Minister. HMSO 1988. Main points summarised on:

http:/www.civilservice.gov. uk/the future of the civil service/ageneics and public bodies/executive agencies and non ministerial departments/background and devel opment/index.asp

Independent Export Group on Mobile Phones, Mobile Phones and Health, published on 11 May 2000 (The Stewart Report), available at: http://www.iegmp.org.uk/completion.htm.

Mutagenicity of dichloros, COM statement COM/02/S2 - January 2002, available at: http://www.advisorybodies.doh.gov.uk/com/dichlorvos.htm.

National Radiation Protection Board, Restrictions on human exposure to static and time varying electromagnetic fields and radiation, Doc NRPB, 4(5) 1993.

National Radiation Protection Board, Advice on the 1998 ICNIRP guidelines for limiting exposure to time-varying electric, magnetic and electromagnetic fields (up to $300 \mathrm{GHz}$ ). Doc NRPB, Vol. 10 No. 21999.

National Radiation Protection Board, Advice on the 1998 ICNIRP guidelines for limiting exposure to time-varying electric, magnetic and electromagnetic fields (up to $300 \mathrm{GHz}$ ), Doc. NRPB Vol. 15, No. 2 2004, Available at: http://www.hpa.org.uk/web/HPAwebFile/HPAweb C/1194947415497.

The Pesticides Safety Directorate's Framework Document, Available at: http://www.pesticides.gov.uk/corporate.asp?id $=232$.

The Precautionary Principle: Policy and Application, Report of the Interdepartmental Liaison Group on Risk Assessment (ILGRA) Report. Available at: hutp://www.hsc.gov.uk/aboutus/meetings/ilgra/pppa.htm. 
White Paper, "This common Inheritance: Britain's Environmental Strategy", presented to Parliament, September 1990, HMSO, Cm 1200.

\section{UNITED STATES OF AMERICA}

\section{Legislative Acts}

Administrative Procedure Act of 1974, 5 U.S.C. 551 (APA)

The Clean Air Act of 1970, 42 U.S.C. 7401.

Data Quality Act, Amendment to the Paperwork Reduction Act, 4 U.S.C. 3501.

Endangcred Species Act of 1973, 16 U.S.C. 1531-1544, Sect. (B) and (D), Sect. 4 (B) (1) (a) ii, Sect. 7 (A) (4).

Federal Advisory Commitlee Act, Public Law 92-463, 5 U.S.C. App. 1.

Federal Food, Drug and Cosmetic Act of 1958, 21 U.S.C. 348, Section 408 and 409.

Federal Food, Drug and Cosmetic Act of 1996 (FFDCA), 21 U.S.C. $\$ 9$.

Federal Water Pollution Control Act (Clean Water Act), 33 U.S.C. 1251.

Food Quality Protection Act of 1996 (FPQA), Pub L. 104-170.

The Fungicide, Insecticide, and Pesticide Act, 15 USC, 2601-2692.

National Environmental Protection Act, 42 U.S.C. 4321.

Radiation Control for Health and Safely Act of 1968, 42 U.S.C. $263 \mathrm{f}$.

The Regulatory Improvement Act of 1998, S. 981, $105^{\text {th }}$ Congress, 627 (1998).

Telecommunications Act of 1996, Pub. L. No. 104-104, 110 Stat. 56.

Toxic Substances Control Act, 7 USC, 136-136y.

\section{Executive Orders}

Executive Order No. 12,291, 3 C.F.R. 127(1982)

Executive Order 12,866, 3 C.F.R. 638 (1994).

\section{Other}

Evaluating Compliance with FCC Guidelines for Human Exposure to Radiofrequency Electromagnetic Fields, OET Bulletin 65, Edition 97-01, August 1997

Office of Management and Budget, Guidelines for Ensuring and Maximizing the Quality, Objectivity, Utility, and Integrity of Information Disseminated by Federal Agencies; Notice; Republication, Federal Register / Vol. 67, No. 36 / 22 February 2002.

Office of Management and Budget, Regulatory Analysis, Circular A-4 To the Heads of Executive Agencies and Establishments, 17 September 17, 2003. 


\section{. Toukim Zanditr}

The Prestential congressinnal Commission on Risk Assensmenl and Risk Managenent, Risk Assosment and Risk Management in Regulatory Decisionmaking Fonal kopont Vol. 2.1997, 2 and 3

Guestions and Answers abut Bulogical Lffects and Potental Hazards of

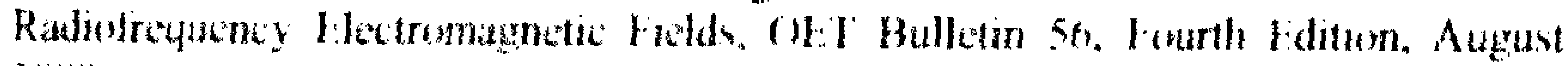
1904

Reorganisation Plan No. 3 af 1470 . Speciat Message from the President to the Congress Ahou Reorganization Plan to Lstablinh the Insironmental Protection Agency and the Natmol Keanc and Atmosphoric Administration. 9 July 1970.

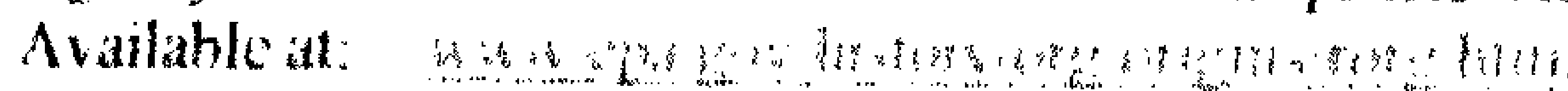




\section{CURRICULUM VITAE}

Joakim Zander was born in Stockholm, Sweden, in 1975. He received a Master of Laws degree (Juris Kandidat) from Uppsala University, Sweden, in 2002. During 2002 he also completed an internship and worked as an assistant to a Swedish MEP in the European Parliament. Between 2003 and 2007, he was employed as a Junior Researcher at Maastricht University, the Netherlands. In 2007 and 2008, Joakim worked as casc handler in DG Enterprise of the European Commission. Since the summer of 2008 he is responsible for cases concerning the free movement of goods and services as an officer at the Internal Market Affairs Directorate of the EFTA Surveillance Authority in Brussels, Belgium. 